\title{
Musica Theorica
}

Revista da Associação Brasileira de Teoria e Análise Musical - TeMA Journal of the Brazilian Society for Music Theory and Analysis

Volume $4 \cdot$ número $1 \cdot$ janeiro a julho de 2019

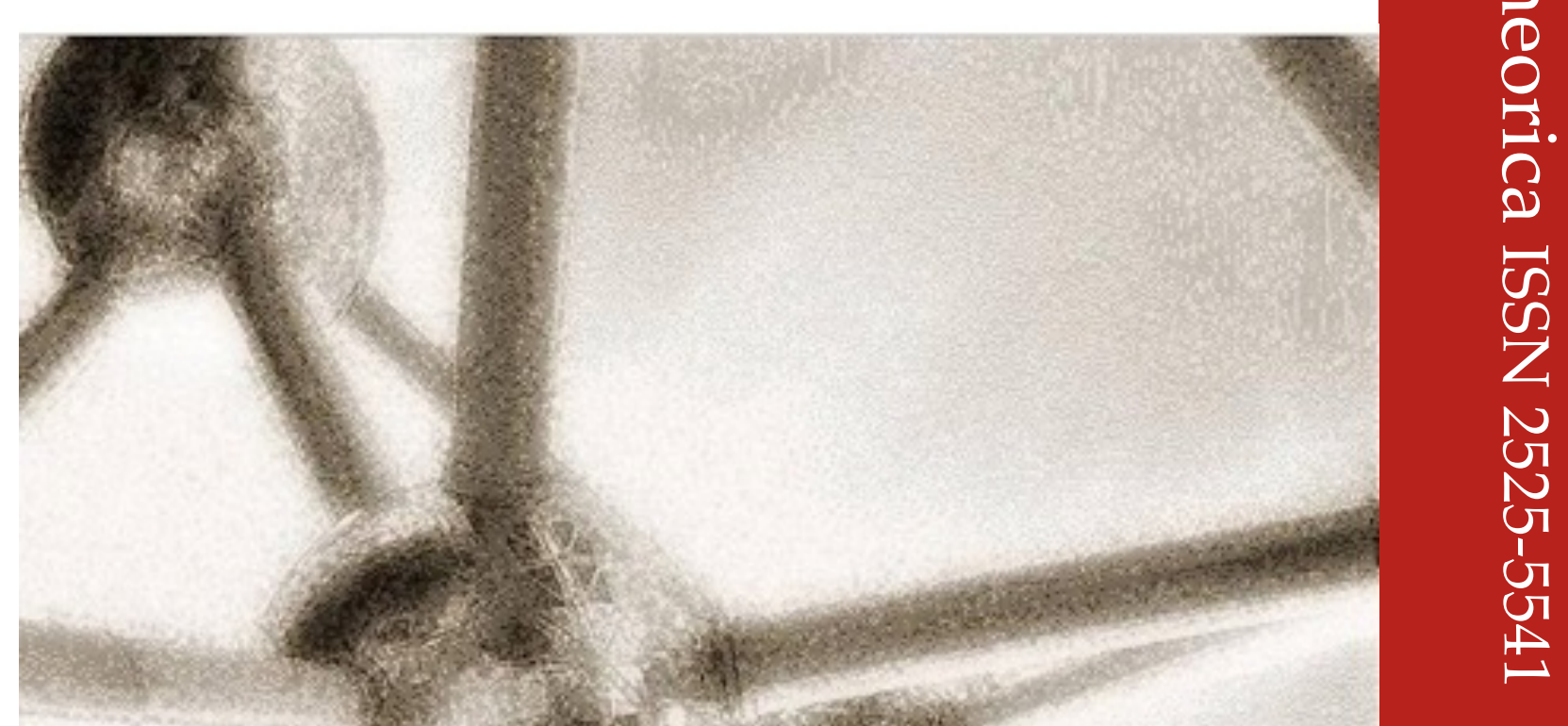



ISSN 2525-5541

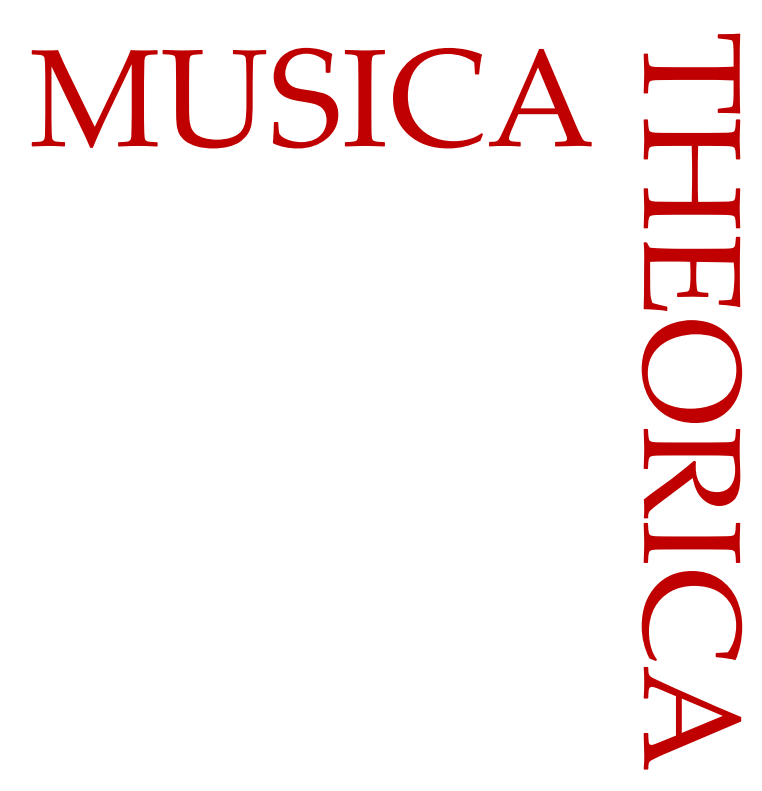

Revista da Associação Brasileira de Teoria e Análise Musical - TeMA

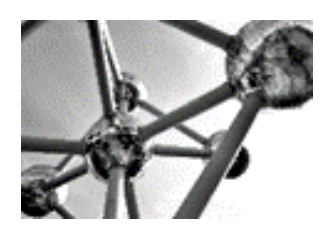

Journal of the Brazilian Society for Music Theory and Analysis

Volume $4 \cdot$ número $1 \cdot$ janeiro a julho de 2019 


\section{Associação Brasileira de Teoria e Análise Musical - TeMA}

Rodolfo Coelho de Souza (USP) - Presidente

Maria Lúcia Pascoal (UNICAMP) - Vice-Presidente

Guilherme Sauerbronn de Barros (UDESC) - Secretário

Cássia Carrascoza Bomfim (USP) - Tesoureiro

Norton Dudeque (UFPR) - Editor chefe

\section{REVISTA MUSICA THEORICA}

Norton Dudeque (UFPR)

Edson Hansen Sant'Ana (IFMT/UNESP)

Gabriel Navia (UNILA)

\section{CONSELHO EDITORIAL}

Carole Gubernikoff (UNIRIO)

Celso Loureiro Chaves (UFRGS)

Fausto Borém de Oliveira (UFMG)

Janet Schmalfeldt (Tufts University)

João Pedro Paiva de Oliveira (Universidade de Aveiro, Portugal)

Jonathan Dunsby (Eastman School of Music)

José Oliveira Martins (Universidade Católica de Portugal, Porto)

Ludwig Holtmeier (Hochschule fuer Musik Freiburg)

Lawrence Kramer (Fordham University)

Maria Alice Volpe (UFRJ)

Maria Lucia Paschoal (UNICAMP)

Mark Evan Bonds (University of North Carolina)

Michael Klein (Temple University)

Michiel Schuijer (Amsterdan University of Arts, Conservatorium van

Amsterdam)

Miguel Roig-Francolí (University of Cincinnati)

Paulo de Tarso Salles (USP)

Paulo Costa Lima (UFBA)

As ideias e opiniões expressas neste periódico são de inteira responsabilidade de seus autores 


\section{Sumário}

\section{i Editorial}

\section{Entrevistas}

1 Liduíno Pitombeira entrevista Patrick McCreless

Carlos Almada entrevista Edgardo Rodríguez

\section{Artigos}

11 A Visita de Beethoven ao carnaval brasileiro em 2017: Ensaio sobre fantasia analítica e hermenêutica narrativa em música Beethoven's Visit to Brazil During the 2017 Carnival: Essay on Analytical Fantasy and Narrative Hermeneutics in Music

Ilza Nogueira

30 Variation and Developing Variation under a Transformational Perspective

Variação e Variação Progressiva sob uma Perspectiva Transformacional

Carlos Almada

62 Categorias de Análise Musical e Modelagem Física como Análise do Timbre

Categories of Musical Analysis and Physical Modeling as Analysis of Timbre Rodolfo Coelho de Souza

98 O Pensamento Musical sobre o Tempo em Durações (1977) de Rodolfo Coelho de Souza

Musical thought about time in Durações (1977) by Rodolfo Coelho de Souza

Cássia Carrascoza Bomfim

124 Espaço, materiais e forma no teatro musical pós-1960: composição e dramaturgia em obras de Mendes, Kagel e Aperghis Space, materials, and form in the post-1960 music theater: composition and dramaturgy in works by Mendes, Kagel e Aperghis

Heitor Martins Oliveira 
160 Rethinking the Ornament with/in Luigi Nono's Late Electroacoustic Works

Repensar o ornamento com/em obras eletroacústicas tardias de Luigi Nono Kevin Gohon

188 The Medial Caesura Declined in Schubert's Sonata-Form Expositions

A Cesura Medial Recusada nas Exposições de Obras em Forma Sonata de Schubert

Gabriel H. Bianco Navia

234 O Desvio no Fluxo Composicional Deviation in the Compositional Flow

Bruno Yukio Meireles Ishisaki

Denise Hortência Lopes Garcia

255 Elementos melódicos e harmônicos recorrentes em Notas Irresponsáveis de Bruno Kiefer: uma abordagem Pós-Tonal Recurring melodic and harmonic elements in Bruno Kiefer's Notas Irresponsáveis: a Post-Tonal approach

Vinicius Dias Prates

280 Sobre os autores 


\section{Editorial}

Este número de Musica Theorica apresenta inicialmente duas entrevistas concedidas por Patrick McCreless e Edgardo Rodríguez que participarão como palestrantes no III Congresso da TeMA a ser realizado conjuntamente com o IV Congresso Internacional de Música e Matemática, organizados pelo Programa de Pós-Graduação em Música da UFRJ.

O primeiro artigo é assinado pela professora e pesquisadora Ilza Nogueira. A autora apresenta uma proposta narrativa para a cognição musical da obra Chacona ao Luar (2017) de Edino Krieger. Com o objetivo de observar analiticamente o discurso musical na obra, Ilza Nogueira aborda aspectos estruturais que contribuam na construção do significado do discurso musical pretendido pelo compositor.

Carlos Almada apresenta em seu artigo um modelo analítico que propõe uma perspectiva transformacional para a variação musical. Ele parte da ideia de um modelo arquetípico de função genérica e que é capaz de transformar uma ideia musical em outra por similaridades. O autor também discute vários conceitos pertinentes ao assunto e propõe uma tipologia para o princípio de variação progressiva schoenberguiana.

Rodolfo Coelho de Souza tem desenvolvido um importante trabalho como compositor e teórico. Atualmente ocupa a presidência da TeMA e é um grande incentivador da pesquisa em teoria e análise musical no país. Neste número de Musica Theorica encontram-se dois artigos que mostram o trabalho de Rodolfo: o primeiro, de sua autoria, trata-se de uma reflexão sobre categorias de análise musical passando pelas técnicas tradicionais até a proposta de análise do timbre; o segundo artigo, de autoria de Cássia Carrascoza Bomfim, explora a interação entre instrumentos e eletrônica em tempo real na obra Durações (1977) de Rodolfo Coelho de Souza.

Heitor Oliveira discute aspectos entre composição e dramaturgia em obras de teatro musical de Mendes, Kagel e Aperghis. Os três aspectos discutidos pelo autor envolvem desde performance musical, passando pela invenção e 
organização de materiais, e estrutura e forma, todos, como delimitadores do espaço cênico.

Kevin Gohon da Universidade de Rennes 2, França, discute em seu texto o papel de fenômenos considerados ornamentais na música eletroacústica de Luigi Nono. O autor discute a contradição de sua rejeição por qualquer tipo de discurso musical figurativo, herdado do modernismo vienense, com a presença de qualquer tipo de ornamentação e de como este se reflete em certas características do estilo tardio de Nono e ecoam como uma lógica ornamental, definida como uma categoria estética geral desde o século XVIII.

Um dos aspectos de articulação da forma sonata é discutido no texto de Gabriel Navia: trata-se da questão da cesura medial (MC). Navia explora este aspecto e as exceções à norma em obras de Schubert. O autor conclui e demonstra que as ressalvas envolvendo MCs em tonalidades não-convencionais requerem algum tipo de "correção" ou "compensação". Nos exemplos selecionados por Navia, Schubert altera a ordem crescente de articulação cultivada no fim do século XVIII por uma inovadora.

Bruno Ishisaki e Denise Garcia são autores de “O Desvio no Fluxo Composicional" onde explicitam sua compreensão das características na criação e da diferença que surge por meio da atualização, ou seja, que promove uma desigualdade entre o resultado e sua idealização.

Por fim, Vinícius Prates apresenta uma análise da obra Notas Irresponsáveis (1986/87) de Bruno Kiefer utilizando como referencial teórico o livro Introduction to Post-Tonal Theory de Joseph N. Straus (2005) e através da análise o autor identifica componentes octatônicos, agrupamentos em terças menores e trítonos como elementos preferenciais do compositor.

Portanto, este número de Musica Theorica é bastante variado e novamente nos mostra a excelente produção acadêmica em teoria e análise musical no Brasil.

Desejamos a todos uma boa leitura!

Norton Dudeque Curitiba, 10 de setembro de 2019 
Por ocasião do III Congresso da TeMA realizado conjuntamente com o IV Congresso Internacional de Música e Matemática, organizados pelo Programa de Pós-Graduação em Música da UFRJ, foram realizadas duas entrevistas com convidados palestrantes do evento. A primeira foi conduzida pelo prof. Liduíno Pitombeira e o entrevistado é o prof. Patrick McCreless da Yale University, EUA. McCreless tem uma vasta atividade como teórico e analista musical. Entre suas inúmeras publicações destacam-se Wagner's Siegfried: Its Drama, History, and Music (1982); "An Evolutionary Perspective on Semitone Relations in the Nineteenth Century" em The Second Practice of Nineteenth-Century Tonality (1996); "Music and Rhetoric" em The Cambridge History of Western Music Theory (2002). Sua atuação e interesses são na música dos séculos XIX e início do XX; sobre cromatismo na música tonal; história e atualidades da teoria musical, e conceitos de retórica e gesto como ferramentas analíticas. Tem sido convidado como principal conferencista em diversos países, tais como: Grã-Bretanha, Espanha, Dinamarca, Holanda, Brasil e China.

A segunda entrevista, conduzida pelo prof. Carlos Almada, foi realizada com o professor Edgardo José Rodríguez da Universidad Nacional de La Plata, Argentina. Rodríguez tem atuado nas áreas da teoria e análise tonal generativa, da linguística musical, e pesquisado sobre a música atonal livre e dodecafônica da Segunda Escola de Viena. Tem uma atuação importante na música popular argentina e no tango contemporâneo, em especial como violonista com os quartetos "La rodriguera" e "Tango chino".

\section{Entrevista com Prof. Patrick McCreless, conduzida pelo Prof. Liduino Pitombeira}

LP How do you evaluate the developments on the study of chromaticism since the publication of your 1983 paper "Ernst Kurth and the Analysis of the Chromatic Music of the Late Nineteenth Century"?

$P M$ I can answer only from the point of view of a theorist working in North America in the early 1980s. At the time, the reigning approach to tonal music was Schenkerian analysis, which certainly offered important insights into chromaticism, but also had its limitations. Schenkerian theory was splendid for 
showing how chromaticism, even quite extreme chromaticism, in tonal pieces could be explained by the combination of linearity and prolongation. For example, in analyzing a lengthy passage in bVI in a major key, a Schenkerian theorist would show how the bVI fits coherently into the linear-contrapuntal workings of a piece, and explain the measures on that key as a prolongation of it, so that the contrapuntal event in a sense generates the harmonic one. Such analyses can be valuable and perceptive, and Schenkerian theory continues to be a useful tool for analyzing chromatic music.

But Schenkerian theory misses some important chromatic techniques that developed in the nineteenth-and even the late eighteenth-century. Here are two straightforward examples. The first technique involves what we call "real sequences" - that is, repetitions of a musical passage at a given interval that are exact transpositions of the original, such as the statement of a phrase successively in minor thirds (e.g., $\mathrm{C}$ major-E , major-F $\#$ major-A major) with no diatonic adjustments. An American theorist, Gregory Proctor, was the first scholar to address this phenomenon, which he called the transposition operation, in detail. His 1978 Princeton dissertation was a must-read text in the early 1980's, and extensive work by other theorists in the past 35 years has carried the idea forward, demonstrating how such "equal divisions of the octave" function in a wide range of repertoires, from Mozart to Schubert to Tchaikovsky to Fauré. The second technique involves the associative use of keys in dramatic music, as in Wagner's Ring, where the river Rhine is in $\mathrm{E}$, major, Valhalla in $\mathrm{D}$, major, Nibelheim in B, minor, the Sword in C major, and so forth. This technique even occurs in instrumental music, in the form of the pitch-class motive: a particular chromatic note, such as the Db in the first movement of Beethoven's Eroica Symphony, or the $\mathrm{C} \#$ in the finale of his Eighth, is posed as a problem, a "sore note," as Joseph Kerman called it, that must be dealt with and resolved for the piece to end. Both of these techniques are ubiquitous in nineteenth-century music, and theorists have addressed them in dozens of pieces since the early 1980s.

A reason why I became interested in the work of Ernst Kurth is that he recognized both of these procedures, which were central to the musical language of the Ring (I had just completed my dissertation on Siegfried), and he discussed them in detail, with many examples. Kurth's work was not well-known at the time, and I was excited about making North American theorists aware of it. My 
article was perhaps flawed, to the degree I was projecting current analytical ideas back on Kurth. But his ideas did line up well with what was happening in music analysis at the time, and we would soon have a much more thorough account of his work in Lee Rothfarb's 1989 book, Ernst Kurth as Theorist and Analyst. Rothfarb's achievement in bringing Kurth's writings-especially those on nineteenth-century chromaticism - to light can serve as an example of another important development in the study of chromaticism in the past 35 years: the return to earlier music theories to contextualize and illuminate current theories. The title of a 1994 book by Daniel Harrison illustrates this phenomenon perfectly: Harmonic Function in Chromatic Music: A Renewed Dualist Theory and an Account of Its Precedents. In the book he returned to nineteenth-century German theorists (theorists who in the early 1990s seemed irrelevant to modern music theory) to develop a theory of his own using the ideas on harmonic dualism (the idea that the minor tonal system is the exact inverse of the major system) of Moritz Hauptmann, Arthur von Oettingen, and Hugo Riemann, as well as the harmonic functionalism of Riemann. His book also inserted into scholarship on chromaticism a renewed concern with chord-to-chord progression, using dualistic ideas that many theorists considered misguided, even ludicrous and not worth bothering with, at the time.

Concern with chord-to-chord motion, and concern with the work of earlier theorists, have also guided the influential ideas of the late David Lewin and Richard Cohn. Lewin's article on Wagner's Parsifal in 1984 was strongly influenced by Riemann, and is still the locus classicus how we can evaluate chromaticism within a tonal context. Also crucial is his mathematically-based transformation theory (1987), which is as involved with tonal music and its chromatic problems as it is with atonal music. And Cohn, using techniques from contemporary atonal theory, developed in the 1990s some important insights into chromatic practice-insights that he initially thought he was deriving from Riemann, but which, by the publication of Audacious Euphony: Chromatic Harmony and the Triad's Second Nature, in 2012, he realized be in a long line of late eighteenth- and early nineteenth-century German theory, including the tradition that led to Riemann, and (interestingly!) the almost unknown theorist Carl Friedrich Weitzmann. Briefly stated, Cohn's work deals with properties and voice-leading connections of major and minor triads, and the fact that even though they function perfectly well in conventional diatonic tonality, they can 
function equally well in a totally independent system of harmony - a system that he shows to have been quite robust in the nineteenth century and beyond-based on parsimonious (that is, as small as possible) voice-leading. Much recent work on tonality in general, and chromaticism in particular, is related, directly or tangentially, to these ideas: David Kopp's Chromatic Transformations in Nineteenth-Century Music (2002), Steven Rings's Tonality and Transformation (2006), Dmitri Tymoczko's A Geometry of Music (2011), and work by Julian Hook and others. The study of chromaticism in tonal music remains a lively area of research in music theory.

LP You have written a very comprehensive chapter on music and rhetoric in the Cambridge History of Western Music Theory. How would you see the use of musical-rhetorical tools both in the analysis of contemporary repertory as well as in the compositional planning of new works (including electroacoustic music)?

PM My chapter on rhetoric in the Cambridge History was entirely concerned with the history of the concept rhetoric as it has been used in Western music, and with a small number of sample musical analyses that illustrated its main points. This historical background is, of course, related to your question, but in answering it, I'll be more interested in an approach to rhetoric that pairs it with the concept of musical gesture, since both terms are so common in our discussions of new music. Musical rhetoric and musical gesture are expressions that we contemporary musicians-whether composers, performers, theorists, ethnomusicologists, or historians - use all the time, often unthinkingly, as a kind of default. They are terms that are indispensable to our musical discourse, in that they say something that a more rigorous theoretical language cannot, and thus we are reluctant to give them up.

What is it about rhetoric and gesture that seem so powerful in helping us to understand all sorts of music? What can they do, if anything, that more formal, explicit music theory does not? I propose to approach this question by asking a different question: how do they relate to one another? Since they share both their ubiquity and their lack of formalism, and since they overlap in ways (one uses gestures to make rhetorical points), it may be productive to consider them together rather than separately. In fact, stepping back for a moment, we see an interesting paradox. On the one hand, rhetoric seems to be the broader, more 
general term, such that gesture is an element of rhetoric. This has been true of rhetoric from the beginning: classical treatises on rhetoric treat gesture as one of a number of techniques that can make one's rhetoric better, not as an art in itself. This is why Quintilian, whose Institutio oratoria (c. $100 \mathrm{CE}$ ) gives us the quintessential Roman pedagogy on rhetoric, puts his chapter on gesture at the very end of his book-Chapter 11 out of 11 chapters. Once all other skills are mastered, gesture is the final touch to make an orator, or his oratory, persuasive. Gesture is thus the icing on the rhetorical cake. Considered in these terms, rhetoric governs the whole communicative act and its content-the whole speech, the whole poem, the whole piece of music - and gestures may be used to inflect, emphasize, and dramatize that content.

When we consider the rhetorical shaping of New Music (which for present purposes I will define as post-1950s art music that is not tonal or tonal-centric, may or may not use discrete pitches, and may use any sort of noise or unpitched sounds), gesture is a term that we can hardly do without. Not only do we, as listeners and analysts, perceive many phenomena in the music as gestures, but the language of gesture permeates discussions of contemporary musical composition-from composition studios at music conservatories, to interviews of composers, to reviews, and to the analysis of new compositions. In composition studios, at least in the USA, teachers offer comments to young composers such as "you should do more with this gesture"-"you need a stronger gesture here to articulate this important point of arrival"-"I like these gestures, but the way you string them together doesn't make any musical sense to me." Similarly, the concept of the musical gesture is often at the heart of how composers describe their compositional process: "I didn't compose this piece from start to finish, but rather found a gesture that I really liked, and built the piece around that." Not that composers consciously choose this expression over others; rather, gesture seems intuitively and intrinsically musical, and it conveys a sense of physical motion through time that these other terms do not. It is for this reason that it often dominates conversations of composers about their work. The term also useful, even necessary, because the actual pitch and rhythmic details of recent music are often so complex that they resist description in more specific terms. We can hear and describe a musical event as a gesture even if we cannot accurately perceive the exact pitches and rhythms of a passage. 
Gesture is also a word that we hear constantly in the world of electroacoustic and computer music. An important aesthetic task in at least some electroacoustic music is to impart a sense of physical motion in an idiom that does not involve bodily gestures of performers at all. For example, in an essay about the notation of electroacoustic music, one composer has recently written, "In concerts of acousmatic pieces, no performers are involved apart from the sound projectionist. This type of music is designed for loudspeaker listening, where the audience does not have visual access to the gestures of soundmaking." The familiar term gesture control, as I understand it, is about making sounds that are not directly produced by human physical motion, but seem as though they are so produced. It is also about developing and engineering technologies whereby actual physical motion with a touchpad or joy-stick-or a T-stick--translates naturally into the illusion of moving sound. Or, conversely, that hearing such sounds produced electroacoustically will stimulate in us the feeling of a physical gesture, perhaps the one we would have to use were we to have to produce a similar succession of sounds on an acoustic instrument. It is a challenge to analysts to think systematically about musical gesture, but in my view, this is entirely possible, and can lead up into important insights about the music with which we are dealing.

LP In your perspective, what is the current situation of musicological and theoretical research in music?

$P M$ It seems to me that musicological and theoretical research in music is in a growth phase. This can be seen in the blossoming of scholarly societies in music theory and musicology all over the world. The two societies meeting here this week are excellent examples of new music-scholarly organizations that bring together musicians and scholars with common interests and common goals. When I entered the field in the late 1970s, the Society for Music Theory in the US had just been founded, and there was only one regional music theory society, the Music Theory Society of New York State. Now there are ten, in all sections of the US. And, as you know, there are now societies in music theory and analysis in many countries and regions of the world, and they all seem to be thriving. There are also specialized societies in the analysis of world music, popular music, music perception and cognition, and many more. With the expansion of music scholarship has come a proliferation of journals, in print and online, that produce 
new work and offer places for scholars, young and old, to publish. And finally, we are seeing a dramatic internationalization of music scholarship. In the 1970s and early 1980s, young scholars - graduate students and junior professors-had little opportunity to present papers abroad. Now, with many more scholarly meetings around the world, and huge conferences like that of EuroMAC, a young scholar can build up an impressive international portfolio within a year or two of entering the field.

The underside of all this energy and activity, though, is that it is taking place at a time when universities and other educational institutions are downsizing and reducing the number of teaching positions available. In a word, this means that there are many more candidates for fewer and fewer jobs, certainly in the USA, but also worldwide. And so students thinking about going to graduate school and entering the rewarding field of music scholarship need to take a close look at the reality of employment possibilities that will await them a few years down the road when they finish their dissertations. One way in which graduate students can prepare themselves for the job market is to develop skills in more than one area-not only, say, publishing in two or more different scholarly fields, but making themselves marketable in administration, in technology, or in related fields in music. Technology is particularly important here; I know young scholars who have relatively low-paying teaching positions, but they are able to sell their skills with music notation software, recording engineering, or video game development and thereby make a productive living.

LP How do you assess the contribution of interdisciplinary studies to the field of musicological research?

PM Interdisciplinarity is crucial these days, in teaching, to be sure, but also in scholarship. When I entered the field, it was to my advantage to have developed a secure knowledge of the historical and literary background of Wagner's Ring, and to have written an article on Roland Barthes and music. But my "bread and butter," as the saying goes, was my musical skills, my knowledge of the classical repertoire, and my experience in analysis. Now, with the dramatic growth of interest in sound studies, music perception and cognition, music in society, popular culture, and much more, scholars at the beginning of their careers need to be aware of what is going on in related fields, and keep up-todate in one or two of them. The days of writing dissertations on a particular 
composer or piece seem to be diminishing. Fewer and fewer students are writing on individual composers repertories, or pieces, and more and more are writing interdisciplinary studies, because they sell, and that's where the energy seems to be. At Yale these days, even in music theory we have very few students writing dissertations on music-analytical topics. In some ways I see this as a healthy development, but in others I see it as a loss. I'm skeptical of the idea that music studies are moving further and further away from music.

LP What is your advice for the professional development of a music analyst?

$P M \quad$ 1) Stay engaged with music: excellent musical skills, a trained ear, and a firm knowledge of one or repertories are still essential to professional development and opportunity. 2) That said, be versatile. More than ever, it's common for music students to be eclectic - to practice Chopin for a while, then listen to electronic dance music on the walk to music history class, and then to jam with friends on a couple of jazz tunes in the evening. I regularly ask my teaching assistants to supply me with popular or jazz tunes that incorporate the harmonic phenomena that we study in class. Students, who seem to feel no dissonance among their wide selection of musical tastes, are always engaged by this didactic behavior. Eclecticism sells. 3) Take a broad view of your discipline, and try to understand its historical and cultural context. Be the best musician, analyst, and teacher that you can, but keep your eyes open: honor and value what you're doing, but be aware of its limitations.

\section{Entrevista com o Prof. Edgardo José Rodríguez, conduzida pelo Prof. Carlos Almada}

$C A \quad$ Você poderia nos contar sobre o cenário acadêmico em relação ao campo da teoria musical na Argentina? Se possível, poderia também, por favor, apresentar uma breve contextualização histórica sobre este aspecto?

ER Na minha opinião, a teoria musical na Argentina, entendida como campo de estudo, reflexão e desenvolvimento específico, foi constituída apenas nas últimas décadas. Antes disso há apenas alguns exemplos isolados, dos quais os mais significativos para mim são: 
(1) os trabalhos de Francisco Kröpfl (1931), entre o final da década de 1960 e início dos anos 1970. Em uma de suas abordagens, desenvolveu uma metodologia composicional baseada em ordenamentos intervalares chamados "micromodos". Isso foi reconstruído por meio das anotações de seus alunos e em alguns artigos publicados, muito tempo depois. Em outra abordagem, ele criou uma metodologia de análise rítmica (Propuesta para una metodología de análisis rítmico. Buenos Aires, 1989. Edición del Departamento de Música, Sonido e Imagen del Centro Cultural Ciudad de Buenos Aires), sobre a qual, até onde eu sei, nenhum estudo musicológico foi publicado.

(2) Sergio Hualpa (1941-1990), professor de Harmonia da Faculdade de Belas Artes UNLP, nos anos 1980, escreveu dois manuais de harmonia (para circulação acadêmica) onde propôs novos conceitos que, na época, não eram redutíveis a concepções tradicionais riemannianas ou schenkerianas. Estas obras não foram publicadas e tampouco estudadas musicologicamente.

CA Poderia, por favor, comentar sobre sua trajetória como compositor, arranjador e instrumentista?

ER Desde criança estou ligado à música. Aos 7 ou 8 anos de idade participei de uma banda juvenil, onde tocava trompete. Um pouco mais tarde, ingressei no conservatório para estudar violão. Cantei em coros durante minha adolescência. Durante o curso secundário, paralelamente ao conservatório, integrei um conjunto de rock e estreei minhas primeiras composições das quais, todavia, não me arrependo hoje. Logo ao graduar-me na universidade, ingressei no sistema nacional de pesquisas e depois no sistema universitário (onde ainda desenvolvo meu trabalho).

Componho assiduamente, música para cena, tango contemporâneo, música popular argentina e acadêmica de vanguarda.

CA Infelizmente, temos no Brasil pouca informação sobre a música contemporânea argentina. É a mesma situação em seu país? Se afirmativo, poderia comentar brevemente possíveis soluções no nível acadêmico/ institucional?

ER Creio que sim. Salvo a obra de Villa-Lobos, a música acadêmica brasileira em geral e, em particular, a contemporânea, é quase completamente desconhecida em meu país. Isso toma parte do desconhecimento cultural e 
político, mútuo e geral (em minha opinião, as únicas exceções são a música popular brasileira, que é um fenômeno mundial e, desde muito, o futebol). As razões para isso podem ser várias. Uma delas, aliás, no caso do Brasil, é a diferença linguística, o que não explicaria no entanto a desconexão entre a Argentina e os demais países em que se fala o castelhano. Evidentemente, nossas sociedades, pela natureza de seus desenvolvimentos históricos, cresceram muito desvinculadas cultural e economicamente das sucessivas e diferentes (no caso do Brasil) metrópoles. A proximidade física de nossos países não conseguiu superar essa distância referencial original. Num determinado momento, pensou-se que o Mercosul proporcionaria uma aproximação substantiva o que, no entanto, não aconteceu.

CA Gostaríamos muito de ouvir sobre seu novo livro, sobre a música do século XX. Poderia, por favor, dar-nos um painel geral básico sobre ele?

ER O livro se limita a alguns apontamentos sobre a Escola de Viena (representada somente por Schoenberg e Webern) e o serialismo integral. É o resultado de todos esses anos de estudo e análises, um resumo, uma sistematização das fontes, uma genealogia intelectual. Em certo sentido, é um registro de nossas ideias sobre esses temas (o livro foi escrito junto com meu colega e amigo Alejandro Martinez). Ao mesmo tempo, pretende ser um suporte excêntrico, realizado por musicólogos que não participam diretamente da tradição que originou as músicas estudadas. 
MUSICA THEORICA 201902

SCIENTIFIC ARTICLE

Data do recebimento: 21/05/2019

Data da aprovação final: 26/06/2019

\title{
A Visita de Beethoven ao carnaval brasileiro em 2017: Ensaio sobre fantasia analítica e hermenêutica narrativa em música ${ }^{1}$
}

\author{
Beethoven's Visit to Brazil During the 2017 Carnival: Essay on Analytical \\ Fantasy and Narrative Hermeneutics in Music
}

\author{
Ilza Nogueira \\ Universidade Federal da Paraíba \\ Academia Brasileira de Música
}

Resumo: $O$ presente trabalho apresenta uma proposta narrativa para a cognição musical da Chacona ao Luar do compositor brasileiro Edino Krieger (Brusque, SC, 1928), uma peça para piano solo composta em 2017. Motivada por uma encomenda da pianista alemã Susanne Kessel, a Chacona integra o projeto internacional "250 Peças para Beethoven", uma gigantesca homenagem antecipada ao compositor alemão pelos vindouros 250 anos de seu nascimento. Segundo o referido projeto, os compositores convidados deveriam criar peças que remetessem à obra de Beethoven. Assim o fez Krieger em sua Chacona, cujo título não deixa dúvidas sobre o cumprimento da exigência. Objetivando a observação da obra enquanto discurso musical potencialmente significativo, este estudo analítico investiga a estrutura formal, os materiais musicais e as técnicas composicionais, no sentido da construção de um argumento que justifique a obra enquanto homenagem musical contextualizada tanto histórica quanto culturalmente. Recursos composicionais intertextuais e interculturais interagindo num plano de inter-historicidade foram fundamentais à percepção de uma semântica musical e estratégicos para o reconhecimento de "agenciamento" e "atorialidade", ou seja, a identificação da atuação de agentes musicais e do papel funcional dessa atuação numa trajetória narrativa. No âmbito teórico, argumentações sobre a narratividade musical derivadas de Byron Almén (2003), aliadas a alguns conceitos da psicanálise freudiana e da teoria lacaniana (notadamente o trinômio "Imaginário", "Simbólico" e "Real") esteiam a argumentação narrativa que se define a partir da escritura musical. Tendo em vista que os aspectos imaginativos da mente na interpretação performática e na escuta submetem a realidade do texto musical a uma re-subjetivação, esta interpretação narrativa propõe-se aberta, ambígua e questionável.

\footnotetext{
${ }^{1}$ Trabalho apresentado no evento "Música Analítica 2019: Simpósio Internacional em Análise e Teoria da Música", ocorrido na Universidade Católica Portuguesa, Campus da Foz, Cidade do Porto, entre 21 e 23 de março de 2019.
} 
Palavras-chave: Música e narratividade; Análise musical interdisciplinar; Música e psicanálise; Homenagem musical; Edino Krieger

Abstract: This paper proposes a narrative analytical approach for Edino Krieger's Mondschein Chaconne, a piano piece composed during the Brazilian carnival season of 2017. Commissioned by German pianist Susanne Kessel, Krieger's chaconne integrates the international project "250 Pieces for Beethoven", an anticipated tribute to the German composer's forthcoming 250th birthday. Considering the potentially meaningful discourse of this music, the analysis observes the formal structure, music materials and compositional techniques in the sense of composing an argument that justifies the chaconne as a historically and culturally contextualized musical tribute. Intertextual and intercultural resources interacting in a level of inter-historicity have been crucial for the recognition of musical semantics and considered strategic to the acknowledgement of musical 'agency' and 'actoriality', namely, the identification of acting musical agents and their functional role in a narrative trajectory. In the theoretical perspective, studies on musical narrativity by Byron Almén associated with concepts from the Freudian psychoanalysis and the Lacanian theory (notably the trinomial "Imaginary", "Simbolic" and "Real") support the narrative plot outlined from the score. Considering that the mind's imaginative aspects in music performance and listening submit the reality of the score to resubjectivations, this narrative proposal ultimately reveals itself as an open, ambiguous and questionable interpretation.

Keywords: Musical narrativity; Interdisciplinary music analysis; Musical tribute; Edino Krieger

\section{Introdução}

Em 2020 o mundo musical celebrará 250 anos do nascimento de Beethoven, o "gênio indomado", um mito aberto a múltiplas tentativas de decifragem. Comemorações já se antecipam, como é o caso do projeto internacional "250 Piano Pieces for Beethoven" da pianista alemã Susanne Kessel. Compositores de todo o mundo foram convidados por ela a "dialogarem" com o ilustre homenageado através da linguagem da música. Concebido em 2015, esse grandioso tributo vem resultando numa multiplicidade de leituras interpretativas da personalidade musical de Beethoven, as quais se expressam como uma notável variedade de diálogos inter-históricos, interculturais e

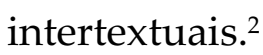

Edino Krieger (Brusque, SC - 1928) foi o compositor brasileiro convidado a fazer parte desse grande "fórum musical" sobre Beethoven. Sua "Chacona ao

\footnotetext{
${ }^{2}$ As 250 obras que integram este projeto serão publicadas em 2020 pela editora Musica Ferrum (Londres, UK). Gravações para transmissão radiofônica e CDs estão sendo realizadas pela WDR (Colônia, Alemanha) desde 2016.
} 
MUSICA THEORICA Revista da Associação Brasileira de Teoria e Análise Musical 2019, v. 4, n. 1, p. 11-29 - Journal of the Brazilian Society for Music Theory and Analysis@ TeMA 2019 - ISSN 2525-5541

Luar" (Mondschein Chaconne em alemão) foi composta no apogeu do carnaval de 2017. O espírito carnavalesco lúdico, alegre e extrovertido motivou a homenagem brasileira ao mal-humorado, taciturno e recluso compositor alemão. ${ }^{3}$ Meu estudo objetiva revelar um possível significado derivado dessa correlação paradoxal na chacona de Krieger.

Antes de adentrar o estudo analítico propriamente dito, algumas considerações sobre recursos estruturais significantes ao discurso narrativo são oportunas à compreensão da escolha do ponto de vista da narratividade musical para este ensaio.

\section{Considerações teóricas}

Um dos recursos estruturais mais valorizados na construção de narrativas é a redundância. Segundo o crítico literário norte-americano Peter Brooks, a repetição é inerente ao discurso narrativo, dando forma à energia, estabelecendo conexões e proporcionando compreensão. A narrativa, diz Brooks, "deve fazer uso perceptível de repetições específicas para criar a trama, ou seja, para nos mostrar uma interconexão significante dos eventos"4 (Brooks 1984, p. 99).

A distinção entre a "repetição pura" e a "repetição diferente" é significativa para a compreensão do poder semiótico da repetição. A diferença na redundância de um evento leva a uma compreensão dos episódios contíguos como um sistema mutualista, funcionando como numa "cadeia significante". ${ }^{5}$

Em seu artigo "Freud and the Semiotics of Repetition", Robert Rogers ${ }^{6}$ atenta para o valor semiótico do conceito freudiano da "compulsão à repetição":

[...] repetição é significado. Repetição é sempre significativa. O verdadeiro significado do que Freud chama compulsão à repetição está [...] no poder de seus aspectos significantes: sua força como significado e não seu significado

\footnotetext{
${ }^{3}$ A estreia da Chacona, ocorrida a 22.5.2017 (Bonn, Haus der Luft- und Raumfahrt), encontra-se disponibilizada na internet em: https://vimeo.com/219808597.

${ }^{4}$ [Narrative] must make use of specific, perceptible repetition in order to create plot, that is to show us a significant interconnection of events.

${ }^{5}$ A teoria psicanalítica de Lacan define a expressão "cadeia significante" como uma combinação associativa de significantes, provocando uma reação em cadeia. Uma explicação do conceito particularizada na análise da Chacona de Krieger se encontra na Nota 15.

${ }^{6}$ Robert Rogers, professor na Universidade Estadual de New York em Buffalo, é reconhecido pela sua produção em crítica literária psicanalítica.
} 
como força. Considerada como significação, [...] repetição é re-apresentação e re-apresentação é representação (Rogers 1987, p. 584). ${ }^{7}$

A estrutura da Chacona, em sua trajetória cíclica, repetitiva e variante, estimula a percepção de narratividade na peça de Krieger. Ademais, enquanto o processo da variação contínua se desenvolve, a estrutura de larga escala da peça se refere a um outro modelo cíclico: a simetria palindrômica ABA. ${ }^{9}$

Outro recurso igualmente valorizado na construção de narrativas é a intertextualidade. A emergência da memória de vivências musicais em dialogia com novas experiências é um expediente estratégico para a compreensão da "atorialidade" e do "agenciamento",10 caraterísticas discursivas essenciais à narrativa. A "voz" do outro propicia o reconhecimento de diálogos; diálogos pressupõem personagens (atorialidade); personagens implicam ações (agenciamento); personagens e ações resultam em tramas.

É de Byron Almén, um dos teoristas expoentes em narratologia musical, o entendimento definitivo sobre a essência da cognição narrativa em música. Segundo ele, "a narrativa musical é o processo através do qual o ouvinte percebe e segue uma transvaloração de relações hierárquicas culturalmente significativa numa determinada temporalidade" (Almén 2003, p. 12). ${ }^{11}$

\footnotetext{
${ }^{7}[\ldots]$ repetition is meaning. Repetition is always meaningful. The true significance of what Freud calls the repetition-compulsion lies in the actual power of its signifying aspects: its force as meaning, not its meaning as force. Considered as signification, repetition is always [...] representation and re-presentation is always representation (Rogers 1987, p. 584).

${ }^{8}$ A Chacona de Krieger corresponde ao conceito que mais se reconhece como passacaglia: a forma variação-ostinato baseada numa linha melódica fundamental (ground).

${ }^{9} \mathrm{O}$ modelo ABA corresponde a uma das 3 categorias da sintaxe agencial definidas por Greimas: aquela que se define na relação de mutualidade binária do tipo "Sujeito - Objeto", na qual "A deseja B, e onde a relação transitiva ou teleológica é o desejo" (Apud Grabócz \& McClelland 1999, p. 20). Interpretando a sequência sintática sob o ponto de vista da semântica, A corresponde a uma ordem inicial transgredida em B e restaurada em A.

${ }^{10}$ Os termos "agenciamento" e "atorialidade" implicam, respectivamente, no reconhecimento da atuação de "agentes musicais" (unidades sintáticas antropomorfizadas na cognição de uma trajetória narrativa) e do papel funcional dessa atuação numa possível trama.

${ }^{11}$ Drawing on Liszka, I define and situate musical narrative as follows: Musical narrative is the process through which the listener perceives and tracks a culturally significant transvaluation of hierarchical relationships within a temporal span (Almén 2003, p. 12).
} 
Transvaloração cultural, intertextualidade e redundância: são estes os três conceitos que subsidiam minha interpretação narrativa da Chacona de Krieger, no sentido da compreensão do caráter referencial e representativo desta obra.

\section{Fantasia analítica}

Minha interpretação da Chacona ao Luar considera Beethoven como personagem de uma suposta e possível narrativa que se define a partir da memória historiográfica acerca da personagem bem como do contexto cultural de onde provém o narrador: Edino Krieger, músico brasileiro de ascendência teuto-italiana.

A peça inicia com a "voz" de Beethoven (Ex. 1). O reconhecimento da frase "magnética" do primeiro movimento da Sonata op. 27 n. 2, da forma como se apresenta desde a anacruse ao compasso 1 até o compasso 4 - uma citação melódica, filtrada do contexto harmônico-textural original e sem algum novo tratamento composicional -, funciona como um retrato, uma ilustração de capa de livro biográfico.

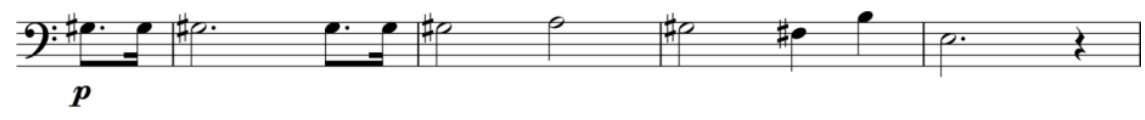

Exemplo 1: Chacona ao Luar, c. 1-4

Após a breve introdução de Beethoven, a composição de Krieger inicia com um contraponto a 3 vozes (Ex. 2), apresentando concepções independentes relativas ao que deverá executar a mão esquerda - um "comportado" e tradicional contraponto ao "cantus firmus" beethoveniano - e a mão direita uma fluente e lírica melodia de contorno ondulante, onde podemos reconhecer uma alusão ao ostinato rítmico que sublinha a condução melódica em todo o primeiro movimento da Sonata de Beethoven (Ex. 3). 


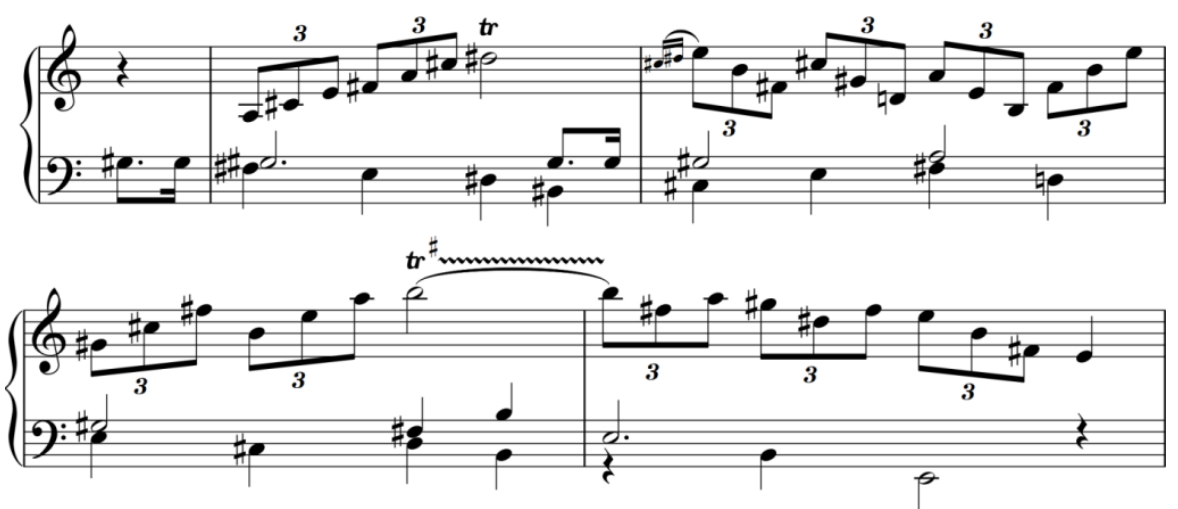

Exemplo 2: Chacona ao Luar, c. 4.4-8

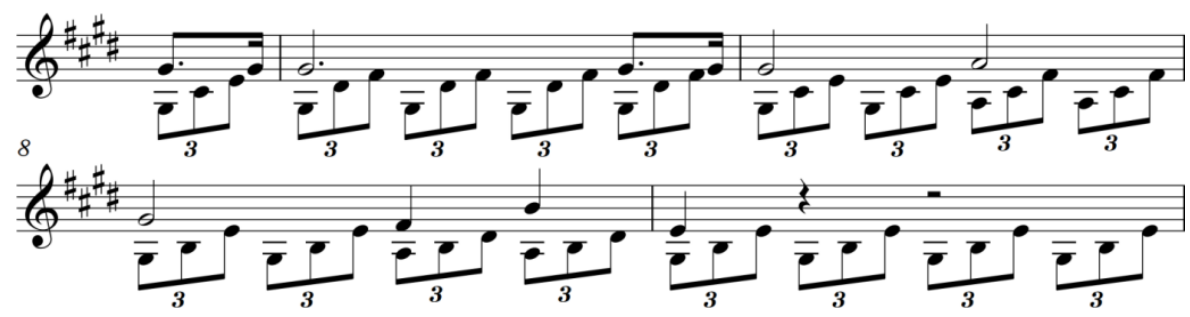

Exemplo 3: Beethoven, Sonata op. 27 n. 2, 1ํㅡㄹ movimento, c. 6-9

Neste primeiro enunciado ${ }^{12}$ (Ex. 2), nota-se, portanto, uma recaracterização do Ur-text, realizada com a inversão das funcionalidades de seus elementos: a melodia original se tornou em Krieger a base estrutural; e o acompanhamento harmônico em tríades arpejadas repetidas reinventou-se na superfície melódica, onde a profusão de ondulações se traduz em exuberante e luminoso lirismo. De início, portanto, a Chacona se mostra como recriação da sua referência musical. Em minha interpretação narrativa, a primeira frase de Krieger funciona como uma apresentação da personagem Beethoven, evidenciando a personalidade artística ambígua, cuja produção concilia aspectos da tradição culta aprendida com a invenção.

A divisa com a variante seguinte (Ex. 4) dá-se pela mudança brusca de centro tonal entre Dó\# menor e Dó Maior, correspondendo ao que ocorre no movimento da sonata de Beethoven. Nessa segunda variante, o contraponto da mão esquerda permanece inalterado em seu estilo, enquanto a insinuante linha

\footnotetext{
${ }^{12}$ Enunciados são unidades discursivas mediadoras de significados. Sendo o objetivo desta análise o reconhecimento de um discurso narrativo, optei pelo termo "enunciado" em detrimento de "frase" (mais adequado a uma análise da sintaxe da obra).
} 
MUSICA THEORICA Revista da Associação Brasileira de Teoria e Análise Musical 2019, v. 4, n. 1, p. 11-29 - Journal of the Brazilian Society for Music Theory and Analysis@ TeMA 2019 - ISSN 2525-5541

melódica da mão direita ganha ímpeto (com as semicolcheias), complexidade (na longa ascendência cromática do compasso 11) e densidade (na transformação do caráter melódico em progressão acórdica). Se considerarmos a melodia da mão direita como signo da livre invenção, podemos dizer que o lado inventivo da personagem "ganhou asas". Na finalização da frase, o progressivo distanciamento das mãos direita e esquerda, em igualmente progressivo aumento de intensidade sonora, sugere a evolução do diálogo entre tradição e invenção a um clímax. Nessa evolução, quando as divergências entre mão direita e mão esquerda se conciliam, percebe-se um ganho em dramaticidade até a grandiloquente chegada à tônica (Dó), projetada em 4 oitavas.
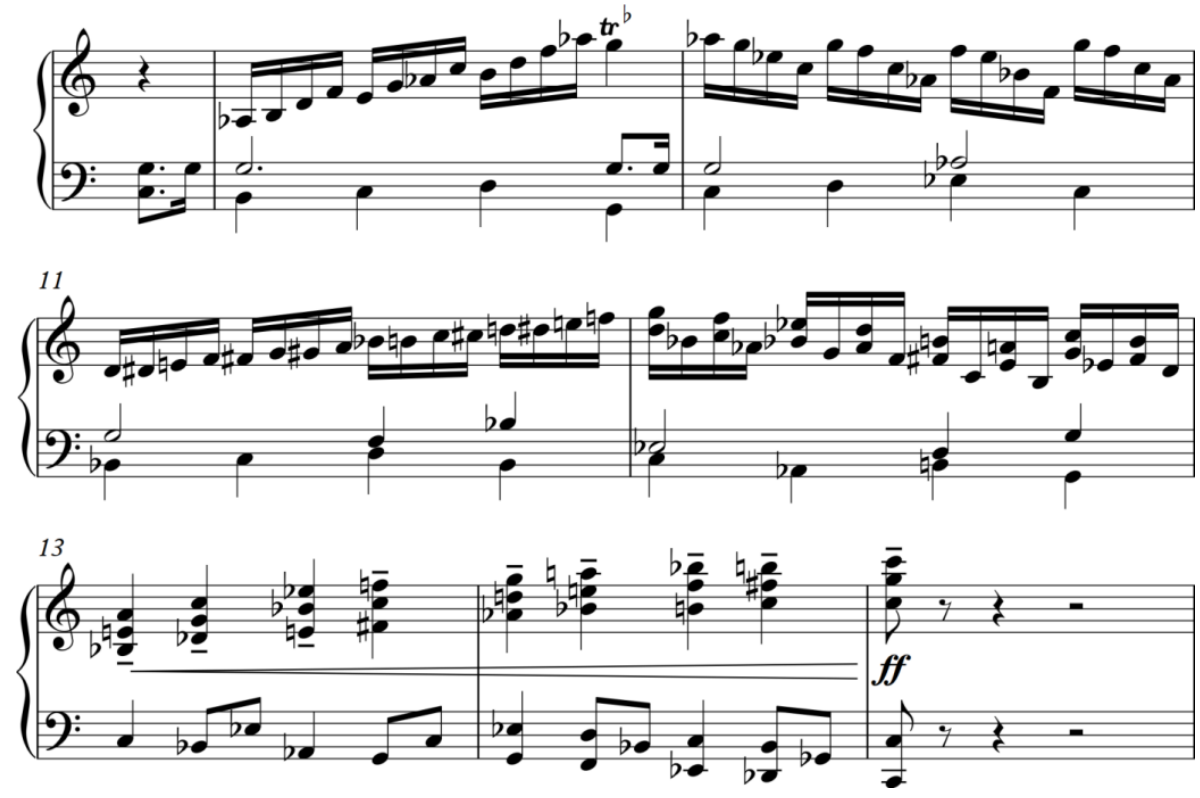

Exemplo 4: Chacona ao Luar, c. 8.4-15.1

O trecho sequente (Ex. 5) se configura como um platô alcançado pela progressão antecedente (c. 13.1-15.1), climatizando a crescente energia com a figuração de fusas. Na interação entre as mãos esquerda e direita, a evolução rítmica se refere à célula pontuada da frase apropriada de Beethoven (mão esquerda), assim como também alude a um dos padrões rítmicos básicos da roda de samba (mãos esquerda e direita). ${ }^{13} \mathrm{~A}$ percepção desta interculturalidade deve por a intuição analítica em "modo de espera".

\footnotetext{
${ }^{13}$ Normalmente executado no pandeiro, o padrão rítmico alterna, sucessivamente, a batida do polegar na borda do instrumento (1a e 4a semicolcheias no registro mais grave) e o toque com as pontas dos dedos e depois com o pulso no centro da pele (2a e à 3a semicolcheias no registro mais
} 

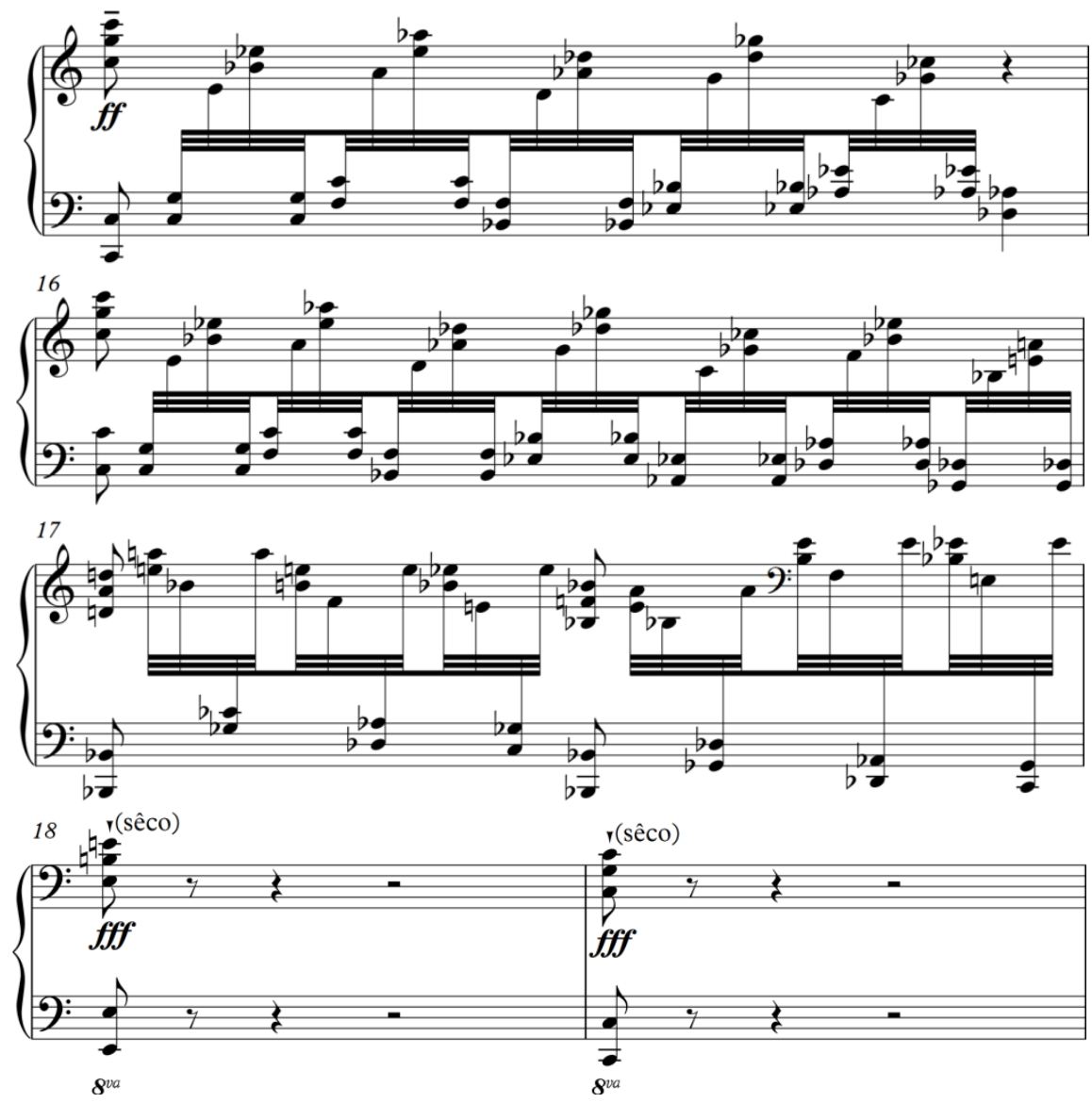

Exemplo 5: Chacona ao Luar, c. 15-19

O expressivo lirismo inicial se transfigurou radicalmente com a troca da polifonia por uma densa homofonia, com a progressiva ampliação da tessitura e da intensidade, e, principalmente, com a transformação da natureza mélica e cantabile no caráter rítmico enérgico e percussivo.

agudo). Devo a percepção dessa referência cultural, importante à minha interpretação narrativa, à pianista brasileira Cristina Capparelli Gerling. Sua execução deste trecho (c. 15-18) difere radicalmente da virtuosística e dramática execução da pianista alemã Susanne Kessel, que o executa com maior velocidade, enquanto o uso do pedal de sustentação dilui a percepção da implícita brasilidade rítmica. Sem uso do pedal ou implementação de andamento, Gerling imprime ao trecho uma feição jocosa, insinuando uma movimentação intercultural do início ao final desta primeira seção da Chacona. O fato me faz lembrar algumas considerações de Byron Almén sobre características influentes na cognição narrativa, salientando que o condicionamento cultural da performance permite ou convida o ouvinte a estar atento a determinados requisitos da compreensão narrativa da música (v. Almén 2003, p. 8). Faz-me também lembrar Marcos Nogueira em seu texto "Dimensões da produção imaginativa musical: movimentos, formas e intenções". Discutindo distintas vertentes do processo cognitivo, Nogueira ressalta a "cognição situada ou incorporada": uma vertente mais recente das ciências cognitivas, que entende a realidade como algo dependente do seu observador, da sua dinâmica interativa do estar-nomundo (Nogueira 2019, p. 20, nota 4). 
MUSICA THEORICA Revista da Associação Brasileira de Teoria e Análise Musical 2019, v. 4, n. 1, p. 11-29 - Journal of the Brazilian Society for Music Theory and Analysis @ TeMA 2019 - ISSN 2525-5541

Mais do que a ambiguidade estética e a repetição variada, a progressiva transfiguração do lírico ao dramático caracteriza a narratividade desta primeira seção estrutural da peça (vamos chama-la de Seção A). Narratividade esta que estimula as seguintes hipóteses interpretativas:

1. A Seção A se refere à apresentação de uma personagem musical ambígua, situada entre dois mundos estéticos;

2. Esta personagem diz respeito ao gênio de Bonn, como o conhecemos historicamente, com um pé no classicismo e outro no romantismo;

3. A progressiva mutação do plácido, lírico e comedido ao agitado, dramático e soberbo pode representar a evolução da personalidade de Beethoven, dos anos de jovem aprendiz aos de um artista maduro, pressionado por dramas pessoais;

4. A enérgica interseção cultural na passagem entre os compassos 15 a 17 estaria representando um excitante processo de embate inconsciente $^{14}$ entre o mundo interior da personagem (realidade) e estímulos que afluem de um universo externo (fantasia), provocando uma espécie de catexia;

5. A dramática irrupção do silêncio nos compassos 18 a 19 pode representar uma anticatexia (a emergência do ego, reprimindo a energia irracional do id);

6. Do ponto de vista de uma versão historiográfica, a enérgica dramaticidade desenvolvida no trecho entre os compassos 15 a 19 poderia referir-se ao drama pessoal de Beethoven - a progressiva perda de audição - manifesto no trágico “Testamento de Heiligenstadt" escrito em 1802 (pouco depois que compôs a Sonata ao Luar).

Se todas estas conjecturas parecerem razoáveis, somente um exame da música posterior, sob o ponto de vista da configuração de uma "cadeia significante", ${ }^{15}$ responderá favoravelmente (ou não) à sua legitimidade.

\footnotetext{
${ }^{14}$ A adjetivação "inconsciente" se justifica pelo razoável obscurantismo da interconexão motívica na passagem (a célula pontuada derivada de Beethoven e o padrão rítmico do samba).

${ }^{15}$ A expressão "cadeia significante" é utilizada no sentido da compreensão de uma necessária remissão sígnica entre os enunciados musicais (metaforicamente compreendidos) para que uma lógica significante se estabeleça durante a escuta da peça (um raciocínio narrativo).
} 
Após a conclusão dramática da Seção A (Ex. 5, c. 18-19), a citação de Beethoven é retomada numa distinta concepção estética (Ex. 6).
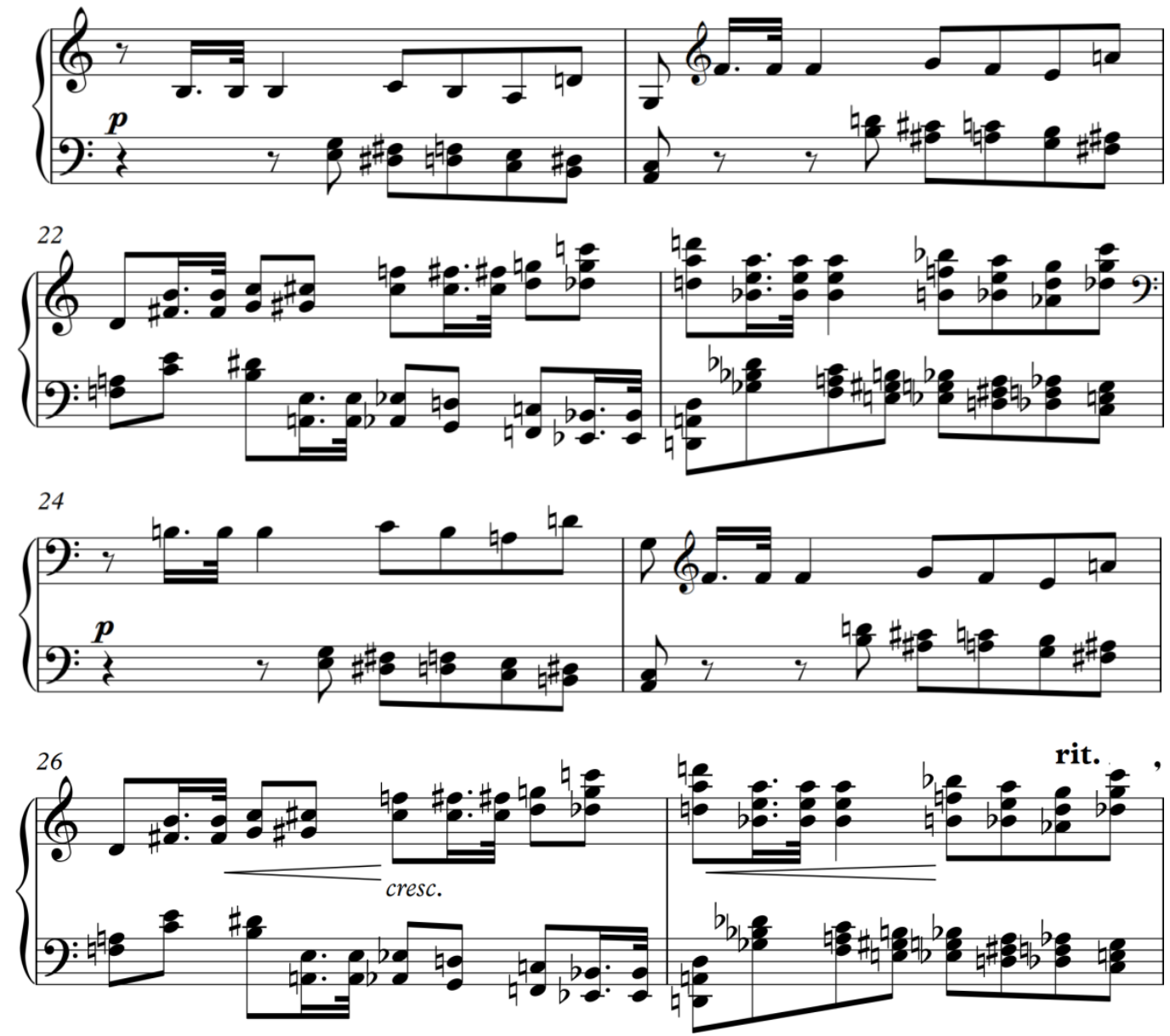

Exemplo 6: Chacona ao Luar, c. 20-27

A languidez das mínimas foi substituída pela marcha apressada das semínimas; assomam-se transposições fugazes, acompanhadas por sequências cromáticas; fragmentações em imitações sequentes se avultam em intensidade, percorrendo direções contrárias. A ascensão na tessitura e a progressiva densidade sonora assinalam para uma conclusão frustrada no compasso 24 . A pequena ruptura e o recomeço da frase prometem novamente - e mais enfaticamente - a conclusão outra vez interrompida pelo início de uma nova variante (vide Ex. 7, c. 28) no processo das variações contínuas. Diferentemente da seção anterior, onde se reconhece um caráter expositivo, este trecho tem características de uma passagem transitiva. Do ponto de vista narrativo, insinuase uma situação de ansiedade, esforço e busca que pode traduzir-se como angústia, ou desejo. 
MUSICA THEORICA Revista da Associação Brasileira de Teoria e Análise Musical 2019, v. 4, n. 1, p. 11-29 - Journal of the Brazilian Society for Music Theory and Analysis @ TeMA 2019 - ISSN 2525-5541

Pergunto: Seria razoável imaginar um vínculo narrativo entre o clímax final da seção anterior e estes oito compassos consecutivos? Poderíamos considerar a transformação da melodia mítica e a perda da eloquência na nova caracterização musical como um processo excitatório da personalidade criativa antevendo um mundo sonoro adiante do seu, em angustiante e desejosa busca da invenção? Poderíamos interpretar esta passagem como uma pulsão direcionada a um vislumbrado objeto de desejo? Poderia esta pulsão ser consequente da ambiguidade cultural insinuada no final da Seção A? A observação da continuidade da música certamente fornecerá subsídios para possíveis respostas.

No compasso 28, a indicação Più mosso, cantabile sinaliza o início da Seção $\mathrm{B}$, correspondendo à exposição de uma ideia de caráter lírico e contorno ondulante em Dó menor (Ex. 7). Os valores estéticos que fundamentaram a composição até então - típicos da tradição culta da Europa central - perdem sua preponderância para traços estéticos emblemáticos da Gestalt vernácula brasileira: o ritmo sincopado, a irregularidade métrica e a ondulação melódica.

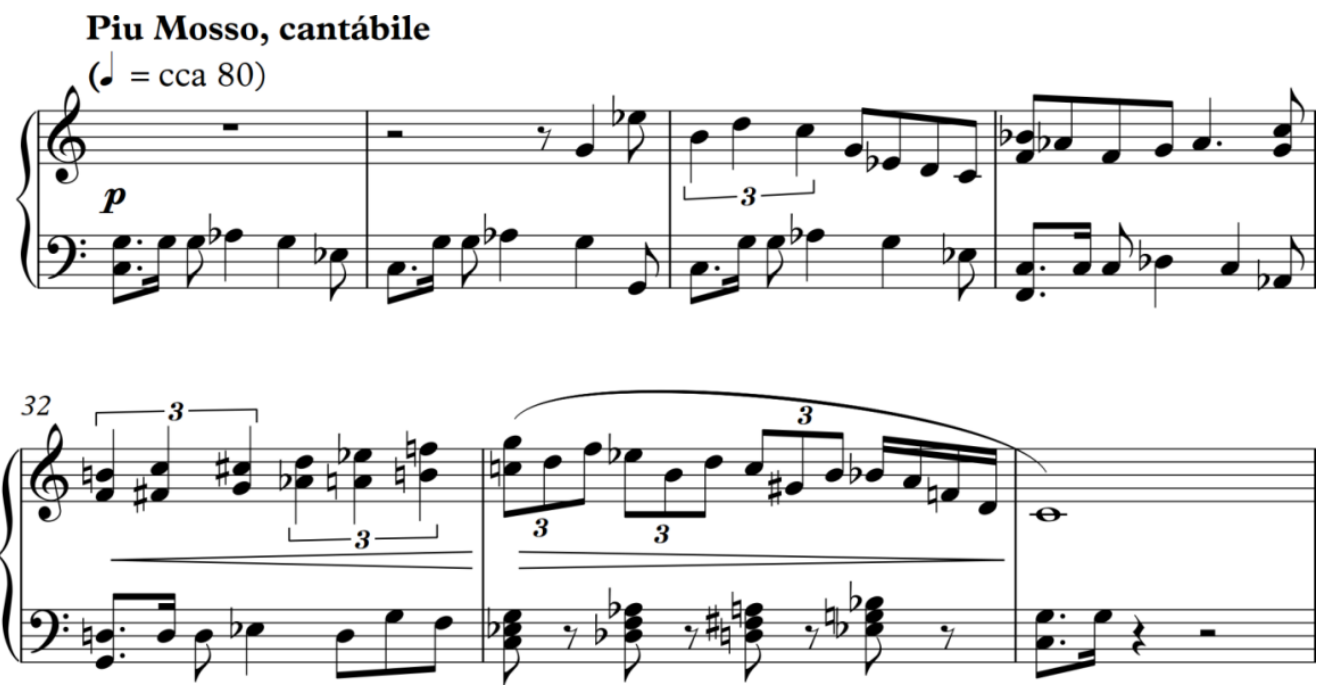

Exemplo 7: Chacona ao Luar, c. 28-34

O referente germânico oitocentista transgride a simetria rítmica característica da sua cultura para adaptar-se à assimetria dos ritmos étnicos afrobrasileiros. ${ }^{16}$ Essa versão "teuto-brasileira" da matriz de Beethoven interage com

\footnotetext{
${ }^{16}$ A estilização da citação de Beethoven poderia ser interpretada como ironia: uma versão do "sublime" em âmbito do "vulgar", do "jargão", do "dialeto", procedimento típico do que, na Teoria da Literatura, se reconhece como "carnavalização": a aproximação entre valores opostos
} 
uma melodia lírica e ondulante, cujo gestual cantabile é típico da brasilidade musical vernácula. ${ }^{17}$ Ademais, essa melodia apresenta características de contorno intervalar análogas às da marcha-rancho "As Pastorinhas" (1937) (Exs. 8a e 8b). A analogia com a canção carnavalesca é outro recurso intertextual significativo na peça. Se a latente brasilidade rítmica nos compassos 15 a 18 pode ser considerada um processo inconsciente, aqui a sua materialização na alusão à canção carnavalesca adquire o status de uma expressão ao nível da consciência.

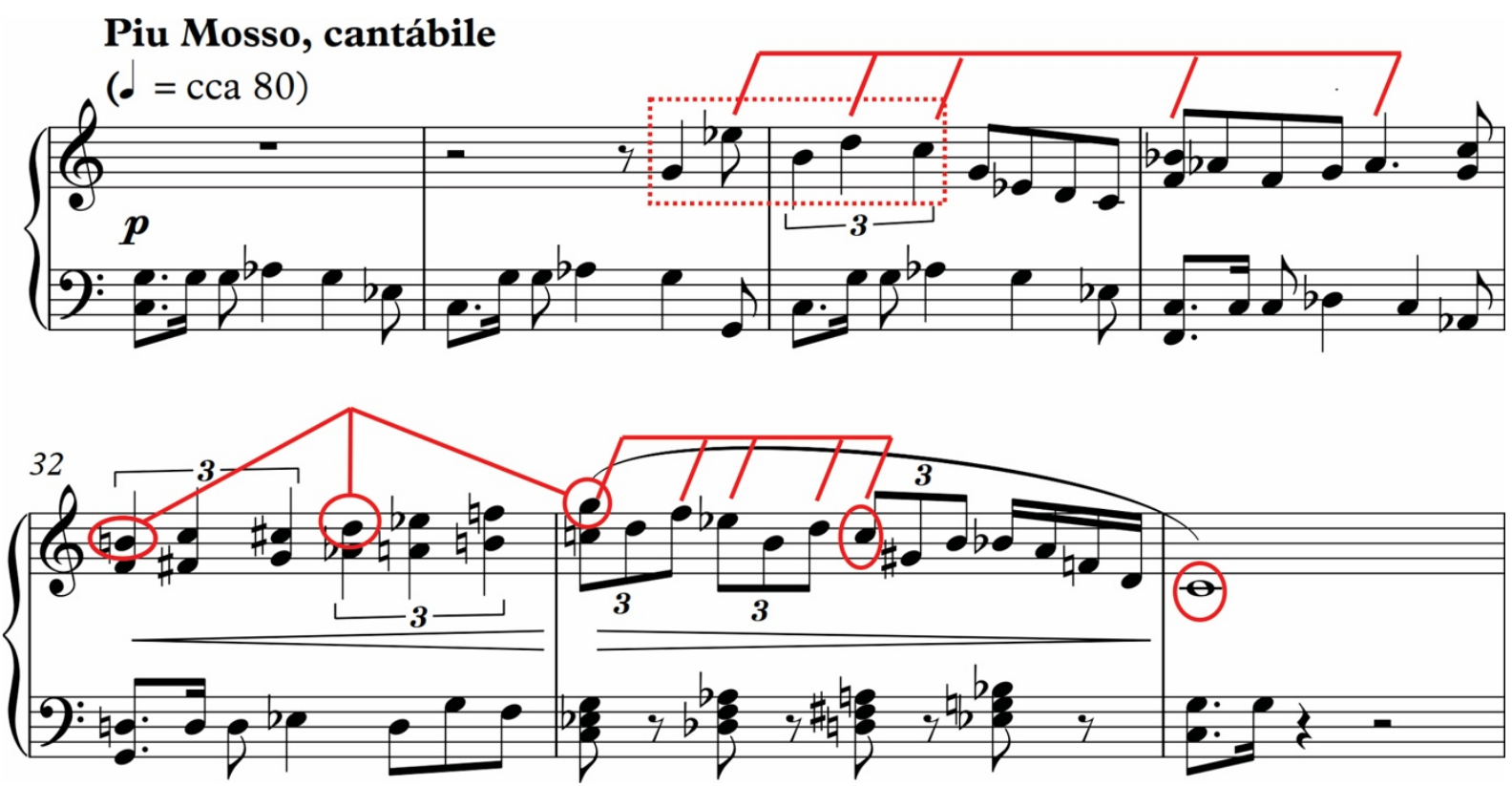

Exemplo 8a: Chacona ao Luar, c. 28-34 (estrutura melódica fundamental)

como o sagrado e o profano, o sério e o cômico, o sublime e o grotesco, o grande e o insignificante, eliminando as distâncias e relativizando as verdades estabelecidas.

${ }^{17} \mathrm{O}$ gesto ondulante que inicia essa melodia - correspondente ao contorno intervalar $[+8,-4,+3,-$ $2,-5]$ - pode ser considerado como característico do inconsciente musical vernáculo brasileiro. 

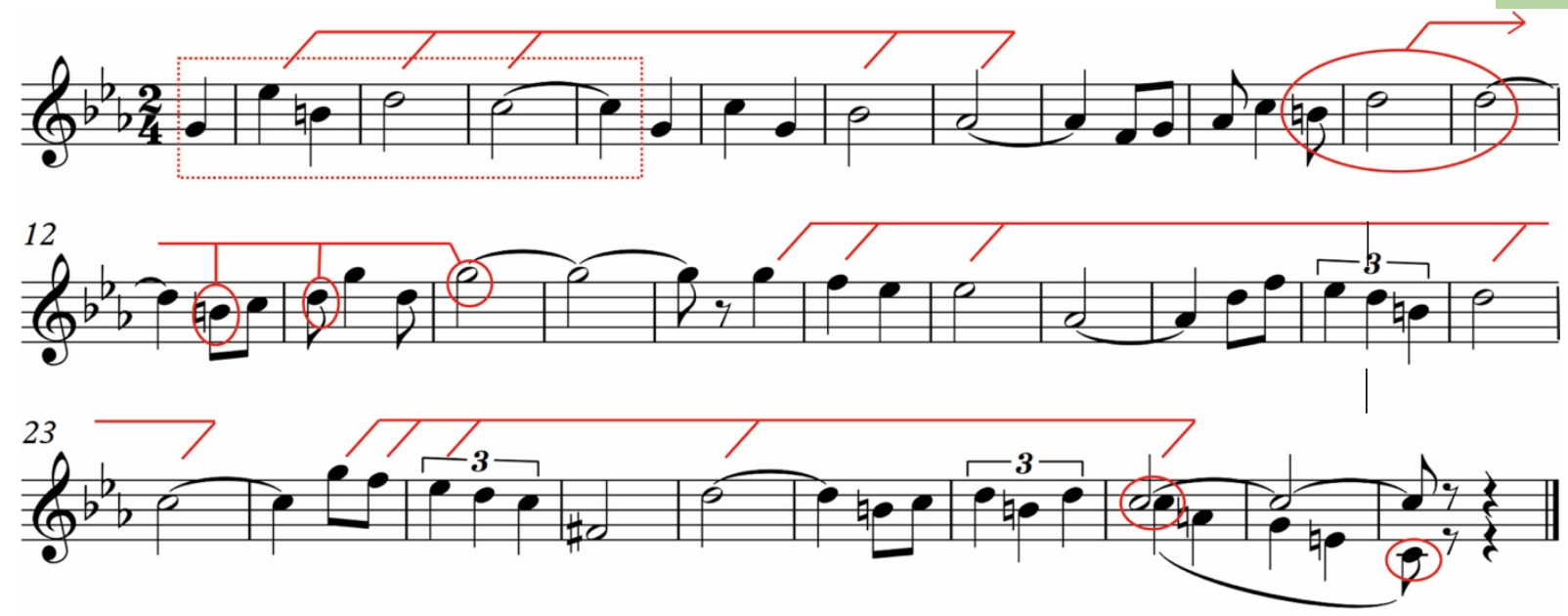

Exemplo 8b: As Pastorinhas (Noel Rosa e Braguinha), c. 1-32 (estrutura melódica fundamental)

$\mathrm{Na}$ frase consequente (Ex. 9), observa-se o ganho em tensão, energia e ímpeto bruscamente interrompido pelo súbito, inesperado reinício da Seção B, novamente inconclusivo.
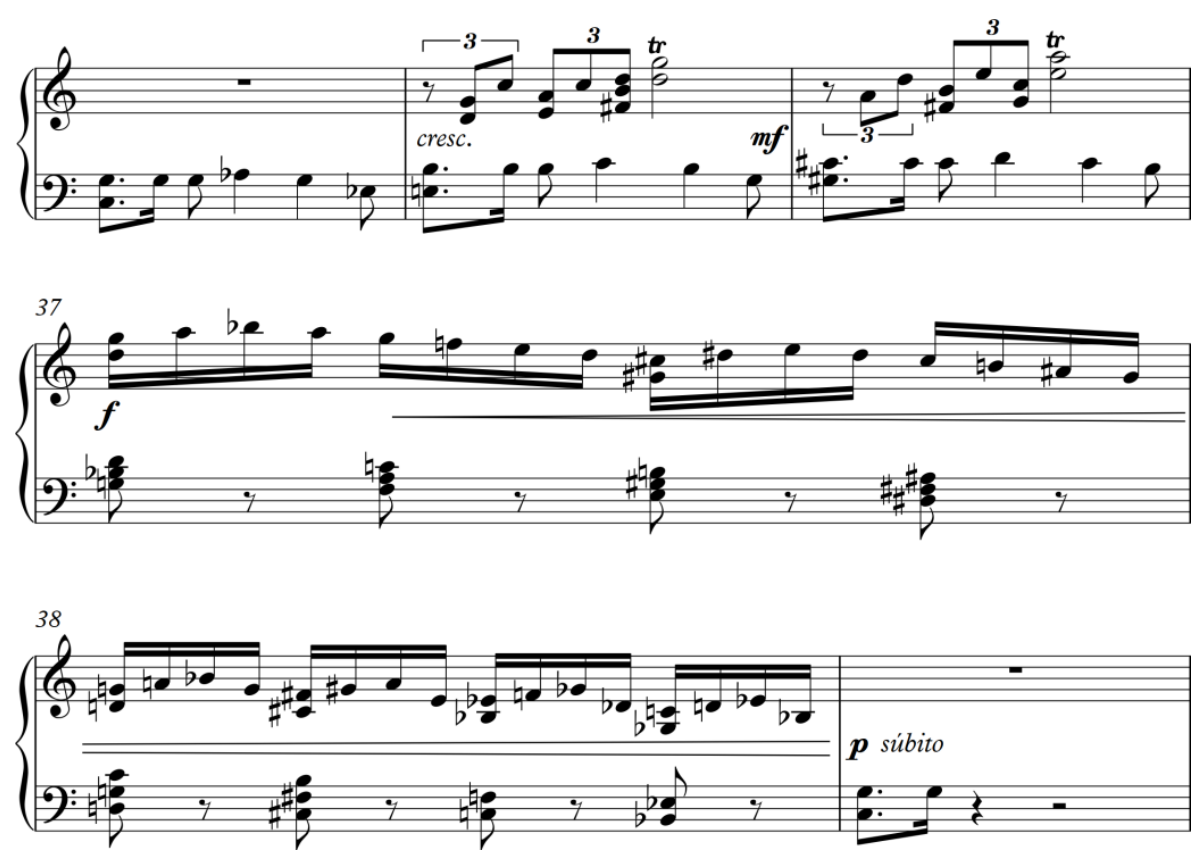

Exemplo 9: Chacona ao Luar, c. 34-39

Considerada em relação à narrativa em progresso, a Seção B foge à realidade. Poderíamos considera-la como um "delírio" da personagem musical? Um surto da imaginação criativa? Ou invocarmos Lacan para encontrar nessa 
evocação carnavalesca o "objeto a" (o objeto causa do desejo, em direção ao qual o sujeito persiste, na ânsia em preencher sua falta primordial)? ${ }^{18}$

Se a expectativa para o que virá após essa espécie de "magia musical" for uma consequência da transvaloração cultural - isto é, o reconhecimento de uma peripeteia ${ }^{19}$ na narrativa -, a música seguinte não a satisfaz. Após a Seção B, o que ocorre é uma repetição da Seção A e da seção transitiva, sem alterações (Ex. $10)$.
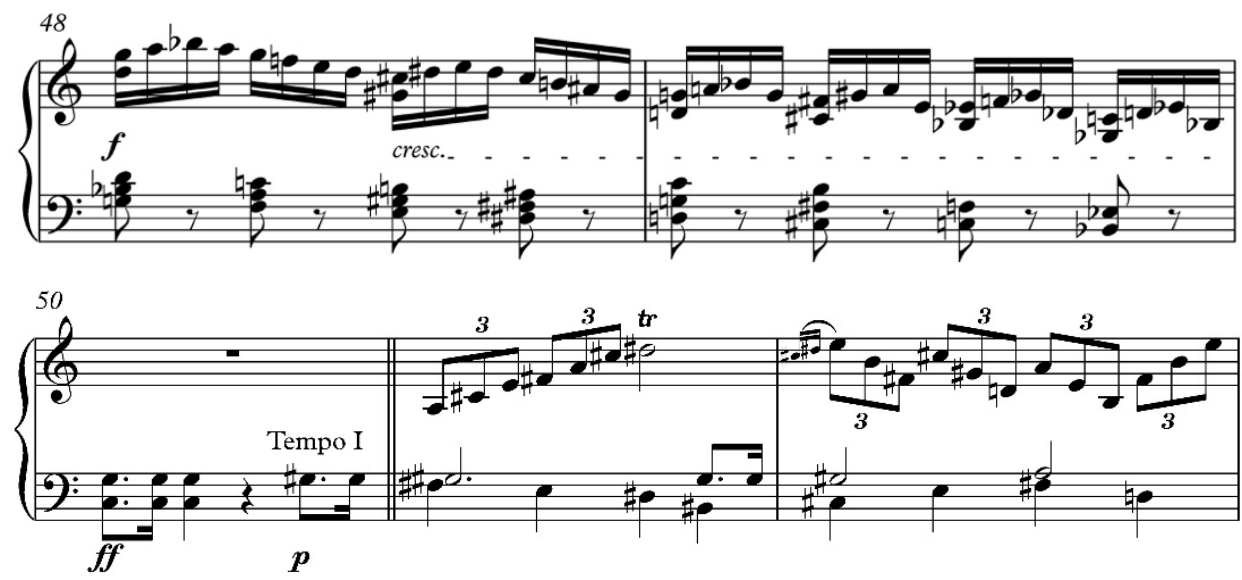

Exemplo 10: Chacona ao Luar, c. 48-52

Uma breve Coda em estilo alla toccata (Ex. 11) finaliza a peça, trazendo à memória a dramática conclusão da Seção A (Ex. 5, c. 18-19). No entanto, se, na finalização da Seção A, a repetição da estrutura acórdica seguida de longas pausas gera tensão e expectativa (uma espécie de propulsão), na conclusão da Coda, diferentemente, o ataque da nota Tônica no registro gravíssimo, em intensidade extrema, após um vertiginoso desabamento da tessitura, traz a sensação de ponto final, de nada mais a dizer.

\footnotetext{
${ }^{18} \mathrm{O}$ "objeto a" é o que perseguimos nas nossas fantasias, sem jamais alcançarmos realmente. É o objeto que constitui e sustenta a fantasia, a qual, por sua vez, é o suporte do desejo; é da fantasia que o desejo se vale nas suas vãs tentativas de satisfação.

19 Peripeteia: reviravolta que caracteriza a narrativa clássica, conduzindo-a a um desfecho catártico.
} 

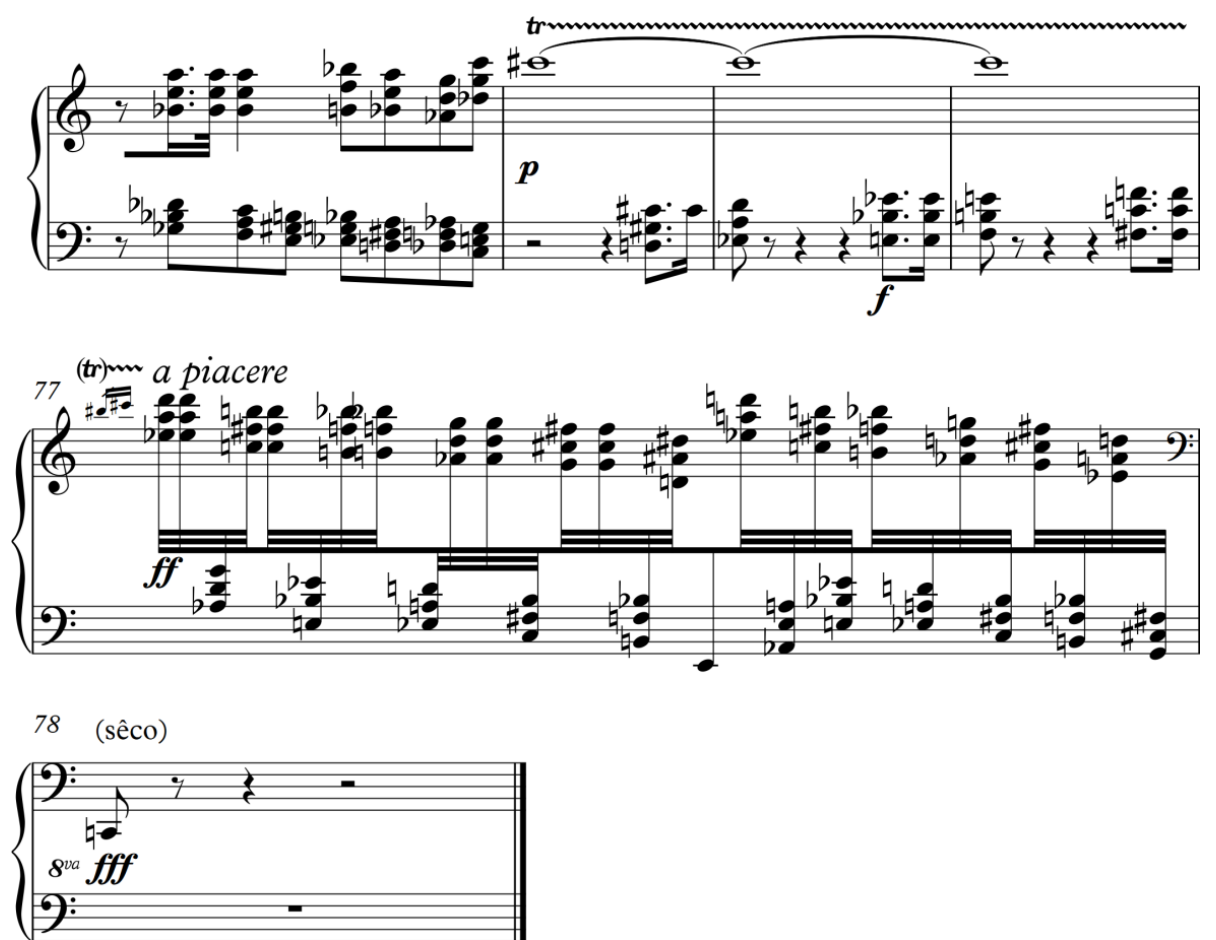

Exemplo 11: Chacona ao Luar, c. 73-78

\section{Hermenêutica narrativa}

Como pudemos observar, a Chacona de Krieger tem uma inquestionável substância narrativa. Ao mesmo tempo, porém, ela apresenta um problema narrativo. A peça se desenvolve numa vertente de sistema tonal expandido, cujo discurso se caracteriza, basicamente, pela causalidade linear, com estruturas de tensão, culminância e relax, conforme o modelo direcional e cumulativo da narrativa clássica. Nesta perspectiva discursiva, a repetição idêntica da Seção A em sequência à Seção B apresenta-se como um enigma: devir sem acúmulo de experiência! Do ponto de vista narrativo, a análise da partitura tropeça no compasso 50. A partir de então, a trama em construção não poderá conduzir-se conforme a expectativa de uma conclusão "coerente" e "decorrente" da Seção B; ou seja, do resultado da confrontação entre uma personagem caracteristicamente apolínea - regida pelo princípio da razão harmoniosa e comedida - e o dionisíaco "outro" - de natureza prazerosa e voluptuosa; esse "outro", que se revela como "o estranho", no sentido freudiano: ${ }^{20} \mathrm{o}$ assustador, que remete ao familiar, ao déjà

20 "O estranho" é uma tradução do conceito freudiano "das Unheimliche", identificado como um assunto da Estética que pertence à categoria "do assustador, do que causa medo e terror" (dass 
vu (a estimulante insinuação da rítmica carnavalesca ao final da Seção A, mostrada no Ex. 5).

O retorno inalterado da Seção A após a Seção B significa, agora para o analista, das Unheimliche: o surpreendente, inesperado regresso ao familiar, causando estranheza. Diante do que se dá a perceber como uma reversão aparentemente ilógica do discurso - uma "dissonância cognitiva"21 -, a atitude do analista é parar, refletir, e admitir que a personagem tem direito a definir sua história; reconhecer que o analista é um mero observador, em vez de "construtor" da trama; e que, como tal, sua tarefa é empenhar-se numa escuta perscrutativa.

Se o tema da narrativa é o sujeito Beethoven, deve-se considerar a complexidade da personagem, cujo problema existencial - o conflito entre a surdez e sua atividade vital e profissional - tem óbvios reflexos sígnicos na sua produção artística tanto quanto na sua interação com a realidade (segundo relatos de época). Por isso, uma interpretação narrativa que pretende referir-se a Beethoven pede por uma hermenêutica multifocal (interdisciplinar), que não minimize o drama existencial.

Quando a busca por auxílio em teorias da literatura e da semiótica não foram suficientes para a decifragem do enigma da reprise, busquei o apoio teórico da psicanálise. ${ }^{22} \mathrm{~A}$ compreensão da interdependência entre as três ordens que compõem a estrutura fundamental da psicanálise lacaniana - o Imaginário (I), o Simbólico (S) e o Real (R) - ajudou-me a encontrar uma solução narrativa para a estrutura da Chaconna. ${ }^{23}$ Entendo que: 1) a Seção A se refere à fase

zum Schreckhaften, Angst- und Grauenerregenden gehört); [...] jene Art des Schreckhaften, welche auf das Altbekannte, Längstvertraute zurückgeht) (Freud [1919] 2012, I, p.1).

${ }^{21}$ Refiro-me à teoria da dissonância cognitiva de Leon Festinger, de acordo com a qual "a relação entre dois elementos é dissonante se [...] um não decorre do outro, ou não se espera que decorra do outro. [...] Se, considerando um par de elementos, qualquer um decorre do outro, então a relação entre eles é consonante" (the relation between two elements is dissonant if [...] the one does not, or would not be expected to, follow from the other. [...] If, considering a pair of elements, either one does follow from the other, then the relation between them is consonant) (Festinger 1956).

${ }^{22}$ Agradeço aos psicólogos Analícea Calmon (Salvador-BA) e Luis Andrade (João Pessoa-PB) a atenciosa supervisão da parte teórica deste estudo, referente ao campo da psicanálise.

${ }^{23}$ Cada uma dessas ordens (ou dimensões) corresponde a um aspecto específico da vida mental do ser humano maduro, nos quais, através dos quais e pelos quais o indivíduo é determinado. $\mathrm{O}$ "nó borromeano" (vide figura abaixo) ilustra a interdependência das três ordens: dois elos separados são unidos por um terceiro de tal forma que, se qualquer deles se desliga, o todo se 
construtiva da imagem da personagem, em gradativo deslocamento para adiante do seu contexto original, na busca da satisfação de uma necessidade intrínseca; 2) a Seção B corresponde à fase de construção do simbólico (o universo do sonho, da fantasia); à desestabilização provisória do Eu submisso à cultura estranha; 3) a reprise da Seção A configura a emergência da dimensão do real, locus da profunda verdade: a falta de sentido; ${ }^{24} 4$ ) a Coda, conduzindo ao trágico final de sensação do "nada mais a dizer", poderia ser compreendida sob o ponto de vista da "pulsão de morte": a tendência ao retorno do que é primordial ao nascimento dos símbolos.

Em outras palavras, a submissão da ansiosa personagem ao estranhamento cultural da Seção B significa um "delírio transitório", entrega ao hedonismo, férias do bom senso, após o que ela volta ao seu mundo dividido entre tradição e invenção, à sua impulsividade dramática, à angustiante busca da originalidade entre ideias inconclusas e recomeços, levando à conclusão de que não há "mais nada a ser". O retorno à Seção A, seguida da seção transitiva que não mais conduz à Seção B e sim à Coda, parece corroborar a suposição de que a Seção B representa o "objeto a" de Lacan; isto é, o objeto causa do desejo, que nunca pode ser alcançado.

Esta perspectiva hermenêutica proveio da escritura da peça; de uma representação simbólica cuja incompletude ontológica demanda a fenomenologia da performance, seu alter ego. A fixidez da escrita, é sabido, desfaz-se na performance. Embora a partitura não apresente nenhuma alteração na reprise da Seção $A$, após a experiência da Seção B é muito provável que o/a “intérprete" não a execute simplesmente como um evento memorizado, mas sob

desmorona; a relação topológica entre eles é o que mantém a estrutura íntegra. Da mesma forma, cada uma das três ordens é fundamental ao todo; a separação de qualquer delas automaticamente resulta no colapso do nexo integral, com resultados catastróficos para o indivíduo.

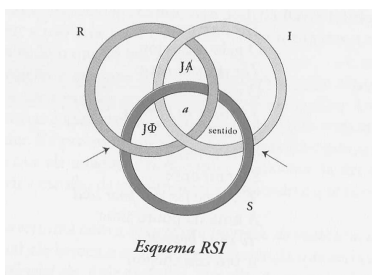

${ }^{24}$ Assim como a batida na porta que interrompe o sonho, o inesperado reinício da peça interrompendo a conclusão da Seção $B$ reconduz a personagem da narrativa à profunda verdade da falta de sentido. 
o efeito da imersão na Seção B; da obra em seu devir. ${ }^{25}$ Também é provável que o ouvinte, por sua vez, escute a reprise interpretada adicionando a memória cumulativa da uma escuta ativa. Possíveis interpretações, portanto, dependem do que se tome como ponto de observação analítica - a partitura (a estrutura muda) ou a performance (a prazerosa "fala" musical).

Concluindo estas reflexões sobre a narratividade implícita na estrutura da Chacona de Krieger de uma forma aberta, ambígua e questionável, cedo a última palavra a Lacan: “Quando se escreve, pode-se muito bem tocar o real, mas não o verdadeiro" (Lacan 2007, p. 78).

\section{Referências}

1. Almén, Byron. 2003. Narrative Archetypes: A Critique, Theory, and Method of Narrative Analysis. Journal of Music Theory, 47/1, p. 1-39.

2. Brooks, Peter. 1984. Repetition, Repression, and Return: The Plotting of Great Expectations. In: Reading for the Plot: Design and Intention in Narrative. New York: Knopf, p. 113-142.

3. Festinger, Leon.1956. An Introduction to the Theory of Cognitive Dissonance. Disponível em: https://www.panarchy.org/festinger/dissonance.html. Acesso em 20 de dezembro de 2018.

4. Freud, Sigmund. [1919] 2012. Das Unheimliche. Bremen: Europäische Literaturverlag $\mathrm{GmbH}$. Disponível em: http://istitutosvizzero.it/wpcontent/uploads/2018/09/ISR_StudioRoma_Freud_DE.pdf. Acesso em 8 de janeiro de 2019.

5. Grabócz, Márta, and Ryan McClelland. 1999. Paul Ricœur's Theories of Narrative and their Relevance for Musical Narrativity. Indiana Theory Review 20/2, p. 19-39.

6. Lacan, Jacques. 2007. O Seminário - livro 23, O sinthoma 1975-1976. Trad. Sérgio Laia. Rio de Janeiro: Zahar.

7. Nogueira, Marcos. 2019. Dimensões da produção imaginativa musical: movimentos, formas e intenções. In: Nogueira, Ilza e Valério Fiel da Costa

${ }^{25}$ Comentando sobre sua visão interpretativa da Chacona, a pianista Cristina Gerling afirmou idealizar a execução da Seção A e da sua reprise distinguindo-as pela valorização dos traços culturais que se entrecruzam. Na primeira vez, o comedido contraponto da mão esquerda (reminiscência da tradição clássica eurocêntrica) seria evidenciado em primeiro plano, enquanto na segunda vez o extravagante lirismo da melodia executada pela mão direita (insinuando o pontilhismo idiomático das cordas dedilhadas) estaria proeminente. 
MUSICA THEORICA Revista da Associação Brasileira de Teoria e Análise Musical 2019, v. 4, n. 1, p. 11-29 - Journal of the Brazilian Society for Music Theory and Analysis@ TeMA 2019 - ISSN 2525-5541

(eds.). A Experiência musical: perspectivas teóricas. Série Congressos da TeMA 3, Salvador: UFBA, p. 17-35.

8. Rogers, Robert. 1987. Freud and the Semiotics of Repetition. Poetics Today, 8:3/4, p. 579-590. 


\title{
Variation and Developing Variation under a Transformational Perspective
}

\section{Variação e Variação Progressiva sob uma Perspectiva Transformacional}

\author{
Carlos Almada \\ Universidade Federal do Rio de Janeiro
}

\begin{abstract}
The present article introduces the current version of an analytical model, which proposes a transformational conception for musical variation. According to this perspective, an archetypical variation is considered as a generic function capable to transform a referential musical idea into another one to which is related by some degree of similarity. The study addresses a number of co-related concepts, classifications, and assumptions whose interaction aims at consolidating this new theoretical formulation. The last section presents a typology for Schoenberg's principle of developing variation under the transformational point of view.
\end{abstract}

Keywords: Variation and Developing variation; Model of Derivative Analysis; Transformational Theory

Resumo: Este artigo apresenta a versão atual de um modelo analítico que propõe uma concepção transformacional para a variação musical. De acordo com tal perspectiva, uma variação arquetípica é considerada como uma função genérica capaz de transformar uma ideia musical referencial em outra a ela relacionada por alguma similaridade. O estudo aborda vários conceitos, classificações e premissas correlatos, cuja interação busca consolidar essa nova formulação teórica. A última seção apresenta uma tipologia para o princípio Schoenberguiano de variação progressiva sob o ponto de vista transformacional.

Palavras-chave: Variação e Variação Progressiva; Modelo de Análise Derivativa; Teoria Transformacional 
MUSICA THEORICA Revista da Associação Brasileira de Teoria e Análise Musical 2019, v. 4, n. 1, p. 30-61 - Journal of the Brazilian Society for Music Theory and Analysis@ TeMA 2019 - ISSN 2525-5541

\section{Introduction}

This article integrates a broad research project whose main goal is the systematical study of musical variation. Initiated in 2011, the research has been constantly developed through adoption of new concepts, premises, and technological strategies, being subdivided into two basic approaches, analytical and compositional. The pursuing of the analytical approach, consolidated as a Model of Derivative Analysis (identified by the acronym MDA), has resulted in a considerable expansion of the theoretical scope of the research, being applied and improved in a number of practical studies. ${ }^{1}$ The current version of MDA explores a new investigative path, by connecting musical variation of the Transformational Theory, inspired by studies by David Lewin (1987), Michael Schiano (1992), and Steven Rings (2011).

The mutually complementary principles of Grundgestalt and developing variation play a central role in MDA's theoretical framework, and are also incorporated to the transformational approach. Both concepts were elaborated by Austrian composer and theoretician Arnold Schoenberg (1874-1951), constituting probably the most far-reaching of his numerous contributions to music theory. The binomial Grundgestalt-developing variation forms a powerful analytical construct associated with an organicist and economic conception of musical creation, a characteristic trait present in a large part of the music of Austro-German Romantic tradition, represented especially by Beethoven, Brahms, and Schoenberg himself. Essentially, a Grundgestalt of an organicallyconstructed musical piece introduces the basic elements from which ideally all material structures (motives, themes, and even subsidiary unities) could be obtained, through intensive use of derivative and progressive procedures, namely the techniques of developing variation. Under this perspective developing variation (from now on DV) can be seen as a highly dynamic process, employed not only for producing new, related material, but also as an important structuring force that acts on the organization of the piece. ${ }^{2}$ The transformational potentiality of DV is evident, which will be here properly explored.

\footnotetext{
${ }^{1}$ See especially Almada (2010; 2011; 2013; 2016), Mayr (2018), and Mayr; Almada (2016; 2017).

${ }^{2}$ Since the death of Schoenberg, both principles have been largely studied by a number of authors, covering a wide spectrum of approaches. See, for example Joseph Rufer (1952), David Epstein (1980), Patricia Carpenter (1983), Walter Frisch (1984), Severine Neff (1984), Michael Schiano
} 
The present article aims to introduce the basis of MDA's current configuration. The first section examines variation as a generic transformational function, proposing a formalization supported by some basic concepts and definitions. The notion of abstract variation, a crucial aspect of the research as a whole, is on the focus of the next section, followed by a description of the concept of transformational operations, the very agents of variation, according to the present conception. Section four presents processes and graphs related to transformational analysis and derivative network. The last section addresses briefly developing variation as adapted to the new format of MDA, which leads to the elaboration of a typology based on the temporal dimension.

\section{Derivative work}

Firstly, I define a musical idea ${ }^{3}$ as a short melodic sequence, relatively complete in itself, in which pitch and temporal structures play a special role. Let these structures be classified as the primary domains of the musical idea. The harmonic context in which the musical idea is (explicitly or not) inserted is considered its secondary domain. ${ }^{4}$

Let us consider that all imaginable musical ideas form a (conceptually infinite) set $S$. In the present context, variation is a generic function $V: S \rightarrow S$, which when applied to a referential musical idea $\mathrm{P}$ (stands por "parent") maps it to another member of S, the musical idea C ("child"), such that both can be related by some degree of similarity. ${ }^{5}$ Therefore, $\mathrm{C}$ is a transformation (or derivation) of

(1992), Jack Boss (1992), Ethan Haimo (1990, 1997), Stephen Collison (1994), Yuet Ng (2005), and Brent Auerbach (2005).

${ }^{3}$ I adopt here basically Schoenberg's definition of musical idea: "A musical idea (...), though consisting of melody, rhythm, and harmony, is neither one nor the other alone, but all three together" (Schoenberg 1984, p. 288).

${ }^{4}$ Evidently, the model could also include other secondary domains, like timbre, dynamics, texture, etc., which would contribute to increase largely its complexity. Aiming at simplicity and concision, I opted therefore to select only harmonic context for this category. The notion of domains can be associated with the concept of (primary and secondary) parameters, proposed by Leonard Meyer (1989).

${ }^{5}$ The relation of similarity is expressed by a real number between 0 (complete divergence) and 1 (identity relation). The measurement of similarity between two related musical ideas is a central aspect of the new configuration of MDA, being the subject of an article in preparation. This specific issue will not be addressed in the present study. 
MUSICA THEORICA Revista da Associação Brasileira de Teoria e Análise Musical 2019, v. 4, n. 1, p. 30-61 - Journal of the Brazilian Society for Music Theory and Analysis@ TeMA 2019 - ISSN 2525-5541

$\mathrm{P}$ by action of function V. C can also be named a variant of $\mathrm{P}$ or simply a derived idea (Figure 1). The adjective "generic" that qualifies the noun "function" in the definition of $\mathrm{V}$ reflects both assumptions that $\mathrm{P}$ is in some way transformed by the action of $\mathrm{V}$ (i.e., it does not matter yet how) ${ }^{6}$ and that $\mathrm{C}$, the output of this transformation, is related to the input $\mathrm{P}$ by some degree of similarity. In other words, $\mathrm{V}$ generically represents all possible manners in which $\mathrm{P}$ can be transformed into C. ${ }^{7}$

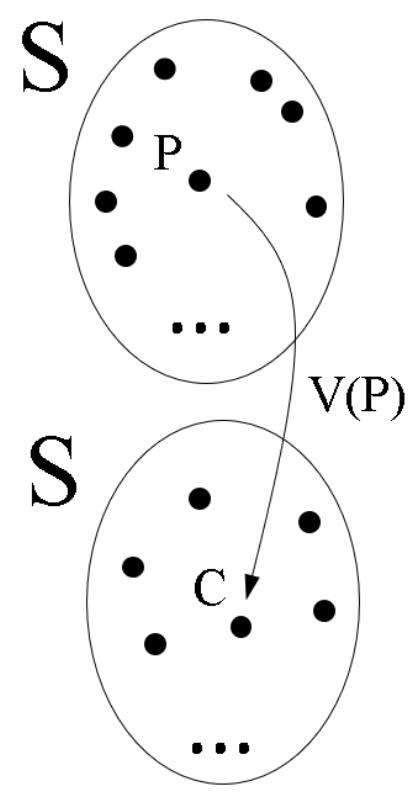

Figure 1: Graphical representation of the action of function $V$

Algebraically, it is then possible to express $\mathrm{C}$ in function of $\mathrm{P}$.

$$
C=V(P)
$$

\section{Equation 1}

The syntactic ordered interaction of the three elements, $\mathrm{P}, \mathrm{V}$, and $\mathrm{C}$ will be from now on referred as a derivative work. Figure 2 proposes the archetypical representation of a derivative work, as a more concise version of the scheme of

\footnotetext{
${ }^{6}$ A detailed investigation about the possible manners that transformations may occur is a part important of this proposal, to be examined in the section 3 .

${ }^{7}$ Put another way, $\mathrm{V}$ is also a set that congregates all possible types of actions (transformations) capable to send a given $\mathrm{P}$ to any possible variant $\mathrm{C}$. From this, we infer that set $\mathrm{V}$ is also conceptually infinite.
} 
Figure 1. Notice how the similarity relation between $\mathrm{P}$ and $\mathrm{C}$ is evidenced by the dashed line and the symbol SP/C. This representation will be resumed in the fourth section of this article, being adapted to the concept of archetypical developing variation.

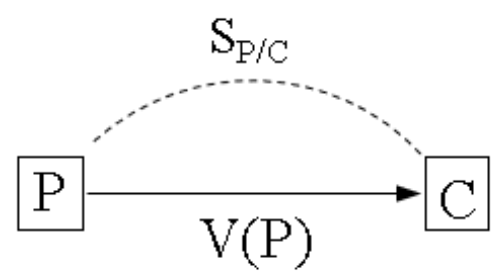

Figure 2: Action of the function $\mathrm{V}$ on $\mathrm{P}$, resulting in the variant $\mathrm{C}$

\section{Decomposable variation}

A derivative work can operate in two basic levels:

- Holistic: when $\mathrm{V}$ acts on the indivisible structure of $\mathrm{P}$ (i.e., encompassing the three domains as a whole).

- Decomposable: ${ }^{8}$ when $\mathrm{V}$ acts on isolated domains of $\mathrm{P}$, letting eventually (but not necessarily) the remaining unaltered.

The notion of holistic variation is reasonably self-explanatory, corresponding to what the common sense would consider "ordinary" variation (Fig. 3 exemplifies some possible holistic transformations of a referential idea P).

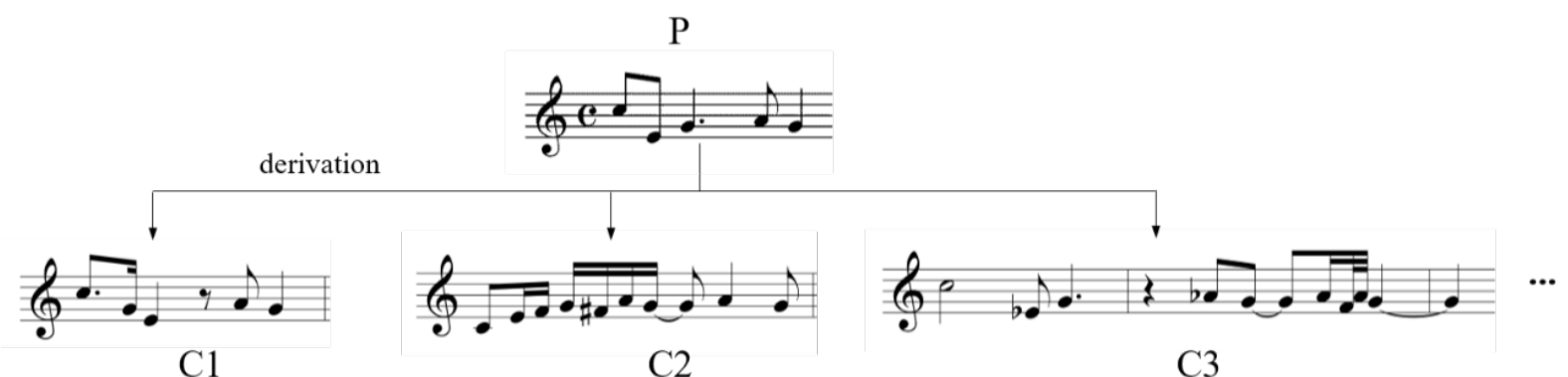

Figure 3: Examples of holistic variation

On the other hand, decomposable variation is not so intuitive and, therefore, deserves a more profound examination.

\footnotetext{
8 The adjectives "holistic" and "decomposable" substitute for, respectively, "concrete" and "abstract", used in previous versions of MDA.
} 
A central premise of MDA is that a large percentual of derivative work in a musical piece involve an isolated structural domain (think of a simple intervallic inversion of a melody maintaining the original rhythmic configuration, for example). In other words, the process of derivation in this case is mediated by a previous stage of abstraction. As shown in Figure 4, pitch and rhythmic "essences" are abstracted from $\mathrm{P}$, respectively, $\mathrm{P}^{\prime}$ and $\mathrm{P}$ ", ${ }^{9}$ becoming in turn referential for independent types of derivation. For a sake of simplicity, let secondary domain of harmony (omitted in the examples) be maintained unaltered along the process.

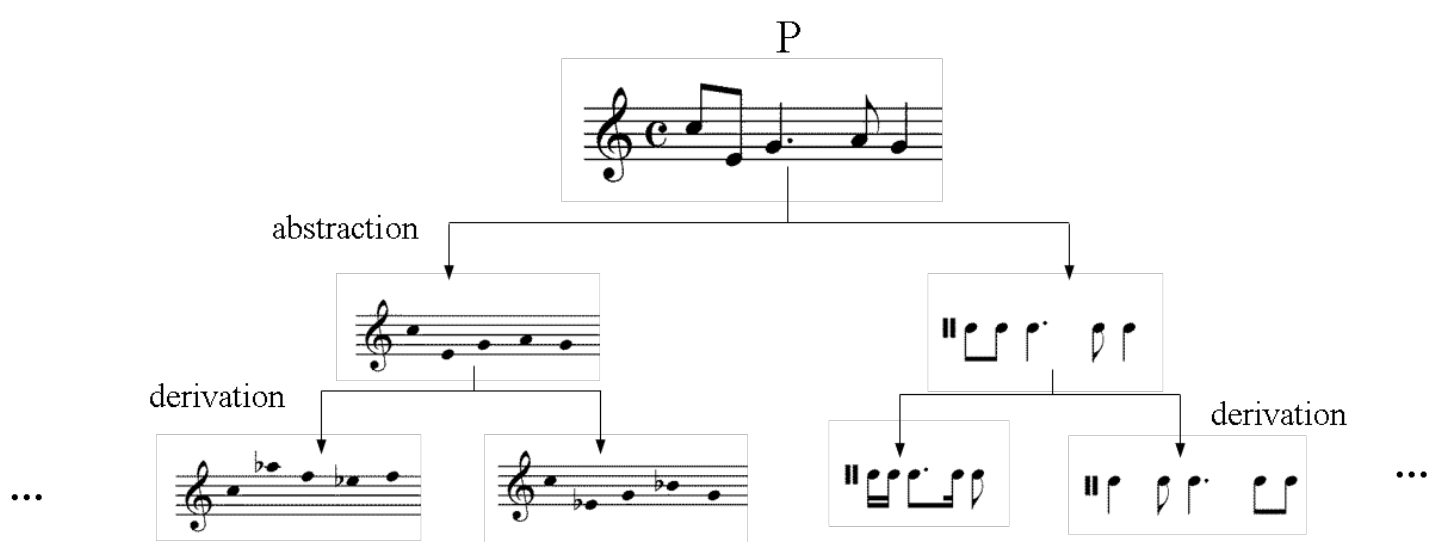

Figure 4: Examples of decomposable variation.

As a basic consideration, the primary domains of pitch and rhythm are taken as privileged in decomposable variation, letting the secondary harmony subordinated to them. Given this, supported by a combination of theoretical knowledge, information from literature, and analytical experience, I argue that, in general, pitch is the most permeable structural domain to the effects of variation. On the other hand, rhythmic figures have the tendency to be preserved (or only superficially transformed) in meaningfully related motivic/thematic unities, since normally they are the main responsible for the characterization of musical ideas themselves. More radical rhythmic variations can, of course, be applied along a derivative process, but almost inevitably they cause deeper distinction between referential and derived forms ( $P$ and $C$, in the present terminology) in opposition to the more common cases of smooth or gradual transformations. From this, a logical conclusion can be drawn: temporal changes

\footnotetext{
9 These are intuitive, but provisory labels that will be further replaced by more precise and adequate terms.
} 
(i.e., rhythmic and metric), though statistically less common than those involving pitch, are potentially more likely of transforming a given referential idea.

The essential process of decomposable variation is performed by three sequential phases, described as follows:

1. Abstraction: in which the content of a domain is isolated from idea $\mathrm{P}$, becoming potential basis for further abstract derivation;

2. Derivation: in which the process of variation properly occurs, being applied to the abstracted, referential unity(ies) and resulting into another abstracted, derived unity(ies);

3. Re-integration: in which the abstracted domains (either those transformed or not) are recombined to form a definitive derived (concrete) idea C. ${ }^{10}$

Figure 5 proposes a graphical schematization of decomposable variation, using new conventions, symbols and terminology: concrete musical ideas ( $\mathrm{P}$ and C) are represented by solid-line rectangles; abstracted ideas ( $\mathrm{p}, \mathrm{t}$, and $\mathrm{h}$, standing for the domains of "pitch", "time", and "harmony") are represented by dashedline rectangles; and derived abstract ideas are numbered inside gray, dashed-line rectangles.

\footnotetext{
${ }^{10}$ The re-integration is observed in the foreground level, i.e., the score, while the other two levels - abstraction and derivation - correspond to analytical constructs that many times exist only as hypothesis (this aspect will be better discussed further on).
} 
MUSICA THEORICA Revista da Associação Brasileira de Teoria e Análise Musical 2019, v. 4, n. 1, p. 30-61 - Journal of the Brazilian Society for Music Theory and Analysis @ TeMA 2019 - ISSN 2525-5541

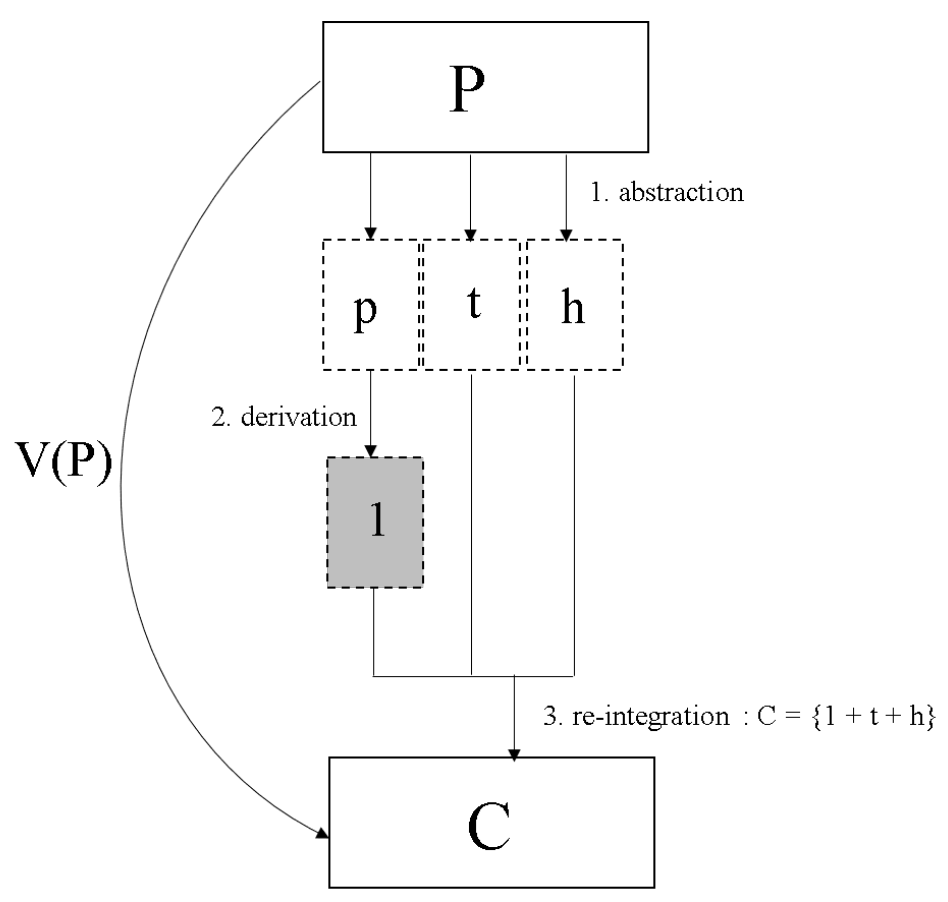

Figure 5: General representation of a decomposable derivative work

Decomposable variation can be classified in two distinct manners:

1. According to the number of stages of transformations required for its application. It can be:

- simple, when transformation occurs in only one stage, or

- compound, when transformation is performed in two or more stages.

2. According to the number of domains involved in the process. It can be:

- $\quad$ ure, when only one domain (for example, pitch) is affected by the transformation, or

- hybrid, if two (or, rarely, the three) domains are simultaneously involved in the derivative work.

A possible question that may naturally arise at this point addresses the differentiation between holistic and hybrid-type variations, since, at first impression, they seem to mean the same thing. In fact, it is not always easy to distinguish both situations. In strict terms, the former case corresponds exactly to a transformation that involves simultaneously all domains (in a practice sense, both pitch and temporal), a definition that could also be applied to the latter type. The subtle difference between them lies in the manner in which the process 
occurs. The label "hybrid variation" is suitable to describe those specific situations in which a complete transformation between two musical ideas can be decomposed into stages of secondary transformations, while in concrete variation that is not possible or, at least, would demand non-logical, very complicated, or far-fetched descriptions.

Using as models the schemes introduced in Figure 5, Figure 6 presents four examples of decomposable derivative work (Fig. 6a-d) combining the four possible combinations of classes (pure/simple, pure/compound, hybrid/simple, and hybrid/compound) in comparison with the holistic variation (Fig. 6d), which, obviously, does not present stages of abstraction and re-integration.

While simple decomposable variation is relatively easy to be identified with precision in analytical situations, compound variation is normally more problematic. In most part of the cases the task of tracking back the intermediary abstract-derivative stages that map P onto C can only be achieved by the analyst as a sequence of plausible hypotheses. 
MUSICA THEORICA Revista da Associação Brasileira de Teoria e Análise Musical 2019, v. 4, n. 1, p. 30-61 - Journal of the Brazilian Society for Music Theory and Analysis @ TeMA 2019 - ISSN 2525-5541
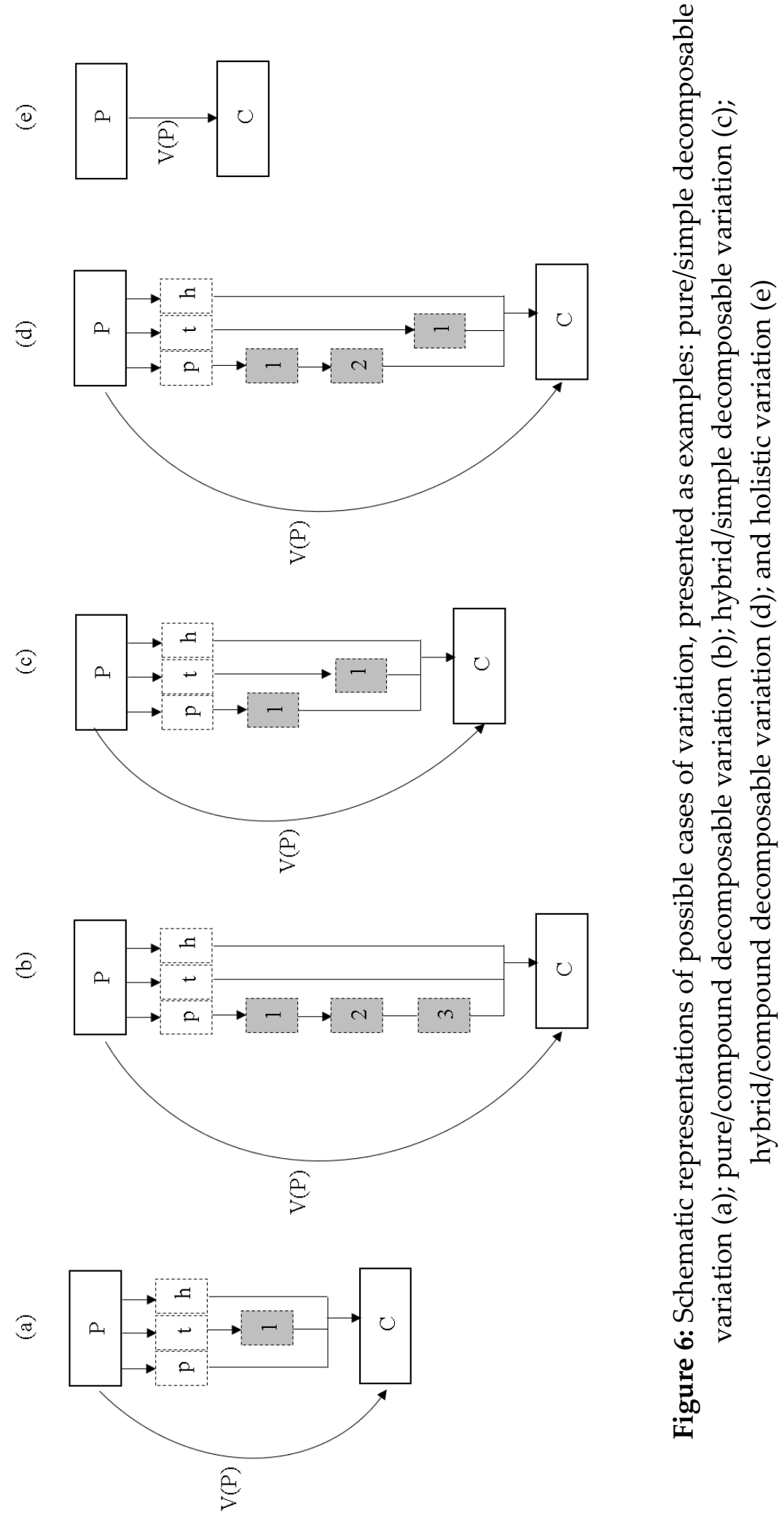
Variation and Developing Variation under a Transformational Perspective

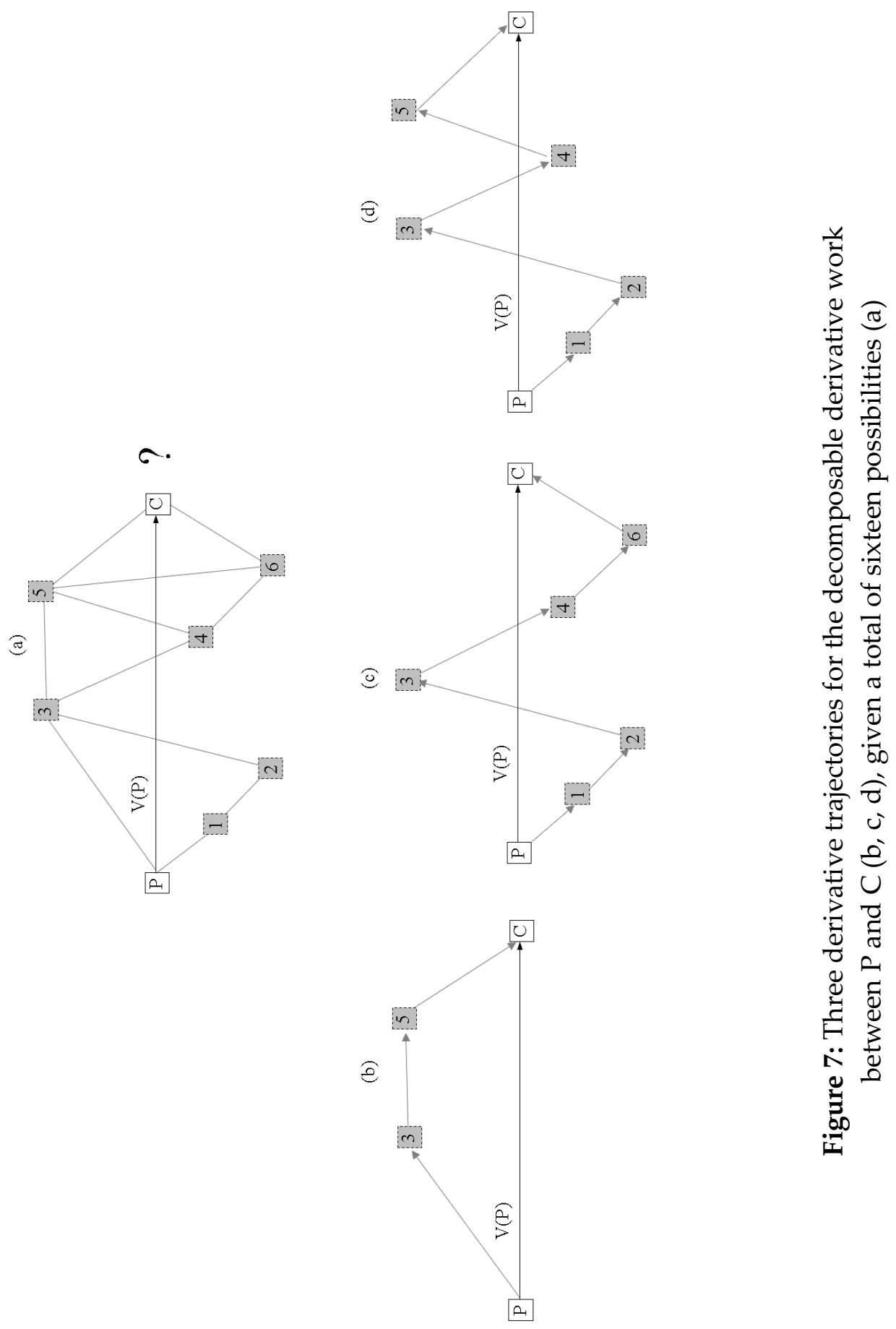

Figure 7 addresses this question. Let us assume that it as a simplified version of the model of Figure $6 \mathrm{~b}$ (pure/compound decomposable variation). ${ }^{11}$ Let us also suppose that an analyst considers variants 1,2,3, 4, 5, and 6 as possible

${ }^{11}$ For clarity, both stages of abstraction and re-integration were omitted in the scheme, letting only derivation. 
MUSICA THEORICA Revista da Associação Brasileira de Teoria e Análise Musical 2019, v. 4, n. 1, p. 30-61 - Journal of the Brazilian Society for Music Theory and Analysis@ TeMA 2019 - ISSN 2525-5541

intermediary, abstract "stations" between P and C. Considering that the edges in Figure 7 a represent valid connections between the stations, ${ }^{12}$ sixteenth distinct trajectories would be possible, three of them depicted in Figure $7 \mathrm{~b}, \mathrm{c}$, and $\mathrm{d} .{ }^{13}$ Assuming that there is not a unique correct "answer" for the "problem", how would be the best choice for the analyst? If disregarded the context (a very important factor in real situations), maybe the most logical, and well-equilibrated approach should be the selection of the option with lesser number of stations (alternative $b$, in this case), and/or that in which the changes are more gradual (this decision would demand an evaluation of the real musical situations, not accessible in this simple example).

An interesting and pertinent metaphor originated in the fields of paleontology and evolutionary biology can be used for comparison. The complete sequence of intermediary evolutive stages for connecting two corelated forms of life (say, dinosaurs and birds) is virtually impossible to be concretely evidenced, due to the absence of the complete fossil register: most of the myriad of variations, species, genera, etc. that would fill this gap simply lived and disappeared without traces. However, the meticulous study of the rare fossils preserved combined with accumulated knowledge, powerful technology, cooperative work, and experience, allow the scientists to reconstruct with a high degree of accuracy the links, despite a time span measured in hundreds of millions of years. Although strongly supported by scientific methods, the reconstruction of the trajectory dinosaurs-birds is, strictly speaking, based on connective hypotheses.

Aside, evidently, the huge differences separating biological and musical realms, undoubtedly there also exist some interesting points of contact between them, reinforcing the metaphorical links. In this particular aspect, considering the scope of MDA, the analytical tasks of identification of variants that act in a piece of music, and of explanation of their derivation from the respective referential ideas is many times dependent on plausible conjectures. ${ }^{14}$

\footnotetext{
${ }^{12}$ These "stations" are formally named hypothetic intermediary stages (HIS) in analytical situations. They will be resumed in section 4 .

${ }^{13}$ These trajectories, graphic representations of decomposable derivative work, will be treated as model for the derivative networks in section 4 .

${ }^{14}$ Commenting a motivic analysis of Beethoven's String Quartet Op. 135/4 $4^{\text {th }}$ movement, made by Schoenberg, Michael Schiano (1992, p. 129-130) points out the fact that Schoenberg proposed
} 
It is worth to add that the hypotheses eventually established by an analyst do not intend to reconstruct the compositional lines of thought. They should rather be seen as a methodological strategy that aims to contribute for the systematization of the analysis.

\section{Transformational operations}

Up to this point, variation was described as a generic function $\mathrm{V}$, capable to transform a given referential musical idea P. As it was also mentioned, the outcome of such transformation (namely, the variant $\mathrm{C}$ ) is related to $\mathrm{P}$ by some degree of similarity, which can be systematically measured in MDA. ${ }^{15}$ In sum, in an archetypical derivative work we can affirm that $\mathrm{C}$ derives from $\mathrm{P}$, maintaining with this some degree of similarity. However, up to now nothing was said about how $\mathrm{P}$ may be transformed into $\mathrm{C}$, or in which manners the application of $\mathrm{V}$ can affect $P$. These questions will be properly addressed in the present section with the aid of a new concept, the transformational operations. A transformational operation, or simply operation, corresponds therefore to a specific manifestation of the generic function $\mathrm{V}$, as an algorithm or set of rules to be applied to an also specific referential element, which can be the complete idea P (in the case of holistic variation), or, considering decomposable variation, an element of a domain or even a subset of it. ${ }^{16}$

In formal terms, one can express a given (decomposable) operation as a function $v$, whose argument, the parent $\rho$, is an abstracted element of the referential idea $\mathrm{P}$, and whose output (child) $\gamma$, is a related transformation of $\rho$,

some possible intermediary variants (that are not in the score) as plausive explanations of the connections between some of the ideas. In his words, "The events that Schoenberg wishes to connect exist on the musical surface. However, the intermediate steps are hypothetical (...) a chain of logical steps between two events is made explicit". As one can perceive, there are interesting similarities between Schoenberg's analytical procedures (as well as the methods developed by Schiano himself) and the present proposal.

${ }^{15}$ As previously stated, the description of the algorithms used for measurement of similarity is not addressed in the present article.

${ }^{16}$ Although it is also possible to consider operations in the realm of holistic variation, I will not explore this issue here, opting to set the focus on decomposable operations. The main reason is that holistic operations are normally strongly idiosyncratic and context-dependent, which prevents proper systematization. From now on, the use of the term "operation" in this section will refer exclusively to decomposable variation. 
MUSICA THEORICA Revista da Associação Brasileira de Teoria e Análise Musical 2019, v. 4, n. 1, p. 30-61 - Journal of the Brazilian Society for Music Theory and Analysis@ TeMA 2019 - ISSN 2525-5541

therefore, also an abstract element. Equation 2 derived from Equation 1 exposes formally the basic syntactic structure of the action of an operation.

$$
\gamma=v(\rho)
$$

\section{Equation 2}

At this point, it is possible to propose a representation of decomposable variation, by including the new elements $\varrho, \gamma$, and $v$, as shown in Figure 8.

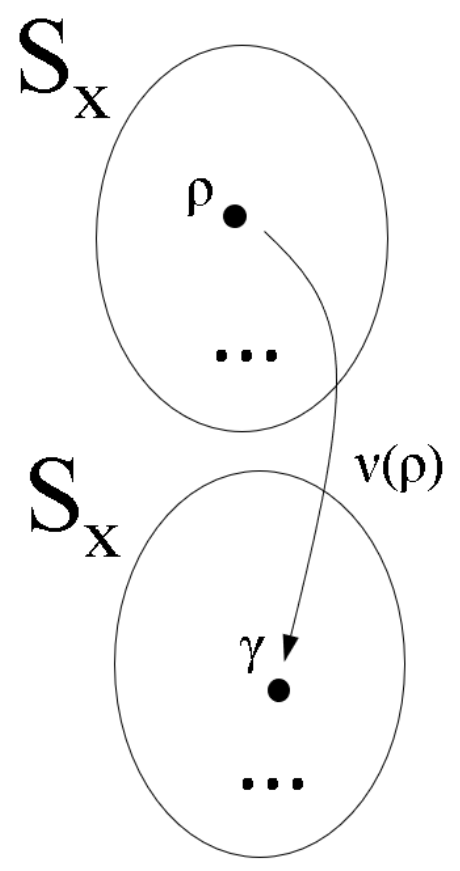

Figure 8: Representation of the action of function $v$ on set $S_{x}$

In this diagram $v$ represents, as already known, a more specific transformational function. As a matter of fact, $v$ (like V) can be seen as a conceptually infinite set (Fig. 9) that contains all possible kinds of transformations (operations, in the present terminology) capable to send a given @ to a related $\gamma$ in a domain-compatible set $S_{x}$. 


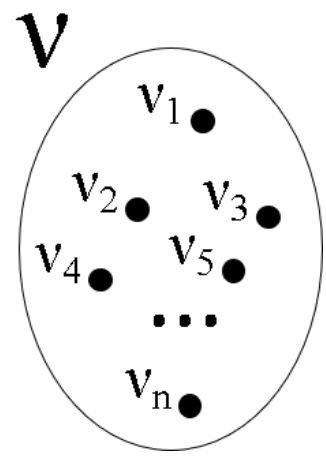

Figure 9: Set $v$ of operations

Consequently, one can think of a number (conceptually also infinite) possible derivations $(\gamma)$ from a given referential $Q$, through applications of operations which are members of set $v$. In more informal terms, it is possible to obtain an offspring of variants of any size from Q, as suggested in Figure 10. In this scenery, the functions $v_{1}, v_{2}, v_{3}$, etc., represent real specific instances of operations, elements which will be described ahead.

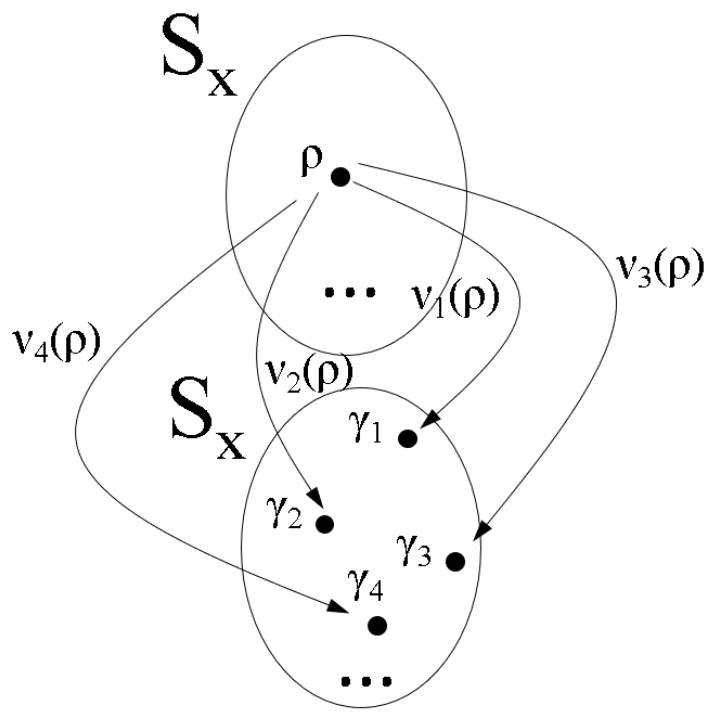

Figure 10: Action of functions v1-4

Operations are here classified according to two categories: type and scope of the argument.

Concerning the first category, operations are classified as canonic and noncanonic. The former type corresponds to "classical" instances of transformation. The canonic operations considered in MDA are: transposition (chromatic and 
diatonic), inversion (chromatic and diatonic), retrogradation, augmentation, and diminution. Non-canonic types comprise any possibility out of the canonic category, forming a conceptually infinite set of possibilities (22 non-canonic operations are currently considered in MDA). A symbolic notation is used for designating both types in analysis, according to the following conventions:

- Canonic operations are identified by a unique bold, uppercase letter ${ }^{17}$ (generally, the initial of the operation's name), for example: augmentation $(\mathbf{A})$, retrogradation $(\mathbf{R})$, chromatic transposition $(\mathbf{T})$, diatonic transposition $(\mathbf{t})$, etc.

- Non-canonic operations are identified by an acronym formed by three bold, uppercase letters (preferentially, but not necessarily, the initial letters of the operation's name), for example: addition (ADD), permutation (PER), metric displacement (MTR), change of register (OCT), etc. ${ }^{18}$

Regarding the category "scope", as before stated, the argument of an operation $v$ can be the integral parent $\rho$ or a subset of it (which is generically labeled as $\mu$ ). While the former case corresponds to the conventional situation in decomposable variation (and, accordingly, will be called "normal"), the latter will be classified as mutational operation, a very important element in this theoretical proposal. Like mutations that occur inside the nucleus of living cells, mutational operations promote in a musical context microvariations, resulting normally in a very subtle transformation.

The notation of the argument of a mutational operation differs from the normal case by the indication of the subset of application, after a comma.

$$
\gamma=v(\rho, \mu)
$$

\section{Equation 3}

\footnotetext{
17 With the exception of diatonic versions of chromatic operations, that use lowercase letter as symbol.

${ }^{18}$ Some operations require special, complementary symbology for a more precise identification of its transformational action. The complementary symbol is subscripted at the right of the identification letter (or acronym, in the case of non-canonic type) of the respective operation, and can be a number or a typographic sign. There are several specific situations (some of them will be detailed in further examples) to which the complementary symbols refer, being also associated with the nature of the operation itself. Examples: $\mathbf{T}_{3}, \mathbf{O C T}_{+}, \mathbf{A D D}_{5}$, etc.
} 
where $\mu$ is a subset of $Q$, the very argument to be transformed by the operation. ${ }^{19}$

Figure $11 a-b$ provides generic schemes of the actions of normal and mutational operations. ${ }^{20}$ Figure 11c depicts the normal application of operation canonic augmentation (A) to the whole rhythmic structure (Q) of a given idea P. The same operation is mutationally applied to the second element of $\varrho$ (a specific instance of $\mu$ ) in Figure 11d.

(a)

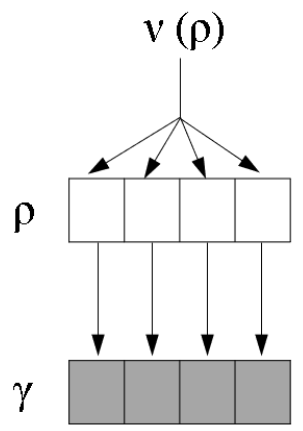

(b)

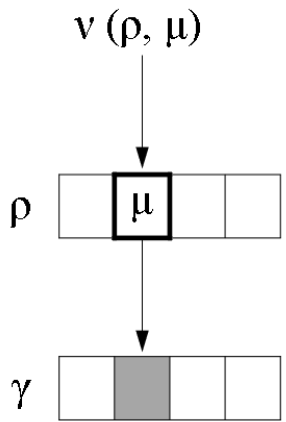

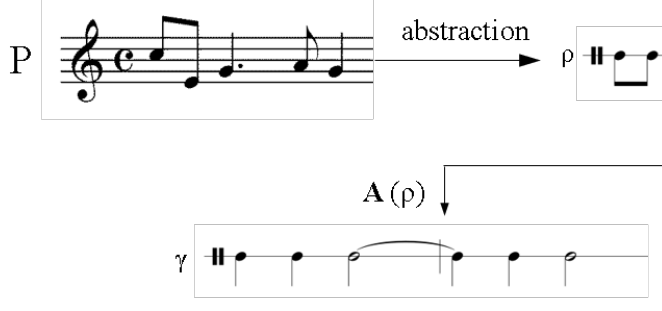

(c)

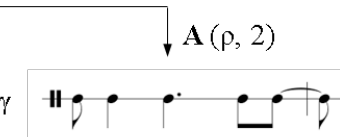

(d)

Figure 11a-d: Generic representation of the action of normal (a) and mutational operations (b), and respective examples, applying to an abstracted temporal sequence the operation augmentation (A), both in normal (c) and mutational (d) scopes

Table 1 lists in alphabetic order the 29 operations currently considered in MDA.

${ }^{19}$ In the case of normal operations $\rho$ is the unique argument of $v$.

${ }^{20}$ An operation has a dual nature if it can be presented in both versions, normal and mutational. 
MUSICA THEORICA Revista da Associação Brasileira de Teoria e Análise Musical 2019, v. 4, n. 1, p. 30-61 - Journal of the Brazilian Society for Music Theory and Analysis@ TeMA 2019 - ISSN 2525-5541

\begin{tabular}{|c|c|c|c|c|}
\hline operation & symbol & domain & scope & description \\
\hline addition & ADD & $\mathrm{p}, \mathrm{t}$ & $\mathrm{d}$ & $\begin{array}{l}\text { Adds a fixed amount to selected pitches or } \\
\text { durations }\end{array}$ \\
\hline augmentation & $\mathbf{A}$ & $t$ & $\mathrm{~d}$ & Duplicates selected durations \\
\hline chord-insertion & CIN & $\mathrm{h}$ & $\mathrm{m}$ & Insert a chord in a harmonic sequence \\
\hline chord-suppression & CSP & $\mathrm{h}$ & $\mathrm{m}$ & $\begin{array}{l}\text { Suppress a selected chord from a harmonic } \\
\text { sequence }\end{array}$ \\
\hline chordal inversion & CHI & $\mathrm{h}$ & $\mathrm{m}$ & Changes the bass of a selected chord \\
\hline chromatic alteration & ALT & $p$ & $\mathrm{~m}$ & Alters a selected pitch chromatically \\
\hline chromatic inversion & $\mathbf{I}$ & $\mathrm{p}$ & $\mathrm{d}$ & Inverts the direction of chromatic intervals \\
\hline $\begin{array}{l}\text { chromatic } \\
\text { transposition }\end{array}$ & $\mathrm{T}$ & $\mathrm{p}$ & $\mathrm{d}$ & $\begin{array}{l}\text { Adds a fixed amount to selected chromatic } \\
\text { intervals }\end{array}$ \\
\hline deletion & DEL & $\mathrm{p}, \mathrm{t}$ & $\mathrm{m}$ & $\begin{array}{l}\text { Suppress selected pitch or duration inside a pitch } \\
\text { or durational sequence }\end{array}$ \\
\hline diatonic inversion & $\mathbf{i}$ & $\mathrm{p}$ & $\mathrm{d}$ & Inverts the direction of selected diatonic intervals \\
\hline $\begin{array}{l}\text { diatonic } \\
\text { transposition }\end{array}$ & $\mathrm{t}$ & $\mathrm{p}$ & $\mathrm{d}$ & Adds a fixed amount to selected diatonic intervals \\
\hline diminution & $\mathbf{D}$ & $\mathrm{t}$ & $\mathrm{d}$ & Divides by two selected durations \\
\hline extension & EXT & $\mathrm{p}, \mathrm{t}$ & $\mathrm{n}$ & $\begin{array}{l}\text { Adds new pitches or durations at the end of a pitch } \\
\text { or durational sequence }\end{array}$ \\
\hline interpolation & INT & $\mathrm{p}, \mathrm{t}$ & $\mathrm{m}$ & $\begin{array}{l}\text { Inserts new pitches or durations into a pitch or } \\
\text { durational sequence }\end{array}$ \\
\hline $\begin{array}{l}\text { merging of } \\
\text { durations }\end{array}$ & MRG & $\mathrm{t}$ & $\mathrm{m}$ & Merges two contiguous duration \\
\hline metric displacement & MTD & $\mathrm{t}$ & $\mathrm{n}$ & $\begin{array}{l}\text { Displaces a rhythmic sequence by some amount of } \\
\text { time }\end{array}$ \\
\hline mode-change & MOD & $\mathrm{p}, \mathrm{h}$ & $\mathrm{n}$ & $\begin{array}{l}\text { Change the mode of a pitch and harmonic } \\
\text { sequence }\end{array}$ \\
\hline modulation & MDL & $\mathrm{h}$ & $\mathrm{n}$ & $\begin{array}{l}\text { Transposes the harmonic sequence by some fixed } \\
\text { interval }\end{array}$ \\
\hline permutation & PER & $\mathrm{p}, \mathrm{t}$ & $\mathrm{m}$ & $\begin{array}{l}\text { Permutates the order two elements of a pitch or } \\
\text { durational sequence }\end{array}$ \\
\hline re-division & RDV & $\mathrm{t}$ & $\mathrm{m}$ & $\begin{array}{l}\text { Reformulates the values of two contiguous } \\
\text { durations }\end{array}$ \\
\hline register-change & OCT & $\mathrm{p}$ & $\mathrm{m}$ & Adds or subtracts an octave to a selected pitch \\
\hline re-harmonization & RHA & $\mathrm{h}$ & $\mathrm{m}$ & Changes the internal elements of a selected chord \\
\hline rest-substitution & RST & $\mathrm{t}$ & $\mathrm{m}$ & Replaces a selected duration by a rest \\
\hline replication & RPL & $\mathrm{p}, \mathrm{t}$ & $\mathrm{m}$ & Replicates a selected group of pitches or durations \\
\hline retrogradation & $\mathbf{R}$ & $\mathrm{p}, \mathrm{t}$ & $\mathrm{n}$ & Inverts the order of a pitch or durational sequence \\
\hline rotation & ROT & $\mathrm{p}, \mathrm{t}$ & $\mathrm{n}$ & $\begin{array}{l}\text { Sends the last element of a pitch or durational } \\
\text { sequence to the first position }\end{array}$ \\
\hline splitting of duration & SPL & $\mathrm{t}$ & $\mathrm{m}$ & Splits a selected duration in two \\
\hline subtraction & SUB & $\mathrm{p}, \mathrm{t}$ & $\mathrm{d}$ & $\begin{array}{l}\text { Subtracts a fixed amount to selected pitches or } \\
\text { durations }\end{array}$ \\
\hline suppression & SUP & $\mathrm{p}, \mathrm{t}$ & $\mathrm{m}$ & $\begin{array}{l}\text { Suppresses an element of the end of a sequence of } \\
\text { pitches or durations }\end{array}$ \\
\hline
\end{tabular}

Table 1: Chart of operations, considering name, symbol, domain (pitch, time or harmony), scope (normal, mutational or dual) and a brief description 
Given the obvious impossibility of providing proper illustration and commentary for the whole group of operations, for a question of space and scope, the following figures privilege just the cases that will be employed as examples in the next section of this article.

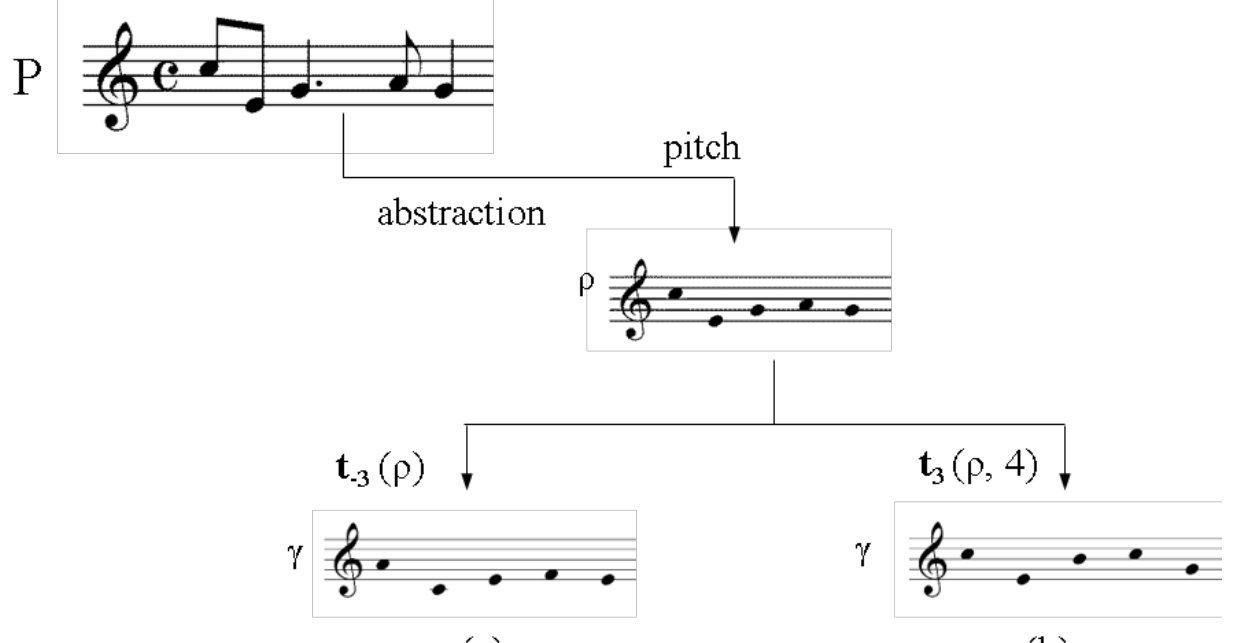

(a)

(b)

Figure 12: Example of application of operation diatonic transposition $(\mathfrak{t})$ : normal/pitch (a); mutational/pitch (b)

The canonic operation diatonic transposition $(\mathbf{t})$ is applied only to pitch domain, having dual scope (Fig. 12) The subscript added to the symbol indicates the diatonic interval ${ }^{21}$ of transposition. In (a) the whole pitch sequence is transposed down a diatonic third. In the mutational example (b), only the fourth element of the sequence is affected by the transposition (or else, $\mu=4$ ), this time an upward diatonic third (pitches $\mathrm{A} \rightarrow \mathrm{C}$ ).

Figure 13 presents two examples of another canonic operation, diminution (D), of exclusive application to the temporal domain. As it can be observed in the mutational situation (b), just the last duration is diminished (quarter to eight note), a very slight sort of transformation.

\footnotetext{
${ }^{21}$ Diatonic intervals do not concern intervallic quality (minor/major, perfect/diminished/ augmented), being measured only according to type: unison (1), second (2), third (3), etc. As a convention, descending diatonic intervals are indicated by a "minus" signal before the corresponding number (ex: "-5" = descending fifth).
} 
MUSICA THEORICA Revista da Associação Brasileira de Teoria e Análise Musical 2019, v. 4, n. 1, p. 30-61 - Journal of the Brazilian Society for Music Theory and Analysis @ TeMA 2019 - ISSN 2525-5541

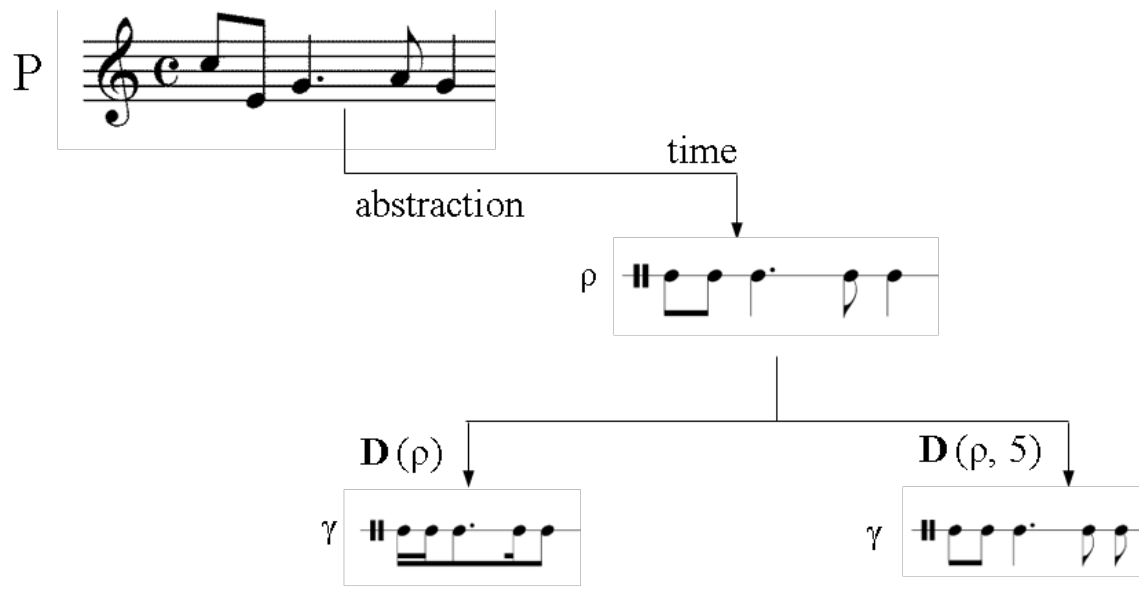

(a)

(b)

Figure 13a-b: Example of application of operation diminution (D): normal/time (a); mutational/time (b)

The two next examples address operations that are act only in mutational scope. In the case of register-change (OCT), an exclusively pitch transformation (Fig. 14), the first element is transposed an octave lower.

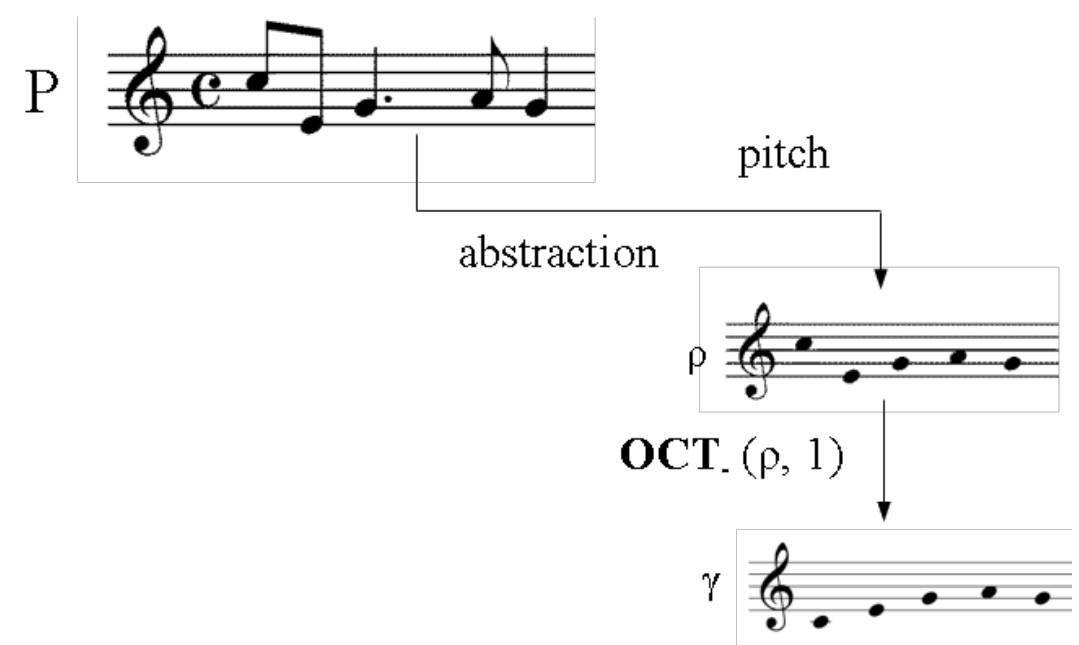

Figure 14: Example of application of operation register-change (OCT), mutational/pitch

Metric displacement (MTD) provokes a temporal dislocation of a given durational, keeping unaltered all internal proportions (Fig. 15). ${ }^{22}$

\footnotetext{
22 In the case of this example the sequence is dislocated to the "right" (in the bar) by two unities (by convention, each durational unity corresponds to a sixteenth note). "Negative" dislocations (i.e., leftwards) are also possible (see Fig. 19).
} 


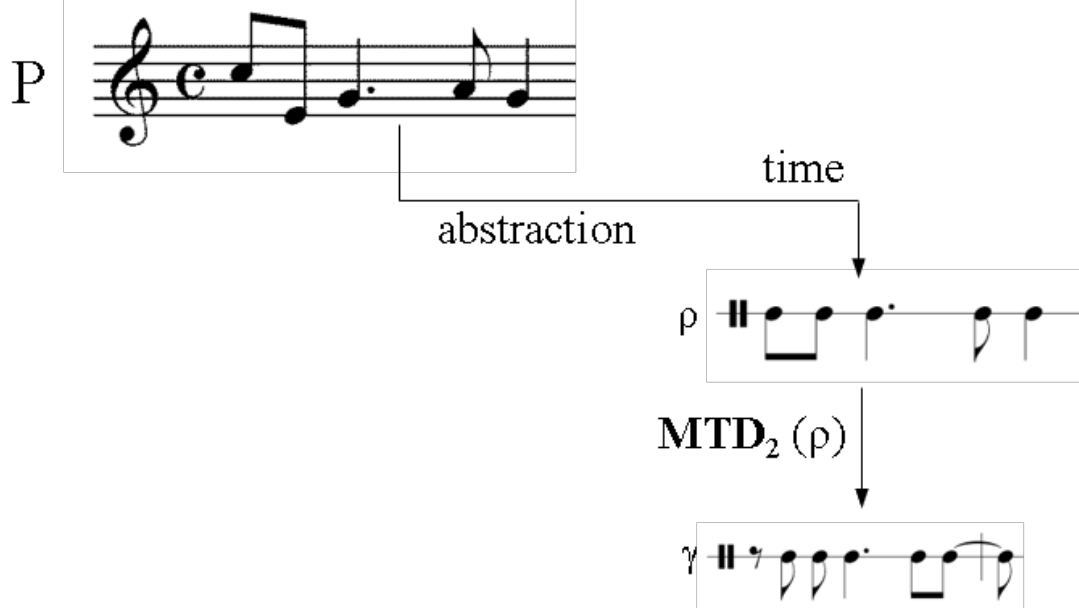

Figure 15: Example of application of operation metric displacement (MTD): normal/time

The last final examples consider operations that can be applied to pitch and temporal domains. Figure 16 depicts two instances of permutation (PER), with application exclusively mutational. In this transformation two (non-necessarily contiguous) elements of sequence change their positions: second and fourth pitches (a) and fourth and fifth durations (b).

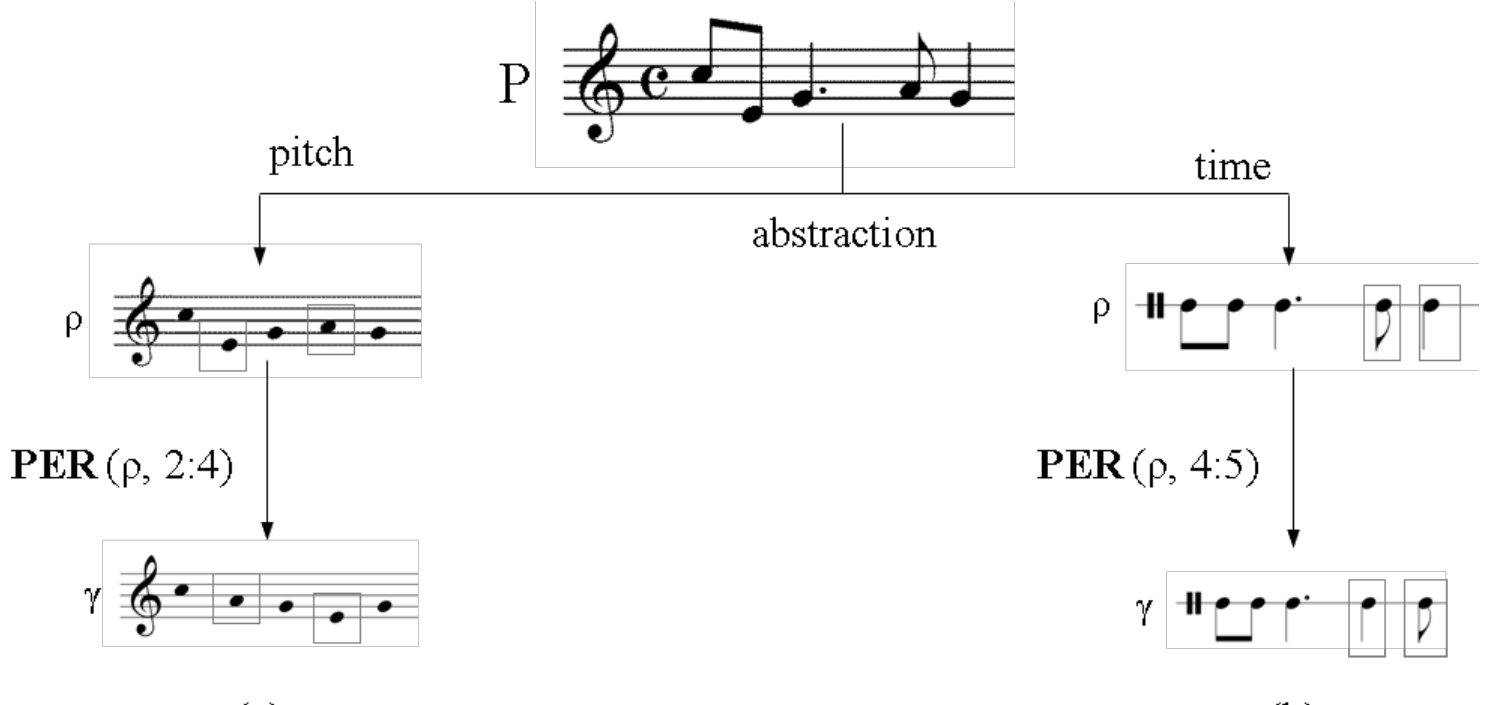

(a)

(b)

Figure 16: Example of application of operation permutation (PER): mutational/pitch (a); mutational/time (b)

Operation addition (ADD) affects intervals (in the pitch domain) and durations (temporal domain) by adding a fixed amount of unities (indicated by 
a subscript number at the right of the symbol). ${ }^{23}$ Unlike PER, ADD is associated with a dual scope. Figure 17 presents four examples of transformation, considering normal and mutational scopes in pitch domain $(\mathrm{a}-\mathrm{b})$, and normal and mutational scopes in temporal domain (d).

\section{Transformational analysis and derivative networks}

Knowledge about operations is central for determining derivative paths in analytical situations, in a process that from now will be called transformational analysis. As it was briefly suggested in section 1, it involves normally the elaboration of hypothetical intermediary stages (identified by the acronym HIS) of plausible derivations connecting a given musical idea $\mathrm{C}$ to its presumed origin P. Methodologically, transformational analysis is made through successive reductions (resembling those used in Schenkerian analysis) that gradually suggest the possible operations employed along the process.

In order to demonstrate succinctly the potentialities of the transformational analysis, let $\mathrm{C}$ be a concrete musical idea which was classified as a variant of a referential idea $\mathrm{P}$ in a hypothetic analytical situation (Fig. 18). Transformational analysis proposes to the analyst the following basic question: How could you systematically explain the chain of transformations that would map C onto P?

${ }^{23}$ The unity considered in pitch domain is the semitone. 


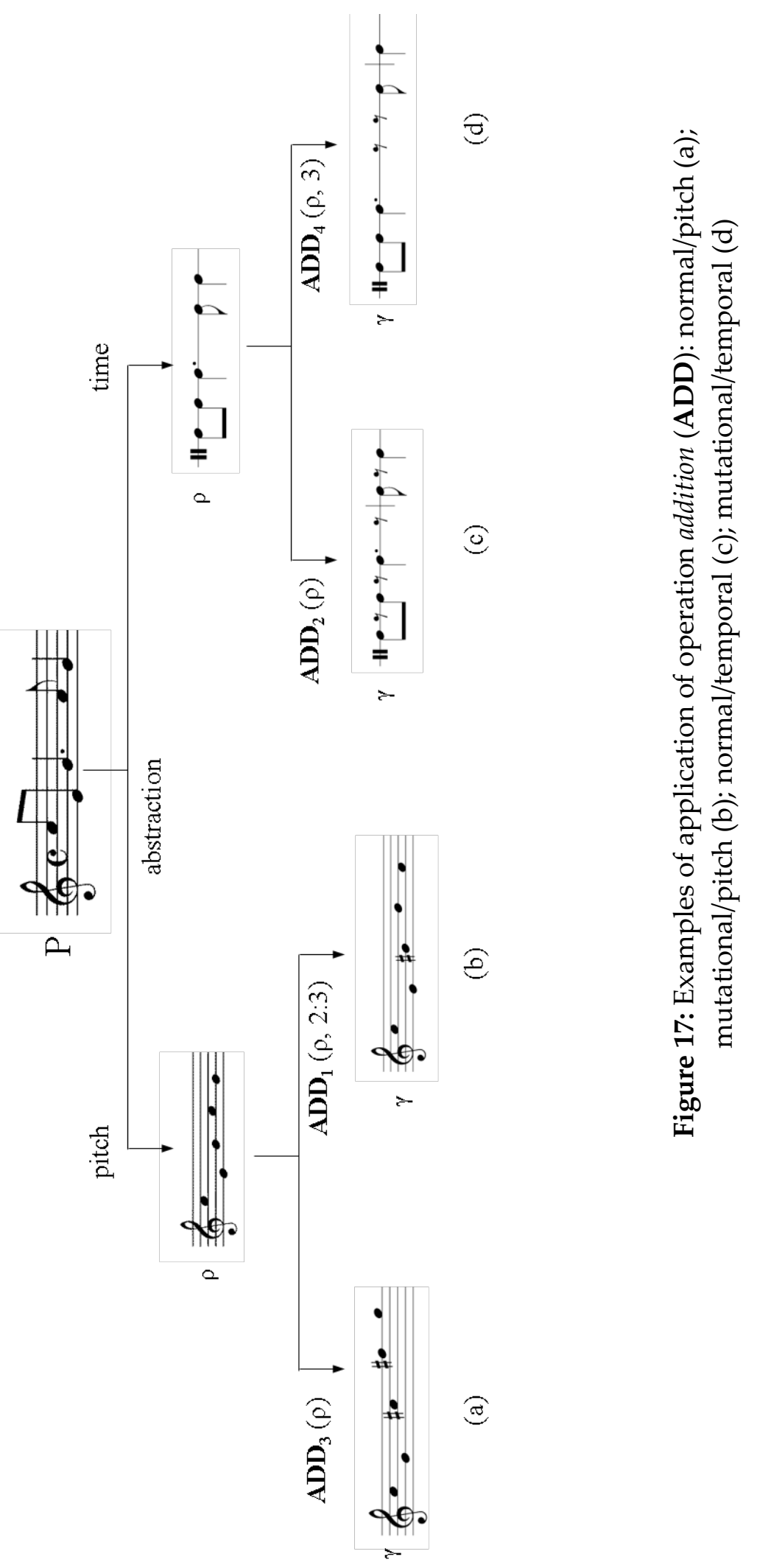


MUSICA THEORICA Revista da Associação Brasileira de Teoria e Análise Musical 2019, v. 4, n. 1, p. 30-61 - Journal of the Brazilian Society for Music Theory and Analysis@ TeMA 2019 - ISSN 2525-5541

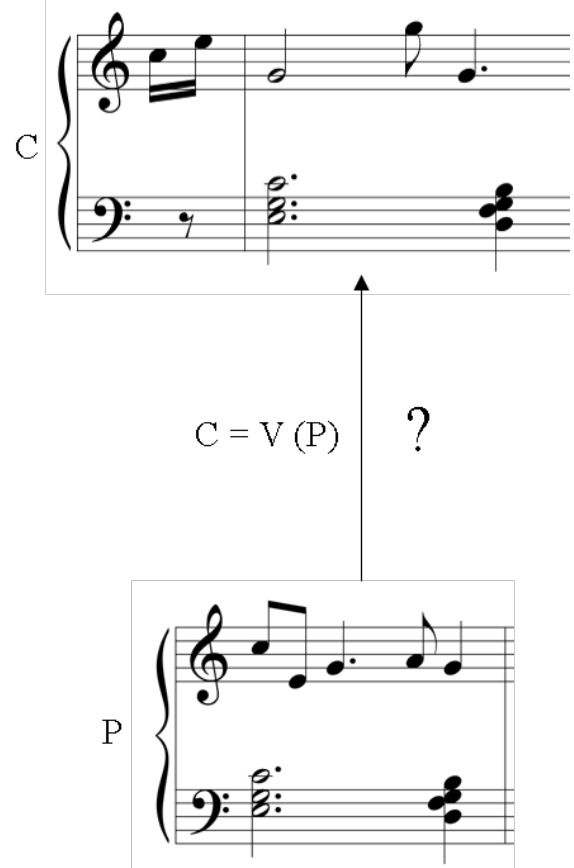

Figure 18: derivative relation between musical ideas $\mathrm{P}$ and $\mathrm{C}$

Suppose that the analyst, after a meticulous examination, decides by a derivative "narrative" based on six transformations distributed by both domains of pitch and time. ${ }^{24}$ The solution for the question, therefore, corresponds to a case of compound/hybrid variation, modeling the scheme of Figure 6b. Figure 19 presents a possible (since a transformational analysis is always based on hypotheses) transformational analysis of the path $\mathrm{C} \rightarrow \mathrm{P}$.

${ }^{24}$ The ways by which he/she supposedly reached these specific conclusions are not here relevant, but I think that they are clearly evident in the example. 


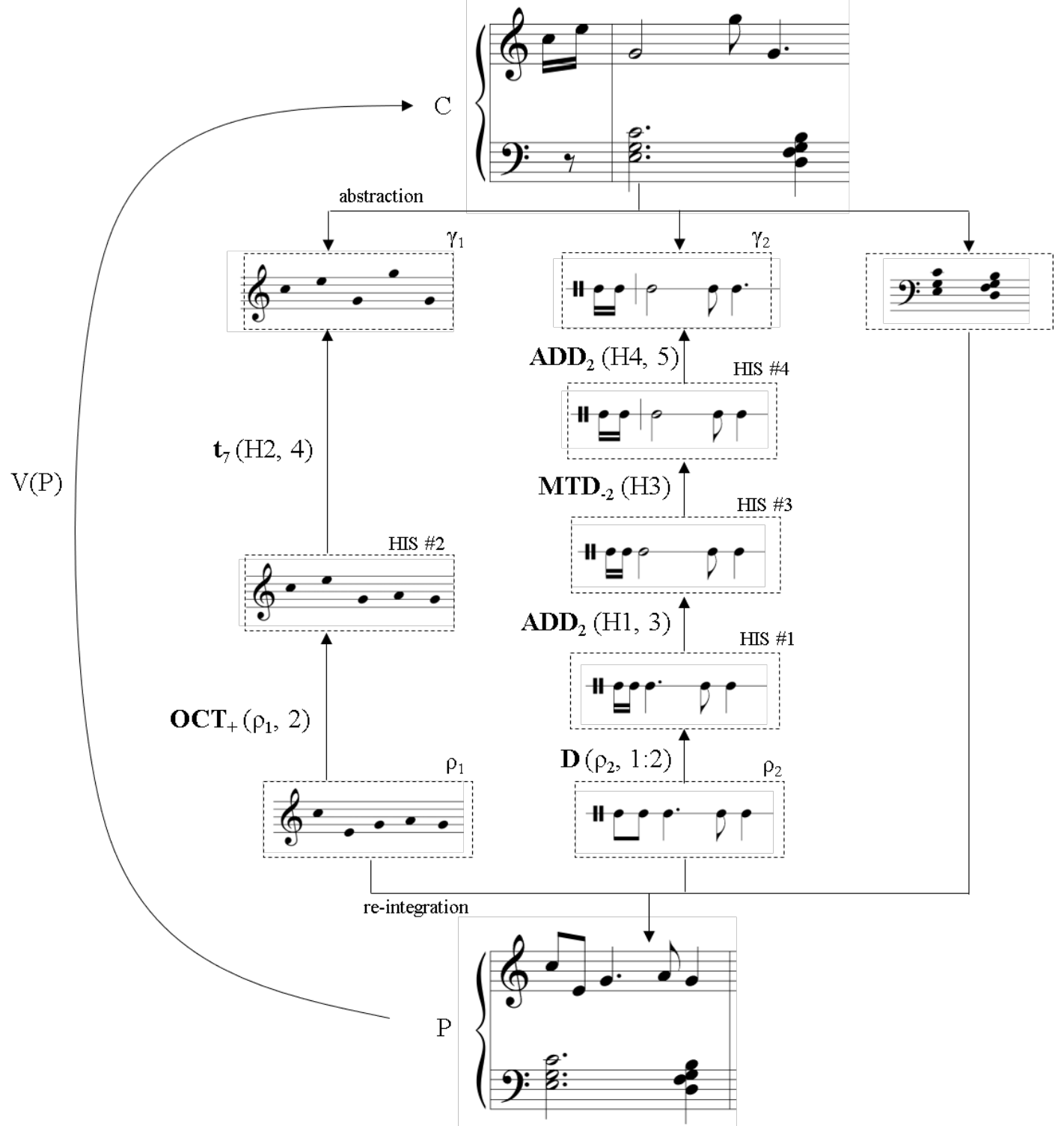

Figure 19: Example of transformational analysis considering compound/hybrid abstract variation

Notice that the arrows related to the generic function $\mathrm{V}$ and the six abstract operations point to the direction bottom-up, instead of top-down, as in Figure 6b. This modification of the model is justified by the fact that transformational analysis is a sequence of proposed hypotheses whose main goal is to reconstruct a possible derivative path, through logical reasoning and the use of simple means. 
MUSICA THEORICA Revista da Associação Brasileira de Teoria e Análise Musical 2019, v. 4, n. 1, p. 30-61 - Journal of the Brazilian Society for Music Theory and Analysis@ TeMA 2019 - ISSN 2525-5541

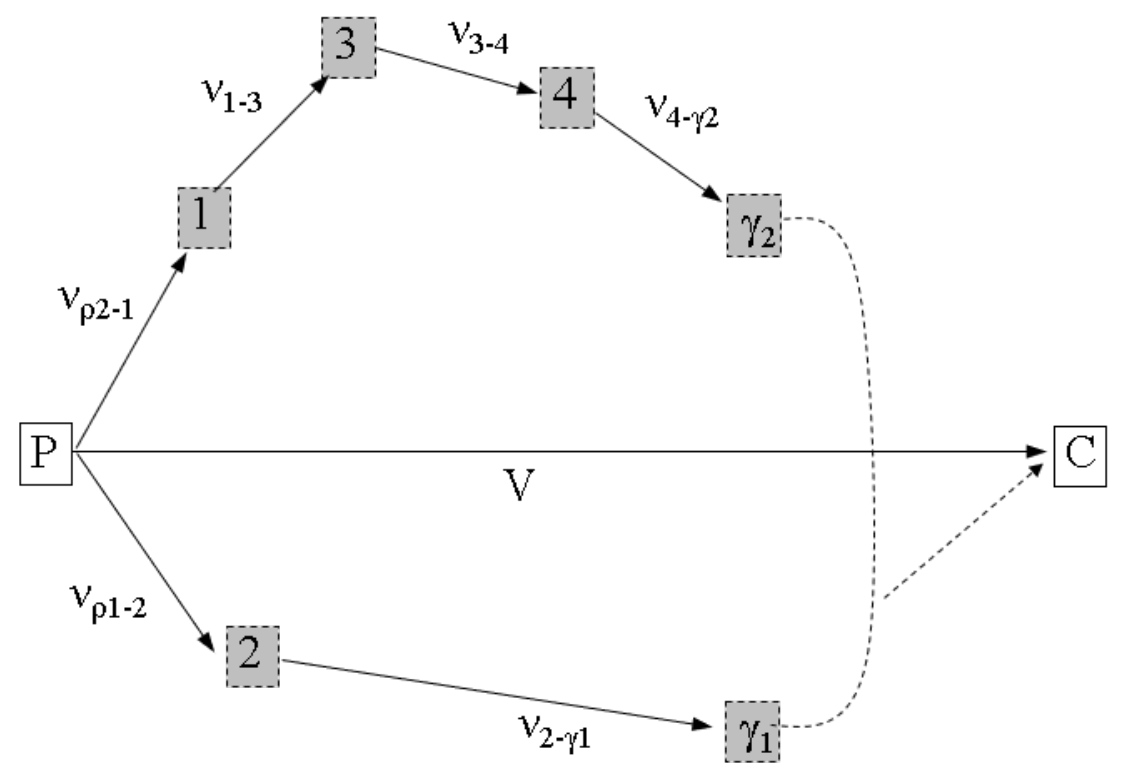

\begin{tabular}{c|c|c|c} 
op. & label & domain & scope \\
\hline$v_{\rho 2-1}$ & D & time & normal \\
\hline$v_{\rho 1-2}$ & OCT & pitch & mutational \\
\hline$v_{2-3}$ & ADD & time & mutational \\
\hline$v_{3-4}$ & MTD & time & mutational \\
\hline$v_{2-\gamma 1}$ & i & pitch & mutational \\
\hline$v_{3-\gamma 2}$ & ADD & time & mutational
\end{tabular}

Figure 20: Transformational network related to Figure 19

Figure 20 provides a concise graphical representation for the transformational analysis of Figure 19, following the model previously sketched in Figure 7. In MDA this graphical scheme is called derivative network. ${ }^{25} \mathrm{~A}$ derivative network essentially depicts the information necessary for explaining the elements of a given transformational process, having the following characteristics:

${ }^{25}$ The idea of derivative network adapts elements of the models proposed by David Lewin (1987), David Kopp (2002), and Steve Rings (2011). 
a) The musical (concrete) ideas $\mathrm{P}$ and $\mathrm{C}$ are linked by a horizontal, leftright arrow representing the generic function $\mathrm{V}$ (the direction of the arrow indicates that $\mathrm{C}$ is derived from $\mathrm{P}$ );

b) For simplicity, the stage of abstraction is omitted from the network;

c) For the same reason, the domains that are not affected by transformations (harmony, in the case of Fig. 19) are also omitted;

d) The stage of re-combination is indicated by a dashed arrow connecting the derivative targets ( $\gamma_{1}$ and $\gamma_{2}$ in Fig. 20) and the concrete unity C;

e) As a convention, derivations related to time domain are depicted arranged to the "north" of line $\mathrm{P}-\mathrm{C}$, while those referred to pitch and harmony occupy the "south" position;

f) Intermediary stages are disposed according to a hypothetical temporal order (previously determined by the analyst) in the respective domain/spaces (time/north and pitch-harmony/south). Angles and sizes of the connecting arrows are arbitrary, oriented just by layout conveniences;

g) Names, domains, and scopes of the employed operations are also provided in a table format, as complementary information.

\section{A transformational typology of developing variation}

Under the present transformational bias of MDA, developing variation (DV) can be concisely defined as a process that encompasses sequential, correlated variations occurring in function of time. ${ }^{26}$ In other terms, DV interconnects isolated transformations in a chain of related actions highly dependent on contextual conditions. Conversely, the "ordinary" derivative work (whose archetypical representation is shown in Fig. 2) is inherently a noncontextualized kind of transformational action and, therefore, can be considered as a, so to speak, timeless process. Based on this conception, I propose also the introduction of a new concept, the unity of developing-variation work, or UDV, whose archetypical representation is depicted in Figure 21.

\footnotetext{
${ }^{26}$ For two comprehensive, "conventional" definitions of developing variation (among many others), see Frisch (1984, p. 9) and Haimo (1997, p. 351).
} 


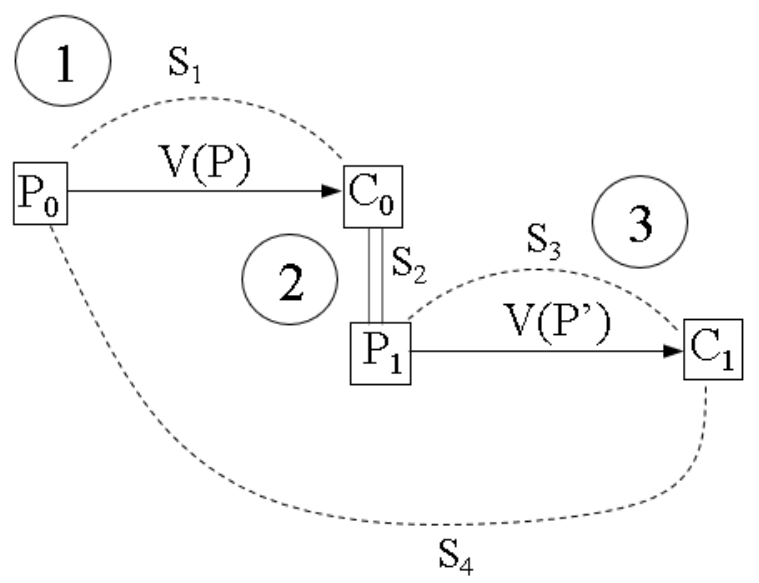

Figure 21: Archetypical representation of a unity of developing-variation work considering steps 1 (first derivation), 2 (child-parent equivalence), and 3 (second derivation)

A UDV presents the minimal, and sufficient conditions for establishing a developing variation process, being therefore labeled as a first-order developingvariation work (DV1). It is composed by three sequential steps: (1) first derivation $\left(\mathrm{P}_{0} \rightarrow \mathrm{C}_{0}\right)$, as a conventional archetypical derivative work; (2) child-parent equivalence, in which the child of the previous stage becomes the parent for the next $\left(\mathrm{C}_{0}=\mathrm{P}_{1}\right)$; and (3) second derivation $\left(\mathrm{P}_{1} \rightarrow \mathrm{C}_{2}\right)$, another derivative work, consequent of the first.

In sum, UDV corresponds to the junction of two simple archetypical derivative works, by an intermediary relation of equivalence acting analogously to a pivot chord in a tonal modulation. Four possible relations of similarity integrate a UDV:

$\mathrm{S}_{1}$ : between $\mathrm{P}_{0}$ and $\mathrm{C}_{0}\left(\mathrm{~S}_{1}\right)$;

$S_{2}$ : between $\mathrm{C}_{0}$ and $\mathrm{P}_{1}$, necessarily equal to $1,{ }^{27}$ considering their obligatory equivalence;

$\mathrm{S}_{3}$ : between $\mathrm{P}_{1}$ and $\mathrm{C}_{1}$;

$\mathrm{S}_{4}$ : between $\mathrm{P}_{0}$ and $\mathrm{C}_{1}$.

This last relation is the most significative, and important in a developingvariation work. Although exceptions can occur, $S_{4}$ is expected to be lesser than $S_{1}$,

\footnotetext{
${ }^{27}$ The maximum value of similarity, as previously stated.
} 
since as a rule DV tends to provoke continuous dilution of similarity between the $\mathrm{P}_{0}$ (or the primordial parent) and its subsequent descendants. ${ }^{28}$

From this, it is possible to propose a generalization of a nth-order developing-variation work (DVn) by "plugging" in series an indefinite number of UDVs, as shown in the model of Figure 22. Notice that eventually "unfertile" variants (indicated by empty rectangles) can be produced along the "generations". These are not relevant for DVn, which is represented only by the main branch of derivations, namely the UDV connections.

The similarity relation between the primordial parent $\mathrm{P}_{0}$ and a nth descendant is represented by the symbol $S_{n+3}$ (for example, the similarity relation between $\mathrm{P}_{0}$ and $\mathrm{C}_{8}$ will be labeled as $\mathrm{S}_{12}$ ). The measurement of this relation is one of the most important aspects of MDA, especially in analytical applications, a point to be examined in future studies.

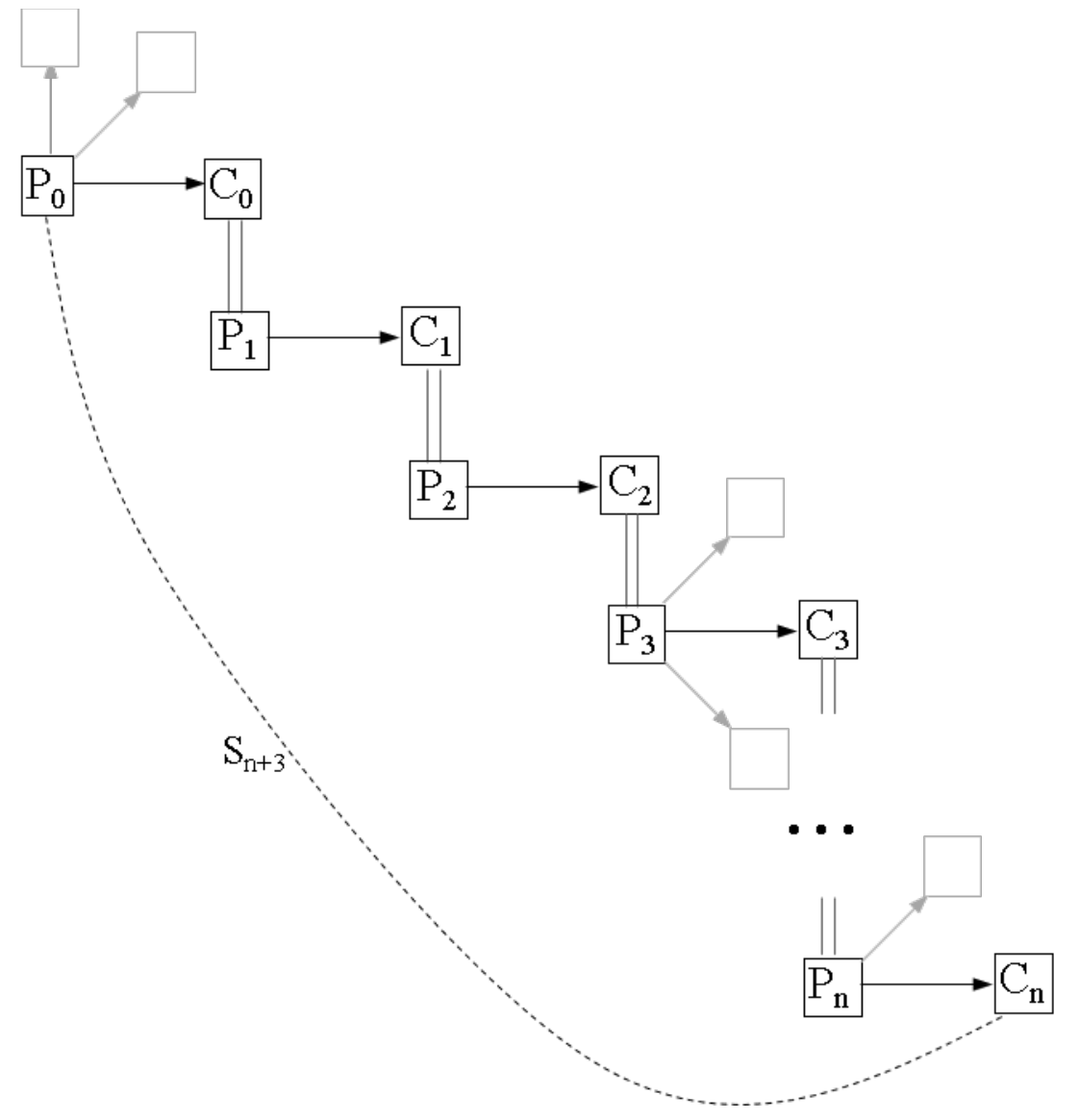

Figure 22: General scheme of a nth-order developing-variation work

\footnotetext{
${ }^{28}$ On the other hand, $\mathrm{S}_{1}$ and $\mathrm{S}_{3}$ are mutually independent and cannot be related based on a general assumption.
} 


\section{Concluding remarks}

The present article addressed the current version of the Model of Derivative Analysis, focusing on the main elements that form its theoretical basis. The interaction of the concepts, methods, and assumptions here introduced (like derivative work, abstract variation, hypothetical intermediary stages, transformational analysis, derivative network, operations, order and unity of development-variation work) contributes to reinforce the premise that variation as be seen as a generic action capable to transform musical ideas into others related by some degree of similarity.

Constrained by the limits of space and scope, several essential aspects of MDA have to be omitted (I would cite especially the algorithms for measurement of similarity, the concept of derivative space, the transformational Grundgestalt, among others) or treated superficially, or only partially (it is the cases of the transformational operations, and transformational analysis). These subjects will be properly addressed in complementary studies.

Another central question concerning the new configuration of the research is related to practical application. The methodology for derivative analysis derived from the theoretical framework described in this text was recently consolidated, providing a more systematic and formal means for derivative analysis. An article in preparation applying the method to a complete work composed by Brahms (the Intermezzo for piano Op. 118, no. 2) is intended to be its first large-scale test.

\section{References}

1. Almada, Carlos. 2016. Derivative Analysis and Serial Music: The Theme of Schoenberg's Orchestral Variations Op. 31. Permusi, 33, p. 1-24.

2. 2013. Simbologia e hereditariedade na formação de uma Grundgestalt: a primeira das Quatro Canções Op. 2 de Berg. Per Musi, 27, p. 7588.

3. . 2011a. A variação progressiva aplicada na geração de ideias temáticas. In: Simpósio Internacional de Musicologia, 2, Proceedings... Rio de Janeiro: UFRJ, p. 79-90. 
4 . 2010. O conceito de variação em desenvolvimento no primeiro movimento da Sonata para Piano Op. 2/1, de Beethoven. Música Hodie, 8/2, p. 83-94.

5. Auerbach, Brent. 2005. The Analytical Grundgestalt: A New Model and Methodology Based on the Music of Johannes Brahms. Thesis (PhD in Music). University of Rochester.

6. Carpenter, Patricia. 1983. Grundgestalt as tonal function. Music Theory Spectrum, 5, p. 15-38.

7. Collison, Stephen. 1994. Grundgestalt, Developing Variation, and Motivic Processes in the Music of Arnold Schoenberg: An Analytical Study of the String Quartets. Thesis (PhD in Music). King's College.

8. Epstein, David. 1980. Beyond Orpheus: Studies in music structure. Cambridge: The MIT Press.

9. Frisch, Walter. 1984. Brahms and the Principle of Developing Variation. Los Angeles: University of California Press.

10. Haimo, Ethan. 1990. Schoenberg's Serial Odyssey: The Evolution of His TwelveTone Method 1914-1928. Oxford: Clarendon Press.

11. 1997. Developing Variation and Schoenberg's Serial Music. Musical Analysis, 16/3, p. 349-365.

12. Lewin, David. 1987. Generalized Musical Intervals and Transformations. New Haven: Yale University Press.

13. Mayr, Desirée. 2018. The Identification of Developing Variation in Johannes Brahms Op.78 and Leopoldo Miguéz Op.14 Violin Sonatas through Derivative Analysis. Thesis (PhD in Music). Federal University of Rio de Janeiro.

14. Mayr, Desirée and Almada, Carlos. 2017. Correlations between Developing Variation and Genetic Processes in the Analysis of Brahms' Violin Sonata Op.78. In: European Congress of Musical Analysis, 9. Proceedings ... Strasbourg: EUROMAC (published as an extended abstract).

15. 2016. Use of Linkage Technique in Johannes Brahms' Op. 78 and Leopoldo Miguéz's Op. 14 Violin Sonatas. Opus, 22/2, p. 429-449.

16. Meyer, Leonard. 1989. Style and Music. Chicago: The University of Chicago Press.

17. Neff, Severine. 1984. Aspects of Grundgestalt in Schoenberg's First String Quartet, Op. 7. Journal of the Music Theory Society, 9/1-2, p. 7-56. 
MUSICA THEORICA Revista da Associação Brasileira de Teoria e Análise Musical 2019, v. 4, n. 1, p. 30-61 - Journal of the Brazilian Society for Music Theory and Analysis@ TeMA 2019 - ISSN 2525-5541

18. Ng, Yuet. 2005. A Grundgestalt Interpretation of Metric Dissonance in the Music of Brahms. Thesis (PhD in Music). Eastman School of Music, University of Rochester.

19. Rings, Steve. 2011. Tonality and Transformation. Oxford: Oxford University Press.

20. Rufer, Joseph. 1954. Composition with Twelve Notes. (Humphrey Searle, trad.). London: Rocklife.

21. Schiano, Michael. 1992. Arnold Schoenberg's Grundgestalt and its Influence. Thesis (PhD in Music). Brandeis University.

22. Schoenberg, Arnold. 1984. Style and Idea: Selected Writings of Arnold Schoenberg. London: Faber \& Faber. 


\title{
Categorias de Análise Musical e Modelagem Física como Análise do Timbre
}

\author{
Categories of Musical Analysis and Physical Modeling as Analysis of \\ Timbre
}

\author{
Rodolfo Coelho de Souza \\ Universidade de São Paulo
}

\begin{abstract}
Resumo: Este artigo traz uma reflexão sobre as categorias de análise que são usadas para obras de diferentes poéticas e estilos. Lembramos que a taxonomia foi primeira categoria de análise a ser usada. Continua sendo muito empregada, como por exemplo na análise harmônica tradicional. A segunda categoria de análise é a funcional, empregada por exemplo na análise harmônica riemanniana. Essa categoria se reinventa na estratégia da engenharia reversa como a que é usada na contagem da série dodecafônica. A terceira categoria é da hermenêutica que também envolve estratégias heurísticas. Ela tem sido a base de diversas teorias analíticas recentes como a das Tópicas e da Narratividade. Finalmente reconhecemos como quarta categoria a estratégia da modelagem, aplicada às obras cuja análise é resistente às categorias anteriores. Propomos que a análise do timbre é particularmente afeita à estratégia da modelagem, reconhecendo que a técnica da modelagem física por meios digitais oferece uma perspectiva promissora nessa direção.
\end{abstract}

Palavras-chave: Análise Musical; Taxonomia; Engenharia Reversa; Hermenêutica; Modelagem de Timbre

\begin{abstract}
This article offers a reflection about the categories of analysis employed for works of different poetics and styles. We remind that taxonomy was the first category of analysis to be used. It remains very useful, as it is used, for instance, in traditional harmonic analysis. The second is the category of functional analysis, employed, for instance, in the Riemannian harmonic analysis. This category reinvents itself in the strategy of reverse engineering, as it is used to count twelve-tone series. The third category is the hermeneutics that also involves heuristics strategies. It has been the basis of many recent analytical theories as the Topic and the Narrative. Finally, we recognize modeling as a fourth strategy of analysis, which can be applied to pieces that resist the approach of other analytical categories. We propose that the analysis of timbre is particularly keen to the modeling strategy, reminding that the physical modeling technique by digital means offers a promising perspective in this direction.
\end{abstract}

Keywords: Musical Analysis; Taxonomy; Reverse Engineering; Hermeneutics; Modeling of Timbre 
MUSICA THEORICA Revista da Associação Brasileira de Teoria e Análise Musical 2019, v. 4, n. 1, p. 62-97 - Journal of the Brazilian Society for Music Theory and Analysis@ TeMA 2019 - ISSN 2525-5541

\section{Introdução: Meta-Análise da Análise Musical}

Ao propor uma reflexão sobre o campo de Análise Musical encontramos a princípio quatro categorias de análise que apresentam características diferentes em função de seus métodos e objetivos. Designamos essas categorias como Taxonômica, Funcional ou Engenharia Reversa, Hermenêutica, e finalmente, Modelagem. A diferenciação entre essas categorias nem sempre é muito clara. Na verdade, uma análise pode envolver mais de uma categoria. Mas há casos em que a natureza do objeto requer uma determinada abordagem e determinadas categorias de análise se revelam inviáveis. Nosso propósito neste trabalho é refletir sobre essas diversas categorias de análise, finalizando com um problema complexo e atual que é a análise do timbre, um tópico de interesse para a música contemporânea (entendida aqui como a música dos séculos XX e XXI). A análise do timbre pode ficar constrangida a limites estreitos com metodologias das três primeiras categorias elencadas. Insights mais produtivos aparecem com a quarta categoria de análise, a Modelagem.

\subsection{Categoria das Análises Taxonômicas}

Diversos métodos clássicos de análise musical encaixam-se nessa categoria. Como se sabe, o desenvolvimento do pensamento taxonômico foi essencial para a crescimento das ciências naturais. Ciências como Botânica, Zoologia e Anatomia Humana tem sua base primordial no modelo taxonômico, ou seja, num processo que busca reconhecer e agrupar elementos dispersos e num estágio subsequente postular uma hierarquia na sua organização. $\mathrm{O}$ pensamento taxonômico não se preocupa com o funcionamento de um sistema que descreve. Preocupa-se com reconhecer os componentes desse sistema e nomear as classes de objetos que compartilham certas características. Em seguida estaremos habilitados a identificar a pertinência de um indivíduo ou objeto a uma classe postulada.

A figura 1 mostra um brinquedo para crianças pequenas que é baseado no pensamento taxonômico. Uma base de madeira com diversos encaixes, que são formas vazias (literalmente, não uma metáfora!), é apresentada para a criança. Em seguida ela recebe uma porção de peças coloridas. Sua tarefa, que requer um pensamento inteligente não tão elementar quanto pode parecer, é combinar a forma e o tamanho dos objetos concretos com as formas vazias. Dependendo do estágio do desenvolvimento da criança, a solução é encontrada de forma 
COELHO de SOUZA, R. Categorias de Análise Musical e Modelagem Física como Análise do Timbre

concreta, por tentativa e erro. Mais adiante, esse tipo de experiência concreta servirá para o desenvolvimento do pensamento abstrato que permite à criança associar a forma vazia com a forma concreta.

Note-se que haveria pelo menos três propriedades que permitem diferenciar os objetos entre si: a forma (triângulo, círculo, retângulo e quadrado, retângulo), o tamanho (grande e pequeno) e a cor (amarelo, vermelho, azul e verde). Duas dessas propriedades são relevantes para a taxonomia proposta pelo brinquedo: a forma e o tamanho. A cor, a princípio, é irrelevante para a solução, mas vemos que os elementos pertencentes a cada forma têm também a mesma cor. Ou seja, as propriedades de forma e de cor configuram uma única categoria. Essa associação certamente ajuda a criança pequena na solução do problema pois, em vez de lidar com três propriedades diferentes, ela precisa manipular apenas duas. O quebra-cabeças sem dúvida ficaria mais difícil para uma criança pequena se houvesse uma mistura aleatória de cores entre as peças.

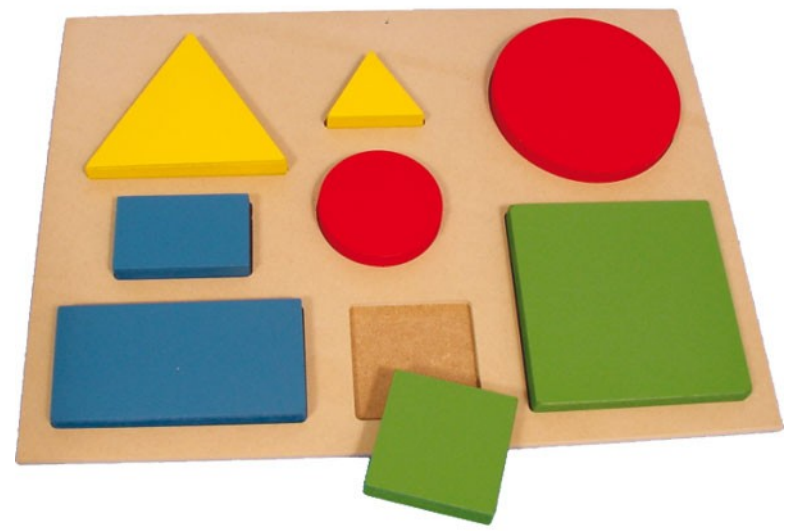

Figura 1: Brinquedo de encaixe de peças em base com formas em baixo relevo (imagem de quebra-cabeça da linha Brink Jogos da Editora Simque)

A escolha de um brinquedo para ilustrar o pensamento taxonômico não foi fortuita. As ciências taxonômicas, apesar de muitas vezes demandarem um árduo trabalho de identificação, classificação e nomeação, são muitas vezes consideradas fora de moda, obsoletas, a despeito de imprescindíveis.

A Análise Musical frequentemente opera no nível taxonômico. Consideremos, por exemplo, a análise harmônica tonal pelo sistema de graus e também a análise de formas musicais do estilo clássico. O objetivo de ambas é identificar a posição de um determinado objeto musical num sistema classificatório construído a priori pelas ciências da Análise Harmônica e da 
MUSICA THEORICA Revista da Associação Brasileira de Teoria e Análise Musical 2019, v. 4, n. 1, p. 62-97 - Journal of the Brazilian Society for Music Theory and Analysis@ TeMA 2019 - ISSN 2525-5541

Análise Formal. Ou seja, o propósito da análise é encaixar um objeto em uma das formas vazias da matriz de possibilidades do sistema.

Consideremos o Exemplo 1. Para uma análise formal, podemos fazer uma simples observação preliminar que indicaria que as vozes se movimentam com parcimônia diatônica, e às vezes cromática no contralto e no baixo, ou com notas repetidas, como na longa sustentação de pedal no soprano. O uso de homofonia homorrítmica e a conservação do quarteto vocal nos permite delimitar a pertinência desse fragmento a uma peça coral (por exemplo a uma frase de moteto ou de música sacra), ou a um tema de música instrumental que se aproprie do estilo coral. Como percebemos que nesse trecho existe uma única cadência no fim do excerto, podemos afirmar que sua forma corresponde à de uma "frase musical". Dado que o fragmento é muito curto, nossa classificação formal estanca aqui, mas já podemos perceber que as hipóteses foram cogitadas somente dentro de um sistema de possibilidades dado pela teoria das formas musicais. Em outras palavras, o que buscamos foi uma classificação taxonômica.

Considerando a análise harmônica do Exemplo 1 podemos afirmar também que ela não revela nada além da identificação da tipologia de cada acorde dentre as limitadas possibilidades oferecidas pelo sistema tonal, como dado a priori. Ou seja, o sistema tonal equivale à chapa de madeira com formas vazias escavadas do brinquedo da Figura 1 e cada acorde é uma réplica concreta positiva de um dos tipos ideais daquela estrutura que é usada então como sistema classificatório. Novamente, um procedimento clássico do pensamento taxonômico.

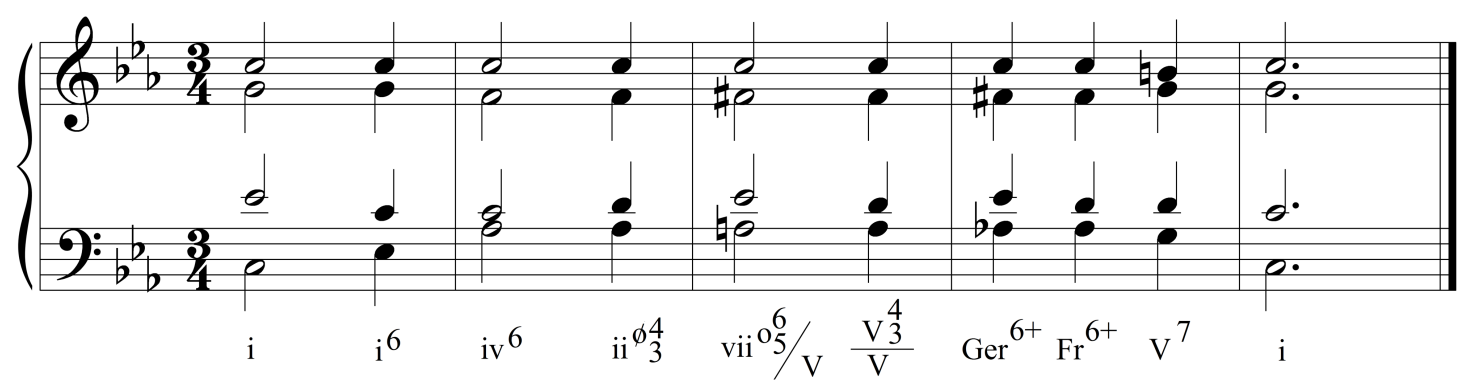

Exemplo 1: Análise de fragmento musical com cifras de harmonia tradicional de graus

Subindo um degrau no processo de abstração poderíamos argumentar que uma gramática é, na sua essência, uma estrutura taxonômica que estuda as regras de correlações válidas num determinado sistema. Num artigo clássico, Roads e Wieneke (1979) mapearam diversos sistemas analíticos musicais que operam por 
COELHO de SOUZA, R. Categorias de Análise Musical e Modelagem Física como Análise do Timbre

princípios taxonômicos baseados em gramáticas. Aquele estudo seminal sugeriu, entre outras coisas, que seria possível desenhar programas computacionais de análise de harmonia tonal bastante eficientes, pois um computador é capaz de realizar com rapidez a comparação de características dos acordes reais de uma música com seus modelos abstratos no sistema tonal. Nos quarenta anos que se passaram desde então, dezenas de projetos implementaram essa ideia. Apenas para mencionar um deles, de um pesquisador vinculado à plataforma comercial "Chordify", destacamos o artigo de Bas De Haas et al. (2014).

Por outro lado, se observarmos a progressão cromática de quatro prédominantes da dominante (5o ao 8a acordes) que emprega duas versões diferentes de acordes de sexta aumentada, podemos cogitar que seria mais provável encontrar essa passagem numa peça de Mozart do que numa de Bach, dada a frequência com que passagens cromáticas desse tipo ocorrem na obra de um e de outro. Esse raciocínio não pertence mais ao campo de uma análise taxonômica. Esta hipótese pertence à próxima categoria de modelos de análise.

\subsection{Categoria das Análises Funcionais e de Engenharia Reversa}

As ciências naturais progrediram gradativamente de conhecimentos classificatórios baseados em características superficiais para conhecimentos funcionais que explicavam o mecanismo interno dos objetos. Exemplos paradigmáticos dessa evolução são a Genética, que passou de uma ciência que trabalhava apenas sobre Fenótipos para um novo estágio, o dos Genótipos. Na Medicina, a Anatomia avança para a Fisiologia, e as descrição das partes do organismo são complementadas pelo entendimento de seu funcionamento.

Esse paradigma científico se espalhou naturalmente para as outras áreas do conhecimento. Nas ciências humanas, a teoria da música embarca na mesma empreitada. Podemos lembrar que no século XIX, acompanhando a onda funcionalista, Hugo Riemann propõe uma nova visão da teoria da harmonia inspirada no paradigma funcionalista. Rehding (2003, p. 38) aponta como a teoria da harmonia funcional riemanniana, baseada num pressuposto dualista, abriu caminho para o entendimento da harmonia cromática a partir do pressuposto de que a harmonia tonal obedece ao paradigma lógico da progressão T-S-D-T, postulada desde sua tese de doutorado (Riemann, 1874). No Exemplo 2 vemos como uma análise funcionalista reinterpreta os graus do Exemplo 1 em termos das funções que os acordes exercem no sistema tonal. Enfatizemos que não há 
MUSICA THEORICA Revista da Associação Brasileira de Teoria e Análise Musical 2019, v. 4, n. 1, p. 62-97 - Journal of the Brazilian Society for Music Theory and Analysis@ TeMA 2019 - ISSN 2525-5541

nenhuma contradição entre as duas análises. A primeira informa que "coisa" é cada acorde no sistema taxonômico baseado nos graus da escala e a segunda diz que "função" exercem aquelas mesmas coisas num sistema funcionalista baseado na lógica das progressões tonais postulada por Riemann.

Uma análise funcionalista, numa acepção rigorosa, não deveria depender de interpretações subjetivas. Deveria obedecer à lógica inerente ao sistema que seria plenamente mecanicista. As complicações que surgem na análise funcional riemanniana derivam do princípio dualista herdado de Hauptmann que Riemann abraçou com entusiasmo. Esse princípio introduz o problema de uma hermenêutica entre alternativas polares. Por exemplo, devemos considerar o terceiro grau de uma tonalidade maior como sendo uma dominante relativa ou uma tônica anti-relativa? Esse problema demanda recorrer à terceira categoria que propusemos, a das análises hermenêuticas. Mas não votaremos a este exemplo porque podemos encontrar outros casos que ilustram melhor a questão.

Note-se ainda que os métodos analíticos estão sempre sujeitos a revisões e novas codificações. As cifras de harmonia funcional usadas no Exemplo 2 tem diferenças consideráveis em relação àquelas propostas originalmente por Riemann. Elas na verdade seguem a prática comum atual nas culturas que adotam esse sistema em suas escolas, como em partes da Alemanha e da Áustria. No Brasil há diversas vertentes, mas, neste caso, optamos por Krämer (1997).

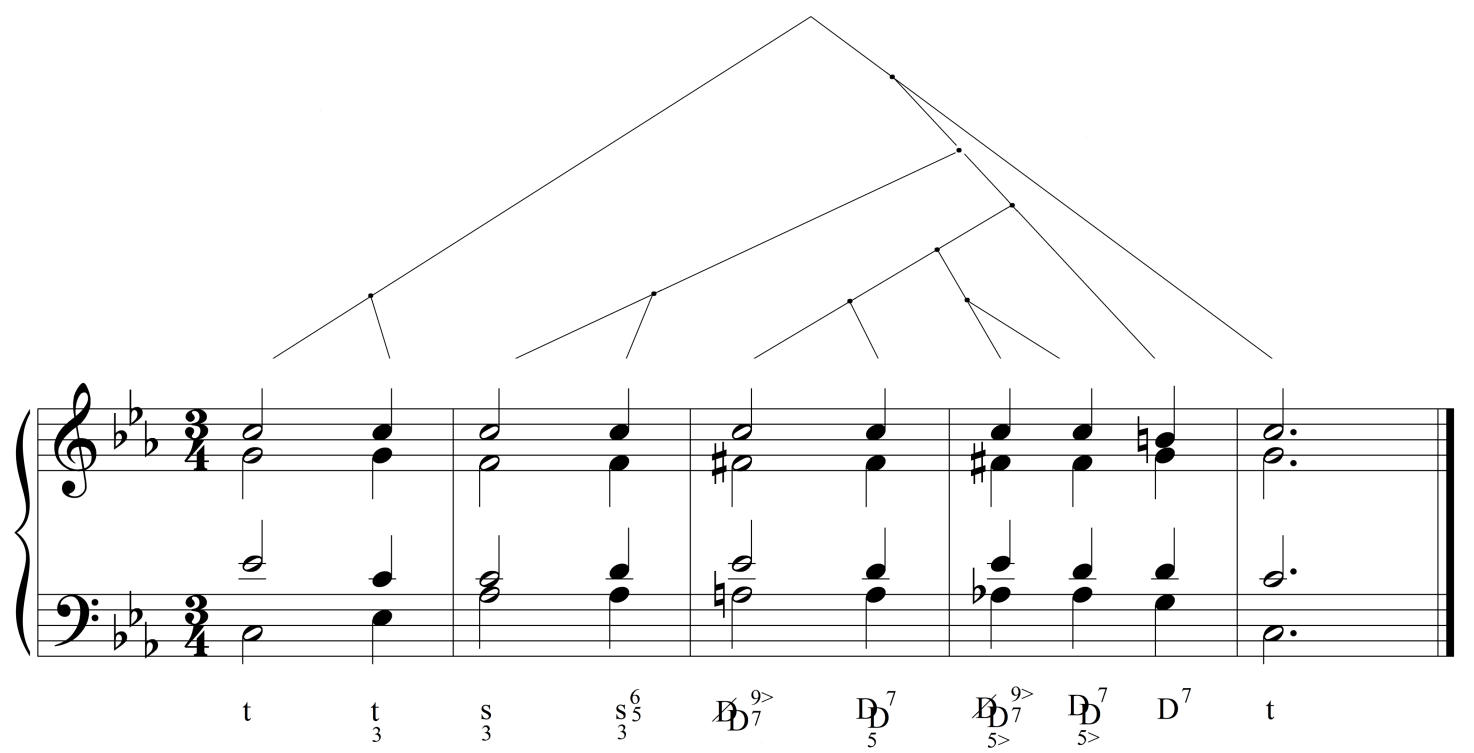

Exemplo 2: Análises funcional riemanniana e gerativa de Lerdahl do mesmo excerto 
COELHO de SOUZA, R. Categorias de Análise Musical e Modelagem Física como Análise do Timbre

As análises funcionais, mesmo de um objeto aparentemente inequívoco, como uma progressão harmônica, podem receber formulações diversas. A mesma progressão que no Exemplo 1 foi analisada por graus, e no Exemplo 2 foi analisada por funções harmônicas, pode ser analisada pela lógica da gramática gerativa de Chomsky, como o fez Lerdahl $(1883,2001)$. Não se trata de uma proposta que refuta o funcionalismo harmônico de Riemann, ao contrário, é uma teoria que procura generalizar o princípio a partir da teoria de Chomsky que propõe reconhecer a sintaxe como um fenômeno universal compartilhado por todas as linguagens, a princípio verbais, mas que Lerdahl propõe valer também para a sintaxe da música tonal. Embora não seja clara a pertinência desse método analítico ao campo das teorias funcionalistas, pois ela também envolve um nível hermenêutico, consideramos que ela equivale do ponto de vista heurístico à teoria da harmonia funcional riemanniana e, portanto, é predominantemente funcionalista.

Menos claramente funcionalistas, são as análises que seguem o paradigma da engenharia reversa. Esse conceito vem da área tecnológica, em que existe essa prática usual de desmontar um dispositivo para entender como ele funciona. Justamente porque o objetivo é compreender um funcionamento, estamos no campo das análises funcionalistas. Fazemos isso, por exemplo, para descobrir como opera uma máquina para poder copiar sua estrutura numa réplica.

Existem diversos métodos de composição no século vinte que não procuram justificar seus princípios com base nas leis naturais da acústica. Por isso não se pode analisar seu processo sintático com base em regras taxonômicas e funcionais universais. Um bom exemplo disso é o método dodecafônico da Segunda Escola de Viena, pelo menos na versão que ficou consagrada pelo breve tratado de Křenek (1940). Qual é o objetivo da análise que faz a chamada "contagem da série"? Esse tipo de análise não revela nada a respeito de um possível sentido latente da obra, e nem mesmo a pertinência de sua linguagem a um modelo de sintaxe universal. Revela apenas como funciona a aplicação do método dodecafônico naquela peça. 


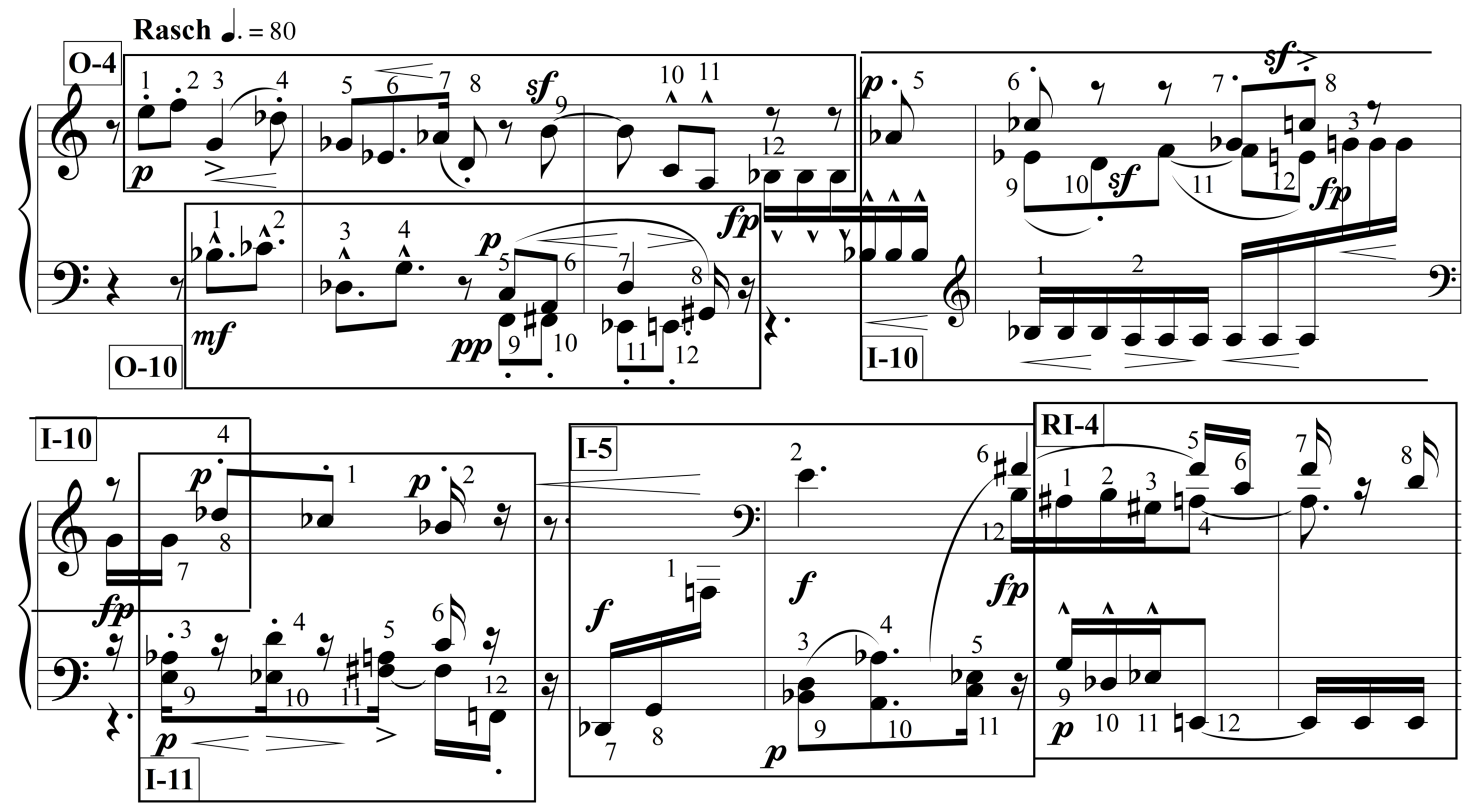

Exemplo 3: Análise dodecafônica do início do Präludium da Suite Op. 25 de Schönberg

O Exemplo 3 mostra um trecho de uma análise, de nível básico, do início do Präludium da Suite Op. 25 de Schönberg. Dado o autor e o período histórico, obviamente o pressuposto da análise é que se trata de uma peça dodecafônica. Presume-se que, logo a princípio, seja exposta uma série de doze sons que seria possível encontrar por um processo de tentativa e erro, característico das análises por engenharia reversa. De fato, encontramos logo no início, na voz superior, uma série que parece ser a série geradora da obra (ver Schönberg 1963, p. 171):

$\mathrm{O}-4=\{\mathrm{E}, \mathrm{F}, \mathrm{G}, \mathrm{D} b, \mathrm{G} b, \mathrm{E} b, \mathrm{~A} b, \mathrm{D}, \mathrm{B}, \mathrm{C}, \mathrm{A}, \mathrm{B} b\}$

As séries subsequentes serão reconhecidas, também por tentativa e erro, como resultantes de variações isomórficas da série original, ou seja, séries obtidas por operações de transposição, inversão ou retrogradação. De fato, a análise esquematizada no Exemplo 3 nos permite entender o mecanismo que foi usado para produzir a música, mas nada além disso. Esse tipo de compreensão nos permite, porém, reproduzir o processo e gerar infinitas variações que funcionariam como réplicas do estilo dodecafônico da peça. Na verdade, a análise dodecafônica tem dificuldade de superar esse nível de engenharia reversa funcionalista, por isso o método dodecafônico foi muitas vezes acusado de automatismo mecânico e desqualificado como mero exercício de estruturação vazia. Reiteramos que análises dodecafônicas, como a do Exemplo 3, hoje contribuem pouco. Para acrescentar algum conhecimento relevante, 
COELHO de SOUZA, R. Categorias de Análise Musical e Modelagem Física como Análise do Timbre

possivelmente precisaríamos incorporar descobertas heurísticas da categoria analítica seguinte.

Uma informação útil que poderia ser acrescentada seria uma análise comparativa com obras de outros autores. Esse tipo de resultado foi alcançado por Straus (2009) ao comparar a música do dodecafonistas norte-americanos com a música da escola vienense, para concluir que nunca houve uma ortodoxia dodecafônica, como se costuma acreditar. Na verdade, basta comparar as regras postuladas para o contraponto dodecafônico por Křenek para se chegar a esse mesmo resultado. Se fossemos medir pelas regras de Křenek (que parecem se conformar bem à música de Webern), a música de Schönberg, criador do dodecafonismo, seria considerada "não ortodoxa". Bastaria constatar que Schönberg diversas vezes divide a série de 12 notas em conjuntos menores com 4 e 6 notas e faz uma parte da série sobrepor-se a outra parte, interrompendo a linearidade da série, um procedimento não descrito por Křenek.

Afirmamos que este tipo de análise de música dodecafônica equivale a um processo de engenharia reversa. Isso tem uma implicação adicional. Essa análise poderia, então, subsidiar o projeto de um algoritmo que produzisse automaticamente resultados similares. Projetos de composição algorítmica dependem sempre de codificações específicas que explicitem detalhadamente as regras gerativas de um determinado estilo descobertas por reversão analítica. $O$ projeto de pesquisa de uma vida inteira desenvolvido por David Cope (vide, por exemplo, Cope 2005), exemplifica com clareza esse problema. Cope demonstra que a o processo de análise e síntese reversa é condicionado pelo entendimento das regras de formação de um estilo. Esse é provavelmente o resultado mais interessante que produzem as análises que através de engenharia reversa descrevem o funcionamento de obras paradigmáticas.

Há ainda um ponto importante a ressaltar no caso da análise da peça de Schönberg. Foi relativamente simples desenvolver a análise do Exemplo 3 porque as regras gerativas usuais da música dodecafônica são de domínio comum. Mesmo na década de 1940, quando o sistema dodecafônico ainda era novidade, um compositor brasileiro como Cláudio Santoro, distante dos proponentes do sistema para ter acesso a informações de primeira mão, foi capaz de usar a análise reversa (de Alban Berg) para entender os procedimentos do sistema e replicá-lo em suas obras. Isso demonstra que a análise reversa no sistema dodecafônico é feita num nível bastante transparente. De fato, no Exemplo 3, a série básica 
MUSICA THEORICA Revista da Associação Brasileira de Teoria e Análise Musical 2019, v. 4, n. 1, p. 62-97 - Journal of the Brazilian Society for Music Theory and Analysis@ TeMA 2019 - ISSN 2525-5541

aparece, como em muitas obras desse estilo, na melodia da voz superior no início da peça. O resto da análise é uma montagem de um quebra-cabeças simples porque a chave para a decodificação estava pendurada na porta de entrada.

Para outras análises reversas nem sempre há transparência e chamaremos esses casos de análise reversa de objeto opaco. Um bom exemplo é a dificuldade que se encontra na análise das obras do serialismo de Darmstadt. Uma das mais celebradas façanhas é a análise de Lev Koblyakov (1990) de Le marteau sans maître (1952-55) de Pierre Boulez. Koblyakov enfatiza a dificuldade da tarefa:

A natureza especial e a dificuldade de analisar música serial são o resultado de sua organização complexa. O problema é que, além da serialização de todos os parâmetros, códigos numéricos são usados, os quais ajudam no desenvolvimento hierárquico do sistema serial. Além disso, com Boulez a série geral de uma composição é principalmente um organismo gerador de uma rede de séries derivadas, e usualmente ela não tem um papel direto na música. Por isso o investigador deve ter pelo menos alguns esboços do próprio compositor, senão ele terá que realizar uma tarefa de incrível complexidade. (Koklyakov 1990, p. 3).

Numa nota de rodapé, Koblyakov comenta que a ausência de análises de obras seriais de Stockhausen e Nono se deve a essa dificuldade de acesso a esboços que pudessem ajudar a elucidar o processo. Alega, porém, não ter tido acesso aos esboços do Marteau de Boulez. Entretanto, em outro parágrafo, Koblyakov reconhece que só conseguiu realizar a análise devido à ajuda do compositor. Ou seja, Boulez passou para Koblyakov as múltiplas chaves das diversas portas de acesso ao mecanismo altamente complexo dessa música serial, altamente opaca à análise reversa.

Para termos uma ideia da tarefa hercúlea, vejamos um excerto da análise de Koblyakov, enfocando apenas os dez primeiros compassos do primeiro movimento Avant "d'artisanat furieux" (Ex. 4). 

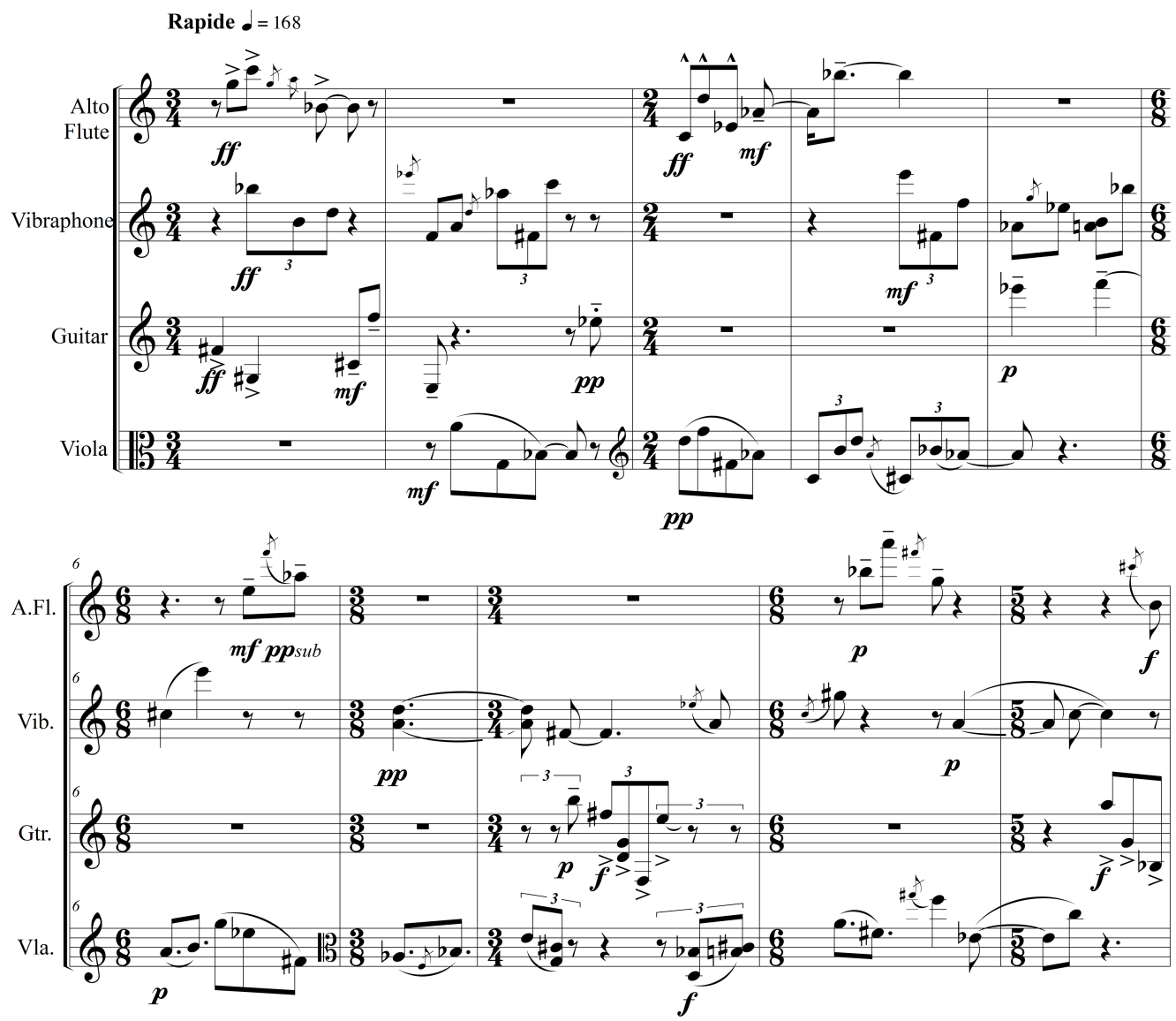

Exemplo 4: Dez primeiros compassos de Le Marteau sans Maître de Pierre Boulez

Como afirmou Koblyakov, as tentativas de reconhecer a série geradora da música a partir de uma leitura direta da partitura não revelam nada. A série usada nesse fragmento (e há outras séries para outras partes da música) está encriptada por um complexo processo de geração de conjuntos derivados pela chamada "multiplicação de Boulez", um processo de replicar os intervalos de um fragmento da série em todas as notas de outro fragmento da série.

A série, que é dodecafônica, usada por Boulez para compor esse fragmento é mostrada no Exemplo 5. Podemos supor, pelo que afirmou Koblyakov, que Boulez forneceu essa série ao analista.

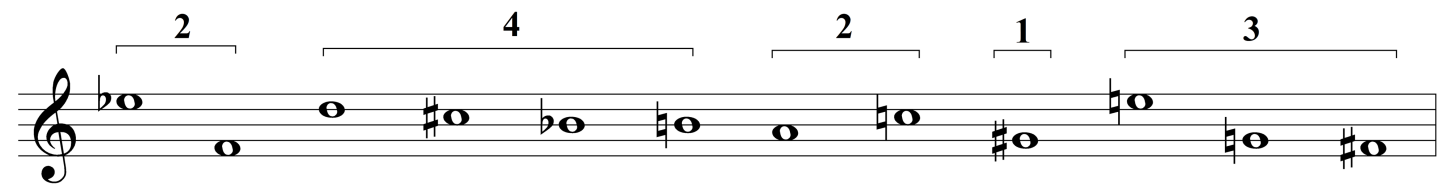

Exemplo 5: Série usada no início de Le marteau sans maître para gerar outras derivações (adaptado de Koblyakov 1990, p. 4) 
MUSICA THEORICA Revista da Associação Brasileira de Teoria e Análise Musical 2019, v. 4, n. 1, p. 62-97 - Journal of the Brazilian Society for Music Theory and Analysis@ TeMA 2019 - ISSN 2525-5541

No processo idiossincrático que Boulez usou para compor essa obra, a série é dividida sucessivamente em diversos agrupamentos. A primeira divisão é feita em conjuntos de 2, 4, 2, 1 e 3 notas, conforme marcado no Exemplo 5. A seguir o compositor construiu matrizes que resultam da multiplicação da série pelos diversos conjuntos recortados na primeira linha e reconfigurados com as multiplicações nas sucessivas colunas. O resultado produziraá diversas matrizes, sendo que a primeira é mostrada no Exemplo 6. A numeração das linhas e colunas da matriz foi modificada em relação a Koblyakov para facilitar a compreensão da análise mostrada no Exemplo 7.

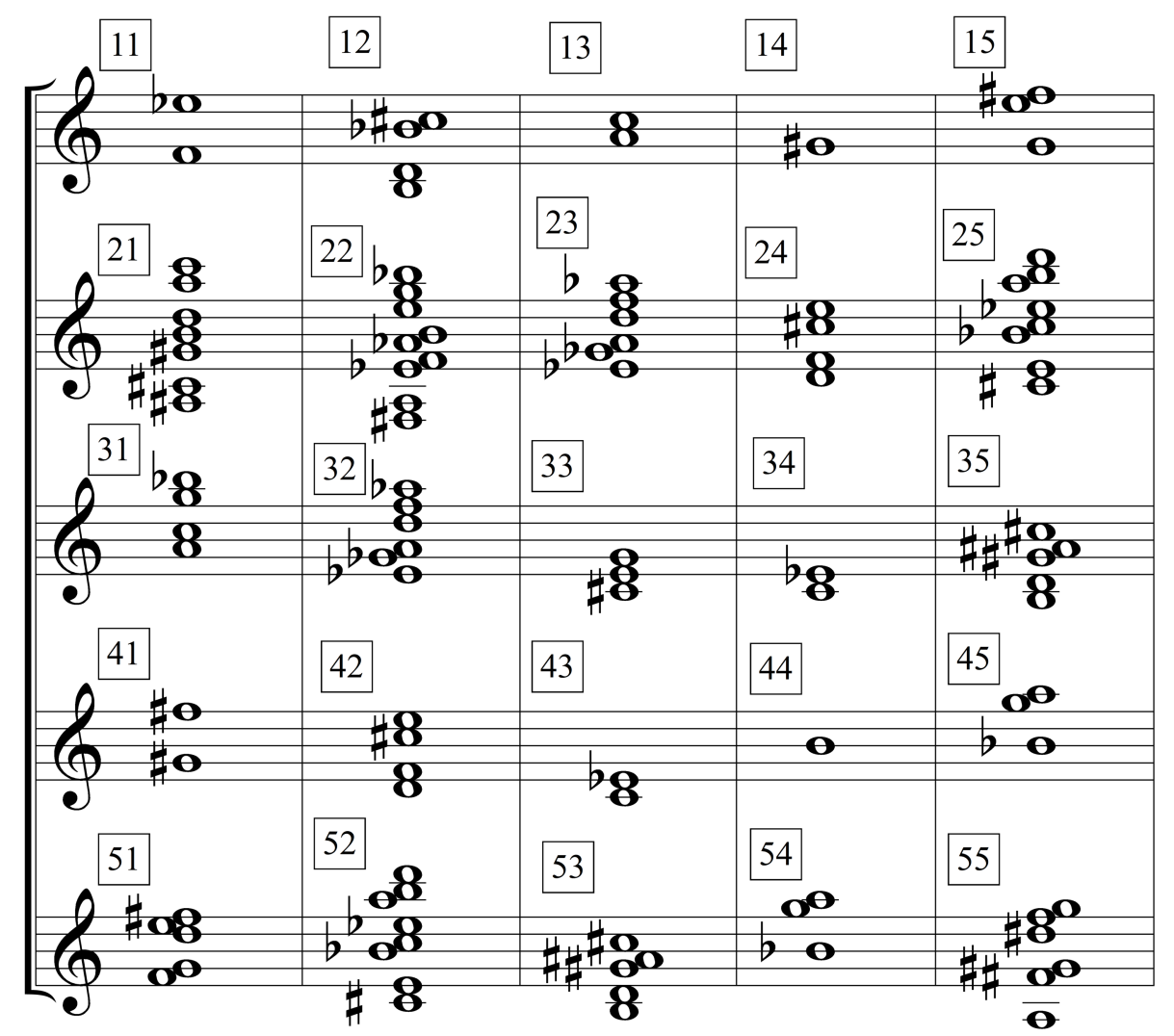

Exemplo 6: Primeira matriz do primeiro ciclo do início de Le marteau sans maître (adaptado de Koblyakov 1990, p. 137)

Com base nos conjuntos identificados 11 a 55 dessa matriz Koblyakov identificou suas ocorrências na partitura, conforme mostrado no Exemplo 7. Os conjuntos que identificamos no Exemplo 7 tem pequenas divergências em relação à análise de Koblyakov, mas isso é irrelevante. As diferenças decorrem da busca de Koblyakov por identificar os percursos sistemáticos de leitura da matriz que Boulez sugeriu. Pela análise de Koblyakov, Boulez leu a matriz seguindo 
COELHO de SOUZA, R. Categorias de Análise Musical e Modelagem Física como Análise do Timbre

caminhos sistemáticos nas diagonais, à semelhança do modo como se calcula determinantes de matrizes, um procedimento que era familiar para quem teve sólida formação em matemática como Boulez. Uma das dificuldades importantes que dificultam na engenharia reversa chegar-se à série original da qual foram geradas as derivações, é que os conjuntos 11 a 55 são conjuntos não-ordenados. Ou seja, o serialismo usado por Boulez nessa obra está muito longe de ser serial porque não há linearidade e ordenação nos materiais que podem ser muito mais bem descritos como formações harmônicas encadeadas. $O$ princípio de conservação das alturas nessas formações verticais tampouco é relevante, porque prevalece o princípio da equivalência de oitava, ou seja, as notas são tratadas como classes de alturas, tal como na teoria dos conjuntos de Forte. O problema fica ainda mais complexo quando lembramos que a segmentação revelada por Koblyakov no Exemplo 7 não pode ser presumida a priori, nem pode ser deduzida pela observação da partitura ou por critérios perceptivos. Portanto, ela só pode ser identificada a partir dos dados da matriz do Exemplo 6.

Note-se ainda que esta obra é paradigmática no estilo do serialismo integral, de modo que todos os outros parâmetros musicais também foram serializados por Boulez. Ou seja, dinâmicas, durações, instrumentação, etc, tudo segue um planejamento rigoroso de derivações seriais. Entretanto não é nosso propósito nos debruçarmos aqui sobre esses tópicos, mesmo porque a análise serial completa está detalhada no trabalho de Koblyakov (1990). Pretendemos apenas demonstrar que a engenharia reversa do algoritmo inventado por Boulez para compor essa obra é de tal complexidade, ou seja é um mecanismo tão opaco, que somente com o conhecimento prévio das chaves da codificação é possível desvendar a criptografia da obra.

No prefácio da publicação do seu trabalho, escrito quinze anos depois de ter defendido a tese de doutoramento em que propôs a análise, Koblyakov reconhece que desvendou posteriormente muitos outros aspectos da obra que não havia percebido na primeira tentativa, mas que isso implicaria em reescrever o trabalho. Isso indica que ele se deu de conta que o gigantesco esforço de revelar todos os detalhes do processo serial de Boulez dava conta apenas do mecanismo de geração da obra, isto é, do algoritmo passo a passo que Boulez inventou e seguiu rigorosamente na composição. Entretanto esse nível de análise revela muito pouco sobre como a obra é ouvida, ou seja, que sentidos perceptivos ela produz. A próxima categoria aborda esse terceiro tipo de objetivo analítico. 


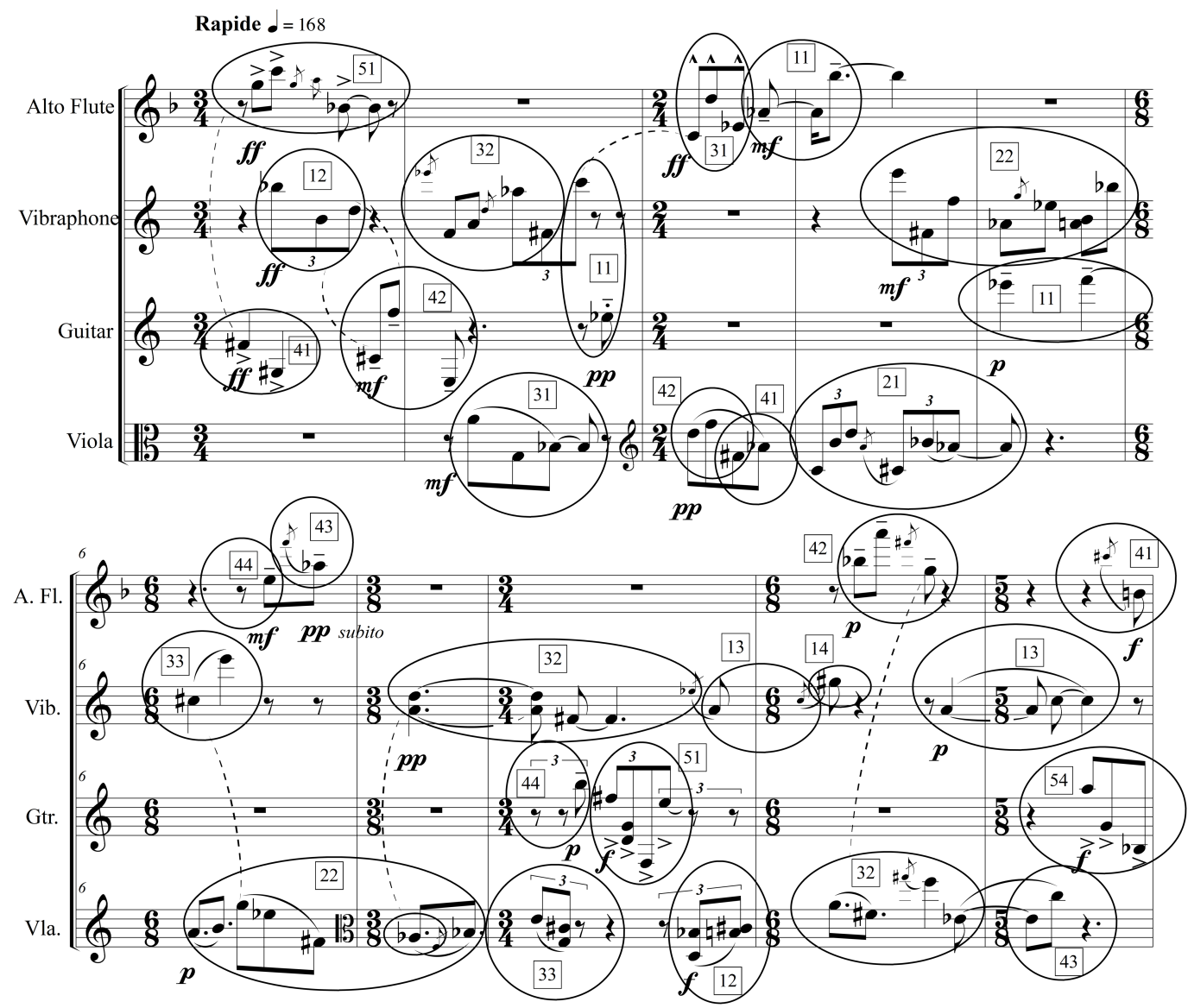

Exemplo 7: Análise do serialismo bouleziano do início de Le marteau sans maître (adaptado de Koblyakov 1990, p. 205)

\subsection{Categoria das Análises Hermenêuticas}

Nas duas categorias anteriores, a correção das afirmações feitas sobre os objetos analisados sempre pode ser verificada por critérios objetivos. Isso não significa, por exemplo, que não se possa propor uma outra análise para a peça de Boulez, mas não se pode questionar a segmentação proposta por Koblyakov porque ela é congruente com as premissas do processo de multiplicação serial de Boulez. Nesse sentido não há ambiguidades nem subjetivismo nas análises propostas. O modelo é dado a priori e a análise simplesmente reconhece a congruência do objeto com o modelo.

Entretanto há outros tipos de processos analíticos em que a decisão não é unívoca. Consideremos o exemplo da Figura 2. Temos uma estante com oito caixas que foi projetada para guardar objetos de modo a separá-los por suas características. Vamos supor que os objetos a guardar sejam sempre cubos e que 
COELHO de SOUZA, R. Categorias de Análise Musical e Modelagem Física como Análise do Timbre

eles apareçam com duas variáveis, cor e tamanho. Considere a seguir que nosso objetivo seja classificar e guardar o cubo que é mostrado à esquerda.
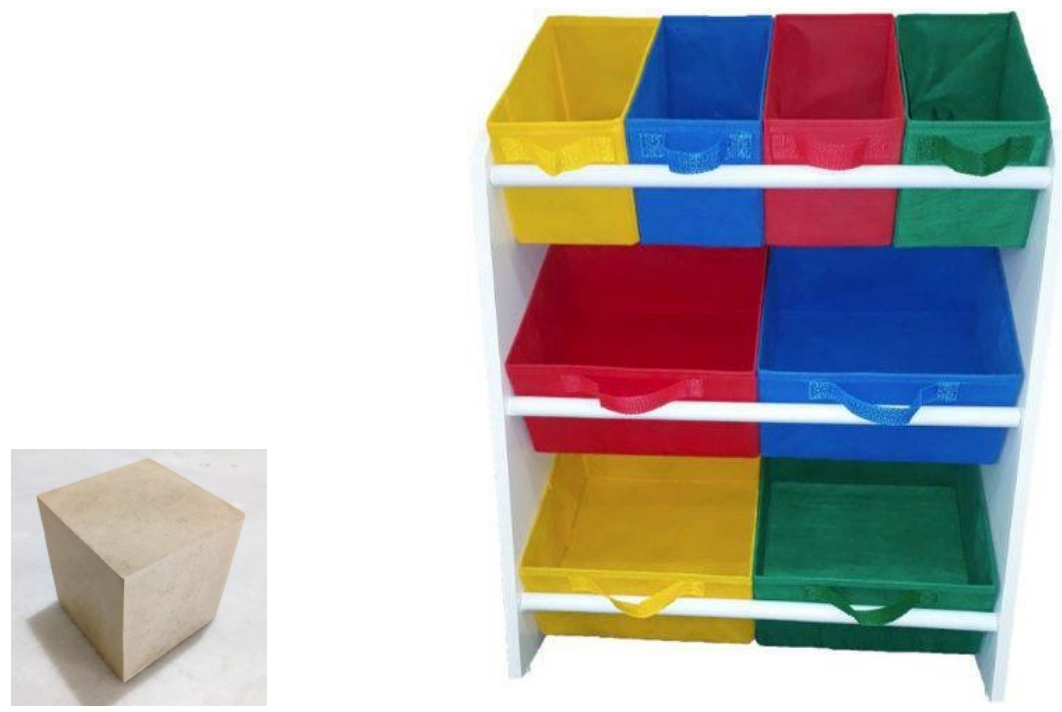

Figura 2: Como classificar este cubo na estante de organização de objetos?

O tamanho do cubo é grande demais para ser acomodado em uma das quatro caixas da prateleira superior, mas as caixas das duas prateleiras inferiores podem acomodá-lo. Até aqui nosso raciocínio seguiu o paradigma taxonômico. No passo seguinte precisamos decidir em qual das quatro caixas inferiores o cubo deve ser guardado. A decisão seria automática se o cubo fosse vermelho, azul, amarelo ou verde. Porém esse cubo não se encaixa adequadamente em nenhuma das categorias disponíveis. Como escolher, então, uma das caixas?

Obviamente não há uma única solução possível e nem sequer uma que seja inequivocamente a mais correta. O problema é a ambiguidade do objeto. Para tomar uma decisão é necessário postular um critério que justifique a escolha. Podemos, por exemplo, argumentar que a palidez do cubo é apenas o resultado da cor amarela ter perdido o brilho. Assim a caixa amarela seria o destino adequado para o cubo. Ou podemos decidir armazenar o cubo branco na caixa azul por um gosto estético pessoal. Estamos no terreno da ambiguidade em que é necessário estipular os princípios que sustentem uma interpretação hermenêutica dos motivos da decisão.

Diversas teorias de análise musical operam no nível hermenêutico. Observemos que uma interpretação hermenêutica normalmente é acompanhada 
MUSICA THEORICA Revista da Associação Brasileira de Teoria e Análise Musical 2019, v. 4, n. 1, p. 62-97 - Journal of the Brazilian Society for Music Theory and Analysis @ TeMA 2019 - ISSN 2525-5541

por um achado heurístico. Todos conhecemos aquele momento do "estalo" em que uma ideia se revela e permite a resolução do problema.

A Teoria dos Conjuntos, em si, é essencialmente taxonômica, pois seu objetivo é fazer um inventário da tipologia de conjuntos de notas existentes no universo cromático, das suas propriedades internas e das relações entre conjuntos. Ainda que se possa considerá-la complexa, ela é plenamente determinística. Entretanto, uma análise baseada na teoria dos conjuntos é necessariamente hermenêutica porque necessita de um passo intermediário que não é dado a priori, qual seja, a segmentação do discurso em conjuntos discretos. A segmentação é, por sua natureza intrínseca, o resultado de uma interpretação, de uma visão heurística. Lembremos que o problema da segmentação tem sido vivamente debatido, e suscitou, por exemplo, o alentado trabalho de Dora Hanninen (2012) sobre o tema. Numa perspectiva oposta, pode-se argumentar que, do ponto de vista de uma análise automatizada através de inteligência artificial, seria possível reduzir o aspecto heurístico a uma busca por padrões classificatórios conhecidos. Entretanto, essa discussão ampliaria o problema para muito além dos limites da análise musical, pois significaria admitir a possibilidade de redutibilidade da própria natureza do pensamento heurístico.

Para ilustrar o problema, efetuamos uma análise segundo a teoria dos conjuntos dos mesmos sete compassos iniciais de Le marteau sans maître de Boulez (vide Exemplo 8). É o mesmo trecho em que, no Exemplo 7, mostramos sua gênese a partir da matriz de multiplicação de uma série, conforme propôs Koblyakov. Comparando as duas análises verifica-se facilmente que seus resultados não apresentam nenhuma equivalência.

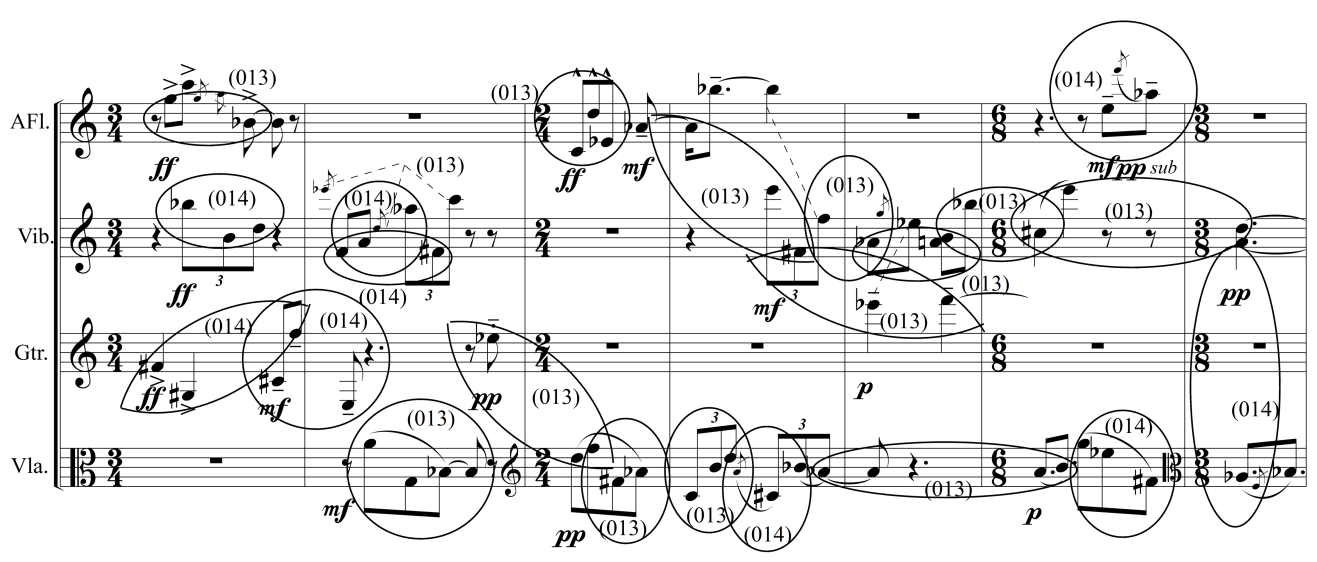

Exemplo 8: Análise pela teoria dos conjuntos do início de Le marteau sans maître 
COELHO de SOUZA, R. Categorias de Análise Musical e Modelagem Física como Análise do Timbre

A análise mostrada no exemplo 8 segmentou a partitura em conjuntos de três notas que pertencem a apenas dois conjuntos elementares de Forte, quais sejam os tricordes 3-2:(013) e 3-3:(014). A preocupação dessa análise foi demonstrar a coesão da obra em torno de duas sonoridades levemente contrastantes, pois seriam formadas ambas por um semitom e uma terça, uma terça menor no conjunto 3-2 e uma maior no 3-3. Portanto o objetivo dessa análise seria revelar uma organicidade que não é possível vislumbrar na análise serial do Exemplo 7. Pelo contrário, aquela análise descrevia uma explosão da coerência serial que parecia impossível de ser reconciliada com qualquer unidade perceptiva. Porém, um tipo de unidade é recuperado nessa análise de conjuntos.

Essa discrepância não significa uma contradição, como se uma estivesse certa e a outra errada. O processo da engenharia reversa do Exemplo 7 pretendeu demonstrar como a peça teria sido construída. A análise hermenêutica do Exemplo 8 quis mostrar uma maneira de entender o resultado perceptivo. Uma operou segunda a categoria funcional, a outra segundo a categoria heurística/hermenêutica.

Outras teorias em voga que pertencem ao universo da hermenêutica são as teorias das Tópicas, da Intertextualidade e da Narratividade. Robert Hatten foi quem mais claramente percebeu que a natureza dessas análises as coloca no campo da hermenêutica. A explicação que Hatten apresenta para o conceito de análise hermenêutica é brilhante na sua concisão e precisão:

Hermenêutica: o termo origina-se nos métodos de interpretação da Bíblia e na longa tradição da crítica literária; foi apropriada no século XX por Kretschman (1902) para a significação musical expressiva. Neste trabalho o termo se refere a uma abordagem interpretativa de qualquer significado que vá além do puramente estrutural ou "sintático" ("implicacional", funcional), baseando-se em evidências de qualquer fonte relevante para (abdutivamente) reconstruir estratégias interpretativas (estilisticamente guiadas) (Hatten 1996, p. 290).

Atente-se para um detalhe na frase de Hatten. Diz ele: "baseando-se em evidências..." como sendo a condição necessária para a abdução (formulação de uma hipótese) interpretativa. Este é o calcanhar de Aquiles do processo hermenêutico, em outras palavras, a possibilidade de que ele se desvirtue em "achismo", na fantasia subjetiva, que só pode ser evitada mantendo-se o foco na objetividade das evidências. O próprio termo "hermenêutica" foi rejeitado pela análise musicológica durante parte significativa do século vinte porque esteva 
MUSICA THEORICA Revista da Associação Brasileira de Teoria e Análise Musical 2019, v. 4, n. 1, p. 62-97 - Journal of the Brazilian Society for Music Theory and Analysis@ TeMA 2019 - ISSN 2525-5541

contaminado pela prática do século dezenove de uma hermenêutica sem amarras propriamente analíticas. Essa prática privilegiava a livre associação de ideias, impressões sensoriais e imagens subjetivas na construção de discursos cuja intenção era fazer o elogio de uma obra musical. Esse estilo de análise persiste no século vinte, às vezes mesclado com alguma objetividade, como se pode ver depreender do seguinte trecho da crítica de Souza Lima, sobre a peça Lenda do Caboclo de Villa-Lobos:

Evoca, com a maior simplicidade de escritura, o nosso sertanejo no seu viver tranquilo, entrosado na natureza que tudo lhe proporciona [...]. Para evocar ainda mais a atmosfera de calma de nossas matas, Villa-Lobos, com uma nota que vibra sobre o balancear dos acordes, nos lembra o canto da juriti. (Souza Lima, apud Versolato 2008, p. 80). ${ }^{1}$

As metáforas do "sertanejo tranquilo", da "calma da mata", dos "acordes que balançam" e do "canto da juriti" são imagens poéticas provavelmente sugeridas pelo título da peça, mas dizem muito pouco da música em si e serviriam para comentar muitas outras peças de Villa-Lobos. Uma análise não pode se ater à recepção estética do ouvinte no nível estésico, conforme objeta Nattiez, mesmo porque haveria uma recepção diferente para cada ouvinte. Enfatizamos que a análise hermenêutica moderna, embora possa expressar uma posição subjetiva, deve estar embasada em evidências objetivas.

Para ilustrar esse dilema entre o objetivo e o subjetivo na análise musical hermenêutica podemos lembrar o seminário que se realizou em torno da Sonata Tempestade de Beethoven publicado pela Universidade de Leuven (Bergé, 2009). Diversos analistas de grande reputação, como Bergé, Burnham, Burstein, Caplin, Hamilton, Hatten, Hepokoski, Kinderman, Rothstein, Seaton e Moortele analisam a mesma obra sob perspectivas analíticas diferentes partindo dos trabalhos seminais de Dahlhaus (1989, p. 13) e Schmalfeldt (2011, p. 39-49). O conjunto dos problemas que eles abordam é muito complexo e extenso para ser tratado neste contexto, mesmo que resumidamente. Vou me ater a um ponto que ilustra a questão da hermenêutica. O início da Sonata, mostrado no Exemplo 9, justapõe um arpejo em tempo lento e uma progressão tensa em andamento rápido. O que "quer dizer" essa frase? É uma introdução? Ou já é o primeiro

\footnotetext{
${ }^{1}$ Original publicado em Comentários sobre a obra pianística de Villa-Lobos. Rio de Janeiro: MEC Museu Villa-Lobos, 1969
} 
tema? Ou trata-se de uma introdução de dois compassos com o tema começando no terceiro compasso?

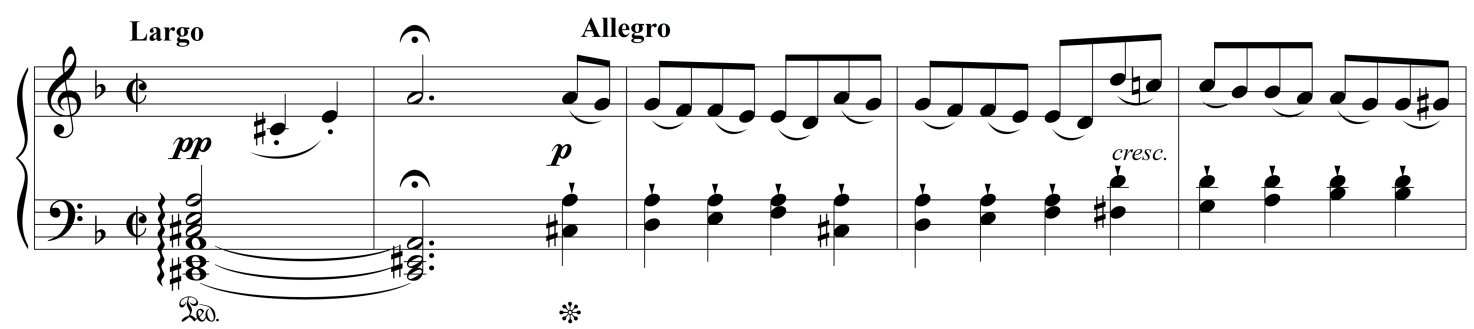

Exemplo 9: Sonata n. 17, op. 31 n. 2, Tempestade, c. 1-6, de Beethoven

Uma leitura hermenêutica atualizada não buscaria atribuir um significado metafórico a esta passagem, mas procuraria indícios nos elementos funcionais e tópicos para dar uma resposta às questões acima aventadas. A solução clássica, que todos os autores mencionados partilham de algum modo, considera que a chave deve ser encontrada na recapitulação (vide Ex. 10). O material do início reaparece ali com uma inserção de quatro compassos que é característico de uma linha vocal de recitativo. Isso esclarece que toda a passagem inicial já era de fato o primeiro tema, composto com dois materiais contrastantes, o primeiro em tópica de recitativo e o segundo em tópica de Sturm und Drang. Schmalfeldt nos esclarece que a significação é sempre retroativa. $O$ futuro esclarece o passado. Hatten nos esclarece que o limite da hermenêutica é o compartilhamento do signo em uma determinada cultura. Recitativo e tempestade só fazem sentido para quem conhece gêneros e estilos oriundos da ópera séria.

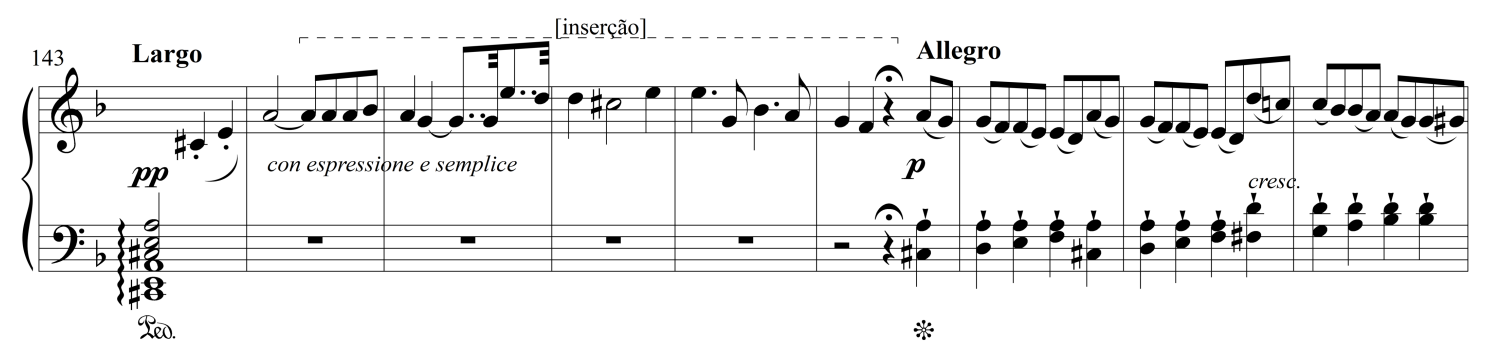

Exemplo 10: Sonata n. 17, op. 31 n. 2, Tempestade, c. 143-151, de Beethoven

Numa outra vertente, há trabalhos analíticos na linha heurística que parecem extrapolar as proporções razoáveis entre estudo do objeto e pura especulação, como se a criatividade hermenêutica não precisasse derivar da análise do objeto, mas ganhasse vida própria. $\mathrm{O}$ melhor exemplo dessa tendência talvez seja o artigo "Set Theory, Derivation and Transformational Structures in 
MUSICA THEORICA Revista da Associação Brasileira de Teoria e Análise Musical 2019, v. 4, n. 1, p. 62-97 - Journal of the Brazilian Society for Music Theory and Analysis @ TeMA 2019 - ISSN 2525-5541

Analizing Webern's Opus 10, Number 4" de David Lewin publicado postumamente em 2007 no livro Musical Form and Transformation.

A partitura de Webern analisada por Lewin é mostrada no Exemplo 11. Como vemos ocupa uma única página, com seis compassos e a execução consome em torno de 20 segundos. Em contraste com a concisão de Webern, o artigo de Lewin tem 29 páginas, atravessa diversas etapas de processos transformacionais, mesmo só tratando do parâmetro alturas, ainda que durações, dinâmicas e timbres exerçam papéis relevantes na peça.

IV.

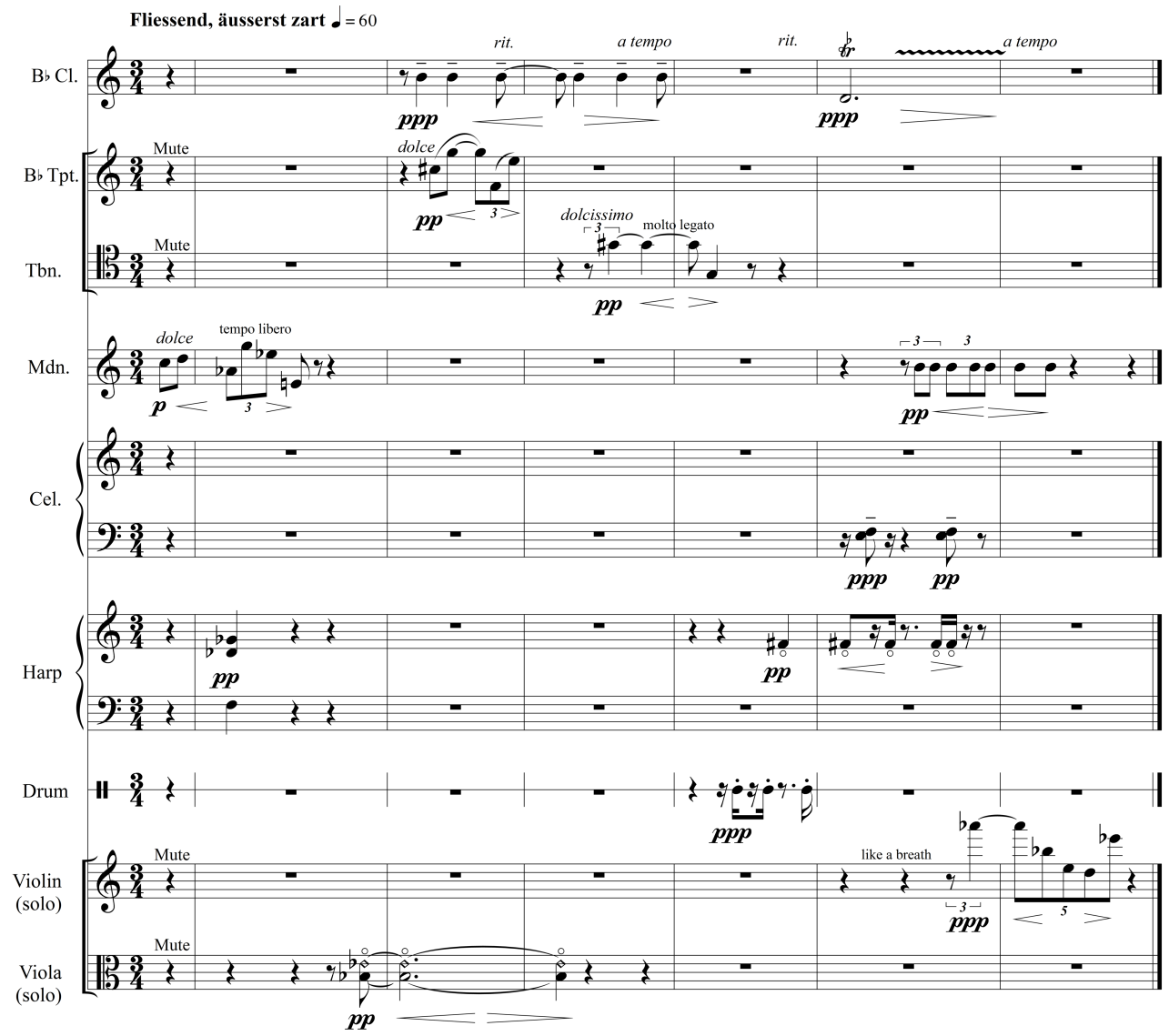

Exemplo 11: Webern op. 10 n. 4 para conjunto misto

O primeiro estágio da análise de Lewin parte de um trabalho anterior de Allen Forte que oferece uma interpretação heurística dentro das expectativas normais das análises com a teoria dos conjuntos. Lewin resume esse resultado no esquema do Exemplo 12, reconhecendo um material básico $\mathrm{H}$, da classe de conjuntos 6-Z43, seu complemento $\mathrm{h}$, da classe 6-Z17, e as transformações isomórficas indicadas por $\mathrm{T}=$ transposição e $\mathrm{L}=$ inversão. 


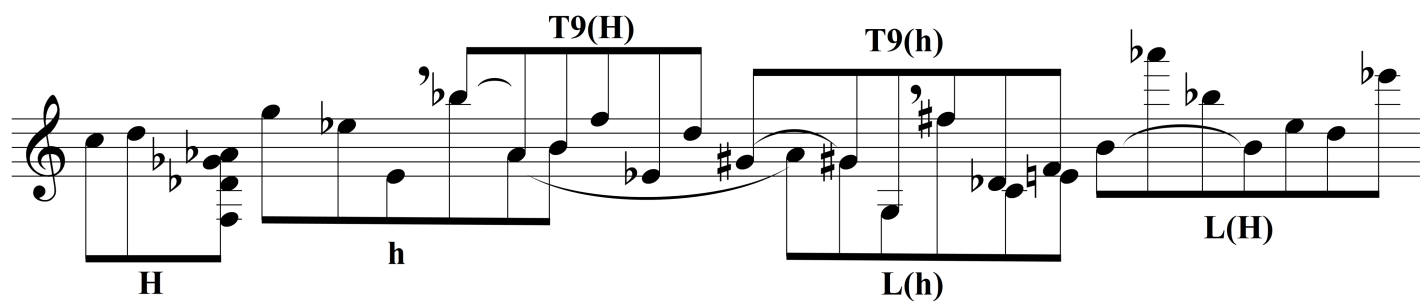

Exemplo 12: Primeiro estágio da análise de Lewin do op. 10 n. 4 de Webern (adaptado de Lewin 2007 p. 69, Example 3.2)

Como dissemos, a análise de Lewin prossegue por diversos estágios (em minha contagem, sete) de teorizações sobre transformações e finalmente o esquema do Exemplo 13 resume os achados analíticos de Lewin em sua forma mais geral e abstrata. Nesse esquema I significa inversão em Mi ou Sib; J significa inversão em Ré/Mi b ou SolÆ/Lá; e K significa inversão em Fá\#/Sol ou Dó/Réb.

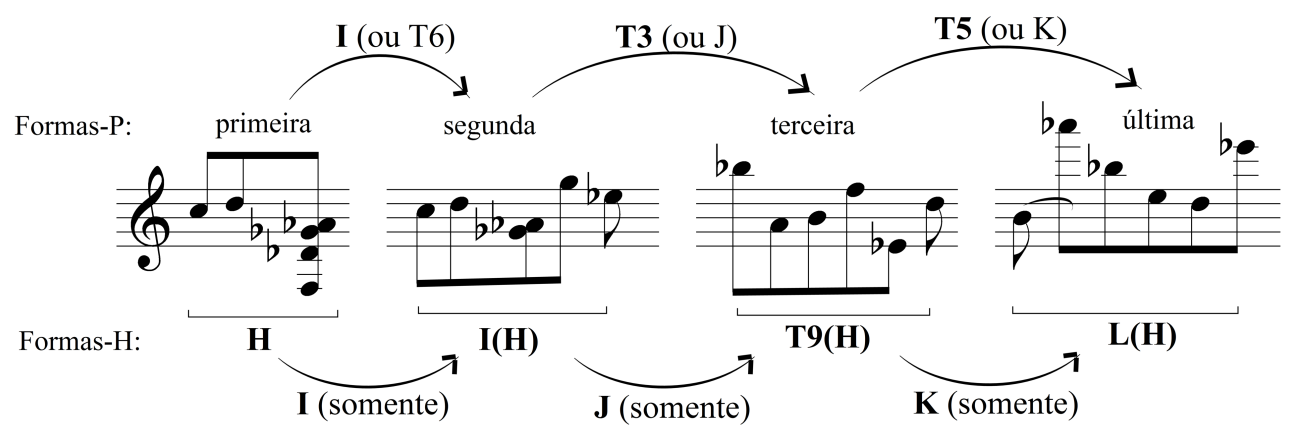

Exemplo 13: Último estágio da análise de Lewin do op. 10 n. 4 de Webern (adaptado de Lewin 2007, p. 85, Example 3.19)

Esse estilo de análise, característico dos anos 1980, sofreu críticas principalmente da corrente da Nova Musicologia que lamentava o afastamento dos aspectos perceptuais e contextuais. Não obstante, o trabalho de Lewin prosseguiu sendo referencial e respeitado porque, por mais que sua imaginação analítica pareça se distanciar da obra e crie uma narrativa estrutural autônoma, sua lógica é impecável e suas conclusões brilhantes. Na defesa dessas chamadas "ficções analíticas", Marion Guck (1994) lembra que nossa percepção de uma obra pode ser profundamente transformada e enriquecida por narrativas analíticas que funcionam como reflexos paralelos à superfície do discurso.

\subsection{Categoria das Análises por Modelagem}

A quarta e última categoria analítica que propomos neste estudo é a da Modelagem. Ela surge como uma necessidade das poéticas musicais a partir da 
MUSICA THEORICA Revista da Associação Brasileira de Teoria e Análise Musical 2019, v. 4, n. 1, p. 62-97 - Journal of the Brazilian Society for Music Theory and Analysis@ TeMA 2019 - ISSN 2525-5541

segunda metade do século vinte. Vimos como a análise do serialismo de Boulez não permite mais a decodificação de uma funcionalidade e é praticamente indevassável por engenharia reversa, a menos que as chaves sejam fornecidas exmachina. Outras obras de autores daquele período ou recentes serão ainda mais resistentes a qualquer daquelas duas estratégias. Por exemplo, peças que sejam compostas por algoritmos que usem o acaso e cálculos probabilísticos em sua geração são inacessíveis à recuperação passo a passo do processo que as produziu visto que não obedecem a uma lógica causal. Como analisá-las então?

Keller e Ferneyhough (2004) apresentam uma alternativa engenhosa que é o recurso à modelagem. Muitas obras musicais recentes utilizam a formaprocesso na sua organização. Para dar conta de sua análise a modelagem busca entender o processo com que foram produzidas e não o resultado específico do processo, visto que ele pode ser considerado uma entre muitas alternativas que o processo poderia ter gerado. Outras obras, que utilizem formas-abertas, isto é, com partes sujeitas a escolhas pelo intérprete gozam do mesmo status de imprevisibilidade do resultado, mas a análise por modelagem seria tautológica porque a partitura manifesta o próprio modelo das variantes possíveis. Entretanto há certos níveis, mesmo em obras geradas deterministicamente, cuja análise pode se beneficiar da estratégia da modelagem, como veremos adiante.

Keller lembra que obras baseadas no fenômeno do processo são frequentes em "performances artísticas, instalações sonoras, música algorítmica e várias formas de sistemas de som ambiental". No artigo mencionado ilustra essa solução analítica modelando a peça ST/10-1 080262 (1967) de Xenakis que é uma das primeiras obras compostas por computador da história da música. A análise por modelagem dessa obra parte de uma partitura e da gravação de uma execução que também servirão como objeto de comparação para validar o modelo. Um dos aspectos críticos do processo é escolher os parâmetros que serão modelados. Embora Keller se concentre no parâmetro das alturas na modelagem proposta no artigo, ele sugere que a timbre também poderia ser modelado. Para tanto oferece um modelo das propriedades de excitação e ressonância dos timbres, com uma análise preliminar taxonômica das categorias empregadas pelo compositor naquela obra, como mostramos na Figura 3. 


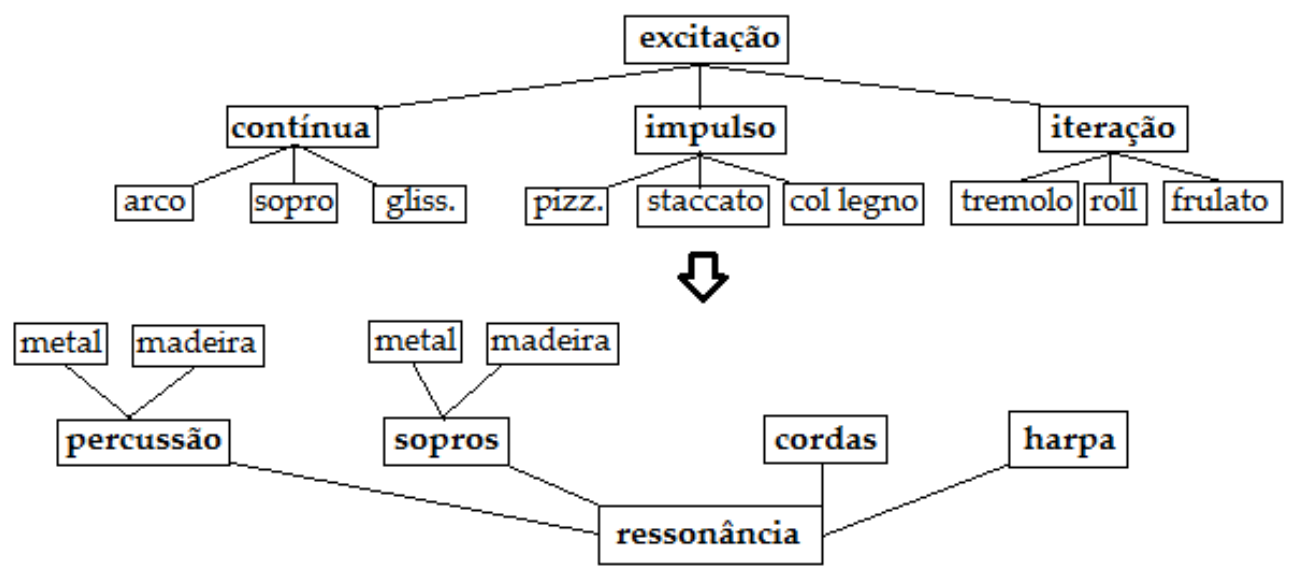

Figura 3: Taxonomia dos timbres orquestrais usados na obra ST/10-1 080262, de Xenakis na parametrização da modelagem analítica de Keller (adaptado de Keller e Ferneyhough 2004, p. 166, Fig. 3)

A proposta de estratégia analítica por modelagem que Keller e Ferneyhough sugeriram para os timbres orquestrais da obra de Xenakis, ainda que não a tenham desenvolvido como análise específica do campo timbrístico, sugeriu-me que a estratégia poderia ser ampliada para a análise do timbre como parâmetro isolado, especialmente nas obras contemporâneas em que as variantes do timbre, geradas por exemplo por técnicas estendidas, sejam um ponto focal da estética da linguagem do compositor. Em seguida expandiremos esse tópico e proporemos como uma das estratégias possíveis de análise do timbre, a modelagem física na síntese digital de instrumentos virtuais.

\section{Análise do Timbre}

Uma crítica, recorrentemente feita à teoria e à musical, é que elas só se preocupam com o parâmetro das alturas. É fato que a quantidade de estudos que focam na questão das alturas é mais numerosa do que a dos que consideram outros parâmetros. Entretanto, tem havido um aumento de estudos que levam em consideração os outros parâmetros, principalmente as durações, e também as dinâmicas principalmente quando elas condicionam a expressão musical.

O tratamento analítico do timbre tem sua própria história que muitas vezes não é considerada nessa crítica. Antes de tudo é importante reconhecer que o timbre não é um parâmetro irrelevante. Ao contrário, muitos estudos sobre percepção e significação musical identificam o timbre como o primeiro, e muitas vezes o mais importante elemento para a identificação e apreciação musical. 
MUSICA THEORICA Revista da Associação Brasileira de Teoria e Análise Musical 2019, v. 4, n. 1, p. 62-97 - Journal of the Brazilian Society for Music Theory and Analysis@ TeMA 2019 - ISSN 2525-5541

Costumo contar uma anedota (verídica) para ilustrar o problema. Certa vez produzi um áudio de demonstração de uma partitura de minha autoria usando sons sintéticos de computador. Mostrei-o para um amigo leigo que, em resposta, fez um comentário lacônico, mas perceptivelmente depreciativo. Algum tempo depois a mesma peça foi executada e gravada por um excelente pianista. Mostrei a nova gravação ao amigo que reagiu entusiasticamente: "agora sim! Esta é uma música muito bonita, muito diferente daquela outra que você me mostrou antes!" Não adiantou argumentar que era a mesma música tocada agora por um piano. Ele se recusou a reconhecer qualquer semelhança entre as duas gravações. A percepção musical desse amigo empacava no impacto inicial do timbre.

Os etnomusicólogos que se dedicam à música indígena relatam experiências da mesma natureza. Bastos (1978) relata que ao retornar a uma aldeia que visitara anos antes, pediu ao mestre das flautas da tribo que tocasse a mesma música que ele havia gravado e transcrito na visita anterior. Como não reconhecia a música, reclamou a seu interlocutor que ele estaria tocando outra música e não a que pedira. $\mathrm{O}$ índio respondeu que era sim a mesma música, que era música de flauta o que ele tocara então e o que estava tocando agora. Ou seja, Bastos demonstra que para a cultura Kamayurá há uma identidade indissociável entre o objeto do instrumento musical, o timbre que ele produz e qualquer sequência melódico-rítmica que com ele se produza.

Entretanto, apesar dessa aparente prevalência do timbre, existe certamente a possibilidade de que ele seja superado pelos outros parâmetros. As inumeráveis transcrições entre instrumentos e as obras compostas para formações optativas comprovam essa possibilidade. Aliás, a experiência descrita acima, da comparação entre uma gravação eletrônica e outra ao piano, está relacionada com esse modo de escuta, visto que um ouvinte que ultrapassasse a percepção imediata do timbre reconheceria a identidade da "mesma música".

Uma consideração a se fazer é que o parâmetro do timbre se tornou muito importante para a música do século vinte em comparação com os períodos precedentes, tanto na música culta, como também na música comercial. Um dos motivos para isso foi a enorme expansão dos meios de produção sonora, não só devido à expansão dos grandes conjuntos orquestrais que incorporaram uma inaudita variedade de instrumentos, como também à produção de sons artificiais por meios elétricos e eletrônicos, além dos registros gravados. 
COELHO de SOUZA, R. Categorias de Análise Musical e Modelagem Física como Análise do Timbre

O foco da música moderna no timbre se radicaliza na música concreta que postula o princípio da escuta reduzida. Essa proposição realiza uma operação conceitual importante: desvincula o som, isto é, o timbre, do instrumento que o produz. Para a análise musical do timbre isso representa uma importante mudança de paradigma.

A análise tradicional do timbre é objeto da Organologia. Essa ciência é basicamente taxonômica pois estuda os instrumentos musicais, inclusive sua evolução histórica, para propor sistemas que permitam sua classificação em sistemas geralmente baseados no modo de produção do som (aerófonos, cordófonos, membranófonos, etc). Ainda que úteis, esses sistemas classificatórios têm limitações evidentes, especialmente quando se trata de analisar obras recentes em que o timbre tem protagonismo. Um exemplo simples ilustra esse problema: quando pensamos num violino, a primeira ideia que vem à mente é o som normal da corda sendo vibrada pelo arco. Entretanto, esse mesmo instrumento é capaz de produzir sons de características espectro-morfológicas muito diversas daquele, como pizzicatos, sul ponticello, col legno battuto, etc. Essas técnicas já eram usadas nos séculos anteriores. Para demonstrar a insuficiência de uma análise do timbre baseada na taxonomia dos instrumentos nem precisamos cogitar em abranger as técnicas estendidas no século vinte.

A principal dificuldade que a análise do timbre tem para superar a etapa taxonômica é que o timbre demonstra pouca propensão para organizações sintáticas. Isso significa que é difícil vislumbrar um método de análise funcional do timbre na linguagem musical. Por outro lado, o timbre sendo um atributo de qualidade sonora, se presta naturalmente a associações semânticas. Listar alguns exemplos pontuais pode ser suficiente para ilustrar essa afirmação: as castanholas significam música espanhola, o órgão significa música religiosa, a guitarra elétrica significa rock, a viola caipira significa música sertaneja, etc. Todos esses exemplos envolvem o nível semântico do signo sonoro, mas não se organizam num sistema claramente sintático, ainda que, em algumas circunstâncias, como na organização implícita da orquestra sinfônica, alguns índices de hierarquia possam ser postulados.

Houve tentativas de avançar a análise do timbre nessa direção. Embora ainda de feitio taxonômico, elas buscaram uma sistematização funcional. Um bom exemplo é o artigo de Gordon e Grey (1978) que propôs um método para se visualizar a estrutura perceptiva das modificações espectrais possíveis de se 
MUSICA THEORICA Revista da Associação Brasileira de Teoria e Análise Musical 2019, v. 4, n. 1, p. 62-97 - Journal of the Brazilian Society for Music Theory and Analysis@ TeMA 2019 - ISSN 2525-5541

produzir no som dos instrumentos orquestrais. O resultado da pesquisa resultou no método de classificação tridimensional ilustrado pela Figura 4.

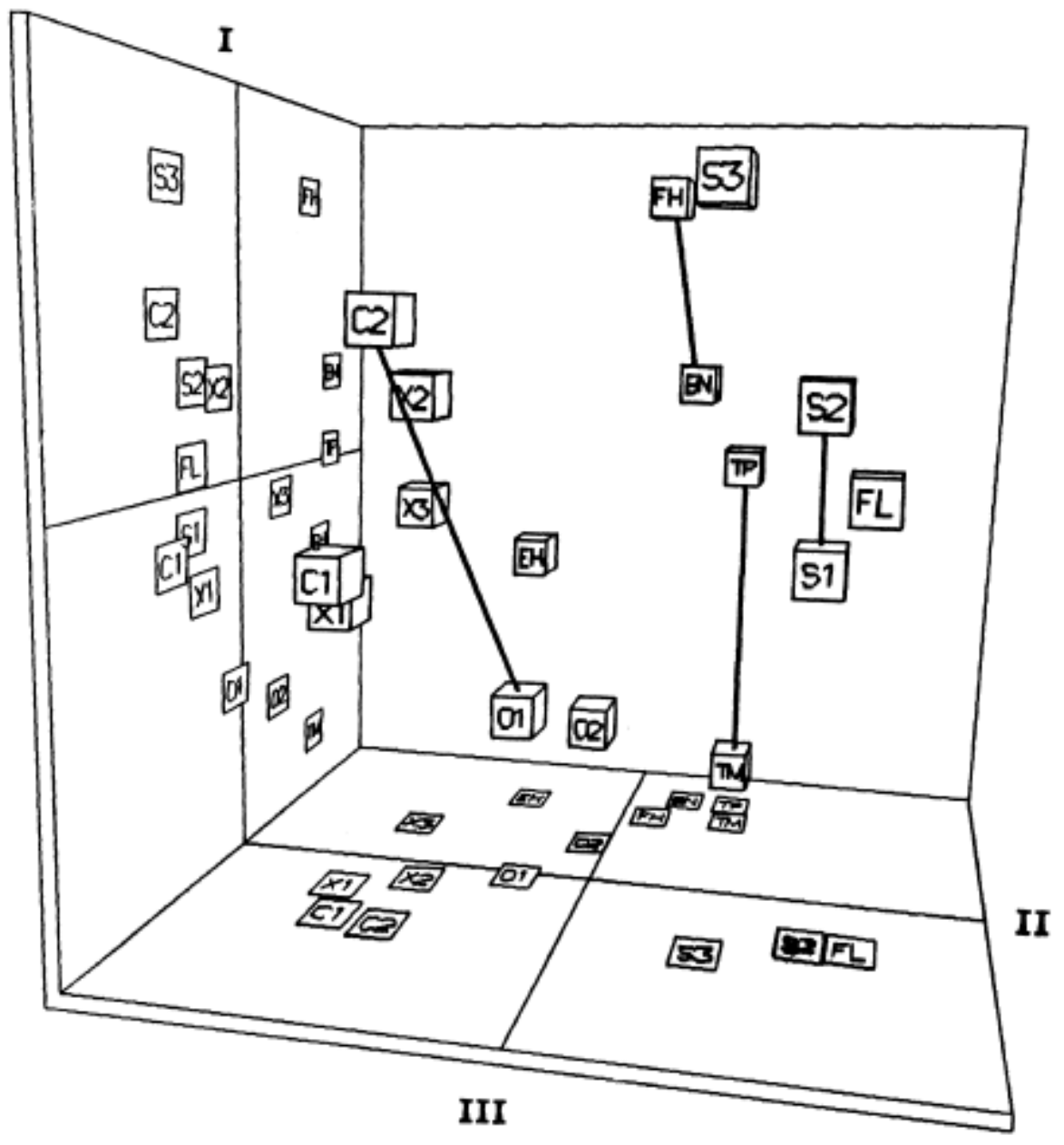

Figura 4: Representação em três dimensões da relação de timbres de 16 instrumentos: flauta (FL); 2 oboés (O1-2); 2 clarinetes (C1-2); trompete (TP); trombone (TM); 3 saxofones (X1-2-3); 3 cordas (S1-2-3); corne inglês (EH); trompa (FH) e fagote (BN). As linhas conectam pares de instrumentos que compartilham envoltórias espectrais (imagem adaptada de Gordon e Grey 1978, p. 26)

Esse tipo de pesquisa sobre o timbre, proposto quatro décadas atrás, não prosperou significativamente para se tornar um paradigma difundido. Mas um estudo de De Poli (1993), ainda nessa linha, mas através da noção de clustering, faz o link com o conceito de descritor, o qual, posteriormente, se tornou o principal paradigma na análise do timbre.

Descritores de áudio são algoritmos de análise computacional que podem ser aplicados em gravações musicais para identificar suas características acústicas, em trechos escolhidos, manualmente ou automaticamente. Essa análise 
pode coletar informações objetivas, tais como frequências fundamentais, composição espectral, aspectos dinâmicos, mas via de regra, para que se tornem úteis para a análise musical, é necessário atrelá-los a categorias perceptivas.

Existem muitos tipos de descritores, que medem certas propriedades do som, como temporais, espectrais, energéticas, harmônicas, perceptuais, etc. Os que se aplicam mais diretamente ao nosso problema são os descritores timbrísticos temporais e os descritores timbrísticos espectrais. As principais aplicações desses descritores são em classificação e recuperação de música. Como exemplos de pesquisa nessa área podemos citar o projeto jAudio do Grupo de Música e Tecnologia da Universidade McGill de Montreal no Canadá, que desenvolveu 27 descritores de baixo, médio e alto nível para extrair informações de sinais musicais. Uma descrição mais completa desse tópico pode ser encontrada em Pires (2011). Podemos também referendar o artigo de Simurra (2018) como um estudo exemplar sobre o uso de descritores para analisar timbres orquestrais. Embora não seja baseada em descritores dos tipos mencionados, o aplicativo Shazam, atualmente de propriedade da Apple, serve para o usuário identificar uma música mediante o fornecimento de um trecho gravado, com base em análise de dados espectrais, e executa tarefas semelhantes à dos descritores para informar o resultado da busca de reconhecimento. $\mathrm{O}$ aplicativo depende, porém, de um banco de dados de músicas classificadas pelas mesmas características e pelo mesmo método de análise usados na identificação da amostra fornecida.

Observa-se que todos esses processos de análise do timbre, em última instância tem propósitos taxonômicos de classificação e recuperação de informação que pertencem à primeira categoria de análise. Também apontamos acima que o timbre parece não se prestar a algum tipo de estruturação sintática que nos permita avançar para a categoria das análises funcionais. Mas, e quanto à engenharia reversa?

A possibilidade de um modelo de engenharia reversa no sentido estrito é descartada pelas nossas capacidades perceptivas. É possível treinar o ouvido para prever o resultado de uma transformação de áudio, como por exemplo: sabemos que aplicando um plugin de reverberação a uma gravação de áudio haverá aumento de volume, prolongamento da duração total, e principalmente sobreposição de características espectrais ao longo do tempo. Mas muitas vezes nem o mais treinado engenheiro de áudio é capaz de afirmar com certeza como 
MUSICA THEORICA Revista da Associação Brasileira de Teoria e Análise Musical 2019, v. 4, n. 1, p. 62-97 - Journal of the Brazilian Society for Music Theory and Analysis@ TeMA 2019 - ISSN 2525-5541

foi gerado um determinado efeito sonoro, mesmo porque a amostra pode ter sofrido múltiplos processamentos. Portanto projetar algoritmos que fossem capazes de reverter o tempo para se obter o som da fonte original é inviável.

Todavia é possível, com base em suposições bem informadas, projetar um modelo que simule computacionalmente uma fonte sonora para se estudar como determinadas fontes produzem sons. Esse processo é a modelagem, conceitualmente semelhante ao usado por Keller na peça de Xenakis, como descrito acima, com a diferença de ser aplicado aqui exclusivamente ao timbre. Propomos, em resumo, que modelagens podem ser usadas como metodologias indiretas de análise do timbre.

Um primeiro cuidado que é preciso ter é diferenciar a modelagem física da imitação de sons de instrumentos acústicos através de técnicas de síntese baseadas em modelos matemáticos clássicos. Pode-se usar a síntese de frequência modulada ou a síntese subtrativa com filtros que reduzam determinadas frequências, para simular o som de uma clarineta. Entretanto esse processo não se presta ao nosso interesse analítico porque não se preocupou com as características idiomáticas de como o instrumento produz o som. Isso pode ser o ponto chave de uma análise de timbres produzidos, por exemplo, por técnicas estendidas, que seria um caso onde a análise do timbre teria uma aplicação produtiva. Välimäki e Takala (1996) enfatizam essa diferença:

Uma diferença fundamental entre a abordagem da modelagem física e outras técnicas de síntese é que a primeira procura imitar as propriedades da fonte sonora (tipo de excitação e ressonador, ressonâncias da tampa de ressonância, etc), enquanto o foco da segunda são as propriedades do sinal sonoro percebido pelo ouvinte (forma de onda, espectro, etc). [...] As principais vantagens da síntese por modelagem física são que os parâmetros da técnica são fisicamente significantes, tais como pressão no bocal dos instrumentos de sopro e assim importantes partes da evolução dos sons (por exemplo, ataque e decaimento) são gerados automaticamente de um modo correto. (Välimäki e Takala 1996, p. 75).

Para ilustrar esta categoria de análise consideremos a pesquisa que desenvolvemos sobre a modelagem da viola caipira. $\mathrm{O}$ algoritmo de síntese do som físico é baseado na técnica das guias de onda digitais (waveguide). Buscou-se também emular algumas das importantes características do instrumento, como inarmonicidade espectral no ataque do pinçamento das cordas, resíduo de ruído devido ao choque das cordas duplas, batimento e flutuações de afinação devido às cordas duplas, controle da afinação pela pressão do dedo atrás do traste e o 
efeito da ressonância da caixa que funciona como um ressonador de Helmholtz e produz reforços das frequências formantes (vide Fig. 5).

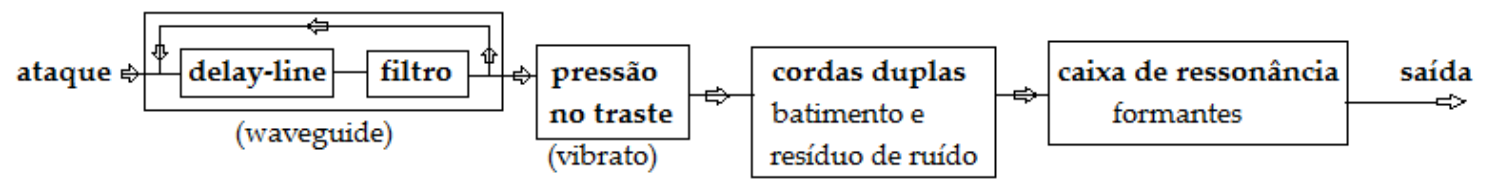

Figura 5: Fluxograma do sinal para a modelagem da viola caipira

Uma vez implementado o modelo em Csound, pode-se, por exemplo, gerar amostras de diversos modos de produção do som desse instrumento virtual com opcodes alternativos do programa e compará-las, auditivamente ou através de análise espectro-morfológica, com uma gravação de uma peça escrita originalmente para viola caipira que usou técnicas idiomáticas e expandidas do instrumento, mapeando-se assim a evolução temporal do trabalho sobre o timbre na composição da obra.

No exemplo que apresentamos a seguir, não vamos discutir os algoritmos de síntese sonora em Csound, pois nosso foco é mostrar como a modelagem dessas sínteses pode ser usada para a análise do timbre. Mencionamos apenas que usamos algoritmos de síntese da viola caipira que desenvolvemos a partir de modelos de Heintz e Lazzarini. Na tabela abaixo estão os opcodes alternativos de Csound que foram pesquisados e os respectivos parâmetros obtidos na aproximação qualitativa do som da viola caipira.

\begin{tabular}{|l|l|l|l|l|l|}
\cline { 2 - 7 } \multicolumn{1}{c|}{} & \multicolumn{5}{c|}{ opcode } \\
\hline Parâmetro & pluck & repluck & wgpluck & wgpluck2 & \multicolumn{1}{|c|}{ Descrição } \\
\hline kamp & 3000 & 12000 & - & 12000 & Amplitude \\
\hline iamp & - & - & 3000 & - & Amplitude \\
\hline kcps & p5 & - & - & - & frequência (Hz) \\
\hline icps & $(1 / 4)^{*}$ p5 & p5 & p5 & p5 & frequência (Hz) \\
\hline idamp & - & - & 2 & - & abafamento/sustentação \\
\hline ifn & 0 & - & - & - & função de decaimento cíclico \\
\hline ifilt & - & - & 90 & - & $\begin{array}{l}\text { Diminuição de duração de altas ou } \\
\text { baixas frequências }\end{array}$ \\
\hline
\end{tabular}


MUSICA THEORICA Revista da Associação Brasileira de Teoria e Análise Musical 2019, v. 4, n. 1, p. 62-97 - Journal of the Brazilian Society for Music Theory and Analysis @ TeMA 2019 - ISSN 2525-5541

\begin{tabular}{|l|l|l|l|l|l|}
\hline imeth & 6 & - & - & - & $\begin{array}{l}\text { método de decaimento natural } \\
(1, . .6)\end{array}$ \\
\hline iplk & - & 0.95 & - & 0.95 & proporção da corda (0-1) tocada \\
\hline kpick & - & 0.2 & 0.1 & 0.2 & $\begin{array}{l}\text { proporção corda (0-1) para coleta da } \\
\text { amostra }\end{array}$ \\
\hline krefl & - & 0.001 & - & 0.001 & coeficiente de reflexão (0-1) \\
\hline axcite & - & $\begin{array}{l}\text { Oscil } \\
0,1,1\end{array}$ & $\begin{array}{l}\text { Oscil } \\
0,1,1\end{array}$ & - & sinal que excita a corda \\
\hline
\end{tabular}

Tabela 1: Parâmetros usados nos opcodes alternativos de Csound visando a comparação para análise do timbre de uma amostra de viola caipira

Abaixo estão representadas graficamente a forma das ondas geradas pelo algoritmo baseado em um modelo de Heintz, utilizando os quatro opcodes (Fig. 7) e pelo algoritmo baseado no modelo de Lazzarini (Fig. 8) aplicado a um arpejo em Mi maior.

(a)

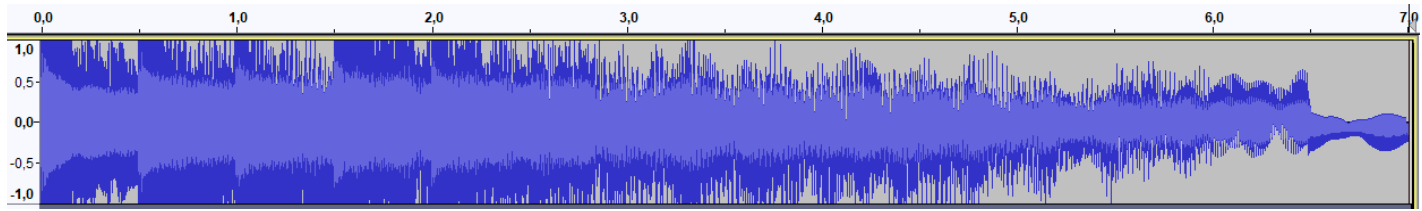

(b)

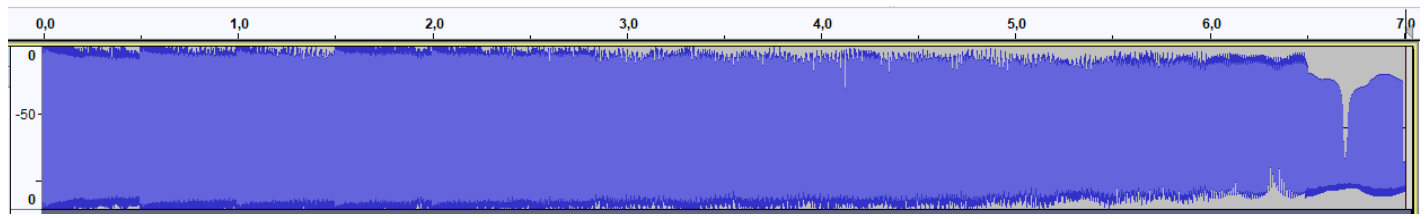

Figura 6: Sonogramas amplitude $x$ tempo de: (a) amplitude oscilando (entre -1 e 1); (b) decibéis do algoritmo Karplus-Strong de Heintz

(a) 
COELHO de SOUZA, R. Categorias de Análise Musical e Modelagem Física como Análise do Timbre

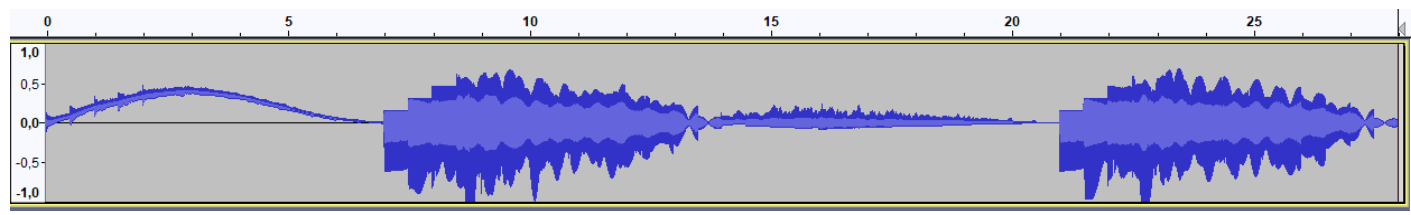

(b)

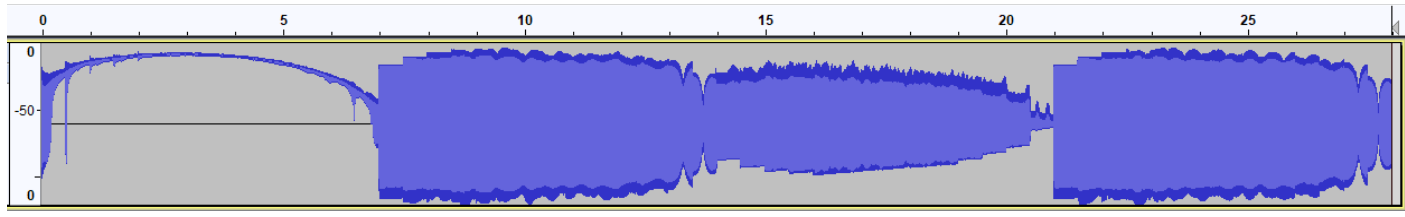

Figura 7: Sonogramas amplitude $\mathrm{x}$ tempo de: (a) amplitude oscilando (entre -1 e 1); (b) decibéis dos opcodes, usando pluck (0-7 segundos), repluck (714 segundos) wgpluck (14-21 segundos) e wgpluck2 (21-28 segundos)

(a)

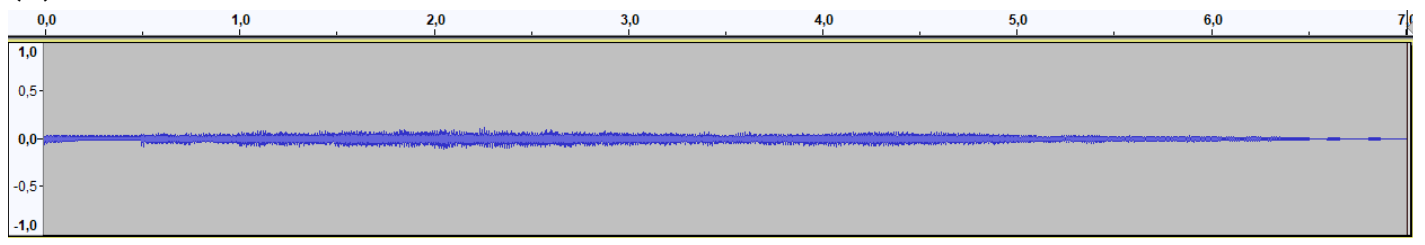

(b)

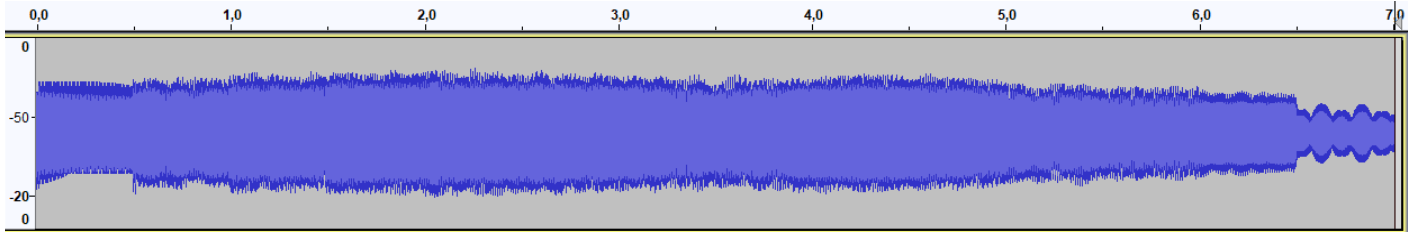

Figura 8: Sonogramas amplitude $x$ tempo de: (a) amplitude oscilando (entre -1 e 1); (b) decibéis usando o modelo de Lazzarini

Abaixo temos trechos iniciais da forma das ondas ao tocar o $5^{-}$par de cordas da viola caipira.

(i)

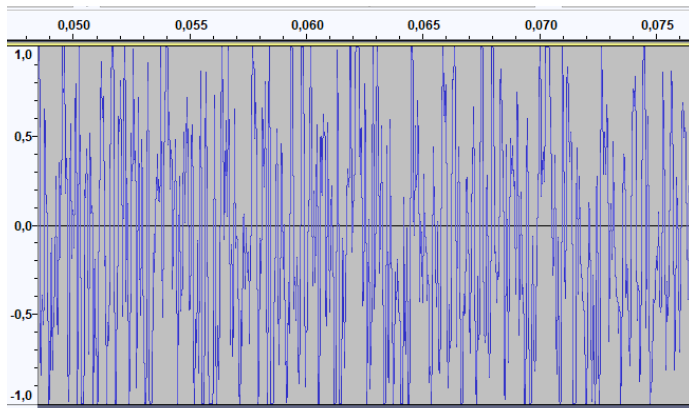

(ii)

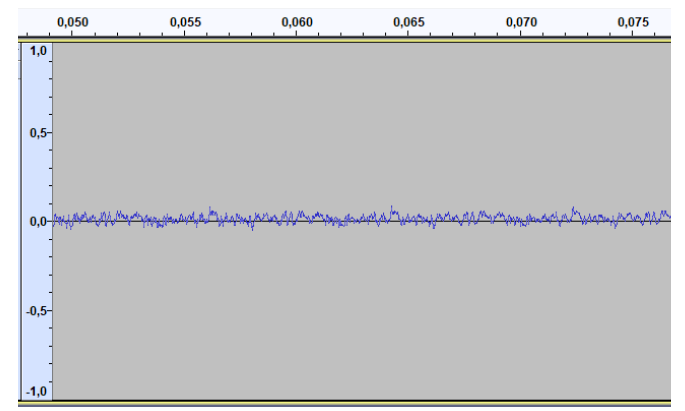


MUSICA THEORICA Revista da Associação Brasileira de Teoria e Análise Musical 2019, v. 4, n. 1, p. 62-97 - Journal of the Brazilian Society for Music Theory and Analysis @ TeMA 2019 - ISSN 2525-5541

(iii)

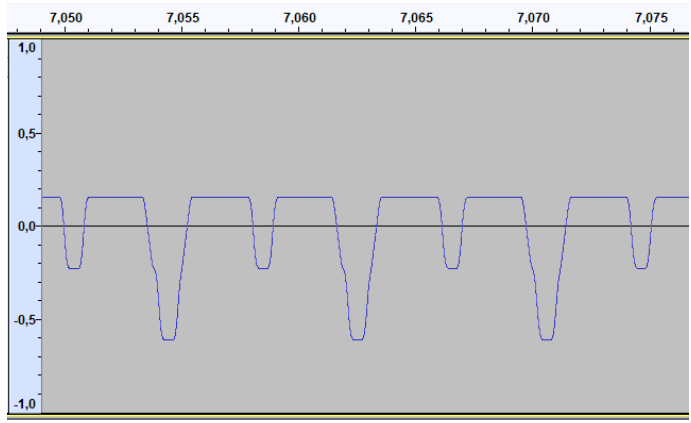

(v)

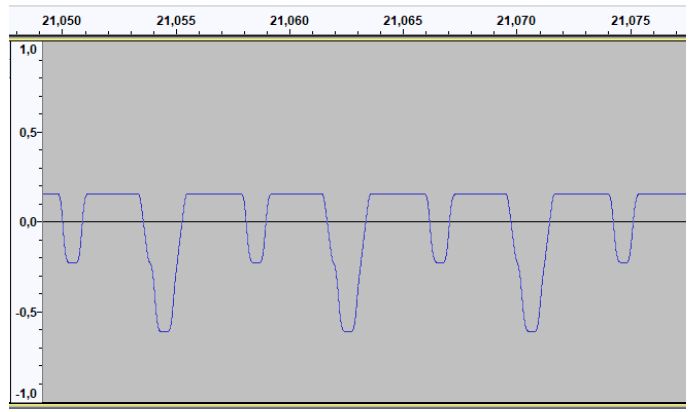

(iv)

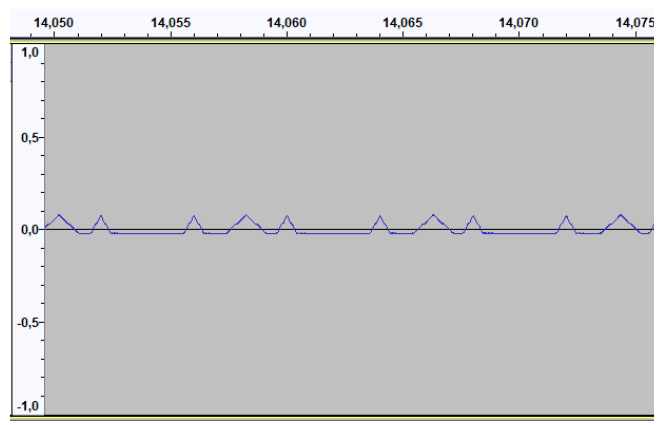

(vi)

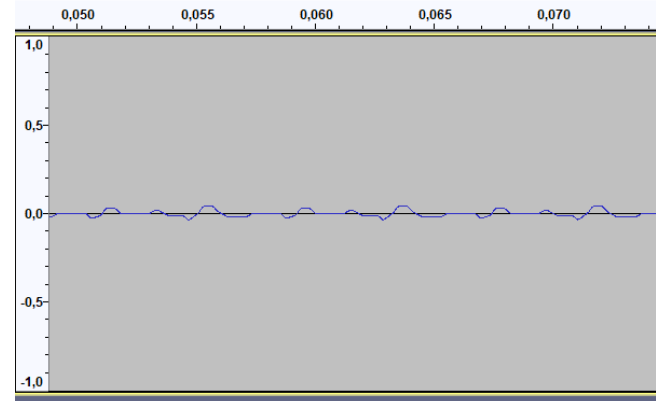

Figura 9: Trecho da forma da onda dos modelos: (i) Karplus-Strong de Heintz, (ii) pluck, (iii) repluck, (iv) wgpluck, (v) wgpluck2 e (vi) adaptado de Lazzarini

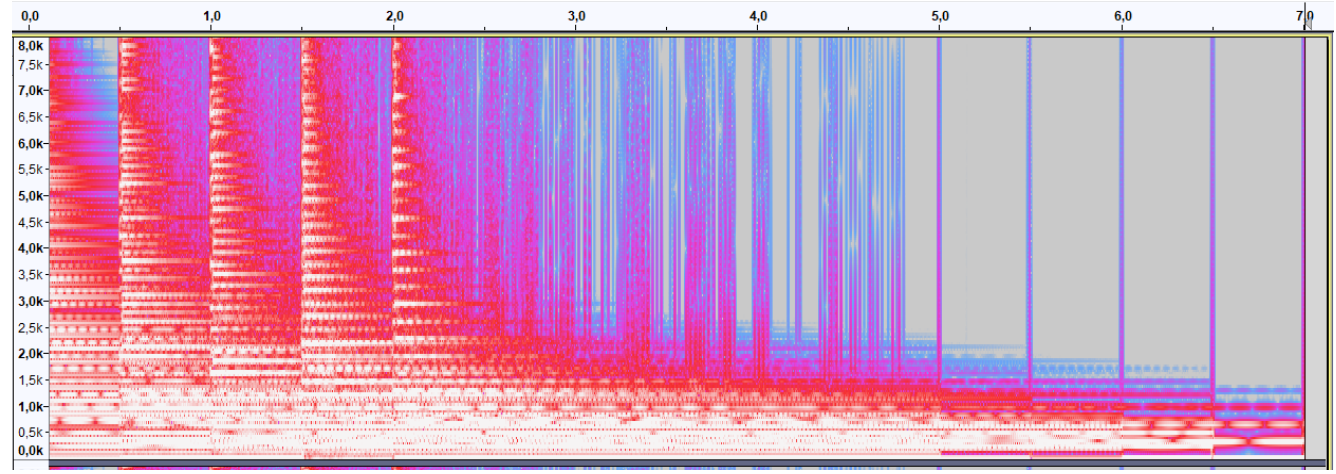

Figura 10: Espectrograma frequência $x$ tempo do modelo Karplus-Strong de Heintz

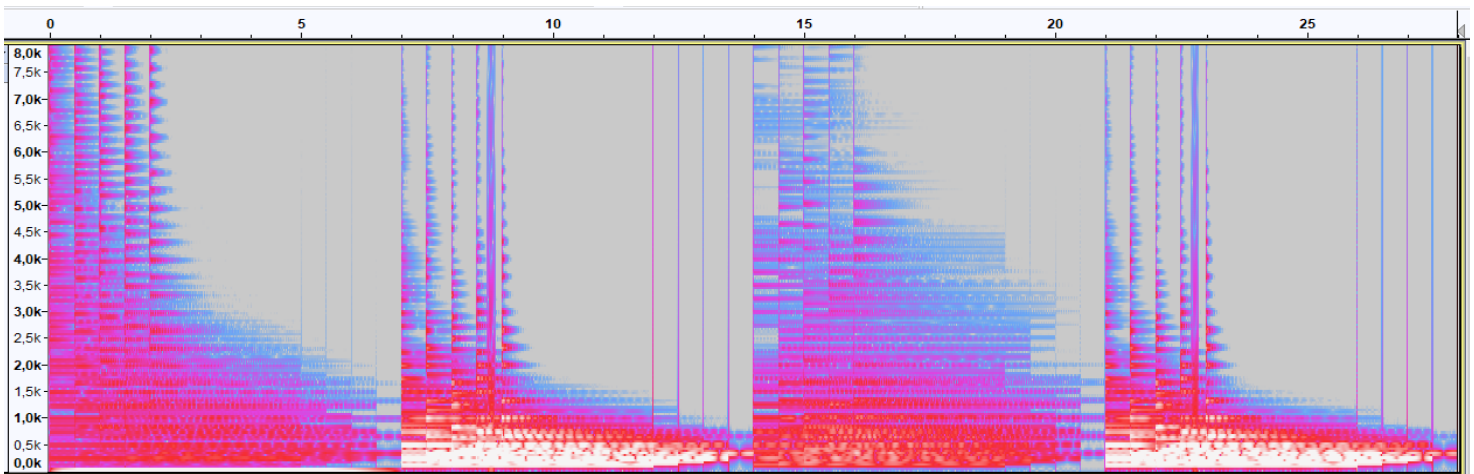

Figura 11: Espectrograma frequência $\mathrm{x}$ tempo usando os opcodes pluck, repluck, wgpluck e wgpluck2, com fenômeno de over-pluck no final das notas, conforme se observa nas linhas em 18-18,5-19 e 19,5 segundos 
COELHO de SOUZA, R. Categorias de Análise Musical e Modelagem Física como Análise do Timbre

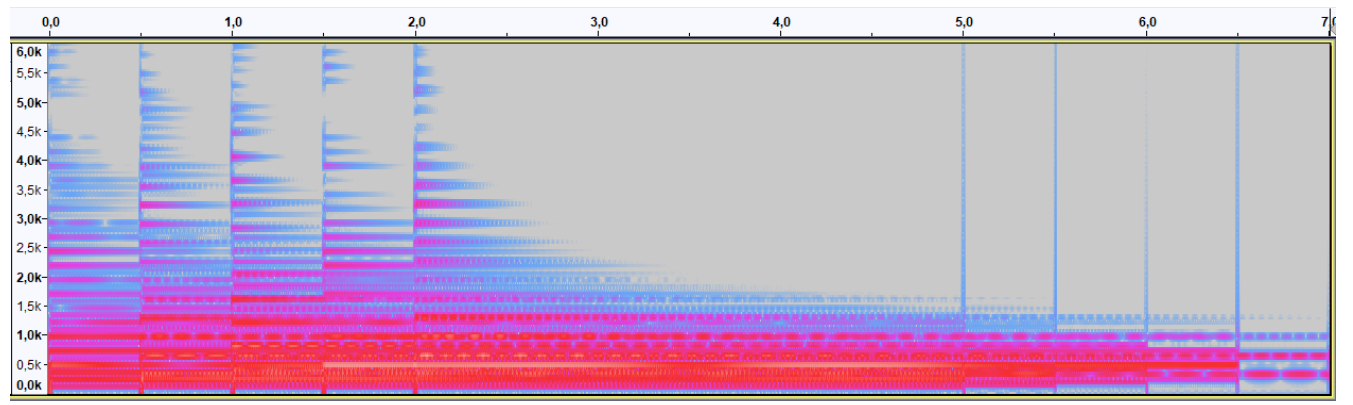

Figura 12: Espectrograma frequência $x$ tempo usando o algoritmo de Lazzarini, com fenômeno de over-pluck no final das notas

Os aspectos físicos das ondas sonoras vinculados à percepção do timbre podem ser organizados na seguinte ordem: forma da onda, amplitude e espectrograma. Deste modo, podemos comentar essa modelagem que envolve características de um sistema complexo. Em relação à forma da onda (composição de notas, efeito de batimento), com a ampliação dos fragmentos das sínteses (Fig. 9) após $0,05 \mathrm{~s}$ do início do arpejo (com o $5^{\mathrm{o}}$ par de cordas tocando) é possível observar semelhanças e distinções entre a forma das ondas entre as abordagens. O modelo de Heintz (Fig. 9i e 10) possui perfil menos regular no qual a componente de ruído se destaca em relação aos demais e sua amplitude é a maior. O perfil do opcode pluck (Fig. 9ii e 11) apresenta características similares ao anterior, com atenuação no ruído e amplitude, mostrando-se rico em componentes de maior frequência. Os opcodes repluck e wgpluck2 (Fig. 9iii e 9v) são similares em quase todos os aspectos, gerando ondas retangulares com algumas atenuações, além de ter componentes graves acentuados (Fig. 11), dificultando a modelagem do aspecto metálico da viola. O opcode wgpluck2 (Fig. 8iv) e a abordagem segundo Lazzarini (Fig. 8vi) apresentam similaridades, porém a onda gerada pelo primeiro opcode é triangular e a de Lazzarini possui algumas atenuações neste perfil. Ambas possuem componente de ruído atenuado, porém com maior distribuição em componentes harmônicas com maior frequência (Fig. 11 e 12), conferindo à modelagem uma sonoridade bem próxima à da viola caipira.

Em relação ao pluck, há a possibilidade de inserir uma maior quantidade de períodos de onda dentro da fundamental, pois icps determina o tamanho do buffer (quantidade de períodos a serem armazenados) e kcps determina o harmônico fundamental. Assim, as parciais inarmônicas geradas no ruído inicial se prolongam além do esperado para a modelagem. $\mathrm{O}$ parâmetro ifilt, existente em wgpluck, exerce um papel similar, possibilitando o controle do brilho no 
MUSICA THEORICA Revista da Associação Brasileira de Teoria e Análise Musical 2019, v. 4, n. 1, p. 62-97 - Journal of the Brazilian Society for Music Theory and Analysis@ TeMA 2019 - ISSN 2525-5541

timbre do instrumento. Acrescentamos um decaimento ao pluck para atenuar o ruído existente no final das notas sintetizadas, aqui chamado de over-pluck.

Os opcodes pluck e wgpluck, usados para uma primeira aproximação ao timbre da viola caipira, apresentaram sínteses com boa aproximação ao instrumento real, porém podem ser complementados com parâmetros adicionais. Já repluck e wgpluck2 não obtiveram a característica sonora de um instrumento com cordas metálicas, resultando em um timbre muito distante do esperado para uma síntese de viola caipira. Usado como parâmetro de uma primeira modelagem com delay lines, o modelo de Heintz apresentou muitas linhas de ruído em relação às abordagens dos opcodes e de Lazzarini. Quanto a essa última abordagem, a sonoridade corresponde ao aspecto qualitativo buscado para este estudo, assim como o pluck e wgpluck.

Em resumo, o exemplo acima demonstra como a modelagem através de processos de síntese sonora nos permite mergulhar na estrutura interna do timbre de um instrumento acústico para se obter uma compreensão analítica bastante detalhada do parâmetro timbre, bem mais completa do que seria possível somente através apenas da percepção ou da organologia taxonômica.

\section{Conclusões}

Este estudo procurou demonstrar como a Análise Musical não é um campo único, mas se serve de diversos métodos para abordar problemas específicos que obras de diferentes estilos, períodos e poéticas oferecem ao analista. Alguns desses problemas podem ser enfrentados usando-se apenas a primeira categoria de análise, que é o método taxonômico. Mostramos como as análises harmônicas tradicionais, a organologia dos instrumentos musicais e mesmo a análise pela teoria dos conjuntos de Forte encaixam-se nessa categoria. Numa segunda categoria enquadram-se os métodos que buscam uma compreensão funcional do objeto. É o caso, por exemplo das análises harmônicas riemannianas e neo-riemannianas. Essa categoria engloba uma estratégia particular que é a chamada engenharia reversa, que busca desvendar o método de produção da composição para compreender seu funcionamento. Exemplos dessa categoria são a contagem da série dodecafônica e a análise da multiplicação de Boulez na música serial. A terceira categoria é a das análises hermenêuticas que partem de estratégias heurísticas para revelar as significações, os sentidos de uma peça. As análises que empregam a teoria das tópicas e da narratividade são 
COELHO de SOUZA, R. Categorias de Análise Musical e Modelagem Física como Análise do Timbre

bons exemplos dessa categoria. Finalmente postulamos, em consonância com Keller e Ferneyhough (2004) a possibilidade de uma quarta categoria, que emprega a estratégia da modelagem. Problemas, como a estrutura de obras estocásticas e a análise do timbre, que se revelam parcial ou integralmente opacos às outras categorias de análise podem eventualmente ser tratados através dessa estratégia. Postulamos enquadrar nessa categoria a técnica da modelagem física que julgamos oferecer uma estratégia adequada para abordar a análise do timbre, seja instrumental, seja dos sons produzidos por meios sintéticos, analógicos ou digitais.

\section{Referências}

1. Bas De Haas, W.; Magalhães, J. P.; Wiering, F.; Veltkamp, R. 2014. Automatic Functional Harmonic Analysis. Computer Music Journal, v. 37 n. 4, p. 37-53.

2. Bastos, Rafael Menezes. 1978. A Musicológica Kamayurá. Brasília: Fundação nacional do Índio.

3. Bergé, Pieter (ed.). 2009. Beethoven's "Tempest" Sonata: Perspectives of Analysis and Performance. Leuven: Peeters.

4. Cope, David. 2005. Computer Models of Musical Creativity. Cambridge, MA: The MIT Press.

5. Dahlhaus, Carl. 1989. Nineteenth-Century Music. Berkeley: University of California Press.

6. De Poli, Giovanni, Paolo Prandoni e Paolo Tonella. 1993. Timbre Clustering by Self-organizing Networks. Milão: Proceedings of X Coloquium on Musical Informatics, p. 102-107.

7. Gordon, John W. e John M. Grey. 1978. Perception of Spectral Modifications on Orchestral Instrument Tones. Computer Music Journal, v. 2, n. 1, p. 24-31.

8. Guck, Marion. 1994. Analytical Fictions. Music Theory Spectrum, v. 16, n. 2, p. 217-230.

9. Hanninen, Dora. 2012. A Theory of Music Analysis: on Segmentation and Associative Organization. Rochester: University of Rochester Press.

10. Hatten, Robert S. 1994. Musical Meaning in Beethoven: Markdness, Correlation, and Interpretation. Bloomington: Indiana University Press.

11. Keller, Damián e Brian Ferneyhough. 2004. Analysis by Modeling: Xenakis's ST/10-1 080262. Journal of New Music Research v. 33, n. 2, p. 161-171. 
MUSICA THEORICA Revista da Associação Brasileira de Teoria e Análise Musical 2019, v. 4, n. 1, p. 62-97 - Journal of the Brazilian Society for Music Theory and Analysis@ TeMA 2019 - ISSN 2525-5541

12. Koblyakov, Lev. 1990. Pierre Boulez a world of harmony. New York: Routledge.

13. Krämer, Thomas. 1997. Lerhbuch der harmonischen Analyse. Wiesbaden: Breitkopf \& Härtel.

14. Křenek, Ernst. 1940. Studies in Counterpoint. New York: Schirmer.

15. Lerdahl, Fred. 2001. Tonal Pitch Space. New York: Oxford University Press.

16. Lerdahl, Fred; Jackendoff, Ray. 1983. A Generative Theory of Tonal Music. Cambridge, MA: The MIT Press.

17. Lewin, David. 2007. Musical Form and Transformation: Four Analytic Essays. Oxford: Oxford University Press.

18. Pires, André Salim. 2011. Métodos de Segmentação Baseados em Descritores Musicais. Dissertação de Mestrado. Instituto de Matemática e Estatística da Universidade de São Paulo.

19. Rehding, Alexander. 2003. Hugo Riemann and the Birth of Modern Musical Thought. Cambridge: Cambridge University Press.

20. Riemann, Hugo. 1874. Musikalishe Logik. Leipzig: C. F. Khant.

21. Roads, C.; Wieneke, P. 1979. Grammars as Representations for Music. Computer Music Journal, v. 3, n. 1, p. 48-55.

22. Schönberg, Arnold. 1963 (ed. original, 1951). El Estilo y la Idea. Madrid: Taurus.

23. Schmalfeldt, Janet. 2011. In the Process of Becoming. Oxford: Oxford University Press.

24. Simurra, Ivan E. 2018. Análise Musical Assistida por Descritores de Áudio: um estudo de caso da obra Reflexões de Jônatas Manzolli. Revista Musica Theorica, v. 3, n. 1, p. 33-67.

25. Straus, Joseph N. 2009. Twelve-Tone Music in America. Cambridge: Cambridge University Press.

26. Välimaki, Vesa e Tapio Takala. 1996. Virtual Musical Instruments - Natural Sound Using Physical Models. Organised Sound, v. 1, n. 2, p. 75-86.

27. Versolato, Júlio César. 2008. Rumos da Análise Musical no Brasil: Análise Estilística 1919-84. Dissertação de Mestrado. Instituto de Artes da Universidade Estadual Paulista. 
MUSICA THEORICA 201905

SCIENTIFIC ARTICLE

Data do recebimento: 10/07/2019

Data da aprovação final: 15/08/2019

\title{
O Pensamento Musical sobre o Tempo em Durações (1977) de Rodolfo Coelho de Souza
}

\author{
Musical Thought about time in Durações (1977) by Rodolfo Coelho de \\ Souza
}

\author{
Cássia Carrascoza Bomfim \\ Universidade de São Paulo
}

\begin{abstract}
Resumo: Os programas computacionais de interação entre instrumentos e eletrônica em tempo real criaram a partir da década de 1980 uma polarização entre o chamado tempo diferido e o tempo real. Este estudo mostra que Durações para quinteto e sons eletrônicos, obra composta em 1977, portanto anterior à disseminação da interação em tempo real, foi pensada com possibilidade de execução nos dois modelos e utilizou princípios da música aleatória e das técnicas expandidas. Por outro lado, a principal experimentação que a peça levou a cabo foi mostrar como diferentes possibilidades de notação das partes instrumentais, com graus variáveis de controle dos eventos e da sincronização, afetam e fertilizam, de modos diferentes, o resultado inventivo da interpretação instrumental.
\end{abstract}

Palavras-chave: Análise Musical; Tempo Musical; Notação Musical; Música Eletroacústica Mista; Música Brasileira; Rodolfo Coelho de Souza

\begin{abstract}
The computer programs for interaction between instrumental music and electronic sounds in real time, created after the 1980's a polarization between the so called fixed and real time. This study shows that Durations for quintet and electronic sounds, composed in 1977, therefore before the dissemination of the real time interaction, was conceived with the possibility of performance in both models, and utilized principles of aleatory music and expanded techniques. On the other hand, the main experimentation that this work developed was to demonstrate that different ways of notation for the instrumental parts, with variable degrees of control of events and synchronization, affected and fertilized, in different ways, the inventive result of the instrumental performance.
\end{abstract}

Keywords: Musical Analysis; Musical Time; Musical Notation; Mixed Media Electroacoustic Music; Brazilian Music; Rodolfo Coelho de Souza 
MUSICA THEORICA Revista da Associação Brasileira de Teoria e Análise Musical 2019, v. 4, n. 1, p. 98-123 - Journal of the Brazilian Society for Music Theory and Analysis@ TeMA 2019 - ISSN 2525-5541

\section{Introdução}

Entre as obras compostas para meios mistos, ou seja, para instrumentos e sons eletrônicos, uma das peças pioneiras na música brasileira é Durações para quinteto instrumental (flauta, trompa, violino, violoncelo, piano) e sons eletrônicos, composta por Rodolfo Coelho de Souza, em 1977. Esta composição tem como princípio focal a questão do tempo na relação entre os performers, os sons eletrônicos e os métodos contemporâneos de notação musical da partitura. Além disso, é uma obra que tem uma posição histórica no contexto da música eletroacústica brasileira (Mamedes, 2010). Ponto de vista semelhante havia sido defendido por Maués no texto a seguir.

A partir de metade da década de setenta a música eletroacústica torna-se forma de expressão principal de diversos novos compositores. As técnicas eletrônicas propriamente ditas, mais acessíveis a partir da possibilidade do emprego de sintetizadores portáteis, são utilizadas regularmente em todas as manifestações artísticas de vanguarda. [...] Esse período é representado, além das de compositores já mencionados, por obras de R. Coelho de Souza, R. Miranda, V. Dantas Leite, R. Caesar, L. A. Rescala, L. Nazário, P. Chagas e a produção Laboratório de Música Eletroacústica do Instituto de Artes do Planalto. [...] Em Duracões (1977), para piano, violino, violoncelo, flauta, trompa e sintetizador, Rodolfo Coelho de Souza (n. São Paulo, 1952) questiona o tempo musical na mais pura tradição experimental. $O$ compositor procura aproximar os sons eletrônicos e os instrumentais de modo (que) uma parte seja tomada como simulacro da outra. A peça é dividida em cinco movimentos, cada um dos quais exige uma nova atitude por parte dos intérpretes. A parte eletrônica, em contraste, se mantém por todos os movimentos semelhante. Essa parte não é sincronizada à parte dos instrumentos. Para a estreia, da peça a parte do sintetizador foi preparada em fita antecipadamente, com a colaboração de Conrado Silva, criando assim uma parte imutável, a partir da qual os instrumentistas prepararam sua interpretação (Maués 1989, p. II-14).

Durações foi encomendada pela Comissão de Música da Secretaria de Cultura, Ciência e Tecnologia do Estado de São Paulo. O Secretário era Max Feffer, e a Comissão de Música formada por Gilberto Mendes, compositor, João Carlos Martins, pianista, Amilton Godoy, pianista, Benito Juarez, maestro ${ }^{1}$ e Samuel Ribeiro, empresário.

\footnotetext{
${ }^{1}$ Informação que consta do Diário Oficial do Estado de São Paulo de 04 de junho de 1976.
} 
As obras encomendadas pela Comissão foram interpretadas num concerto realizado no MASP, dia 07 de junho 1978, quando foram realizadas as primeiras audições de Durações, de Rodolfo Coelho de Souza, Quando olhos e mãos de Flávio Oliveira, Appassionato, Cantilena e Toccata de Osvaldo Lacerda, Issei de Hans Joachim Koellreutter e Sursum Corda: uma Nenia de Willy Correa de Oliveira.

Para integrar o grupo de compositores foram escolhidos representantes nascidos em diferentes décadas: Koellreutter (1915), Lacerda (1927), Correa de Oliveira (1938), de Oliveira (1944) e Coelho de Souza (1952).

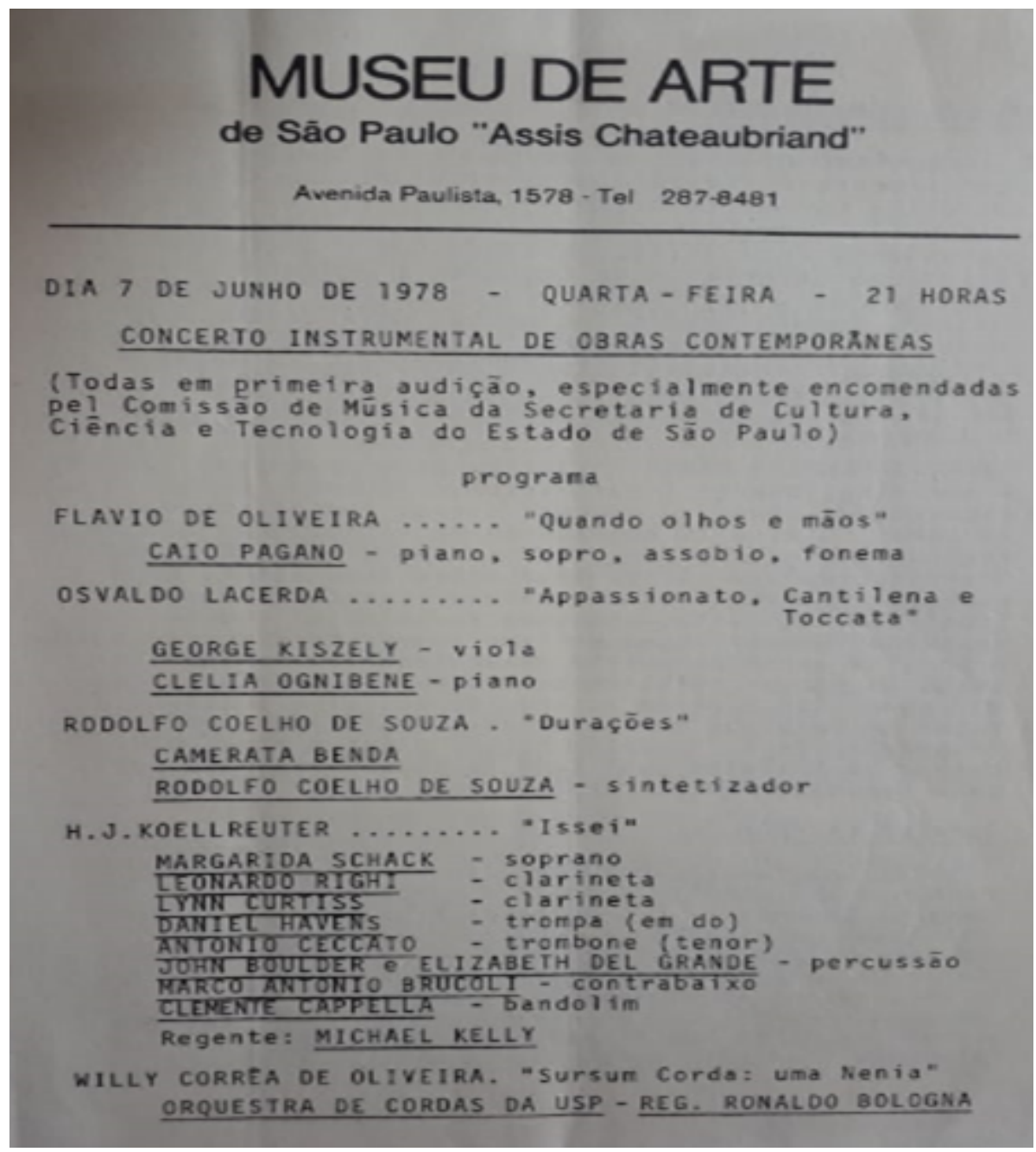

Figura 1: Programa de concerto da primeira audição de Durações

Durações foi executada pela Camerata Benda, integrada pelo pianista suíço Sebastian Benda, a violinista Lola Benda, a flautista Grace Lorraine Henderson, o trompista Daniel Havens, o violoncelista Christian Benda e o compositor no sintetizador. A gravação disponível em fita cassete que acompanha o livro 
MUSICA THEORICA Revista da Associação Brasileira de Teoria e Análise Musical 2019, v. 4, n. 1, p. 98-123 - Journal of the Brazilian Society for Music Theory and Analysis@ TeMA 2019 - ISSN 2525-5541

referenciado a seguir, foi realizada ao vivo por Conrado Silva que também realizou sua montagem e edição (Coelho de Souza 1983, p. 79).

Embora a partitura publicada em 1978 prescreva um conjunto com trompa, em comunicação pessoal o compositor informa que a obra foi pensada inicialmente para a formação de um "quinteto Pierrot", isto é, flauta, clarinete, violino, violoncelo e piano, a mesma usada por Arnold Schoenberg em sua obra Pierrot Lunaire, com a voz humana substituída pelo sintetizador. A substituição da clarineta pela trompa deveu-se à formação peculiar da Camerata Benda que havia sido contratada para o concerto de estreia da obra.

Rodolfo Coelho de Souza, engenheiro civil formado em 1975, na época já estabelecia uma carreira musical com participações no Festival Música Nova, nos concertos da série Música Hoje no Teatro Municipal de São Paulo e também como redator de música do jornal O Estado de São Paulo. Consideramos a formação do compositor nas ciências exatas relevante para a composição de Durações. Pode-se verificar essa influência através dos autores das epígrafes, todas ligadas a conceitos da Física, que antecedem os quatro primeiros movimentos, chamados de Tempos 1 a 5. A epígrafe antes do primeiro é de Albert Einstein e Leopold Infeld; do segundo Issac Newton; do terceiro Bertrand Russel; do quarto, os russos B.M. Yvorski e A. A. Detlaf. A epígrafe que antecede o Tempo 5 dá o nome à obra. É um fragmento de Duración, poema de Octavio Paz que será discutido adiante.

Entretanto Coelho de Souza não é o único compositor dessa geração que tem dupla formação. Vários outros músicos com formação nas ciências exatas têm sido essenciais para o desenvolvimento da música eletroacústica, entre eles, no Brasil, Jorge Antunes, Conrado Silva, Jonatas Manzolli, Mikhail Malt e no âmbito internacional Iannis Xenakis, Jean Claude Risset, Max Mathew, entre muitos outros.

Como informação introdutória final, Gilberto Mendes viajou a trabalho para os Estados Unidos em 1978 e saiu da Comissão de Música da Secretaria Estadual. Coelho de Souza foi indicado para substituí-lo, tomou posse, mas permaneceu apenas por um ano, pois em 1979 transferiu-se para Brasília.

\section{Sobre a composição de Durações}

Foi no estúdio Travessia, fundado e dirigido pelo compositor e engenheiro acústico uruguaio Conrado Silva, que Coelho de Souza iniciou seus estudos de 
música eletroacústica e realizou as primeiras experiências no gênero que o levaram à composição de Durações:

Naquele ano compus, usando os recursos do estúdio de Conrado, Durações, minha primeira peça para instrumentos e sons eletrônicos. Assim como eu, diversos outros compositores eletroacústicos iniciaram sua carreira naquele ambiente fértil e efervescente (Coelho de Souza 2014, p. 1).

O compositor pertence à segunda geração de compositores a se envolver com a música eletroacústica no Brasil, precedido por poucos nomes como Reginaldo Carvalho, Jorge Antunes, Marlene Fernandes, Aylton Escobar, Jocy de Oliveira, Cláudio Santoro, Damiano Cozzella, Rogério Duprat e Conrado Silva.

O compositor descreve os recursos disponíveis para a realização da gravação do suporte fixo empregado na obra no texto a seguir.

As principais ferramentas do estúdio eram dois gravadores Revox, estéreo, pista inteira, usados para as técnicas clássicas de edição sonora em fita magnética e um sintetizador analógico modelo VCS3 - Synthi A, da EMS Electronic Music Studios que Conrado trouxera da Inglaterra em uma de suas viagens. Este sintetizador portátil vinha acondicionado numa maletinha executiva e continha três osciladores que se interligavam em múltiplos esquemas através de um engenhoso sistema de pinos conectados num patchbay matricial (Coelho de Souza 2014, p.1).

Os primeiros gravadores Revox são de 1949, mas o modelo estéreo utilizado para a edição da fita magnética de Durações foi um Revox A77 fabricado na década de 1970 (Fig. 2).

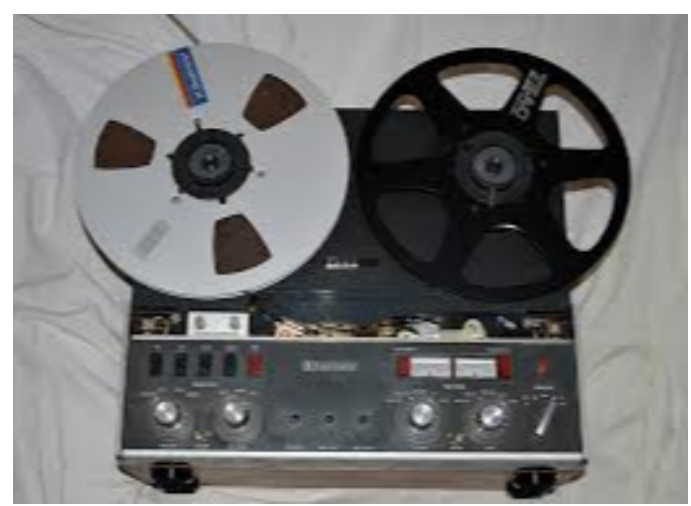

Figura 2: Gravador Revox A77; Fonte:

https://www.hifiengine.com/manual_library/revox/a77.shtml

Como mostra a Figura 3, o mesmo equipamento usado por Coelho de Souza na parte eletrônica de Durações - um sintetizador portátil EMS VCS3 Synthi A, que faz parte da primeira geração de sintetizadores analógicos, assim 
MUSICA THEORICA Revista da Associação Brasileira de Teoria e Análise Musical 2019, v. 4, n. 1, p. 98-123 - Journal of the Brazilian Society for Music Theory

como o Moog e o Buchla - havia sido utilizado pouco tempo antes pela banda inglesa Pink Floyd para gerar diversos efeitos sonoros no famoso álbum de 1973, The Dark Side of the Moon. Esse aparelho permite uma gama de operações de manipulação de síntese sonora que são realizadas por conexões físicas de cabos que se conectam a receptores, que por sua vez são controlados por potenciômetros, variando as características dos sinais sonoros ou dos sinais de controle. Desse modo é possível realizar modulações AM e FM, modulação de anel, assim como outros algoritmos básicos de síntese que produzem controles relativamente complexos do sinal sonoro. Outros músicos do universo pop que utilizaram na época o EMS Synthi AKS foram Brian Eno no álbum do grupo Roxy Music de 1972 chamado de Roxy Music e Jean Michel Jarre nos álbuns Oxtgène e Équinoxe.

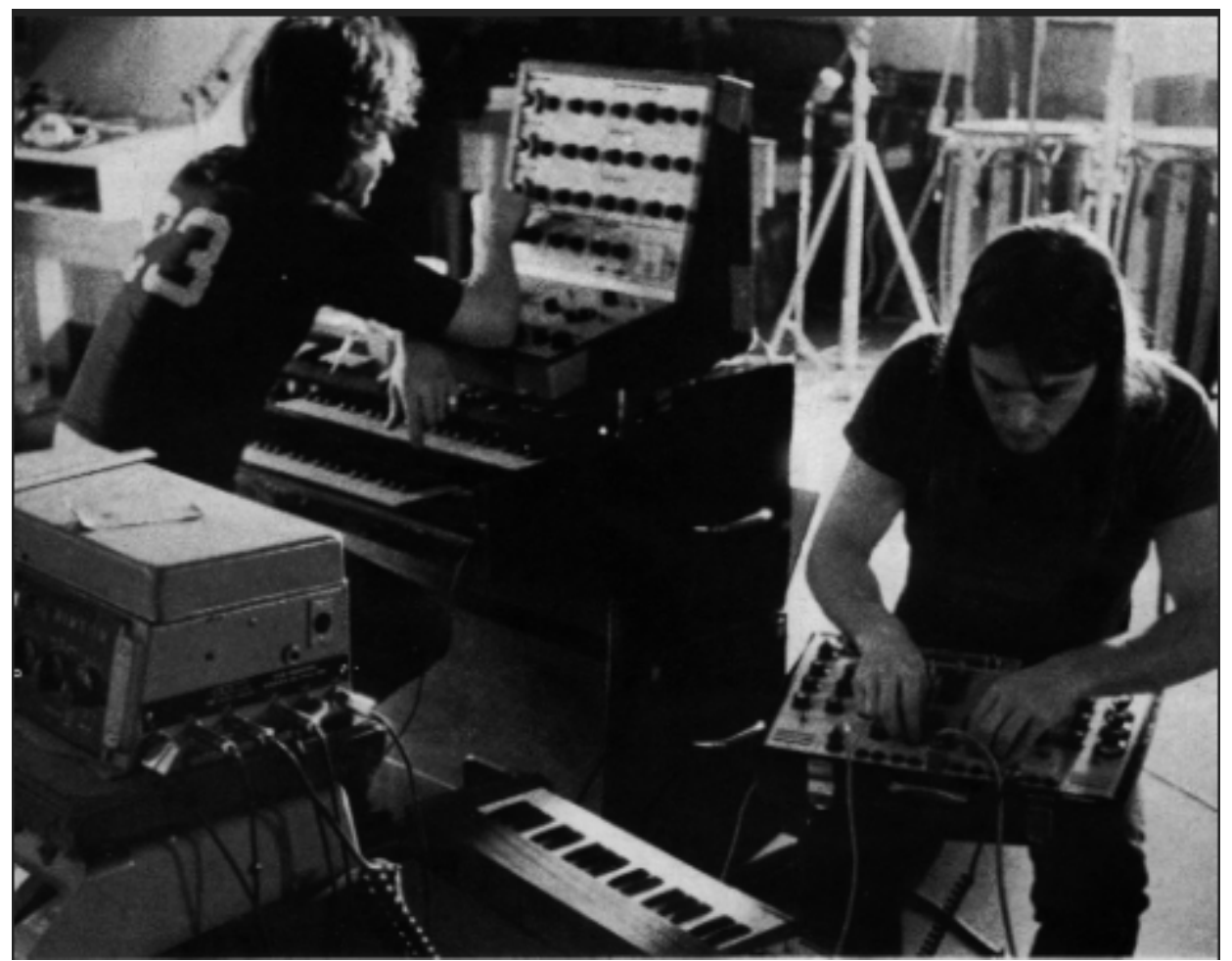

Figura 3: Pink Floyd no Abbey Road Studios: gravação do álbum, The Dark Side of the Moon, 1973 (Fonte: emssynthesisers.co.uk/floyd.gif)

A menção feita acima aos grupos de rock não é fortuita. Reconhecemos semelhanças importantes entre as sonoridades eletrônicas de Durações e aquelas usadas pelas bandas de música pop mencionadas. Isto obviamente reflete uma questão geracional, visto que entre os cinco compositores com obras encomendadas, Coelho de Souza foi o único a empregar sons eletrônicos e 
ademais numa vertente estética em que é possível reconhecer semelhanças com a sonoridade da música pop de sua geração.

A obra é dividida em cinco movimentos independentes, que devem ser executados na ordem especificada. Na partitura verificamos instruções para performance contendo informações sobre a formação, explicações sobre a decodificação das partes gráficas, andamentos e a integração da parte eletrônica com os instrumentos. No terceiro movimento as instruções incluem a interpretação do gráfico por tessitura, além de uma bula com explicações das técnicas expandidas empregadas.

A parte eletroacústica de Durações é composta somente por sons sintetizados. A obra não utiliza qualquer tipo de manipulação de amostras gravadas, como é característico da música concreta. Todos os sons da fita magnética foram gerados eletronicamente pelo sintetizador, a partir de operações de seus osciladores eletrônicos internos.

\section{Operação do sintetizador eletrônico}

Instruções em fluxogramas para a geração da parte eletroacústica da obra constam nas últimas páginas da partitura publicada pela ECA-USP em 1978. A composição do suporte fixo de cada um dos movimentos tem duas partes separadas, uma para cada canal estéreo, o que significa que a fita, quando préproduzida, na verdade simula dois sintetizadores em operação simultânea. Cada canal tem uma parte de sintetizador que obedece a uma execução, em tempo real, de uma série de "operações sequenciais" (nome da lista-algoritmo que consta da partitura) que são sucessivos comandos de alteração do sinal sintetizado. Estes comandos devem ser produzidos por inserções de cabos em determinados módulos, ou por mudanças de valor de determinados potenciômetros. Para isso a partitura fornece inicialmente um diagrama de blocos do esquema de conexões de cada canal, em cada movimento, e uma lista de comandos que correspondem ao acionamento sucessivo de módulos, ou de modificações das conexões dos componentes descritos no diagrama de blocos. Nota-se a semelhança desse modelo de geração de sons eletrônicos dividido em duas partes, a do fluxograma e a das operações sequenciais, com a concepção de dois algoritmos interdependentes, chamados de "orchestra" e "score", com que é estruturado o 
MUSICA THEORICA Revista da Associação Brasileira de Teoria e Análise Musical 2019, v. 4, n. 1, p. 98-123 - Journal of the Brazilian Society for Music Theory and Analysis @ TeMA 2019 - ISSN 2525-5541

programa Csound, ${ }^{2}$ anos antes que o programa estivesse disponível para uso público.

As operações sequenciais de cada movimento devem ser realizadas no tempo total especificado, que coincide para os dois canais, em cada movimento. Entretanto, não há tempos parciais especificados para cada operação sequencial dentro da duração global determinada. Há, portanto, uma certa margem de liberdade no controle do tempo de execução da parte do sintetizador, o que se torna especialmente atrativo para a possibilidade de fazer a performance ao vivo com dois sintetizadores, em vez da versão montada previamente em suporte fixo.

Entretanto, como dispunha de um único sintetizador, o compositor realizou a estreia da obra gravando o sintetizador eletrônico conforme as instruções das "operações sequenciais" em dois canais de uma fita magnética que foi reproduzida ao vivo em tempo fixo. Entretanto, pelo que pudemos apurar, a alternativa da performance ao vivo da parte eletrônica ainda não foi realizada e nas execuções posteriores utilizou-se a mesma fita preparada para a estreia.

Para exemplificar o procedimento, as Figuras 4 e 5 mostram os diagramas de bloco e as operações sequenciais do projeto de geração dos canais 1 e 2 do Tempo II de Durações, conforme consta da partitura.

\footnotetext{
2 Csound é um sistema computacional para síntese sonora em aplicações musicais que foi originalmente desenvolvido em 1985 por Barry Vercoe no MIT Media Laboratory. Na década seguinte a plataforma foi aberta para a colaboração de uma vasta comunidade de contribuintes voluntários gerenciados por um núcleo de desenvolvedores.
} 
O Pensamento Musical sobre o Tempo em Duraçães (1977) de Rodolfo Coelho de Souza

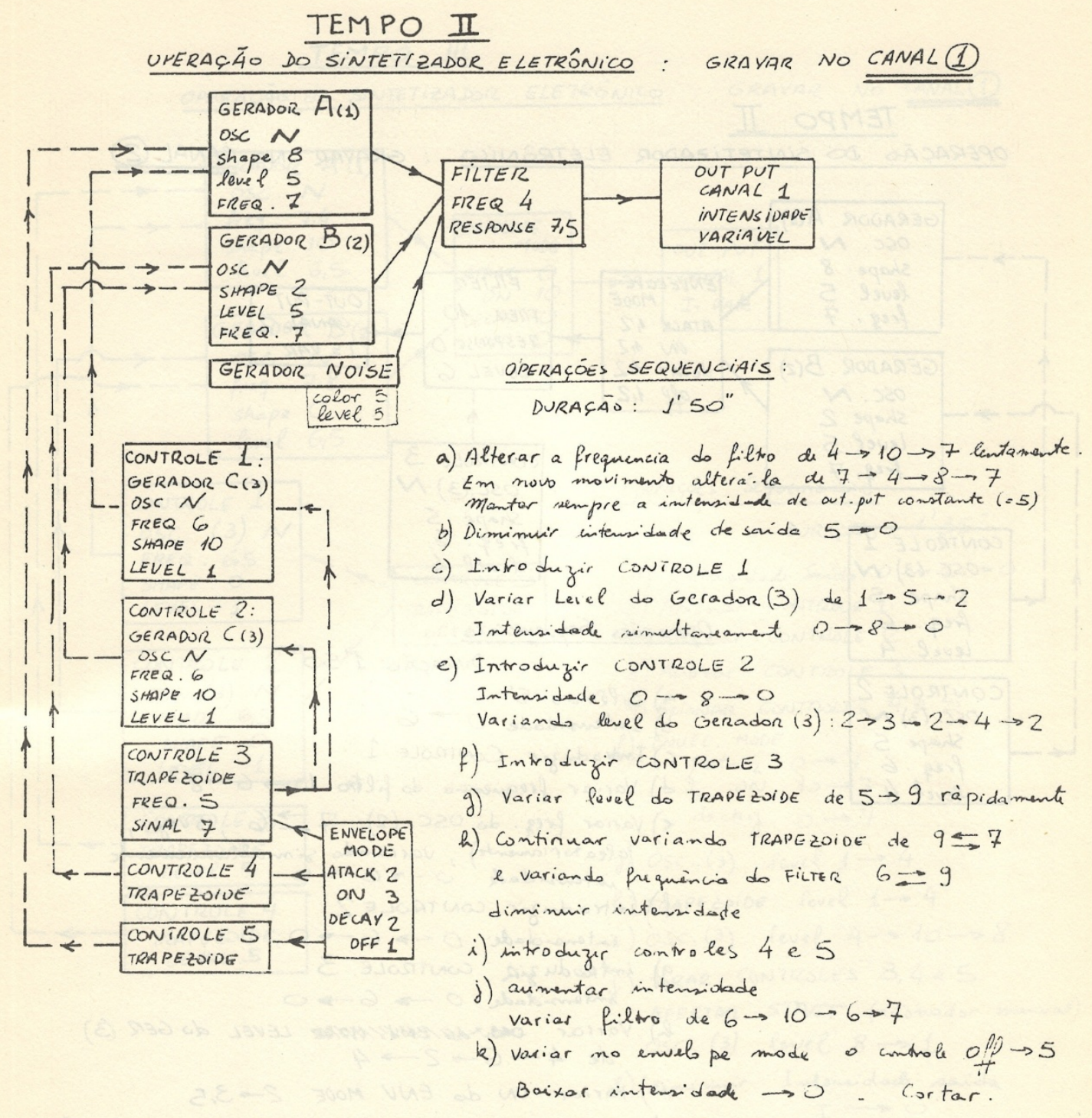

Figura 4: Diagrama do Projeto do Canal 1 do Tempo II de Durações 
MUSICA THEORICA Revista da Associação Brasileira de Teoria e Análise Musical 2019, v. 4, n. 1, p. 98-123 - Journal of the Brazilian Society for Music Theory and Analysis @ TeMA 2019 - ISSN 2525-5541

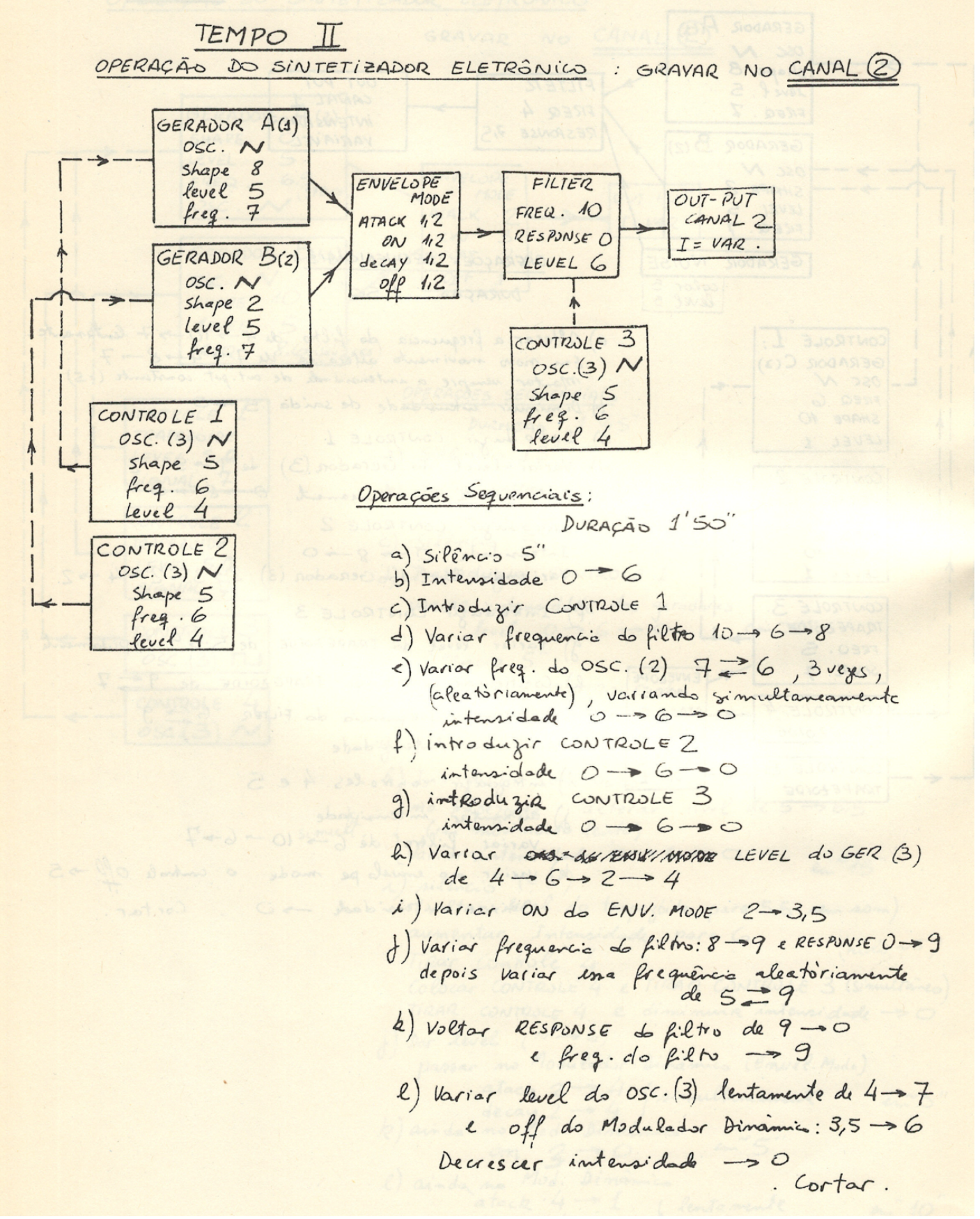

Figura 5: Diagrama do Projeto do Canal 2 do Tempo II de Durações 


\section{Uma análise da obra}

Além dos aspectos inovadores da produção da parte eletrônica, Durações propõe, nos diversos movimentos, uma discussão conceitual de aspectos que concernem à concepção do tempo musical. Ainda que concebida num ambiente tecnológico cujas limitações permitiam apenas a difusão em suporte pré-gravado da parte eletroacústica, a obra propõe um questionamento das relações temporais entre as partes eletrônica e instrumentais através de diversas soluções alternativas para a notação musical.

No influxo do experimentalismo que foi característico da geração que esteve à frente do Festival Música Nova nos anos 1970, Durações emprega cinco modos diferentes de notação musical, um para cada movimento. Esses métodos de notação musical, alguns deles experimentais, outros tradicionais, tem direta relação com a percepção do tempo pelos performers e consequentemente afetam a relação temporal com a parte eletrônica. Na verdade, somente o segundo movimento é escrito em notação tradicional, com fórmulas e barras de compasso, além de indicação de andamento $\cdot=60$ que equivale, paradoxalmente, a uma contagem dos pulsos como se fossem segundos do relógio. Não por acaso, essa seção, escrita em notação tradicional, é o único trecho da obra em que o conjunto instrumental toca sozinho e a fita magnética silencia.

$\mathrm{Na}$ Tabela 1 a seguir esquematizamos a instrumentação de cada movimento e as variantes técnicas de notação musical utilizadas.

\begin{tabular}{|c|c|c|}
\hline & Instrumentação & Tipo de notação \\
\hline $1^{\mathrm{o}}$ Tempo & Flauta, trompa, piano, eletrônica & Forma aberta, partes isoladas \\
\hline $2^{\mathrm{o}}$ Tempo - $1^{\mathrm{a}}$ parte & Quinteto, mas sozinho & Tradicional \\
\hline $2^{\underline{o}}$ Tempo - $2^{\underline{a}}$ parte & Quinteto e eletrônica & Tradicional \\
\hline $3^{\circ}$ Tempo & Violino, cello, piano, eletrônica & Planimétrica \\
\hline $4^{\mathrm{o}}$ Tempo & Quinteto e eletrônica & Proporcional, em segundos \\
\hline $5^{\mathrm{o}}$ Tempo & Quinteto e eletrônica & Gráfica livre \\
\hline
\end{tabular}

Tabela 1: Formação instrumental e técnica de notação nos movimentos de Durações 
MUSICA THEORICA Revista da Associação Brasileira de Teoria e Análise Musical 2019, v. 4, n. 1, p. 98-123 - Journal of the Brazilian Society for Music Theory and Analysis@ TeMA 2019 - ISSN 2525-5541

TEMPO 2
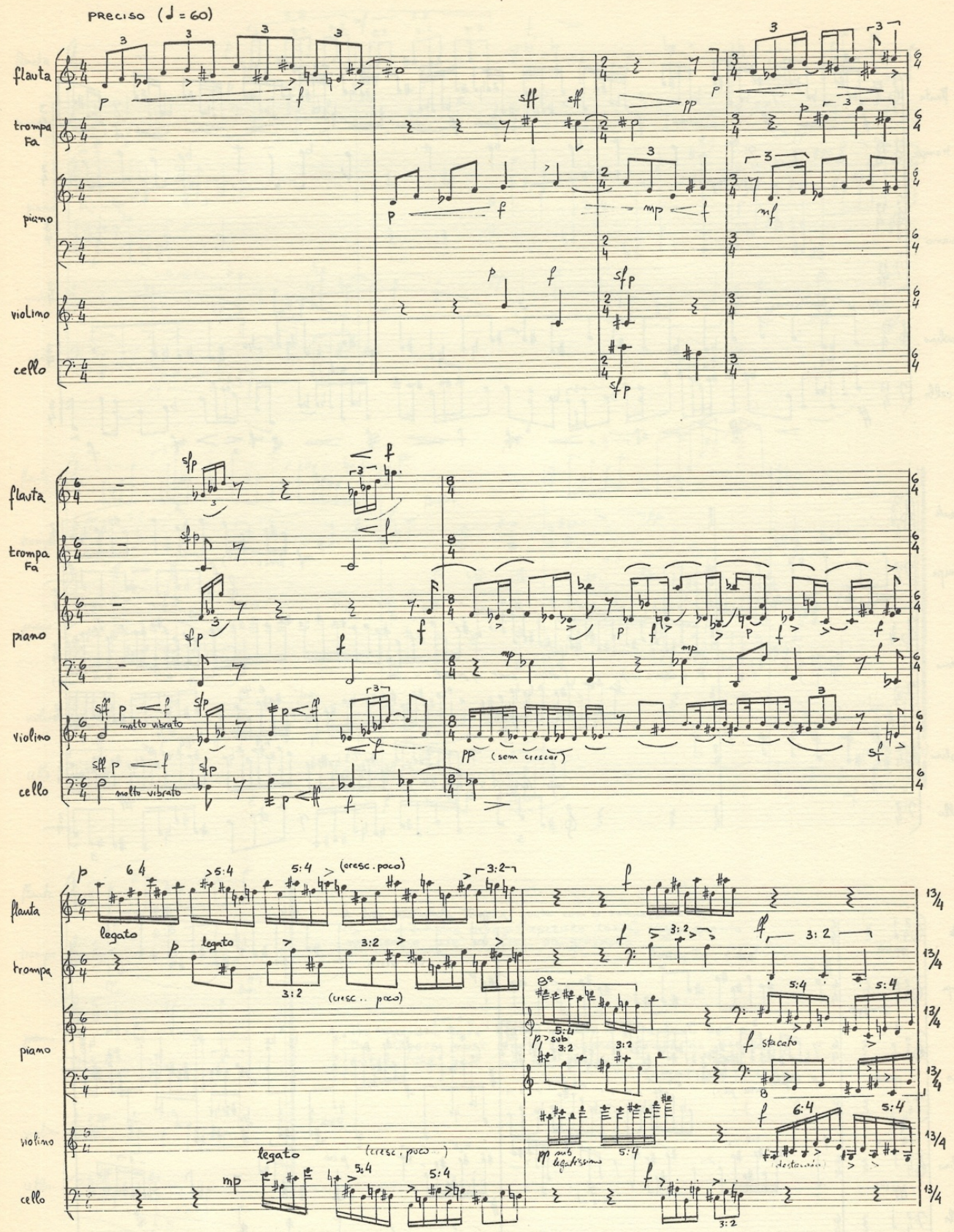

Exemplo 1: Durações, início do Tempo 2 com notação tradicional ${ }^{3}$

\begin{abstract}
${ }^{3}$ Note-se que a posição das dinâmicas, acima do pentagrama, não é usual na música instrumental. O uso desse tipo de notação, todavia usual na música vocal, pode ser atribuído à experiência do compositor como ativo participante do movimento coral, seja no Madrigal Ars Viva em torno do qual gravitou o Festival Música Nova, seja em outros corais ligados àquele movimento. Entretanto no Tempo 4, conforme mostra o Exemplo 5, a posição da notação de dinâmicas obedece a tradição. Também no Tempo I não parece haver uma motivação especial para a alternância.
\end{abstract}




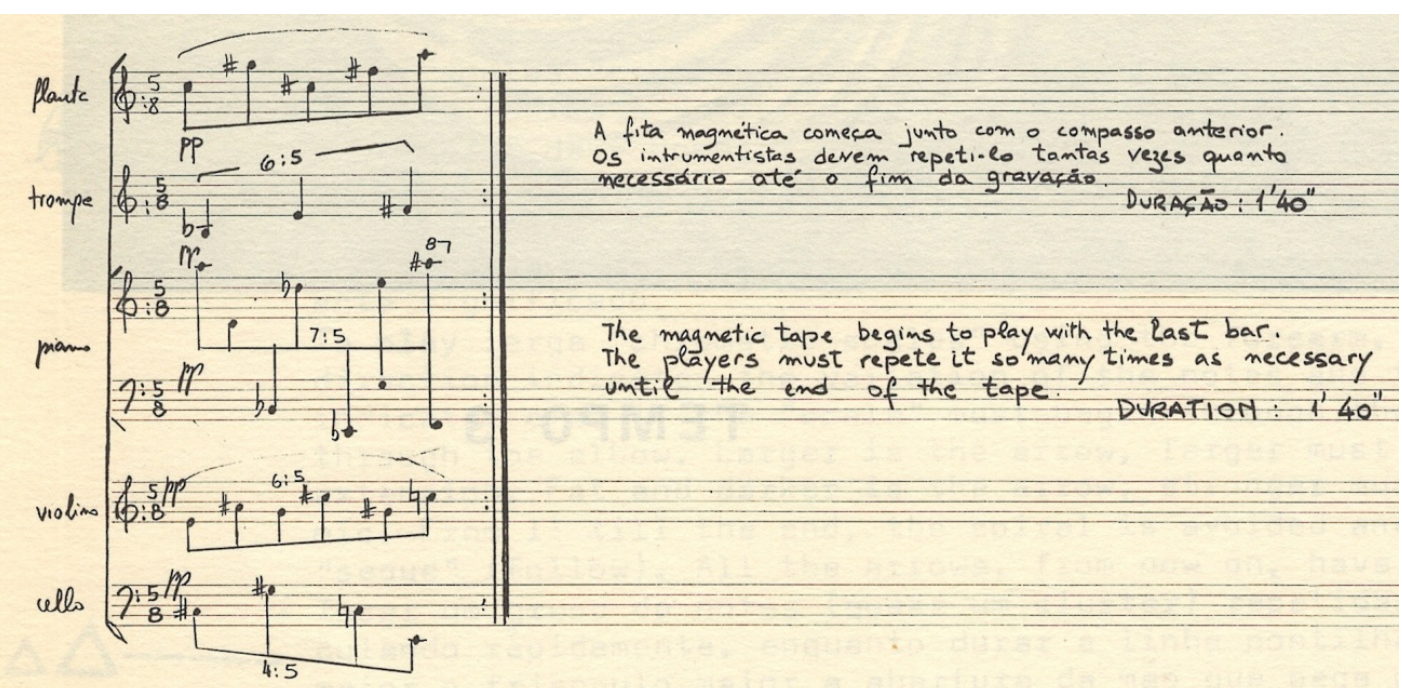

Exemplo 2: Durações, ostinato instrumental no final do Tempo 2, sobreposto à eletrônica

Quando termina a seção em que o conjunto instrumental toca sem sobreposição com os sons eletrônicos, os cinco instrumentos iniciam um módulo de cinco segundos de duração que deve ser repetido vinte vezes, e que se sobrepõe à parte da fita que dura 1'40". A dificuldade que os instrumentistas têm em manter a contagem das repetições por tantas vezes só pode ser superada com o conhecimento dos músicos da parte eletroacústica, analogamente ao que acontece na música de câmara. Ainda que para o ouvinte externo a constante novidade trazida pela fita magnética renove o interesse pelo discurso musical, podemos reconhecer nessa passagem o uso do efeito hipnótico de múltiplas repetições, como sendo precursor do estilo minimalista que predominaria na fase subsequente da obra de Coelho de Souza (Mariz, 2005).

No início desse segundo movimento o compositor cita na partitura um fragmento dos Princípios Matemáticos da Filosofia Natural de Isaac Newton (1686), que diz:

o tempo absoluto, verdadeiro e matemático flui sempre por igual, por si mesmo e por sua natureza, sem relação com qualquer coisa externa, chamando-se com outro nome, de 'duração'; o tempo relativo, aparente e vulgar é uma certa medida sensível e externa da duração por meio do movimento...

Podemos inferir que nessa seção o compositor procurou demarcar o papel rígido que a contagem metronômica do tempo exerce sobre a percepção do mesmo, tanto para os intérpretes quanto para o ouvinte externo. Entretanto, a repetição modular no trecho final cria uma distorção perceptiva nos intérpretes 
MUSICA THEORICA Revista da Associação Brasileira de Teoria e Análise Musical 2019, v. 4, n. 1, p. 98-123 - Journal of the Brazilian Society for Music Theory and Analysis @ TeMA 2019 - ISSN 2525-5541

que abre uma porta para a percepção da relatividade do tempo, introduzida pela relação entre movimento e imobilidade tal como preconiza a citação de Newton.

Por outro lado, no primeiro movimento atuam três instrumentos: flauta, trompa e piano. Cada um desses instrumentos tem uma parte individual. Não há uma organização do discurso coletivo. Isso significa que cada músico vai reagir aos estímulos da fita magnética e dos outros instrumentos para decidir o momento e o material que vai enunciar. Trata-se, portanto, de um trecho de "obra aberta", uma improvisação coletiva de três instrumentistas, baseada em materiais fornecidos pelo compositor. Cada uma das partes não é composta por um discurso contínuo, mas por fragmentos que podem ser encadeados de muitas maneiras diferentes, permitindo a interatividade de forma livre. O Exemplo 3 mostra a parte da flauta do primeiro movimento na qual podemos observar as características acima descritas.

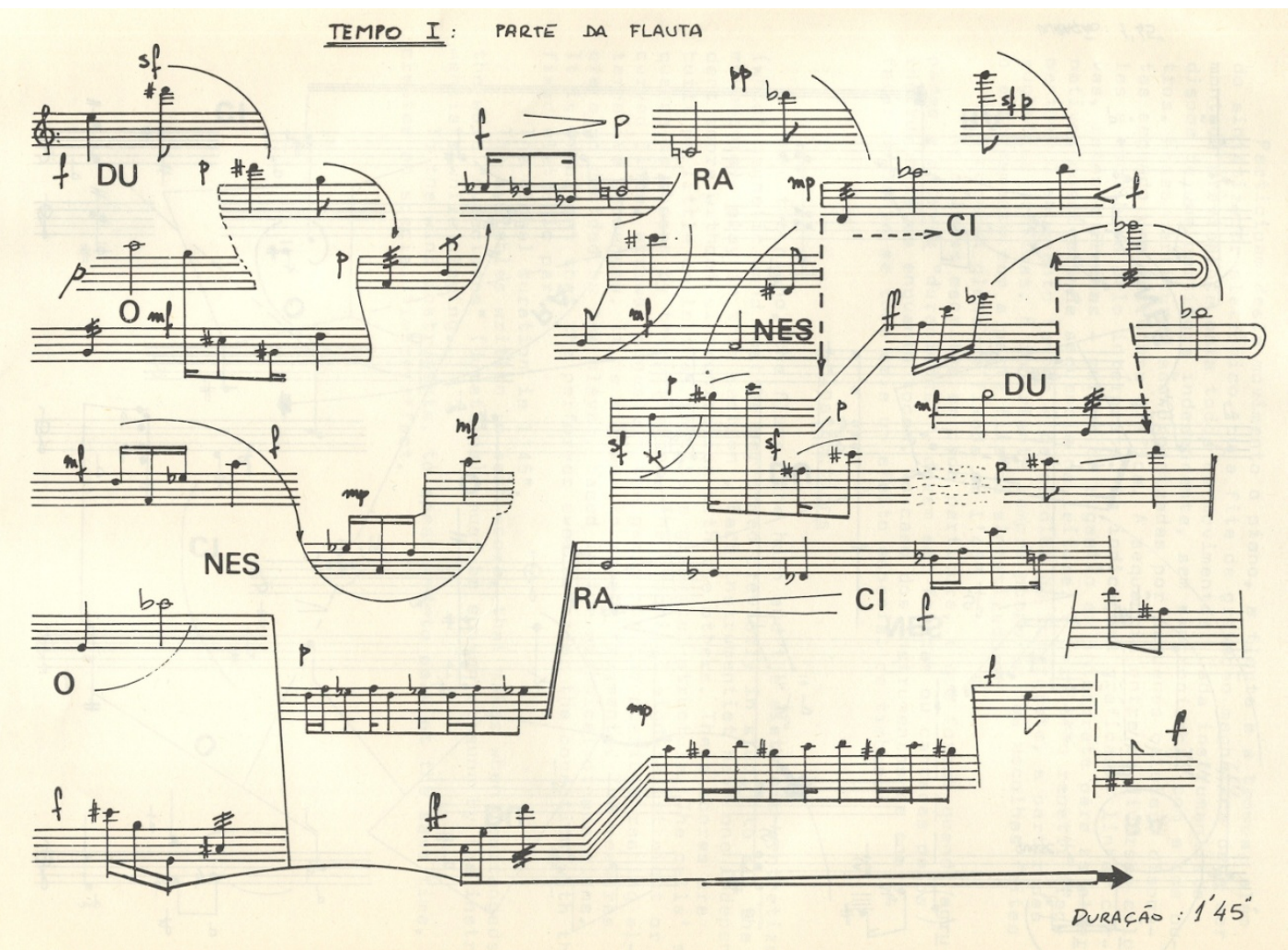

Exemplo 3: Durações, parte de flauta do Tempo I

Note-se que não estão especificados nem o fragmento inicial, nem qual a regra de ordenação dos fragmentos. Existe a possibilidade que um mesmo fragmento seja tocado mais de uma vez porque na trajetória da interpretação pode-se chegar a ele por mais de um caminho. Paradoxalmente, num estilo como 
este, de alta entropia de informação, essa possibilidade surge como uma atenuante que permite alguma redundância do discurso musical. Há símbolos, como flechas e ligaduras, que sugerem algumas continuidades, mas muitas dessas indicações são ambíguas. Pode-se cogitar também existir nessa passagem uma possível influência da obra seminal minimalista in $C$ de Terry Riley.

Outra característica marcante dessa seção é que as partes dos três instrumentos trazem sílabas soltas que, conforme a bula, devem ser faladas, com expressão, pelos próprios músicos, durante a performance. Nos dois instrumentos de sopro essas falas podem ser simultâneas à execução das frases anotadas, resultando em uma técnica expandida. As sílabas soltas formam um anagrama da palavra DU-RA-CI-O-NES, porque, como afirma o próprio compositor em Música/Rodolfo Coelho de Souza (1983, p. 80), que aliás continha a gravação em fita cassete da estreia da obra, ela foi inspirada no poema Duración de Otávio Paz. Naquela análise aparece como epígrafe um fragmento em espanhol de um poema de Octávio Paz, do livro Salamandra, escrito entre 1958 e 1961. Esse poema não só é a chave para as falas em espanhol no corpo da peça, como, também indica, por outro lado, a sintonia do compositor com um projeto de integração cultural latino-americana que defendeu em outras oportunidades. O mesmo poema aparece como epígrafe para o último movimento da peça.

DURACIÓN

Trueno y viento: duración

(I)

I Ching

Negro el cielo

Amarilla la tierra

El gallo desgarra la noche

El agua se levanta y pregunta la hora

El viento se levanta y pregunta por $t i$

Pasa um caballo blanco

O poema dá também algumas indicações das influências conceituais do autor ao escrever a peça. A referência ao I Ching na epígrafe do poema conota a técnica de composição de música aleatória utilizada por John Cage em suas obras, embora, como esclarece o compositor, não tenham sido usados processos estocásticos semelhantes ao de Cage na composição da obra. Todavia há certamente o uso do acaso nas sincronizações entre as partes, e em maior grau nos movimentos com forma aberta. Ademais uma reflexão contemporânea sobre 
MUSICA THEORICA Revista da Associação Brasileira de Teoria e Análise Musical 2019, v. 4, n. 1, p. 98-123 - Journal of the Brazilian Society for Music Theory and Analysis@ TeMA 2019 - ISSN 2525-5541

o tempo passaria necessariamente sobre o problema da causalidade que está implícito nas questões do estocástico e do aleatório.

Na partitura, logo antes do primeiro movimento, aparece uma citação que ajuda a esclarecer como as questões acima levantadas se articulavam na mente do compositor:

O físico antigo se preocupa apenas com a transformação do espaço, porquanto o tempo para ele é absoluto. Acha natural e conveniente a divisão do contínuo quadridimensional mundial em espaço e tempo. Mas do ponto de vista da teoria da relatividade, tanto o espaço como o tempo se alteram ao passar de um sistema de coordenadas para outro e a transformação de Lorentz considera as propriedades de transformação do contínuo quadridimensional de espaçotempo de nosso quadridimensional mundo dos acontecimentos (Einstein; Infeld, 1938).

Devido ao contraste do primeiro com o segundo movimento, percebemos que o compositor coloca em primeiro plano uma percepção "contemporânea" do tempo. Essa nova percepção é relativa e não absoluta, com todas as suas consequências para a física e para a cognição. $\mathrm{O}$ segundo movimento aparece como regressão a uma forma antiga de perceber o tempo.

Diz o compositor sobre o primeiro movimento:

a coisa vem do caos [...]. São fragmentos, células dispostas sem uma ordem estruturada. Cada um reage por associação ao que os outros lhe falam. Há um movimento nitidamente circular do tempo. Tudo volta ao princípio (Coelho de Souza 1983, p. 81).

E sobre o segundo movimento:

Primeira fase - o tempo se cristaliza em estruturas rígidas, nitidamente rítmicas, francamente instrumentais. A crescente densidade sugere complexidade. Segunda fase - os instrumentos se cristalizam na repetição de um compasso flutuante. O tempo estanca. O sintetizador reina sozinho sobre essa nuvem imóvel e nos conduz em seu vento sonoro (idem).

Encontramos materializado aí o "vento" do poema de Otavio Paz, o tempo estancado pela velocidade crescente e o tempo cíclico da filosofia oriental revisitado pelo afrouxamento de uma rigidez estruturalista.

Embora diversas das técnicas de notação que aparecem ao longo da obra possam sugerir uma influência da tradição experimental americana de Cage, Feldman e ao mesmo da europeia, como de Ramón Barce, a técnica de escrita específica do terceiro movimento deve ser creditada à influência de $\mathrm{H}$. J. Koellreutter no ambiente musical brasileiro da época. A escrita empregada é uma derivação do que Koellreutter chamava de "notação planimétrica", nesse caso 
levado ao rigor da música ser escrita em papel milimetrado, como é usado nas ciências exatas para o desenho de gráficos cartesianos, conforme se constata no Exemplo 4. Isso se evidencia pelo fato de que em 1970, Koelreutter ministrou um curso na Pró-Arte de São Paulo, do qual participou o compositor, em que o objeto de estudo foi notação planimétrica com técnicas instrumentais expandidas.

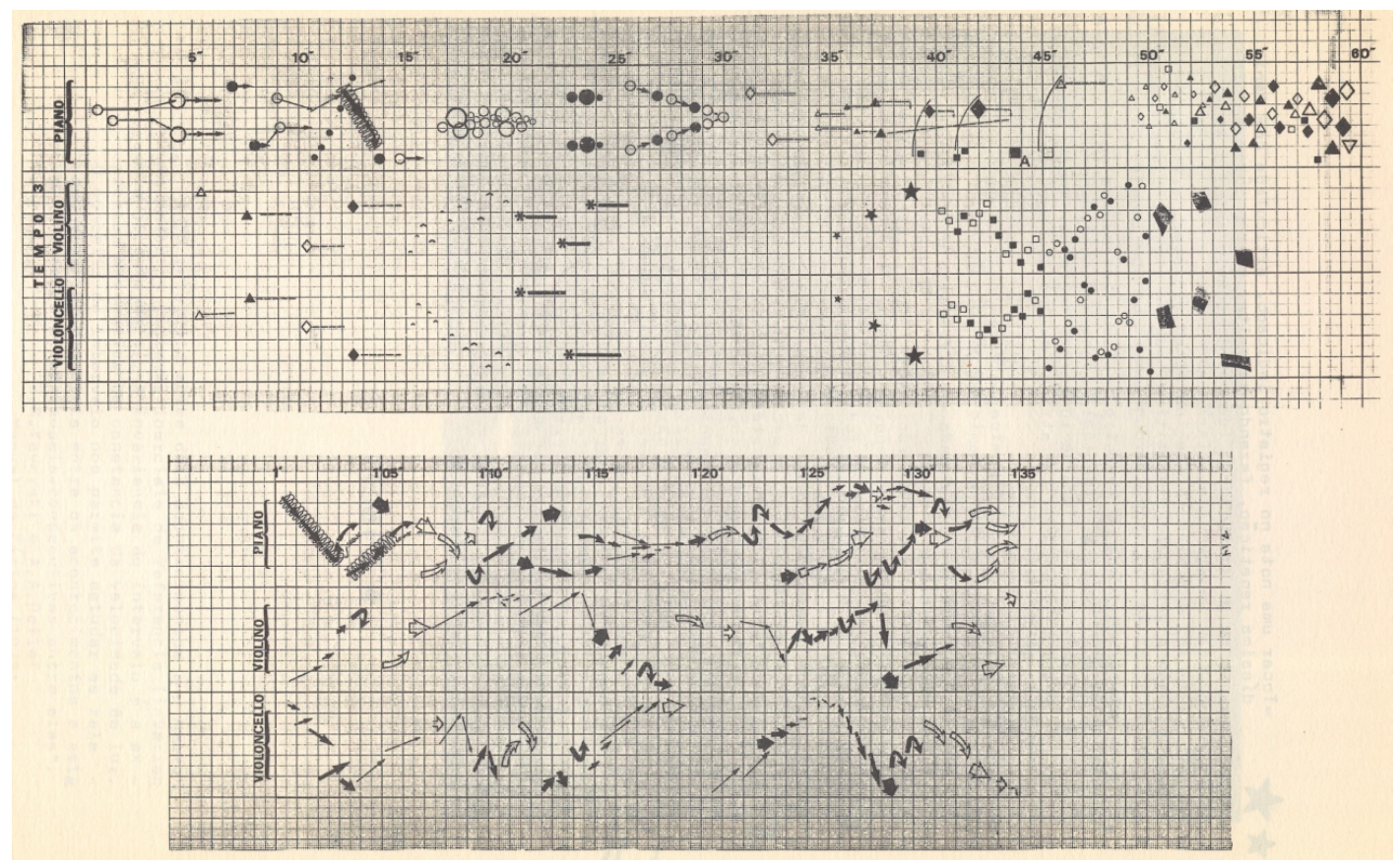

Exemplo 4: Durações, partitura da parte instrumental do Tempo 3

O terceiro movimento da obra é composto para violino, violoncelo e piano. Não apresenta indicação de andamento e embora não esteja pedido na partitura, subentende-se na partitura que deve ser utilizado o cronômetro e a numeração do eixo horizontal corresponde a segundos. Portanto, embora a relação do segundo como unidade de tempo desse movimento seja análoga a do anterior com a indicação da semínima igual a sessenta, aqui não existe um pulso a ser contado. O compositor oferece aos intérpretes um questionamento sobre as diferenças e semelhanças na percepção relativa do tempo nas duas abordagens sobre a medida de tempo. O ouvinte externo não tem elementos para participar desse nível de discussão sobre a percepção do tempo que parece estar dirigido somente aos intérpretes. Nesse terceiro movimento, assim como no primeiro, o pulso está ausente. Entretanto no primeiro não havia nenhuma preocupação de coordenação entre as partes dos três executantes, o que já acontece aqui. 
Este movimento emprega, mais intensivamente do que nos dois anteriores, algumas técnicas expandidas. Por isso, e também devido aos problemas da notação planimétrica, o compositor forneceu uma lista instruções, cuja primeira página pode ser vista na Figura 6.

As técnicas não usuais podem eventualmente participar da música que usa linguagens mais tradicionais, como já ocorrera, por exemplo, com o sul ponticello na Suite Lírica de Alban Berg ou com o cluster para piano nas primeiras obras de Henry Cowell, entre outras. Ainda assim é inegável que as técnicas expandidas convidam o tempo a se tornar mais flexível, porque a maioria delas concentra a atenção, tanto do intérprete quanto do ouvinte, no "som em si", isto é, nas qualidades intrínsecas do timbre sonoro, nas propriedades de expressão internas à emissão de cada som, e não apenas na predominância do fluxo de um evento sonoro para outro, como na música tradicional. É precisamente esse fenômeno que ocorre no terceiro movimento de Durações, em que não se mede a duração de cada cluster ou cada glissando através da precisão de contagem de um ritmo e do pulso, mas com um tempo flexível necessário para que cada evento ganhe expressão e significado naquele contexto. Isto está diretamente relacionado, ainda que metaforicamente, à citação que abre este movimento na partitura. Nela, Bertand Russell afirma que "as contagens do espaço e do tempo não são mais independentes uma da outra... e assim o tempo e o espaço não são mais independentes como não o são as três dimensões do espaço". Ou seja, ao utilizar uma partitura-diagrama, o compositor converte espaço em tempo e amarra tempo e espaço numa unidade indissociável. 


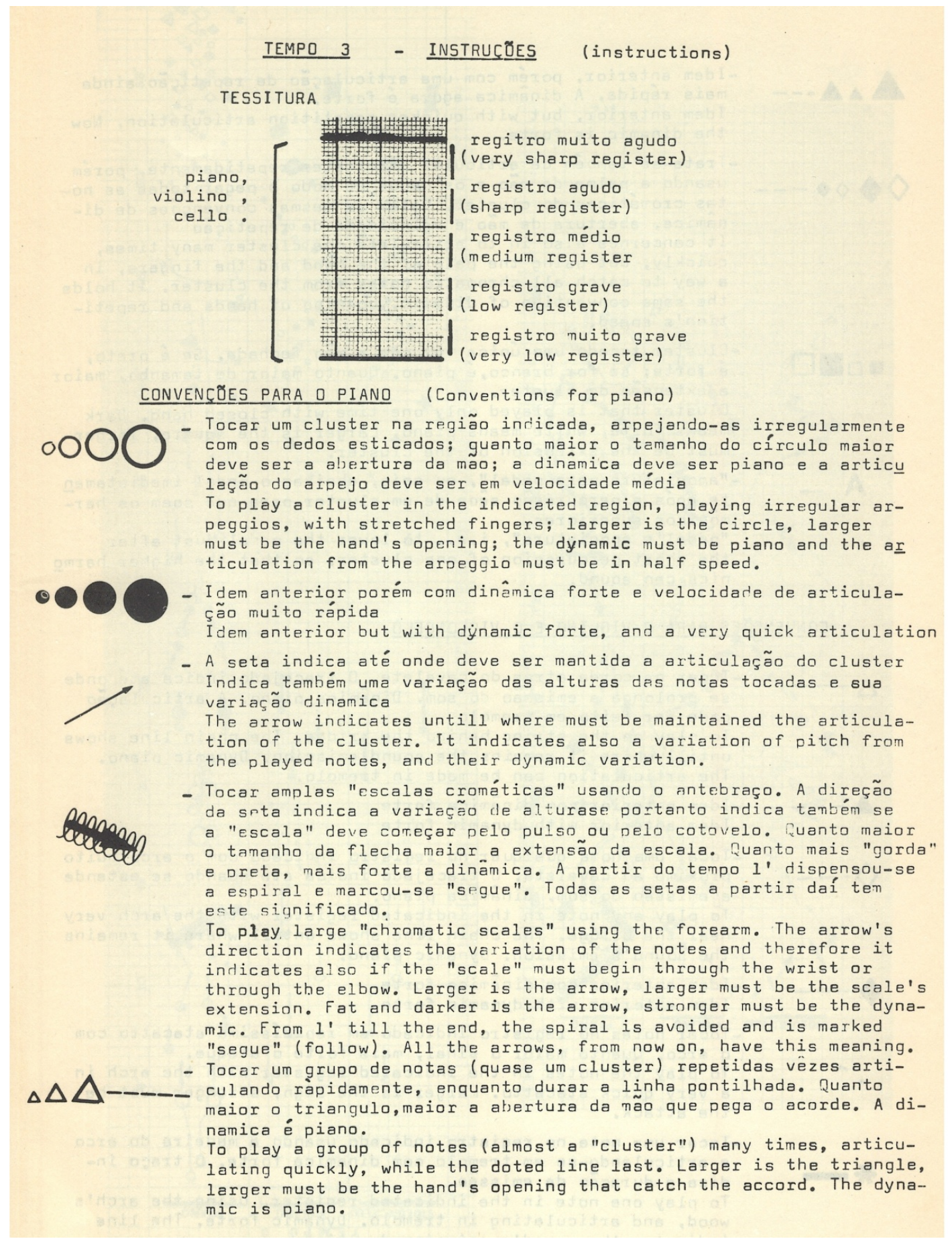

Figura 6: Instruções para o Tempo 3 de Durações

Essa escrita, por outro lado, é caracterizada pelo controle das texturas. Aproxima-se, portanto, da música estocástica de Xenakis, entre outros compositores ativos na época e da música textural de Ligeti e Penderecki. A oposição entre Gesto e Textura domina a retórica da obra. Tomando a tricotomia de Ferneyhough (1993), que ainda inclui a noção de Figura, constata-se que esta 
MUSICA THEORICA Revista da Associação Brasileira de Teoria e Análise Musical 2019, v. 4, n. 1, p. 98-123 - Journal of the Brazilian Society for Music Theory and Analysis@ TeMA 2019 - ISSN 2525-5541

última categoria não é relevante para a escrita desse movimento, o que nos remete então às teorias de Denis Smalley (1997) para a música eletroacústica, que prescindem das categorias figurais. Exatamente por isso, creio que nesse terceiro movimento a integração entre partes eletroacústicas e partes instrumentais é a mais efetiva em Durações. Isto porque a parte instrumental é escrita, num certo sentido, como se fosse música eletroacústica. Creio que isto justifica a afirmação do compositor de que nesse movimento "tudo se converte em gestos, em impulsos mecânicos [...] a partitura é um diagrama em que cada flecha é um bloco em movimento que impulsiona os outros" e conclui afirmando que o tempo se converte num "maciço impenetrável" (Coelho de Souza 1983, p.81). O que o compositor advoga, é que a impenetrabilidade do tempo é o resultado perceptivo da coesão obtida entre as partes instrumentais e a eletrônica.

O quarto movimento, assim como o segundo, pode ser considerado regressivo, na medida em que os eventos voltam a ser escritos com notas musicais, embora a contagem de tempo permaneça sendo feita em segundos, como no movimento anterior. Entretanto essa contagem de tempo é menos precisa do que a da seção anterior, visto que a marcação de tempo se faz em blocos de 15 segundos, no interior dos quais os eventos ocorrem sem a exigência de muita precisão, regidos apenas pelas relações espaço-temporais da notação gráfica. Observe-se no Exemplo 5 a relativa liberdade de execução permitida por esse tipo de notação.

O compositor comenta alguns aspectos dessa partitura: “o tempo desliza como num coral de vozes; as intensidades oscilam como ondas, convertem-se em vibrações; o tempo é um frêmito que nos atravessa; só o medimos por barras, a longos intervalos". O conceito de intervalo é determinante aqui. Uma citação do Manual de Física de Yavorski e Detlaf (1972, p. 95), que encabeça na partitura este movimento, reitera que "o conceito de intervalo nos permite estudar as relações espacial-temporal entre os acontecimentos e estabelecer as relações causaisconsecutivas entre eles". Encontramos aqui uma sincronia peculiar entre uma proposta de um jovem compositor brasileiro, em 1977, e a teoria desenvolvida na mesma época por David Lewin, reputado professor de Harvard, que propunha um GIS - Generalized Interval System para dar conta da complexidade crescente nas relações da música do século XX, na qual as relações fundamentais não mais se limitavam a intervalos de alturas, mas se expandiam a todos os parâmetros musicais. Uma análise de Durações usando a metodologia dos intervalos 
generalizados, ou GIS de Lewin, foge ao escopo desta pesquisa, mas é possível que seja uma ferramenta capaz de trazer à luz outras relações estruturais presentes nessa obra.

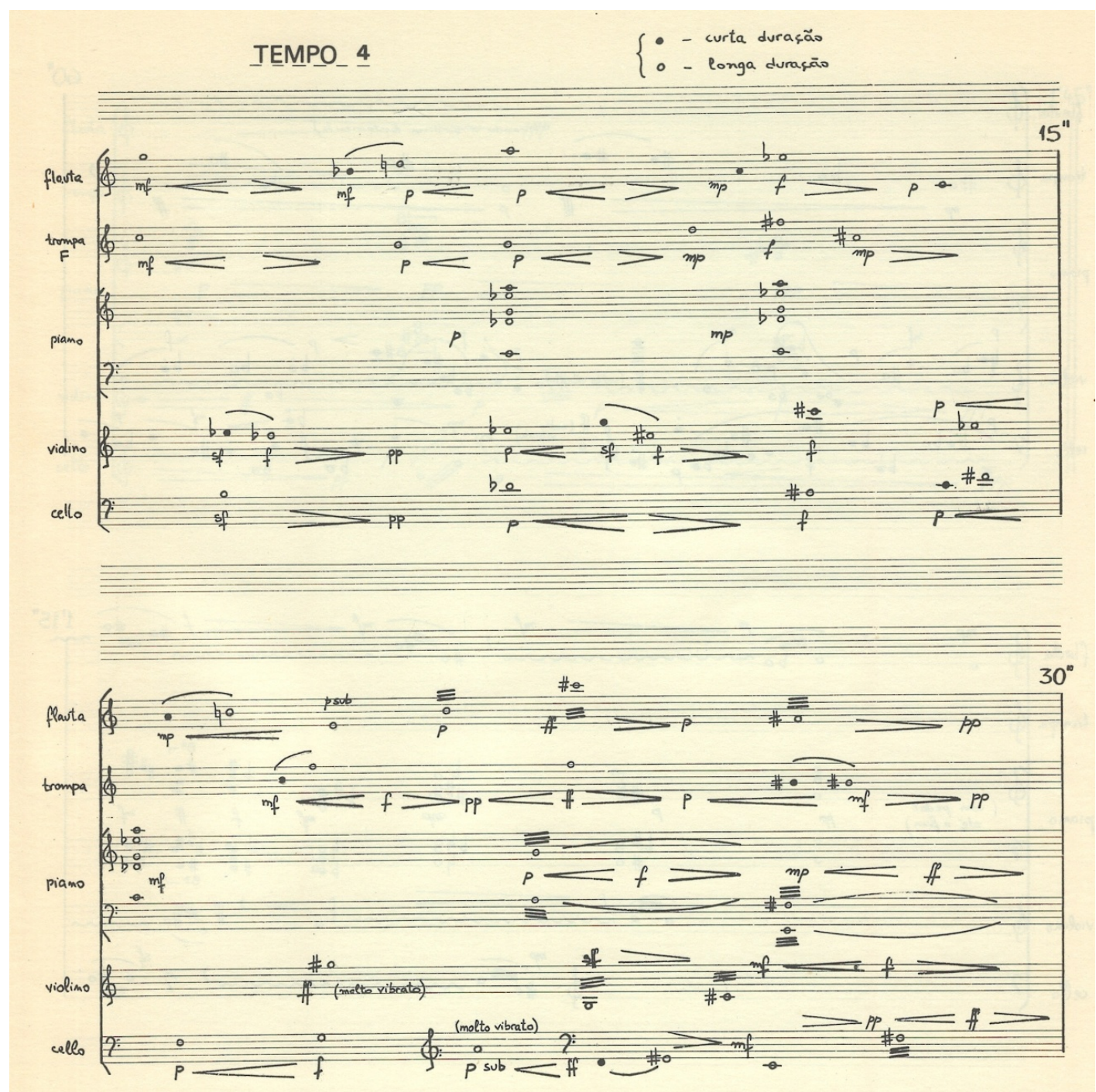

Exemplo 5: Durações, início da partitura do Tempo 4

O quinto e último movimento desta peça é o mais enigmático de todos. A proposta de improvisação livre que já circulara em menor proporção nos movimentos anteriores, torna-se então, neste último movimento, o princípio fundamental. É preciso mencionar que essa escolha refletia uma corrente influente na música aleatória daquela época que preconizava o estímulo de partituras gráficas como processo gerador ou inspirador de eventos sonoros. Uma obra paradigmática neste tipo de estratégia de notação é, por certo, o 
MUSICA THEORICA Revista da Associação Brasileira de Teoria e Análise Musical 2019, v. 4, n. 1, p. 98-123 - Journal of the Brazilian Society for Music Theory and Analysis @ TeMA 2019 - ISSN 2525-5541

Concerto para piano (1966) de John Cage. Podemos ver na Figura 7 um excerto da parte de piano dessa obra. Outros dois conceitos de Cage, da fase do Concerto para piano, conforme Griffiths (1995, p.97), são também paradigmáticos para Durações: a não-sincronização do grupo de câmera e a participação do intérprete na composição.

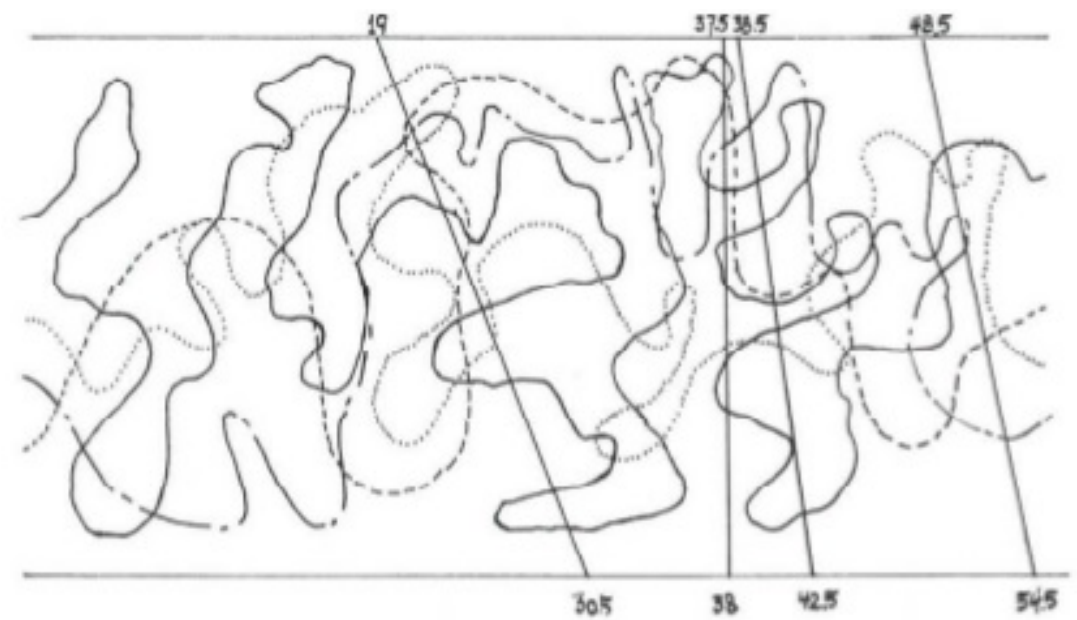

Figura 7: Fragmento de partitura do Concerto para piano de John Cage (Griffiths, 1995, p. 98)

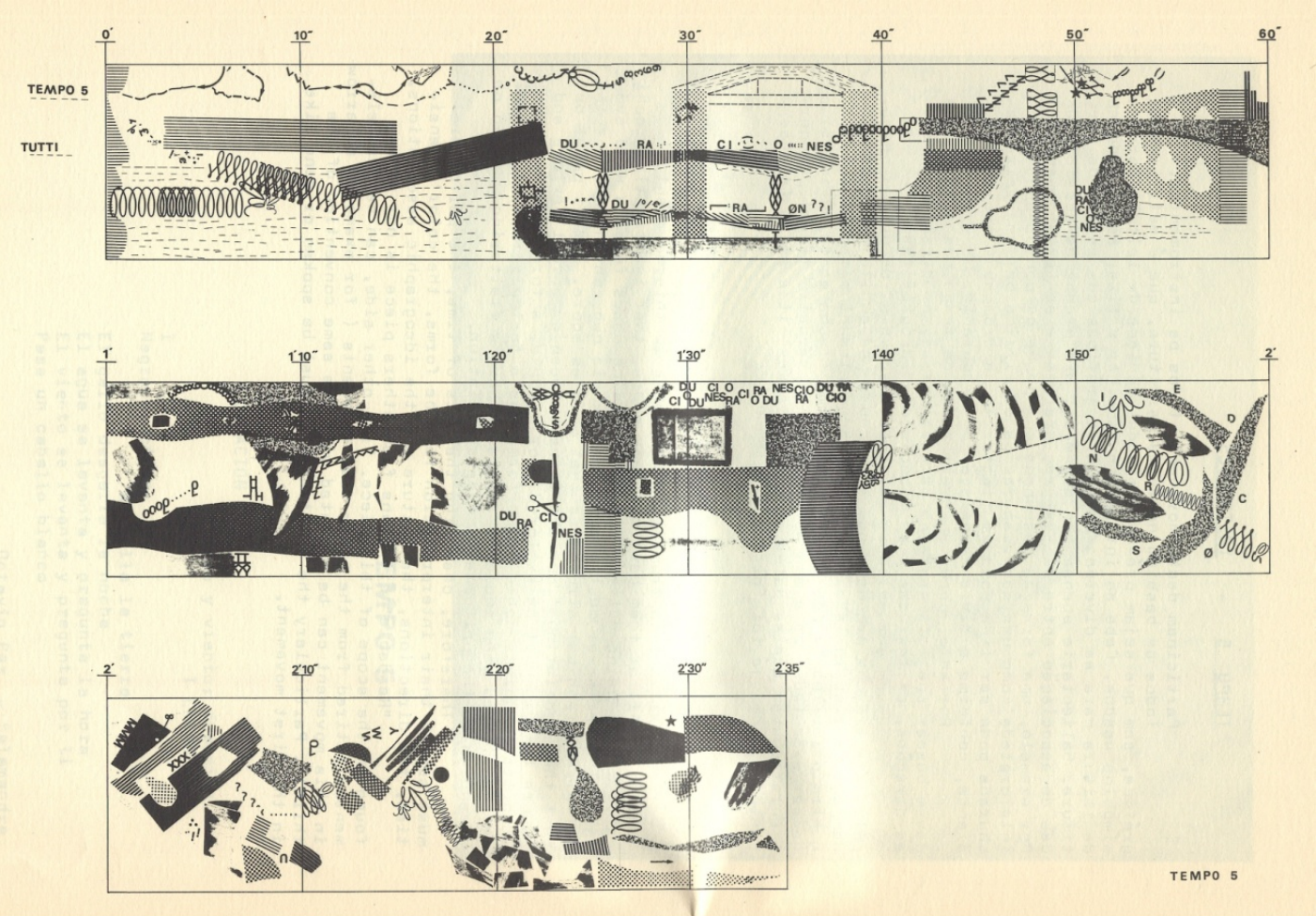

Exemplo 6: Durações, partitura gráfica do Tempo 5 (a mesma para todos os instrumentos) 
Conforme podemos ver no Exemplo 6, o último movimento de Durações utiliza uma partitura gráfica e partilha com o Concerto de Cage, composto duas décadas antes, um conceito similar de forma aberta. Utiliza, porém, uma escrita planimétrica que controla o fluxo temporal do discurso através da marcação cronométrica proposta pelos gráficos cartesianos de Koellreutter. Desde o curso de Darmstadt de 1959, as consequências da estética da "não-composição", materializada na adoção do acaso como processo de composição, haviam se espalhado pelo mundo e alcançado o Brasil através do Festival Música Nova de Santos. Portanto é previsível encontrar na obra de Coelho de Souza, envolvido no movimento do Festival desde o início da década de 1970, esse tipo de influência direta de Cage.

Se há semelhanças com a linguagem de Cage daquela época, há também diferenças, especialmente na questão do tempo. O compositor reconhece, em comentário sobre este último movimento, que a estratégia de composição é inspirada pela forma da cadenza clássica. E mais ainda, “o tempo é livre, mas só na aparência. Os signos [da partitura] são figuras cujo sentido não nos é revelado. As grades do tempo nos aprisionam. O tempo é um desastre que se abate sobre nós" (Coelho de Souza 1983, p. 82). De fato, a audição desse movimento da obra sugere que ele se enquadra na corrente da "arte-catástrofe" que frequentou as exposições da Bienal de Artes de São Paulo nesse período.

As duas páginas centrais da partitura de Durações, que podem ser vistas na Figura 8, trazem quatro diagramas que se referem aos quatro primeiros movimentos da obra. São desenhos que traduzem graficamente a parte eletrônica dessas seções. Uma nota manuscrita em letras reduzidas, no topo da página, esclarece que esses gráficos abstratos devem ser usados como um artifício gráfico para a memória e a preservação de informações, ou seja, "apenas como recurso auxiliar para os instrumentistas sincronizarem com a fita magnética". Por isso a página porta o título de "Memória Gráfica da Execução do Sintetizador Eletrônico". Desde então tem se tornado cada vez mais comum analistas e compositores usarem, em projetos de análise, sonorização e composição de música eletroacústica, esse tipo de transcrição gráfica livre. 


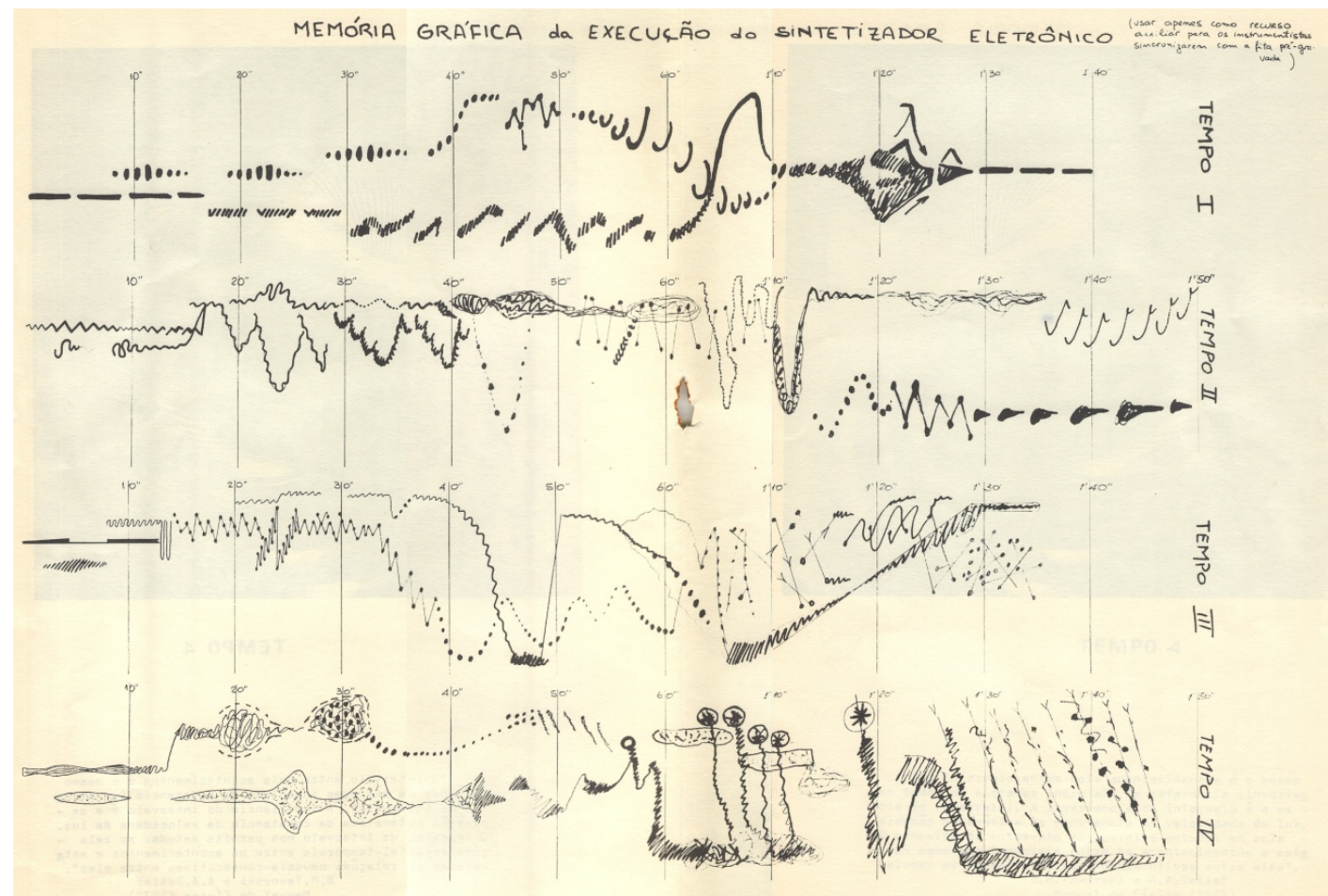

Figura 8: Páginas centrais da partitura de Durações

O uso de desenhos gráficos como recurso de apoio na interpretação continua, desde então, sendo utilizado em diferentes práticas da música contemporânea, seja na música eletroacústica para uma referência dos intérpretes como apoio de memorização da parte eletrônica, seja na improvisação livre como condutor de narrativa pré-estabelecida. Esse recurso não dá conta de auxiliar as sincronizações sonoras que muitas vezes são parte estrutural das obras, mas funciona como um impulso criativo para o músico intérprete. Em Durações o emprego dos desenhos enfatiza que nossa representação do tempo precisa ser convertida em representação espacial para que possa ser apreendida conceitualmente.

\section{Considerações Finais}

Atualmente, com os recursos tecnológicos em constante desenvolvimento, a pesquisa e o desenvolvimento dos programas de interação em tempo real fazem emergir uma polarização entre o que passou a ser chamado de tempo diferido em oposição ao tempo real, ou seja a prática da música eletroacústica passou a ter duas possibilidades de difusão: a interface do suporte fixo, chamado tempo 
diferido, e a resposta sonora digital em tempo real apoiada ou não por seguidor de partitura.

Com o estudo e a análise de Durações, evidenciamos a conceituação e desenvolvimento de um discurso musical profundamente ligado à pesquisa sobre o tempo, seja ele o tempo musical, as relações tempo-espaço, a aproximação dos conceitos a prática dos intérpretes com as diferentes propostas de notação e suas consequências para a performance, além de relação temporal entre os sons eletrônicos e a execução instrumental numa obra mista.

A conclusão é que esta relação não varia apenas em função das características de tempo diferido e de tempo real da trilha eletrônica, ou seja, se os sons eletrônicos estão registrados em meio fixo ou são gerados ao vivo, mas que essa relação é mediada visualmente pela partitura, na qual o tempo se converte em espaço. Ou seja, a representação visual, tanto da parte instrumental, como mesmo da eletrônica, é tão relevante para a interação entre instrumentos e eletrônica quanto a possível rigidez ou flexibilidade da geração dos sons eletrônicos. Essa é a principal experimentação que Durações levou a cabo, demonstrando como as diferentes possibilidades de notação da parte instrumental, com graus variáveis de controle dos eventos e da sincronização, afetam e fertilizam, de modos diferentes, o resultado inventivo da interpretação instrumental.

No entanto, a alternativa de executar a parte eletrônica de Durações em tempo real torna-se perfeitamente viável nos dias atuais com dois computadores laptop rodando programas como Max ou $\mathrm{Pd}$, com patches que emulem os diagramas de bloco projetados na partitura e dois músicos difundindo ao vivo as sucessivas modulações projetadas pela lista de operações sequenciais de cada canal, em cada movimento.

Obviamente seria possível programar os instantes em que essas operações devem ser realizadas, mas a releitura da obra com as possibilidades do uso de interface atuais poderia ser realizada com caráter improvisatório que corresponde à parte instrumental e se alinha aos conceitos explicitados sobre as questões do tempo que estão presentes nas epígrafes de cada movimento. Essa releitura da obra com recursos tecnológicos atualizados poderá promover outras camadas de percepção e discussão sobre o tempo na música, sobretudo no que diz respeito a relação dos intérpretes com a interface tecnológica. 
MUSICA THEORICA Revista da Associação Brasileira de Teoria e Análise Musical 2019, v. 4, n. 1, p. 98-123 - Journal of the Brazilian Society for Music Theory and Analysis@ TeMA 2019 - ISSN 2525-5541

\section{Referências}

1. Coelho de Souza, Rodolfo. 1983. Música (livro e fita magnética cassete). São Paulo: Novas Metas.

2. . 2014. Uma memória viva de Conrado Silva. Revista Vórtex, Curitiba, v. 2, n. 1, p. 1-3

3. Einstein, Albert e Infeld, Leopold. 1938/1972. A Evolução da Física. Rio de Janeiro: Zahar.

4. Ferneyhough, Brian. 1993. Form-Figure-Style: An Intermediate Assessment. Perspectives of New Music, v. 31, n. 1, p. 32-40.

5. Griffiths, Paul. 1995. Modern Music and After: Directions since 1945. Oxford: Oxford-Clarendon.

6. Mamedes, Clayton Rosa. 2010. Música eletroacústica no estado de São Paulo: segunda geração (anos 1981-2009). Dissertação de mestrado. IA/UNICAMP.

7. Mariz, Vasco. 2005. História da Música no Brasil. Rio de Janeiro: Nova Fronteira.

8. Maués, Igor Lintz. 1989. A Música Eletroacústica no Brasil: composição utilizando o meio eletrônico (1956-1981). Dissertação de Mestrado. Escola de Comunicações e Artes da Universidade de São Paulo. 1989.

9. Smalley, Denis. 1997. Spectromorphology: Explaining Sound-Shapes. Organised Sound, v. 2, n. 2, p. 107-126.

10. Paz, Octavio. 1962. Salamandra. México: Editorial Joaquín Mortiz.

11. Yavorski, B. M. e Detlaf, A. A. 1972. Manual de Física. Moscou: Editorial Mir. 


\title{
Espaço, materiais e forma no teatro musical pós-1960: composição e dramaturgia em obras de Mendes, Kagel e Aperghis $^{1}$
}

\author{
Space, materials, and form in the post-1960 music theater: composition and \\ dramaturgy in works by Mendes, Kagel e Aperghis
}

\author{
Heitor Martins Oliveira \\ Universidade Federal do Tocantins
}

\begin{abstract}
Resumo: O teatro musical pós-1960 integrou as investigações composicionais das vanguardas musicais. Procedeu a uma renovação de perspectivas que abarca sonoridades e técnicas desenvolvidas nos anos 1950 para expandi-las, na direção da exploração de elementos não-sonoros da performance musical. Ao colocar em jogo enção e organização de materiasi elementos de teatralidade, abriu-se a possibilidade de considerar a relação entre composição - invenção e organização de materiais sonoros - e dramaturgia, entendida de maneira ampla, como organização de eventos cênicos. Este ensaio discute três aspectos das abordagens composicionais no limiar música/gesto: a situação de performance musical como espaço cênico; a seleção, invenção e organização de materiais como jogo cênico; estrutura (divisibilidade em partes) e forma (conteúdos e suas continuidades) como encenação. A concretização desses aspectos em obras específicas dos três compositores - Mendes, Kagel e Aperghis - revela a aproximação entre composição e dramaturgia principalmente por meio da aplicação de critérios e procedimentos composicionais musicais aos materiais cênicos; e da construção e deslizamento de sentidos narrativos na performance musical.
\end{abstract}

Palavras-chave: Composição Musical; Teatro Musical; Dramaturgia

\begin{abstract}
The post-1960 music theater integrated the compositional investigations of the musical avant-gardes, proceeding to a renewal of perspectives that included sonorities and techniques developed in the 1950s to expand towards the exploration of non-sonic elements of musical performance. By putting elements of theatricality into play, composers made possible to consider the relationship between composition - invention and organization of sound materials - and dramaturgy, broadly understood as the organization of scenic events.

${ }^{1} \mathrm{O}$ ensaio apresenta material extraído da minha tese de doutorado "Música-como-teatro: uma prática composicional e sua autoanálise" (Oliveira, 2018), pesquisa realizada com apoio de bolsa Capes/Prodoutoral, no Programa de Pós-Graduação da Universidade Federal do Rio Grande do Sul, sob orientação do Prof. Dr. Celso Loureiro Chaves.
\end{abstract}


MUSICA THEORICA Revista da Associação Brasileira de Teoria e Análise Musical 2019, v. 4, n. 1, p. 124-159-Journal of the Brazilian Society for Music Theory and Analysis@ TeMA 2019 - ISSN 2525-5541

This essay discusses three aspects of the compositional approaches on the music/gesture threshold: the musical performance situation as a scenic space; the selection, invention and organization of materials as scenic play; structure (divisibility into parts) and form (contents and their continuities) as staging. The accomplishment of these aspects in specific works of composers - Mendes, Kagel and Aperghis - reveals the approximation between composition and dramaturgy mainly through an application of musical compositional criteria and procedures to scenic materials; and to the construction and sliding of narrative meanings in musical performance.

Keywords: Music Composition; Music Theater; Dramaturgy

\section{Introdução}

Na complexa teia de possibilidades exploradas por compositores desde a década de 1960, encontra-se uma série de interações música/gesto, cuja diversidade dificulta a formulação de uma definição simples ou mesmo a adoção de uma terminologia única. ${ }^{2}$ Trubert (2015) propõe uma efetiva delimitação geral do fenômeno, aberta quanto aos elementos estéticos colocados em jogo e pontual quanto ao contexto histórico:

A partir da segunda metade do século XX, o teatro musical (Musiktheater, em alemão) é um gênero que designa as obras de compositores da jovem geração do pós-guerra, que utilizam como material situações, eventos, elementos extramusicais - o corpo, o gesto, a voz, a cenografia, a iluminação - , concomitantemente ou não a um enredo ou a uma condução dramatúrgica, e no qual o aspecto visual e gestual torna-se um componente essencial ${ }^{3}$ (Trubert 2015, p. 1269; tradução nossa).

\footnotetext{
2 Além dos termos mencionados neste texto, encontram-se ainda, na literatura, termos como músicas de ação (Bosseur; Bosseur 1990), ópera contemporânea e novo teatro musical (Salzman; Dési 2008), música-teatro (Serale 2009), drama épico (Trubert 2015) e teatro musical experimental (Bithell 2016), cada qual justificado por um recorte ou desejo de especificidade e pertinente de alguma maneira à compreensão do campo. A expressão "teatro musical" traduz aqui as expressões correspondentes em inglês (music theater), francês (théâtre musical) e alemão (Musiktheater), que possuem um histórico documentado de aplicação ao repertório aqui abordado (Trubert 2015, p. 1270). Entretanto, em sentido mais geral, essas expressões são tomadas como referência abrangente a diversas vertentes cênico-musicais, incluindo ópera, comédia musical, teatro de revista. Seu uso, neste trabalho, refere-se exclusivamente ao sentido específico do repertório derivado das experimentações iniciadas por compositores da vanguarda nos anos 1960 e de seus desdobramentos nas décadas seguintes, até os dias atuais.

3 "A partir de la seconde moitié du XXe siècle, le théâtre musical (Musiktheater, en allemand) est un genre désignant les oeuvres des compositeurs de la jeune génération d'après-guerre, qui utilisent comme matériau des situations, des événements, des éléments extramusicaux - le corps,
} 
OLIVEIRA, H. M. Espaço, materiais e forma no teatro musical pós-1960: composição e dramaturgia em obras de Mendes, Kagel e Aperghis

A delimitação que o autor propõe refere-se à abordagem criativa e considera obras musicais nas quais aspectos gestuais e visuais revelam-se como inerentes ao pensamento composicional. A abordagem de Trubert tem como objetivo não somente delimitar esse teatro musical - ou mesmo o teatro instrumental ${ }^{4}$ - como gênero, mas compreender seu lugar e sua relevância para os desdobramentos das investigações composicionais da música nova europeia no período pós-1960: “Longe de ser o simples veículo de uma mensagem qualquer, é ao nível mais fundamental da organização da linguagem composicional, da forma e da irrupção do gesto que esse gênero procede da maneira mais radical a uma renovação de perspectivas" ${ }^{\prime 5}$ (Trubert 2015, p. 1294; tradução nossa).

A relação estabelecida entre material musical e material cênico, conforme salienta Trubert (2015), fornece um dos critérios mais relevantes para mapear o terreno do teatro musical pós-1960, permitindo distinguir formas convergentes, fragmentárias e divergentes. Em formas convergentes, há uma simetria estrutural entre as forças musicais e cênicas, que resulta em continuidade dramática e preserva as características essenciais da ópera, ainda que as sonoridades empregadas tenham afinidade com a música criada no período pósguerra. Nas formas fragmentárias, a condução dramatúrgica é implodida pelo contexto crítico, efeitos de distanciamento e teleologia narrativa de cunho épico. Nas formas divergentes, há uma polifonia informacional e os gestos ganham um caráter incidental, interveniente, relacionado à materialização de uma poética composicional (Trubert 2015, p. 1272).

A delimitação de Trubert (2015) destaca a integração da abordagem do material cênico ao trabalho composicional. Nesse contexto, compositores passam

le geste, la voix, la scénographie, la lumière -, concomitamment ou non à une intrigue ou à une conduite dramaturgique, et dont l'aspect visuel et gestuel devient une composante essentielle."

${ }^{4} \mathrm{Na}$ abordagem do autor, a designação teatro instrumental é reservada à obra de Mauricio Kagel (1931-2008). Cinco características ganham evidência e particularizam o teatro instrumental de Kagel: a teatralização da execução instrumental; o tratamento do lugar de execução como cena; o movimento como elemento fundamental do gênero; o músico como instrumento "ideal", por ser ele que realiza os movimentos; a assimilação da execução e dos movimentos à notação, levando em conta a função do público na recepção da peça para elaboração e realização da partitura (Trubert 2015, p. 1289).

5 "Loin d'être le simple véhicule d'un quelconque message, c'est au niveau le plus fondamental de l'organisation du langage compositionnel, de la forme et de l'irruption du geste que ce genre procède de la manière la plus radicale à un renouvellement des perspectives." 
MUSICA THEORICA Revista da Associação Brasileira de Teoria e Análise Musical 2019, v. 4, n. 1, p. 124-159-Journal of the Brazilian Society for Music Theory

a criar também com os aspectos gestuais e visuais da performance musical e com elementos de espetáculos cênicos, tais como figurinos, cenário e iluminação. Esse processo é distinto daquele empregado tradicionalmente na ópera, onde a encenação é construída em uma etapa criativa posterior à composição musical. Em decorrência dessa importante distinção, a dimensão teatral do teatro musical da segunda metade do século XX é constitutiva da abordagem composicional. ${ }^{6}$ Trata-se de composições musicais para serem assistidas tanto quanto ouvidas, instaurando processos cênicos peculiares, aqui analisados em diálogo com a categoria teatralidade, conforme discutido por teóricos das artes cênicas.

A teatralidade aparece como um processo ligado, antes de tudo, às condições de produção do teatro e não ao grau de semelhança ou desvio em relação ao real representado. Nesse sentido, é possível dizer que não há assuntos mais teatrais que outros, imitações mais teatrais que outras, e que a teatralidade tem a ver com o próprio processo de representação (Féral 2015, p. 97).

Do ponto de vista da recepção, uma vez colocada em jogo uma teatralidade, a apresentação (performance musical) passa a ter, quase inevitavelmente, uma dimensão de representação, de mimese, "ainda que fragmentária e intermitente, ainda que relativa ao espírito do espectador que não pode impedir-se de projetá-la, de criá-la" (Danan 2010, p. 119). O compositor depara-se com a dramaturgia, conforme ela passa a ser entendida na criação cênica a partir do século XX:

Estabelecer um dispositivo, um quadro, para que o jogo e o sentido aí se produzam, sob o risco (desejável) de transbordar do quadro. Seria, pois, a dramaturgia esse quadro (e não mais, como ocorreu por muito tempo, imposição, ou proposição de uma leitura)? Sim. Mas ela é também aquilo que ocorre no interior do quadro, o desenrolar do tempo que aí se inscreve, o jogo entre corpos, as palavras trocadas... a peça que se joga, tal como ela foi escrita e tal como é reinventada... (Danan 2010, p. 121).

Nesse sentido, as investigações criativas na interface música/gesto aproximam a composição musical da noção de dramaturgia, por meio da exploração do potencial de teatralidade da performance musical. As reflexões apresentadas neste ensaio buscam compreender como essa aproximação se

\footnotetext{
${ }^{6}$ Remeto também o leitor a dois artigos anteriores nos quais abordei relações entre composição musical e teatralidade (Oliveira 2015; Oliveira 2016).
} 
OLIVEIRA, H. M. Espaço, materiais e forma no teatro musical pós-1960: composição e dramaturgia em obras de Mendes, Kagel e Aperghis

concretiza nas concepções e no trabalho com os materiais musicais e os materiais cênicos.

A seguir apresento análises de aspectos de obras de compositores reconhecidos por sua atuação na fronteira música-teatro. O objetivo é discutir o pensamento composicional desses autores e sua realização em obras específicas, com foco nas questões referentes às possibilidades de representação e narrativa construídas cenicamente no contexto da performance musical. As fontes primárias da pesquisa são partituras e registros audiovisuais das obras, bem como depoimentos dos compositores.

\section{Situação de performance musical como espaço cênico: Santos Football Music (1969), de Gilberto Mendes}

Em Santos Football Music (1969), ${ }^{7}$ há uma teatralização da situação de performance orquestral, a partir da releitura que Gilberto Mendes (1922-2016) realiza de ações, relações e sonoridades implicadas em uma partida de futebol. A ressignificação da sala de concerto como espaço cênico e a inserção do público no roteiro de ações para concretização da performance são os principais interesses composicionais que situam essa peça específica no âmbito das relações entre composição e dramaturgia.

Do ponto de vista do enquadramento teórico, o espaço é uma das condições fundamentais da experiência teatral. Efetivamente, por si só, “a disposição 'teatral' do lugar cênico traz em si certa teatralidade" (Féral 2015, p. 84). A constituição cênica do espaço refere-se à disposição das pessoas e objetos e ao uso eventual de recursos complementares como iluminação e cenografia. $O$ trabalho espacial se desdobra em toda a transposição do texto (roteiro) para o teatral (cena). O sentido das ações apresentadas no decorrer do acontecimento teatral está emoldurado pelas relações estabelecidas e desenvolvidas entre os elementos dispostos no espaço cênico.

No campo da composição musical, as intervenções na disposição espacial promovem implicações sonoras e visuais que, em conjunto, potencializam a dimensão de teatralidade em performances musicais, inclusive na música orquestral. A expansão da área de performance para incluir palco e plateia é a

\footnotetext{
7 Partitura: Mendes (1979). Vídeo: Mendes (2005a), <https://youtu.be/V3bmKryl-cl $>$, acesso em maio de 2019.
} 
MUSICA THEORICA Revista da Associação Brasileira de Teoria e Análise Musical 2019, v. 4, n. 1, p. 124-159-Journal of the Brazilian Society for Music Theory and Analysis @ TeMA 2019 - ISSN 2525-5541

escolha fundante para a construção de uma teatralidade em Santos Football Music. Parto da leitura mais imediata - e coerente com o que se sabe da intenção expressiva e recepção inicial - de que a peça contém um episódio cênico, para uma leitura pessoal, contextualizada na temática selecionada para este texto, que considera a teatralidade como dimensão estética de toda a peça. Essa leitura remete primordialmente às escolhas composicionais de Gilberto Mendes para envolvimento do público.

\subsection{Teatro musical como dado característico da música de vanguarda}

O comentário de Mendes sobre Santos Football Music em seu livro memorial, enumera elementos e revela sua concepção sobre a relação entre música e teatro nesta peça:

Santos Football Music integra, numa só experiência, quase todos os dados mais característicos da música de vanguarda da segunda metade do século - entre os que lhe são mais caros - como o som concreto (em fitas magnéticas, as três locuções esportivas), o som orquestral atonal, sem melodias (um magma sonoro sempre em transformação, sempre diferente), a participação do público na execução da obra (um segundo regente indica por meio de cartazes o que deve ser feito por ele), o teatro musical (os músicos, no final, fazem o simulacro de um jogo de futebol) e um novo grafismo para a notação de toda essa trama contrapontual; à qual ainda se agrega uma charanga no meio do público, que toca ritmos de escola de samba, à maneira do que se ouve num estádio (Mendes 1994, p. 126).

O elemento teatro musical é definido a partir de ações não vinculadas a qualquer dos dispositivos de produção sonora empregados na peça e caracterizado como simulacro. Um pensamento composicional polifônico organiza os diversos elementos, construindo o resultado estético a partir da interrelação de camadas independentes.

O posicionamento de Mendes, sintetizado numa lista de dados característicos da música de vanguarda e na explicitação de uma concepção criativa que aplica métodos de composição e notação desenvolvidos a partir do campo musical a diversos materiais, converge com as conclusões de Trubert (2015) e Rebstock (2012) $)^{8}$ sobre os avanços de compositores da música de concerto

\footnotetext{
8 Proponente da noção de Teatro Composto que abarca diversas abordagens criativas nas quais os criadores expandem o alcance das estratégias composicionais musicais para os elementos teatrais.
} 
OLIVEIRA, H. M. Espaço, materiais e forma no teatro musical pós-1960: composição e dramaturgia em obras de Mendes, Kagel e Aperghis

do século XX na direção da teatralidade. Note-se que, de acordo com as afirmativas de Mendes, esse desenvolvimento paralelo se deu de maneira independente. O compositor afirma desconhecer boa parte da obra de John Cage e Mauricio Kagel (Mendes 1994, p. 109-110) e contextualiza seu teatro musical no diálogo com a poesia concreta e com os demais compositores do Grupo Música Nova (Mendes 1994, p. 72-76; e p. 133).

A maneira como o compositor rememora o desenvolvimento de sua linguagem composicional, alinhando-se ao que denomina música nova a partir da década de 1960, deixa transparecer o impulso de assumir a multisensorialidade da performance musical como elemento relevante dessa tomada de posição estética.

Por um lado, mesmo em peças como Motet em Ré Menor - Beba Coca-Cola (1966), ${ }^{9}$ não classificadas como teatro musical, gestos e imagens integram o espectro dos materiais composicionais, seja pelas implicações visuais das escolhas de fontes sonoras, pela gestualidade das vocalizações resultantes da dessemantização dos textos ou pela indicação deliberada de gestos ou elementos visuais, como a exibição de cartazes. Por outro lado, o compositor considera Santos Football Music como passo fundamental de sua afirmação composicional:

Foi um trabalho altamente experimental, equivalente ao que realizei quando compus nascemorre. ${ }^{10}$ As duas obras são os momentos máximos de meu radicalismo composicional, ao mesmo tempo que os pontos inicial e final, entre 1962 e 1969, do processo de desenvolvimento de uma linguagem musical, a minha linguagem musical, com pretensões de ser inteiramente nova, em termos brasileiros. A minha última invenção mais radical (Mendes 1994, p. 126).

A mútua relevância de elementos gestuais e visuais em diversas peças e da exploração do teatro musical para consolidação de uma linguagem pessoal perpassam o pensamento composicional de Gilberto Mendes. Esse é o sentido em que melhor se compreende a concepção do compositor do teatro musical como dado característico e integrante da (sua) música de vanguarda.

Em Santos Football Music, está presente o recurso composicional da indeterminação, que Mendes também utiliza em outras obras relacionadas à sua exploração do teatro musical. A notação indeterminada proporciona a

\footnotetext{
${ }^{9}$ Vídeo: Mendes (2005b), <https://youtu.be/6DKRtGjIaD4>, acesso em maio de 2019.

10 Obra de 1962-1963 para coro, duas máquinas de escrever e fita magnética.
} 
MUSICA THEORICA Revista da Associação Brasileira de Teoria e Análise Musical 2019, v. 4, n. 1, p. 124-159-Journal of the Brazilian Society for Music Theory and Analysis @ TeMA 2019 - ISSN 2525-5541

delimitação de qualidades de ação gestual/sonora que preenchem durações específicas, como por exemplo, improvisos com sons sustentados (trompas) sobrepostos a vários sons curtos sucessivos (trombones e flautas) por cerca de 16 segundos (Ex. 1). As combinações contrapontísticas e formais desses elementos, emolduradas pela referencialidade das difusões sonoras e das vocalizações de músicos da orquestra (Ex. 2), do público e, ao final, pelo episódio cênico, proporcionam a sustentação temporal e articulação estrutural da peça.

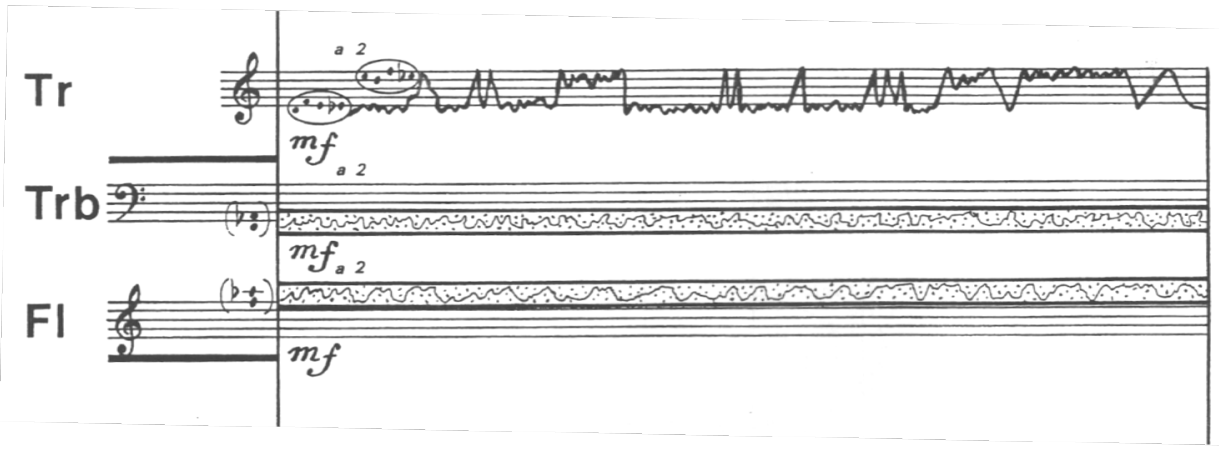

Exemplo 1: partes de trompas, trombones e flautas na página 10 de Santos Football Music, de Mendes

A inserção de gestos, ações e elementos visuais não vinculados diretamente à execução musical, porém integrados à situação de performance, constituem o teatro musical como dado característico e integrante da música de vanguarda, na concepção de Mendes. Este dado é posto em relação com as intenções expressivas, bem como com os recursos e procedimentos de elaboração e organização de materiais explorados pelo compositor, resultando nas possibilidades concretizadas em diversas de suas obras.
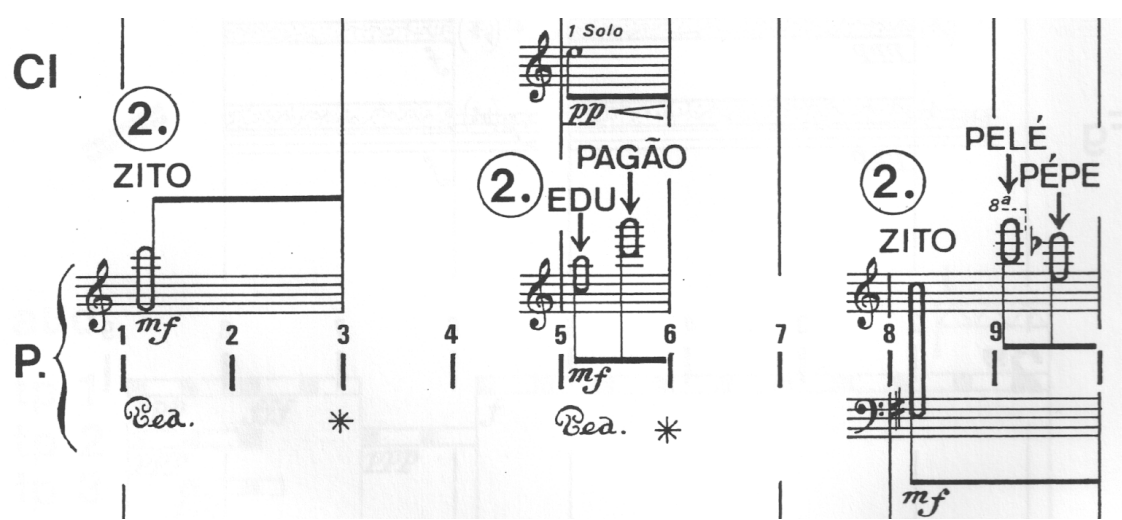

Exemplo 2: detalhe da página 24 da partitura de Santos Football Music, de Mendes, mostrando as indicações para vocalizações a serem realizadas por músicos da orquestra citando nomes de jogadores de futebol 
OLIVEIRA, H. M. Espaço, materiais e forma no teatro musical pós-1960: composição e dramaturgia em obras de Mendes, Kagel e Aperghis

\subsection{Envolvimento do público}

A concepção de teatro musical como dado integrante, camada independente na trama audiovisual da peça, é também evidenciada pela alternativa, sugerida por Mendes nas instruções da partitura, para realização de uma versão de concerto de Santos Football Music:

Uma VERSÃO DE CONCERTO é possível, para esta música, sem a participação do público ouvinte e sem os acontecimentos teatrais. Um coro mixto executa a parte da audiência, sobre o palco. "Tapes" e charanga também sobre o palco. Nesta versão, o regente pode interromper a música em qualquer ponto da página 34, depois de sua metade; e imediatamente retomar a música da última linha da página 35 (7 compassos de pausa e "piano/violino/trombone" em seguida), prolongando a execução do trio final durante o tempo que considerar necessário (Mendes 1979, p. vi).

A versão de concerto é obtida pela remoção dos "acontecimentos teatrais", da participação do público e do uso do espaço da plateia pela "charanga". A "música" permanece viável a partir dos devidos cortes e deslocamento da parte da audiência, "tapes" e charanga para o palco. Ao examinar essas instruções, verifica-se que a participação do público se localiza de fato na intersecção entre duas camadas composicionais. No âmbito sonoro, está vinculada à exploração do som concreto: “O público participa gerando uma espécie de som concreto, ruidoso, ao vivo, pela execução das instruções dos cartazes mostrados por um segundo regente [...]" (Mendes 1994, p. 132). Assim, sob o aspecto sonoro, a participação do público precisa ser substituída por um coro sobre o palco. No âmbito teatral, implica na expansão do espaço de performance e na criação de uma moldura de sentido para ressignificação de toda a situação de performance como representação da partida de futebol. Sob esse aspecto, para que se obtenha a versão de concerto é feita a contenção da expansão do espaço de performance, retida no espaço do palco.

$\mathrm{Na}$ versão de concerto, fica preservado o ímpeto composicional que dá origem à peça e define a intenção expressiva. $\mathrm{O}$ compositor fora estimulado pelo então jornalista Enio Squeff a compor algo relacionado à temática do futebol. Apesar do desinteresse pelo esporte em si, a escuta da transmissão radiofônica de uma partida, principalmente as sonoridades geradas no trabalho vocal de um locutor esportivo, instiga Mendes a iniciar a composição da peça: "Imaginei três irradiações simultâneas, como três instrumentos de um mesmo naipe, na orquestra, soando ora dois, ora um, três, nenhum. Um contraponto a três partes" 
MUSICA THEORICA Revista da Associação Brasileira de Teoria e Análise Musical 2019, v. 4, n. 1, p. 124-159-Journal of the Brazilian Society for Music Theory and Analysis@ TeMA 2019 - ISSN 2525-5541

(Mendes 1994, p. 126). Mendes recompõe sonoridades geradas a partir do contexto da partida de futebol - tanto as do próprio estádio, quanto das transmissões radiofônicas do evento -, organizando-as a partir de recursos composicionais e integrando-as a sonoridades instrumentais da orquestra. Está aí sintetizada a proposta musical que dá sustentação à versão de concerto.

A versão integral, por sua vez, acrescenta a dimensão de teatralidade a partir de um trabalho sobre os sentidos da disposição espacial dos envolvidos na performance. Na sala de concerto, a relação palco-plateia implica na separação entre o espaço de performance e o espaço de fruição. Traz consigo uma série de convenções sobre o tipo de atitude de atenção passiva a ser adotada pelo público, vedado de interferir na performance ou mesmo perturbá-la com sons ou ações espontâneas. No estádio, a relação campo-arquibancada envolve a expectativa de interação e, como nos clichês dos comentários esportivos, a torcida faz parte do espetáculo. Produz ruídos e reage, em tempo real, ao que acontece dentro do campo.

O envolvimento do público na performance, desde o espaço físico da plateia, subverte o sentido da relação de frontalidade na performance musical em salas de concerto. A experiência de teatralidade construída em Santos Football Music consiste em ver de dentro, como se estivesse vendo de fora, uma dimensão teatral da performance que representa a relação palco-plateia como campoarquibancada. Note-se que, com os modos de interação previamente roteirizados e ensaiados, trata-se mesmo de representação e não de transposição de convenções de uma a outra situação. A plateia do concerto não ganha a liberdade de ação que possui a torcida.

Duas outras escolhas composicionais estão relacionadas a essa representação. Primeira, o posicionamento da "charanga" também na plateia, complementando a ressignificação desse espaço como arquibancada. Segunda, a inserção do público no modo de envolvimento na performance ao qual também estão submetidos os músicos, por meio da leitura de uma notação indeterminada. 
OLIVEIRA, H. M. Espaço, materiais e forma no teatro musical pós-1960: composição e dramaturgia em obras de Mendes, Kagel e Aperghis
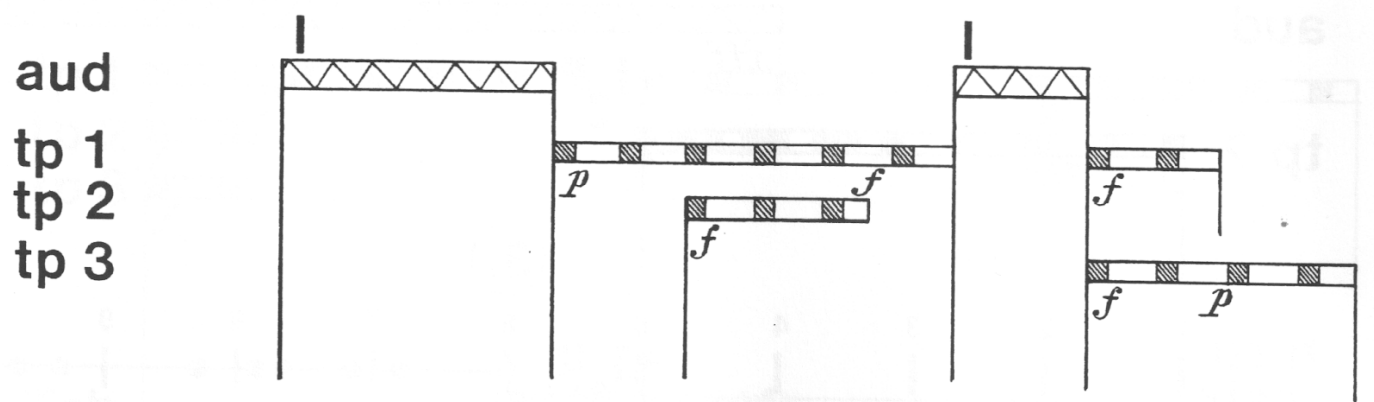

Exemplo 3: reprodução parcial da página 22 da partitura de Santos Football Music, de Mendes, mostrando a notação das intervenções sonoras do público e sua relação com a difusão sonora das fitas magnéticas

A notação usada para orientar o público é constituída de cartazes identificados com as letras A a I, contendo instruções sintéticas para ações sonoras: cantar motivos musicais com a palavra Santos, cantar vogais, falar lentamente em voz baixa, protestar em voz alta, falar "mais um" em voz alta, sustentar som sibilante, sustentar som nasal, gritar a palavra gol e fazer ruídos diversos. Ao longo da partitura, as intervenções do público são indicadas por meio das letras, com a duração de cada ação sonora sendo indicada graficamente, a partir do alinhamento vertical com as demais partes (Ex. 3). De acordo com as instruções para performance presentes na partitura, “O PÚBLICO PARTICIPA SEMPRE INDEPENDENTEMENTE DO TEMPO ORQUESTRAL, EM SEU PRÓPRIO TEMPO”' (Mendes 1979, p. II, caixa alta no original). Ou seja, há uma simultaneidade de camadas sonoras, sem necessidade de sincronia métrica.

Entretanto, o envolvimento do público tem implicações ainda mais abrangentes para a concepção da peça. A descrição do compositor é a seguinte:

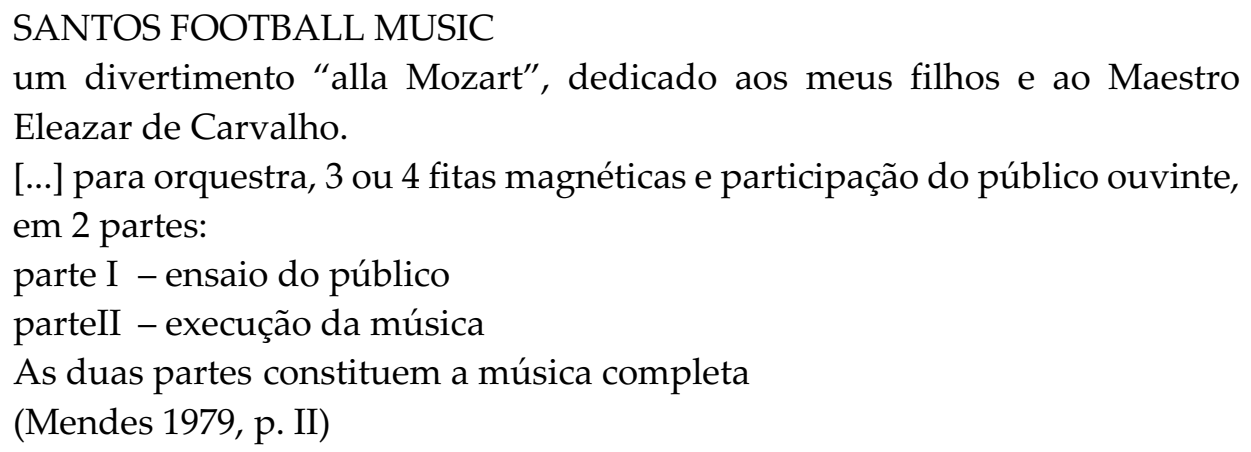

A necessidade de preparação prévia com o público é assimilada à estrutura da peça. O compositor interfere na relação a ser estabelecida com o público, subvertendo seu papel passivo na recepção de um concerto. Assim, o debate aqui proposto sobre a questão da teatralidade se relaciona a essa questão 
MUSICA THEORICA Revista da Associação Brasileira de Teoria e Análise Musical 2019, v. 4, n. 1, p. 124-159-Journal of the Brazilian Society for Music Theory and Analysis@ TeMA 2019 - ISSN 2525-5541

ainda mais ampla, de incorporação do tempo de preparação ao tempo da experiência artística completa que o compositor pretende promover. O público assume uma corresponsabilidade com a execução, tendo toda a sua experiência de recepção mediada por um conhecimento parcial do que irá transcorrer e por uma atitude de atenção distinta da mera escuta passiva. O que destaco na abordagem de Mendes é justamente a operação de trazer essas relações para o âmbito das escolhas composicionais.

\section{Seleção e organização de materiais como jogo cênico: MM51 (1976), de Mauricio Kagel}

MM51 (1976) ${ }^{11}$ é uma peça de Kagel para pianista com uso do metrônomo como objeto sônico-cênico. A presença visual e sonora do metrônomo de pêndulo remete o público ao artesanato profissional do músico e estabelece um jogo de ações e potenciais significações no âmbito da relação entre expressão sonora e passagem do tempo.

O subtítulo de MM51, "Ein Stück Filmmusik für Klavier" define a obra como uma peça de música de filme para piano. Kagel dirigiu uma realização audiovisual da peça em $1983,{ }^{12}$ que inclui a projeção de uma colagem de cenas do filme mudo Nosferatu (1922), de F.W. Murnau (1888-1931). Entretanto, o subtítulo remete ao fato ainda mais fundamental de o material musical apresentado ao ouvinte ser baseado em clichês de música descritiva: “Já com os primeiros acordes da peça, o ouvinte pode reconhecer aquele repertório de anedotas acústicas prontamente dissociáveis da ilustração de imagens em movimento"13 (Kagel 1977, "Introduction", \#1; tradução nossa). Assim, a situação musical teatral é a de um pianista tocando música relacionada a imagens em movimento, como ocorria em salas de exibição na era do cinema mudo, situação que o compositor espera que o público reconheça, com auxílio do subtítulo e devido às sonoridades, mesmo sem a projeção de imagens. Aliás, embora tenha sido

\footnotetext{
11 Partitura: Kagel (1977). Vídeo: Kagel (2017), versão em sala de concerto, $<$ https://youtu.be/usdBER8zUZU>, acesso em maio de 2019.

12 Vídeo: Kagel (1983), versão televisiva, $<$ https://youtu.be/Gu-fLh2sGT0>, acesso em maio de 2019.

13 "Already with the first chords of the piece, the listener may recognize that repertoire of acoustic anecdotes readily dissociable from the illustration of moving pictures".
} 
OLIVEIRA, H. M. Espaço, materiais e forma no teatro musical pós-1960: composição e dramaturgia em obras de Mendes, Kagel e Aperghis

utilizada para a versão audiovisual televisiva de 1983, a proposta da projeção de imagens não consta na partitura publicada em 1977.

No geral, a relação que Kagel estabelece entre música e teatro é enquadrada pela perspectiva composicional. Para ele,

torna-se normal utilizar uma maneira musical de pensar no teatro. A fala, a iluminação e o movimento se articulam como os sons, os timbres e os andamentos; o evento cênico não pode fazer sentido sem a musicalidade, porque a criação do homem de teatro inspira-se mais por verdadeiros métodos de composição musical que por todos os outros (e essa é uma das razões para eu abrir pouco a pouco meu ofício musical ao ofício teatral) (Kagel apud Bousseur 1971, p. 111-112; tradução nossa). ${ }^{14}$

Levando à frente avanços que, desde o início do século $\mathrm{XX}$, propuseram o tratamento de elementos cênicos por meio de critérios musicais, Kagel expande o alcance de seu trabalho composicional. Ao mesmo tempo, as premissas e possibilidades estéticas desse trabalho composicional são transformadas pela materialidade cênica. A situação musical teatral que está na base da criação de cada uma de suas peças coloca em movimento a formulação de critérios e ferramentas para seleção e organização de materiais sonoros e cênicos, estratégias de notação e, muitas vezes, como no caso de MM51, a coleção ou construção de objetos necessários para concretização da performance.

Pensar, de maneira musical, a ressignificação do músico como ator, o jogo a ser estabelecido no espaço cênico, incluindo materiais concretos para sua realização, e a formulação de escrituras cênicas para integrar o roteiro da performance à partitura são aspectos inferidos das abordagens de Kagel que se tornam fundamentais para compreensão da invenção de relações entre música e cena no teatro musical pós-1960.

\subsection{Colagem de fórmulas musicais e gestos estereotipados}

A situação musical/teatral que Kagel explora em MM51 remete a uma prática profissional em que pianistas executavam acompanhamento musical para projeções de filmes mudos, nos primórdios da história do cinema, nas primeiras

14 ... il devient normal d'utiliser une manière de penser musicale au théâtre. La parole, la lumière et le mouvement s'articulent comme des sons, des timbres et des tempi; l'événement scénique ne peut prendre tout son sens sans la musicalité, car la création de l'homme de théâtre s'inspire plus des véritables méthodes de composition musicale que de toutes autres (et c'est une des raisons pour moi d'ouvrir peu à peu mon métier musical au métier théâtral)." 
MUSICA THEORICA Revista da Associação Brasileira de Teoria e Análise Musical 2019, v. 4, n. 1, p. 124-159-Journal of the Brazilian Society for Music Theory

décadas do século XX. De acordo com Carrasco (2015, p. 38-44), historicamente, o acompanhamento musical de filmes, antes que surgisse a possibilidade técnica das trilhas sonoras propriamente ditas, passa por pelo menos três fases distintas. $\mathrm{Na}$ primeira fase, eram feitas seleções musicais do repertório tradicional e a execução tinha pouca ou nenhuma preocupação de sincronia com os eventos apresentados na tela. Na segunda fase, editoras passam a publicar coletâneas de peças características, música descritiva classificada em categorias abrangentes como mistério, aventura, romance, terror. Os realizadores de acompanhamentos musicais nas salas de execução tendiam cada vez mais a cortar os trechos musicais para se adequar aos eventos apresentados na tela. Por fim, na terceira fase, os filmes passam a ser distribuídos com uma planilha de seu acompanhamento musical e, em alguns casos, com as primeiras partituras originalmente compostas para filmes específicos.

Esse contexto contribui para a compreensão da intenção expressiva que motiva Kagel e que ele apresenta na introdução da partitura:

Assim como em "Acompanhamento a uma cena cinematográfica" de Schoenberg, o tema desta peça para piano é a ameaça de medos e perigos não verbalizados. Mas, em contraste com a composição orquestral de Schoenberg, que está escrita na linguagem musical autônoma do expressionismo, a presente peça usa apenas fórmulas estereotipadas, tiradas do tipo de música comercial familiar a todos os espectadores. Ao rejeitar deliberadamente um estilo "contemporâneo" atual, tentei um ponto de partida diferente para um problema que permite soluções e realizações contrastantes (Kagel 1977, “Introduction”, \#1; tradução nossa). ${ }^{15}$

Ao dialogar com a referência da peça de Schoenberg, Kagel destaca uma similaridade de ímpeto composicional e diferencia os meios de realização. Em sua abordagem, o material é constituído de fórmulas estereotipadas, dissociadas de sua função descritiva e reorganizadas em um arco formal inerente ao próprio percurso sonoro da peça. Trata-se de uma colagem de segmentos sucessivos de 4 a 16 compassos, nas quais uma determinada característica rítmica, textural e

15 "Rather as in Schoenberg's 'Accompaniment to a cinematographic scene', the theme of this piano piece is the threat of unspoken fears and dangers. But in contrast to Schoenberg's orchestral composition, which is written in the autonomous musical language of expressionism, the present piece uses only stereotyped formulae, drawn from the kind of commercial music familiar to every viewer. By deliberately rejecting a current "contemporary" style, I tried a different starting point for a problem that allows for contrasting solutions and realisations." 
OLIVEIRA, H. M. Espaço, materiais e forma no teatro musical pós-1960: composição e dramaturgia em obras de Mendes, Kagel e Aperghis

expressiva é sustentada. O segmento musical reproduzido no Exemplo 4 (a seguir), é preenchido pelo movimento rítmico em tercinas e concluído com uma pontuação no registro grave.

Em termos estruturais, a peça está organizada em três momentos distintos. No primeiro, mais longo (c. 1-91), a sucessão de segmentos musicais descortina nuances de um caráter relativamente uniforme de suspense. Num segundo momento (c. 92-136), mudanças mais pronunciadas e constantes em articulação, densidade rítmica, andamento e métrica tendem a uma maior agitação, estabelecendo caráter ameaçador. Por fim (c. 137-150), o caráter inicial é brevemente restabelecido, permanecendo, como que suspensos no ar, os medos não-verbalizados que impregnam o caráter expressivo da peça.

Na versão em sala de concerto (Kagel 2017), o jogo cênico envolvendo o pianista e o mecanismo do metrônomo (mais sobre esse aspecto abaixo, 2.2) é sobreposto à camada de sentido do percurso formal musical. A disposição do espaço sugere uma dimensão de teatralidade desde o início da performance. A ressignificação do pianista como ator se intensifica a partir da inserção de vocalizações de riso "perverso e malicioso" (Kagel 1977, p. 14-17, c. 120-136) e culmina com o gesto final da peça (p. 15, c. 149), um suspiro em que o pianista deve também levar uma das mãos ao peito. O princípio composicional de colagem, utilizado na construção da forma musical a partir de fórmulas estereotipadas de música descritiva de filmes de terror, é também aplicado à seleção e organização de ações não vinculadas à execução instrumental, procedendo a uma colagem de gestos estereotipados de vilania e medo. 

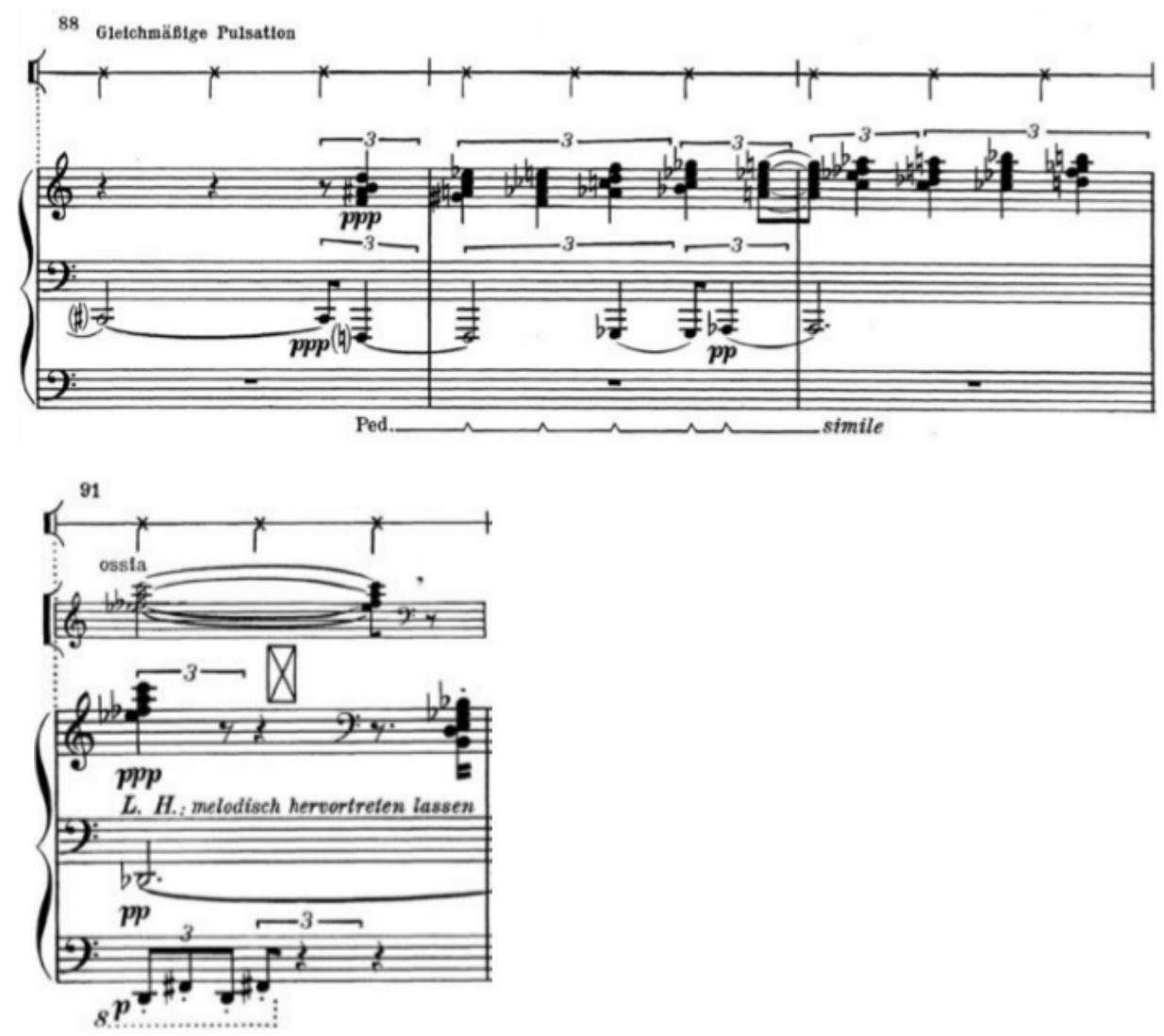

Exemplo 4: uma seção curta (c. 88-91) de MM51, de Kagel

Na versão televisiva (Kagel 1983), a sobreposição da projeção de uma colagem com cenas do filme Nosferatu não restitui as fórmulas musicais estereotipadas à sua função descritiva. A projeção adiciona uma camada de sentido à performance e possibilita que o espectador construa relações entre as camadas musical, gestual e imagética. O Exemplo 5 apresenta um trecho da partitura ao lado da imagem que, na versão televisiva é apresentada junto ao ataque do acorde do compasso 50. Nos momentos que precedem esse quadro, à medida que o material musical se direciona para o ponto de chegada da pequena seção musical, vemos uma figura aterrorizante se esgueirando pela portinhola até apoiar sua mão e voltar o olhar na direção de algo ou alguém fora do enquadramento. 
OLIVEIRA, H. M. Espaço, materiais e forma no teatro musical pós-1960: composição e dramaturgia em obras de Mendes, Kagel e Aperghis
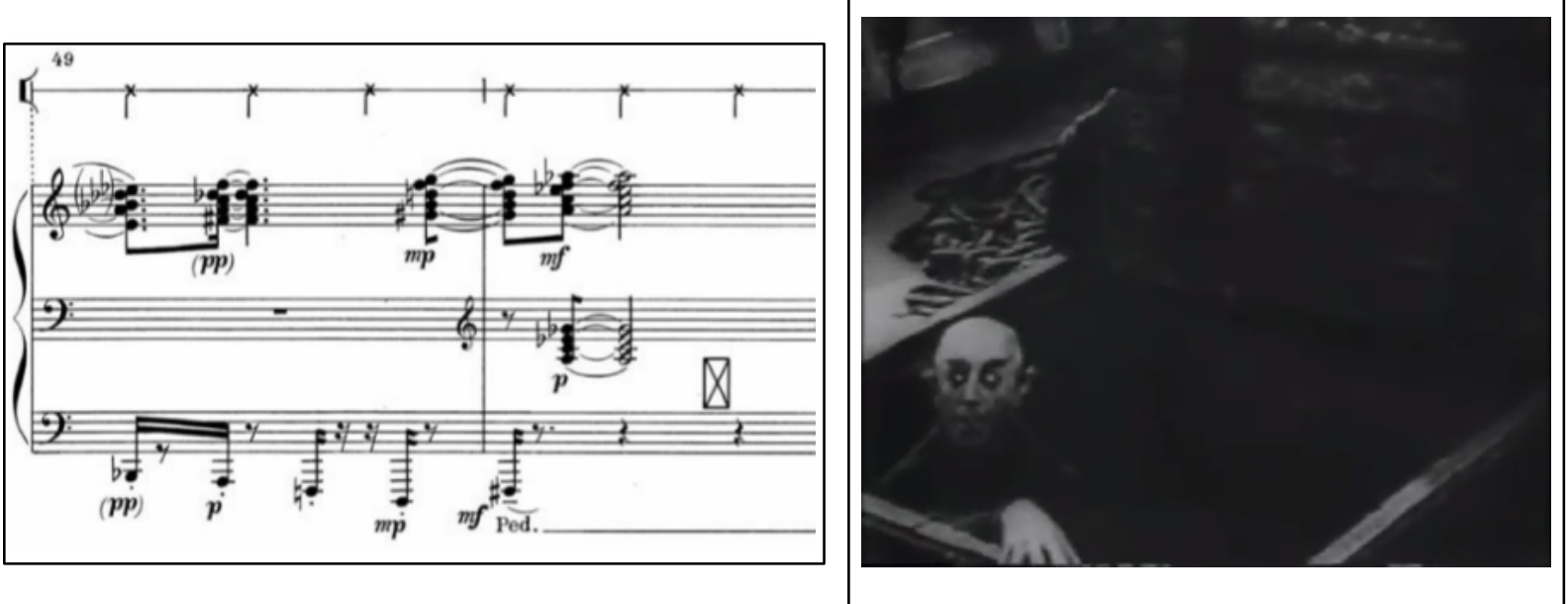

Exemplo 5: fragmento de MM51 (c. 49-50), de Kagel, à esquerda, e a imagem sincronizada com o acorde atacado com ambas as mãos (c. 50), à direita

Neste exemplo, está em jogo o que Chion (2011) designou como ilusão audiovisual. A apresentação simultânea de imagens e sons, inclusive música, tende a gerar um valor expressivo acrescentado, especialmente em situações como a descrita, em que imagem e som convergem para um ponto de sincronia, um momento inevitavelmente saliente na cadeia audiovisual (Chion 2011, p. 51). O espectador busca essas relações, independente de terem sido planejadas. Em MM51, as camadas são compostas como colagens, cada uma com sua lógica interna independente. Quando sobrepostas, ora marcham paralelamente, ora parecem convergir rítmica ou expressivamente.
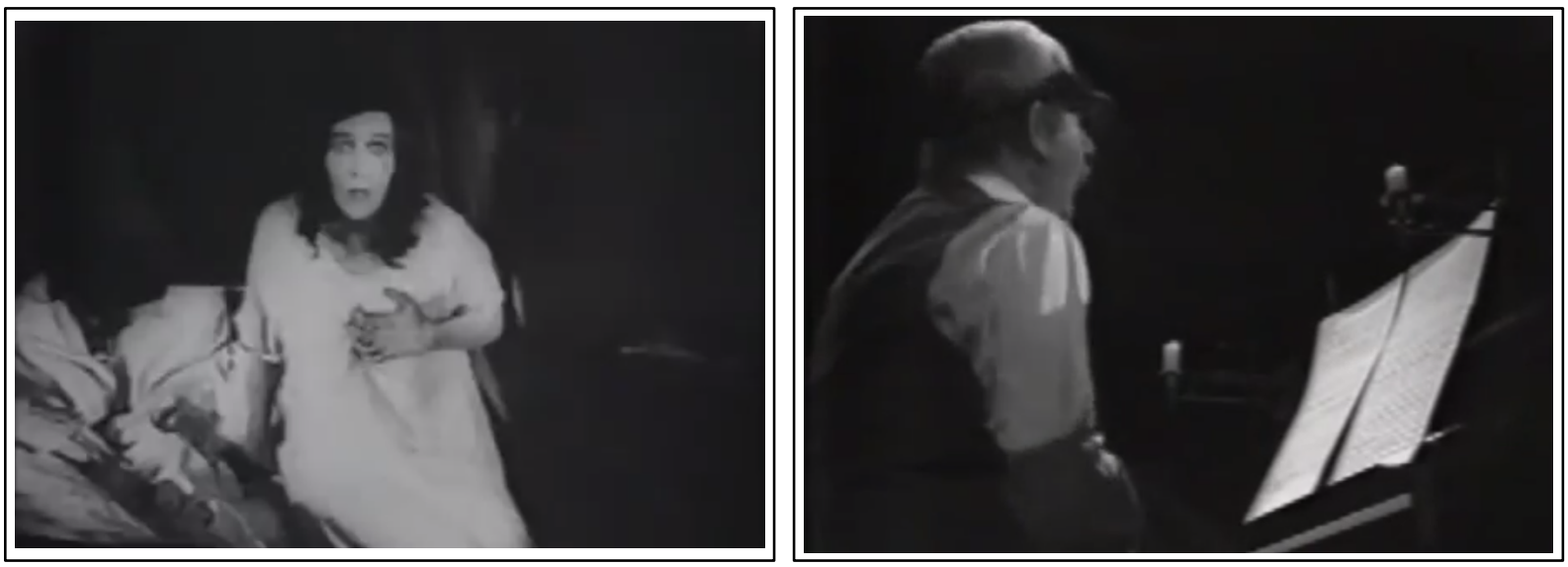

Figura 1: a figura feminina aterrorizada, da colagem de cenas de Nosferatu, e o gesto final do pianista em performance de MM51

O mesmo ocorre entre a projeção e os gestos que resignificam o músico como ator. Nessa relação, emergem paralelos, como a similaridade entre o gesto 
MUSICA THEORICA Revista da Associação Brasileira de Teoria e Análise Musical 2019, v. 4, n. 1, p. 124-159-Journal of the Brazilian Society for Music Theory and Analysis @ TeMA 2019 - ISSN 2525-5541

final do susto do pianista e a postura de uma figura feminina aterrorizada que aparece anteriormente na projeção (Fig. 1).

O material musical, os gestos e a projeção são selecionados a partir da situação musical/teatral do pianista de cinema mudo, e organizados por meio de um método composicional comum, a colagem. Paralelamente, o mecanismo do metrônomo cria mais uma camada cênica, com implicações sonoras e visuais, que alimenta a possibilidade de construção de sentidos ficcionais na recepção da performance.

\subsection{O metrônomo e o jogo sônico-cênico}

O metrônomo, regulado para o andamento de 51 batidas por minuto, e o mecanismo com o qual ele é manipulado geram um jogo sônico-cênico que não se submete de maneira óbvia à apreensão da situação musical/teatral que enquadra os sentidos de MM51: nas salas de projeção em que pianistas executavam acompanhamento musical de filmes mudos não havia metrônomos. A inserção desse elemento gera uma camada de sentido que, como as demais, segue independente, ao mesmo tempo que interage com aspectos sonoros, gestuais e visuais da performance.

Kagel dá mais de uma opção de montagem do metrônomo. A que é utilizada nas versões aqui referenciadas (Kagel 2017; Kagel 1983) preconiza que:

O metrônomo é [...]

a) montado em um hemisfério, a alguma distância do pianista (pelo menos 2 metros); um pedal operado pelo pé esquerdo leva a hemisfera a uma posição inclinada.

O metrônomo é preso à superfície plana com um imã. Esta construção é montada atrás do pianista (Kagel, 1977, “Introduction", \#3; tradução nossa). ${ }^{16}$

Assim, o mecanismo é integrado à performance do pianista que, de acordo com as instruções ao longo da partitura, deve acionar o pedal que causa a inclinação da plataforma sobre a qual o metrônomo está montado. A natureza do mecanismo é tal que a inclinação da plataforma pode levar o metrônomo a

\footnotetext{
16 "The metronome is $[\ldots]$
}

a) mounted on a hemisphere, at some distance from the pianist (at least 2 meters); a pedal operated by the left foot brings the hemi-sphere into an inclined position.

The metronome is fastened to the flat surface with a magnet. This construction is set up behind the pianist." 
OLIVEIRA, H. M. Espaço, materiais e forma no teatro musical pós-1960: composição e dramaturgia em obras de Mendes, Kagel e Aperghis

produzir pulso irregular ou interromper o pulso. Assim, no compasso 71, por exemplo, encontra-se a indicação: “O metrônomo é virado lentamente para uma posição oblíqua. (Há uma pulsação cada vez mais desigual)" (Kagel 1977, p. 8; tradução nossa). ${ }^{17} \mathrm{E}$, no compasso 84: "gradualmente restabelecer a posição normal" (Kagel 1977, p. 10; tradução nossa). ${ }^{18}$

A inserção do som do pulso gerado pelo metrônomo, que Kagel faz questão de agregar à notação da peça (ver Ex. 6, a seguir), possui uma relevante implicação para o resultado sonoro da escritura rítmica. Devido ao andamento lento, na ausência dos pulsos metronômicos, a sucessão de ataques poderia ser percebida como ritmo não métrico, uma vez que o pulso e seu agrupamento métrico não são enfatizados na escritura rítmica para o piano. Com o uso do metrônomo, nos trechos em que seu funcionamento regular é mantido, a performance e a escuta têm como um de seus focos os efeitos de deslocamento dos ataques em relação ao pulso.

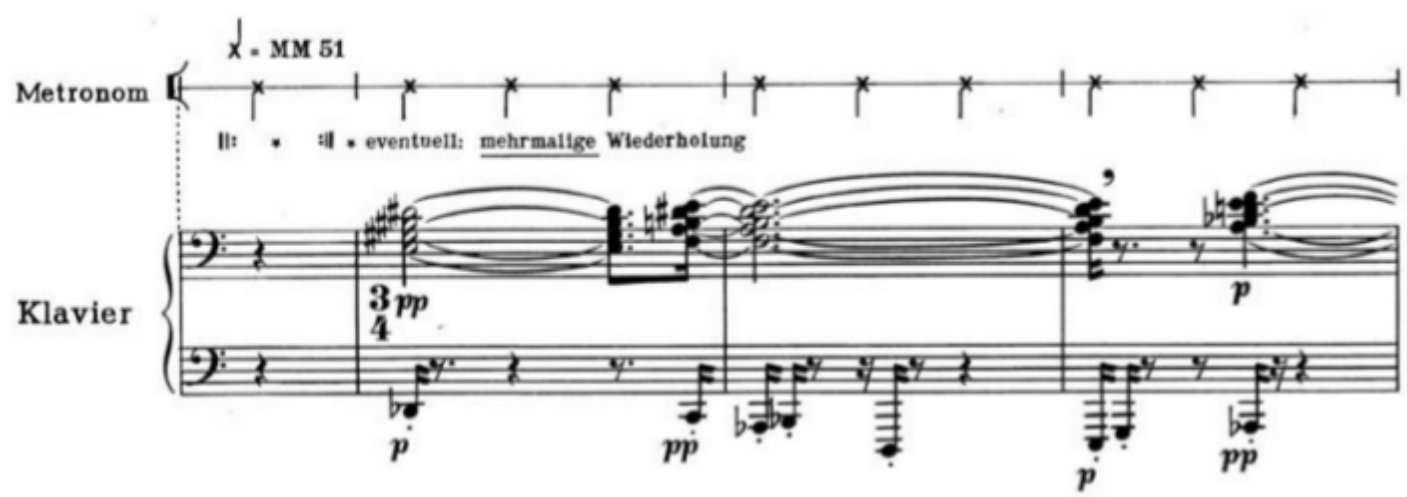

Exemplo 6: trecho inicial (c. 1-3) de MM51, de Kagel

Uma vez estabelecida essa relação fundamental de referência métrica, e valendo-se do mecanismo criado para montagem do metrônomo em cena, Kagel explora uma série de interações. O Quadro 1 apresenta a sequência de indicações do pulso metronômico e a sua relação com a execução ao piano.

\begin{tabular}{|l|l|l|l|}
\hline Localização na partitura & $\begin{array}{l}\text { Piano (fórmula de } \\
\text { compasso e andamento) }\end{array}$ & Metrônomo (pulso) & Relação \\
\hline c. $1-71$ & $3 / 4 \cdot=51$ & Regular (51 b.p.m.) & sincronia \\
\hline
\end{tabular}

17 "Metronom äußesrt langsam in schräge Lage bringen. (Es enisteht eine zunehmend ungleichmäßige Pulsation)"

18 "Allmählich in normal Lage bringen" 
MUSICA THEORICA Revista da Associação Brasileira de Teoria e Análise Musical 2019, v. 4, n. 1, p. 124-159-Journal of the Brazilian Society for Music Theory and Analysis@ TeMA 2019 - ISSN 2525-5541

\begin{tabular}{|l|l|l|l|}
\hline c. $72-87$ & $3 / 4 \cdot=51$ & Irregular & aleatória \\
\hline c. $88-96$ & $3 / 4 \cdot=51$ & Regular $(51$ b.p.m.) & sincronia \\
\hline c. $97-103$ & $3 / 4 \cdot=51$ & Irregular & aleatória \\
\hline c. $104-119$ & $9 / 8 \cdot=102$ & Tacet & - \\
\hline c. $120-124$ & $3 / 4 \cdot=51$ & Regular $(51$ b.p.m.) & sincronia \\
\hline c. $125-139$ & $9 / 8 \cdot=68$ & Regular $(51$ b.p.m.) & $\begin{array}{l}\text { Assincronia ou } \\
\text { polirritmia }\end{array}$ \\
\hline c. $140-150$ & $9 / 8 \cdot:=102$ & Tacet & - \\
\hline
\end{tabular}

Quadro 1: o pulso metronômico e sua relação com o material musical do piano em MM51, de Kagel

O pulso regular soando em sincronia com a execução do piano está presente em três trechos (c. 1-71, 88-96 e 120-124). Em outro trecho (compassos 125-139), o "metrônomo continua a correr independente do andamento da execução" (Kagel 1977, p. 15; tradução nossa). ${ }^{19}$ Aqui, o efeito pode ser de assincronia, com a simultaneidade de dois pulsos, ou de polirritmia, se a precisão de início da execução do trecho e dos andamentos indicados na partitura for mantida. Nesse caso, o pulso metronômico soaria a cada quatro colcheias em uma periodicidade distinta daquela que rege os agrupamentos rítmicos na fórmula de compasso 9/8. O pulso irregular, resultando em uma relação ritmicamente aleatória entre os pulsos gerados pelo metrônomo e a rítmica gerada pelo piano, está presente em dois trechos distintos (c. 72-87 e 97-103). Por fim, há dois trechos (c. 104-119 e 140-150) em que o metrônomo é colocado em pausa.

A interação entre o metrônomo e o piano desencadeia um processo formal independente, em contraponto com a estrutura em três partes descrita na seção anterior. Por meio do mecanismo de manipulação do metrônomo, Kagel compõe variantes de um parâmetro sonoro e suas relações com os demais materiais sonoros da peça. Organiza essas variantes e relações de maneira a gerar um senso de coerência e direção.

A presença visual e sonora do metrônomo e do mecanismo construído para sua manipulação também cria uma camada adicional de sentido para o jogo cênico. Deve ser montado atrás do pianista, de tal forma que seu olhar nunca está

19 “Metronom läuft weiter unabhängig vom Spieltempo" 
OLIVEIRA, H. M. Espaço, materiais e forma no teatro musical pós-1960: composição e dramaturgia em obras de Mendes, Kagel e Aperghis

direcionado ao mecanismo. Na versão televisiva (Kagel 1983), esse aspecto é ainda mais proeminente: o pianista tem seu olhar voltado para a tela de projeção, permitindo ao ouvinte/espectador atribuir o sentido de uma relação consciente, profissional e intencional entre suas ações e as imagens em movimento, relação claramente similar àquela que haveria na situação real do pianista de cinema mudo. As flutuações do mecanismo do metrônomo, entretanto, não são pertinentes à situação real e estão como que ocultas da figura cênica do instrumentista.

Assim, para além das funções sonoras e formais descritas nos parágrafos anteriores, o mecanismo do metrônomo passa a interferir na representação, nos sentidos construídos na performance. Representa aspectos que tendem a permanecer inconscientes nas atitudes e ofícios cotidianos do músico. No suspiro final (c. 149), a apresentação deliberada de figuras e cenas estereotipadas de terror dá lugar ao sobressalto que acomete o pianista quando aparentemente toma consciência da previsibilidade e rigidez de seu artesanato profissional.

\section{Estrutura e forma como encenação: Graffitis (1980), de Georges Aperghis}

Para Georges Aperghis (n. 1945) (apud Trubert 2015, p. 1281), o trabalho a que se propõe é de inventar maneiras de relacionar música e teatro distintas daquelas herdadas da ópera ou do concerto. Em obras como 7 crimes de l'Amour $(1979)^{20}$ e Retrouvailles (2013), ${ }^{21}$ ele parte de situações que emulam o realtriângulo amoroso e dois conhecidos numa mesa de bar, respectivamente -, mas que perdem sua factibilidade devido às manipulações composicionais da voz e dos gestos.

Já em Graffitis, Aperghis elabora o material cênico a partir da própria execução instrumental, explorando a irrupção do gesto e a teatralidade latente da percussão múltipla e das vocalizações. Em outra obra percussiva, Les guetteurs de sons (1981), ${ }^{22}$ fica evidenciada uma abordagem composicional semelhante. Aqui,

\footnotetext{
${ }^{20}$ Partitura: Aperghis (2006a). Vídeo: Aperghis (2013a), $<$ https://youtu.be/aZ48kO LiRs $>$, acesso em maio de 2019.

${ }^{21}$ Partitura: Aperghis (2013c). Vídeo: Aperghis (2013d), <https://youtu.be/0-3LFmAf DM>, acesso em maio de 2019.

${ }^{22}$ Partitura: Aperghis (2006c). Vídeo: Aperghis (2011a), <https://youtu.be/7ly1VuBMQuk>, acesso em maio de 2019.
} 
MUSICA THEORICA Revista da Associação Brasileira de Teoria e Análise Musical 2019, v. 4, n. 1, p. 124-159-Journal of the Brazilian Society for Music Theory and Analysis@ TeMA 2019 - ISSN 2525-5541

o gesto de execução musical, dissociado de sua implicação sonora, assume o primeiro plano em diversos momentos da performance: decomposição do gesto percussivo, sua realização com ou sem implicação sonora e sustentação de posturas corporais em longas pausas. Em prefácio disponibilizado junto à partitura, Gaston Sylvestre (apud Aperghis 2006c), um dos três artistas a quem essa peça foi dedicada, complementa a leitura cênica da peça. Para ele, é possível atribuir uma persona a cada percussionista, sugerindo que sua gestualidade deva refletir tanto essa caracterização, quanto o desenvolvimento da narrativa da peça, do nascimento à morte.

No contexto geral do teatro musical de Aperghis, tanto a situação teatral é apresentada e desenvolvida como performance musical, quanto gestualidade e visualidade da performance musical são desenvolvidas a ponto de adquirir sentido teatral. Lidar com o deslizamento entre performance (apresentação de ações inerentes ou não à execução vocal e instrumental) e representação (construção ou sugestão de uma narrativa ficcional no espaço cênico) é uma questão relevante para compreensão do trabalho do compositor grego radicado na França, como verificamos também em Mendes e Kagel.

\subsection{Da vocalização à linguagem, da linguagem ao teatro musical}

Em entrevista de 2010, Aperghis discorria sobre duas maneiras de ir da linguagem ao teatro musical:

A primeira é remover o significado, removendo pedaços de palavras, ou não colocando as palavras onde elas deveriam estar para dar significado, mas, ao contrário, colocá-las para fazer música. A partir daí, a partir do momento em que não entendemos, ouvimos, porque tentamos entender, e é isso que torna esse fenômeno muito musical. O público se pergunta: o que é isso? É uma linguagem? É outra coisa? E, a propósito, é o mesmo para o teatro musical (Aperghis apud Donin; Trubert 2010; tradução nossa). ${ }^{23}$

A primeira maneira consiste, portanto, em um trabalho de fragmentação do texto ao nível sintático (reordenação de palavras) e fonético (reordenação de fonemas), reorganizando as sonoridades vocais por meio de procedimentos

23 “La première c'est d'enlever du sens, en enlevant des bouts de mots, ou en ne mettant pas les mots où ils doivent être pour donner sens mais au contraire, de les placer pour faire de la musique. À partir de là, à partir du moment où on ne comprend pas, on écoute, parce qu'on essaye de comprendre, et c'est ça qui rend ce phénomène très musical. Le public s'interroge : $c^{\prime}$ est quoi ? C'est une langue ? C'est autre chose ? Et d'ailleurs c'est pareil pour le théâtre musical." 
OLIVEIRA, H. M. Espaço, materiais e forma no teatro musical pós-1960: composição e dramaturgia em obras de Mendes, Kagel e Aperghis

composicionais. A intenção expressiva é provocar a escuta atenta a partir de uma experiência de estranhamento com o deslocamento do propósito de gestos vocais originados da linguagem. As ações são reconhecidas como quase palavras, embora não resultem em mensagens reconhecíveis.

Alternativamente, ao invés de remover o significado, o compositor se propõe a acrescentá-lo, até o limite. “A outra maneira é acrescentar muito, como uma linguagem sobredeterminada, mas com tantos meandros e contradições que finalmente não sabemos em absoluto sobre o que falamos, como uma espécie de redemoinho" (Aperghis apud Donin; Trubert 2010; tradução nossa). ${ }^{24}$ Nesse caso, a intervenção é diretamente ao nível semântico. Enquanto as unidades sintáticas são mantidas intactas, sua proliferação macarrônica dissolve o sentido geral da ação vocal rumo a uma musicalidade/teatralidade peculiar. Essa abordagem é uma das possibilidades exploradas em Luna Park (2011). ${ }^{25}$

Aperghis também constrói vocalizações com uso de sílabas onomatopaicas. Esse tipo de escrita integra as vocalizações à textura percussiva. Ora a voz alterna com o instrumento de percussão, ora são combinados verticalmente, como na primeira seção de Le corps à corps (Aperghis 2006b, p. 19) (ver Ex. 7).

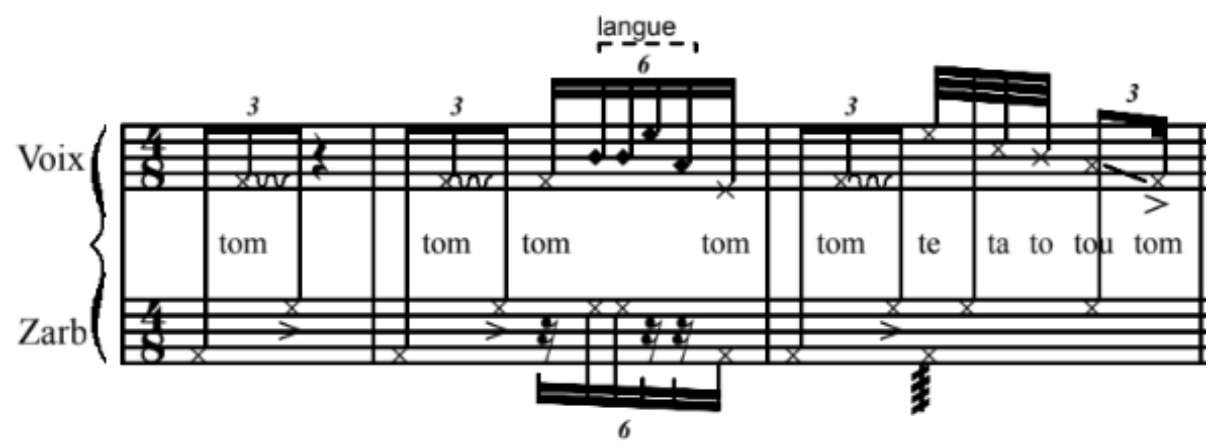

Exemplo 7: a escrita para percussão e voz com sílabas onomatopaicas nos três primeiros compassos da página 4 da partitura de Le corps à corps, de Aperghis

24 “L'autre façon, c'est d'en ajouter énormément, comme un langage surdéterminé, mais avec tellement de méandres et de contradictions que finalement on ne sait plus du tout de quoi on parle, comme une espèce de tourbillon."

25 Vídeo: Aperghis (2011b), <https://youtu.be/biTGIRROgZA>, acesso em maio de 2019. 
MUSICA THEORICA Revista da Associação Brasileira de Teoria e Análise Musical 2019, v. 4, n. 1, p. 124-159-Journal of the Brazilian Society for Music Theory and Analysis@ TeMA 2019 - ISSN 2525-5541

Em Graffitis, o material vocal é construído, inicialmente com sílabas onomatopaicas e, depois, com a primeira maneira de ir da linguagem ao teatro musical descrita acima. Um pequeno trecho do Fausto (1832), de Johann Wolfgang von Goethe (1749-1832), é fragmentado e apresentado gradativamente, de tal maneira que, a partir de um certo ponto na performance, seu sentido semântico emerge (para os ouvintes familiares com o idioma alemão).

Procedimentos de apresentação progressiva dos materiais são característicos em Aperghis. Frequentemente, na sua escrita, uma unidade lógico-temporal é recortada e redistribuída pela partitura em sequências mais ou menos aleatórias de interjeições sonoras. "Acontece assim que uma seção pode ser ao mesmo tempo totalmente emancipada de qualquer continuidade lógica e, ao mesmo tempo, completamente integrada a um vasto processo de elaboração que mantém a coerência do trabalho" (Donin; Trubert 2010; tradução nossa). ${ }^{26} \mathrm{~A}$ impressão de materiais sonoros entrecortados e fragmentados é sustentada, ao mesmo tempo que gradativamente emerge um senso de direção formal, decorrente da coerência de procedimentos e da gradativa completude dos materiais.

Em Graffitis, especificamente, não há um procedimento único que seja concretizado de maneira ininterrupta e corresponda à própria forma da peça. Uma série deles são aplicados e interpolados com outros materiais que podem resultar de procedimento similar ou de escolhas mais pontuais para gerar as sucessivas seções da peça. Entre as páginas 1 e 2, a construção progressiva de uma série fixa de sílabas onomatopaicas ("do i vo do va man..." etc.) é interpolada com materiais percussivos (Ex. 8).

\footnotetext{
26 "Il advient ainsi qu'une section puisse être à la fois totalement émancipée de toute continuité logique, et en même temps complètement intégrée à un vaste processus d'élaboration qui maintient la cohérence de l'œuvre."
} 
OLIVEIRA, H. M. Espaço, materiais e forma no teatro musical pós-1960: composição e dramaturgia em obras de Mendes, Kagel e Aperghis
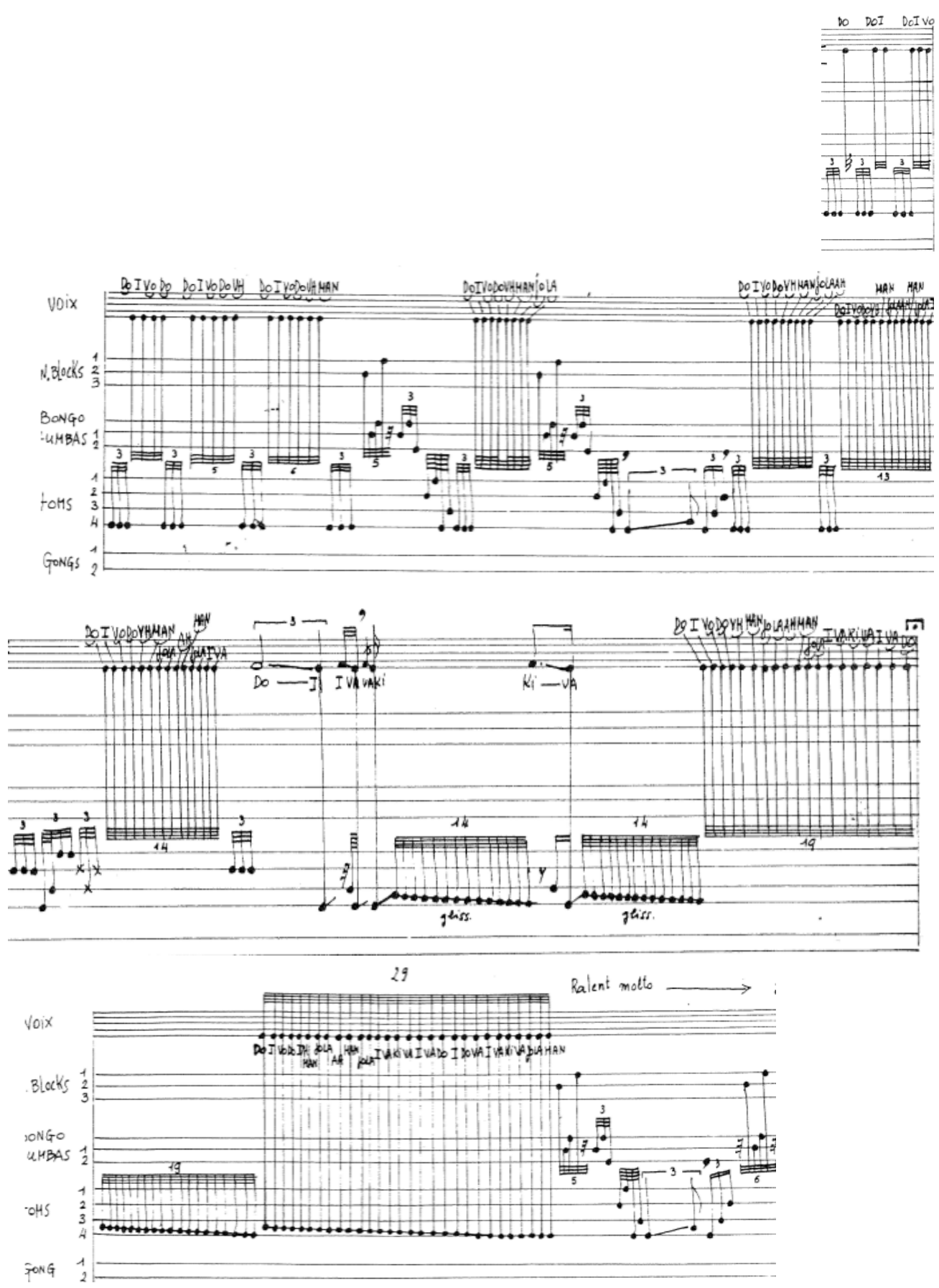

Exemplo 8: procedimento composicional de construção progressiva de uma sequência de vocalização de sílabas onomatopaicas em trecho das páginas 1 e 2 da partitura de Graffitis, de Aperghis

A forma da peça emerge de uma série de processos interligados. Quanto às vocalizações, em um primeiro momento são apresentadas sílabas onomatopaicas. Depois, sílabas e palavras em alemão são inseridas na textura. Por fim, a declamação rítmica do texto em alemão passa ao primeiro plano da 
MUSICA THEORICA Revista da Associação Brasileira de Teoria e Análise Musical 2019, v. 4, n. 1, p. 124-159-Journal of the Brazilian Society for Music Theory and Analysis @ TeMA 2019 - ISSN 2525-5541

performance vocal. Paralelamente, a relação entre vocalização e percussão também é transformada no decorrer do tempo da peça. Inicialmente, as vocalizações aparecem como fonte sonora em uma textura percussiva. Gradativamente, a declamação textual ganha proeminência até o ponto em que passa a ser acompanhada apenas por gestos de execução instrumental, realizados, entretanto, sem implicação sonora (Ex. 9). O Exemplo 9 mostra as transformações das vocalizações e sua relação com a parte percussiva ao longo da partitura: a) declamação do texto alternada com sílabas onomatopaicas e acompanhamento percussivo (p. 6, $3^{\circ}$ sistema); b) palavras do texto alternadas com células percussivas (p. 7, $3^{0}$ sistema); c) declamação do texto com acompanhamento de gestos de execução percussiva (p. 9, 1ํㅗㄴ sistema).
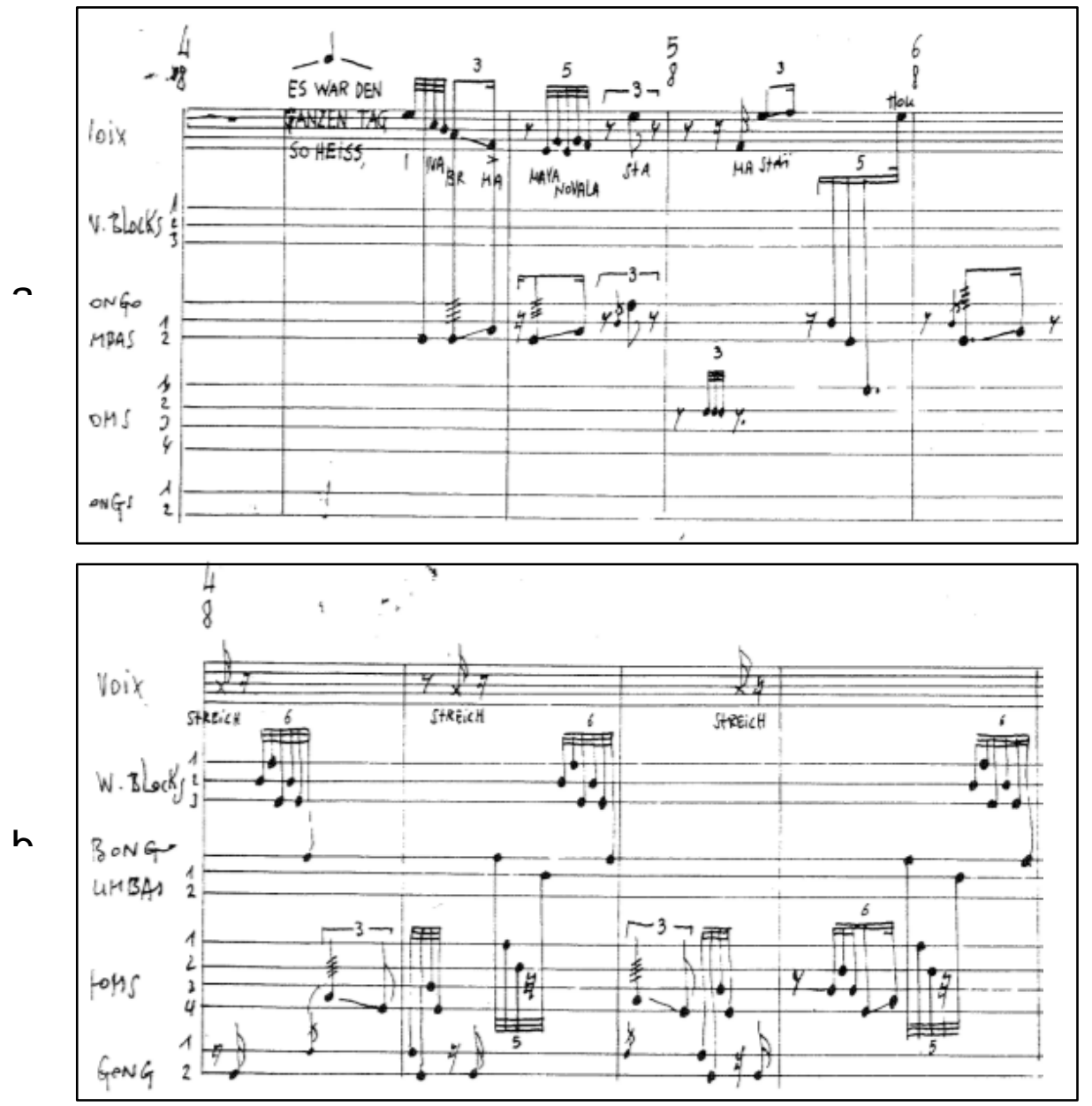
OLIVEIRA, H. M. Espaço, materiais e forma no teatro musical pós-1960: composição e dramaturgia em obras de Mendes, Kagel e Aperghis

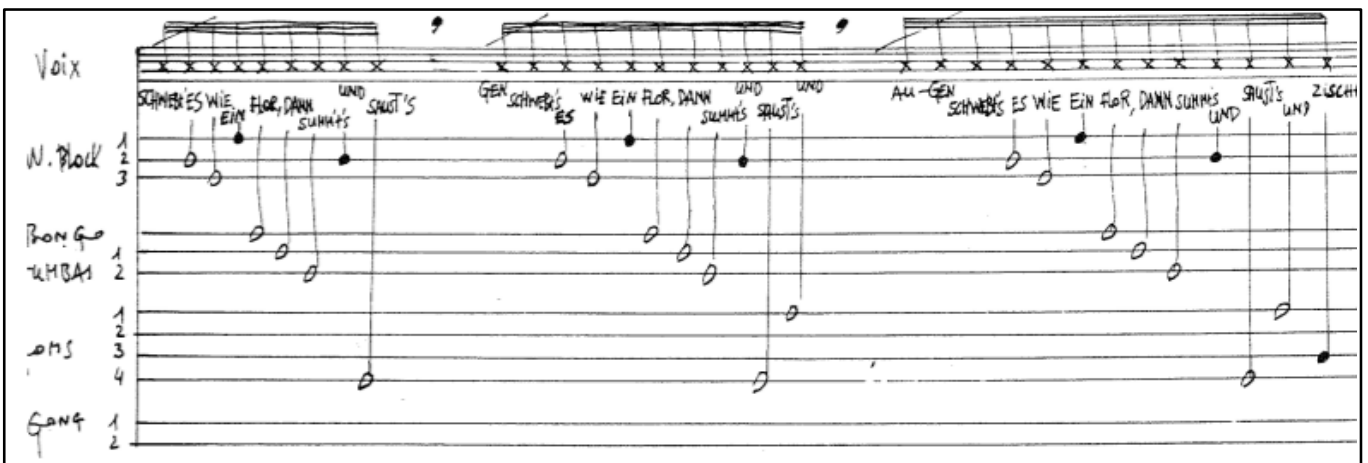

Exemplo 9: fragmentos de diferentes partes de Graffitis, de Aperghis

Essa sequência na organização dos materiais delineia um percurso da vocalização à linguagem e da linguagem ao teatro musical. Especificamente, a cena construída funciona como uma espécie de melodrama em que o percussionista exerce, simultaneamente, as funções de narrador e acompanhamento instrumental.

\subsection{Da abertura à narrativa}

A partir da página 6 da partitura de Graffitis, Aperghis inicia a roteirização de uma sequência de ações não vinculadas à execução instrumental que enfatiza a ressignificação do músico como ator e que se revela como solução formal para o desdobramento e, eventualmente, desfecho da peça. A primeira dessas ações é olhar para um par de baquetas. ${ }^{27}$ Em uma série de interrupções à execução vocal/instrumental, indicadas nas páginas seguintes, a sequência de ações é gradativamente complementada, em mais uma instância do procedimento composicional de construção progressiva.

Os processos formais de toda a peça são construídos por interpolações diversas em que sonoridades e ações são reveladas gradativamente e em alternância com os demais materiais. Estes, por sua vez, submetidos também a procedimentos similares de fragmentação e construção gradativa. O performer vai da vocalização onomatopaica à linguagem e, nos termos do compositor, da linguagem ao teatro musical, ao mesmo tempo em que a relação entre voz e percussão vai da textura rítmica à declamação acompanhada de gestos. $\mathrm{O}$

\footnotetext{
${ }^{27} \mathrm{Na}$ página de rosto, Aperghis faculta ao performer escolher instrumentos e objetos distintos daqueles indicados na partitura. No texto, faço referência predominantemente ao roteiro conforme consta na partitura.
} 
MUSICA THEORICA Revista da Associação Brasileira de Teoria e Análise Musical 2019, v. 4, n. 1, p. 124-159-Journal of the Brazilian Society for Music Theory and Analysis@ TeMA 2019 - ISSN 2525-5541

resultado estético é de uma performance que vai da execução musical à atuação cênica.

Na seção anterior, chamava atenção para paralelos entre Graffitis e Le corps à corps, quanto à escrita vocal e quanto à relação entre vocalização e percussão. Entretanto, os paralelos entre as peças não estão restritos àqueles aspectos e são particularmente profícuos para a compreensão do aspecto estrutural. Em Le corps à corps, Aperghis explicitava a segmentação da partitura em dois movimentos: "I. Ouverture" e "II. Le recit" (Aperghis 2006b, p. 1, p. 9). O início do segundo movimento, o conto, é precedido pela pronúncia das primeiras palavras inteligíveis do texto (ali, em francês) e por uma breve interrupção da execução vocal-instrumental pela ação: "vire a cabeça para a direita, como se estivesse surpreso com algo" (Aperghis 2006b, p. 9; tradução nossa). ${ }^{28}$

Em Graffitis, embora a segmentação não venha indicada com subtítulos, a estrutura utilizada por Aperghis é exatamente a mesma. Após a abertura, a execução vocal-instrumental é interrompida por uma ação de olhar, seguindo-se a apresentação gradativa da narrativa. Há, entretanto, uma diferença relevante. Em Le corps à corps, a ação de olhar é repetida para marcar as sucessivas retomadas da narrativa, apresentada em construção progressiva. Em Graffitis, a ação de olhar, ao ser repetida, não apenas marca a retomada da narrativa (e sua apresentação gradativa que mescla, nesse caso, procedimentos de construção progressiva, bidirecional e retrógrada). ${ }^{29}$ Mas, é também acrescida de outras ações (em seu próprio processo de construção progressiva), culminando no momento final em que o performer pega as baquetas e as luzes se apagam.

O exame do texto declamado, retirado de um episódio do Fausto de Goethe em que um soldado descreve a selvageria e absurdidade da experiência do campo de batalha, revela uma nova camada de sentido. Ainda que as qualidades fragmentadas e repentinas da execução vocal e instrumental possam ser relacionadas a posteriori com a violência e a desorientação referenciadas pelo conteúdo semântico do texto, a relação entre os materiais musicais, cênicos e textuais não é de modo algum ilustrativa. A passagem literária, embora seja fragmento de texto do gênero dramático, não é o ponto de partida para a

\footnotetext{
28 "tournez la tête à droite, comme si vous étiez surpris par quelque chose"

${ }^{29}$ Para uma discussão de procedimentos composicionais em Le corps à corps, ver Dos Santos et al (2015).
} 
OLIVEIRA, H. M. Espaço, materiais e forma no teatro musical pós-1960: composição e dramaturgia em obras de Mendes, Kagel e Aperghis

concepção teatral. É agregada à peça como mais um de seus materiais sonoros e dispositivos de construção de sentido.

Cada camada da composição prossegue com suas próprias lógicas internas e potenciais de sentido, de tal maneira que se desenham distintos arcos narrativos e representacionais. Em uma camada, a própria performance encena um percurso da execução musical à atuação cênica. Em outra camada, a sequência de ações introduzidas a partir da página 6 da partitura precipita a eventual dissolução da performance ao sugerir, na figura do performer, a representação de alguém dividido entre a responsabilidade de executar um roteiro de ações e o desejo de apanhar algo que lhe falta, mas se encontra fora de seu alcance. Note-se que a execução percussiva é toda realizada com as mãos e o objeto sugerido pelo compositor é justamente um par de baquetas. ${ }^{30}$ Em outra camada, o percussionista é ressignificado como narrador melodramático relatando a história do texto, ainda que essa representação seja distorcida pelas manipulações composicionais da vocalização e da corporalidade do músico/ator.

As soluções composicionais para organização dos materiais correspondem simultaneamente, por um lado à coerência e senso de direção musical e, por outro lado, à proposta de concretização cênica da peça, ou seja, sua encenação. A teatralidade decorre das próprias condições criadas para a performance, passando ao largo da questão da verossimilhança. Há aqui, novamente, um importante ponto de contato com as discussões teóricas em artes cênicas. No que se refere às experimentações cênicas pós-1960, campo no qual se enquadra por analogia o teatro musical de Aperghis e demais obras discutidas neste trabalho, a noção de teatralidade é menos um dado assumido a priori que um resultado da própria proposta criativa.

Ao abordar a teatralidade como dimensão estética da música de concerto, o processo de representação é indissociável do transcorrer da execução musical no tempo real de performance. E é nesse sentido que, em uma peça como Graffitis, as escolhas composicionais relacionadas à estrutura (divisibilidade em partes) e à forma (disposição dos conteúdos e suas continuidades) musicais implicam na criação de condições para a concretização cênica da performance.

\footnotetext{
${ }^{30} \mathrm{O}$ compositor, entretanto, faculta a substituição dos objetos. Em uma alternativa teatralmente interessante, o percussionista Alexander Wnuk (Aperghis 2014) utiliza uma taça de vinho. Nesse caso, o desejo adquire um sentido narrativo externo à execução musical e, talvez até, de fuga à responsabilidade da performance.
} 


\section{Considerações finais: composição e dramaturgia}

A dramaturgia, entendida como função de organização de eventos cênicos, ou seja, como composição, coloca-se como noção privilegiada para explicitar as investigações criativas de compositores interessados na teatralidade da performance musical.

Para Danan (2010), “a dramaturgia não é talvez nada além do pensamento do teatro em marcha, pensamento sempre em vias de se constituir [...]" (p. 119120). E esse pensamento "constitui por sua vez um motor, o que põe em movimento e ordena a ação, as ações - as organiza, as dispõe - segundo uma certa ordem, que se pode denominar composição" (p. 120). Ao se desvencilhar de convenções da fábula, a dramaturgia passa a ter um sentido mais geral de organização do evento cênico e articulação de seus elementos, de composição.

Não se limita, portanto, à autoria de textos do gênero dramático e à figura do autor, concepção predominante na produção teatral do século XIX. Ela abarca as transformações e experimentações teatrais no século $X X$, bem como a incorporação de métodos de geração e organização de material para a cena oriundos de outras linguagens artísticas e a descentralização dos processos criativos para a cena (Mota 2017, p. 35). Ao invés de se constituir como técnica inequívoca para construção de uma peça, a dramaturgia "passa a ser compreendida [...] como um campo semântico de tensões criativas" (Torres Neto 2016, p. 162), decorrentes das propriedades, dinâmicas e possibilidades de sentido das distintas materialidades apresentadas no espaço cênico.

O trabalho de ordenamento das sonoridades e ações composição/dramaturgia - realizado pelos compositores ligados ao teatro musical pós-1960 decorre de um pensamento da situação musical/teatral em marcha e em constituição. As escolhas composicionais são suscetíveis às tensões ocasionadas pelas distintas demandas, propriedades e dinâmicas das materialidades visuais, gestuais e sonoras.

Ao discutir obras específicas de Mendes, Kagel e Aperghis, abordei três categorias dessas escolhas composicionais. Na primeira categoria, a situação de performance musical é abordada como espaço cênico, considerando escolhas composicionais referentes ao lugar, à disposição e tipo de relação entre músicos e público e ao emprego de outros elementos visuais - objetos, figurinos, iluminação. Na segunda categoria, a seleção, invenção e organização de materiais é abordada como estabelecimento de um jogo cênico, no qual a gestualidade da 
OLIVEIRA, H. M. Espaço, materiais e forma no teatro musical pós-1960: composição e dramaturgia em obras de Mendes, Kagel e Aperghis

execução instrumental é teatralizada pela manipulação de múltiplas fontes sonoras e outros objetos, pela organização rítmica das ações e interações e, eventualmente, por vocalizações e por ações não vinculadas à execução musical. $\mathrm{Na}$ terceira categoria, estrutura (divisibilidade em partes) e forma (conteúdos e suas continuidades) são abordadas como encenação, na qual as ações são concatenadas em episódios sonoro-gestuais e em percursos narrativos. $\mathrm{O}$ pensamento sobre a organização da peça como um todo coordena as considerações estruturais/formais musicais e a colocação em cena do mesmo material, levando em conta aspectos técnicos e artísticos para concretização da performance.

A concepção atual de dramaturgia considera a presença do ator, seus gestos e sua voz, bem como os demais elementos da encenação, de maneira autônoma, com potencial de construir seus próprios discursos cênicos (Torres Neto 2016, p. 162). No teatro musical pós-1960, as relações entre o músico/ator, a ficção da situação musical/teatral e o jogo das ações, interações e materialidades apresentadas no espaço cênico da performance musical são múltiplas. A abrangência das escolhas composicionais é estendida para o âmbito dessas relações, compondo, de fato, distintas possibilidades de constituição e desenvolvimento do processo de teatralidade.

Nas propostas mais radicais desse teatro musical pós-1960, o nexo narrativo é quase totalmente abolido. O texto dramático, como dado a priori para o trabalho composicional em teatro musical, perde seu caráter unificante (Trubert 2015 , p. 1279), dando origem a um processo de teatralidade que pode ser compreendido à luz de sua tensão com a performatividade. Tanto o ator - por sua concretude corporal no interior do espaço cênico - quanto o jogo - pela maior ou menor arbitrariedade de suas convenções - mediam o aspecto de performance, como apresentação de ações, com o aspecto de representação, como significação ficcional dessas mesmas ações. Há uma dinâmica de permanente disjunção-unificação entre as estruturas simbólicas do teatro e os fluxos energéticos que se atualizam na performance (Féral 2015, p. 112).

Nas transformações da criação cênica no século $X X$, a performatividade ganha um maior peso: "diversos autores e encenadores buscaram criar essa dissociação unívoca entre um discurso (verbal ou visual) e um sentido dado" (Féral 2015, p. 118-119). O teatro assume, em diversos graus e variações, o caráter de descrição dos acontecimentos em detrimento da narrativa ficcional e de 
MUSICA THEORICA Revista da Associação Brasileira de Teoria e Análise Musical 2019, v. 4, n. 1, p. 124-159-Journal of the Brazilian Society for Music Theory and Analysis@ TeMA 2019 - ISSN 2525-5541

criação de espetáculos centrados na imagem e na ação em detrimento do texto. A noção de teatralidade, à luz desses desdobramentos na história da criação teatral, remete a um teatro em que "o sentido deixa completamente de ser global; é sempre local e fragmentário" (Sarrazac 2009, p. 28).

A partir dessa ruptura fundamental, os processos criativos para a cena apostam no curto-circuito dos elementos e das convenções dramáticas, propondo novas possibilidades de construção cênica e novos tipos de narrativas. "A composição desloca-se, pois, do foco do drama para o plano da ação, não a dramática, mas a performativa" (Torres Neto 2016, p. 159). O teatro passa a ser visto como "um evento singular, multifacetado, multidisciplinar e interartístico" (Mota 2017, p. 35).

As ideias de teatro musical como dado característico da música de vanguarda (Mendes), uma maneira musical de pensar no teatro (Kagel) e invenção de relações entre música e cena (Aperghis) aproximam a composição musical dessas reflexões recentes sobre a dramaturgia em dois sentidos, sucessivamente. $O$ primeiro sentido é o da aplicação de critérios e procedimentos composicionais musicais às materialidades cênicas. ${ }^{31}$ As ações são organizadas e dispostas a partir de um pensamento voltado para os recortes no tempo, para a escolha de sons e silêncios pelo critério da expressividade e para a construção de um senso de coerência e direção. As escolhas composicionais visam à costura gradativa do percurso sonoro, indissociável nesse tipo de abordagem criativa, da roteirização da performance a ser colocada sobre o palco na situação concreta de realização da peça. O segundo sentido é o da admissão do potencial mimético (representacional) das materialidades sonoras e gestuais/visuais com as quais se compõem e do estabelecimento de dispositivos para que jogos de construção e deslizamento de sentidos se realizem na performance.

No trabalho composicional, a manutenção desse tipo de relação, e seu desenvolvimento ao longo de cada peça específica, implica na busca do equilíbrio entre duas demandas. De um lado, a invenção e organização das ações com ou sem resultantes sonoras. De outro lado, a marcha de possíveis sentidos de representação cênica implicados nessas mesmas ações. No teatro musical pós1960, essas demandas e, consequentemente, as funções de composição e

\footnotetext{
${ }^{31}$ Sentido esse análogo aos postulados de Kagel (por exemplo, apud Bosseur 1971) e à moldura teórica dos pesquisadores proponentes da noção de Teatro Composto (Rebstock 2012; Roesner 2012).
} 
OLIVEIRA, H. M. Espaço, materiais e forma no teatro musical pós-1960: composição e dramaturgia em obras de Mendes, Kagel e Aperghis

dramaturgia - organização de estruturas musicais e eventos cênicos - se integram e se sobrepõem.

\section{Referências}

1. Aperghis, Georges. Graffitis (1980). 2014. [Vídeo] Alexander Wnuk, percussão. Copenhagen: Royal Danish Academy of Music. URL: <https://youtu.be/UUj0knMsA78>, acesso em maio de 2019.

2. 7 crimes de l'Amour. 1979. [Vídeo] Sarah Maria Sun, soprano; Sebastian Wendt, clarinete; Stephan Meier, percussão. Hannover: Musik 21 Niedersachsen, 2013a. URL: <https://youtu.be/aZ48kO LiRs>, acesso em maio de 2019.

3 . Retrouvailles. 2013. [Partitura] Paris: Didascalia, 2013c. URL: $<$ https://drive.google.com/file/d/0B4bDGe8g1UPhQkZRSTE3cFFYS2M/view $>$, acesso em maio de 2019 .

4. Retrouvailles. 2013. [Vídeo] Richard Dubelski e Christian

Dierstein. Witten: Wittener Tage für neue Kammermusik Festival, 2013d. URL: < https://youtu.be/0-3LFmAf DM>, acesso em maio de 2019.

5. Graffitis. 1980. [Vídeo] Juanjo Llopico, percussão. Onda (Espanha), 2013e. URL: <https://youtu.be/UUYlt7v6S00>, acesso em maio de 2019.

6. Les guetteurs des sons. 1981. [Vídeo] Agnieszka KoprowskaBorn, Louisa Marxen e Yuriko Sekiguchi. Basel: Mimiko, 2011a. URL: $<$ https://youtu.be/7ly1VuBMQuk>, acesso em maio de 2019.

7. Luna Park. 2011. [Vídeo]. Eva Furrer (flauta, Octabase and voice), Johanne Saunier (voice and danse), Mike Schmidt (base flute and voice), and Richard Dubelsky (air percussion and voice). Paris: IRCAM, 2011b. URL: <https://youtu.be/biTGIRROgZA >, acesso em maio de 2019.

8. . 7 crimes de l'Amour. 1979. [Partitura] Paris: Didascalia, 2006a. URL: <https://drive.google.com/file/d/0B4bDGe8g1UPhSTg3d DE0bmhQbVU/view $>$, acesso em maio de 2019.

9 . Le corps à corps. 1978. [Partitura] Edição do autor, 2006b. URL: $\quad<$ https://drive.google.com/file/d/0B4bDGe8g1UPhZDBmMV

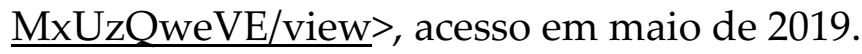

10. Les guetteurs des sons. 1981. [Partitura] Edição do autor,

2006c. URL: $\leq$ https://drive.google.com/file/d/0B4bDGe8g

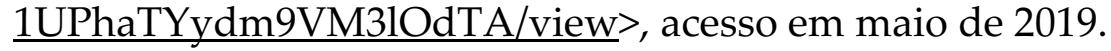


MUSICA THEORICA Revista da Associação Brasileira de Teoria e Análise Musical 2019, v. 4, n. 1, p. 124-159-Journal of the Brazilian Society for Music Theory

11. Le corps à corps. 1978. [Vídeo] Françoise Rivalland. Paris: POLediteur, 2004. URL: <https://youtu.be/M1ONFZ042fc>, acesso em maio de 2019.

12. Graffitis. 1980. [Partitura] Paris: Salabert, 1980.

13. Bithell, David. Experimental music theater. In: Grove Music Online. Oxford Music Online. URL: <http://www.oxfordmusiconline.com/subscriber/ article/grove/music/A2240884>, acesso em novembro de 2017. Oxford University Press, 2016.

14. Bosseur, Dominique; Bosseur, Jean-Yves. 1990. Revoluções musicais: a música contemporânea depois de 1945. Lisboa: Editorial Caminho.

15. Bosseur, Jean-Yves. Entretien avec Mauricio Kagel. 1971. Musique en jeu, 5, França, nov., p. 99-106.

16. Carrasco, Ney. 2005. A infância muda: a música nos primórdios do cinema. ouvirOUver, Uberlândia, n. 1, p. 35-45. URL: <http://www.seer.ufu.br/ index.php/ouvirouver/article/view/24/38>, acesso em maio de 2019.

17. Chion, Michel. 2011. A Audiovisão: som e imagem no cinema. Portugal: Texto e Grafia.

18. Danan, J. 2010. Mutações da dramaturgia: tentativa de enquadramento (ou de desquadramento). MORINGA - Artes do Espetáculo, v. 1, n. 1, p. 117-123.

19. Donin, Nicolas; Trubert, Jean-François. 2010. Georges Aperghis - Noyaux, matrices, oignons (...et corbeille). Genesis, 31, p. 65-76.

20. Dos Santos, Kemuel Kesley Ferreira; Chaib, Fernando Martins de Castro; De Morais, Ronan Gil; De Oliveira, Fabio Fonseca. 2015. Processo de adaptação de uma tradução de texto como parte da preparação interpretativa da obra cênico musical Graffitis de Georges Aperghis. In: Seminário Nacional de Pesquisa em Música da UFG, XV, Anais..., pp. 99-109.

21. Féral, Josette. 2015. Além dos limites: teoria e prática do teatro. São Paulo: Perspectiva.

22. Kagel, Mauricio. MM51. 1976. [Vídeo] Klaus Steffes-Holländer, piano. Freiburg: Ensemble Recherche, 2017. URL: <https://youtu.be/ usdBER8zUZU>, acesso em maio de 2019.

23. MM51. 1976. [Vídeo]. Aloys Kontarsky, piano; Mauricio Kagel, direção. Zurique: Schweizer Fernsehens DRS, 1983. Disponível em: <https:/youtu.be/Gu-fLh2sGT0>, acesso em maio de 2019.

24. . MM51. 1977. [Partitura] Londres: Universal Edition. 
OLIVEIRA, H. M. Espaço, materiais e forma no teatro musical pós-1960: composição e dramaturgia em obras de Mendes, Kagel e Aperghis

25. Mendes, Gilberto. Santos Football Music. 1969. [Vídeo] In: A Odisseia Musical de Gilberto Mendes [DVD]. São Paulo: Berço Esplêndido, 2005a. Disponível em $<$ https://youtu.be/V3bmKryl-cI >, acesso em maio de 2019.

26.

Beba Coca-Cola. 1966. [Vídeo] Coro da OSESP; Naomi Munakata, regência. In: A odisseia musical de Gilberto Mendes [DVD]. São Paulo: Berço Esplêndido, 2005b. Disponível em <https://youtu.be/6DKRtGjIaD4>, acesso em maio de 2019.

27. 1994. Uma odisséia musical: dos mares do sul à elegância pop/art déco. São Paulo: Editora da Universidade de São Paulo, Editora Giordano.

28. Santos Football Music. 1979. [Partitura] Brasília: Sistrum.

29. Mota, Marcus. 2017. Dramaturgia: conceitos, exercícios e análises. Brasília: Editora UnB.

30. Oliveira, Heitor Martins. 2018. Música-como-teatro: uma prática composicional e sua autoanálise. Tese (Doutorado em Música) - Instituto de Artes, Universidade Federal do Rio Grande do Sul. Porto Alegre.

31. 2016. Composição musical e teatralidade em Speaking Drums, de Péter Eötvös. Dramaturgias - Revista do Laboratório de Dramaturgia - LADI - UnB, v. 2/3, p. 58-71. URL: <http://periodicos.unb.br 〈index.php/dramaturgias/article/view/21895>, acesso em junho de 2017.

32. 2015. Música e teatralidade: a perspectiva composicional. Debates (Unirio), n. 15, p. 49-66.

33. Rebstock, Matthias. 2012. Composed Theatre: mapping the field. In: Rebstock, Matthias; Roesner, David. Composed Theatre: aesthetics, practices, processes. Kindle Edition. Bristol, UK / Chicago, USA: Intellect, Chapter 1.

34. Roesner, David. 2012. Introduction: Composed Theatre in context. In: Rebstock, Matthias; Roesner, David. Composed Theatre: aesthetics, practices, processes. Kindle Edition. Bristol, UK / Chicago, USA: Intellect.

35. Salzman, Eric; Dési, Thomas. 2008. The New Music Theater: seeing the voice, hearing the body. Kindle Edition. New York: Oxford University Press.

36. Sarrazac, Jean-Pierre. 2009. A invenção da teatralidade. Apresentação e tradução: Alexandra Moreira da Silva. Senhora da Hora: Deriva Editores.

37. Serale, Daniel Osvaldo. 2009. Música, teatro, música-teatro e percussão na música-teatro. Cadernos do Colóquio, v. 10, n. 1, p. 210-221.

38. Torres Neto, Walter Lima. 2016. O termo dramaturgia hoje. In: Ensaios de cultura teatral. Jundiaí-SP: Paco Editorial, p. 149-164. 
MUSICA THEORICA Revista da Associação Brasileira de Teoria e Análise Musical 2019, v. 4, n. 1, p. 124-159-Journal of the Brazilian Society for Music Theory

39. Trubert, Jean-François. 2015. Théâtre musical et théâtre instrumental. In: Donin, Nicolas; Feneyrou, Laurent. Théories de la composition musicale au XXe siècle volume 2. Lyon: Symétrie, p. 1269-1295. 


\title{
Rethinking the Ornament with/in Luigi Nono's Late Electroacoustic Works
}

\author{
Repensar o ornamento com/em obras eletroacústicas tardias de Luigi Nono
}

Kevin Gohon

Université Rennes 2, France

\begin{abstract}
This paper aims at examining the manifestations of the ornamental phenomenon in the musical project that Luigi Nono developed in the last ten years of his life. Indeed, despite the fact that the musical language of his late style seems to be in contradiction with the presence of any kind of ornamentation -whether because of his inheritance from the Viennese modernism or his rejection to any kind of figurative musical discourse -, certain features of Nono's late style echo in some way an ornamental logic, as it is set as a general aesthetic category since the 18th century. Therefore, this paper demonstrates that the first manifestation of the "mobile sound" is related to a shifting of the traditional techniques of ornamentation, and then tries to enlighten the expression of the musical discourse in the late spatialized works from the perspective of an ornamental logic.
\end{abstract}

Keywords: Luigi Nono; Electroacoustic Music; Ornamental Aesthetic; Das atmende Klarsein; Risonanze erranti

Resumo: O objetivo deste artigo é examinar as manifestações do fenômeno ornamental no projeto musical que Luigi Nono desenvolveu nos últimos dez anos de sua vida. De fato, apesar da linguagem musical de seu estilo tardio parecer estar em contradição com a presença de qualquer tipo de ornamentação - seja por sua herança do modernismo vienense ou pela sua rejeição por qualquer tipo de discurso musical figurativo -, certas características do estilo tardio de Nono ecoam como uma lógica ornamental, já que é definida como uma categoria estética geral desde o século XVIII. Portanto, este trabalho demonstra que a primeira manifestação do "som móvel" está relacionada a um deslocamento das técnicas tradicionais de ornamentação e, em seguida, tenta iluminar a expressão do discurso musical nos trabalhos espaciais tardios a partir da perspectiva de uma lógica ornamental.

Palavras-chave: Luigi Nono; Música Eletroacústica; Estética Ornamental; Das atmende Klarsein; Risonanze erranti 
MUSICA THEORICA Revista da Associação Brasileira de Teoria e Análise Musical 2019, v. 4, n. 1, p. 160-187-Journal of the Brazilian Society for Music Theory and Analysis@ TeMA 2019 - ISSN 2525-5541

\section{Introduction}

In a long talk with Massimo Cacciari and Michele Bertaggia, presented in the program notes of the performance of Prometeo in Paris in 1987, Luigi Nono explained his interest in infinite listening possibilities and exposed that

[...] the composition of a music that wants today to restore the infinite possibilities of listening by using a "non-geometrisable" space also faces the dissolution of the normal time, the time of narration and visualization... (Bertaggia 1987, p. 138). ${ }^{1}$

The fundamental rejection of the logic of discourse and the "imaged" acceptance of the musical tone, notably reaffirmed in an interview given to Philippe Albèra, ${ }^{2}$ seems to exclude de facto madrigalism, and rhetorical embellishment, which is the main criteria of the ornamental principle. In this respect, the Venetian composer's approach fits with his inheritance of the Viennese modernism, reaffirming at the same time his attachment to Schoenberg's music. Indeed, even if Schoenberg demonstrates that embellishments are not minor additions to Baroque music in "About ornaments, primitive rhythms, etc., and bird song" (1922), Schoenberg has expressed the same stance as Adolf Loos did in his Ornament and Crime, as he considers the ornamental figure obsolete since homophonic writing became predominant in the development of Western music.

However, the ornamental phenomenon cannot be reduced to ornamentation, as evidenced by the numerous studies of and attempts to define the ornament in art and philosophy. ${ }^{3}$ It is even set as an independent aesthetic category since the 18th century - at least - as its progressive diversification has revealed a complex relationship between the background and the surface, the material and its ornamentation, which cannot be restricted to the hierarchy

\footnotetext{
1 “De manière plus générale, la composition d'une musique qui veuille aujourd'hui restituer des possibilités d'écoute infinies, en usant d'un espace non géométrisable, se heurte aussi à la dissolution du temps normal, du temps de la narration et de la visualisation..."

2 "The logic of discourse is something terrifying to me. The taste of formulation, of the formula, causes in me an almost physical reaction" (Albèra 1987, p. 20). "La logique du discours est pour moi quelque chose de terrifiant. Le goût de la formulation, de la formule, provoque chez moi une réaction presque physique."

${ }^{3}$ For example, see Golsenne 2012, Carboni 2012, Golsenne, A. et al. 2010, Buci-Glucksmann 2008, Dewitte 2010, Dewitte 2005, Saint Girons 2005 or Bettini 2016.
} 
imposed by its initial decorative function. Thereupon, the ornament induces an "ornamental mode" defined by a "manner of expressing, which reduces or completely eliminates the referential dimension of the arts. The created thing [...] is not an end in itself but leads to the transfiguration of the one that it affects" (Grabar 1996, p. 186; Buci-Glucksmann 2008, p. 90). Hence, the involvement of the ornamental phenomenon in Nono's late works can be reassessed.

In this perspective, this paper will try to demonstrate that the sound and space concepts that Luigi Nono developed in his late electroacoustic works employ a particular setting of the ornamental phenomenon in order to "restore the infinite possibilities of listening". An analysis of Das atmende Klarsein will show that Nono unfolds the traditional ornamental principles between a pitchbased and a sound-based writing and echoes the methods of variation defined by Schoenberg in order to increase the complexity of the sound and the structure of the work. Then, an analysis of Risonanze erranti based on the writing processes highlighted in Das atmende Klarsein will expose that the renewal of the musical discourse operated by the composer follows a specific logical pattern that one can describe as ornamental and deeply affects the expression of the musical work.

\section{Luigi Nono and the "Venetian reality", from a rhetorical to an ontological approach to the ornament}

As mentioned in the introduction of this paper, the modes of presentation and writing developed during Viennese modernism, in music, architecture and visual arts, cannot fit with the concept of embellishment. In "About ornaments, primitive rhythms, etc., and bird song" (1922), Schoenberg offers a detailed study of the problem of ornamentation in early twentieth-century music. The first part of the text reminds that the exclusion of ornamental practices during the second half of the nineteenth century, yet established as one of the main expressive means in occidental musical writing since the Baroque era at least, relies both on a criterion of intelligibility and the evolution of the audiences. Indeed, in a cultural context largely influenced by the ideas of the French Revolution, the fact that art should be accessible to everyone required to open and enlarge the places of performance in order to reach a larger number of listeners. On another hand, it became necessary to level the complexity of its languages so that it could be understood by everyone, including those who had been deprived of artistic erudition until then. Consequently, according to the composer, "style became 
MUSICA THEORICA Revista da Associação Brasileira de Teoria e Análise Musical 2019, v. 4, n. 1, p. 160-187-Journal of the Brazilian Society for Music Theory and Analysis@ TeMA 2019 - ISSN 2525-5541

broader; repetitions (sequences) regained the upper hand; quicker notes (fluidity) dropped out as far as possible; one limited oneself to main points; wherever possible, ornaments were regarded as minor points and so mostly left out" (Schoenberg 2010, p. 298).

Nevertheless, the so-called secondary value of embellishment appears to him as a misunderstanding and the argument of eviction unconvincing. The latter would be influenced by the hierarchy imposed on principal notes and embellishment figures, which are represented by non-integrated signs in the musical symbolic system, "in a way which soon nobody understood any more, since it was passed on purely by word of mouth" ${ }^{4}$ (Schoenberg 2010, p. 199). As the composer explains, ornaments are not as loose as the austerity of the information contained in the score implies, precisely because of the polyphonic nature of writing. While "the expression of the idea, its marking-off and workingout, happened so precisely and exactly within the notes written down" (Schoenberg 2010, p. 303), the continuo realized by the performer was certainly secondary, in relation to the content of the work, but it was not less obliged than a fully prescribed accompaniment: its function is precisely an adornment of the structure which closely follows its evolution. For Schoenberg, the Baroque practice of ornamentation is less the result of a freedom of expression acquired to the performing musician than a variable of adjustment of the sound mass allowing to adapt the discourse to the instruments available at the time of performance.

However, it is because the ornament is not a negligible decoration in the context of the traditional polyphonic style that the modern composer must oppose its preservation. As Schoenberg develops in a short text entitled "Ornaments and construction", which complements the previous article, the homophonic style of the new music requires the abandonment of the melodicharmonic adornment inherited from the contrapuntal and polyphonic aesthetics. The musical discourse no longer resides in the realization of a "sketch" which needs embellishment to be expressive, but it arises from the thematic development derived from a fundamental motive. In this particular kind of composition, "there will have to be a rather slower rate of succession among the

\footnotetext{
4 Schoenberg contradicts this thesis following a summary observation of the stylistic characteristics of Johann Sebastian Bach and his contemporaries.
} 
notes, even for reasons of comprehensibility" (Schoenberg 2010, p. 312), so as not to interfere both with the exposure of the material and the logical deduction process. In this perspective, Schoenberg reinvests a fundamental stance of Modernity defended by Adolf Loss in Ornament and crime (1908).

Indeed, the architect considers that the embellishment - which he compares to an "epidemic" (Loos 2003, p. 63) - cannot be suitable for modern man according to its supererogatory nature, because it implies a vain expense of work, money and material. The aesthetics of utility defended in this text submits the form exclusively to the expression of the function so as to prevent it from the exhaustion of taste, estimated faster than that of the useful features of the tool. As Loss writes,

the modern man who sacralises the ornament as a sign of artistic overfull of past eras will immediately recognize the tortured, laborious and sickly aspect of modern ornaments. Ornament can no longer be created by somebody living at our cultural stage (Loos 2003, p. 69).

Despite the fact that Ornament and Crime constitutes the manifesto of the most widespread idea of modernity in Western music during the twentieth century, it depicts the culmination of a long series of criticisms and essays specifically aimed against Gustav Klimt, who actually represents a different kind of modernity through the Art nouveau, as noticed by Christine Buci-Glucksman (see Buci-Glucksmann 2008, p. 36). Moreover, one can find many aesthetic approaches of an "ornamental modernism" across the century, notably thought by Wilhelm Worringer, Hans Georg Gadamer, Jacques Derrida or Gilles Deleuze.

According to Gadamer, the relationship between the ornament and the object it embellishes necessarily falls under the authority of a criterion of coherence which fits the latter's form to the space where evolves the embellishment:

[...] the ornament is precisely not primarily a thing that is sufficient for itself and then added to another, but it is part of the way in which what its supports is represented. One can also say of the ornament that it is part of the representation; however, representation (Darstellung) is an ontological process, it is a representation (Repräsentation) (Gadamer 2018, p. 262). ${ }^{5}$

\footnotetext{
5 “[...] l'ornement n'est précisément pas d'abord une chose qui se suffit à elle-même et qu'on ajoute ensuite à une autre, mais il fait partie de la manière dont ce qui le porte se représente. C'est à juste
} 
MUSICA THEORICA Revista da Associação Brasileira de Teoria e Análise Musical 2019, v. 4, n. 1, p. 160-187-Journal of the Brazilian Society for Music Theory

This observation is not only valid for ornamentation in its sensitive manifestation; it also creates an aesthetic criterion corresponding to any art "that gives a configuration to space" (Gadamer 2018, p. 259), according to the model of architecture. We can then consider that it applies to music, due to the fact that the sound phenomenon is closely dependent on the spatial context in which it emerges. As Gadamer writes,

it is not a question of finding, in addition and outside, a place for a work in itself completed; on the contrary, it is necessary to submit to the power, which is that of the work itself, to structure space. The work must thus adapt to the given, just as it lays down its own conditions (Gadamer 2018, p. 260). ${ }^{6}$

For comparison, Gadamer's ontological principle of "decoration" can be illustrated with Nono's particular approach to spatialization, as his music no longer confronts the neutralized spaces enumerated by the philosopher (the model of theater or concert hall) but calls to be performed in any resonant space by harmonizing with the space itself while the musical discourse characterizes it acoustically.

If the idea of an ontological ornamental perspective of music is akin to a theoretical metaphor whose scope is limited here to the description of the singular relationship that is being made between all sound production and the environment in which it spreads, it introduces however two essential postulates for the attempt to identify a renewal of the ornamental dimension in electroacoustic music. In the first place, the ornament appears as a category of thought which, although still related to the concept of decoration, is not confined to its figurative property, nor to the supererogatory nature that Adolf Loos denounced. However, this approach of the ornament "which diverts from the task of ornamentation" (Dewitte 2005, p. 41), which departs from its representative essence, seems to echo the principle of variation in Western music:

titre qu'on peut dire aussi de l'ornement qu'il fait partie de la représentation; or, la représentation (Darstellung) est un processus ontologique, elle est représentation (Repräsentation)."

6 " [...] il ne s'agit pas de trouver, en plus et du dehors, place à une œuvre en elle-même achevée; il faut au contraire se soumettre à la puissance, qui est celle de l'œuvre même, de structurer l'espace. L'œuvre doit ainsi s'adapter au donné, tout comme elle pose ses propres conditions $[\ldots] . "$ 
it does not act on a secondary level in the formation of shape but influences the development, and even dictates the structure at times. ${ }^{7}$

Secondly, Nono's electroacoustic music maintains a particular affinity with a thought of the ornamental phenomenon of which Venice can be considered as the quintessential representation. The fact that the composer has emphatically claimed the musical, pictorial, architectural and historical heritage of his hometown during the 1980s is not trivial. As Laurent Feneyrou points out, the singular approach to the origin of Prometeo, and the formulation of the mixed musical perspectives accompanying it, "rest on the rereading of Venice" (Feneyrou 1993, p. 16). When Enzo Restagno questions him about the source of what he considers to be an "unveiling of the Venetian reality", Nono answers:

First of all, I have to tell you that this unveiling is still going on today. I would say to you that it seems to me that I have unveiled, known, listened, seen, felt Venice especially in recent years. Especially through the experience I have been living for seven years with the experimental Studio in Freiburg, an experience that, by revealing me other acoustic spectra, has given me other abilities to see and listen (Nono; Restagno 1993, p. 23). ${ }^{8}$

If the two musicologists insist on the influence of the urban environment in which Nono evolved during his whole life, it is because of the uniqueness of the archipelago city in the European cultural landscape. The geographical location of the city and the history of the Empire of which it was the capital for several centuries confer in fact a singularity justifying in itself its importance in the Western artistic imagination, which Sergio Bettini qualifies as a work of living art, like "all non-ordinary cities" (Bettini 2016, p. 27). Created without any topological constraint a priori, it is de facto a building whose formal structure does not obey any predetermination. Venice figures then a symbolic experience of art calling to be reinterpreted, conceived on the merge of a network of divergent practices and languages. That is why the architect envisages the city less as a simple urban and social construction than as a discursive model. As it is

\footnotetext{
${ }^{7}$ For example, in her philosophical evaluation of the ornament as an aesthetic category, Christine Buci-Glucksmann evokes the Baroque ornamental variation (see Buci-Glucksmann 2008, p. 18).

8 "Avant tout, je dois te dire que ce dévoilement continue encore aujourd'hui. Je te dirais justement qu'il me semble que j'ai dévoilé, connu, écouté, vu, senti Venise surtout ces dernières années. Surtout à travers l'expérience que je vis depuis sept ans auprès du studio expérimental de Fribourg, une expérience qui, en me révélant d'autres spectres acoustiques, m'a donné d'autres capacités pour voir et pour écouter."
} 
MUSICA THEORICA Revista da Associação Brasileira de Teoria e Análise Musical 2019, v. 4, n. 1, p. 160-187-Journal of the Brazilian Society for Music Theory and Analysis@ TeMA 2019 - ISSN 2525-5541

an open form in becoming, where every decision taken on structural and aesthetic criteria shapes the space of the lagoon from the foundations of the form to the realization of its adornment, Venice is the product of a sum of intentions whose coherence is not limited solely to functional criteria. According to Bettini, what is then to be referred to as the Venetian aesthetics is based on a fundamental principle of multiplicity. Indeed, it tends to encourage a centrifugal and reflexive vision of the structure:

The Grand Canal flows in successive meanders of curves, rounded and thus of uninterrupted expansions but not less contained, which also offer an experience, and thus a reading, of the radiation of the spaces that leave, or that converge ${ }^{9}$ (Bettini 2016, p. 79).

The oblique writing drawn from this example extends both "in a longitudinal direction (along the axis of our progression and our gaze) but also, could we say, transversally" (Bettini 2016, p. 81). The structuring of the space does not obey a flat geometry, it reveals itself by creating "counter-looks" (BuciGlucksmann 2008, p. 69) in the attention brought to these folds, in the manner of the Arabesque. To use the word of Bertaggia, the one who looks therefore becomes "himself protagonist not only of the execution, but also of the work of composition" (Bertaggia 1987, p. 134), modifying the shape of the Canal according to what he perceives in the plurality of perspectives.

This example then transcends the simple metaphor of illustration because it brings to light a complex spatial approach that all artistic practices originating in Venice integrate. What Bettini considers a "lateral expansion" is de facto a stylistic of the ubiquitous gap in the music of the archipelago since the Renaissance. The cori spezzati of 16th century written by the musicians who officiated at the Basilica San Marco is probably the most famous example: the dispersion of sources in space and the antiphonic writing direct the hearing towards a multi-axis development requiring an attentive listening opposed to the contemplation of a work arranged on the frontal plane of the Italian theatre. Examples of this configuration can also be found in the pictorial domain. As Jeannie M. Guerrero summarizes, “Tintoretto's foreground figures and

\footnotetext{
9 “Le Grand Canal s'écoule en méandres successifs de courbes, d'arrondis, et donc d'expansions ininterrompues mais non moins contenues, qui proposent également une expérience, et donc une lecture, du rayonnement des espaces qui en partent, ou qui y convergent."
} 
GOHON, K.

background architecture create a compound perspective rather than a single system of planes receding toward a single point" (Guerrero 2010, p. 26). As we will try to demonstrate with the analysis of Das atmende Klarsein and Risonanze Erranti, this plurivocal and reflexive logical approach can also be identified in Luigi Nono's electroacoustic works, in which the dislocation of the linguistic and conventional structures, the delayed projection of the instrumental voices in space and the altered image of the structures varied between the two types of writing that the composer summons generate a "lateral" listening similar to the "counter-looks" aroused by the Venetian ornamental mode.

\section{Towards a multidimensional ornamental structure in Das atmende Klarsein (1980-83)}

Das atmende Klarsein can be considered as the first work of Luigi Nono's late style, probably more than Fragmente - Stille, an Diotima. Not that the quartet does not announce certain features that the composer will develop in his last works, but it is not as representative as Das atmende Klarsein is to some extent, for its instrumental formation, the use of electronics it makes and the different sound and space concepts it testifies. Moreover, it establishes a reflexive logic between a traditional and pitch-based writing - that comes directly from his previous Works -, and the first elements of a new musical language based on perception and very precise sound variations. At first sight, the score is built on the opposition between "the hectic soli of the flute, based on the breath and its variations filtered by the live electronics, and the hieratic style of the pure voices of the choir with its consonant intervals and the permutation of the chords in space $^{\prime 10}$ (Albèra 2007, p. 323), echoing the ancient responsorial form. However, the treatment applied to the musical material and deployed throughout the score offers multiple ways to understand the structure, depending on the parameter we focus on.

\footnotetext{
10 “[...] l'opposition entre les soli mouvementés de la flûte, fondés sur le souffle et ses fluctuations, filtrés par la live electronics, et le hiératisme des voix pures du chœur, avec ses intervalles consonants et ses permutations d'accords dans l'espace".
} 
MUSICA THEORICA Revista da Associação Brasileira de Teoria e Análise Musical 2019, v. 4, n. 1, p. 160-187-Journal of the Brazilian Society for Music Theory and Analysis @ TeMA 2019 - ISSN 2525-5541

\subsection{A "pitch-based" ornamental variation}

Das atmende Klarsein is divided in eight sections - four written sections sung by the choir; three written sections and an improvised one that stands as a coda performed by the bass flute. The choir, which evokes the ancient Venetian cori spezatti11 - as it is mainly homophonic and artificially distributed in space with the help of an electronic device -, begins the work and exposes the initial material, which is built on different configurations of a fifth or a fourth associated to a minor second. As one can see in the first musical phrase (Ex. 1), these intervals underlie each melodic (horizontally) and harmonic (vertically) relationships in the polyphony. In this regard, the A on which the soprano line concludes the phrase is more likely related to the D sung by the contraltos, as it sets a fifth between the two voices and introduces the main cadential model used by Nono in this work. Then, it introduces every configuration of this initial intervallic material, from the most local level of the polyphony - where the intervals constitutes a referential cell of the melodic lines - to the largest structure of the section - the vocal introduction is led by an underlying harmonic progression evolving from $\mathrm{F} \#$ to $\mathrm{C} \#$ and goes back to $\mathrm{F} \#$, reinforced by the succession of an upward and a downward melodic movement.

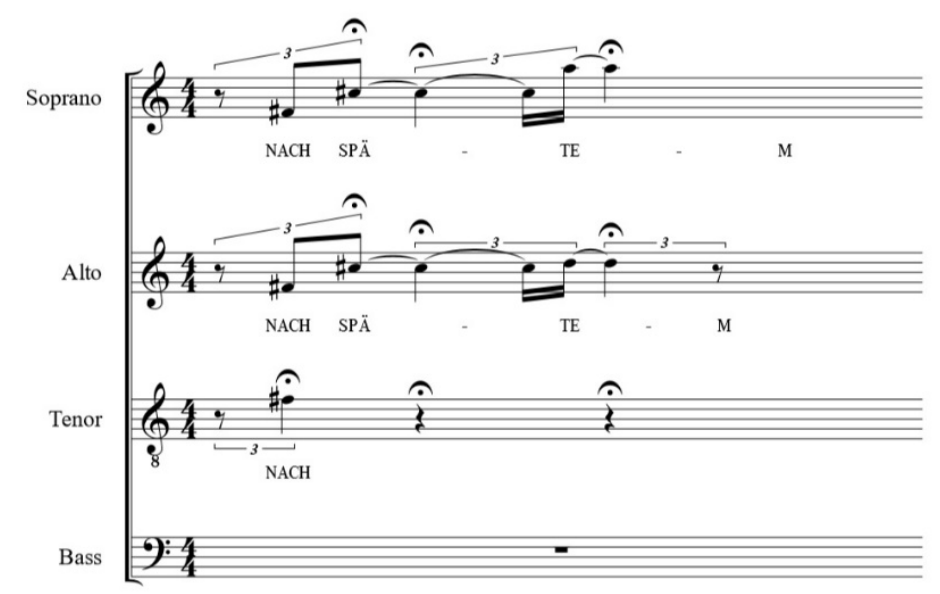

Example 1: first vocal phrase, choral introduction m. 1, Das atmende Klarsein

The next section, played by the flute, contrasts with the choir both by its length and the complexity of its melodic line. As it is illustrated in Example 2, the

\footnotetext{
11 According to Denis Arnold, "Homophony predominates, perhaps because it makes performances easier when choirs are distant from one another, certainly because imitative counterpoint would be less effective in such a mass sound" (Arnold 1959, p. 6).
} 
flute varies and expands the intervallic material, with the usual techniques of ornamentation. In the melodic dimension, the main pitches deducted from the application of the referential intervals starting on the initial $\mathrm{F} \#$ are separated with short melodic embellishments built from substitution pitches which incidentally implies another layer of melodic motives and intervals. For example, the main motive of the introductive gesture $(\mathrm{F} \#-\mathrm{B}-\mathrm{A})$ is intertwined with at least two triads involving the second pitch (F-E-B and $\mathrm{D}-\mathrm{E},-\mathrm{B})$ in the first measure and a motive built around $\mathrm{A}_{\sharp}(\mathrm{D}-\mathrm{A} \xi-\mathrm{A} b)$ which contradicts the cadential suspension on $\mathrm{A}$. Vertically speaking, some phrases use harmonic and multiphonic sounds in order to vary the cell by superimposing its pitches and different virtual melodic lines.
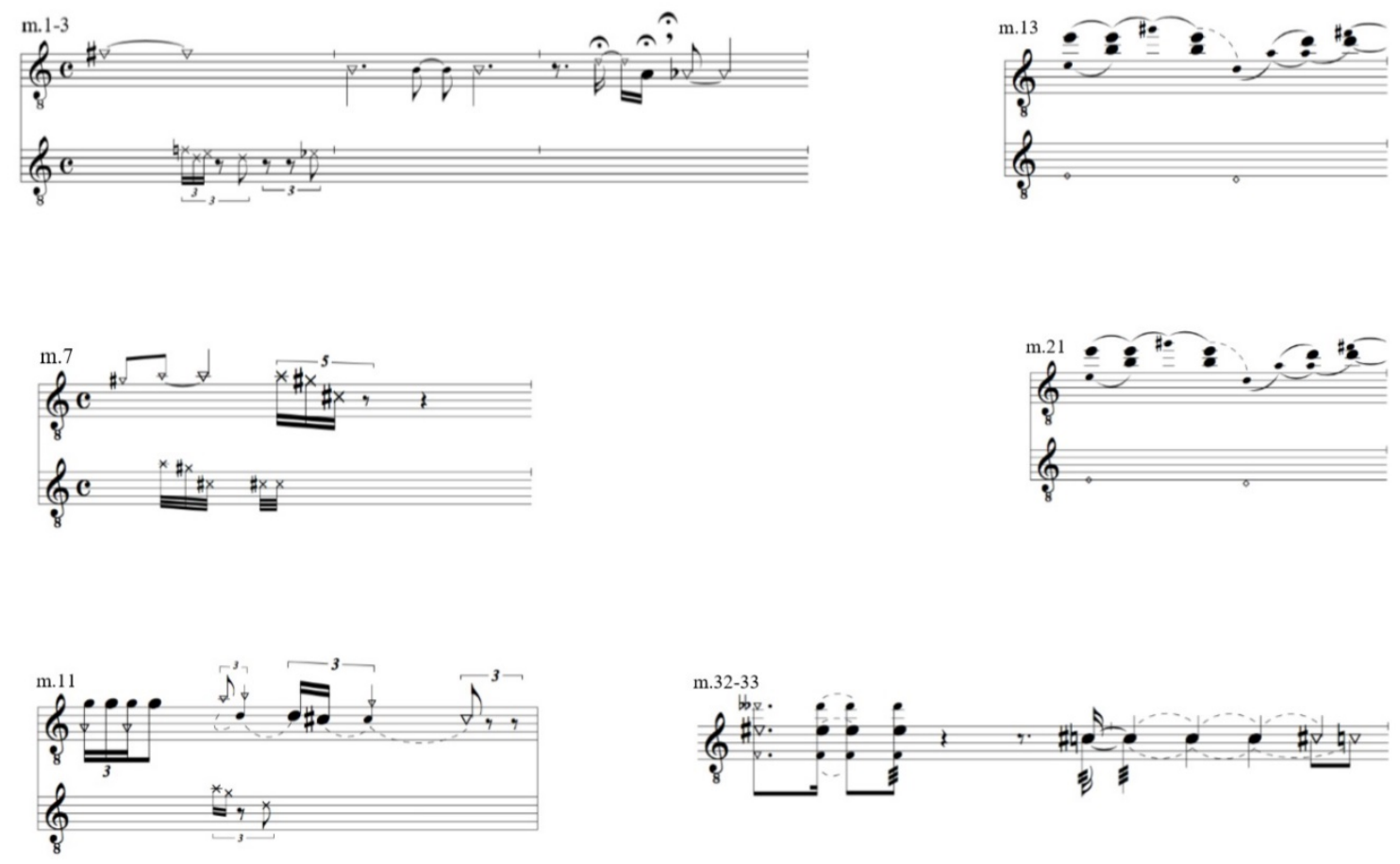

Example 2: Horizontal and vertical variations of the initial material in Flute section I,

Das atmende Klarsein

The second sections of the choir and the flute are related in the same way. The vocal writing is more complex and partially breaks the homophonic style exposed in the first section. Example 3 is an excerpt of choir section II. Indeed, the irregular distribution of the three text fragments - Aus Lust ins Freie / Siehe / عiт $\varepsilon \tilde{\mathcal{L}}$ - tends to create a contrapuntal configuration based on a dynamic pairing of the voices. While the first measure is strictly homophonic, the vocal texture becomes more complex and less constrained on the word "Freie". The 
relationship between tenors and basses is built on two kinds of polyphonic gestures. On the one hand, if the bass line sustains the $\mathrm{A}$, , one can consider that the phoneme [i] on which it enters has been anticipated by the tenor line, according to the strictly syllabic writing of the second choir. This textual anticipation can be considered as resolved as the tenor line joins the bass at the beginning of the next measure, on A,. On the other hand, in a more perceptible manner, the fact that the bass line sustains the $\mathrm{A}$, implies a suspension pattern with the tenor line. The relationship between the two upper voices is also led by a contrapuntal setting, though more complex than the one that has just been described. The soprano voice does not only complete the melodic line of the first phrase by establishing the fifth $\mathrm{A} / \mathrm{E} / \mathrm{E}$, while contraltos sustain "Frei-", it also echoes the final cadential triton $\mathrm{A} \approx / \mathrm{E}$, of the fragment.

This process is continued in choir section III, but with a different text setting that will be discussed further. The second flute section offers a new kind of ornamental variation of this writing process. Indeed, every phrase played by the flute is reintroduced twice into the speakers after a delay of 3 and 3.5 seconds respectively. Thus, one can consider that the contrapuntal style created by the electronic device are similar to the vocal writing of the previous choir section, even if the "text" is completely played by every voice - the real flute and the two virtual ones-: the texture is created with anticipations and suspensions created by the distribution of the same text in time and space.

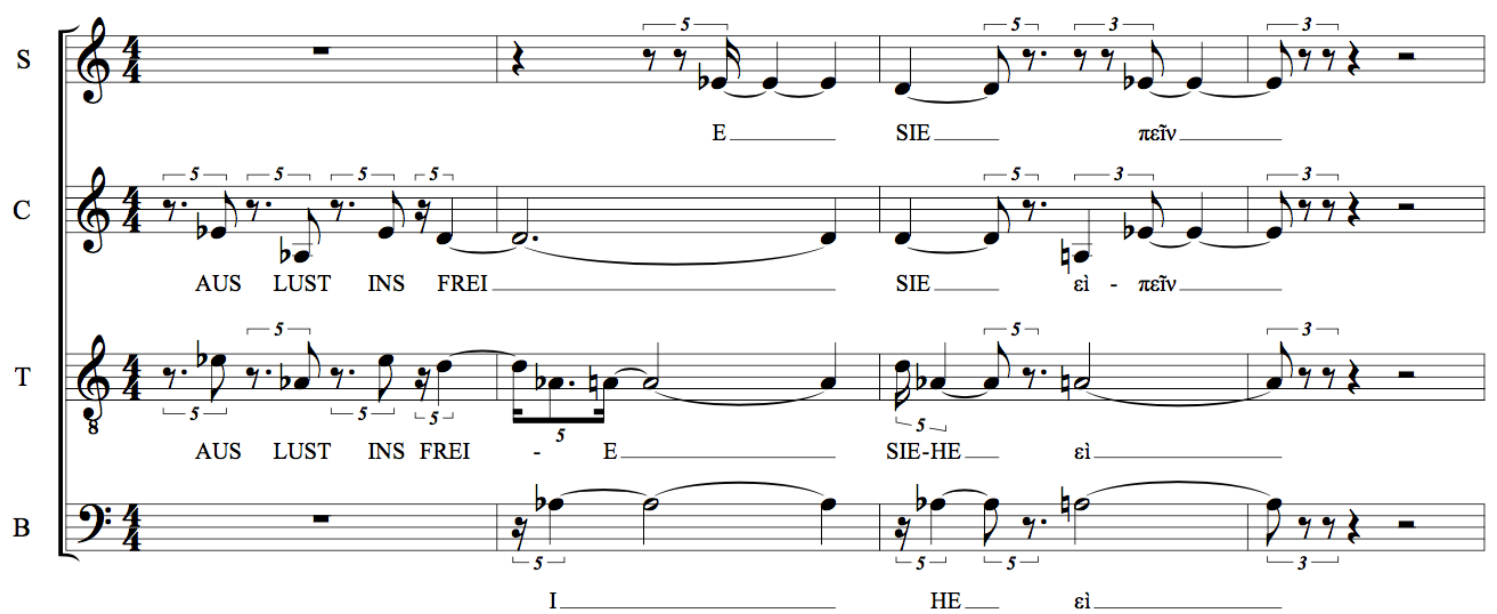

Example 3: Distribution of the notes and the syllables in Choir section II mm. 35-38, Das atmende Klarsein 
Once more, the third choir and flute sections present the same configuration. The voices develop the process heard before but the complexity of the vocal texture is now induced by the fact that different text fragments are sung simultaneously. Example 4 is an excerpt of the third flute section - which is its last written section in the score. The flautist plays all three staves simultaneously, without the support of any electronic device - the only electronic transformation used in this section is made of two static harmonizers that transpose the flute part a quarter note up and down. The bottom staff is the main line: it prescribes the fingering imposed to perform the other virtual voices, and its melodic line is the most intelligible one because of the modes of emission it summons. The second line is built on "eolien"12 harmonics, which follow the rhythm of the main line almost systematically but vary the pitches. The third line is made of whistle tones with both absolute and relative pitches and rhythms. Hence, one can consider that it is an ornamental variation of the vocal writing developed in the technical repertoire of the flute: the entire section is based on a homophonic writing but the texture is locally more complex because of the coincidental simultaneity of the three independent lines that develop their own texture.

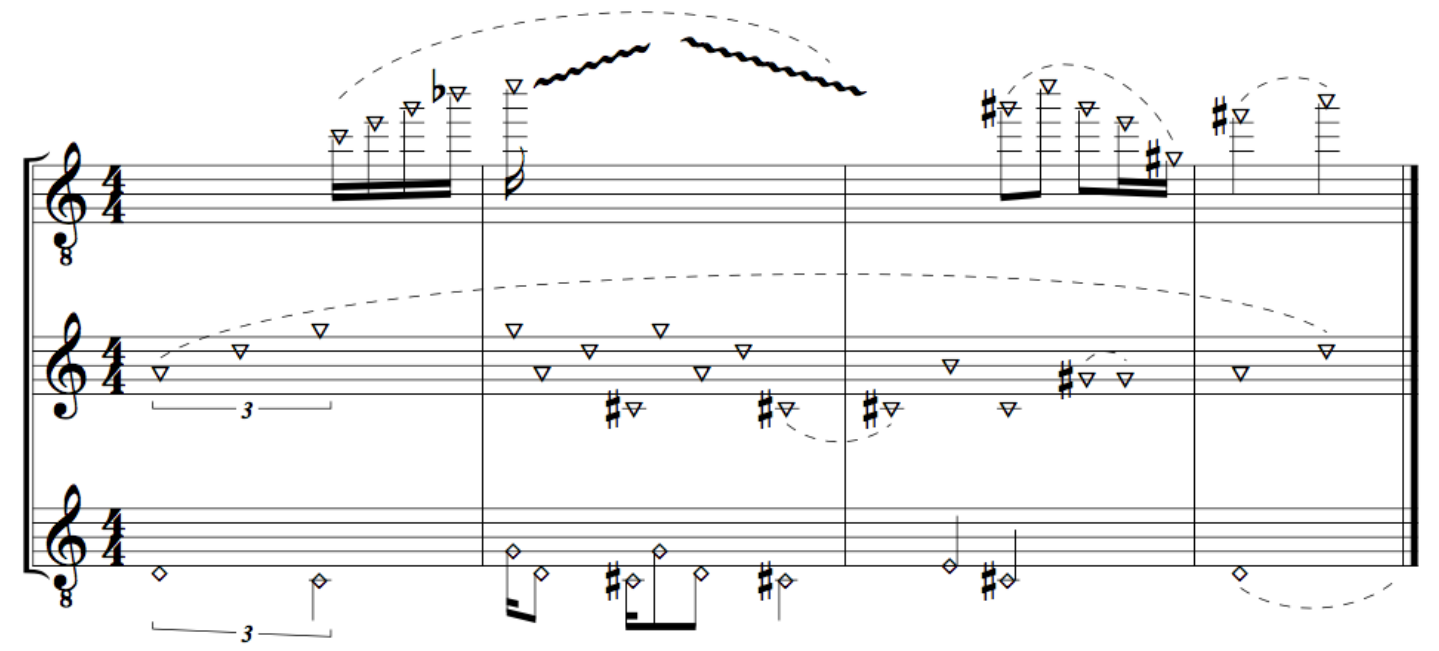

Example 4: Distribution of the notes in Flute section III mm. 13-16, Das atmende Klarsein

Thus, as the first three flute sections are built on variations of the writing processes developed in the first three choir sections, one can understand the

\footnotetext{
${ }^{12}$ As André Richard and Marco Mazzolini explains in the score of Risonanze erranti, "the term 'eolien' used by Nono means 'wisthle-tones': the eolien are therefore very high partials, isolated and reinforced within a given sonic spectrum. The fundamental sound appears and disappears like a shadow ('shadow sound')" (Richard; Mazzolini 2015, p. XXVIII).
} 
MUSICA THEORICA Revista da Associação Brasileira de Teoria e Análise Musical 2019, v. 4, n. 1, p. 160-187-Journal of the Brazilian Society for Music Theory and Analysis@ TeMA 2019 - ISSN 2525-5541

relationship between the choir and the flute as a long ornamental variation according to Schoenberg's definition:

One can distinguish two methods of varying a motive. With the first, the variations usually seem to have virtually nothing more than an ornamental purpose; they appear in order to create variety and often disappear without a trace $[\ldots]$. The second method can be termed developing variation. The changes proceed more or less directly toward the goal of allowing new ideas to arise (Schoenberg 1917, p. 38-39; Schoenberg 2006, p. 247).

The understanding of the musical structure of Das atmende Klarsein as an ornamental variation is a result of a pitch-based analysis, which only considers the diagrammatic symbolic notation of the written score. However, the material and variation processes of Das atmende Klarsein cannot be understood through the analysis of its pitches and durations systems, as Nono's writing is mainly based on the experimentation of sound parameters and specific timbres.

\subsection{A "sound-based" developing variation}

As mentioned previously, the flute writing develops a sound-based discourse made of fluctuations of breath rather than a pitch-based one, which is mainly attributed to the choir. Returning to Example 1, with this in mind, the first flute section seems to be based on two different kinds of variation: the expansion based on the usual ornamentation process that has been identified previously and a variation of the initial cell in the sound domain. Indeed, as a result of Nono's research of new sound possibilities in his music, it appears that almost each note played by the flutist uses a different mode of emission. Thus, the pitchbased expansion of the motive is hidden by the diversity of the sound qualities because the pitches cannot be distinctly heard. This is particularly apparent in Example 1. Moreover, the different sounds played by the flute and scaled from the usual timbres of the instrument to a complete breath induce a particular hierarchy that influences the listening.

One can distinguish therefore a large-scale phrasing marked by the recognizable "pitched sound" of the flute, which partially contradicts the pitchbased writing identified previously and sounds adorned and enhanced by the breathy and unpitched sounds. Regarding the homophonic style of the first choir section, the flute section will be heard as an increasing of the sound complexity opposed to the pure and homophonic sound of the choir whereas the writing 
processes remains homogeneous throughout both sections. This flute section then appears to be related to the second choir section in a new way: one can relate the vertical distribution of the syllables of each text fragment that break the homophonic style with the large-scale structure of the flute section as it presents a musical phrase expanded by an increasing complexity in the sound domain.

The polyphonic writing of the choir previously presented even seems to be linked to the cells of the flute written in whistle tones in the vertical variations presented in Example 1. The different notes that form the musical phrase are presented with suspensions and anticipations that create a particular polyphonic writing and announce the text distribution highlighted in Example 2. Once again, the second flute section and the third choir section can be related in a similar way: if the second flute section unfolds a writing process similar to the one exposed in the previous choir section, it also varies it by a sound oscillation between breath and pure note. Once again, it leads the writing to more complex sound qualities. In a certain way, it is continued in the third choir section. Considering that there is no change operated in the writing process between the flute and the choir section, the variation is almost only contained in the sound domain and induced by the superimposition of the different text fragments. The vocal treatment is then formed on the sound characteristic of the syllables, their "timbre", with almost no consideration of their meaning.

Consequently, the pitch-based writing inherited from the serial technique, mainly built on permutation, transpositions and motivic variations of a limited material, seems to be gradually forsaken in favor of the expansion of the sound dimension of the music, which leads to the particular device of the last section of the work. Indeed, this section is built on a particular ornamental structure that evokes the arabesque as the flautist has to improvise and interact with a tape recorded with sounds that he played in the previous sections: he unfolds therefore a musical line that is based on the sound material he played before, and the person in charge of the sound direction has to interact with what he hears by adjusting the dynamics of the tape and its movements in space accordingly. Luigi Nono will further explore this setting of structural ornamental relationship in its soloist works as La Lontananza Nostalgica Utopica Futura (1988).

From this perspective, one can define Das atmende Klarsein as a soundbased developing variation, according to Schoenberg's second method: each section of the flute increases the sound complexity of the writing processes 
MUSICA THEORICA Revista da Associação Brasileira de Teoria e Análise Musical 2019, v. 4, n. 1, p. 160-187-Journal of the Brazilian Society for Music Theory

developed in each choir section, and each choir section seems to be influenced by sound richness of the flute sections, which heterogeneity is echoed by the increasing fragmentation and discontinuity between the lines of the polyphony, both in their harmonic relationship and in the treatment of the poem. Furthermore, the writing processes do not affect the initial cell in the usual way - it is almost not varied in the "pitch-domain" and can be found in its original form until the end of the score - but are only developed in terms of sound complexity: the bass flute uses a wide range of modes of emission and electronic transformations and the vocal treatment tends to exploit the sound qualities of the phonemes only. By setting up the flute and the voices as an heterogeneous reservoir of acoustic and sound resources used to vary the initial cell - which is preserved throughout the score -, Das atmende Klarsein exposes one of the project that will be developed in the composer's late works, namely to free the ear "from its visualizing, selective and unidirectional habits, in an almost ritual manner, according to the wide diversity of the acoustic life, which constantly accompany us“(Nono 2007, p. 524). ${ }^{13}$

This kind of multidimensional structure is not only developed in this first work of Nono's late style, but can be found in each vocal work written by the composer during the last ten years of his life.

\section{Rethinking the musical discourse in the light of the ornamental phenomenon: the case of Risonanze erranti (1987)}

If Das atmende Klarsein introduces the main elements of Luigi Nono's late style, the work is not actually representative of the works created in the ten last years of the composer's life, especially in terms of musical discourse and space conception of music: even if it is developed in a new musical dimension, the fact that the piece is entirely directed towards an increasing of complexity - whether related to a motivic or a sound domain -, which ends with a return to silence, evokes the traditional model of conducting a musical phrase according to the arsis-thesis sequence, or, as Claude Abromont highlights it, the tonal phrasing of the melodic cell organized around the triad "anacrusis [anacrouse], emphasis

13 "La perception et l'écoute peuvent être rendues plus difficiles, mais à la vérité, elles peuvent vraiment libérer les oreilles des habitudes monodirectionnelles, visualisantes et sélectives, de manière presque 'rituelle', par rapport à la très riche variété de la vie acoustique qui nous accompagne sans cesse." 
[accent], inflexion [désinence]" (Abromont; De Montalembert 2008, p. 140). Nevertheless, some of the works written after Prometeo seem to reuse the developing variation principles in order to create a new kind of structural relationship between the voice and the instrument - or between a pitch-based and a sound-based approach -, and extends it to an upper formal level between sound and space, as it is the case of Risonanze erranti (1986-87), written for a mezzo-soprano, a bass flute, a tuba and six percussionists.

\subsection{A new ornamental relationship between pitch and sound}

The score is composed of five groups of fragments taken from literature one group is based on excerpts of Ingeborg Bachmann's Keine Delikatessende and another one on Herman Melville's poems - or from musical works - Mahleur me bat written by Ockeghem, Josquin's Adieu Mes Amours or Machaut's Lay de Plour - and creates two interwoven conceptual spaces from the characteristic of the voice and the instruments, in a way that is reminiscent of Das atmende Klarsein. The first one can be termed as a semantic space: it unfolds a pitch-based musical discourse and contains the text fragments set to music in a way that makes them sufficiently recognizable to activate the listener's language memory, as well as the different musical quotations. On this basis, the different idiomatic and figurative materials echoing a traditional way to conduct the musical discourse can be declined in this space. The second space is a sound space and unfolds the writing tools characteristic of the late style of the composer: the development of a wide range of modes of emission, the electronic sound transformations that expand a sound by simultaneously transposing it a quarter-tone up and down, and the exploitation of text fragments that only use the sound qualities of phonemes. The musical discourse can then be understood as the articulation of different combinations of these two conceptual spaces, which conducts the variations of the fragment groups.

Example 5 outlines the different materials attributed to the two spaces in the Bachmann fragment group. The five fragments are distributed throughout the score. The first fragment of the group is only exposed in the sound space: there is no musical phrase and the different notes and chords are separated by long silences. Furthermore, the three words sung in this fragment present a similar structure and are best heard as three successive variations of the timbre characterized by a brief attack (" $n-{ }^{\prime \prime}$ and " $\left.m-{ }^{-}\right)$, a sustained closed vowel (/' $\mathrm{I} /$ in 
MUSICA THEORICA Revista da Associação Brasileira de Teoria e Análise Musical 2019, v. 4, n. 1, p. 160-187-Journal of the Brazilian Society for Music Theory and Analysis @ TeMA 2019 - ISSN 2525-5541

"Nicht" and "Mir", and /'e:/ in "Mehr") and a noisy and brief stop (/çt/ and /r/) than three intelligible words. Hence, one can consider the semantic space as an ornament of the sound space in this fragment as it is set up as a figurative embellishment of the sound of the voice. The second and the third fragments propose two different semantic variations of Bachmann. In the first one, the flute develops a long and regularly pulsated melodic line built on a succession of sequences, each clearly identified by a phrasing shape and dynamic shades. Even if the reference to Keine Delikatessen is never presented in the fragment, except for its title in the score, it is highly suggested by the homophonic texture realized with an instrument characterized by the proximity of its inflections with voice, and by the fact that the musical processes unfolded in this fragment echo a traditional expressive approach which contrasts with the erratic and nondirectional nature of Risonanze erranti musical discourse.
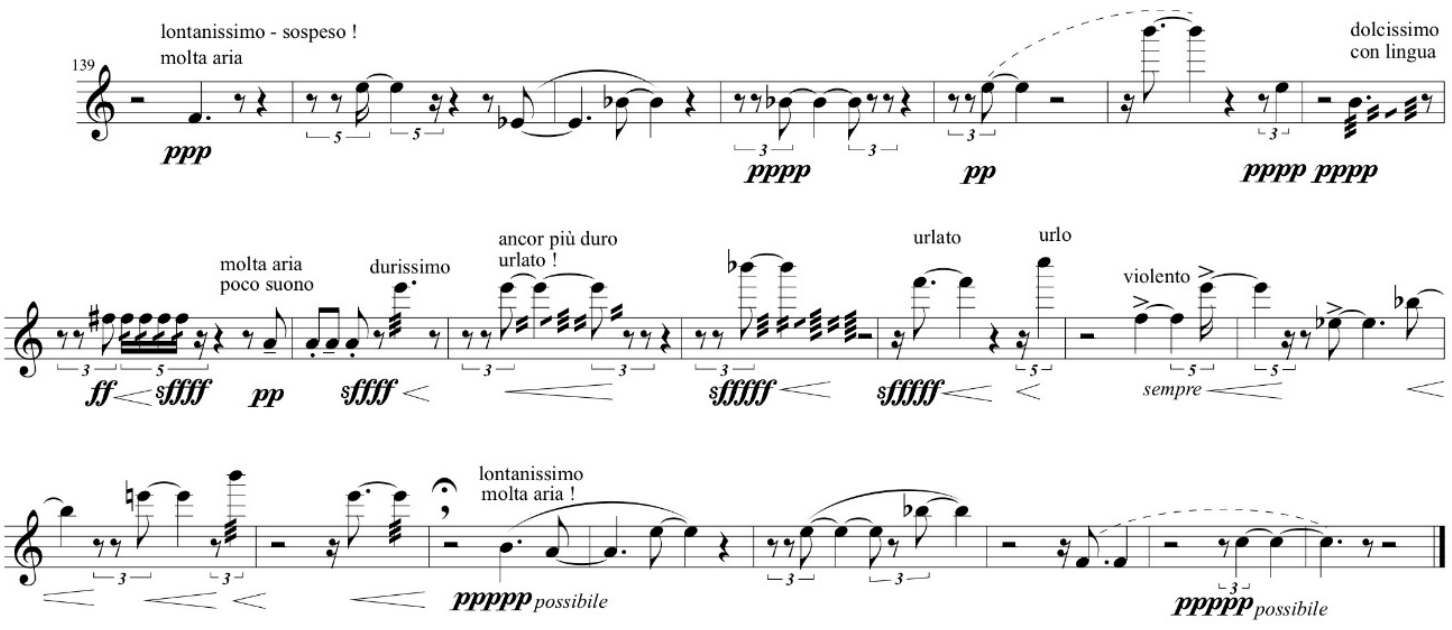

Figure 1: Piccolo part, Bachmann 2, mm. 139-160, Risonanze erranti

Bachmann 3 then synthetizes the configuration of the two first fragments. The text returns, but it is faded in a recto tono based on the alternation between the trombonist, the flutist and the mezzo-soprano in order to create a continuous pitch in which the words are not only a literary content, but also integrates a cyclic dynamic process that one can define as a sound-based musical gesture. Indeed, the first four vocal interventions are based on two syllables echoing the similarity of "Nicht", "Mir" and "Mehr" in Bachmann 1. Due to the expression indication - "dentro al microfono, quasi solo fiato-pochissimo suono, molto articulate le consonanti" -, the words "einsehn", "gelernt", "hunger" and "tränen" appears as modes of articulation of the recto tono. In this perspective, the musical gesture 
can also be understood as a complete phrase, as the word "finsternis" interrupts the cyclic process in terms of metric structure and homogeneity but it is logically implied by the text and integrated in the recto tono.

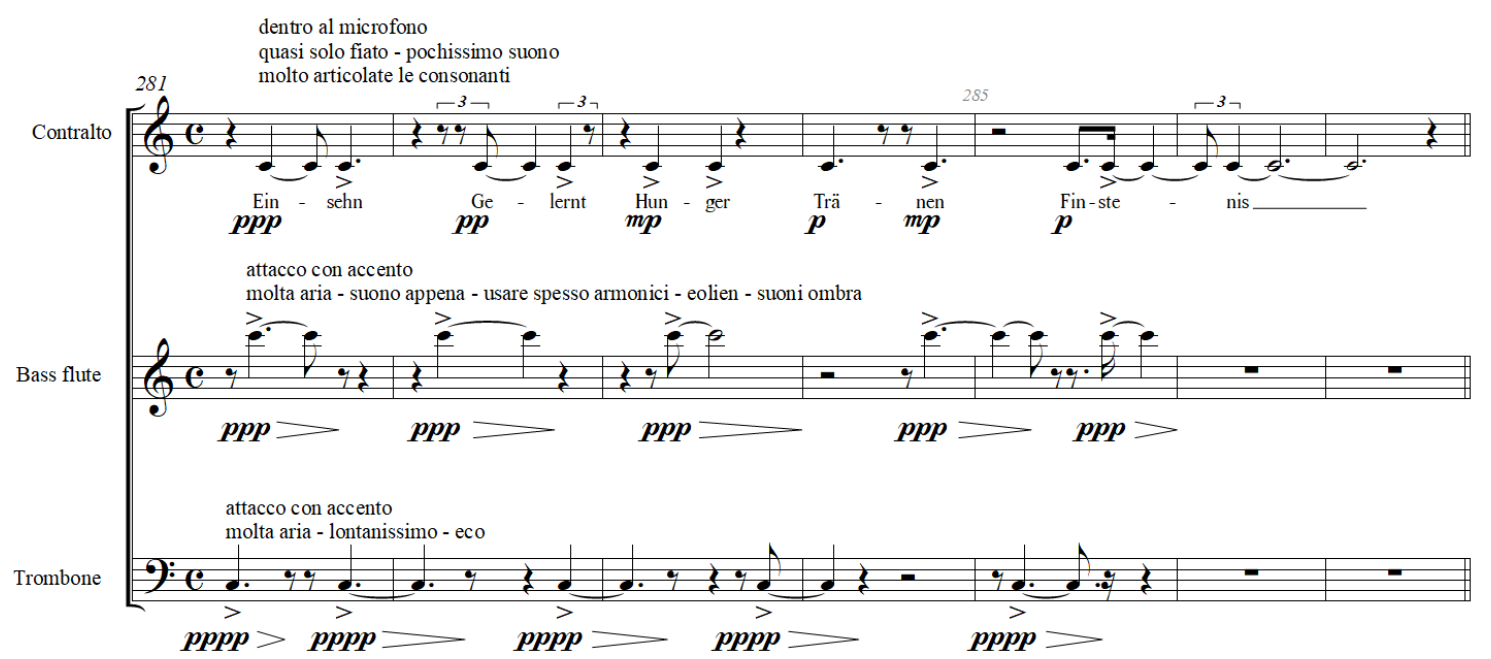

Figure 2: polyphonic distribution, Bachmann 3, mm. 281-287, Risonanze erranti

In the fourth fragment, the relationship between the two spaces seems to be overturned. The musical material is almost entirely contained in the semantic space as the voice sings an intelligible text split in two musical gestures with a melodic gesture that echoes the flute in the second fragment, as the vocal line is irregular, disjointed and contrasted. ${ }^{14}$ The sound space only outlines the voice with electronic transformations and punctuates the fragment with the last two words ("Noch" and "Vor") written in the vocal model of Bachmann 1. Finally, the two spaces appear to be equally distributed in the last fragment, which lasts almost six minutes and ends the work. On the one hand, the instrumental parts develop the recto tono heard in the third fragment with different modes of emission and a dynamic profile reminiscent of Bachmann 2 - as the musical texture is formed by isolated pitches in a series of short crescendos and contrasted dynamics. On the other hand, the words sung by the voice are intelligible, but the text is only made with the German personal pronouns ("ich, $d u$, er, sie, es, wir, $\left.i h r^{\prime \prime}\right)$ and it is scattered in time, without any phrase-oriented mode of organization. Thus, if each fragment seems to present an original configuration

14 The harmonic material of the phrase is also based on semitones and fourth/fifth as it is introduced in Bachmann 1 and developed in Bachmann 2. 
MUSICA THEORICA Revista da Associação Brasileira de Teoria e Análise Musical 2019, v. 4, n. 1, p. 160-187-Journal of the Brazilian Society for Music Theory and Analysis@ TeMA 2019 - ISSN 2525-5541

of the two conceptual spaces, the entire group is set up as a developing variation that unfolds the semantic space with the materials exposed in the sound space. In the same perspective, the Ockeghem fragment group progresses towards the semantic space: the famous phrase "Malheur me bat" is performed first by the crotales - Nono uses the text to guide the phrasing in the manner of FragmenteStille-, and it becomes more intelligible in the other fragments as the voice sings "-lheur me" in the second one and "Malheur" in the last one.

On the contrary, Josquin fragments unfold an opposite developing variation, which is oriented towards the sound space. Example 6 summarizes the materials and their distribution between the two spaces in the five fragments of the group. In the first fragment of the group, the sound space has no other function than to accompany the musical quotation of Josquin's work sung by the voice and doubled by the flute and the tuba. In Josquin 6, the structure is inverted: the text is split in two cells that evoke the variations of the timbre mentioned previously about Bachmann 1; the phrase played by the tuba is also split and the sound spectrum is more complex due to the different modes of emission and the dynamic curve applied to the percussion instruments. The next fragments continue the process, even if the semantic space is more active in Josquin 10 than in Josquin 9 because the musical phrases are based on the complete quotation of "Adieu mes amours". Finally, the last iteration of the quotation is only contained in the sound space, even if the performance of the crotales is guided by the text "Adieu". The group formed with Machaut's quotation is similarly organized.

Hence, Risonanze erranti unfolds a new kind of musical discourse by superimposing different developing variations based on the writing processes introduced in Das atmende Klarsein. The distribution of the fragments in the score continuously breaks the variation dynamic and avoids directing the work towards one conceptual space or the other. Thus, they appear as two adjacent lines that locally meet and adorn the other one, but without succumbing to it. Then, it reveals the gap between the two spaces without leading the listening in favor of one or the other and it engenders a counter-listening - as an analogy to Christine Buci-Gluckmann's "counterlook" - of "the close and the distant, devoid of any illusion and perspective, without a hold on things, similar to infinity" (Buci-Glucksmann 2008, p. 67), which originates from the Byzantine ornamentalism omnipresent in Venice, according to the philosopher. 


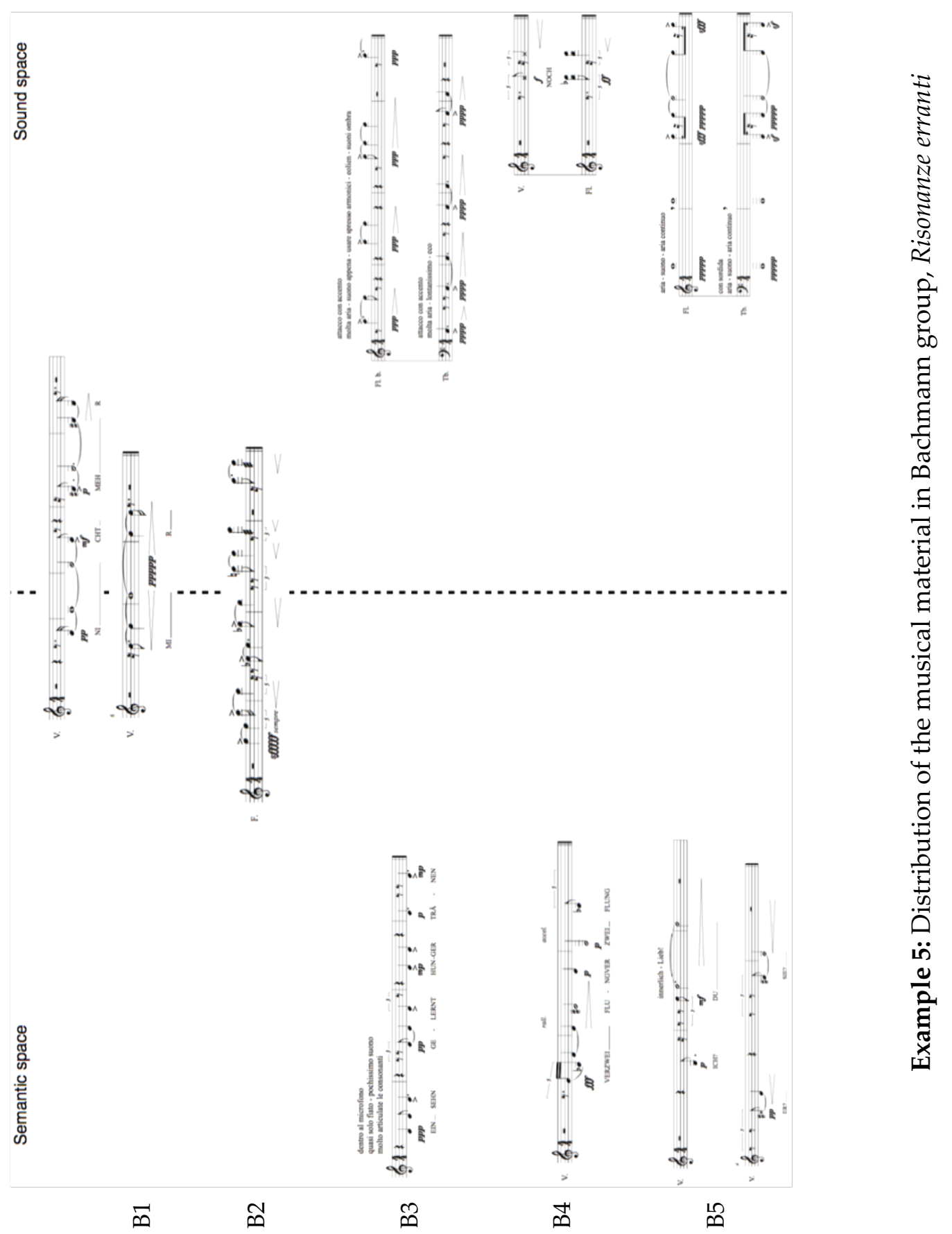


MUSICA THEORICA Revista da Associação Brasileira de Teoria e Análise Musical 2019, v. 4, n. 1, p. 160-187-Journal of the Brazilian Society for Music Theory and Analysis @ TeMA 2019 - ISSN 2525-5541

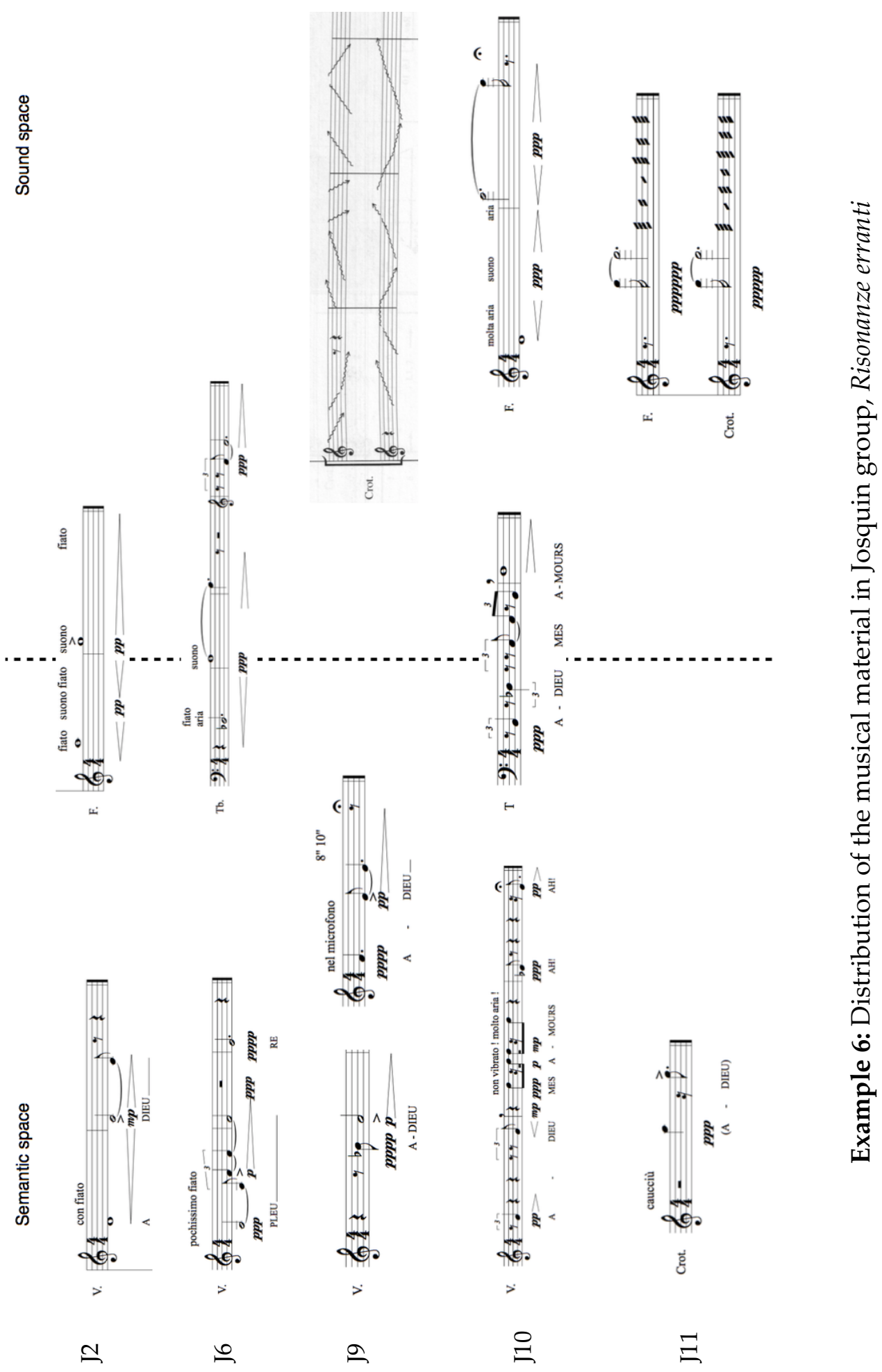




\subsection{Towards the musical discourse as an ornament of space}

Risonanze erranti cannot be reduced to the relationship between the semantic and the sound space. These two conceptual spaces form de facto a dynamic texture that conducts the same kind of relationship with the spatial feature of the work. The spatial dimension of the score is not only represented by the use of a dynamic electronic spatialization, but also with specific motives played by the percussion instruments. It is almost silent, with unpitched sounds and the rhythm and the sources of emission are unrecognizable because of the two delay lines combined to the distribution and the movements of the sounds between the loudspeakers. One can de facto define this motive as an ornament of space according to the fact that it accomplishes the dynamic spatialization in the sound domain and is only dedicated to the representation of the spatial component of the work, a true "reading of space" (Bertaggia 1987, p. 144). Example 7 details two patterns of the motive.

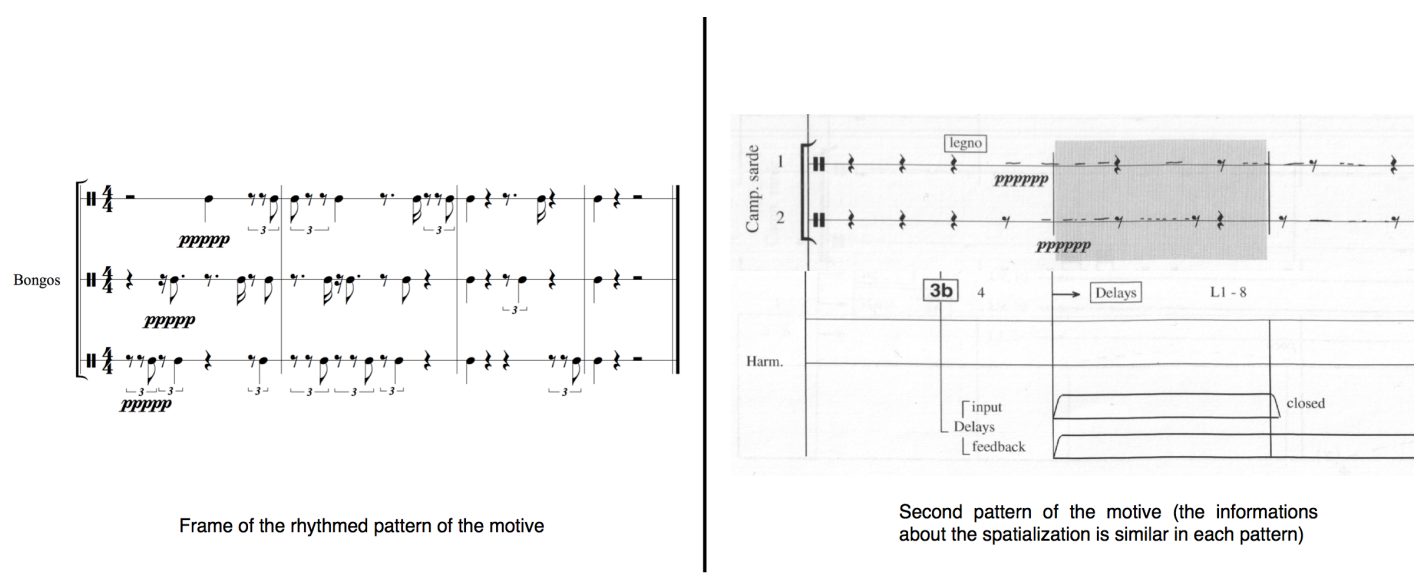

Example 7: Two patterns of the "ornament of space" motive, Risonanze erranti

The first pattern appears in the first five fragments of the work in alternation with the vocal phrases based on Melville's Misgivings poem, but it cannot be considered as a sound material of the fragment group as it is excluded from the writing processes of the group. This motive - now in the ornamental meaning of the term - is then set as an independent musical object that punctuates the writing developments between the sound and the semantic spaces identified previously. The alternation slowly disappears as the motive intertwines with the fragments. The second pattern can be heard after the first Ockeghem fragment and accompanies a Melville's fragment. However, this "sound ornament of space" and the dynamic figures of spatialization associated 
with it extend and locally split, generating different variations of the motive in contact with the sound or the semantic space. The space seems actively involved in the Machaut fragments group. In Machaut 4, the motive separates the two instances of the repeated phrase "Ahimé". As shown in Example 8, it is built on the superimposition of two variations of the second pattern played by the Sardinian bells and the crotales. The dynamic distribution of the space, though, is not only limited to the motive: the voice is also distributed in the loudspeakers and successively forms two inverted circular figures. Hence, the spatialization is used in two ways: on the one hand, it is set as a manifestation of the spatial texture of the work, which is very dynamic and ungeometrical - represented by the sound motive. On the other hand, there is a spatial ornament of the semantic space that evokes a geometrical figure, which is superimposed on the spatial texture. The second and the fifth fragments continue this process with a different spatial ornamental figure applied to the sound space. Finally, the only representation of the spatial component of the work in the fourth fragment is the initial spatialization pattern applied to a different sound material, without the motive. This double dimension can also be found in Josquin group.

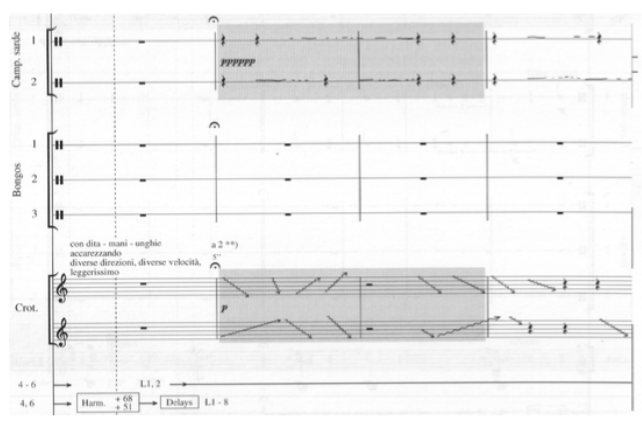

"Ornament of space", m. 105-108
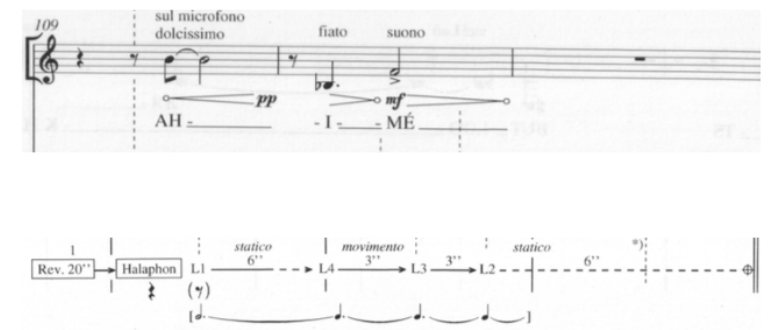

Spatial ornament of the voice, m. 109-111

Example 8: ornament of space and spatial ornament of the semantic space in Machaut

\section{4, Risonanze erranti}

To these elements must be added a third variation of the motive that complexifies the perception of the space in this piece. The "ornament of space" can be found several times in the percussion parts, but without any electronic spatialization. For example, the sound material of the third Machaut fragment is almost entirely formed by the rhythmic pattern of the motive statically projected in front of the audience with a dynamic profile oscillating between $p p p p p$ and fff. 
The ornament of space is then used as a different kind of ornament of the sound space as, in this case, it only exploits the sound qualities of the motive - which is set as a sound representation of the space -, contrary to the previous variation that uses a spatial figure to adorn the sound and the semantic space. This variation can be found repeatedly throughout the score and creates, thereupon, a dialectic relationship between the spatial and the sound dimension of the motive. This dialectic culminates in the last three fragments of the piece, in which the two patterns of the motive can be heard with and without the delays and the spatialization. Thus, as it is emancipated from its usual figurative and "geometrisable" - in the Euclidian meaning of the term - representation, the spatial component of the work allows the listener to experience a "true listening" of the space, according to Massimo Cacciari:

a conditioned listening, which resolves itself in the 'belief', is reduced to a visualizing listening of metaphors and constitutes a limited form of research that impedes the possibilities of perception and thus of a true listening (Bertaggia 1987, p. 137). ${ }^{15}$

Finally, the entire musical discourse of Risonanze erranti is built on an ornamental logic, a "specifically artistic manner of a recursive process of distinction" (Golsenne, A. et al., p. 11-26) according to Michael Dürfeld's definition. Indeed, as it unfolds multiple dimensions of space that locally meet and enlighten each other, resonate in each other, but don't change in favor of one or another, the work wanders between musical representations of the multiple dimensions of a concept of space which cannot be positively presented, establishing a "genuine stylistic of the gap in which the nihil atopia turns into [...] a vibrant figure", to borrow the expression that Christine Buci-Glucksmann uses to define the Venetian vision of the ornamental phenomenon.

\section{Conclusion}

The new features that Luigi Nono develops in his late works seem to be related to the ornamental phenomenon in many ways. On the one hand, the fact that the traditional techniques of ornamentation are unfolded in the sound

\footnotetext{
15 “[...] une écoute conditionnée, qui se résout dans la 'croyance', se réduit à une écoute visualisée de métaphore, constituant une forme de recherche limitée qui entrave les possibilités mêmes de la perception et partant, d'une véritable écoute..."
} 
domain in order to realize the well-known "mobile sound" in Das atmende Klarsein testifies a form of denial of the traditional ornamental manifestation in music by deflecting it from its figurative function. On the other hand, it has been demonstrated in Risonanze erranti that the work itself can echo an ornamental function considering its relationship with Nono's multidimensional and "ungeometrisable" conception of space, as it summons a "representative language of what escapes to the representation" (Buci-Glucksmann 2008, p. 77). Thereupon, the work avoids any narrative or discursive form as it only enlightens the multiple dimension of space in a negative way, on their periphery. With Luigi Nono, the music becomes an ornamental line, a virtual surface in which the heterotopias that form the space collide and allow them to be only heard through a differential listening.

\section{References}

1. Abromont C.; De Montalembert E. 2008. Guide de la théorie de la musique. Paris: Fayard/Henry Lemoine.

2. Albèra Philippe. 2007. Le Son et le Sens. Essais sur la musique de notre temps. Genève: Contrechamps.

3. Albèra Philippe. 1987. Entretien avec Luigi Nono. Luigi Nono 1987. Paris: Contrechamps/Festival d'Automne à Paris, p. 13-22.

4. Arnold Denis. 1959. The significance of "Cori Spezzati". Music E Letters, v. 40, n. 1, p. 4-14.

5. Borio G.; Morelli G.; Rizzardi Veniero. 1999. La nuova ricerca sull'opera di Luigi Nono. Firenze: Olschki.

6. Bertaggia Michele. 1987. Prometeo - Conversation entre Luigi Nono et Massimo Cacciari. Luigi Nono 1987. Paris: Contrechamps/Festival d'Automne à Paris, p. 132-146.

7. Bettini Sergio. 2016. Venise. Naissance d'une ville. Trans. by Farazzi P. Paris: L'Éclat.

8. Buci-Glucksmann Christine. 2008. Philosophie de l'ornement. D'Orient en Occident. Paris: Galilée.

9. Carboni Massimo. 2012. Ornement et Kunstwollen. Images Re-vues, v. 10, http://journals.openedition.org/imagesrevues/2032. 
10. Dewitte Jacques. 2005. Le sens ontologique de l'ornement. in Laroque D.; Saint Girons B. (Eds.). 2005. Paysage et ornement. Paris: Verdier, p. 39-48.

11. Dewitte Jacques. 2010. La manifestation de soi. Eléments d'une critique philosophique de l'utilitarisme. Paris: La Découverte.

12. Edwards Peter I. 2008. Object, Space, and Fragility in Luigi Nono's Das atmende Klarsein. Perspectives of New Music, v. 46, n. 1, p. 225-243.

13. Feneyrou Laurent. 1993. Introduction. in Nono Luigi. 1993. Ecrits. Paris: Bourgois.

14. Gadamer Hans G. 2018. Vérité et méthode. Les grandes lignes d'une herméneutique philosophique. trans. By Fruchon Pierre; Grondin J.; Merlio G. Paris: Seuil.

15. Geiger F.; Janke A. (Eds.). 2015. Venedig, Luigi Nono und die komponierte Stadt. Zur musikalischen Präsenz und diskursiven Funktion der Serenissima. München: Waxmann.

16. Griffiths Paul. 2010. Modern music and after. 3rd ed. New York: Oxford University Press.

17. Golsenne Thomas. 2012. L'ornement aujourd'hui. Images Re-vues, v. 10, http://journals.openedition.org/imagesrevues/2416.

18. Golsenne T.; Dürfeld M.; Roque G.; Scoot K.; Warncke C.-P. 2010. L'ornemental: esthétique de la différence. Perspective, v. 1, http://journals.openedition.org/perspective/1200.

19. Grabar Oleg. 1996. Penser l'art islamique. Une esthétique de l'ornement. Paris: Albin Michel.

20. Guerrero Jeannie Ma. 2010. Non-Conventional Planar Designs in the Works of Nono and Tintoretto. Music Theory Spectrum, v. 32, n. 1, p. 26-43.

21. Laroque D.; Saint Girons B. (Eds). 2005. Paysage et ornement. Paris: Verdier.

22. Loos Adolf. 2015. Ornement et crime. trans. by Cornille S.; Ivernel P. Paris: Payot-Rivages.

23. Melkert Hella. 2001. "Far del silenzio cristallo": Luigi Nono, Chorkompositionen im Rahmen des "Prometeo". Saarbrücken, PFAU Verlag.

24. Morgan David. 1992. The Idea of Abstraction in German Theories of the Ornament from Kant to Kandinsky. The Journal of Aesthetics and Art Criticism, v. 50, n. 3, 1992, p. 231-242.

25. Nielinger-Vakil Carola. 2016. Luigi Nono. A composer in context. Cambridge: Cambridge University Press. 
MUSICA THEORICA Revista da Associação Brasileira de Teoria e Análise Musical 2019, v. 4, n. 1, p. 160-187-Journal of the Brazilian Society for Music Theory and Analysis @ TeMA 2019 - ISSN 2525-5541

26. Nono Luigi. 1993. Écrits. trans. by Feneyrou L. Paris: Christian Bourgois.

27. Nono Luigi. 2007. Écrits. trans. by Feneyrou L. Genève: Contrechamps.

28. Nono Luigi. 2007. Das atmende Klarsein. 139378. Milan: Ricordi.

29. Nono Luigi. 2015. Risonanze erranti. 139646. Milan: Ricordi.

30. Nono L.; Restagno E. 1993. Une autobiographie racontée par l'auteur. In Nono L. 1993. Écrits. Paris: Christian Bourgois.

31. Ramazzotti Marinella. 2007. Luigi Nono. Palermo: L'Epos.

32. Reissig Elfriede E. 2014. Luigi Nono, Das atmende Klarsein. Text - Musik Struktur. Saarbrücken: PFAU Verlag.

33. Saint Girons Baldine. 2005. Pour une théorie de "l'ornance": les leçons de l'art mural. In Laroque D.; Saint Girons B. (Eds). 2005. Paysage et ornement. Paris: Verdier, p. 57-73.

34. Schoenberg Arnold. 2006. The Musical Idea and the Logic, Technique, and Art of its Presentation. trans. by Carpenter P.; Neff S. Bloomington: Indiana University Press.

35. Schoenberg Arnold. 2010. 1st ed, 1975. Style and Idea. Oakland: University Press of California.

36. Vieira de Carvalho Mário. 1999. Towards Dialectic Listening: Quotation and Montage in the Work of Luigi Nono. Contemporary Music Review, v. 18, n. 2, p. 37-85. 
MUSICA THEORICA 201908

SCIENTIFIC ARTICLE

Data do recebimento: 07/08/2019

Data da aprovação final: 27/08/2019

\title{
The Medial Caesura Declined in Schubert's Sonata-Form Expositions
}

\author{
A Cesura Medial Recusada nas Exposições de Obras em Forma Sonata de \\ Schubert
}

Gabriel H. Bianco Navia

Universidade Federal da Integração Latino-Americana

\begin{abstract}
The medial caesura (MC) is a mid-expositional break that divides a sonata-form exposition into two parts. It acts as a tonal and formal proposition, a suggested plan of action that, to be accepted, requires a convincing S-candidate and a key other than the tonic. Failure to launch any of the typical S-opening types or to move away from the tonic after the MC may indicate that the proposed gesture is being retrospectively declined, as if the subsequent music were unable, or perhaps refused, to move past the MC effectively. This situation often results in the reopening of pre-MC space, suggesting a return to either $\mathrm{P}$ or TR and an eventual articulation of a new, rhetorically stronger MC. In this paper, I investigate Schubert's handling of declined MCs within sonata expositions, demonstrating how the strategy's formal and expressive outcomes may be directly associated with a given MC pair. I examine four different declined/accepted MC pairs, organized as follows: 1) a declined Classical MC is followed by another Classical MC; 2 ) a declined MC in a non-normative key is followed by a Classical MC; 3) a declined Classical MC is followed by an MC in a nonnormative key; and 4) a declined MC in a non-normative key is followed by an MC in the same key or in another non-normative key. The conclusion shows that declined/accepted pairs involving tonally unconventional MCs often implicate formal and tonal complications that require some kind of correction or compensation, resulting, for instance, in a multimodular S, a modulatory CF, or a direct motion to the EEC. Interestingly, even when dealing with the Classical/Classical pair, Schubert constantly avoided the Classical deployment sequence, experimenting with innovative strategies that impacted the exposition's layout in some way. It seems that, in Schubert, the declined-MC strategy exceeds its inherent rhetorical (and coloristic) function, frequently incorporating structural significance.
\end{abstract}

Keywords: Medial Caesura Declined; Schubert's Instrumental Music; Sonata Form; TwoPart Exposition; Continuous Exposition 
MUSICA THEORICA Revista da Associação Brasileira de Teoria e Análise Musical 2019, v. 4, n. 1, p. 188-233-Journal of the Brazilian Society for Music Theory and Analysis@ TeMA 2019 - ISSN 2525-5541

Resumo: A cesura medial (MC) é uma articulação formal que divide a exposição da forma sonata em duas partes. Ela age como uma proposta tonal e formal, um plano de ação que para ser acatado depende da introdução de um tema capaz de assumir a função de tema secundário (S-theme) e de uma tonalidade que não a inicial. O não cumprimento de ao menos um desses requerimentos pode sugerir a recusa retrospectiva da proposta apresentada pela MC. Situações como esta implicam, em geral, na reabertura do espaço pré-MC, sugerindo um retorno ao tema primário $(\mathrm{P})$ ou à transição (TR) e uma eventual articulação de uma nova $\mathrm{MC}$, retoricamente mais acentuada. Neste artigo, investigo a forma como Schubert manuseia cesuras mediais recusadas (declined MCs) nas exposições de suas obras em forma sonata, demonstrando como as consequências formais e expressivas derivadas do uso desta estratégia estão diretamente associadas a um par de MCs específico. Examino quatro pares de MCs recusada/aceita, organizados da seguinte maneira: 1) MC Clássica recusada seguida por MC Clássica aceita; 2) MC em uma tonalidade não-convencional recusada seguida por MC Clássica aceita; 3) MC Clássica recusada seguida por MC aceita em uma tonalidade nãoconvencional; e 4) MC recusada seguida por MC aceita, ambas em tonalidades nãoconvencionais. A conclusão demonstra que pares envolvendo MCs em tonalidades nãoconvencionais, na maioria dos casos, implicam em complicações formais e tonais que requerem algum tipo de correção ou compensação, resultando, por exemplo, em uma zona temática secundária multimodular, um preenchimento de cesura modulante, ou mesmo a evitação da MC por meio de um movimento direto à EEC. É interessante notar que, mesmo ao manusear o par que envolve duas MCs Clássicas, Schubert evita constantemente a ordem crescente de articulação cultivada no fim do século XVIII, provando estratégias inovadoras que afetam a organização da exposição de alguma forma. Pode-se afirmar que, em Schubert, a MC recusada excede sua função retórica (e colorística), frequentemente incorporando um significado estrutural.

Palavras-chave: Cesura Medial Recusada; Obra Instrumental De Schubert; Forma Sonata; Exposição Em Duas Partes; Exposição Contínua

\section{Introduction: Medial Caesura Declined}

Much of the current research on musical form has pursued a cadenceoriented approach in which the cadence is not only a crucial component of the harmonic syntax of a given musical passage as the progression's ultimate goal, but also a central element in the process of formal articulation (see selectively Caplin 1998 and 2013; and Hepokoski; Darcy 2006). Among the conventional cadential gestures most relevant to articulating the inner parts of a sonata form is the cadence that punctuates the end of the transition and sets up the entrance of the S-theme, termed by Hepokoski and Darcy (1997 and 2006, p. 23-50) the medial caesura. The medial caesura (MC) is a mid-expositional break that divides a sonata-form exposition (and recapitulation) into two parts: the first part comprising the primary theme zone $(\mathrm{P})$ and the transition (TR), and the second, 
the secondary theme zone (S) and the closing section (C) (2006, p. 23-25). This formal articulation is often associated with a sequence of four events that defines its rhetorical strength, harmonic quality, and, ultimately, its formal role: 1) TR's energy gain in the approach to the structural dominant, 2) the articulation of a half cadence and subsequent dominant prolongation, 3) the MC gap itself, and 4) the appearance of an appropriate S-theme that retrospectively confirms the proposed MC gesture (2006, p. 30-36).

Before being ratified by the S-theme, the medial caesura acts as a tonal and formal proposition, a suggested plan of action that, to be accepted, requires a convincing S-candidate-often characterized by a new texture and a low dynamic level-and a key other than the tonic. As noted by Hepokoski and Darcy, "the change of texture and/or dynamics functions as a standard gesture that accepts and ratifies the preceding caesura as the $\mathrm{MC}^{\prime \prime}(2006, \mathrm{p}$. 36). Failure to launch any of the typical S-opening types or to move away from the tonic after the $\mathrm{MC}$ may indicate that the proposed $M C$ is being retrospectively declined, as if the subsequent music were unable, or perhaps refused, to move past the MC effectively. This situation often results in the reopening of pre-MC space, suggesting a return to either P or TR and an eventual articulation of a new, rhetorically stronger MC (2006, p. 45-47).

In the Classical period, the standard strategy was to restore TR-activity in order to attain the next temporally available cadential option (e.g., declined I:HC MC/accepted V:HC MC, or declined V:HC MC/accepted V:PAC MC) (2006, p. 36-40). For Hepokoski and Darcy (1997), "the expressive purpose of the medial caesura declined is normally to show the compositional decision to spring into a proportionally larger frame-the decision to manufacture a grander, perhaps monumentalized exposition (and hence movement as a whole)" (p. 138). Indeed, declining a proposed MC may suggest the need for a stronger, more solidly articulated caesura, set up by a more characteristic energy-gain module, to the end of a more imposing, highly dramatized exposition.

\section{Declining a Proposed MC}

Hepokoski and Darcy offer a detailed study of four situations that may result in a declined MC (1997, p. 138-145; 2006, p. 45-46). In the first, the proposed $\mathrm{MC}$ is canceled by the return of the P-theme in the tonic, suggesting a restart. Frequently, the new P-module soon dissolves into transitional rhetoric, 
MUSICA THEORICA Revista da Associação Brasileira de Teoria e Análise Musical 2019, v. 4, n. 1, p. 188-233-Journal of the Brazilian Society for Music Theory and Analysis @ TeMA 2019 - ISSN 2525-5541

eventually articulating a new MC. In most instances, the overall effect is that of a "grand antecedent" (P), punctuated by an overemphasized I:HC, being followed by a "grand dissolving consequent" (TR), a module that manages to secure the real $\mathrm{MC}$ - usually a V:HC MC. An example of this procedure is found in the first movement of Mozart's Symphony No. 40 in g, K. 550 (2006, p. 45).

The second situation involves the return of the tonic key, following a proposed I:HC MC, but with the introduction of new thematic material, as in the finale of Beethoven's Second Symphony (see 2006, p. 45-46).

In the third situation, a sudden motion into a distant and non-normative key declines the proposed MC. The music that follows the proposed gesture may incorporate a variety of characters: lyrical or non-lyrical, calm or agitated, soft or loud, slow or fast. Regardless of its initial character, the new module often proceeds to reinvigorate TR-activity, thus retrospectively clarifying its non-S status and creating the need for a stronger MC. For Hepokoski and Darcy (2006), the sudden tonal detour "might suggest a willful, forte assertion of personality or eccentricity; a dogged determination not to succumb to a weak caesura; or, conversely, a momentary failure of nerve and tragic slippage onto the wrong key or into a zone of shadowy escape" (p. 46). Regardless of the analyst's final interpretation, there is no question that the non sequitur shift plays an important role within the work's tonal and rhetorical trajectory. An example is found in the first movement of Beethoven's String Quartet in c, op. 18 No. 4 (see ibid).

In the fourth situation, the module that follows the proposed MC begins in the expected key but fails to express convincing S-rhetoric. In most instances, the music refuses to drop to piano, instantly restoring TR-activity. Since S-themes may incorporate a wide range of characters, including the normative forte and bustling types, the analyst should be cautious, considering the possibility of interpreting the new module as a forte $\mathrm{S}$ or even an S-deformation. ${ }^{1}$ When dealing with ambiguous situations, Hepokoski and Darcy advise "[considering] such things as the persistence or nonpersistence of TR-motives after the supposed MC" (ibid). The first movement of Mozart's Symphony No. 20 in D, K. 133, provides an example of the procedure (see ibid, p. 47).

\footnotetext{
${ }^{1}$ For a comprehensive list of S-theme types within allegro movements, see Hepokoski; Darcy 2006, p. 131-142.
} 


\section{Declined MCs and the Trimodular Block}

MC-declined situations may occasionally be in dialogue with trimodular block strategies. Let us consider the following hypothetical situation: a proposed $\mathrm{MC}$ is followed by a convincing $S$ candidate, which, incapable of securing the EEC, eventually dissolves into TR-activity, leading into a rhetorically stronger MC and a new S-like theme. One could argue that the restored transitional rhetoric within what seemed to be S-space retrospectively cancels the proposed $\mathrm{MC}$, reopening the exposition's first part as in a declined-MC situation. This interpretation, however, overlooks the conspicuous "S-ness" expressed by the theme following the first MC, an essential part of the work's narrative.

An alternative would be to conceive the post- $\mathrm{MC}^{1}$ area as a trimodular block; i.e., an independent multimodular zone featuring three distinct formal units: an S-like theme (TM $\left.{ }^{1}\right)$, often troubled in some way; an area of renewed TRactivity $\left(\mathrm{TM}^{2}\right)$ that will lead into a new $\mathrm{MC}\left(\mathrm{MC}^{2}\right)$; and a second S-like theme that will eventually attain the EEC (TM ${ }^{3}$ ) (see Hepokoski; Darcy 2006, p. 170-177). The analyst should not downplay the ambiguity of such cases, exploring instead the tension between both readings. In addition, one should be aware that trimodular blocks might occasionally be conceived as highly dramatized instances of declined-MC situations, an interpretation that would reconcile both conflicting views. $^{2}$

\section{Declined MCs in the Continuous Exposition}

Declined MCs are dramatic gestures within continuous expositions; i.e., expositions that are characterized by the absence of an accepted mid-expositional break and, consequently, of a secondary theme zone. ${ }^{3}$ The procedure's highlighting of the exposition's inability to launch, or rejection of entering Sspace, establishes a close connection between the two expositional types, two-

\footnotetext{
${ }^{2}$ Due to the limited space available here, a detailed discussion about the interaction between declined MCs and trimodular-block structures is not included in this paper. For more on this subject, see Navia 2016, p. 206-221.

3 Although widely accepted within what has been called the "new Formenlehre" (see Caplin; Hepokoski; Webster 2010, p. 7-9; Moortele 2017, p. 1-4), the concept of a continuous exposition is not unanimous. William Caplin, for instance, does not acknowledge the possibility of a continuous exposition, claiming instead that all sonata expositions have a subordinate theme (see Caplin; Martin 2016).
} 
part and continuous. The impression is that of a formal refusal to construct the first-level default two-part exposition. Hepokoski and Darcy (2006) identify two continuous-exposition situations in which proposed MCs - or mild MC effectsmay be involved. In the first situation, a TR $\Rightarrow$ FS module implies an imminent MC by extending the structural dominant, but eventually collapses back into Fortspinnung activity. In the second, TR articulates an MC, perhaps even followed by $\mathrm{CF}$, but the subsequent material refuses to enter S-space, reinvigorating TRrhetoric. These are instances of what Hepokoski and Darcy call the bait-and-switch tactic in which the music "baits" the listener into anticipating an MC, implying a two-part exposition, then veers away from the imminent caesura and switches to a continuous exposition (p. 52-63).

\section{Two Different Approaches to Declined MCs}

The limited tonal schemes cultivated within Classical sonata expositions restricted the MC practice of the period to a maximum of three standard cadential options, each carrying specific tonal, temporal, and rhetorical characteristics: 1) a half cadence in the new key, a half cadence in the home key, and a PAC in the new key, ranked by Hepokoski and Darcy as first-, second-, and third-level default, respectively, according to their frequency in the repertoire (2006, p. 2529). Conversely, the more wide-ranging harmonic practice of the Romantic period allowed more distant keys as stable harmonic areas within sonata expositions. Schubert often colored his expositions with excursions into nontraditional keys before reaching a Classically expected one (see selectively Webster 1978, p. 26-31; Beach 2017, p. 82-83; Hunt 2009, p. 65-102), a practice that also contributed to the increased number of MC articulators featured in his oeuvre (see Navia 2016, 43-99). Indeed, tonally unconventional MCs and non sequitur tonal preparations of $S$ were incorporated into his set of favored procedures as stylistic traits.

The new harmonic possibilities of the Romantic era naturally amplified the role of declined MCs within sonata movements. Declining an MC in a nontraditional key not only implied the need for a stronger candidate but also a formal refusal of the proposed key, a conscious decision to strive for a more normative option - perhaps relief at not going down the "wrong" harmonic path. It could be argued that in the Romantic period declined MCs contributed to a 
richer tonal experience, establishing a dialogue between realized and nonrealized harmonic regions.

\section{Schubert's Approach to Declined MCs}

Schubert's inclusive MC practice affected his treatment of declined MCs, which combines the Classical emphasis on rhetoric with the poetic license introduced by the broader and more colorful tonal narratives of the Romantic period. ${ }^{4}$ His penchant for tonally unconventional and non sequitur $\mathrm{MCs}^{5}$ greatly increased the available combinations for declined/accepted MC pairs, establishing a direct dialogue between the normative and the non-normative. Frequently, declined MCs in non-traditional keys are followed by Classical MCs and vice versa, both strategies expressing different effects and resulting in different formal outcomes. Moreover, Schubert occasionally associates the MCdeclined strategy with trimodular blocks and continuous expositions, assigning the procedure a structural role.

In the following discussion, I investigate Schubert's handling of declined MCs within sonata expositions, demonstrating how the strategy's formal and expressive outcomes may be directly associated with a given MC pair. ${ }^{6}$ I examine four different declined/accepted MC pairs, organized as follows: 1) a declined Classical MC is followed by another Classical MC; 2 ) a declined MC in a nonnormative key is followed by a Classical MC; 3) a declined Classical MC is followed by an MC in a non-normative key; and 4) a declined MC in a nonnormative key is followed by an MC in the same key or in another non-normative key.

\footnotetext{
${ }^{4}$ Many authors have discussed Schubert's treatment of transitions and his approach to the secondary key. See selectively Webster 1978, p. 22-26; Wollenberg 1998, 2007 and 2011; Black 2015.

${ }^{5}$ In a non sequitur MC, the key announced at the half cadence does not match the key introduced at the onset of the S-theme.

${ }^{6}$ For reasons of organization and space, I do not discuss Schubert's treatment of declined MCs within recapitulations in this paper.
} 


\section{Formal and Expressive Implications of Four Declined/Accepted MC Pairs}

\subsection{The Classical/Classical Pair}

This Declined-MC pair corresponds to the first-level default strategy in the Classical period. In short, in this category, a declined MC matching Classical expectations is eventually followed by the next temporally available option, often a rhetorically stronger cadential gesture that manages to secure the MC (I:HC MC $\rightarrow \mathrm{V}: \mathrm{HC}$ MC $\rightarrow \mathrm{V}: \mathrm{PAC} \mathrm{MC})$. Schubert frequently handles this strategy differently from his predecessors. ${ }^{7}$ In the following discussion, I analyze four works that illustrate his innovative handling of the Classical/Classical pair: the finale of the String Quartet No. 6 in D, D. 74, the Overture in D, D. 556, the first movement of the String Quartet No. 4 in C, D. 46, and the Overture in D, D. 12

\section{Insisting on the Same Cadential Option: String Quartet No. 6 in D, D. 74/iv}

In the String Quartet No. 6 in D, D. $74^{8}$ (Ex. 1), the P-theme, featuring initially a thin contrapuntal texture and a low dynamic level, culminates in a festive tutti fortissimo (m. 10) that seems to merely confirm the tonic key. ${ }^{9}$ The new module-perhaps first identified as a codetta to $\mathrm{P}$-quickly articulates a tonicized I:HC in measure 19, followed by dominant lock and a proposed MC, suggesting instead a transitional function. The subsequent music declines the proposition, reintroducing the P-theme in the tonic-Hepokoski and Darcy's situation 1 (see 2006, p. 45). Following an exact restatement of the presentation phrase, the theme's continuation is slightly modified, leading again into the tutti module, this time implying a I:HC from its onset (m. 34), followed by dominant lock and a potential MC in measure 38. The sudden appearance of the dominant at this point may impress the listener as a desperate attempt to move into S-space, as if fearing another recurrence of $\mathrm{P}$. The proposed $\mathrm{MC}$ is instantly evaded, being

\footnotetext{
${ }^{7}$ From time to time Schubert does follow the Classical MC deployment sequence, offering a traditional treatment of the declined-MC situation. An instance is found in the finale of the String Quartet No. 4 in C, D. 46, a Type 4 sonata (see Navia 2016, p. 168-169).

${ }^{8}$ The finale of D. 74 is structured as a Type 1 sonata with dominant recapitulation.

${ }^{9}$ Many have commented on the similarities between the outer movements of Schubert's D. 74 and Mozart's “Paris” Symphony, K. 297 (see Black 1996, p. 147-155; and Rosen 1988, p. 357-360).
} 
now followed by conspicuous TR-activity, which, after restating the initial tutti module, manages to finally secure the MC in measure 54-once again, a I:HC $\mathrm{MC}$, this time marked by a clear MC gap and followed by a convincing S-theme. Despite insisting on the same cadential option three consecutive times, Schubert approaches it differently each time, as if trying to find a way to properly open Sspace. The third attempt is indeed the most emphatic, as would be expected based on Classical practice: while the first two may sound abrupt and weak, perhaps not even being heard as proposed MCs, the final one constitutes a much stronger gesture, being solidly set up by real TR-activity.

Declined MCs may turn the apprehension of the form as a whole into a difficult task. In D. 74, P ultimately takes the form of an interrupted small ternary with a dissolving reprise. In other words, with the return of the initial theme in the tonic in measure $25\left(\mathrm{~A}^{\prime}\right)$, the transitional tutti module (mm. 10-23) is retrospectively conceived as a contrasting middle. However, $\mathrm{A}^{\prime}$ is not repeated in its entirety; the module is slightly modified towards its end and leads into a proposed $M C$, implicating its reinterpretation as a dissolving reprise $\left(A^{\prime} \Rightarrow T R^{1.1}\right)$. The subsequent module finally introduces real transitional activity, being then interpreted as $\mathrm{TR}^{1.2}$.
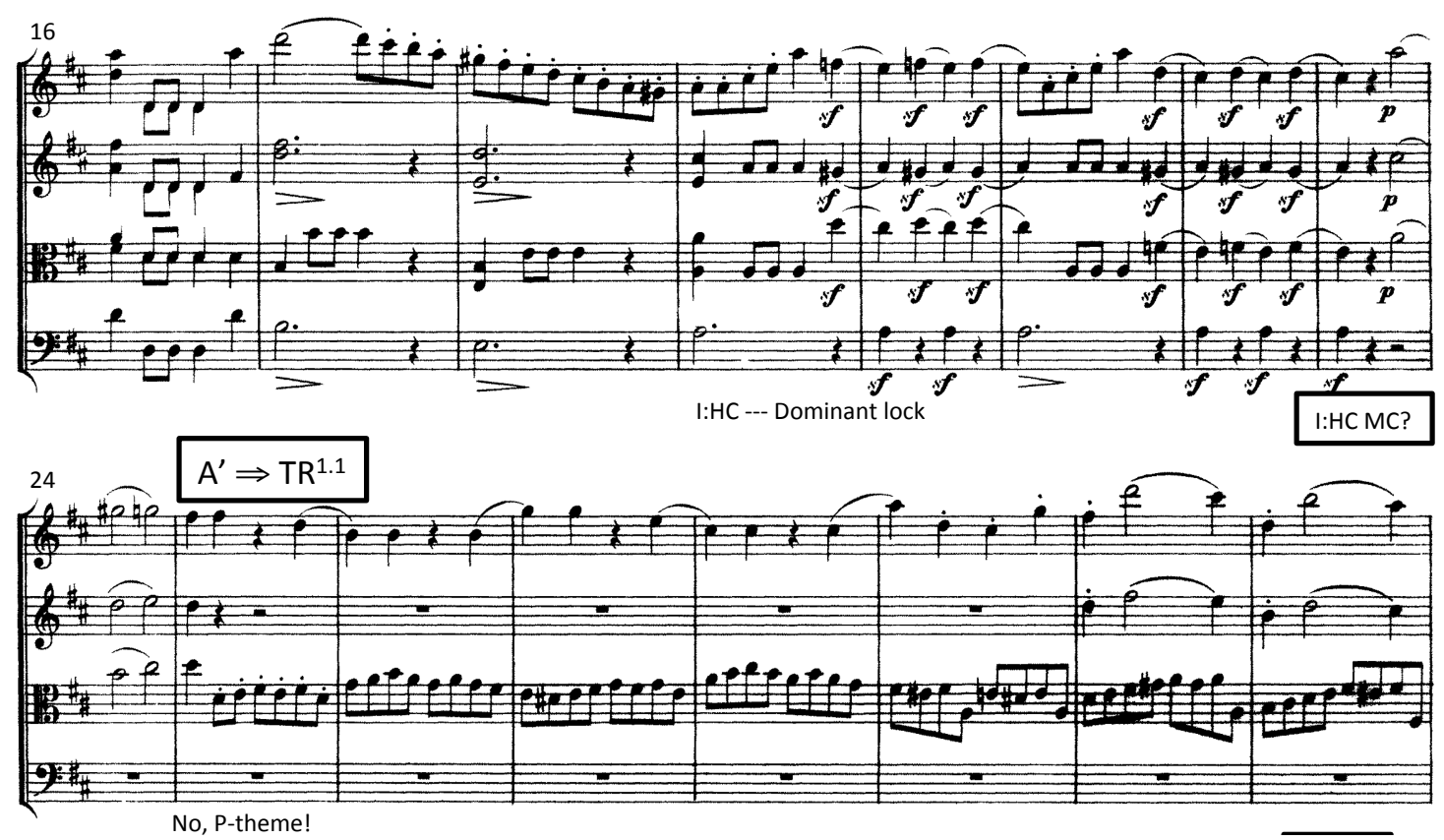

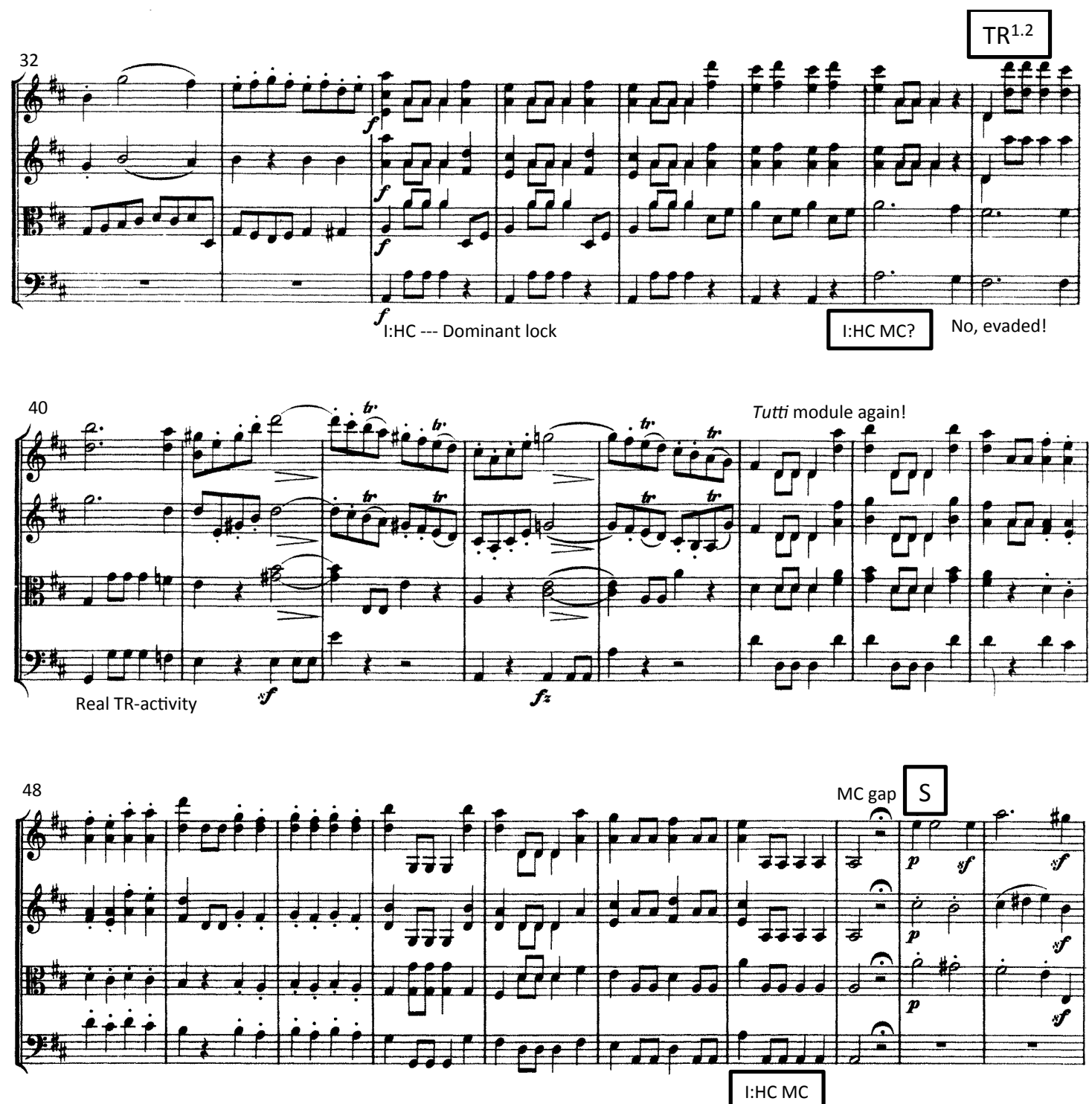

Example 1: String Quartet No. 6 in D, D. 74/iv (mm. 16-57)

Active Caesura-Fill in Declined-MC Situations: Overture in D, D. 556

In some instances of the Classical/Classical pair, the first proposed $\mathrm{MC}$ is declined by active caesura-fill, being shortly followed by the real MC, a situation that may occasionally resemble the $\hat{5}-\hat{1}$ expanded caesura-fill with apparent cadential arrival. ${ }^{10}$ Here, the analyst should always consider such things as the

\footnotetext{
${ }^{10}$ For an extended discussion of Schubert's treatment of the de-energizing active CF in connection with PAC MCs, see Navia 2016, p. 86-89. For more on the 5-1̂ linear fill, see Hepokoski; Darcy 1997, p. 129-135.
} 
character of $\mathrm{CF}$ and the rhetorical impact of the final punctuation before selecting one interpretation.

In the Overture in D, D. 556 (Ex. 2), the P-theme is constructed as a normative sentence that, after a few reiterations of its final cadence, is interrupted by TR-rhetoric, characterized by a tutti affirmation and the surprising arrival of an E-major minor-seventh harmony $\left(\mathrm{V}_{5}^{6} / \mathrm{V}\right)$. Normative transitional activity persists until measure 54, when the music comes to a halt, suggesting a I:HC MC, followed by an ambiguous CF. At this point, the repeated As in the first violin, the continuous piano dynamic, and the light texture suggest that we are within CF space, waiting for the arrival of an S-theme. Conversely, the character of the material introduced in measure 56, its sentential structure, and the return of the tonic imply an instant cancellation of the MC gesture, suggesting instead a return to pre-MC space. The role of the passage is retrospectively clarified in measure 64, where the restored harmonic motion and the continued absence of TRrhetoric define it as a de-energizing active CF: a module that does not belong to neither TR nor $S$, but manages to take control of the music, leading eventually into a V:PAC MC (m. 72).

D. 556 features an MC-declined situation that follows in part the increasing rhetorical scale favored in Classical works. One could argue that, despite the clear TR-activity that precedes the first proposed MC, its sudden articulation reveals a "flawed" condition that must be "corrected" or compensated by a stronger gesture. Interestingly, Schubert skips the Classical first-level default, V:HC MC, moving directly to a V:PAC MC. This is a common strategy in declined-MC situations that involve active CFs, since a V:HC MC would most likely require the reinvigoration of TR-activity. 

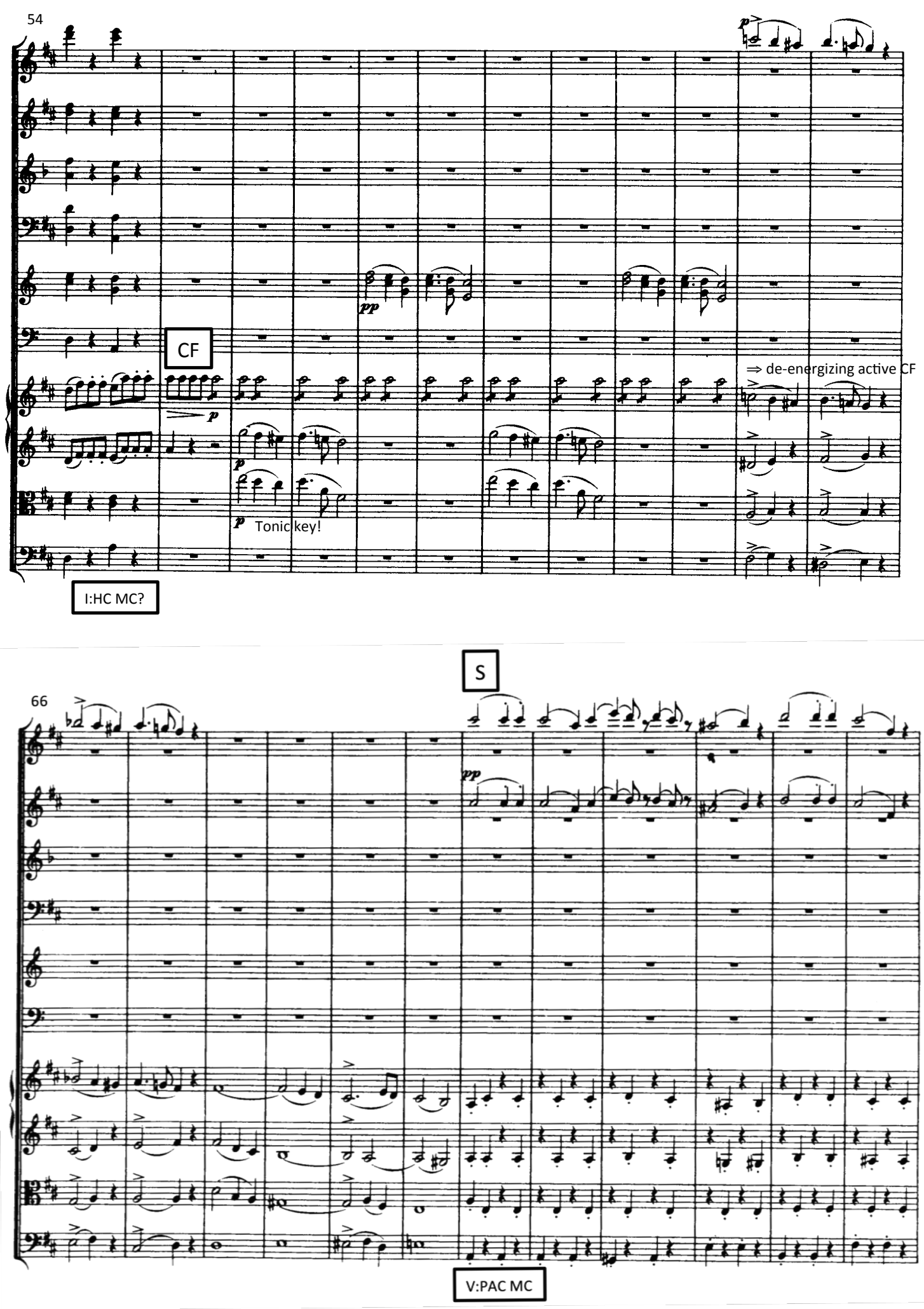

Example 2: Overture in D, D. 556 (mm. 54-77) 
The Classical/Classical Pair and the Continuous Exposition: String Quartet No. 4 in C, D. $46 / i$

The rhetorical correspondence between structural cadences is further dramatized in continuous expositions. The procedure establishes a close connection between the declined gesture and its accepted counterpart, the EEC. This cadential interaction incorporates structural significance, bringing to the fore the exposition's inability or refusal to manufacture S-space.

The first movement of D. 46 (Ex. 3a) begins with an elegiac slow introduction in fugato style, featuring the "mournful" chromatic descent from $\hat{1}$ to $\hat{5}$ as subject. The "somber" character is enhanced by the initial tonal ambiguity, which begins to settle in measure 13 with the arrival of the major mode marked by a PAC. Following the cadence, the music extends C-major harmony by minorinflected neighbor motions, setting up the onset of the sonata proper.

The P-theme begins in measure 20, instantly expressing a "tormented" character that seems to reflect the darkness manifested at the beginning of the work. The module prolongs $\mathrm{C}$ major through neighbor motion without conveying real harmonic activity - as if imprisoned by the constant minor-mode interventions. $\mathrm{P}$ culminates in a fortissimo $6 / 4-5 / 3$ gesture (mm. 33-36) that, despite its non-cadential status, articulates the theme's ending point, triggering the hitherto missing transitional activity. Based on the introductory fugal subject, TR descends chromatically from tonic to dominant, culminating in a I:HC MC (m. 42). At first, the subsequent music seems to accept the proposed gesture, being characterized by a much lighter texture, a piano dynamic, and an Scandidate in the highly unorthodox key of F (IV). However, F major is soon reinterpreted as IV in the key of C major, leading eventually into a PAC in the tonic (m. 48). The return of the tonic key at this moment implicates the retrospective cancellation of the $\mathrm{MC}$ gesture, reopening pre-MC space. The new module introduces a playful melody and is firmly anchored in C, creating the impression of a conscious return of the tonic key-as if it had encountered an opportunity to exist freely, without being threatened by the minor mode. TRactivity is restored in measure 55, leading into a V:IAC in measure 64 (Ex. 3b). Considering its location within the exposition, the cadence might initially suggest the articulation of a new MC; however, the non-thematic character and the 
MUSICA THEORICA Revista da Associação Brasileira de Teoria e Análise Musical 2019, v. 4, n. 1, p. 188-233-Journal of the Brazilian Society for Music Theory

absence of harmonic activity expressed by the subsequent music result in reinterpreting the just-heard V:IAC as the EEC in a continuous exposition. ${ }^{11}$

This is an extreme example of the bait-and-switch tactic. Schubert not only implies the articulation of an MC, but actually enters S-space and then decides to return to the tonic, transforming a suggested-although briefly-two-part exposition into a continuous one. The declined MC stands as an expressive gesture, making the decision to remain in $\mathrm{C}$ major explicit. ${ }^{12}$
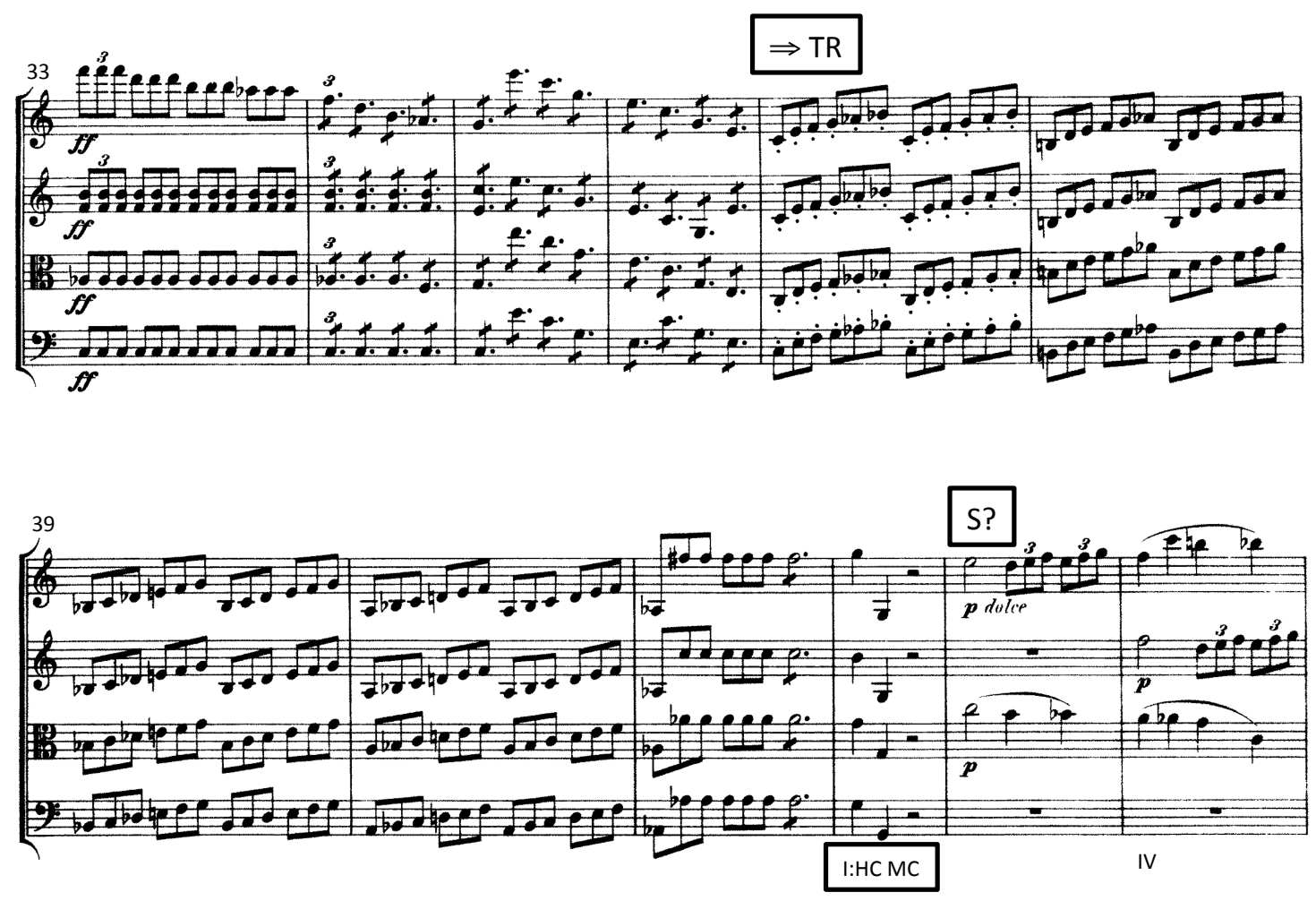

${ }^{11}$ For Black (1996), the absence of a subordinate theme results from Schubert's preoccupation with rigid motivic control (see p. 131-139).

${ }^{12}$ A related instance is found in the first movement of the Piano Sonata in A, D. 664. Here, the reinvigoration of TR-activity and the unexpected appearance of A minor (i) after a solidly articulated V:PAC MC (m. 33) retrospectively cancels the proposed gesture, resulting eventually in a continuous exposition. The dramatic rejection of the V:PAC MC may be conceived as a reaction to the premature introduction of an S-like theme in $\mathrm{V}(\mathrm{mm} .25 \mathrm{ff})$, preceding the actual articulation of the MC. 


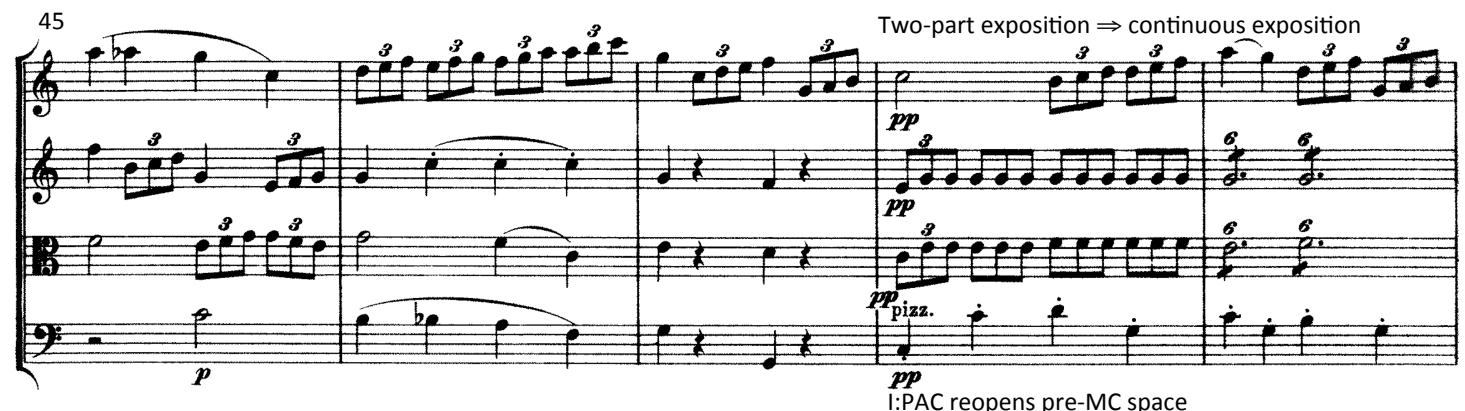

Example 3a: String Quartet No. 4 in C, D. 46/i (mm. 33-49)

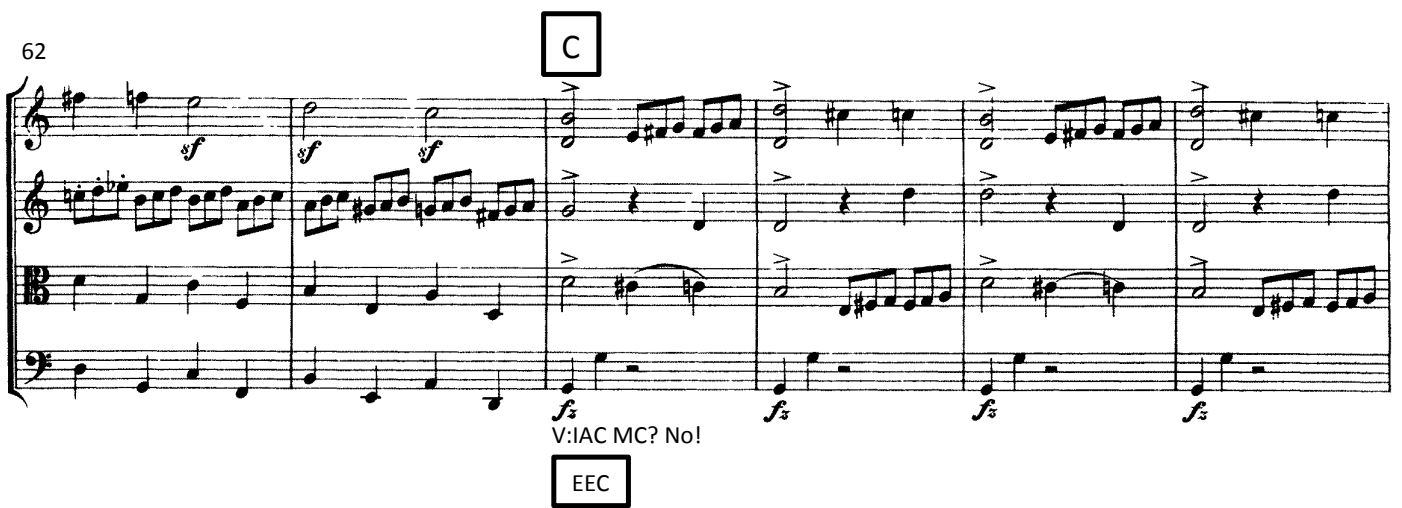

Example 3b: String Quartet No. 4 in C, D. 46/i (mm. 62-67)

Declined MC and the "One-Key Exposition": Overture in D, D. 12

From 1811 through 1812, Schubert wrote four works in a pseudo-sonata form involving an "exposition" that never leaves the tonic: the Overtures D. 4, D. 12, and D. 26, and the first movement of the String Quartet No. 7 in D, D. $94 .{ }^{13}$ All these works conserve aspects of both two-part and continuous expositions, but fail to establish a secondary key, which brings into question their formal status. J. A. Westrup (1969) has claimed that D. 94 "is so diffuse that it is no longer possible to discern any form" (p. 89). On the other hand, according to Brian Black (1996), "that Schubert was at least attempting some type of sonata form is evident from the superficial layout of the structure [of D. 94/i]" (p. 95). It could also be argued that such tonally over-determined expositions give the impression of a double bait-and-switch effect involving three interpretive stages: two-part

\footnotetext{
${ }^{13}$ D. 94 (1814) was actually the eighth quartet composed by Schubert, but was published as No. 7 in the Gesamtausgabe because D. 87 (November 1813), his seventh written quartet, was originally misdated and consequently published as No. 10 (see Whaples 1968, 192-193).
} 
MUSICA THEORICA Revista da Associação Brasileira de Teoria e Análise Musical 2019, v. 4, n. 1, p. 188-233-Journal of the Brazilian Society for Music Theory and Analysis @ TeMA 2019 - ISSN 2525-5541

exposition $\Rightarrow$ continuous exposition $\Rightarrow$ one-key exposition (or "is this an exposition at all?"). ${ }^{14}$

All four works include numerous proposed I:HC MCs that are eventually cancelled by the return of the tonic key. Some MC gestures are followed by clear S-candidates that fail to materialize simply because of their tonal quality. Others are declined by the reinvigoration of TR-activity.

In the Overture in D, D. 12, TR (mm. 61-76), structured as a dissolving grand consequent, comes to a sudden stop on a $\mathrm{V}^{7}$ chord in measure 76, suggesting a weak I:HC MC (Ex. 4a). The gesture is instantly cancelled by the following music, which is firmly anchored in D major. TR-activity is restored in measure 93 -triggered by a fortissimo tutti affirmation-and leads into a new proposed I:HC MC (Ex. 4b), this time accompanied by dominant lock, hammerblows, and caesura gap (mm. 104-107). The MC's rhetorical effort results in an unambiguous S-candidate but fails to establish a secondary key, implicating its retrospective cancellation. The new theme comprises two sentential antecedents followed by the reinvigoration of TR-rhetoric, which leads into another attempt to open S-space: a I:HC MC (Ex. 4c) and CF (m. 141). The active caesura-fill seems to cast doubt on the MC's capability to manufacture an S-theme in a proper key, and repeats the final cadential gesture, articulating another I:HC MC (m. 153). Once again, the $\mathrm{MC}^{\prime}$ 's rhetorical insistence manages to produce a new theme, but proves unable to initiate a key other than the tonic. Derived from the Overture's introduction, the new theme's lyrical melody is eventually interrupted by a new module that slowly accumulates energy in a gradual crescendo ( $\mathrm{mm} .171 \mathrm{ff})$. The module turns out to function as RT; i.e., it culminates in a I:HC in measure 189, followed by a largely expanded caesura-fill, setting up the onset of the recapitulation (mm. $205 \mathrm{ff}$ ) and confirming the exposition's inability to establish a secondary key.

Thus, in D. 12, each proposed MC incorporates new elements that increase their rhetorical strength and consequently their prominence within the work's narrative, a Classical approach to the MC-declined situation that also sheds light

\footnotetext{
${ }^{14}$ These "pseudo-expositions" that never leave the tonic are also found in some of Chopin's early works. In both the Piano Trio in g, op. 8/i (1829), and the Piano Sonata No. 1 in c, op. 4/i (1828), the "exposition" remains in the tonic all the way through, despite some brief modulations at the surface level. In the Piano Concerto No. 1, op. 11/i (1830), both orchestral and solo expositions stay firmly grounded in the tonic, changing from minor to major mode.
} 
upon the exposition's failed tonal trajectory. For obvious reasons, Schubert does not follow the Classical MC deployment sequence but insistently reiterates the tonally weaker I:HC MC, as in the finale of D. 74.

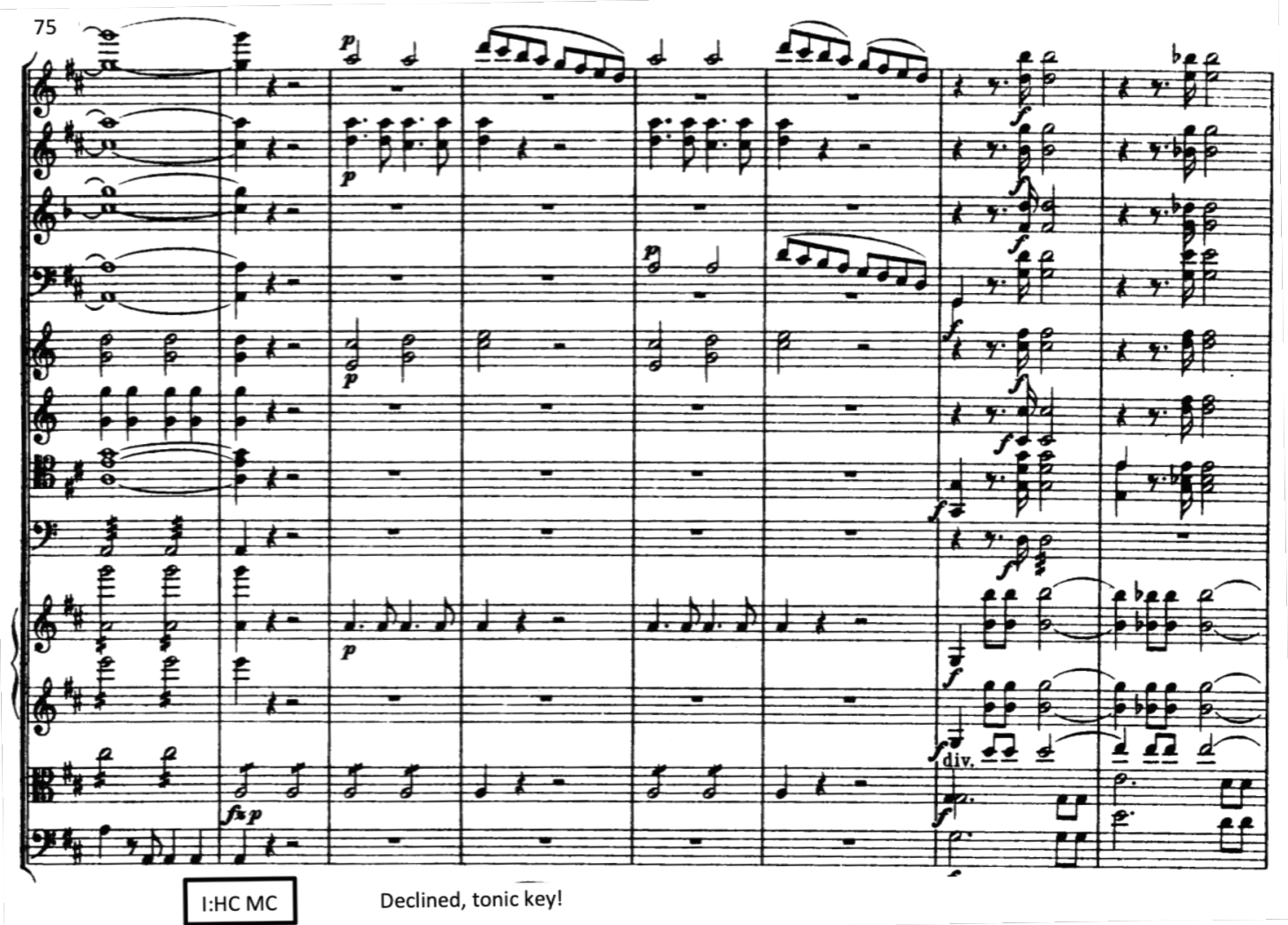

Example 4a: Overture in D, D. 12 (mm. 75-82) 

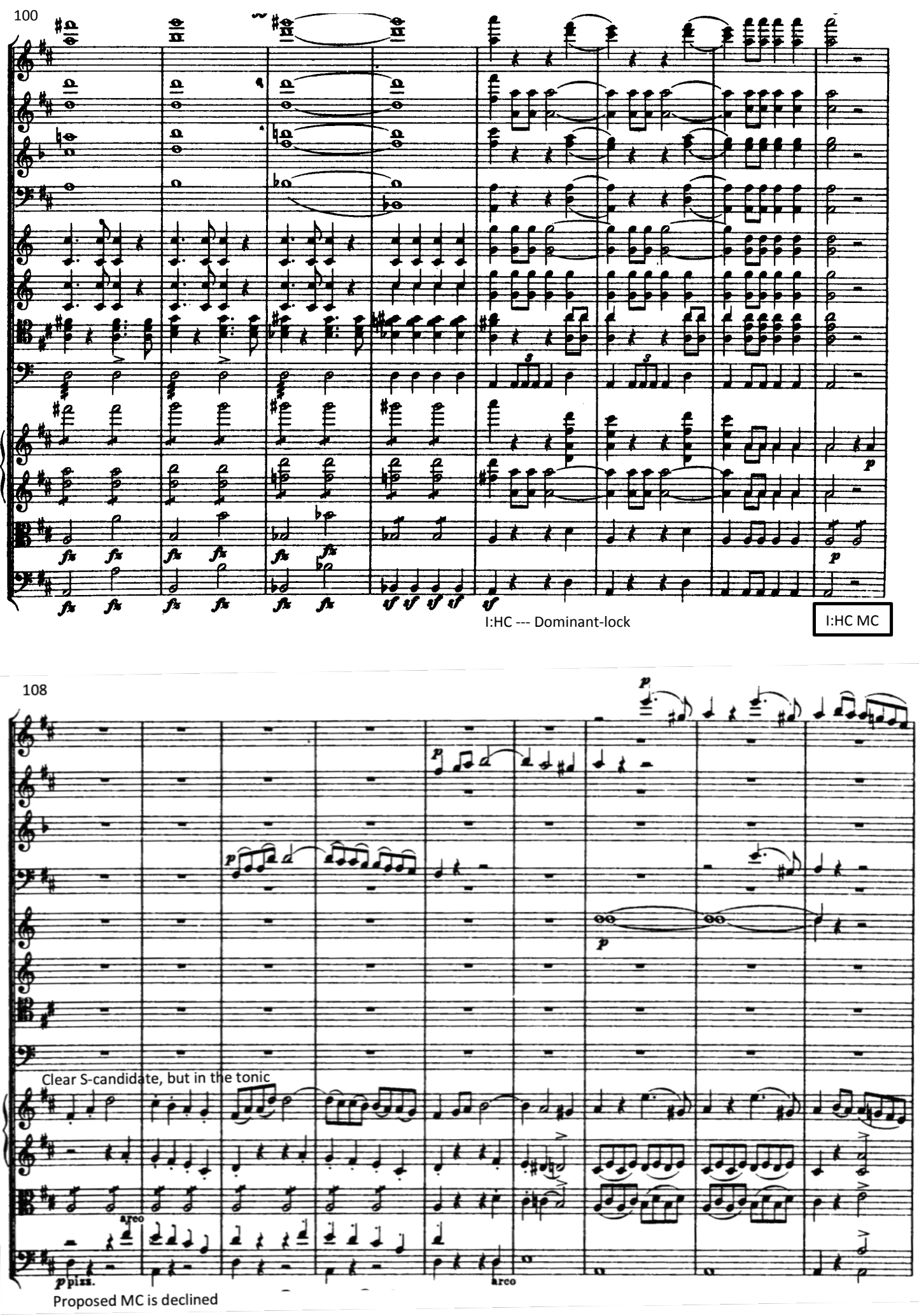

Example 4b: Overture in D, D. 12 (mm. 100-116) 

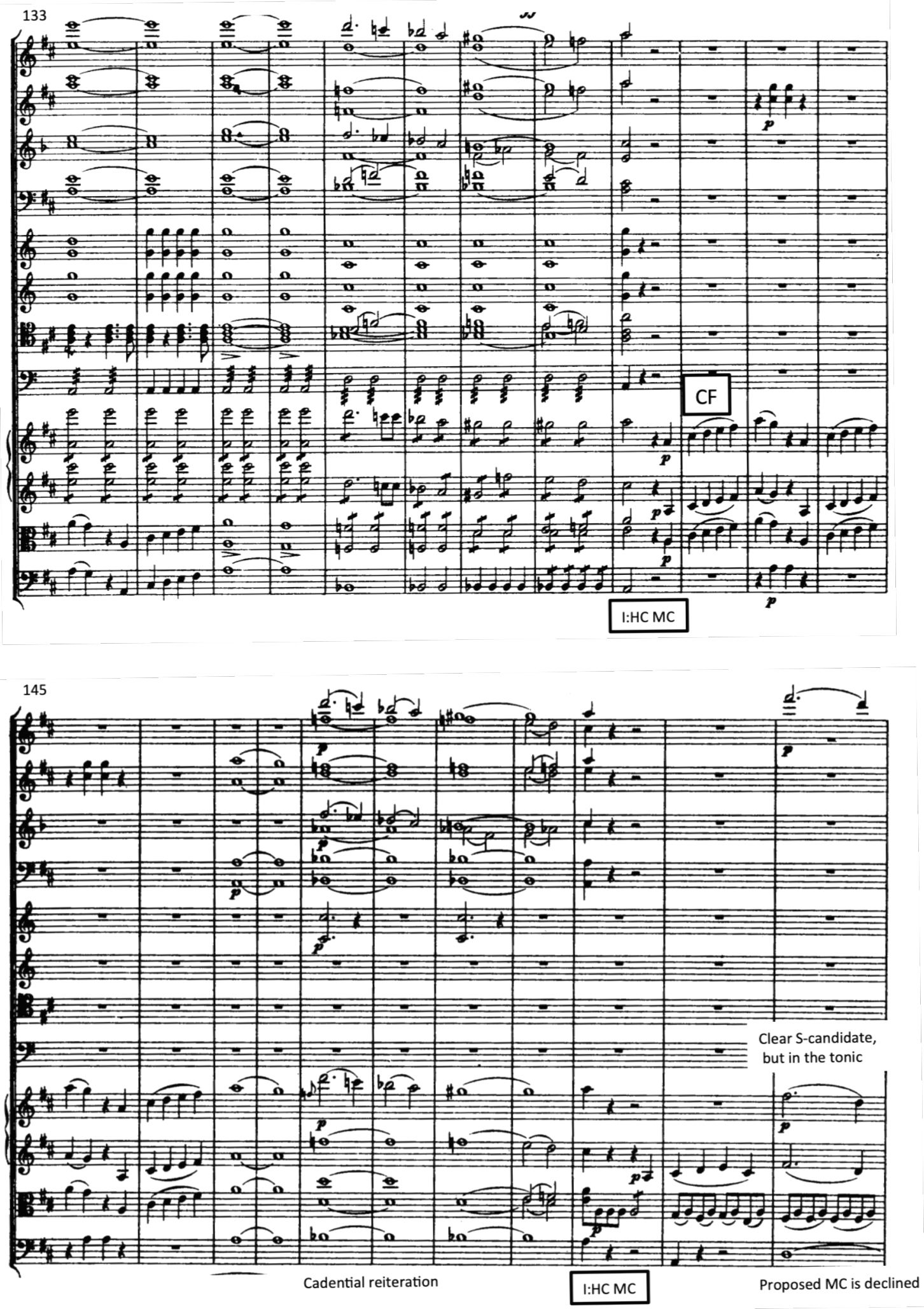

Example 4c: Overture in D, D. 12 (mm. 133-155) 
MUSICA THEORICA Revista da Associação Brasileira de Teoria e Análise Musical 2019, v. 4, n. 1, p. 188-233-Journal of the Brazilian Society for Music Theory and Analysis @ TeMA 2019 - ISSN 2525-5541

\subsection{The Tonally Unconventional/Classical Pair}

This MC pair comprises a declined MC in an unorthodox key followed eventually by a Classical MC. Schubert rarely employs it in a traditional manner. In most instances, the procedure is used in connection with trimodular blocks, defining the relationship between $\mathrm{MC}^{1}$ and $\mathrm{MC}^{2}$. In other situations, the declined gesture is not paralleled by another MC but instead followed directly by the EEC, as in a continuous exposition. Another apparent characteristic is that the rhetorical emphasis that traditionally marks the accepted cadential gesture is often nonexistent in this category, being highlighted instead by its Classical tonal quality.

The expressive effect of this MC pair may vary widely. The proposed tonally unconventional MC may suggest a desperate attempt to escape the tonic area, a resistance to following the traditional harmonic path, a conscious decision to manufacture a grander exposition, the search for a more colorful tonal trajectory, or a sudden tonal collapse - perhaps caused by an already infiltrated key. Its retrospective cancellation and eventual replacement, however, may imply a tonal correction, the fear of visiting a distant harmonic region, the avoidance of a collapse, a sudden change of mind, or a decision to strive towards a "safer" goal. The analyst should always consider the tonal, rhetorical, and formal elements that precede and follow the proposed MC in order to understand the procedure's role within the work's narrative. To illustrate Schubert's handling of this MC pair, I analyze the incomplete finale of the "Reliquie" Sonata in C, D. 840, the finale of the Third Symphony, D. 200, and the opening movement of the String Quartet No. 2 in C, D. 32

\section{A Traditional Approach: Piano Sonata in C, D. 840/iv}

The incomplete finale of the "Reliquie" Sonata in C, D. 840, offers an instance of the tonally unconventional/Classical pair handled in a quite traditional fashion-as pointed out above, rare in Schubert. Here, the initial modular arrangement suggests a compact P-theme structured as an uninterrupted small ternary form (mm. 1-31) with a brief contrasting middle that prolongs the initial tonic through a descending-third arpeggiation. The theme's final cadence is not reiterated as in its first appearance but followed instead by a sudden modulation to the dominant, which implies the onset of an "underdetermined" TR. After retracing the contrasting middle's tonal trajectory 
at the dominant level, the new module dissolves into real TR-activity, initiating a descending-second sequence that eventually leads into a firmly articulated iii:HC MC (m. 74) and caesura-fill (Ex. 5a).

Perhaps motivated by the tonal detours to both tonic and dominant's major submediants, the proposed MC seems to invite the subsequent music onto a longer excursion into the key of $\mathrm{E}$ minor. However, $\mathrm{CF}$ eventually takes control of the music, abruptly transforming the greatly extended B-major harmony into a $\mathrm{V}^{7}$ in the original key. The procedure results in the retrospective declining of the proposed MC gesture, setting up instead the return of the main theme.
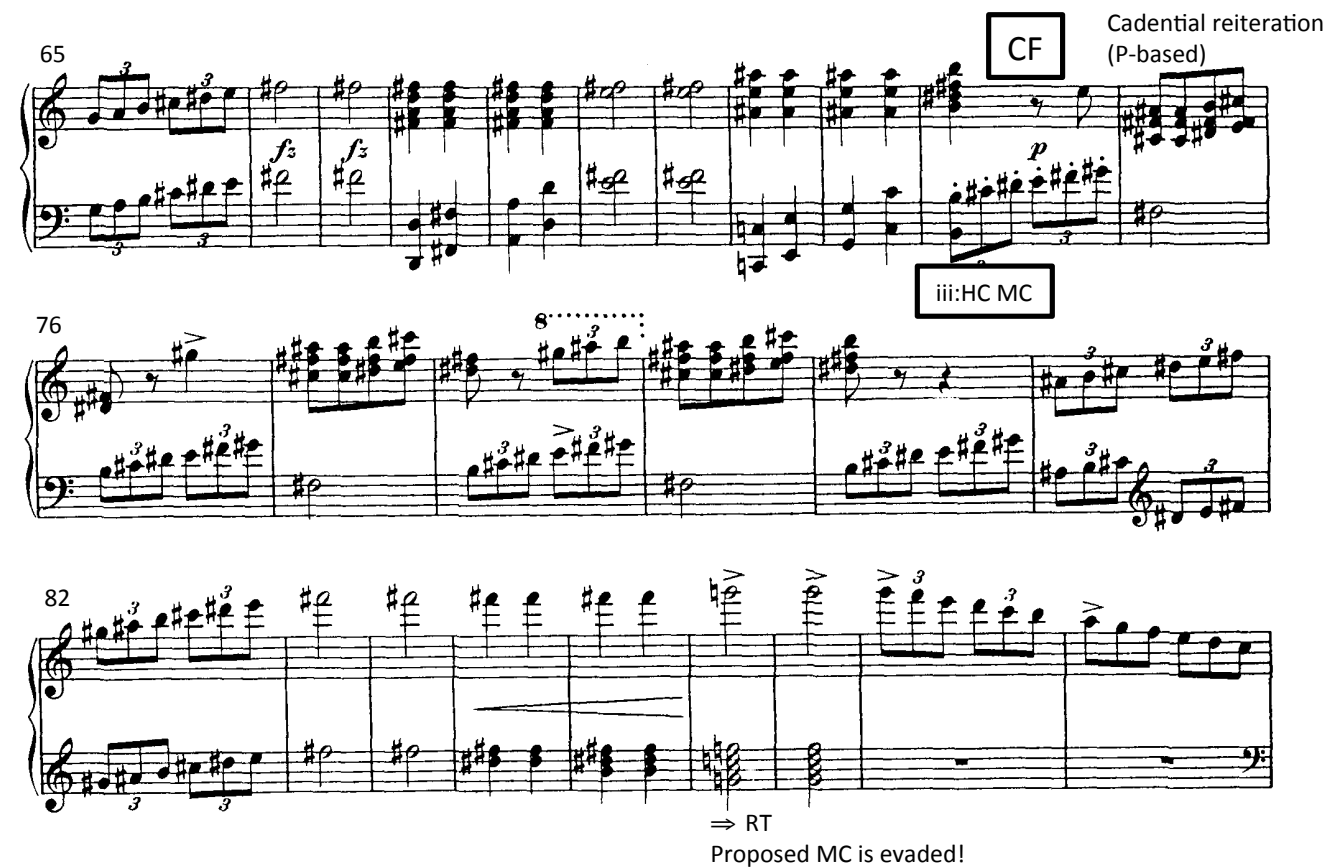

Example 5a: Piano Sonata in C, D. 840/iv ("Reliquie") (mm. 65-90)

The return of the P-theme marks the module's third statement, implying an interrupted structure based on three varied rotations of the same thematic idea: A (I) - A' (V) || A" (I). Ultimately, A" becomes the transition: it incorporates TR-rhetoric, articulating a V:HC MC confirmed by an MC gap and a cogent Stheme in the dominant. The final MC concludes the process of tonal and formal correction that follows its declined equivalent; a process initiated by the return of the P-theme in the tonic, further developed by its eventual transformation into TR, and finally confirmed by a Classical V:HC MC (Ex. 5b). 

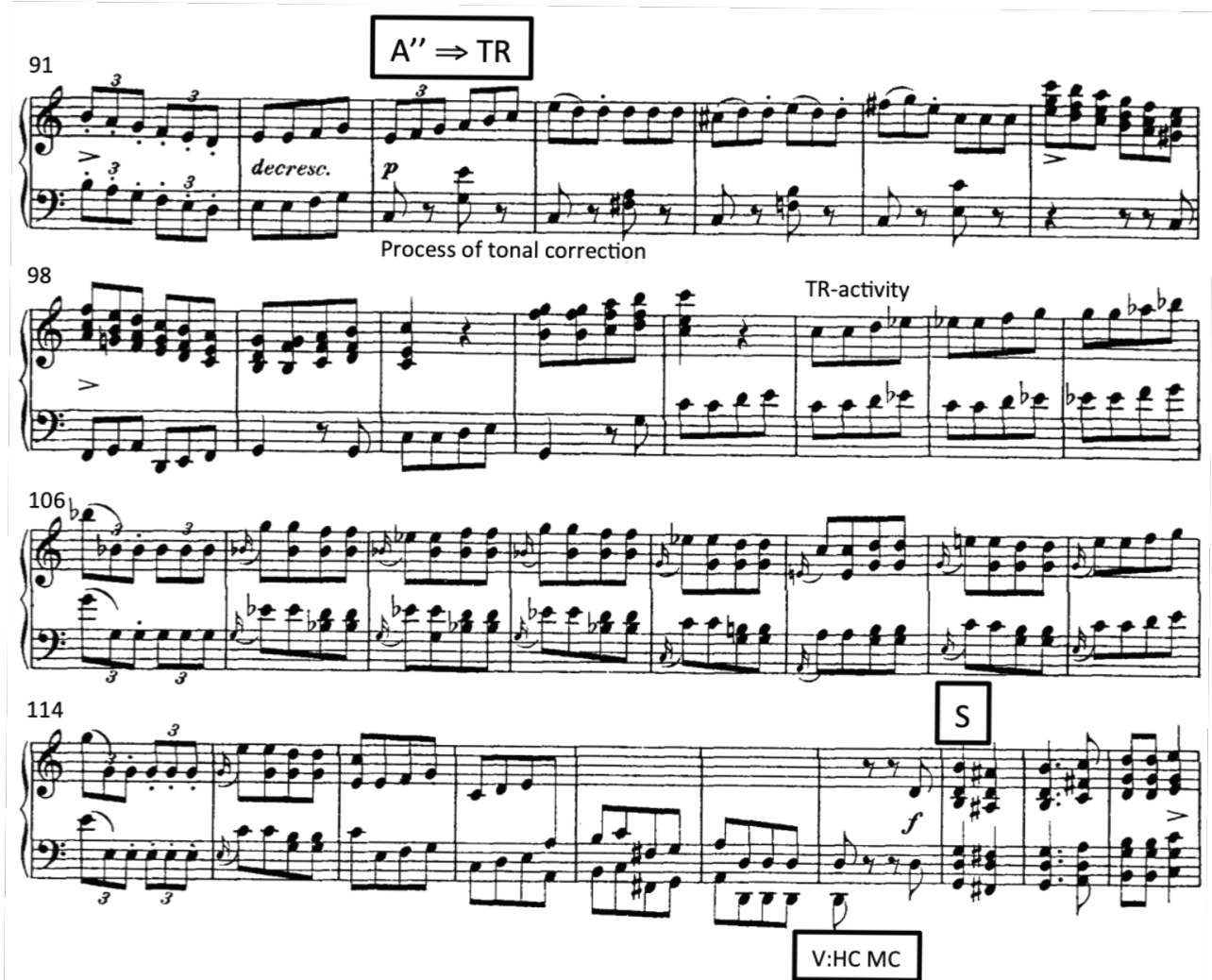

Example 5b: Piano Sonata in C, D. 840/iv (“Reliquie") (mm. 91-123)

\section{Declined MC/Accepted EEC: Symphony No. 3 in D, D. 200/iv}

Another instance of the tonally unconventional/classical pair is found in the finale of the Third Symphony (Ex. 6). Here, a highly deformational IV:PAC MC (m. 83) marks the onset of a bustling S-theme in G major (IV), characterized by much motivic repetition and a strong forward momentum. After briefly prolonging the new key through neighbor motion $\left(\mathrm{I}-\mathrm{ii}^{4} / 2-\mathrm{V}^{6} / 5-\mathrm{I}\right)$, the S-theme seems to doubt the validity of $G$ major as a secondary key, initiating an ascending-second sequence (mm. $95 \mathrm{ff}$ ) that culminates in a ii:HC (m. 107) followed by dominant lock and a proposed MC punctuation (m. 115). The articulation of a tonally unconventional MC within a secondary area already set in a non-traditional key is a dramatic gesture: it exposes the theme's inability to establish the key of the dominant and implies the possibility of a trimodular block structure that may perhaps manage to "correct" the exposition's "tonal alienation." Fortunately, the proposed MC gesture is instantly declined by a juggernaut CF that takes responsibility for the work's tonal trajectory, firmly leading into a V:PAC EEC (m. 129), an emphatic cadential gesture marked by a 
tutti crescendo. The cadence denies the $\mathrm{MC}^{\prime} \mathrm{s}$ threatening tonal and formal propositions, bringing the "troubled" $S$ to an end. Interestingly, the closing theme comprises an S-based module that jubilantly "celebrates" the surprising arrival of the dominant, a task that had seemed so distant, perhaps even unattainable for this thematic material.

The tonally unconventional/classical pair is deployed at two different hierarchical levels in this example. At the lower level one finds the traditional declined/accepted pattern defined not by two MCs, but by the proposed ii:HC MC and the EEC. The structural level, on the other hand, consists of two successful cadential gestures of differing formal, tonal, and rhetorical quality and relevance. It comprises the accepted, but problematic IV:PAC MC, and the EEC, suggesting that the $\mathrm{MC}^{\prime} \mathrm{s}$ "inadequate" tonal condition is eventually rectified by a structural PAC in the dominant that closes the S-theme. This two-level set-up is often found in expositions that combine declined-MC situations with trimodular blocks (see Navia 2016, p. 206-221).

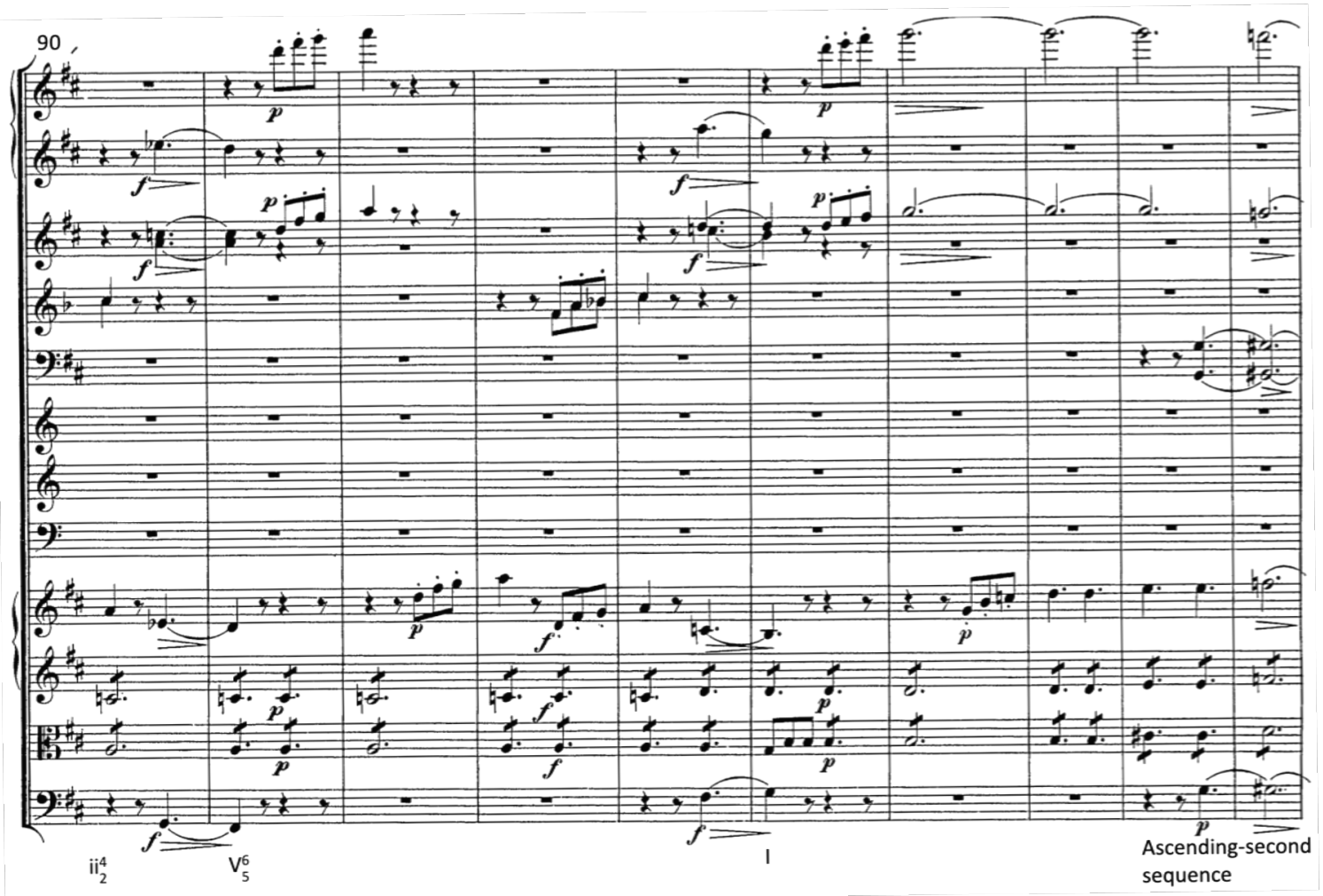


MUSICA THEORICA Revista da Associação Brasileira de Teoria e Análise Musical 2019,

v. 4, n. 1, p. 188-233-Journal of the Brazilian Society for Music Theory and Analysis@ TeMA 2019 - ISSN 2525-5541
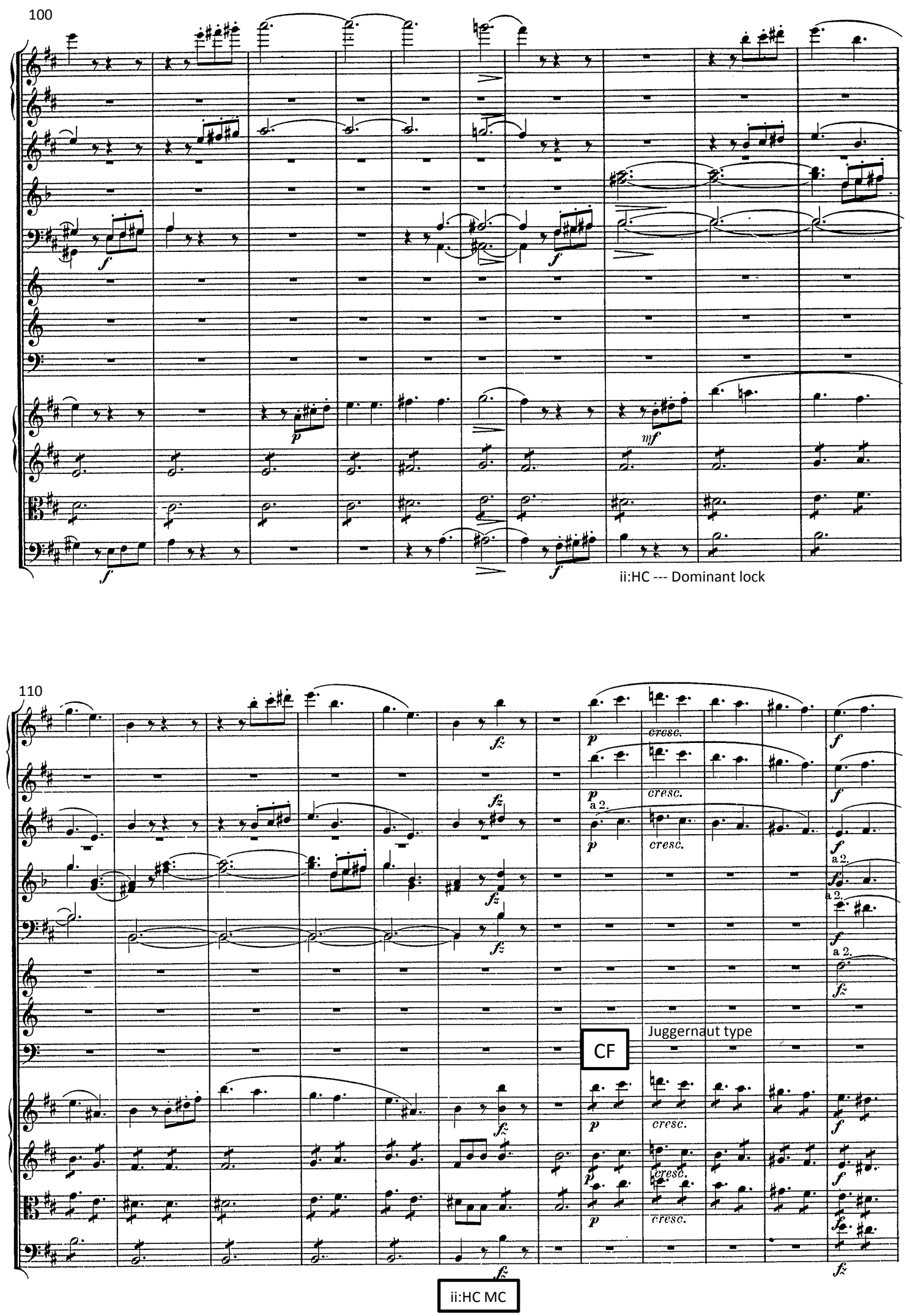


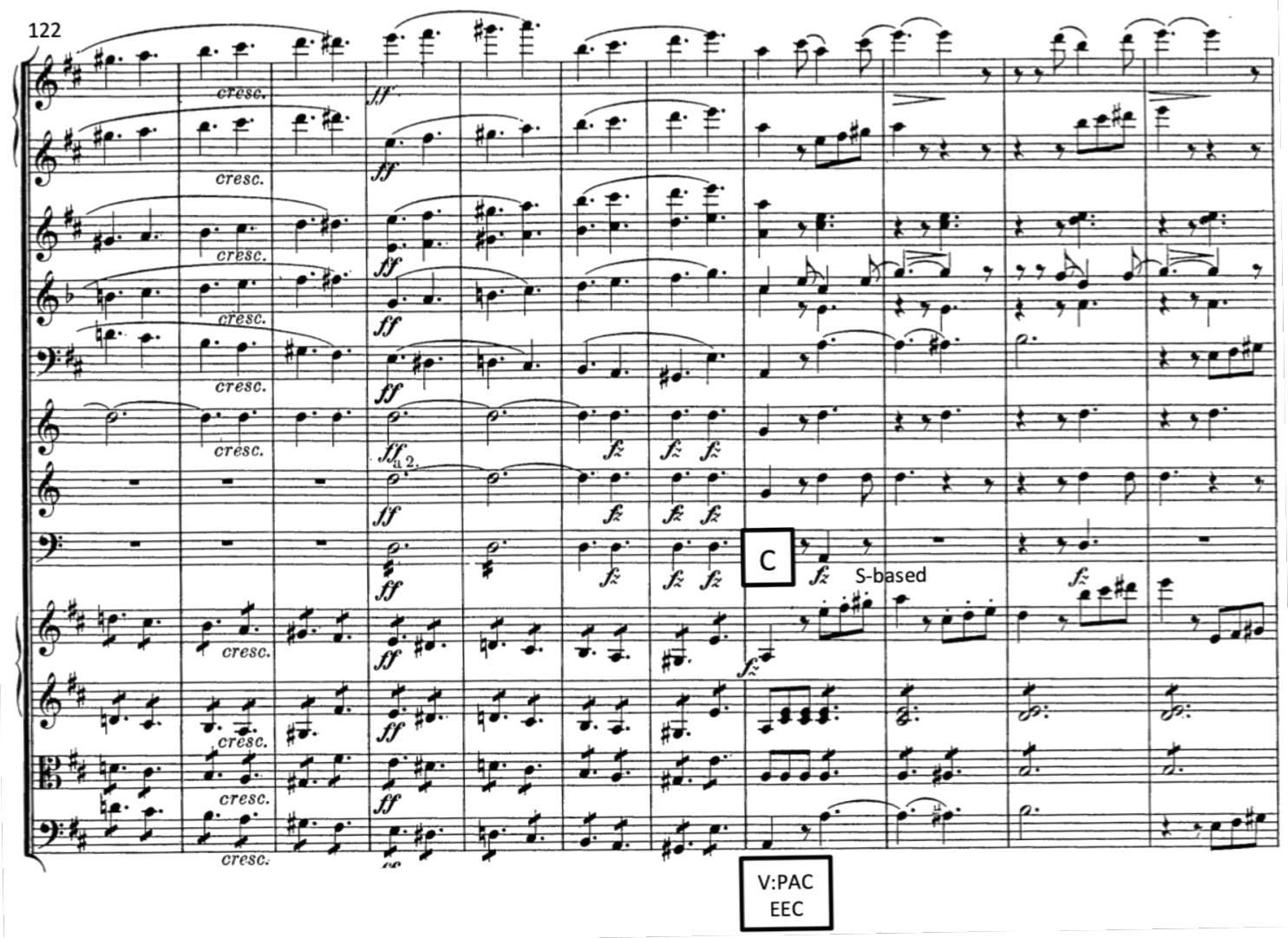

Example 6: Symphony No. 3 in D, D. 200/iv

Another Instance of the "One-Key Exposition": String Quartet No. 2 in C, D. 32/i

In the String Quartet No. 2 in C, D. 32, P comprises a forte unison module structured as a sentence with an expanded continuation. The theme attempts to articulate a I:PAC in measure 19 but is interrupted by the return of the opening unison motive that, despite the absence of a cadence, marks the onset of TR $-\mathrm{a}$ rhetorically "defective" module that manages to destabilize the tonic key. The sequential motion beginning at TR's onset ceases on a G-minor harmony extended for eight complete measures with a rarefied texture and $p p$ dynamic, as if the music were unsure about how to proceed harmonically. The G-minor chord moves unexpectedly to the dominant of $\mathrm{F}$, resulting in a premature and underprepared IV:HC MC (Ex. 7a).

The following music introduces a lively S-candidate in $\mathrm{F}$ major that seems to confirm the proposed MC gesture. However, after two statements of its compound basic idea, the theme is interrupted by Fortspinnung activity, developing the cadential ascending four-note motive derived from the work's initial unison gesture-perhaps expressing $\mathrm{P}^{\prime} \mathrm{s}$ rejection of the new F-major 
theme. The turbulent passage eventually leads into an emphatic I:PAC (m. 62) accompanied by the return of the initial motive, implicating the retrospective cancellation of the IV:HC MC and, consequently, the reopening of pre-MC space. In addition, it validates the proposed interpretation of the previous energetic passage as a refusal of the non-traditional and untimely key of $\mathrm{F}$ major.

The subsequent music confirms the key of $\mathrm{C}$ major, leading into one more $\mathrm{I}:$ PAC (m. 72) followed by a piano and dolce new theme (Ex. 7b). At this point, one might wonder if the exposition will ever leave the tonic. Indeed, a listener familiar with Schubert's early experiments with sonata form might even conceive the just-heard cadential articulation as the EEC of a "one-key continuous exposition," a reasonable interpretation vis-à-vis the new theme's inherent closing character and its late appearance within such an active exposition. The theme ends with a PAC in the tonic and is followed by the return of the opening motive, implying initially a contracted variant of P. Here, the proposed one-key form seems to be consummated: the tonic-anchored C-candidate and the P-based module seem to confirm the exposition's failed tonal trajectory, avoiding the establishment of a secondary key-perhaps as a prolonged reaction to the underprepared appearance of $\mathrm{F}$ major. However, instead of reaffirming the tonic key, the P-based module introduces harmonic activity and brings back the conflicting treatment of the ascending four-note motive that represented "doubt" within TR and denial within the proposed S (Ex. 7c). This tonal and rhetorical instability culminate eventually in a belated V:PAC followed by a zone of tonal affirmation, raising structural questions: Is this the real EEC? The exposition seemed to have abandoned its tonal task long ago, why would it change its mind now?

For Brian Black (1996), "both the timing and the nature of the move to G major cast doubt on this tonality's role as a true subordinate theme. The delay of the modulation until the very end of the exposition and the abrupt way it is accomplished make it appear as an afterthought" (p. 107). In addition, the modulatory passage releases its energy prematurely through a continuous dynamic and textural decrescendo, resulting in a weak cadential punctuation that does not allow it to incorporate any structural role. Had the late FS rhetoric persisted until the cadential punctuation, the V:PAC would probably be heard as the real EEC, invalidating any previous candidates. Thus, the first movement of D. 32 features a "one-key continuous exposition" with a tardy and non-structural 
modulation to the dominant. As Brian Black (1996) has noted, the formal strategy suggests a more elaborate version of Schubert's practice in some quartet movements up to this point in his career: while in D. 18 and D. 94, the one-key exposition ended with a half cadence in the tonic, in D. 32 "the music has proceeded one step further and ended in the dominant" (p. 107-108). Accordingly, the proposed IV:HC MC constitutes the only realistic attempt to establish a secondary key, the exposition's only opportunity to accomplish its tonal task. The $\mathrm{MC}^{\prime}$ s retrospective declining exposes its tonal weakness and, for the first time, reveals a difficulty in leaving the tonic area that would persist until it was too late. The MC is paralleled by the firmly articulated I:PAC EEC, which is, in turn, "unofficially corrected" by a late modulation to the dominant.
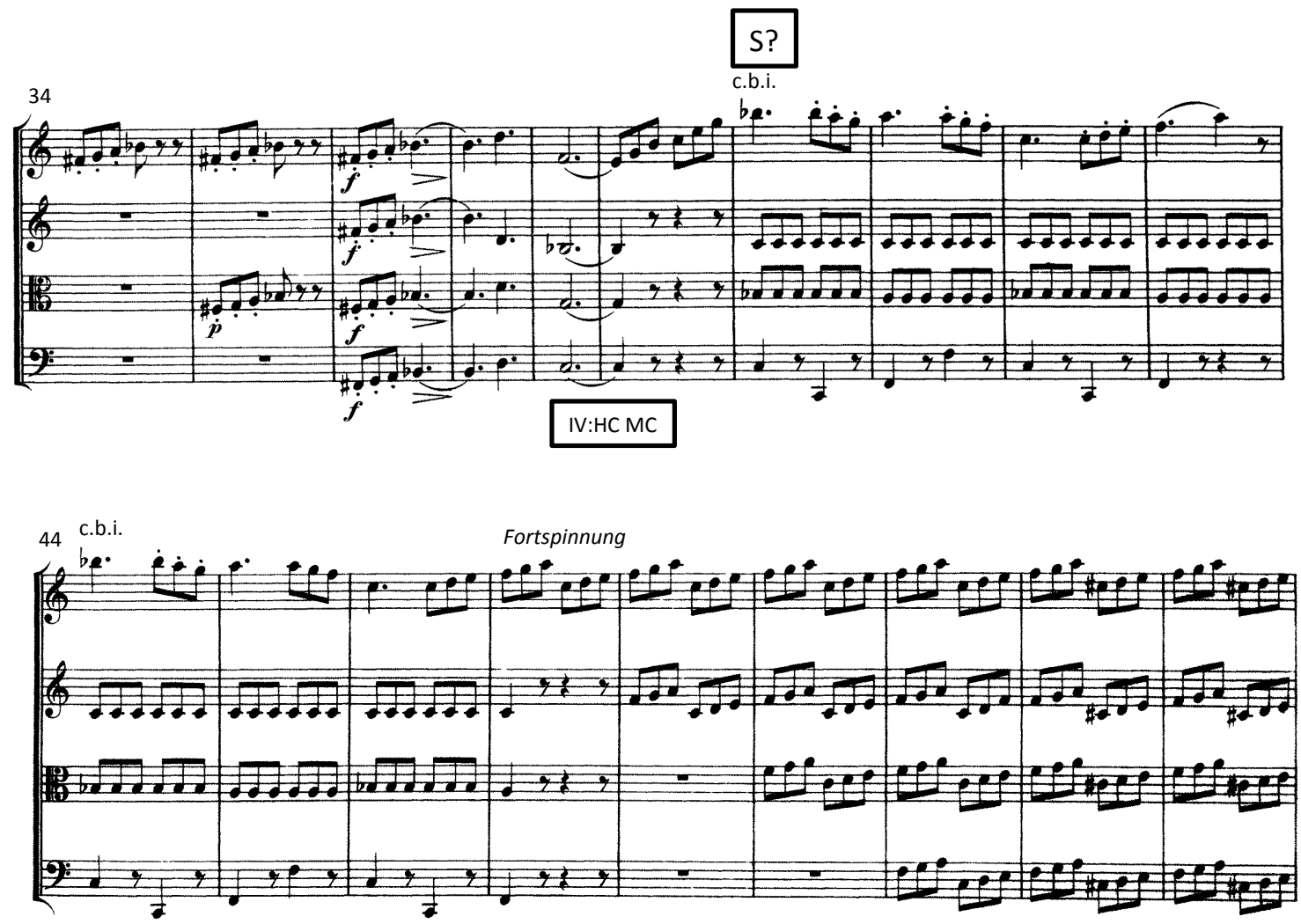

Example 7a: String Quartet No. 2 in C, D. 32/i (mm. 34-52) 
MUSICA THEORICA Revista da Associação Brasileira de Teoria e Análise Musical 2019, v. 4, n. 1, p. 188-233-Journal of the Brazilian Society for Music Theory
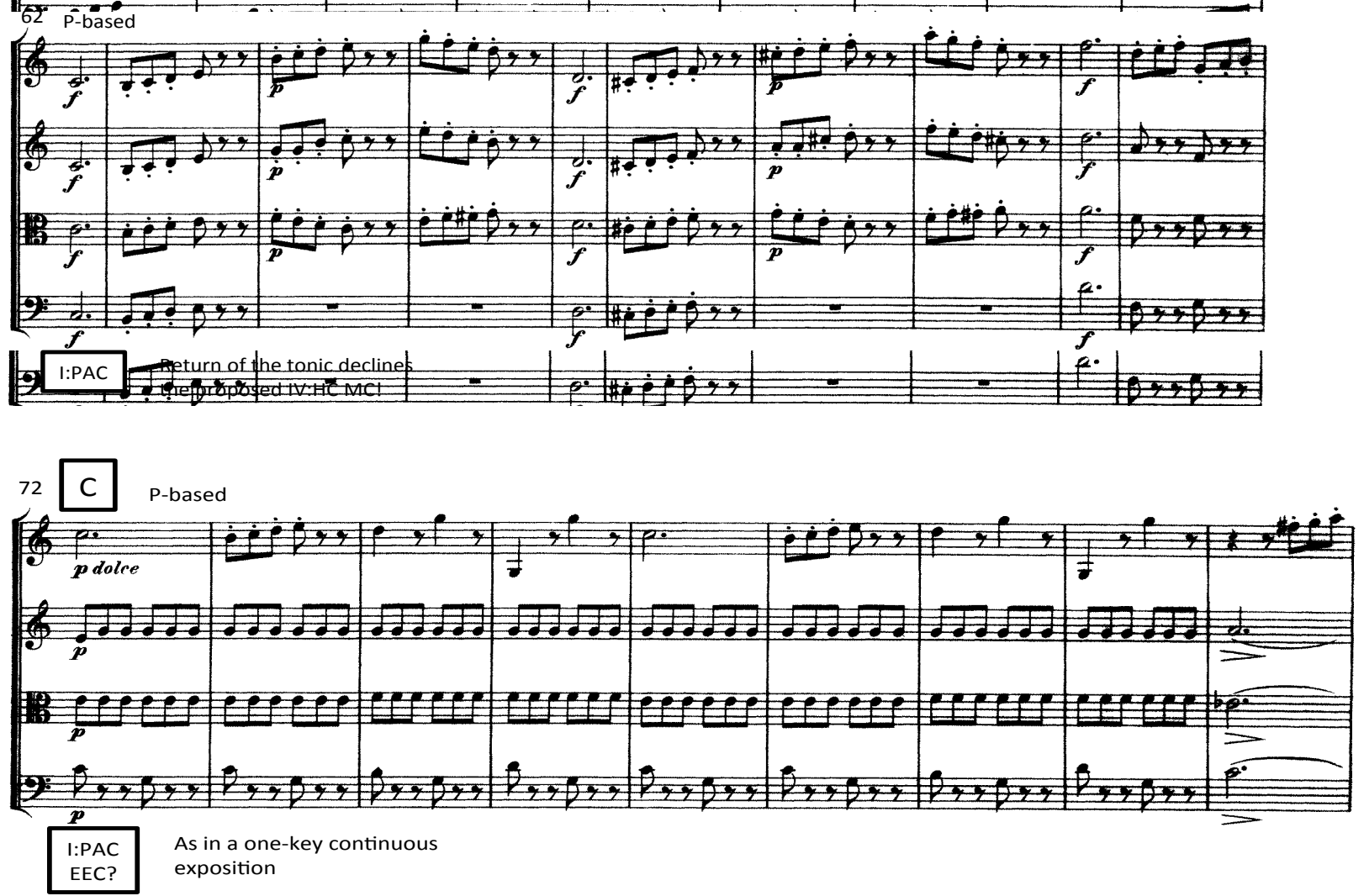

Example 7b: String Quartet No. 2 in C, D. 32/i (mm. 62-80)
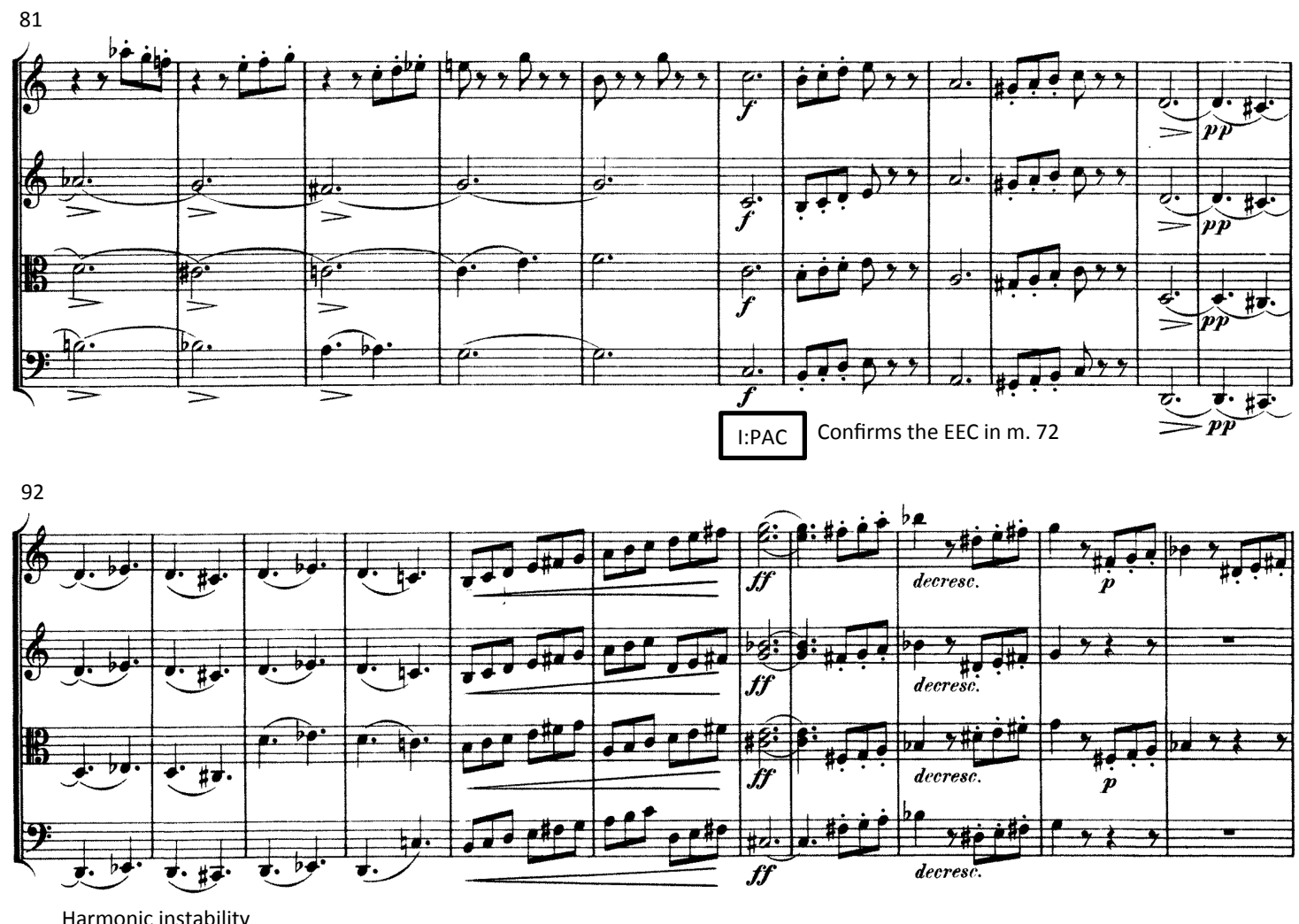


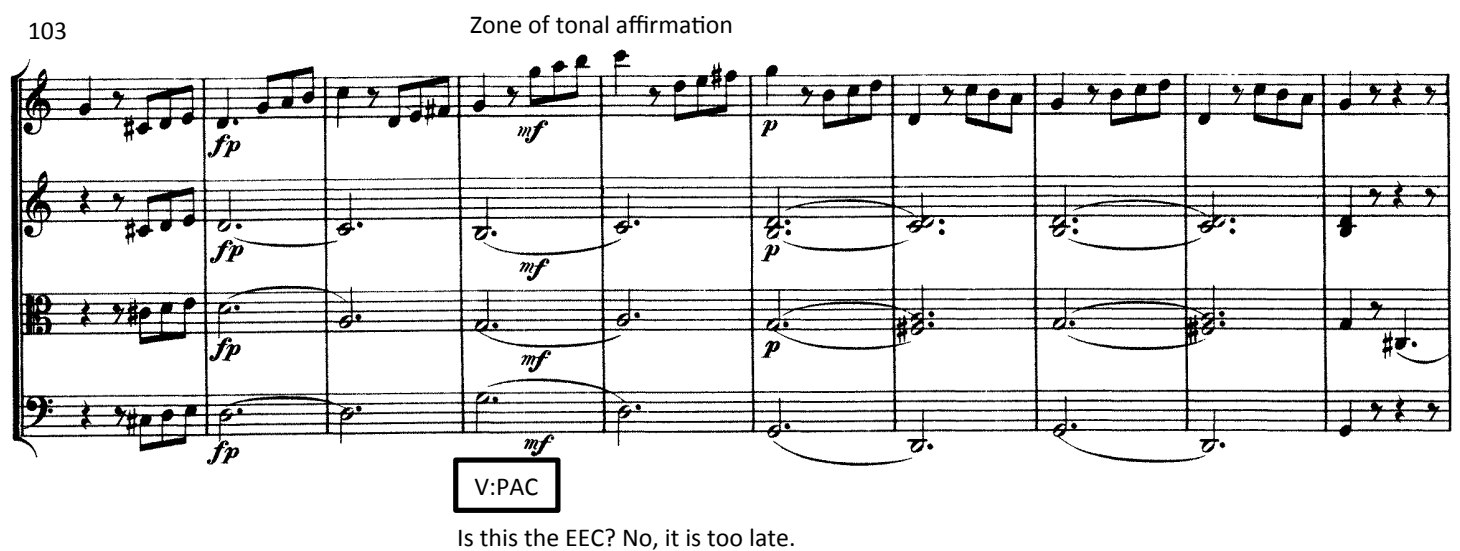

Example 7c: String Quartet No. 2 in C, D. 32/i (mm. 81-112)

\subsection{The Classical/Tonally Unconventional Pair}

In this category, a proposed MC in a Classical key is declined, being eventually replaced by an MC in a non-traditional key. In most instances, the denial of the Classical MC is associated with its underprepared and premature articulation, as a consequence of a "flawed" TR module. The refused gesture is often followed by real TR-activity, culminating in a rhetorically marked tonally unconventional $\mathrm{MC}$, retrospectively confirmed by the introduction of a convincing S-candidate. This strategy may imply the exposition's inability to take the "correct" harmonic path, collapsing into unknown territory, or conversely, a conscious decision to explore distant harmonic regions. Regardless of the analyst's final interpretation, the procedure invariably plays an important role within the sonata's narrative: it highlights the prominence granted the nontraditional key over its normative counterpart and directly affects the work's formal and tonal structure.

The non-traditional key is eventually replaced by a more normative option that concludes the exposition, securing the EEC. The arrival of the expected key and its subsequent tonal affirmation constitute important events within the sonata's trajectory and must be examined in relation to the declined/accepted MC pair. The EEC may be interpreted as (formally) parallel to the accepted tonally unconventional MC, as if "correcting" the work's tonal trajectory. In this context, it could be argued that the Classical/tonally unconventional pair comprises not two but three stages: a denied MC in a traditional key, an accepted MC in a nontraditional key, and the EEC in a traditional key. These cadences are perceived at two different levels: a lower, more localized level involving the declined/accepted MC pair, and a higher level comprised of both accepted 
MUSICA THEORICA Revista da Associação Brasileira de Teoria e Análise Musical 2019, v. 4, n. 1, p. 188-233-Journal of the Brazilian Society for Music Theory and Analysis @ TeMA 2019 - ISSN 2525-5541

cadential gestures, resulting in a structural tonally unconventional/Classical relationship. The two gestures define the work's tonal trajectory and embody a structural function (Fig. 1). To illustrate this category, I provide an analysis of the Violin Sonata in A, D. 574/i and the Impromptu in f, D. 935 No. 1.

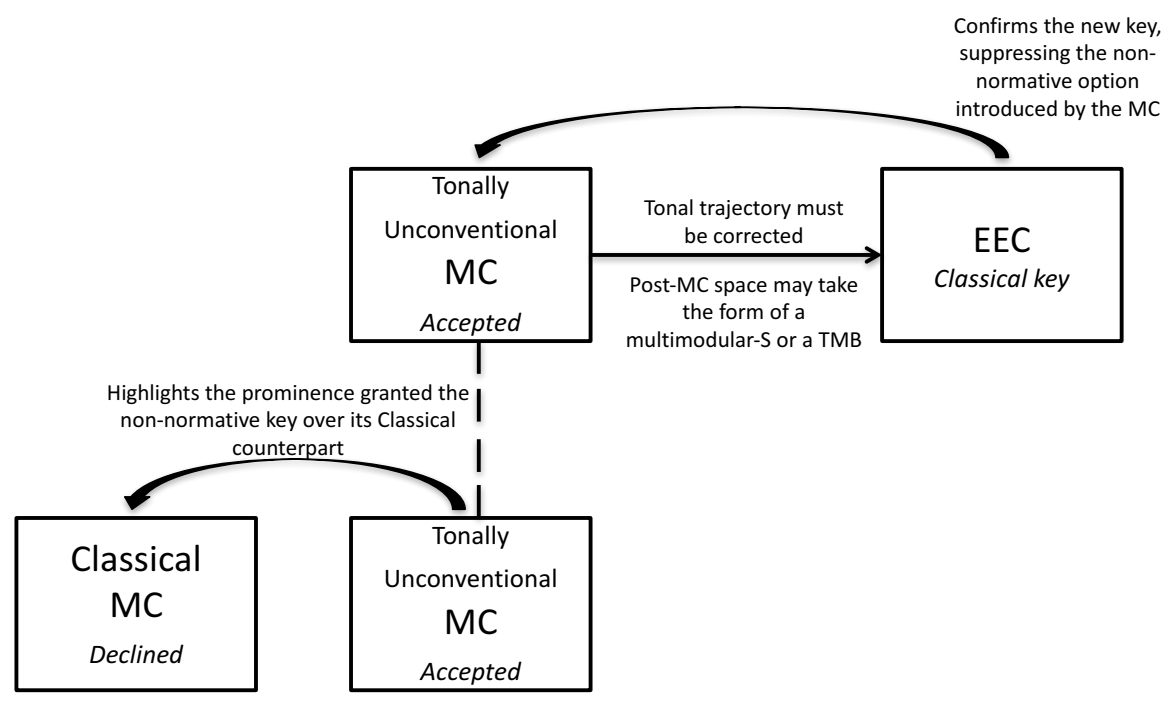

Figure 1: The Classical/Tonally Unconventional Pair and its two-level cadential organization

Tonal "Correction" and the Multimodular-S: Violin Sonata in A, D. 574/i

The Violin Sonata in A, D. 574, begins with a piano and cantabile P-theme that sets a calm, almost meditative atmosphere (Ex. 8). The module comes to a I:PAC in measure 20 and is followed by a repeated triplet figure that suggests a de-energizing P-codetta. Contradicting expectations, the music abruptly articulates a V:PAC in measure 24-reiterated four measures later (m. 28)which implicates the reinterpretation of the passage as a rhetorically "defective" $\mathrm{TR}$ that prematurely attempts to secure the MC. Incapable of moving yet into Sspace, the subsequent music collapses into the minor mode and introduces the hitherto missing TR-rhetoric, retrospectively denying the untimely and underprepared MC.

The new module is structured as a sentence with two thematically identical presentations, the first in $\mathrm{E}$ minor and the second in $\mathrm{G}$ major (the ascending-third transposition is accompanied by a sudden drop to pianissimo, perhaps implying that the proposed major mode might eventually enable the return of P's serene state). Despite a brief "energy bump" at the beginning of its 
continuation phrase, TR remains piano until the end, articulating another MC candidate in measure 40, this time punctuated by a gentle bVII:PAC-but seriously attenuated by the absence of root-position bass at the moment of resolution. The cadence elides with the onset of a harmonically stable new theme (S1) that ratifies the proposed MC gesture. Accepting such a tonally and rhetorically "deficient" MC evinces the precipitate quality of the declined V:PAC MC and exposes the music's difficulty in establishing the key of the dominant.

After prolonging $\mathrm{G}$ major for five measures, $\mathrm{S}^{1.1}$ reinvigorates TR-activity, eventually articulating an attenuated II:PAC. The following music $\left(\mathrm{S}^{1.2}\right)$ begins as a transposed restatement of the first S-theme but soon dissolves into a series of Fortspinnung modules that ultimately lead into a V:PAC. The cadence triggers a new theme $\left(\mathrm{S}^{2}\right)$ characterized by bustling ascending arpeggios that seem to "celebrate" the arrival of the dominant. S2 secures the EEC in measure 67, finally accomplishing the exposition's tonal task.

Thus, the arrival of the dominant and its subsequent affirmation with the EEC "correct" the tonally "defective" ,VII:PAC MC, consolidating the MC's pivotal role within the work's narrative: the MC (m. 40) looks backward, highlighting the exposition's temporary inability to move into E major and, at the same time, looks forward, triggering an obstinate search for the dominantwhich, in this case, involves two statements of the same thematic material at different tonal levels as well as the reinvigoration of TR-activity. ${ }^{15}$

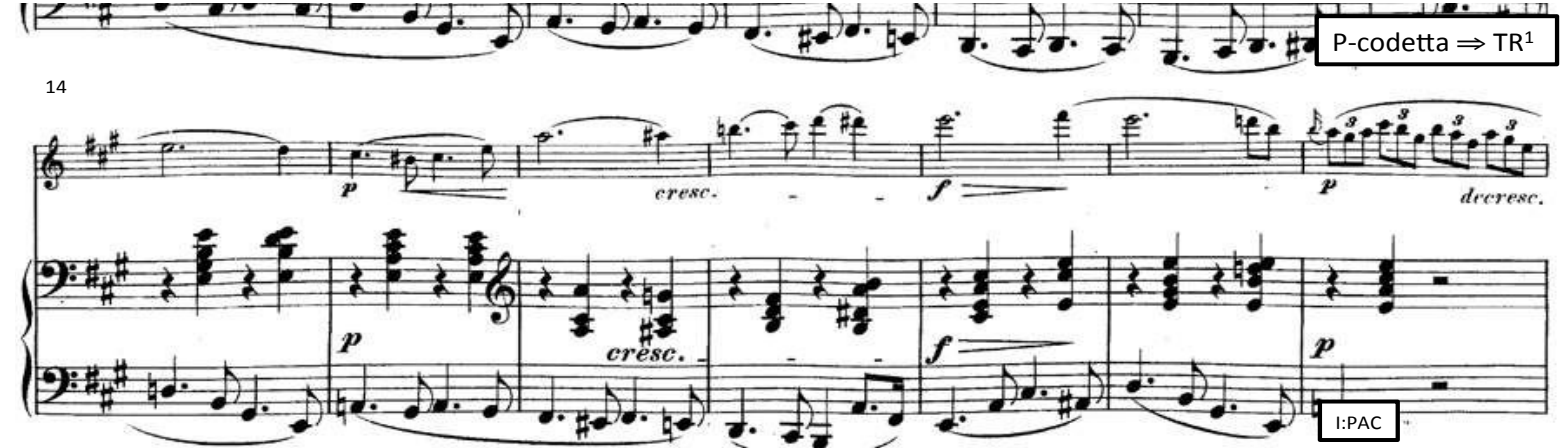

\footnotetext{
${ }^{15}$ Related instances are found in the Piano Sonata in C, D. 840/i (see Navia 2016, p. 86-88) and in the String Quartet No. 5 in B,, D. 68/i (see ibid, 212-214).
} 
MUSICA THEORICA Revista da Associação Brasileira de Teoria e Análise Musical 2019, v. 4, n. 1, p. 188-233-Journal of the Brazilian Society for Music Theory
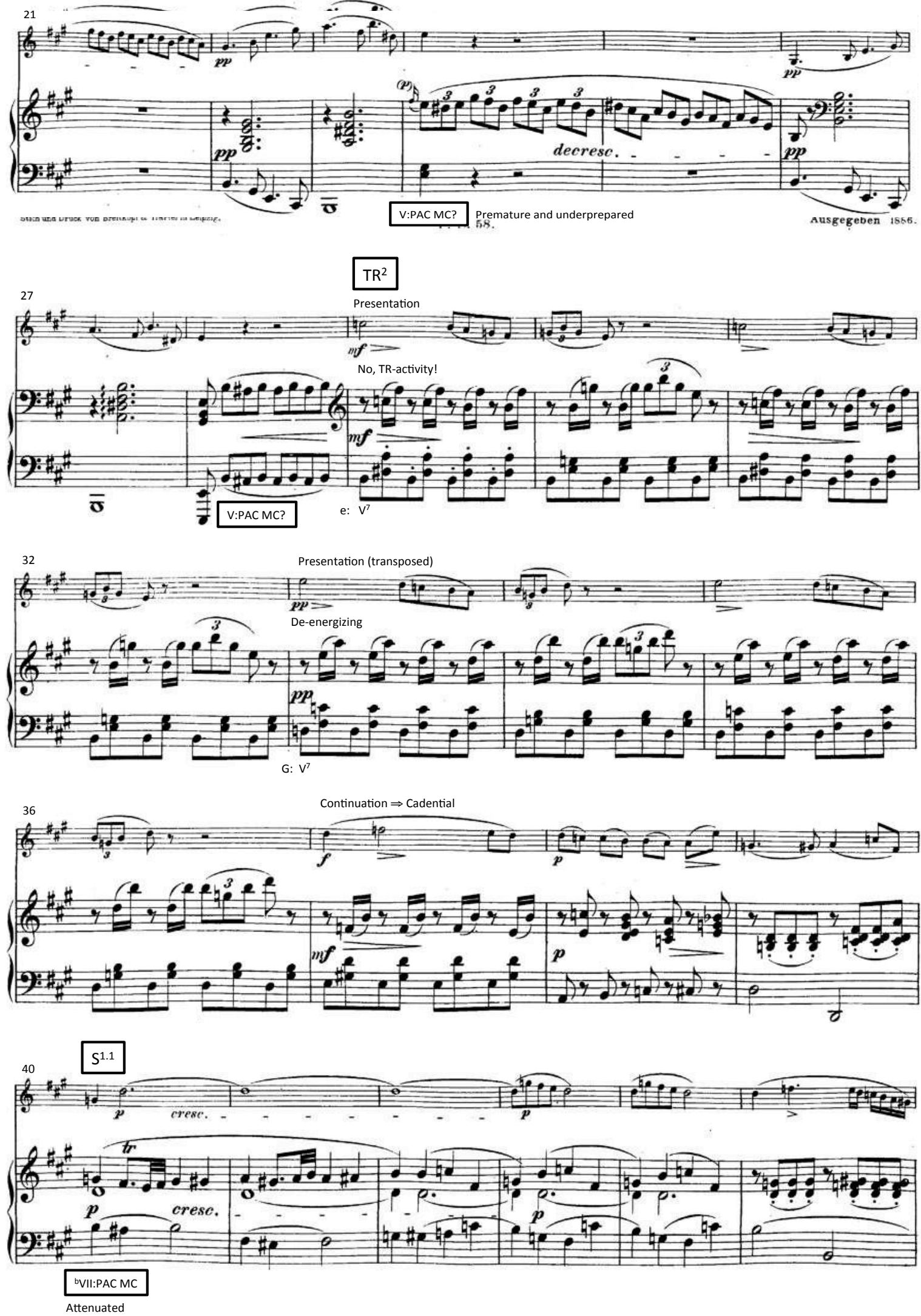
NAVIA, G. H. B.

The Medial Caesura Declined in Schubert's Sonata-Form Expositions
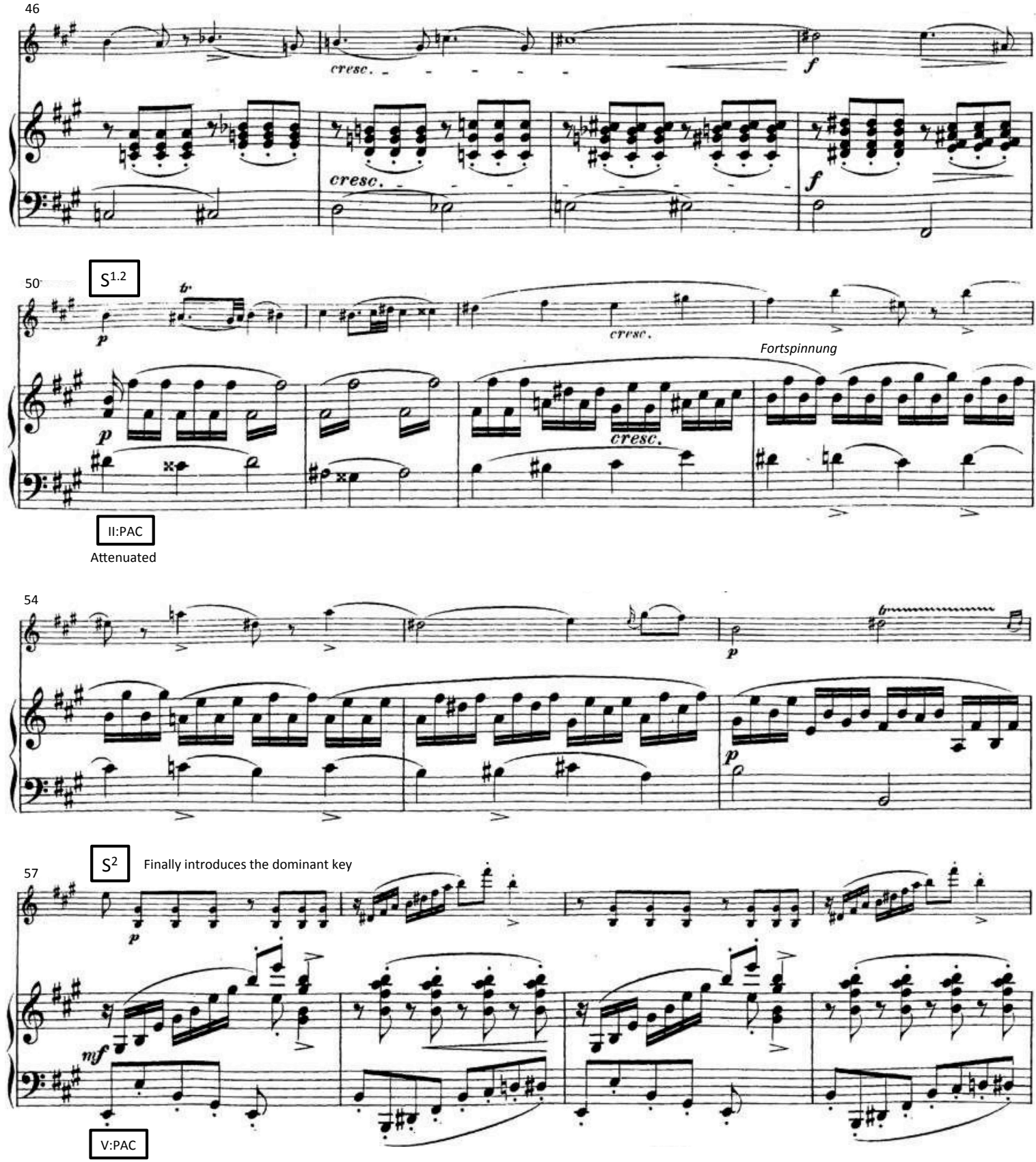

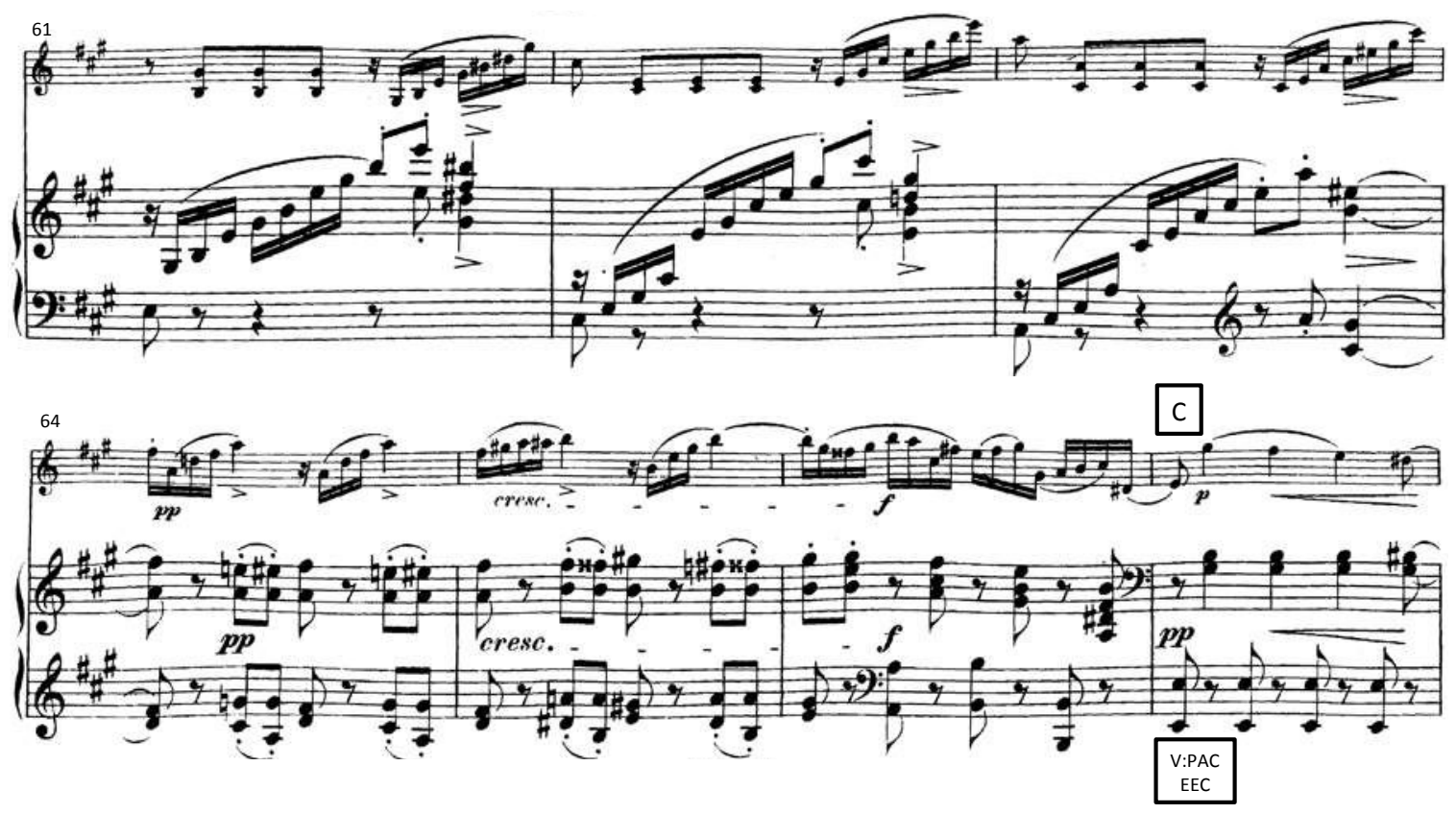

Example 8: Violin Sonata in A, D. 574/i (mm. 14-67)

Tonal "Correction" and the Modulating CF: Impromptu in f, D. 935 No. 1

Another instance of the Classical/tonally unconventional pair is found in the Impromptu in f, D. 935 No. 1. The movement begins with an introductory module (mm. 1-13), characterized by a quasi ad libitum, declamatory style, as if setting the stage for the sonata process to follow. It ends in measure 13 with a $\mathrm{i}: P A C$, followed by a continuous sixteenth-note texture and a new theme $(\mathrm{mm}$. 13-21).

The steady rhythmic activity and the harmonic stability projected by the new module seem to confirm the introductory function expressed by the initial passage, leading one to interpret measure 13 as the onset of P. However, after reaffirming the key of $\mathrm{F}$ minor, the music veers away from the tonic, eventually articulating a PAC in III (m. 21), which, at this point, surprises the listener as an MC-candidate (Ex. 9a). The premature arrival of $\mathrm{A}$, major consequently requires the retrospective reinterpretation of the just-heard P-theme and introductory modules as TR and $\mathrm{P}$, respectively. In other words, the unexpected articulation 
of a proposed III:PAC MC results in two interthematic transformations in which Introduction $\Rightarrow$ P-theme and P-theme $\Rightarrow$ TR. ${ }^{16}$

By refusing to move into S-space, however, the following music declines the proposed $\mathrm{MC}$, maintaining TR-rhetoric in a more eloquent restatement of the previous passage (mm. 21-30). The module comes to another III:PAC in measure 30 , a clear MC-candidate that seems to finally bring the exposition's first part to an end (Ex. 9b). However, the music denies the proposed gesture once again, moving forward with an even more eloquent TR variant. The new passage $(\mathrm{mm}$. $30 \mathrm{ff}$ ) descends in thirds from $\mathrm{A}$, (I) to $\mathrm{D}$, (IV) and then ascends to $\mathrm{F}$ in stepwise motion, culminating in a fortissimo iv: $\mathrm{HC}$ (m. 39), yet another potential MC candidate, properly reinforced by a dominant lock. Despite its decidedly nontraditional key, the rhetorical gesture expressed by the cadence is much stronger than those of the previously proposed MCs. It suggests a desperate attempt to open S-space, even if that requires a drastic tonal detour. Interestingly, midway through the MC's dominant lock, the music undergoes a "moment of crisis," prematurely releasing energy in a sudden dynamic drop from ff to $p$-as if questioning its ability to secure the MC. The rhetorical collapse weakens but does not suppress the MC, which is articulated in measure 42, followed by CF. As if "afraid" of visiting the subdominant area at this point within the exposition, CF treats the root, F, as an upper neighbor to the dominant of $\mathrm{A}$, major, quickly recovering the mediant key, this time accompanied by a piano and cantabile TRbased S-theme (mm. 45-66) (Ex. 9c). ${ }^{17} \mathrm{~S}$ comes to the EEC in measure 66, bringing the exposition to an end (and having utterly suppressed the key of $\mathrm{B}$, minor, proposed at the $\mathrm{MC}$ ).

Thus, in D. 935 No. 1, the tonally unconventional MC manages to open Sspace but (fortunately!) fails to establish the implied key. In other words, the rhetorical gesture is accepted but the tonal proposition is instantly denied in favor of a more traditional option. Despite its tonal declining, one should not underestimate the structural role played by the tonally unconventional $\mathrm{MC}$,

\footnotetext{
${ }^{16}$ For a study of the role of formal reinterpretation in Schubert's works for solo piano, see Venegas 2013. Additionally, for a comprehensive study on formal reinterpretation in early $19^{\text {th }}$-century music, see Schmalfeldt 2011.

17 The many formal anomalies exhibited in this piece allow for more than one plausible interpretation. Gabriel Venegas (2013), for instance, conceives the V-I motion into Ab (mm. 44$45)$ as the EEC of a continuous exposition (p. 52-54).
} 
MUSICA THEORICA Revista da Associação Brasileira de Teoria e Análise Musical 2019, v. 4, n. 1, p. 188-233-Journal of the Brazilian Society for Music Theory

which manages to accomplish what its A,-major predecessors had been attempting for some time, allowing the S-theme to finally spring free. In addition, the apparent III:IAC in measure 45 should not be conceived as the real MC, but instead as a secondary cadential arrival resulting from the non sequitur exit taken by CF (i.e., an unexpected harmonic shift that fortuitously provides tonal relief, instantly overriding the uncertainties implied by the iv:HC MC). ${ }^{18}$
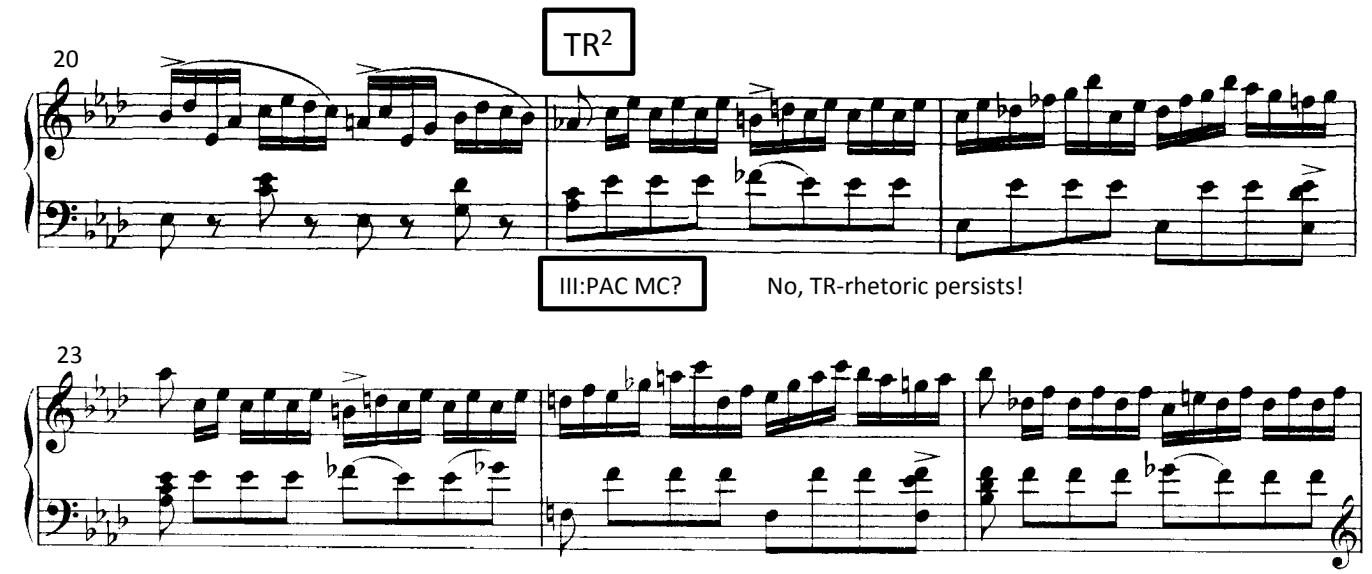

Example 9a: Impromptu in f, D. 935 No. 1 (mm. 20-25)

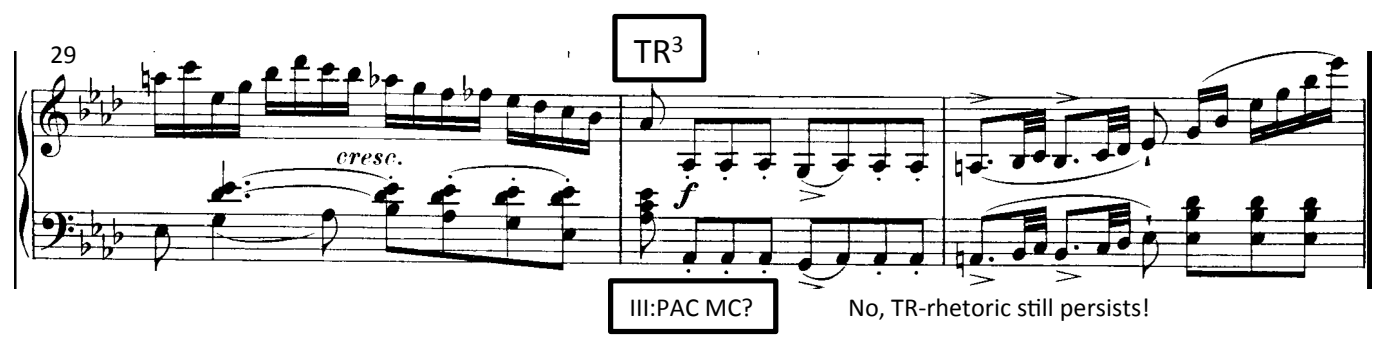

Example 9b: Impromptu in f, D. 935 No. 1 (mm. 29-31)

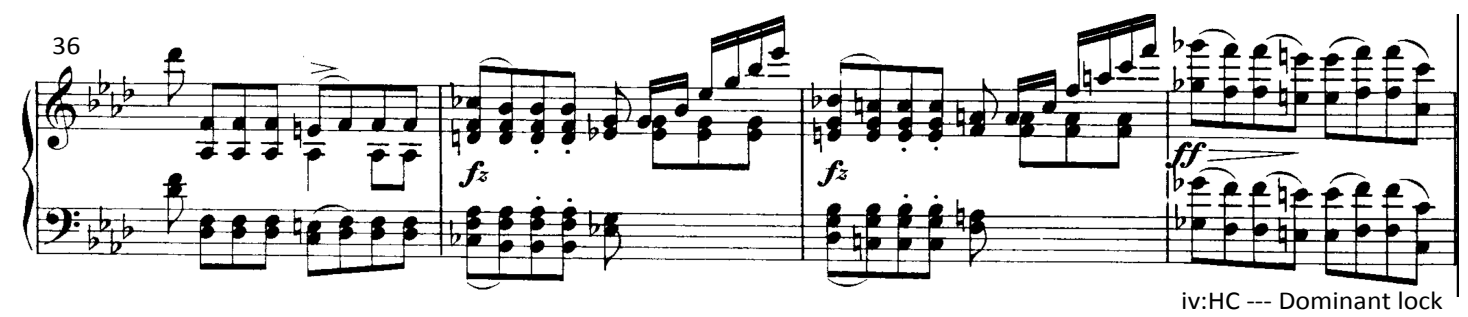

${ }^{18}$ A similar MC situation is found in the Piano Sonata in C, D. 279/i, in which a iii:HC MC (m. 41) is followed by an active CF that, contradicting the cadence's tonal proposition, introduces the dominant of $\mathrm{G}$ major $(\mathrm{V})$, leading into an S-theme in $\mathrm{V}(\mathrm{mm}$. $45 \mathrm{ff})$. For a detailed analysis of $\mathrm{D}$. 279's non sequitur MC, see Navia 2016, p. 93-94. 


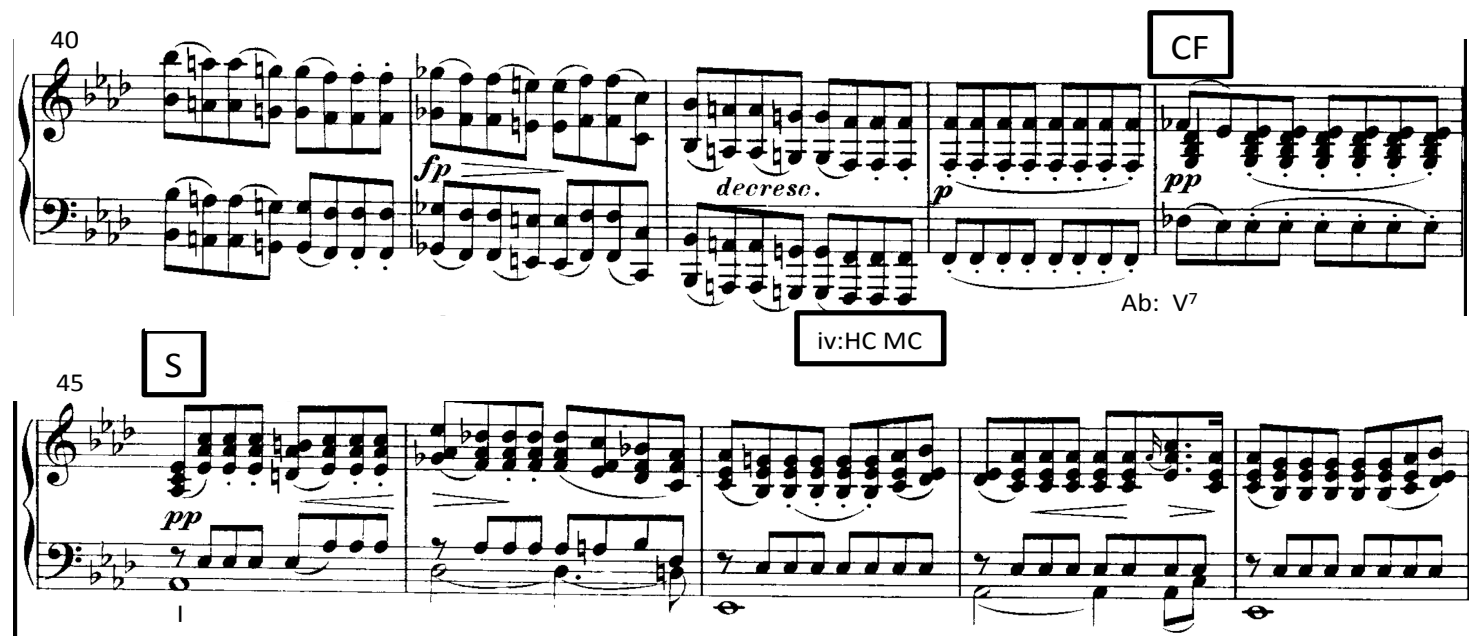

Example 9c: Impromptu in f, D. 935 No. 1 (mm. 36-49)

\subsection{The Tonally Unconventional/Tonally Unconventional Pair}

In this category, both the declined and accepted MCs imply an S-theme in a non-traditional key. ${ }^{19}$ The strategy exposes TR's inability or reluctance to establish a Classically expected key, failing even to consider it as a plausible tonal destination. This new key may directly follow the accepted MC through a non sequitur shift or, conversely, may only be attained well into S-space, perhaps resulting in a TMB structure. Regardless of the way it is introduced, the classically oriented harmonic area manages in most cases to secure the EEC, suppressing the exposition's former harmonic paths. As in the Classical/tonally unconventional pair, the result is a three-stage process perceived at two levels: a lower level involving the declined/accepted MC pair, and a structural level formed by the accepted tonally unconventional MC and the EEC.

The Double Tonally Unconventional MC Pair and the Failed Exposition: Piano Trio in $B$, D. $898 / i$

An instance of the procedure is found in the first movement of the Piano Trio in B b, D. 898. ${ }^{20}$ The work begins with a sentential P-theme that establishes

\footnotetext{
${ }^{19}$ The double tonally unconventional pair is often employed within recapitulations as a way to expand-perhaps color - the sonata's tonal narrative. An instance is found in the String Quartet in a, D. 804, first movement (see Navia 2016, p. 204-206).

${ }^{20}$ For a related instance, see the exposition of the Piano Sonata in C, D. 279/i, see Navia 2016, p. 93-94.
} 
MUSICA THEORICA Revista da Associação Brasileira de Teoria e Análise Musical 2019, v. 4, n. 1, p. 188-233-Journal of the Brazilian Society for Music Theory

the tonic key, ending with a I:PAC in measure 12. The cadence triggers a playful and innocent module that turns out to function as TR - despite initially projecting a P-like character marked by a light and staccato triplet rhythm. Following a sequential descent from $\mathrm{B},(\mathrm{I})$ to $\mathrm{E}_{b}$ (IV), the passage starts a rhetorical crescendo that leads into an abrupt MC gesture (Ex. 10a). In fact, as if in a sudden change of mind, $\mathrm{E}_{b}$ major is reinterpreted as a neighbor to $\mathrm{D}$ major ( $\mathrm{V}$ in $\mathrm{g}$ ), culminating in a vi:HC accompanied by an imposing dominant lock and MC punctuation ( $\mathrm{m}$. 22). The MC is followed by an active CF that, contradicting the implied harmonic path, introduces the dominant of $\mathrm{B}$, major, setting up the return of $\mathrm{P}$ in the tonic and, therefore, retrospectively declining the proposed MC. The impression is that of $\mathrm{P}$ taking control of the music, as if trying to avoid a tonal collapse. In addition, it reveals the MC's premature and fragile condition, a direct consequence of its inadequate preparation.

Following a complete restatement of its presentation phrase, $\mathrm{P}$-perhaps in response to TR's failure to set up a normative key-modulates to the dominant, coming to a V:PAC in measure 37 (Ex. 10b). Such an affirmative arrival of the dominant raises questions regarding the cadence's real status: Is this the MC? Or an early arrival of the secondary key? The subsequent music comprises a piano TR-based module that seems to simply confirm the just-heard cadence. The role of the passage is only made clear in measure 41 when, instead of introducing an S-theme, the music becomes rhythmically and harmonically active, as if determined to finally achieve the MC. This triggers an ascendingfifths sequence that ultimately leads into a iii:HC, dominant lock, and MC punctuation, a slightly varied transposition of the first MC attempt (example 10c). The proposed iii:HC MC is once again followed by a chromatic ascending line $(\mathrm{CF})$ that this time comes to rest on an unaccompanied $\mathrm{A}$, leading into a clear S-candidate. Instead of confirming D minor (iii), the S-theme $\left(S^{1}\right)$ introduces the key of $F$ major $(V)$, reinterpreting the common tone $A$ as the third of the new key. ${ }^{21}$

${ }^{21}$ Both declined and accepted MCs feature a non sequitur shift characterized by a descending major-third motion: in the declined vi:HC MC, a D-major chord is followed by the key of $\mathrm{B}$, major, and, in the accepted iii:HC MC, an A-major chord is followed by the key of F major. In each case, an active $\mathrm{CF}$ softens the harmonic juxtaposition: in the first, an intervening dominant sets up the arrival of B, and in the latter a sustained common tone connects A and F. Susan Wollenberg (1998) interprets the non sequitur shift from the dominant of $\mathrm{D}$ minor (iii) to $\mathrm{F}$ major as a "double deception" (p. 16) since "the right key is in fact reached, but via the preparation for a more remote 
Before continuing, a few points must be considered: first, it should be noted that the proposed iii:HC MC (m. 55) manages to properly open S-space, despite its non sequitur follow up; i.e., the MC is rhetorically accepted but tonally denied. Secondly, despite the rhetorical similarity between the MC gestures themselves, the accepted iii:HC MC is properly prepared by real TR-activity, while its declined counterpart is not. Third, it seems clear that the V:PAC in measure 37 never materializes as an MC but instead signals the premature arrival of the secondary key; one that is denied by TR but abruptly recovered at the onset of $S .{ }^{22}$

$\mathrm{S}^{1}$ (mm. $59 \mathrm{ff}$ ) comprises two statements of a parallel interrupted period firmly rooted in F. It comes to a V:PAC in measure 77, triggering a second Stheme $\left(\mathrm{S}^{2}\right)$ that introduces harmonic instability and even tries to function as $\mathrm{TM}^{2}$; i.e., following a brief modulation to Ab major, the music moves chromatically to the dominant of F minor, implying an imminent v:HC MC (example 10d). ${ }^{23}$ This expressive gesture suggests a potential "correction" of the previous tonally unconventional MCs, perhaps a requirement for the eventual attainment of the EEC. However, the MC attempt is declined by the return of $\mathrm{S}^{2}$-based motives, which also fail to articulate the EEC. In other words, at the moment of resolution, the concluding tonic chord is substituted by a whole-measure rest followed by a quiet S-based closing theme that seems to regret the exposition's inability to secure its final cadence.

Thus, it could be argued that the double tonally unconventional MC pair incorporates a structural function in the first movement of D. 898/i: it motivates a v:HC MC attempt within S-space and could be interpreted as the final cause of the exposition's ultimate failure. The strong presence of the dominant key throughout the exposition softens the negative connotations often associated with this MC pair, which are brought to the fore only later, with the EEC's declining. Moreover, the absence of such a structural punctuation does not allow

choice" (ibid). A strategy Schubert uses to transform "the potentially ordinary" into "the special" (ibid). For more on Schubert's non sequitur MCs, see Navia 2016, p. 91-105.

${ }^{22}$ For more on the early arrival of the secondary key in Schubert's sonata forms, see Navia 2016, p. 148-156.

${ }^{23}$ See David Beach 2017, p. 12-15 for a harmonic analysis of this passage from a Schenkerian perspective. 
the three-step cadential process (declined MC-accepted MC-EEC) to be completed. ${ }^{24}$
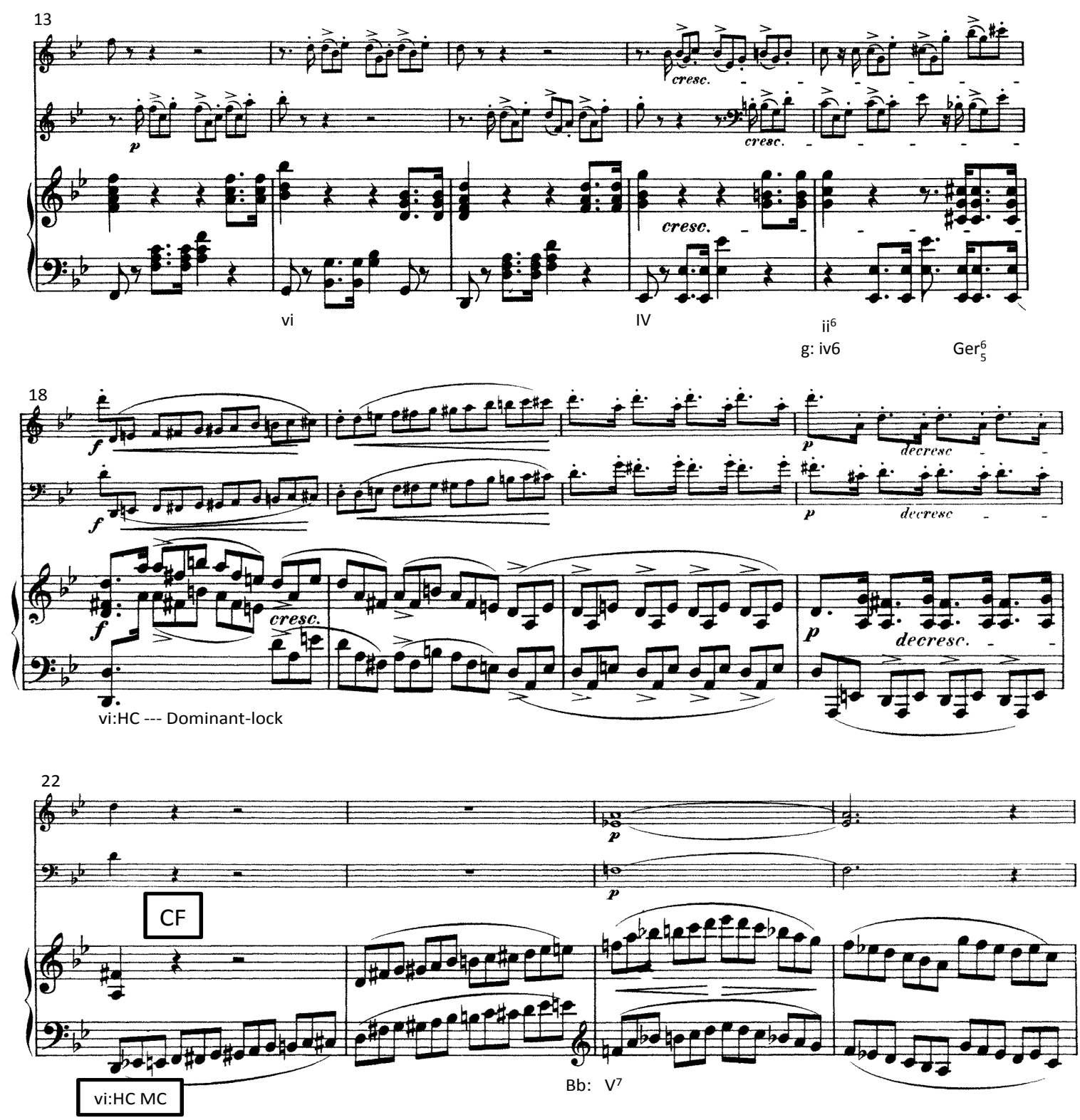

${ }^{24}$ An interesting example of the double tonally unconventional MC pair is found in Schumann's Symphony No. 3 in Eb, op. 97/i (1850) where the "heroic" El-major opening theme seems to be constantly "threatened" by the key of G minor (iii); an intricate instance of tonal pairing that defines the exposition's harmonic scheme. In this example, the first attempt to establish the minor mediant as the secondary key comes in measure 43 , marked by a proposed iii:PAC MC and CF (mm. 43-46). The eventual return of $\mathrm{P}$ in the tonic (m. 57) declines the MC gesture, implying a "fresh start." However, once again, TR attempts to move to G minor, securing a iii:HC MC (m. 91), confirmed by a clear S-candidate in the proposed key. In contrast to the cases studied in this chapter, in Schumann's Third Symphony, the tonally unconventional/tonally unconventional pair features two attempts to modulate to the same (non-normative) key. 


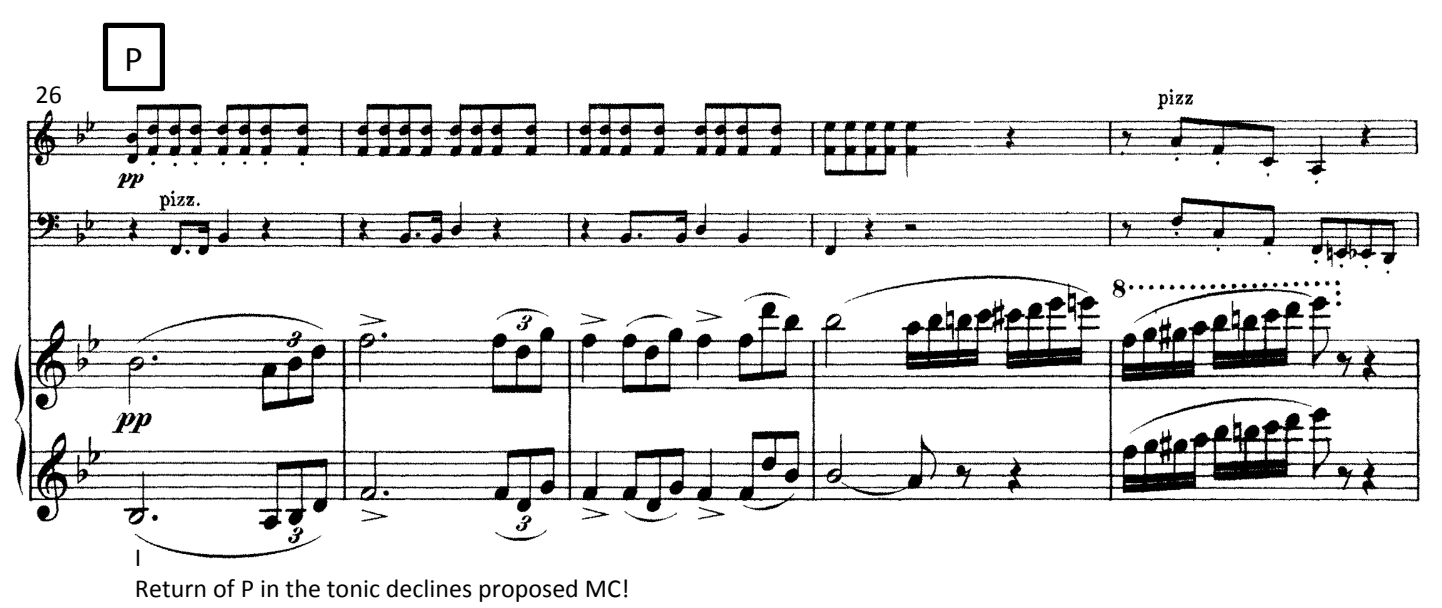

Example 10a: Piano Trio in B b, D. 898/i (mm. 13-30)
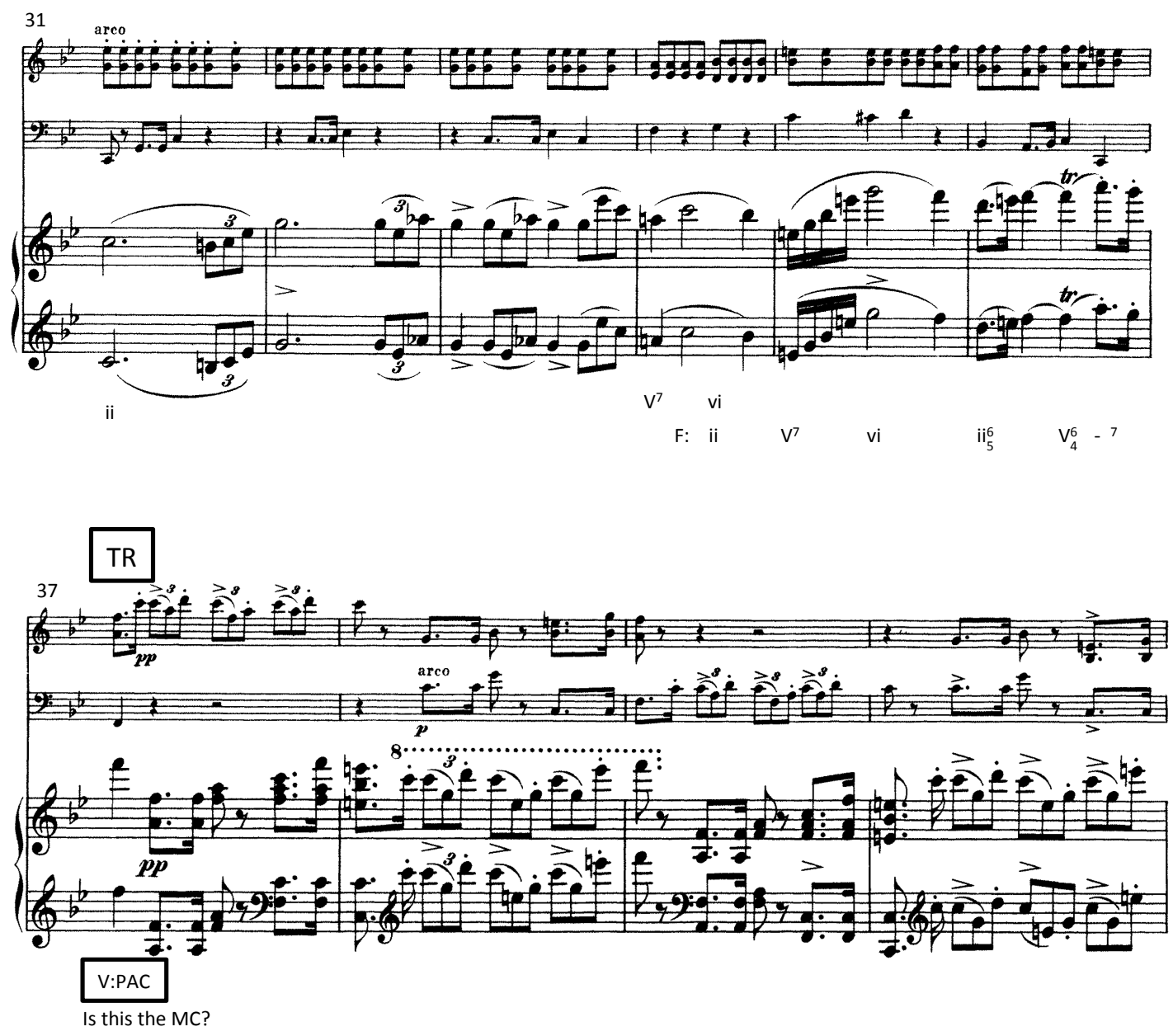


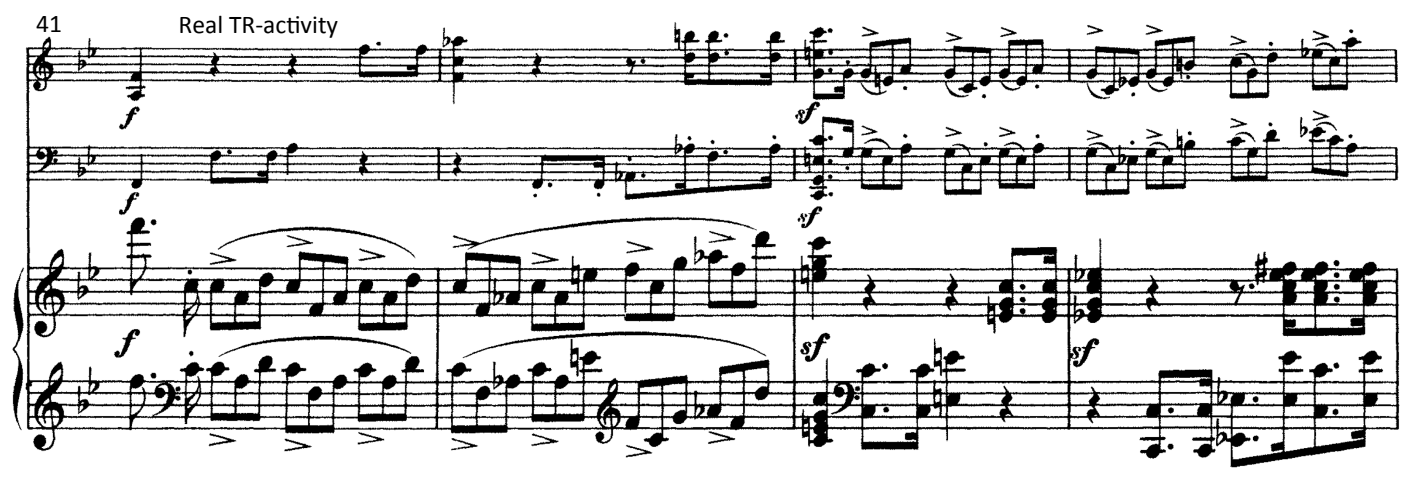

Example 10b: Piano Trio in B,, D. 898/i (mm. 31-44)

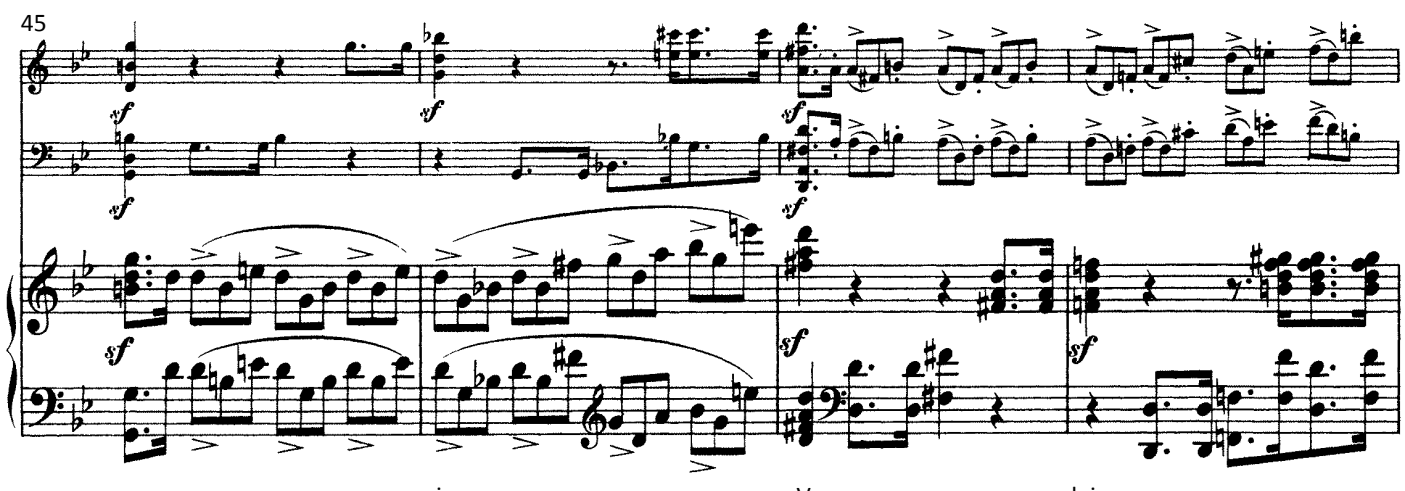

g: i

$\mathrm{d}: \mathrm{i}$

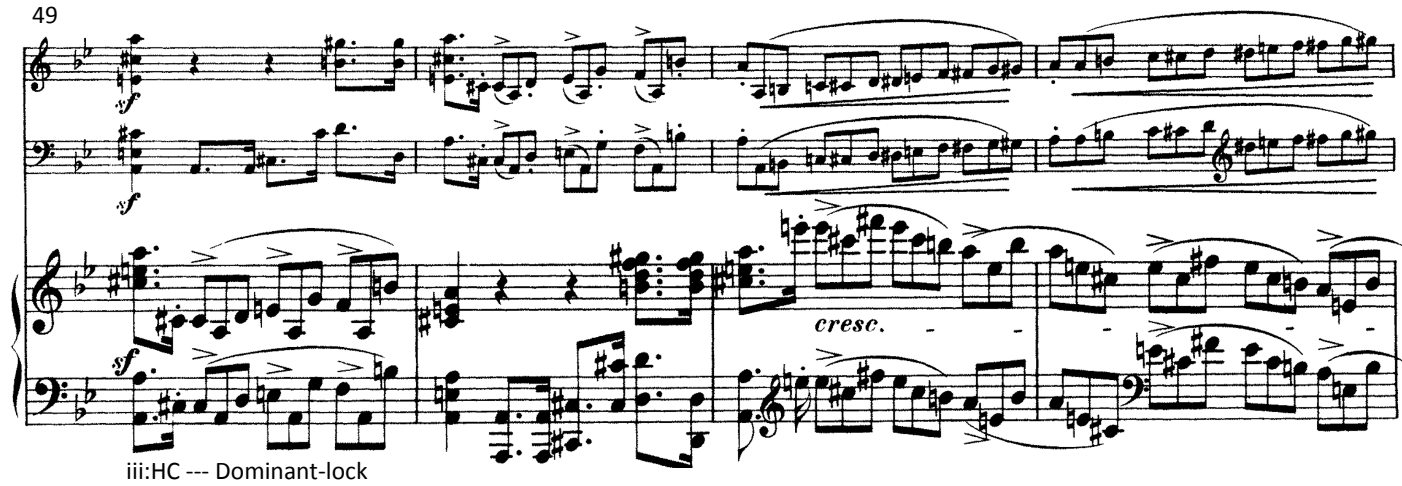




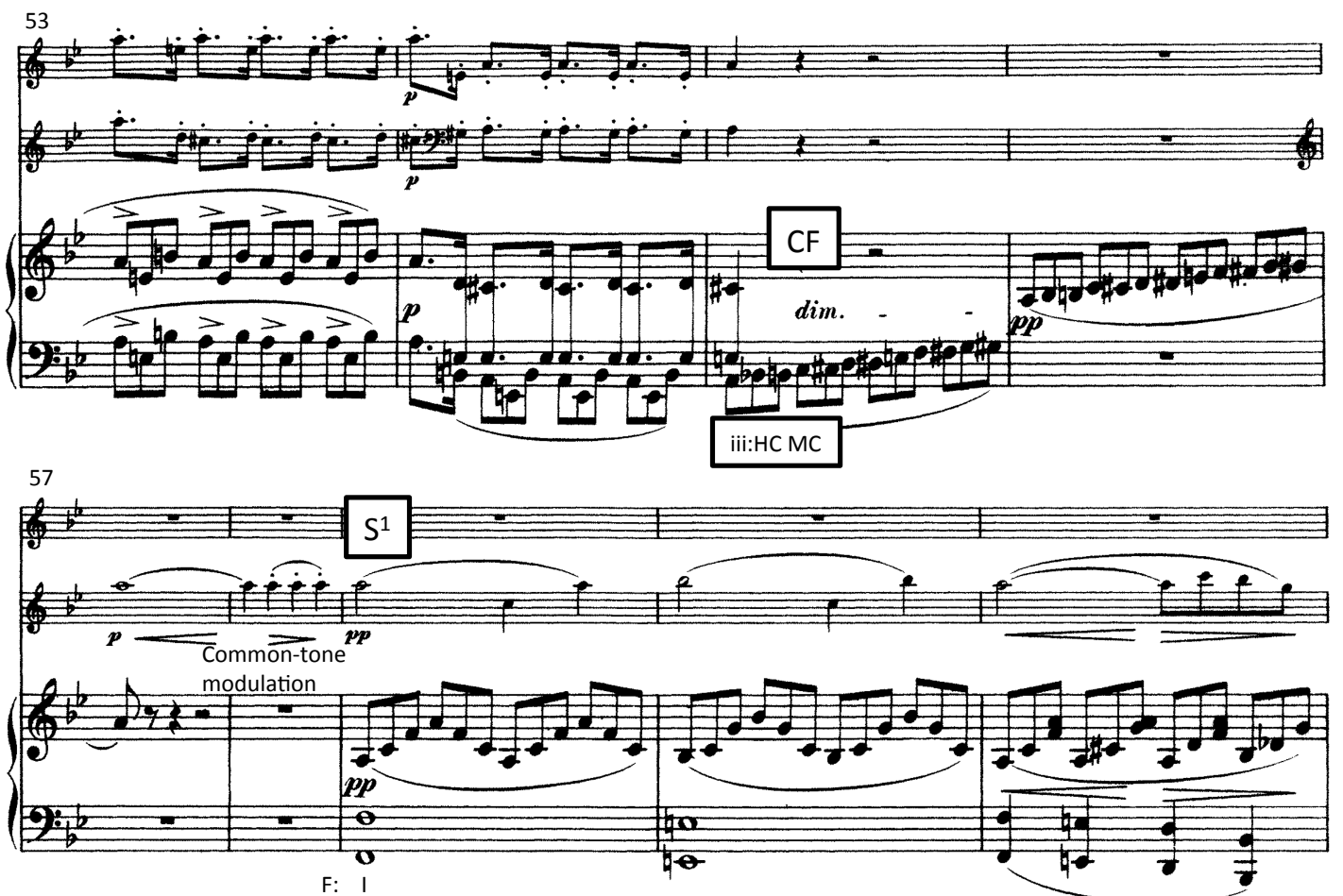

Example 10c: Piano Trio in B b, D. 898/i (mm. 45-61)
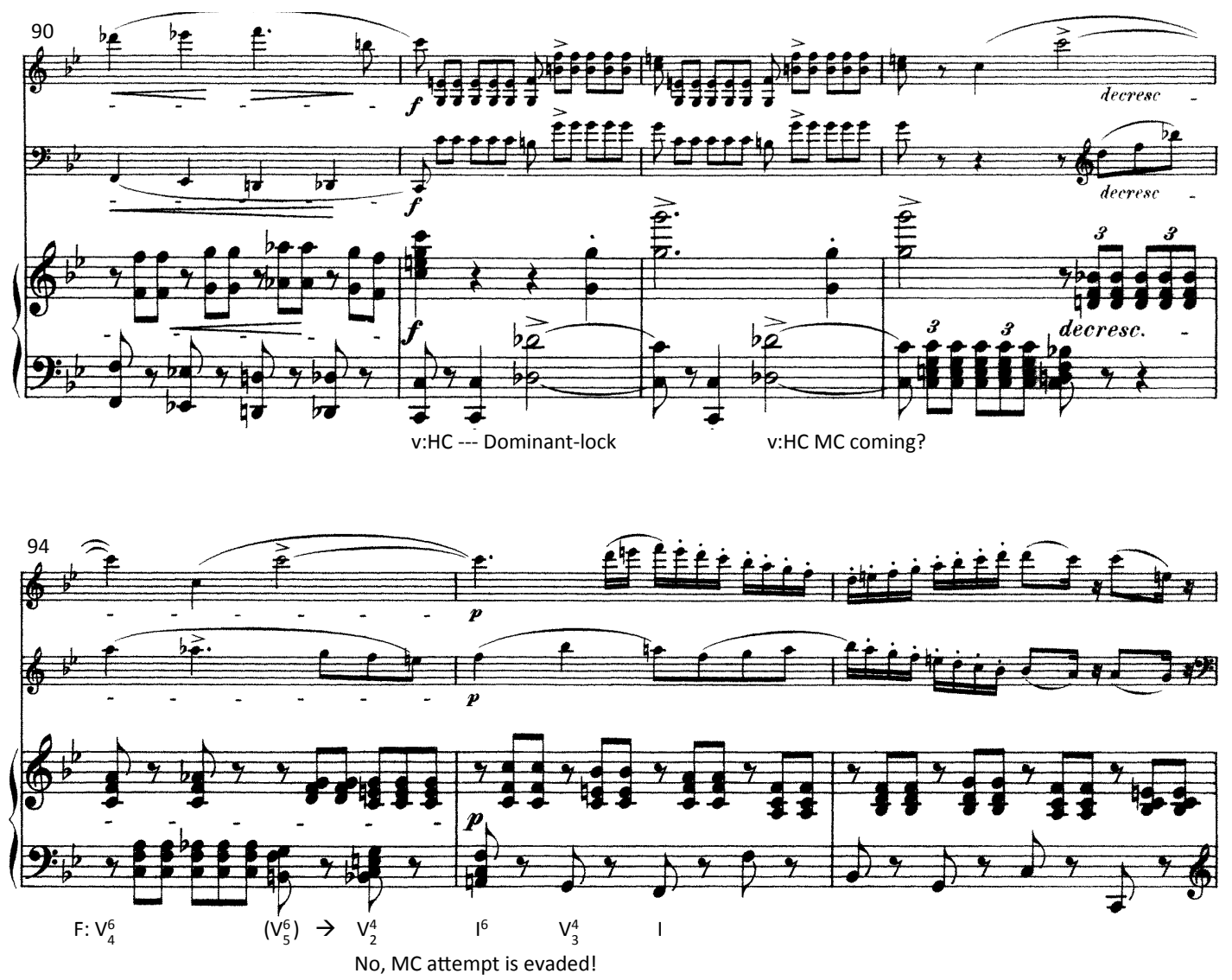


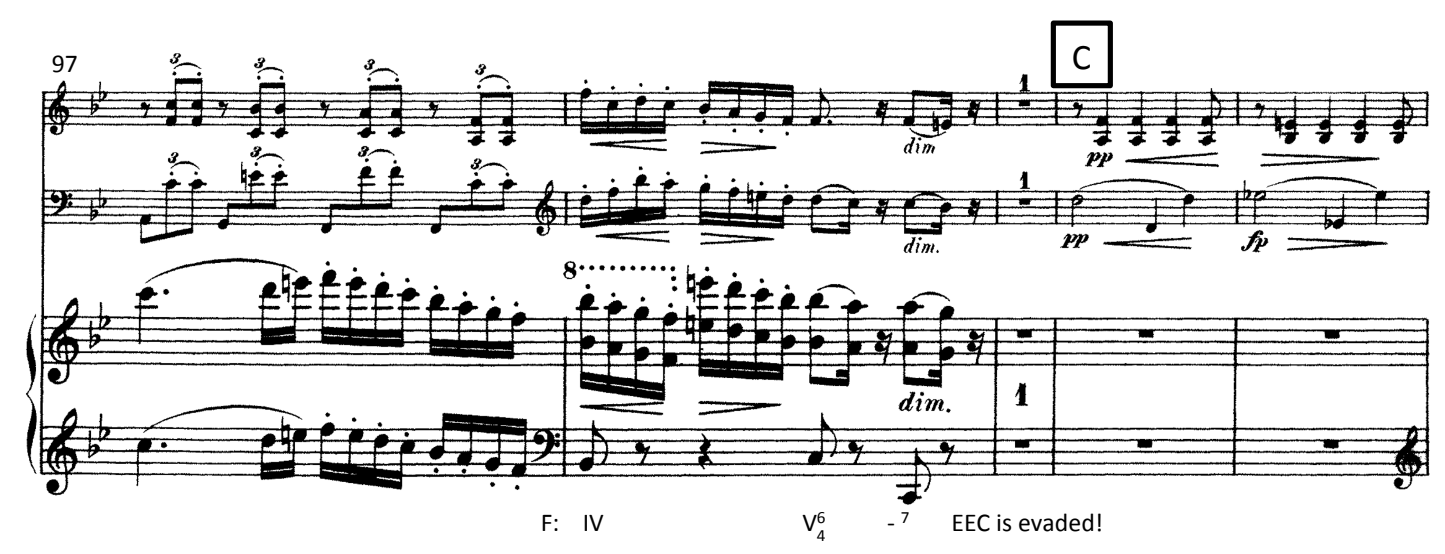

Example 10d: Piano Trio in B,, D. 898/i (mm. 90-101)

\section{Closing Remarks}

In conclusion, Schubert expanded the declined-MC practice of the Classical period, increasing the procedure's tonal and expressive role within sonata movements. His colorful harmonic practice as well as his eclectic treatment of the MC allowed him to organize the procedure in four different declined/accepted pairs, each producing its own distinctive effect on the work's formal narrative. Declined/accepted pairs involving tonally unconventional MCs often implicate formal and tonal complications that require some kind of correction or compensation, resulting, for instance, in a multimodular $\mathrm{S}$, a modulatory $\mathrm{CF}$, or a direct motion to the EEC. Interestingly, even when dealing with the Classical/Classical pair, Schubert constantly avoided the Classical deployment sequence, experimenting with innovative strategies that impacted the work in some way. It seems that, in Schubert, the declined-MC strategy exceeds its inherent rhetorical (and coloristic) function, frequently incorporating structural significance.

\section{References}

1. Beach, David. 2017. Schubert's Mature Instrumental Music: A Theorist's Perspective. Rochester: University of Rochester Press.

2. Black, Brian. 1996. Schubert's Apprenticeship in Sonata Form: The Early String Quartets. PhD diss., McGill University.

3. . 2015. Schubert's 'Deflected-Cadence' Transitions and the Classical Style. In: Steven Vande Moortele, Julie Pedneault-Deslauriers, and 
Nathan John Martin (eds.) Formal Functions in Perspective: Essays on Musical Form from Haydn to Adorno. Rochester: University of Rochester Press, p. 165197.

4. Caplin, William. 1998. Classical Form: A Theory of Formal Functions for the Instrumental Music of Haydn, Mozart, and Beethoven. New York: Oxford University Press.

5. ; Hepokoski, James; Webster, James. 2009. Musical Form, Forms, and Formenlehre. Edited by Pieter Bergé. Leuven: Leuven University Press.

6. . 2013. Analyzing Classical Form: An Approach for the Classroom. New York: Oxford University Press.

7. ; Martin, Nathan John. 2016. The 'Continuous Exposition' and the Concept of Subordinate Theme. Music Analysis 35/1, p. 4-43.

8. Hepokoski, James; Darcy, Warren. 1997. The Medial Caesura and Its Role in the Eighteenth-Century Sonata Exposition. Music Theory Spectrum 19/2, p. 115-154.

9 . 2006. Elements of Sonata Theory: Norms, Types, and Deformations in the Late-Eighteenth-Century Sonata. New York: Oxford University Press.

10. Hunt, Graham. 2009. The Three-Key Trimodular Block and its Classical Precedents: Sonata Expositions of Schubert and Brahms. Intégral 23, p. 65-119.

11. Moortele, Steven Vande. 2017. The Romantic Overture and Musical Form from Rossini to Wagner. New York: Cambridge University Press.

12. Navia, Gabriel. 2016. The Medial Caesura in Schubert's Sonata Forms: Formal and Rhetorical Complications. Tucson, Ph.D. dissertation, University of Arizona.

13. Rosen, Charles. 1988. Sonata Forms. Rev. ed. New York: Norton.

14. Schmalfeldt, Janet. 2011. In the Process of Becoming: Analytic and Philosophical Perspectives on Form in Early Nineteenth-Century Music. New York: Oxford University Press.

15. Venegas, Gabriel. 2013. Formal Reinterpretation in Schubert's Works for Piano Solo. Tucson, MM thesis, University of Arizona.

16. Webster, James. 1978. Schubert's Sonata Forms and Brahms's First Maturity. Part 1. 19th-Century Music 2/1, p. 18-35.

17. Westrup, Jack. 1969. Schubert Chamber Music. Washington: University of Washington Press.

18. Whaples, Miriam. 1968. On Structural Integration in Schubert's Instrumental Works. Acta Musicologica 40/2, p. 186-195. 
MUSICA THEORICA Revista da Associação Brasileira de Teoria e Análise Musical 2019, v. 4, n. 1, p. 188-233-Journal of the Brazilian Society for Music Theory and Analysis @ TeMA 2019 - ISSN 2525-5541

19. Wollenberg, Susan. 1998. "Schubert's Transitions." In Brian Newbould (ed.) Schubert Studies. Aldershot: Ashgate.

20. . 2007. "Schubert's Poetic Transitions." In: Xavier Hascher (ed.) Le style instrumental de Schubert: Sources, Analyse, Evolution. Paris: Sorbonne.

21. . 2011. Schubert's Fingerprints: Studies in the Instrumental Works. Farnham: Ashgate. 


\title{
O Desvio no Fluxo Composicional ${ }^{1}$
}

\author{
Deviation in the Compositional Flow
}

\author{
Bruno Yukio Meireles Ishisaki \\ Denise Hortência Lopes Garcia \\ Universidade Estadual de Campinas
}

\begin{abstract}
Resumo: Neste texto buscamos compreender, no contexto dos processos criativos em composição musical, as características do desvio no fluxo composicional a partir da perspectiva do virtual deleuziano. Acreditamos que a manifestação do desvio é um acontecimento inevitável dentro do fluxo criativo que, ao produzir diferença por meio da atualização, promove uma dessemelhança entre o que é criado e o que é pensado. Neste caso, a atualização contribuiria para um processo mais espiralar do que linear, em oposição à imagem do fluxo criativo como um trajeto teleológico em linha reta (que iria das ideias para os estados de coisas).
\end{abstract}

Palavras-chave: Virtual; Atualização; Composição Musical; Desvio; Deleuze

\begin{abstract}
In the context of creative processes in musical composition, this paper seeks to understand the deviation characteristics in the compositional flow, from the perspective of Deleuzian virtual. We believe that the deviance manifestation is an inevitable event within the creative flow, and that by producing difference through actualization it also promotes a dissimilarity between what is created and what is thought. In this case, the update would contribute to a more spiral rather than linear process, opposing the image of creative flow as a straight-line teleological path (that would go from idea to state of things).
\end{abstract}

Keywords: Virtual; Actualization; Musical Composition; Deviation; Deleuze

${ }^{1}$ O presente trabalho foi realizado com apoio da Coordenação de Aperfeiçoamento de Pessoal de Nível Superior - Brasil (CAPES) - Código de Financiamento 001. 
MUSICA THEORICA Revista da Associação Brasileira de Teoria e Análise Musical 2019, v. 4, n. 1, p. 234-254-Journal of the Brazilian Society for Music Theory and Analysis@ TeMA 2019 - ISSN 2525-5541

\section{Teleologia e composição musical}

Mesmo as escolas dos estilos composicionais mais díspares frequentemente trazem um traço comum em seus discursos: falam da ideia musical como norteadora do processo criativo. Assim, o planejamento composicional se configuraria como um projeto teleológico que teria por finalidade a materialização fidedigna de um determinado conjunto de Ideias. Tal noção, apesar de não ser hegemônica, está bastante presente nas práticas derivadas dos idealismos de um desenvolvimentismo temático que se fundamenta, em um primeiro momento, no tratamento motívico e na macroforma, para depois se estender aos campos texturais para o tratamento timbrístico, os perfis rítmicos e as coleções intervalares, até alcançar todo tipo de categorização teórica que se baseie em uma noção de identidade.

Em todo caso, estamos falando especificamente de um tipo de pensamento teleológico fundamentado na representação. Neste contexto, é sempre inescapável a comparação entre o que foi feito e o que foi pensado - por exemplo, uma performance musical como representação da partitura (ou vice-versa). Em seu artigo Virtual works - Actual things, Paulo de Assis expõe o panorama da representação como um problema ontológico no campo da teoria musical:

Apesar de suas profundas diferenças e discussões, as três teorias mais abrangentes existentes - Platonismo, nominalismo, ficcionalismo compartilham um traço comum: todas elas são sustentadas por um modelo de representação do pensamento e por práticas musicais de representação. Há sempre a performance ou apreensão de algo "como" algo, ou a performance "de" algo. Qualquer que seja o modo de perceber o aqui-e-agora (uma performance, uma gravação, uma descrição), ele é a "representação" de algo mais. Platonistas insistem na primazia de uma ideia original e de estruturas sonoras perfeitamente encapsuladas que podem ser representadas através de performances. Nominalistas focam nas entidades materiais internas à prática musical, rejeitando abstractas ${ }^{2}$ mas mantendo a suposição da performance como algo baseado na repetibilidade e variabilidade de uma obra claramente bem articulada, porém gerada imanentemente, que crucialmente pré-existe à performance, e sobre a qual a performance é comparada, reintroduzindo assim uma entidade transcendental no panorama. Para os ficcionalistas não há obras de fato, mas por meio de suas

\footnotetext{
2 Abstractas referem-se, aqui, às operações intelectuais que consistem em "isolar, por exemplo, num conceito, um elemento à exclusão de outros, do qual então se faz abstração" (Durozoi; Roussel 1993, p. 11). Trata-se, portanto, de exprimir relações e de tudo aquilo que pode, em termos de pensamento, ser considerado geral em uma determinada classe de fenômenos.
} 
construções das obras "como se elas existissem", eles cometem - em termos práticos - o mesmo modelo de performance como apresentando (ou representando) uma entidade musical já dada (mesmo que seja fantasmática) (Assis 2018, p. 22).

O pensamento teleológico que parte da ideia aos estados de coisas está intimamente conectado a uma lógica da representação no processo composicional, já que “a própria noção de representação implica em algo anterior que tem a capacidade de ser representado" (Assis 2018, p. 22); ou seja, se há uma ideia que antecede a feitura de uma composição musical, esta ideia funda uma teleologia e pressupõe métodos mais ou menos eficientes para se fazer existir como coisa no mundo. Pensados desta forma, esses processos composicionais são todos tributários de um modelo ontológico que irá encontrar sua origem em Platão. Segundo Assis,

Surpreendentemente, as maiores e mais abrangentes ontologias musicais existentes (mesmo aquelas que não são oficialmente classificadas como "Platônicas") estão conectadas com a teoria das Ideias de Platão. As questões fundamentais das diversas ontologias musicais assumem a existência de obras musicais identificáveis e estáveis (sejam elas abstracta ou concreta), ${ }_{1}^{3}$ de sujeitos incorruptíveis capazes de apreendê-las de forma imaculada, e de uma conexão transparente entre a codificação escrita de uma obra e sua manifestação sonora na performance. Essas ontologias não levam em conta as condições intensivas e energéticas e seus processos de chegar a ser, nem as complexidades de sua transmissão através do tempo e da história (Ibidem, p. 24).

Contudo, todo compositor conhece as neuroses e as alegrias do desvio. Sabemos que há um abismo entre o que se registra em notação musical e o que acontece na performance. Do mesmo modo, todo compositor experimenta, em algum momento da composição de sua música, a frustração de ver sua ideia inicial ser desviada para um caminho que desfigura totalmente o planejamento composicional. Mas se há uma neurose, ela acontece por nos apoiarmos demasiadamente na ilusão da identidade, por confiarmos demais na prevalência da ideia sobre as coisas do mundo; em outras palavras, por sermos platônicos demais. Assis fala da possibilidade de se pensar uma ontologia da teoria musical

\footnotetext{
${ }^{3}$ Durozoi e Roussel comentam que "é qualificada de concreta qualquer circunstância vivida em sua dimensão social e histórica por cada homem na situação" (Ibidem, p. 98). Concreta tem a ver, portanto, com aquilo que é individual e circunstancial e se opõe à noção de abstracta, que é generalizante e relacional.
} 
MUSICA THEORICA Revista da Associação Brasileira de Teoria e Análise Musical 2019, v. 4, n. 1, p. 234-254-Journal of the Brazilian Society for Music Theory and Analysis @ TeMA 2019 - ISSN 2525-5541

que possa superar a neurose dos platonismos; que, ao invés de fazer subir categorizações, classes e espécies, possa nos auxiliar na construção de uma imagem do pensamento que corresponda melhor àquilo que há de real nos processos de criação de música:

Assim, tal imagem do pensamento precisa também reverter o Platonismo, ${ }^{4}$ no senso estrito de redirecionar as distinções fundamentais entre ícones e fantasmas, entre imagens e simulacros. Em poucas palavras, ela tem que excluir as hierarquias de categoria e a transcendência idealista (Ibidem, p. 25).

Neste trabalho, buscamos entender os aspectos daquilo que seria chamado de "desvio" dentro de uma perspectiva platônica (o simulacro ${ }^{5}$ seria a consequência atual dessa noção). Entendemos que o desvio é um aspecto imanente incontornável nas práticas de criação; assim, ao invés de ser preterido e evitado, propomos como alternativa um estudo que possa delinear os atributos que fazem dele um elemento potente no fluxo composicional.

Nos debruçaremos, daqui em diante, sobre os conceitos de "virtual" e "atual", tendo como principais referências os filósofos Henri Bergson, Gilles Deleuze e Pierre Lévy. A partir do estudo dos conceitos do virtual e do atual, será possível construir entendimento do fluxo criativo que não dependa mais de um princípio idealista ou de uma trajetória teleológica, permitindo a emergência de outra imagem do desvio no processo composicional.

\footnotetext{
${ }^{4} \mathrm{O}$ projeto de reversão do platonismo empreendido por Deleuze tem a ver com a valorização do simulacro, enquanto acontecimento imanente, em detrimento da superioridade atribuída por Platão à semelhança e à noção de "cópia". A proposta de reversão platônica encontra suas origens em Nietzsche, e é a partir deste autor que Deleuze pensa a sua reversão - na qual o simulacro surge como coisa em si, sem fundamento (daí o termo a-fundamento que utilizaremos mais à frente) nem semelhança com a Ideia, mas conectado a ela e trazendo para a atualização o desvio que sempre foi inerente ao virtual de direito. Enquanto Platão condena os simulacros, Deleuze vê neles a potência para a criação do novo, inaugurando a possibilidade de um pensamento em processos criativos no qual o objeto não é o fim do processo e não está separado, em termos Reais, nem da Ideia, nem do fluxo que percorre a ambos.
}

${ }^{5}$ Em Diferença e Repetição, Deleuze escreve que "por simulacro não devemos entender uma simples imitação, mas antes o ato pelo qual a própria ideia de um modelo ou de uma posição privilegiada é contestada, subvertida" (Deleuze 2018, p. 99). Para um contato mais aprodundado com o conceito de "simulacro" em Deleuze, ver os textos Platão e o Simulacro e Lucrécio e o Simulacro, ambos apêndices do livro Lógica do Sentido (2011). 


\section{O virtual e o atual}

O termo "virtual" está originalmente relacionado à noção de potência. ${ }^{6}$ Pierre Lévy reforça, em O que éo Virtual?, as definições que contornam o conceito, apontando a origem etimológica do termo:

A palavra virtual vem do latim medieval virtualis, derivado por sua vez de virtus, força, potência. Na filosofia escolástica, é virtual o que existe em potência e não em ato. $\mathrm{O}$ virtual tende a atualizar-se, sem ter passado, no entanto, à concretização efetiva ou formal. A árvore está virtualmente presente na semente. Em termos rigorosamente filosóficos, o virtual não se opõe ao real mas ao atual: virtualidade e atualidade são apenas duas maneiras de ser diferentes (Lévy 2011, p. 15).

Para Aristóteles (2002, p. 403), “algo é em potência se o traduzir-se em ato daquilo que se diz ser ele em potência não implica nenhuma impossibilidade". Nesse sentido, o virtual pode ser entendido como um campo formado por complexos de tendências que ainda não estão fixadas no ato, abarcando uma abertura para o porvir na qual todos os polos, oposições e antagonismos coexistem entre si, tal como Deleuze (2012, p. 81) aponta quando escreve que "a coexistência de todos os graus, de todos os níveis, é virtual, somente virtual". O virtual abriga todas as gradações e detém uma realidade própria, pois ele "não se opõe ao real, mas apenas ao atual. O virtual possui uma plena realidade como virtual" (Idem 2018, p. 276), e aquilo que é potência só deixa de sê-lo quando se torna ato: "o ato é o existir de algo, não porém no sentido em que dizemos ser em potência" (Aristóteles 2002, p. 409).

Em Deleuze, a ênfase em sua própria realidade afastará o virtual de uma mera presença prévia - a realidade do virtual não é menor que a do atual. Conforme escreve, "aquilo que chamamos de virtual não é algo ao qual falte realidade, mas que se envolve em um processo de atualização ao seguir o plano que lhe dá sua realidade própria" (Deleuze 2002, p. 16), desviando-se, assim, da noção aristotélica que sugere pesos distintos de realidade para o virtual e o atual. Pierre Lévy considera que

[...] o virtual, rigorosamente definido, tem somente uma pequena afinidade com o falso, o ilusório, o imaginário. Trata-se, ao contrário, de um modo de

\footnotetext{
${ }^{6}$ A palavra "virtual" correspondendo à tradução latina do termo aristotélico para "potência" é assim definida no Dicionário de Filosofia: "a virtualidade designa em Aristóteles o que tende a se realizar e que só existe em potência, e não em ato" (Durozoi; Roussel 1993, p. 485).
} 
MUSICA THEORICA Revista da Associação Brasileira de Teoria e Análise Musical 2019, v. 4, n. 1, p. 234-254-Journal of the Brazilian Society for Music Theory and Analysis@ TeMA 2019 - ISSN 2525-5541

ser fecundo e poderoso, que põe em jogo processos de criação, abre futuros, perfura poços de sentido sob a platitude da presença física imediata (Ibidem p. 12).

O virtual não deve ser entendido como sinônimo de indeterminação - pelo contrário, sua realidade é constituída por estruturas, relações e singularidades. $\mathrm{O}$ que caracteriza o virtual é a ausência de uma existência em ato, de uma consistência (de objeto ou de corpo) que dê a essas relações um aspecto fixo, que o torne, enfim, atual. Deste modo, podemos dizer que o virtual corresponde à porção ideal do objeto (Deleuze 2018, p. 276-277).

$\mathrm{O}$ virtual determina a porção ideal do objeto, aquilo que o torna completo - o que não implica necessariamente que ele esteja inteiro, pois só pode sê-lo no atual; assim, "há, pois, outra parte do objeto, que se encontra determinada pela atualização" (Deleuze 2018, p. 277):

[...] deve-se distinguir cuidadosamente o objeto como completo e o objeto como inteiro. O completo é apenas a parte ideal do objeto, aquela que, na Ideia, participa com outras partes de objetos (outras relações, outros pontos singulares), mas que nunca constitui uma integridade como tal. O que falta à determinação completa é o conjunto das determinações da existência atual (Ibidem).

O objeto completo pode, portanto, ser entendido como a porção ideal do objeto, enquanto o objeto inteiro implica em uma atualização do mesmo. É no virtual que reside o complexo problemático da ideia: voltando ao exemplo de Pierre Lévy, o problema da semente é como se tornar árvore; a semente é a ideia que, atualizada, adquire uma compleição de objeto inteiro (árvore) que não se assemelha à do objeto completo da ideia (a semente). As soluções da problemática não se assemelham às suas condições, já que "a atualização é pensada como um processo verdadeiramente criador, pois ela produz respostas que não guardam nenhuma semelhança com os problemas virtuais que a engendraram" (Henriques 2016, p. 190). Pois

O virtual tem a realidade de uma tarefa a ser cumprida, assim como a realidade de um problema a ser resolvido; é o problema que orienta, condiciona, engendra as soluções, mas estas não se assemelham às condições do problema. Bergson portanto tinha razão ao dizer que, do ponto de vista da diferençação, mesmo as semelhanças que surgem nas linhas de evolução divergentes (por exemplo, o olho como órgão "análogo") devem ser, primeiramente, referidas à heterogeneidade no mecanismo de produção (Deleuze 2018, p. 281). 
Há, na terminologia deleuziana, uma importante distinção entre a diferenciação e a diferençação; para Deleuze (Ibidem, p. 277), "enquanto que a diferenciação determina o conteúdo virtual da Ideia como problema, a diferençação expressa a atualização desse virtual e a constituição das soluções (por integrações locais)". É esta diferençação que faz com que o virtual não se assemelhe ao atual. Podemos, nesse momento, evocar outra imagem arbórea, desta vez uma de Paul Klee (1971, p. 35-36), na qual o artista metaforiza os vetores do processo criativo imaginando-o como a constituição de uma árvore, partindo da seiva (virtual) para as folhagens (atual): neste exemplo, Klee sugere que o artista é um mediador, ele está no tronco, entre o virtual e o atual, atravessado por forças aquém e além de sua subjetividade; a presença de um virtual que se atualiza se dá pela diferençação, pela construção de uma solução da raiz para a folhagem.

Embora a metáfora da árvore de Klee (por nos apresentar uma imagem compartimentada do processo criativo e servir para ilustrar a diferençação na atualização do virtual) pareça tentadora por seu apelo e concisão, devemos alertar para o fato de que o virtual não é a mera efetuação de ideias em um plano material; assim, o virtual não deve ser pensado como um campo ideal que apenas adquire uma materialidade atual. Neste ponto, cabe apontar uma distinção entre o virtual e o possível feita por Deleuze (2018, p. 279): “o possível opõe-se ao real; o processo do possível é, pois, uma 'realização'. O virtual, ao contrário, não se opõe ao real, pois ele possui uma realidade plena. Seu processo é a atualização". O conceito de possível tem a ver com a efetivação estrita de uma estrutura ou forma (Lévy 2011, p. 16); contudo, essa efetivação possui um caráter retroativo. O possível não é prévio ao real: ele é uma projeção do real no passado. Apesar do possível poder ser entendido como uma forma a priori, é necessário que se perceba, à luz de Bergson, a sua modalidade de acontecimento, que contradiz de imediato o conceito de possível como algo prévio ao real.

Segundo Bergson (2006, p. 114), “o possível é apenas o real com, em acréscimo, um ato do espírito que repele sua imagem para o passado assim que ele se produziu". Em termos práticos, o possível habita o passado e é percebido como se fosse um a priori, mas ele sempre acontece a posteriori, sendo um produto do real - assim, o real precede o possível. Deleuze (2018) reforça o conceito bergsoniano ao dar continuidade ao desenvolvimento da distinção entre o possível e o virtual em Diferença e Repetição: 
MUSICA THEORICA Revista da Associação Brasileira de Teoria e Análise Musical 2019, v. 4, n. 1, p. 234-254-Journal of the Brazilian Society for Music Theory and Analysis @ TeMA 2019 - ISSN 2525-5541

Em segundo lugar, o possível e o virtual se distinguem porque um remete à forma de identidade no conceito, ao passo que o outro designa uma multiplicidade pura na Ideia, que exclui radicalmente o idêntico como condição prévia. Enfim, na medida em que o possível se propõe à "realização", ele próprio é concebido como a imagem do real, e o real como semelhança do possível. Eis porque se compreende tão pouco o que a existência acrescenta ao conceito, duplicando o semelhante com o semelhante. É esta a tara do possível, tara que o denuncia como produzido posteriormente, fabricado retroativamente, feito à imagem daquilo a que ele se assemelha (Deleuze 2018, p. 280).

Aquilo que é possível só pôde sê-lo porque antes houve o real. Em um contexto de criação artística, Bergson (2006, p. 115) irá escrever "que um homem de talento ou de gênio surja, que ele crie uma obra: ei-la real, e por isso mesmo, ela torna-se retrospectivamente ou retroativamente possível". Podemos considerar que, a partir de Bergson, o possível pode ser imaginado como efetuação de uma forma, mas deve ser pensado em realidade como um acontecimento a posteriori; assim, não deve ser tomado (como o é no senso comum) como o fundamento de um idealismo identitário; tampouco deve ocupar uma posição transcendental em relação ao real. A negação de tal posição nos leva, portanto, partindo do ponto de vista da composição musical, a um processo que foge à mera tradução das ideias musicais em cópias mais ou menos perfeitas no mundo; consequentemente, o real será o palco para o surgimento da novidade e da imprevisibilidade que ele não poderia portar se fosse apenas causalidade e mecanicismo ou mera efetivação de conceitos:

Que possamos inserir algo real no passado e trabalhar assim de marcha a ré no tempo, nunca o pretendi. Mas que possamos ali alojar o possível, ou antes, que o possível vá ali se alojar por si mesmo a todo instante, isto não é de se duvidar. Ao mesmo passo que a realidade se cria, imprevisível e nova, sua imagem reflete-se atrás dela no passado indefinido; descobre-se assim ter sido, desde sempre, possível; mas é nesse momento preciso que começa a têlo sido sempre, e eis porque eu dizia que sua possibilidade, que não precede sua realidade, a terá precedido uma vez que a realidade tiver aparecido. $\mathrm{O}$ possível é, portanto, a miragem do presente no passado (Bergson 2006, p. 115).

O possível não é o real menos alguma coisa (como se fosse um conceito menos sua efetivação); para Bergson (Ibidem, p. 116) é justamente o contrário: o possível constitui-se como o real mais uma operação do pensamento que o coloca no passado. Considera-se, desse modo, que o possível não é um fantasma prévio 
à realidade, carente de materialidade; ele de fato surge junto com o real, mas sem habitá-lo no devir: somente no momento em que o real surge no presente, o possível passa a habitar o passado.

Bergson (Ibidem, p. 118) nos oferece uma reflexão acerca do possível no contexto de criação artística: “todas essas considerações se impõem quando se trata de uma obra de arte. Acredito que acabaremos por achar evidente que o artista cria o possível ao mesmo tempo que o real quando executa sua obra". Aqui, o real passa a ser o lugar de produção da novidade, do inesperado, da liberdade, e o possível se torna a consequência do exercício desta liberdade. Ele ainda (Ibidem, p. 119) desenvolve as implicações desta perspectiva, arrematando que é o real que traz em si a possibilidade de existir, ao contrário do senso comum que imagina o possível como algo preexistente que de alguma forma se efetua e adquire realidade.

O possível, ao existir a partir do real, marca no passado o desenho das zonas limítrofes do atual, cujos contornos são aqueles impostos pelos obstáculos que o co-produzem na diferençação. Assim, os processos composicionais não precisam ser pensados a partir da mera efetivação de possíveis no real (ou, no caso da composição musical, da transposição fiel de ideias musicais em notação ou performance); tampouco basta que sejam pensados como fluxogramas, algoritmos, projetos automatizados ou mecanicamente executados. Em termos absolutos, pouco pode ser dito a respeito de um suposto "sucesso" ou "fracasso" de um processo criativo, já que tais processos, no âmbito da composição musical, estarão sempre vinculados a uma atualização que diferençará a porção virtual presente em uma ideia musical.

Apesar dos objetivos serem outros e das possíveis distinções conceituais e terminológicas entre o presente trabalho e o campo da crítica genética, há de se levar em conta o que a pesquisadora Cecília Salles diz ao comentar que o processo criativo

[...] pode ser visto como um movimento falível com tendência, sustentado pela lógica da incerteza. Um percurso que engloba a intervenção do acaso e abre espaço para o mecanismo de raciocínio responsável pela introdução de ideias novas. Como se pode perceber, essa visão de processo com tendência não envolve uma visão teleológica baseada em progresso linear ou prédeterminação de fins. A própria ideia de criação implica desenvolvimento, crescimento e vida; consequentemente, não há lugar para metas estabelecidas a priori e alcances mecânicos (Salles 1998, p. 27). 
MUSICA THEORICA Revista da Associação Brasileira de Teoria e Análise Musical 2019, v. 4, n. 1, p. 234-254-Journal of the Brazilian Society for Music Theory and Analysis @ TeMA 2019 - ISSN 2525-5541

Em ressonância com a metáfora da árvore de Klee, para Salles o que é produzido não se assemelha ao que foi concebido de início. O processo de atualização desvia o resultado final de seu planejamento prévio, pois este planejamento não é um agrupamento de conceitos completamente nítidos a serem efetivado no real, e sim um conjunto de ideias detentoras de porções virtuais, um aglomerado de problemáticas com potência para a multiplicidade que adquirirá outra compleição ao se atualizar:

O processo de criação é o lento clarear da tendência que, por sua vagueza, está aberta a alterações. $O$ final pode ser que nada tenha a ver com a "maquete inicial", pois o plano não tem nada da experiência que se adquire na medida em que vai se escrevendo a história (Ibidem, p. 31).

Pensemos nestes termos levando em consideração que aquilo que é virtual sempre conterá um complexo problemático (a diferenciação) que se resolverá na atualização - esta com seus desvios, obstáculos e deformações (diferençação) -, enquanto o possível é o real viabilizado, que se joga ao passado preservando estrutura, forma e operando conceitos a partir do viés da semelhança. A atividade criativa se dá entre o virtual e o atual. Nesse contexto, quando dizemos que a arte engendra novas realidades, não estamos simplesmente evocando uma metáfora: por ser criação, ela consiste nos resultados dos acontecimentos, nos produtos da atualização e do virtual, sendo, de fato, produção de realidade.

A atualização leva em conta, na diferençação, os obstáculos inesperados que participarão da solução da problemática, atuando como agentes de alteridade, promovendo todo tipo de desvio que facilite a resolução dos complexos da diferenciação. Salles (1998, p. 33-34) associa tais obstáculos à noção de acaso, pensando-o como um atributo desviante, posicionando-o quase em termos dicotômicos em relação à noção de tendência. O que Salles chama de acaso pode ser entendido como um fator desviante, intrínseco ao processo de diferençação, que acontecerá inevitavelmente, em maior ou menor medida, independentemente de haver ou não algum fator arbitrário de produção do inesperado no processo; talvez não seja o acaso que seja acolhido pelo artista, e sim o artista que se joga em um movimento de produção de diferença, de sair de si:

A atualização do virtual, ao contrário, sempre se faz por diferença, divergência ou diferençação. A atualização rompe tanto com a semelhança como processo quanto com a identidade como princípio. Os termos atuais 
nunca se assemelham à virtualidade que eles atualizam: as qualidades e espécies não se assemelham às singularidades que elas encarnam. A atualização, a diferençação, neste sentido, é sempre uma verdadeira criação (Deleuze 2018, p. 280).

A distinção entre os pares possível-real e virtual-atual se acentua no fato de que aquilo que é virtual, ao se atualizar, produz a diferença, como bem observa Pierre Lévy (2011, p. 17): “o real assemelha-se ao possível; em troca, o atual em nada se assemelha ao virtual: responde-lhe". Além disso, conforme Henriques,

Para Deleuze, a diferença entre eles reside no fato de que o possível sempre foi pensado pela tradição como uma instância ideal a que falta a realidade (e daí a necessidade de ele se "realizar"), ao passo que o virtual é algo a que não falta nenhuma realidade: ele não é um conjunto de possibilidades dado num intelecto humano ou divino, mas a própria parte ideal do real, algo tão real quanto os próprios corpos e os estados de coisa. Há também uma segunda diferença marcante entre eles, para Deleuze, a saber: que há entre o possível e sua realização uma clara relação de semelhança, pois o possível é basicamente o conceito da coisa sem sua efetivação material (o que comumente chamamos de "forma"), ao passo que entre o virtual e sua atualização reside uma profunda dessemelhança, dado que o virtual consiste basicamente numa questão ideal que encontrará seu esboço de solução na atualização dele derivada, devendo-se observar que entre essa questão e sua solução não pode haver nenhuma relação de semelhança [...]. O virtual se distingue, assim, claramente do possível (Henriques 2016, p. 184-185).

Deste modo, o possível que vem do real pode ser visto como a simples efetivação de um estado (para Bergson, somente passível de ser conhecido após ter sido realizado), enquanto o virtual que se atualiza é a invenção de solução para um complexo problemático. $\mathrm{O}$ virtual e o atual coexistem como realidades distintas, enquanto aquilo que já foi atualizado comporta o conjunto das coisas possíveis no real.

Podemos pensar o possível como a página de um texto que viramos após escrevê-lo. O possível é o registro, a notação, a intelecção imediata, a experiência que acaba de se tornar passado, o que acabou de acontecer; ele jamais poderá ser confundido com o fator ígneo que alimenta o processo criativo. A ideia não se origina no possível, pois nada de novo pode surgir no que já foi: a escrita acontece na próxima página em branco, e não naquela que foi virada. Pensar o possível como originário de um processo significa forçar um transcendentalismo em um 
MUSICA THEORICA Revista da Associação Brasileira de Teoria e Análise Musical 2019, v. 4, n. 1, p. 234-254-Journal of the Brazilian Society for Music Theory and Analysis@ TeMA 2019 - ISSN 2525-5541

campo de criação que depende de uma imanência da atualização. Nesse sentido, Salles comenta que

Não se pode limitar o conceito de processo com tendência, nesse contexto de uma obra específica, a um grande insight inicial. Se assim fosse visto, o processo de criação seria um percurso quase mecânico de concretização de uma grande ideia que surge no começo do processo. No contato com diferentes percursos criativos, percebe-se que a produção de uma obra é uma trama complexa de propósitos e buscas: problemas, hipóteses, testagens, soluções, encontros e desencontros. Portanto, longe de linearidades, o que se percebe é uma rede ele tendências que se inter-relacionam (Salles 1998, p. 36).

\section{Planos de organização e de consistência (ou o Plano)}

O que Salles aponta vai de encontro com duas maneiras de pensar o plano de criação sugeridas por Deleuze e Guattari no quarto volume de Mil Platôs. Segundo Döbereiner, o termo "plano" pode indicar tanto a noção de um campo de ação quanto um lugar para o planejamento formal:

No volume de Mil Platôs de 1980 Deleuze e Guattari identificam dois modos opostos de conceitualizar o que eles chamam de "planos". Haveria duas maneiras distintas de pensar as dimensões da criação, um "absoluto localizado" compartilhado por atos conceituais singulares de criação. A formulação ambígua do termo "planos" serve tanto para significar um plano ontologicamente neutro, ou seja, um plano não hierárquico ou um horizonte conceitual que serviria para orientar o pensamento filosófico, quanto um plano ou estrutura da composição artística (Döbereiner 2014, p. 269).

Nesse sentido, para Deleuze e Guattari haveria dois tipos distintos de plano: planos de organização e planos de consistência. O plano de organização é aquele que, no contexto da composição musical, corresponde ao não audível, ao que não está dado no mundo sonoro da música, ao que ocupa uma posição transcendente em relação ao som.

Assim como na música, o princípio de organização ou de desenvolvimento não aparece por si mesmo ou para si mesmo. Isto permite todas as interpretações possíveis. As formas e seus desenvolvimentos, os sujeitos e suas formações remetem a um plano que opera como unidade transcendente ou princípio oculto. Poderemos sempre expor o plano, mas como uma parte à parte, um não-dado naquilo que ele dá (Deleuze; Guattari 2012, p. 57).

Para entendermos melhor o que Deleuze e Guattari querem dizer neste trecho do texto, é necessário contextualizar ao que exatamente esses autores se 
referem ao falar de um campo de organização transcendente. Logo após o trecho citado acima, os autores mencionam o compositor Karleinz Stockhausen: "mas também Stockhausen não precisa expor a estrutura de suas formas sonoras como que 'ao lado' delas, na falta de fazer ouvi-la?" (Ibidem).

Podemos perceber nessa questão que os autores estão se referindo às estruturas abstratas dos sistemas composicionais. Especificamente, no caso de Stockhausen, aos materiais pré-composicionais: séries, grupos e fórmulas. Isto é corroborado por Döbereiner, que escreve:

Deleuze e Guattari enxergam um exemplo de modelo composicional inaudito no trabalho de Karlheinz Stockhausen, o qual eles interpretam como sendo baseado em uma unidade transcendental escondida, um princípio que cria formas, mas que nunca aparece por si só e pode apenas ser inferido dessas formas. De fato, este modo de pensar é mais presente e claramente discernível na música serial de Stockhausen da década de 1950. Defendendo a inaudibilidade da ordem serial, Stockhausen escreve, "quem enxerga os átomos? Ainda assim, todos sabem que toda a aparência da matéria depende de sua estrutura" (Döbereiner 2014, p. 270).

O plano de organização, no contexto da composição musical, está relacionado com a organização conceitual dos processos composicionais. A escolha das técnicas, o pensamento sobre a forma, sobre os materiais, e até mesmo conceitos elementares (como altura, duração, dinâmica, textura, densidade, timbre) protagonizam este plano. Nesse sentido, o plano de organização é prévio à concretização sonora.

O plano de organização não se situa em uma posição transcendente em relação ao todo do processo composicional (se assim fosse, elas seriam inacessíveis dentro do próprio processo); a transcendência aí se encontra na perspectiva perceptiva do receptor em relação à organização estrutural - ou seja, é transcendente para o ouvinte que não escuta as séries, que não conhece as fórmulas, que não participou das manipulações estruturais, mas que frui o resultado sonoro de tais organizações.

Assim, percebe-se que a transcendência do plano de organização não é absoluta - para o compositor, os conceitos que constituem esse plano surgem de 
MUSICA THEORICA Revista da Associação Brasileira de Teoria e Análise Musical 2019, v. 4, n. 1, p. 234-254-Journal of the Brazilian Society for Music Theory and Analysis @ TeMA 2019 - ISSN 2525-5541

forma imanente em sua imaginação; em outras palavras, o plano de organização é constituído sobre um plano de imanência. ${ }^{7}$

Este plano imanente corresponde ao que Deleuze e Guattari (2012, p. 5758) irão chamar de plano de consistência. Nele não cabe qualquer transcendência. Neste plano, as coisas são causas de si mesmas e nada do que acontece tem uma existência a priori. Deleuze e Guattari atribuem a esse plano a proliferação, o povoamento, mas sem que haja nele um princípio teleológico embutido; nele não há finalidade ou evolução. Este plano é análogo às instâncias do "acaso" mencionadas anteriormente por Salles. Döbereiner (2014, p. 270-271) escreve que “esse plano 'nunca tem uma dimensão suplementar' da qual um princípio oculto poderia funcionar; ao invés disso, ele é dado por si só naquilo que faz surgir". $\mathrm{O}$ plano de consistência pode ser relacionado com o "acaso" no sentido de, ao afirmar sua natureza imanente, ser portador de uma capacidade de "destruição" do princípio transcendente.

Devemos questionar de que modo esses campos se relacionam com o virtual e o atual. Poder-se-ia imaginar que tais campos seriam correlatos aos conceitos prévios, o que significa dizer que o plano de organização corresponde ao virtual e o plano de consistência ao atual. O plano de organização contém aspectos do virtual, pois nele residem as relações conceituais, as estruturas e formas. Contudo, ele é construído justamente à revelia das multiplicidades do virtual. Para ilustrar essa afirmação, consideremos o seguinte exemplo:

Um compositor trabalha mentalmente em uma peça para quarteto de cordas. Em sua imaginação, ele começa a delinear a primeira frase do violoncelo, e esta frase contém algumas durações e um perfil rítmico definido. Estes são elementos do plano de organização - todo os elementos restantes, não definidos, não estão contidos no plano de organização e são, contudo, elementos do virtual, componentes da ideia que gerarão problemáticas no momento da atualização, tais como: 1) qual será o tratamento timbrístico? 2) quais serão as dinâmicas? 3) que tipos de golpe de arco serão empregados?

Essas questões serão respondidas no campo de consistência, que inclui os modos de atualizar a ideia empregados pelo compositor (que podem ser o solfejo, a notação, a improvisação ao instrumento, o computador). Deste modo, podemos

\footnotetext{
${ }^{7}$ Deleuze e Guattari (2010, p. 47) escrevem, em O que é a Filosofia, que "o plano de imanência não é um conceito pensado nem pensável, mas a imagem do pensamento, a imagem que ele se dá do que significa pensar, fazer uso do pensamento, se orientar no pensamento".
} 
considerar os planos de organização e de consistência como "áreas de trabalho", onde a primeira refere-se às concatenações entre conceitos e a segunda às germinações do virtual no atual. É neste sentido que podemos considerar que ambos os planos estão integrados em uma dinâmica:

De modo que o plano de organização não para de trabalhar sobre o plano de consistência, tentando sempre tapar as linhas de fuga, parar ou interromper os movimentos de desterritorialização, lastreá-los, reestratificá-los, reconstituir formas e sujeitos em profundidade. Inversamente, o plano de consistência não para de se extrair do plano de organização, de levar partículas a fugirem para fora dos extratos, de embaralhar as formas a golpe de velocidade ou lentidão, de quebrar as funções à força de agenciamentos, de microagenciamentos (Deleuze; Guattari 2012, p. 63).

Apesar de seguir uma linha teórica completamente distinta, Richard Willgross apresenta, em seu artigo intitulado Creativity in Contemporary Art Music Composition, uma imagem muito similar à das dinâmicas entre os planos de organização e consistência de Deleuze e Guattari:

Primeiramente nós descobrimos que aquela arte, em particular a musical, se revolta contra conceitos essenciais baseados na razão, sem a qual, paradoxalmente, a arte é inconcebível em primeiro lugar. A arte debilita os conceitos para deixar o não-conceitual falar. Em segundo lugar, a razão estrutura para reprimir e subordinar a novidade, mas a arte, invariavelmente relacionada ao novo, não é redutível à razão (Willgross 2012, p. 425).

Sugerimos, assim, que o processo composicional não é simplesmente a efetivação de um princípio teleológico: pensando o virtual e o atual dentro de tais processos, poderemos entender melhor o papel dos planos - considerando que planos de organização e de consistência tendem a se aniquilar mutuamente, produzindo um "resto" ou uma "sobra" no real que vem a ser a música concretizada. Os planos de organização e consistência funcionam como polos codependentes, como movimentos da ideia no pensamento e no ato.

Em termos práticos, não há planejamento propriamente estrito de uma obra, mas sim estes planos, movimentos da diferença no virtual e no atual a partir dos quais a obra poderá crescer e se desenvolver. Deleuze já havia comentado que as imagens virtuais reagem sobre o atual; nesta reação temos um processo de virtualização em andamento, no qual o ato funda novas questões no campo do 
MUSICA THEORICA Revista da Associação Brasileira de Teoria e Análise Musical 2019, v. 4, n. 1, p. 234-254-Journal of the Brazilian Society for Music Theory and Analysis@ TeMA 2019 - ISSN 2525-5541

virtual; quando o atual reestrutura o virtual, provocando o seu a-fundamento, o objeto é virtualizado. ${ }^{8}$

As imagens virtuais não são mais separáveis do objeto atual que este daquelas. As imagens virtuais reagem, portanto, sobre o atual. Desse ponto de vista, elas medem, sobre o conjunto de círculos ou sobre cada círculo, um continuum, um spatium determinado em cada caso por um máximo de tempo pensável. A esses círculos mais ou menos extensos de imagens virtuais, correspondem camadas mais ou menos profundas do objeto atual. Estes formam o impulso total do objeto: camadas virtuais, e nas quais o objeto atual torna-se, por sua vez, virtual. Ambos, objeto e imagem, são aqui virtuais, e constituem o plano de imanência onde se dissolve o objeto atual (Deleuze; Parnet 1998, p. 174).

O objeto virtualizado se abre a novos nós problemáticos, engendra novas diferenciações, retroalimentando o fluxo criativo. Do ponto de vista deste fluxo, a virtualização é a última etapa do giro de um processo de aquisição de concretude da composição musical, seja esta aquisição um acontecimento em performance musical ou notacional. ${ }^{9}$

A virtualização, enfim, passa do ato - aqui e agora - ao problema, aos nós de coerções e de finalidades que inspiram os atos. [...]

A virtualização sai do tempo para enriquecer a eternidade. Ela é a fonte dos tempos, dos processos, das histórias, já que comanda, sem determiná-las, as atualizações. Criadora por excelência, a virtualização inventa questões, problemas, dispositivos geradores de atos, linhagens de processos, máquinas de devir (Lévy 2011, p. 140).

Para Deleuze e Parnet (1998, p. 173), "não há objeto puramente atual". Com isso, o filósofo quer dizer que o processo de reconhecimento dos objetos implica na existência de um circuito virtual-atual-virtual no modo de percebêlos, que exige uma mobilidade dos campos virtuais envolvidos. Esta noção de circuitos se adequa à visão de Bergson (1990, p. 112) que diz que "a lembrança se transforma à medida em que se atualiza". Como exemplo, podemos pensar em escutas repetidas de uma mesma obra musical: cada circunstância de escuta

\footnotetext{
${ }^{8}$ Nas notas de rodapé anteriores, comentamos brevemente a relação do a-fundamento com a terceira síntese do tempo em Deleuze. Para um aprofundamento do conceito, ver o tópico "O que é decisivo no problema da diferença: o simulacro, a resistência do simulacro" em Diferença e Repetição (2018, p. 95-99).

${ }^{9}$ A atualização pode ocorrer tanto na produção de um som quanto em alguma forma de escrita (partituras, rascunhos, anotações etc.).
} 
implica em instantes do tempo que não se repetem, em diferentes configurações afetivas, de memória, de contexto e de atenção. Não se percebe duas vezes um mesmo objeto da mesma maneira, pois a percepção atualiza as lembranças de um passado virtual.

Nesse sentido, não há contemporaneidade absoluta entre sujeito e objeto, pois, por sermos seres lentos, nossos organismos contraem o presente em passado, projetando lembranças sobre as percepções, transformando o mundo da matéria (velozes movimentos de partículas e ondas) em unidades e qualidades estáveis - como as sensações de sons e cores. Como bem aponta Henriques (2016, p. 126), “todo objeto real percebido por nós nunca é algo simplesmente atual, pois nele há sempre uma contraparte virtual, que não é nada mais que as lembranças que projetamos sobre ele a fim de dotá-lo de um sentido".

A noção de que o reconhecimento dos objetos está calcado nos circuitos virtuais-atuais-virtuais nos permite pensar a ideia musical como uma esfera passível de mudança: algo no atual pode ocasionar uma alteração na ideia. Este é o ponto em que mais nos distanciamos do pensamento platônico, no qual a ideia é tida como eterna e imutável: a diferença se manifesta não só no produto do atual como também no campo virtual que lhe deu origem. $O$ desvio se opera não só na obra, mas também, simultaneamente, no projeto: ${ }^{10}$

Como já foi dito em relação à natureza da tendência em sentido amplo, o percurso criativo conhece uma lenta definição do projeto poético do artista. O tempo da criação seria o tempo da configuração do projeto. Pode-se, assim, dizer que o processo de criação de uma obra é a forma do artista conhecer, tocar e manipular seu projeto de caráter geral (Salles 1998, p. 39).

Fazendo mais um paralelo entre Salles e o quarto volume de Mil Platôs de Deleuze e Guattari, nos é dado um outro modo de descrever este mesmo percurso:

[...] o plano, plano de vida, plano de escrita, plano de música etc., só pode fracassar, pois é impossível ser-lhe fiel; mas os fracassos fazem parte do

\footnotetext{
${ }^{10}$ Esta imagem relaciona-se com a noção deleuziana de $a$-fundamento na terceira síntese do tempo. Se a primeira síntese do tempo (o presente) funda o tempo e a segunda (o passado) o fundamenta, a terceira síntese o a-funda: é o futuro que faz passar o presente e destrói a materialidade do passado; o a-fundamento é responsável, portanto, por reconfigurar as outras sínteses do tempo, por "sabotar" a fundação e o fundamento.
} 
MUSICA THEORICA Revista da Associação Brasileira de Teoria e Análise Musical 2019, v. 4, n. 1, p. 234-254-Journal of the Brazilian Society for Music Theory and Analysis @ TeMA 2019 - ISSN 2525-5541

plano, pois ele cresce e decresce com as dimensões daquilo que ele desenvolve a cada vez (Deleuze; Guattari 2012, p. 62).

Sugerimos, aqui, que a noção de um platonismo do processo composicional, caracterizado por um planejamento norteador e assertivo de um conjunto de conceitos a serem totalmente materializados ou de um macroprojeto formal a ser efetuado, não corresponde às dinâmicas do processo de criação, pois "há uma forte relação entre tendências e desafios que, para se manterem como tais, precisam estar sempre em mutação"11 (Salles 1998, p. 31); ou seja, a ideia, longe de ser imutável e perfeita, deve ser tão maleável quanto o produto do ato, o que é um outro modo de dizer que o atual interfere no virtual.

Entretanto, não negamos que existe um plano de organização nos processos composicionais. Contudo, a suposta teleologia implicada na existência destes elementos por si só não constitui, resume ou explica o aspecto criativo neste caso, é necessário levar em conta a multiplicidade do virtual.

\section{Considerações finais}

Não é possível fazer um corte no fluxo criativo ${ }^{12}$ e apontar com exatidão onde o virtual se atualiza ou onde o atual se virtualiza. $O$ fluxo criativo corre continuamente, as ideias surgem e perpassam os planos: o atrito entre os planos produz uma sobra: objetos que "escapam" dos planos durante a atualização.

[...] todos os planos se confundem, conforme a via que leva ao atual. O plano de imanência compreende, a um só tempo, o virtual e sua atualização, sem que possa haver limite assinalável entre os dois. O atual é o complemento ou o produto, o objeto da atualização, mas esta só tem por sujeito o virtual. A atualização pertence ao virtual. A atualização do virtual é a singularidade, enquanto o próprio atual é a individualidade constituída. $\mathrm{O}$ atual cai para fora do plano como fruta, enquanto a atualização o relaciona ao plano como ao que reconverte o objeto em sujeito (Deleuze; Parnet 1998, p. 175).

Devemos nos lembrar de evitar pensar o virtual como um campo a priori constituidor da realidade - isso seria o mesmo que confundir o real com o

11 Traçando um paralelo com o conceito de a-fundamento, o desvio desfigura não só a materialidade da obra em relação à Ideia na atualização, mas também promove uma transformação na própria Ideia no virtual: se a Ideia não possui rigidez, se não é eterna e imutável, isto inviabiliza qualquer forma de platonismo.

${ }_{12}$ Do mesmo modo como, para Bergson (1990, p. 154-158), não é possível cortar ou dividir o movimento. 
possível, ou atribuir ao virtual a qualidade transcendental que já negamos ao possível. $\mathrm{O}$ virtual diz respeito às diferenciações e suas questões, enquanto o atual tem a ver com as respostas das diferençações, e ambos participam do real ao mesmo tempo - virtual e atual não estão, portanto, separados, mas congregam a realidade do mesmo objeto, de modo que o virtual não é algo que tenha qualquer precedência sobre o mundo dos objetos, e sim uma das metades do processo de constituição do real (a atualização sendo a outra metade). Henriques comenta que

Com efeito, pensar o virtual como uma espécie de fundamento ideal do atual seria na verdade concebê-lo como um campo de possibilidades que se realizaria nos corpos e estados de coisa. Ora, reduzir o virtual ao possível seria, como vimos, o maior erro que poderíamos cometer. Longe de ser uma espécie de fundamento oculto do atual, o virtual deve antes ser pensado, para Deleuze, como a instância problematizadora e questionante da Ideia, ao passo que o atual seria a instância de resolução dos problemas, de resposta às questões (Henriques 2016, p. 190).

Assim, o virtual e o atual podem ser considerados como modos simultâneos de constituição do real. Nesse sentido, Henriques (2016, p. 183) escreve que "o virtual deleuziano é uma parte da estrutura ontológica do real, a qual comporta tanto um polo material e atual (os corpos e os estados de coisa), quanto um polo ideal e virtual (a ideia ou o sentido)". A “ilusão" da ideia como um princípio nos processos composicionais se explica pelo mesmo mecanismo que faz com que consideremos o possível como algo que antecede o real: ao lidarmos com a ideia, que surge imanente como uma imagem mental, imediatamente a projetamos no passado e a consideramos pertencente a uma realidade a priori. Ao nos darmos conta da qualidade imanente da ideia musical, o fluxo criativo pode ser visto como um acontecimento de captura em tempo real das forças do virtual e de sua imediata atualização nos corpos:

Para Deleuze, a questão da arte, sua problemática, não é a criação de formas, e sim a "captura de forças". Para haver uma sensação lá, uma força precisa ser enxertada em um corpo. A força, contudo, não é dada ou sentida em si, ao invés disso ela permanece virtual, e é a tarefa da arte fazer com que essas forças imperceptíveis se tornem perceptíveis (Döbereiner 2014, p. 281).

É nesse contexto que Deleuze e Guattari (2012, p. 174) escrevem que "é desde sempre que a pintura se propôs a tornar visível, ao invés de reproduzir o visível, e a música a tornar sonoro, ao invés de reproduzir o sonoro"; nesta 
colocação está o resumo de toda a crítica à lógica da representação apresentada neste texto. A questão dos processos composicionais encontra aí sua formulação mais clara, que sempre será resolvida no próprio ato de compor: o problema de traçar um continuum entre o intensivo e o extensivo, entre o plano de organização e o de consistência, em atualizar um virtual e virtualizar um algo do atual, em enxertar e extrair forças dos corpos. Assim, conforme o comentário do compositor Silvio Ferraz (2005, p. 69), “não se diz mais que é música aquilo que é sonoro, mas sim que fazer música é tornar sonoro forças não sonoras: forças de crescimento, forças de conexão humana, forças de guerra, forças táteis, forças visuais etc.". O fluxo composicional deixa de ser teleológico, de ir de A para B de perseguir a meta da música ideal ao se jogar subitamente nos planos de imanência, nos jogos de intensidade, nos movimentos dos ritornelos - para girar nos ciclos de atualização e virtualização e desviar cada vez mais do seu centro, inaugurando, a cada nova órbita, relações gravitacionais inauditas.

\section{Referências}

1. Aristóteles. 2018. Metafísica. São Paulo: Edições Loyola.

2. Assis, Paulo de. 2018. Virtual works-Actual things. In: Essays in music ontology, p. 19-43. Leuven: Leuven University Press.

3. Bergson, Henri. 2006. O pensamento e o movente. São Paulo: Martins Fontes.

4. 1990. Matéria e memória. São Paulo: Martins Fontes.

5. Deleuze, Gilles. 2018. Diferença e Repetição. Rio de Janeiro/São Paulo: Paz e Terra.

6. 2012. Bergsonismo. São Paulo: 34.

7. 2002. A imanência: uma vida... In: Educação e Realidade, n. 27, v. 2 , p. $10-18$.

8 . 2011. Lógica do sentido. São Paulo: Perspectiva.

9. Deleuze, Gilles; Guattari, Felix. 2012. Mil platôs, v. 4. São Paulo: 34. 10 . . 2010. O que é a filosofia? São Paulo: 34.

11. Deleuze, Gilles; Parnet, Claire. 1998. Diálogos. São Paulo: Editora Escuta.

12. Döbereiner, Luc. 2014. The virtuality of the composition model: Varèse with Deleuze. In: Acta Musicologica, v. 86, Fasc. 2, p. 267-285. 
13. Durozoi, Gérard; Roussel, André. 1993. Dicionário de filosofia. Campinas: Papirus.

14. Ferraz, Silvio. 2005. Livro das sonoridades: notas dispersas sobre composição. Rio de Janeiro: 7Letras.

15. Henriques, Fernando Meireles Monegalha. 2016. O atual e o virtual em Bergson e Deleuze. Tese (Doutorado em Filosofia) - Universidade Federal de São Carlos.

16. 15. Klee, Paul. 1971. Teoria del arte moderno. Buenos Aires: Ediciones Caldén.

17. Lévy, Pierre. 2011. O que é o virtual. 2ª edição. São Paulo: Editora 34.

18. Salles, Cecília Almeida. 1998. Gesto inacabado: processo de criação artística. São Paulo: FAPESP.

19. 2006. Redes de criação: construção da obra de arte. São Paulo: Editora Horizonte.

20. Willgross, Richard. 2012. Creativity in contemporary art music composition. International Review of the Aesthetics and Sociology of Music, v. 43, n. 2, p. 423437. 


\title{
Elementos melódicos e harmônicos recorrentes em Notas Irresponsáveis de Bruno Kiefer: uma abordagem Pós- Tonal
}

\author{
Recurring melodic and harmonic elements in Bruno Kiefer's Notas \\ Irresponsáveis: a Post-Tonal approach
}

\author{
Vinicius Dias Prates \\ Universidade Federal do Rio Grande do Sul
}

Resumo: Este trabalho apresenta um estudo analítico dos componentes melódicos e harmônicos de Notas Irresponsáveis (1986/87) para trio de flautas transversais de Bruno Kiefer (1923-1987). Utilizamos o livro Introduction to Post-Tonal Theory de Joseph N. Straus (2005) como referencial teórico com o objetivo de nos embasar na Teoria Pós-Tonal. Delimitamos os conjuntos melódicos e harmônicos de Notas Irresponsáveis tendo como critério parâmetros motívicos e texturais presentes na obra. Uma vez identificados os agrupamentos sonoros e analisados conforme com a Teoria Pós-Tonal, buscamos categorizá-los de acordo com suas ocorrências em cada uma das seções da composição. Entre os conjuntos mais recorrentes observamos a presença de formações octatônicas, cromáticas e pseudo-cromáticas além de agrupamentos com características diatônicas. Através dos resultados de nossas análises, procuramos entender quais são os elementos melódicos e harmônicos característicos do compositor, bem como encontrar traços em comum entre a peça escolhida para este artigo e o repertório investigado por Gerling (2001) e Mayer (2005), autores que estudaram a obra de Kiefer sob a ótica Pós-Tonal. Verificamos que, assim como em nossa literatura de apoio, os componentes octatônicos, agrupamentos em terças menores e trítonos surgem como elementos preferenciais do compositor em Notas Irresponsáveis. Observamos que, assim como demonstrado nos estudos de Mayer (2005), a terça menor se apresenta como componente de autocitação no trio de flautas de Kiefer.

Palavras-chave: Bruno Kiefer; Elementos Melódicos e Harmônicos; Teoria Pós-Tonal; Flauta transversal

\begin{abstract}
This paper is an analytical study of the melodic and harmonic elements present in Notas Irresponsáveis (1986/87) for flute trio by Bruno Kiefer (1923-1987). We used the book Introduction to Post-Tonal Theory by Joseph N. Straus (2005) as a theoretical framework with the objective of basing ourselves on the Post-Tonal Theory. We delimited the melodic and harmonic sets of Notas Irresponsáveis taking motivic and textural parameters presents in the work as criterion. Once the sets have been identified and analyzed according to the Post-Tonal Theory, we tried to categorize
\end{abstract}


PRATES, V. D. Elementos melódicos e harmônicos recorrentes em Notas Irresponsáveis de Bruno Kiefer: uma abordagem Pós-Tonal

them according to their occurrence in each of the piece sections. We observed the presence of octatonic, chromatic and pseudo-chromatic formations, as well as sets with diatonic characteristics among the most recurrent sets. Through the results of our analysis, we tried to understand the composer's melodic and harmonic characteristics, as well as to find common traits between the work chosen for this article and the elements investigated by Gerling (2001) and Mayer (2005), authors who studied Kiefer's work from a Post-Tonal perspective. We found that, just as in our support literature, the octatonic components, as well as minor thirds and tritones sets, appear as the composer's preferential elements in Notas Irresponsáveis. We observed that, as demonstrated in Mayer's studies, the third minor presents itself as a self-citation element in Kiefer's flute trio.

Keywords: Bruno Kiefer; Melodic and Harmonic Elements; Post-Tonal Theory; Flute

Este artigo é parte integrante de um estudo que busca identificar os traços característicos da escrita para flauta transversal de Bruno Kiefer (1923-1987) (Prates, Winter e Carvalho (2014), Prates (2015), Prates (2017) e Prates e Winter 2018)). Aqui é exposta uma análise dos elementos melódicos e harmônicos encontrados em Notas Irresponsáveis (1986/87) para trio de flautas transversais. Buscamos traçar paralelos entre a peça escolhida e a literatura analítica da obra de Kiefer que nos permitissem identificar a familiaridade estética de Notas Irresponsáveis com o repertório do compositor já investigado por Gerling (2001) e Mayer (2005). Nosso objetivo foi encontrar em Notas Irresponsáveis a possível recorrência dos elementos melódicos e harmônicos identificados por esses autores utilizando a Teoria Pós-Tonal proposta por Straus (2005) no livro Introduction to Post-Tonal Theory.

\section{O Referencial teórico}

A fim de analisar e compreender os elementos melódicos e harmônicos adotados pelo compositor em Notas Irresponsáveis, utilizamos como referencial teórico a obra Introduction to Post-Tonal Theory de Joseph N. Straus (2005). A Teoria Pós-Tonal tem como princípio a utilização de números em substituição a nomes de notas e classificação de intervalos. A seguir, apresentamos conceitos importantes para o entendimento da teoria segundo Straus (2005):

- Notação Numérica: ao tratarmos notas com nomes diferentes mas mesma frequência ${ }^{1}$ chegamos ao número de 12 sons diferentes.

\footnotetext{
${ }^{1}$ Equivalência Enarmônica conforme Straus (2005).
} 
MUSICA THEORICA Revista da Associação Brasileira de Teoria e Análise Musical 2019, v. 4, n. 1, p. 255-279-Journal of the Brazilian Society for Music Theory and Analysis@ TeMA 2019 - ISSN 2525-5541

Dessa forma, a cada som será atribuído um número em substituição de sua nomenclatura tradicional conforme o quadro abaixo:

\begin{tabular}{|c|c|}
\hline Notação Numérica & Classe de Nota e Equivalência Enarmônica \\
\hline 0 & Si $¥$, Dó, Réb, \\
\hline 1 & Dó\#, Réb \\
\hline 2 & Dó*, Ré, Mi bb \\
\hline 3 & Ré\#, Mi \\
\hline 4 & Ré*, Mi, Fáb \\
\hline 5 & Mi $\#$, Fá, Sol \\
\hline 6 & Fá\#, Solb \\
\hline 7 & Fá*, Sol, Lábl \\
\hline 8 & Sol\#, Láb \\
\hline 9 & Sol*, Lá, Si b, \\
\hline 10 & Lá\#, Si, \\
\hline 11 & Lá», Si, Dób \\
\hline
\end{tabular}

Quadro 1: notações numéricas das classes de notas

- Classe de Intervalo: representação numérica atribuída ao intervalo na sua formação mais simples. Não são levados em consideração intervalos compostos, sendo entendidos como sons integrantes dentro de uma oitava. Também podem ser consideradas as inversões de intervalos superiores a 6 semitons (trítono) como por exemplo: Dó-Si = sétima maior, intervalo 11 (semitons) é considerado Si-Dó, Classe de Intervalo 1 (semitom).

Straus (2005) comenta que o tipo de Notação de Intervalo que adotaremos depende do tipo de análise que pretendemos realizar. Dessa forma, para essa pesquisa adotamos classificações intervalares que se encaixem no espaço de uma oitava levando em consideração a inversão, conforme quadro abaixo:

\begin{tabular}{|l|l|}
\hline Notação Numérica & Classe de Intervalos \\
\hline 0 & oitava, uníssono \\
\hline 1 & segunda menor \\
\hline 2 & segunda maior, terça diminuta \\
\hline 3 & segunda aumentada, terça menor \\
\hline
\end{tabular}


PRATES, V. D. Elementos melódicos e harmônicos recorrentes em Notas Irresponsáveis de Bruno Kiefer: uma abordagem Pós-Tonal

\begin{tabular}{|l|l|}
\hline 4 & terça maior, quarta diminuta \\
\hline 5 & terça aumentada, quarta justa \\
\hline 6 & quarta aumentada, quinta diminuta \\
\hline 5 & quinta justa (invertida) \\
\hline 4 & quinta aumentada, sexta menor (invertidas) \\
\hline 3 & sexta maior, sétima diminuta (invertidas) \\
\hline 2 & sexta aumentada, sétima menor (invertidas) \\
\hline 1 & sétima maior (invertida) \\
\hline
\end{tabular}

Quadro 2: notações numéricas das classes de intervalos e inversões

Conjunto de Classe de Notas, que chamaremos de Conjunto de Notas ou simplesmente Conjunto: ao analisarmos uma peça, identificamos as Classes de Notas que compõe algum trecho e agrupamos de maneira a formar um conjunto (coleção) de sons que pode possuir muitas maneiras diferentes de agrupamento ou ordenamento. Portanto, uma vez identificado os sons (Classe de Notas), devemos ordenar o conjunto na sua Forma Normal, que é sua configuração intervalar mais compacta da esquerda para a direita (vide também Forte (1973)), ou seja, observando o espaço ascendente dentro de uma oitava, sempre com o menor intervalo entre a primeira e a última Classe de Nota.

Straus (2005) traz exemplos de inversões e transposições de conjuntos a partir de uma determinada Classe de Nota para outra. Isso possibilita que vários outros conjuntos surjam em decorrência de um e estabelecendo entre eles uma identidade intervalar, o que se chama Classe de Conjuntos. Contudo, não utilizamos esse procedimento nessa pesquisa. Buscamos apenas as transposições de conjuntos a fim de iniciar com a Classe de Notas 0 (Dó), chamada de Forma Prima, pois assim tivemos a possibilidade de verificar mais facilmente a disposição intervalar do conjunto, nos remetendo à lista de Classes de Conjuntos segundo Forte (1973) que Straus (2005) apresenta no final do livro.

Uma vez entendidos esses conceitos, trouxemos como ferramenta de auxílio o programa PC Set Calculator, ${ }^{2}$ desenvolvido em 2001 por David Walters. Ao inserir dados numéricos relacionados aos sons o aplicativo calcula as Formas Normais e Primas, bem como fornece a classificação dos conjuntos segundo Forte (1973). Após as análises da peça, delimitamos os conjuntos encontrados por meio do programa e identificamos por parênteses as Formas Normais e Formas Primas

\footnotetext{
2 Disponível na internet em http://www.mta.ca/faculty/arts-letters/music/pc-set_project/calculator/ pc_calculate.html\#.
} 
MUSICA THEORICA Revista da Associação Brasileira de Teoria e Análise Musical 2019, v. 4, n. 1, p. 255-279-Journal of the Brazilian Society for Music Theory and Analysis @ TeMA 2019 - ISSN 2525-5541

desses agrupamentos utilizando Notação Numérica e os nomeamos de acordo com Forte (1973) através de colchetes.

\section{Metodologia}

A metodologia se guiou por análises que buscaram identificar os elementos melódicos e harmônicos recorrentes em Notas Irresponsáveis. Seguindo os conceitos propostos por Straus (2005), adotamos os seguintes passos: identificação de conjuntos presentes na obra classificando-os em suas Formas Normais e Formas Primas e categorizando-os na nomenclatura segundo Forte (1973); cruzamento de dados com o objetivo de compreender uma possível identidade temática presente entre Notas Irresponsáveis e outras obras de Kiefer já analisadas por Gerling (2001) e Mayer (2005). Estes autores embasam seus dados conforme a Teoria-Pós Tonal. Por esta razão, optamos pela mesma ferramenta de análise a fim de aproximar nossos resultados à linguagem adotada por estes autores.

Devido à ausência de registro sonoro da obra que escolhemos para esse artigo, realizamos uma gravação da mesma a fim de auxiliar no processo de análise. É possível conferir o registro através do link https://soundcloud.com/ vinicius-prates-7/notas-irresponsaveis-bruno-kiefer. A gravação que disponibilizamos tem o objetivo de auxiliar o leitor na compreensão das ideias explanadas neste trabalho, e por ter sido realizada paralelamente ao nosso processo de análise deve ser entendida como um referencial sonoro de apoio sem fins interpretativos e/ou performáticos. Os resultados de nossas investigações contribuíram para o melhor entendimento dos materiais propostos por Kiefer, nos permitindo relacioná-los de forma interpretativa e agregar coerência e sentido aos parâmetros melódicos e harmônicos.

\section{Notas Irresponsáveis (1986/87): abordagem analítica}

Nesta análise utilizamos o termo Seção para designar os trechos musicais de maiores dimensões e que apresentem ideias completas com início, meio e fim. O termo Região temática, ou simplesmente região é utilizado para destacar os trechos que apresentem melodias, fragmentos melódicos e/ou motivos que, em combinação, configurem pequenas ideias musicais. 
PRATES, V. D. Elementos melódicos e harmônicos recorrentes em Notas Irresponsáveis de Bruno Kiefer: uma abordagem Pós-Tonal

Notas Irresponsáveis possui estrutura dividida em três seções distintas na forma ABA'. A Seção $A$ possui três regiões temáticas (" $a$ ", " $b$ " e “c") com 11, 17 e 24 compassos respectivamente. A Seção B é formada por quatro regiões temáticas (" $d$ ", " $e$ ", “ $d$ " " e "f"). A região $d$, em forma de cânone possui 9 compassos; a região e, espécie de recapitulação de motivos já apresentados, totaliza 9 compassos; $d$ 'é um desenvolvimento do cânone anterior com 26 compassos; a região $f$ possui material novo de caráter coral em 10 compassos. A Seção $A^{\prime}$ apresenta duas regiões temáticas, sendo $a^{\prime}$ uma recapitulação do início da obra totalizando 13 compassos, seguida de uma Coda de 5 compassos.

\begin{tabular}{|c|c|c|}
\hline \multirow{3}{*}{ Seção A (c. 1-52) } & região a (11 compassos) & c. $1-11$ \\
\hline & região b (17 compassos) & Anacruse para c. $12-28$ \\
\hline & região c (24 compassos) & c. $29-52$ \\
\hline \multirow{4}{*}{$\begin{array}{c}\text { Seção B (anacruse para c. 53- } \\
116)\end{array}$} & região d (9 compassos) & Anacruse para c. 53-62 \\
\hline & região e (9 compassos) & 2 depois de $60-10$ depois de $60^{3}$ \\
\hline & região d' (26 compassos) & $\begin{array}{l}\text { Anacruse para } 11 \text { depois de c. } 60-65 \\
\text { depois de } 100\end{array}$ \\
\hline & região f (10 compassos) & 6 depois de 100 - c. 116 \\
\hline \multirow{2}{*}{ Seção A' (c. 117-134) } & região a' (13 compassos) & c. $117-129$ \\
\hline & Coda (5 compassos) & c. $130-134$ \\
\hline
\end{tabular}

Quadro 3: Notas Irresponsáveis; forma

Sobre a escrita, Notas Irresponsáveis apresenta características de notação tradicional no que se refere aos parâmetros de altura, ritmo e dinâmica. Sua métrica é guiada pela fórmula de compasso 2/4 (binário simples), e por vezes alterada para 3/4 (ternário simples), mas imediatamente após poucos compassos restabelece o binário simples por longos períodos. Além disso, Kiefer propõe alterações de andamentos em Notas Irresponsáveis. A obra inicia com indicação de “Andamento Firme" com semínima igual a 84. As alterações ocorrem nos inícios

3 Usamos o termo "2 depois de 60 " porque a partitura que tivemos acesso contém erros na marcação de números de compasso. Entre os números 60 e 110 há equívocos de numeração. Dessa forma, optamos por adotá-los como referência de local e não como contagem de compasso. A partir do número 110 a contagem está correta. Sendo assim, tudo que estiver entre os números 60 e 110 destacamos com "antes de" e/ou "depois de". A partir de 110, destacamos como números de compassos. 
MUSICA THEORICA Revista da Associação Brasileira de Teoria e Análise Musical 2019, v. 4, n. 1, p. 255-279-Journal of the Brazilian Society for Music Theory and Analysis@ TeMA 2019 - ISSN 2525-5541

dos cânones, onde a indicação solicita "um pouco mais lento" com semínima igual a 76 e retomando o "tempo I" ao término do episódio (apenas no primeiro cânone), e na região $f$ (6 depois de 100 - c. 116), onde há uma solicitação de "Lento" com semínima igual a 66 e retomada de "tempo I" após conclusão da região até o final da peça.

Kiefer explora dois tipos de textura em Notas Irresponsáveis: homofônica e polifônica. Berry (1987) afirma que

homofonia literalmente denotaria uma condição de interdependência das vozes, mas sua conotação tradicional é de textura na qual uma voz primária é acompanhada por um tecido subordinado algumas vezes interativo de maneira provisória, o baixo normalmente em direção contrária ou em outra relação contrapontística com a voz (ou vozes) principal (Berry 1987, p. 192).

Hyer (2001) define homofonia como "música polifônica na qual as vozes se movem juntas mais ou menos no mesmo ritmo" (Hyer 2001, s.p.). Kiefer explora fortemente esta textura (partes que seguem no mesmo ritmo) na região a (c. 1-11), por vezes a três vozes, mas frequentemente a duas vozes. Além disso, pequenas inserções homofônicas ocorrem em diferentes regiões temáticas e em momentos de transição, como, por exemplo, o final do segundo cânone. A região $f$ (6 depois de 100 - c. 116) é inteiramente nessa textura, assim como a grande parte da região a' (c. 117-129), agora em caráter de recapitulação.

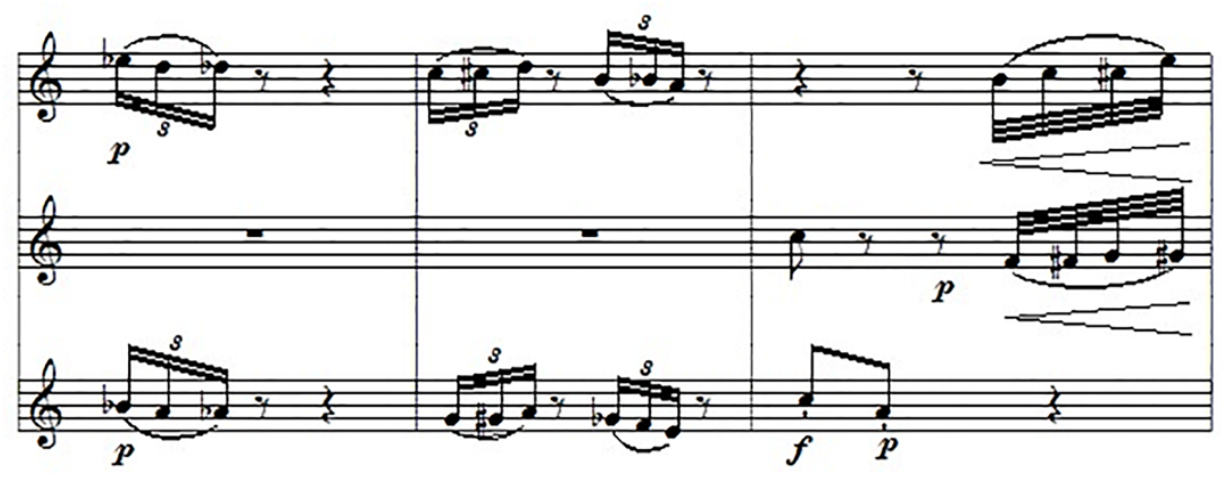

Exemplo 1a: Notas Irresponsáveis c. 4-6, homofonia 
PRATES, V. D. Elementos melódicos e harmônicos recorrentes em Notas Irresponsáveis de Bruno Kiefer: uma abordagem Pós-Tonal
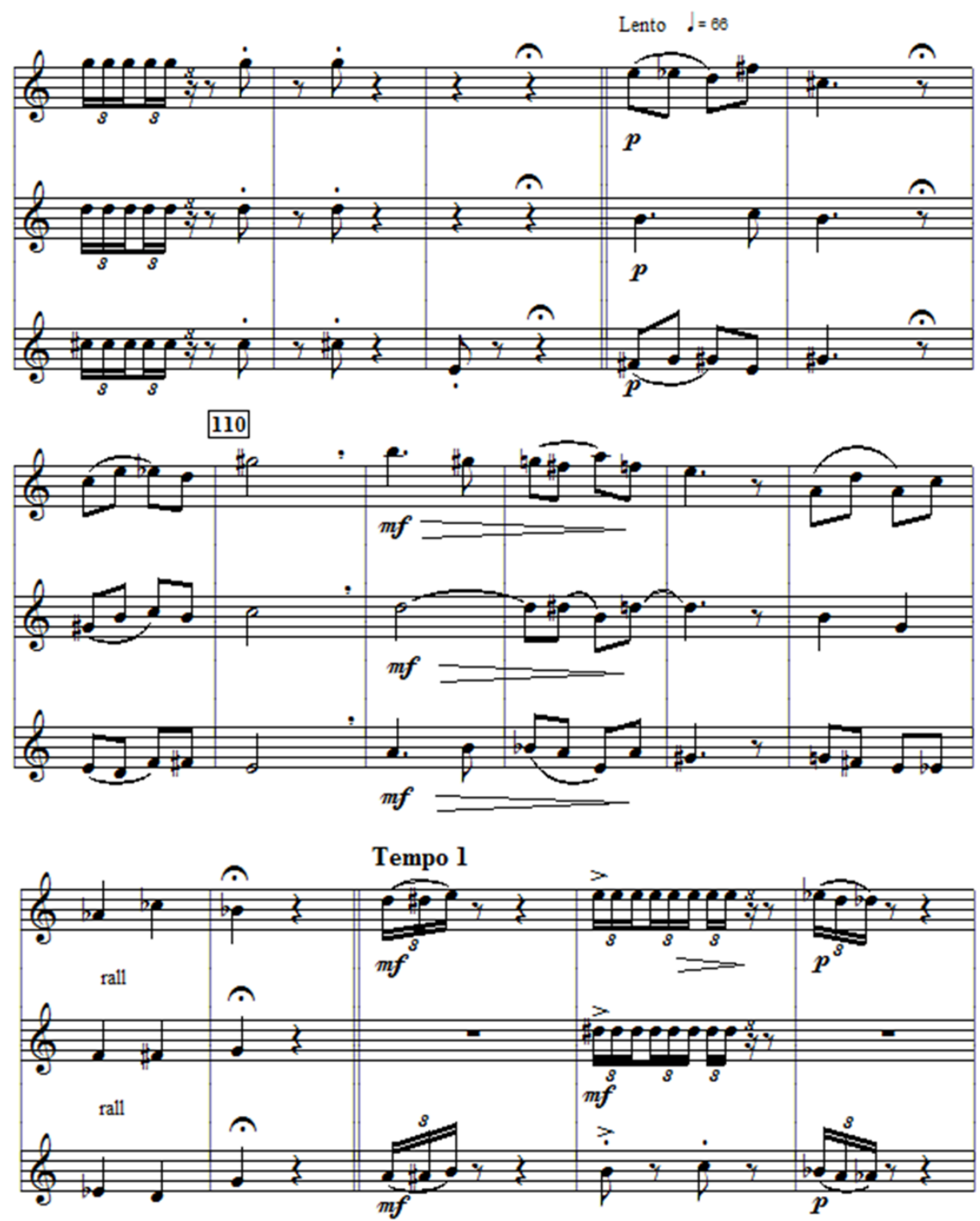

Exemplo 1b: Notas Irresponsáveis. 6 antes de 100-1204 (transição do segundo cânone para região f em "Lento" e início da Seção C em "tempo I"), homofonia

Frobenius, Cooke e Bithell (2001) definem polifonia como "música em mais de uma parte, música em muitas partes, estilo na qual todas ou a maioria das partes da música se movem de forma independente" (Frobenius; Cooke; Bithell 2001, s.p.). Kiefer explora esse recurso de duas maneiras distintas em Notas Irresponsáveis:

\footnotetext{
${ }^{4}$ Ver nota anterior.
} 
MUSICA THEORICA Revista da Associação Brasileira de Teoria e Análise Musical 2019, v. 4, n. 1, p. 255-279-Journal of the Brazilian Society for Music Theory and Analysis@ TeMA 2019 - ISSN 2525-5541

1) como forma de diálogo entre as vozes, passando fragmentos motívico/melódicos de voz para voz, dando uma ideia de conexão e continuidade de fraseado (Ex. 2a);

2) como contraponto de vozes em imitação nos cânones (Ex. 2b).

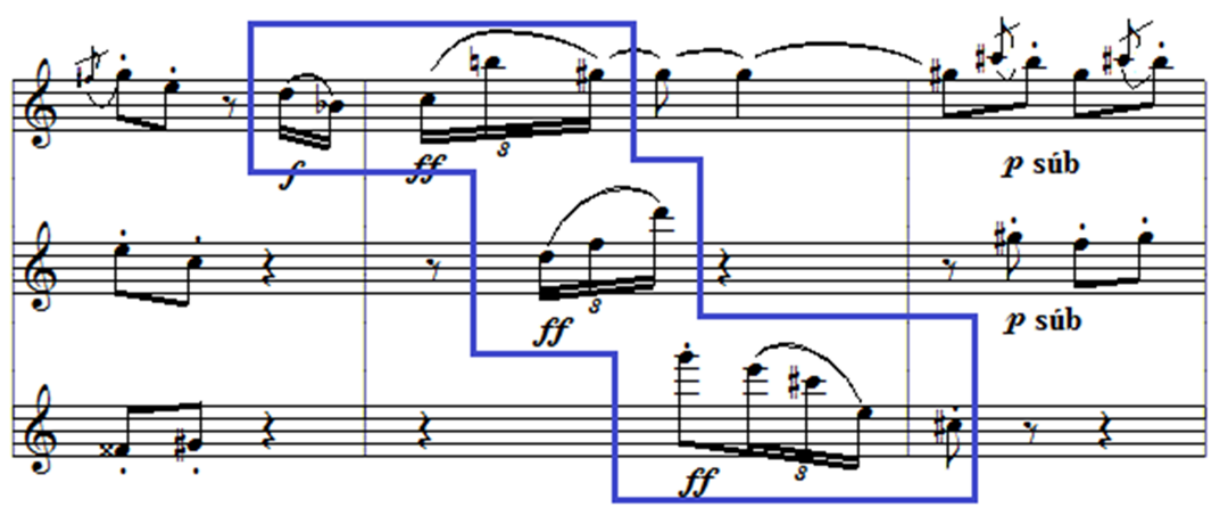

Exemplo 2a: Notas Irresponsáveis c. 22-24. Fragmentos melódicos que passam de voz para voz
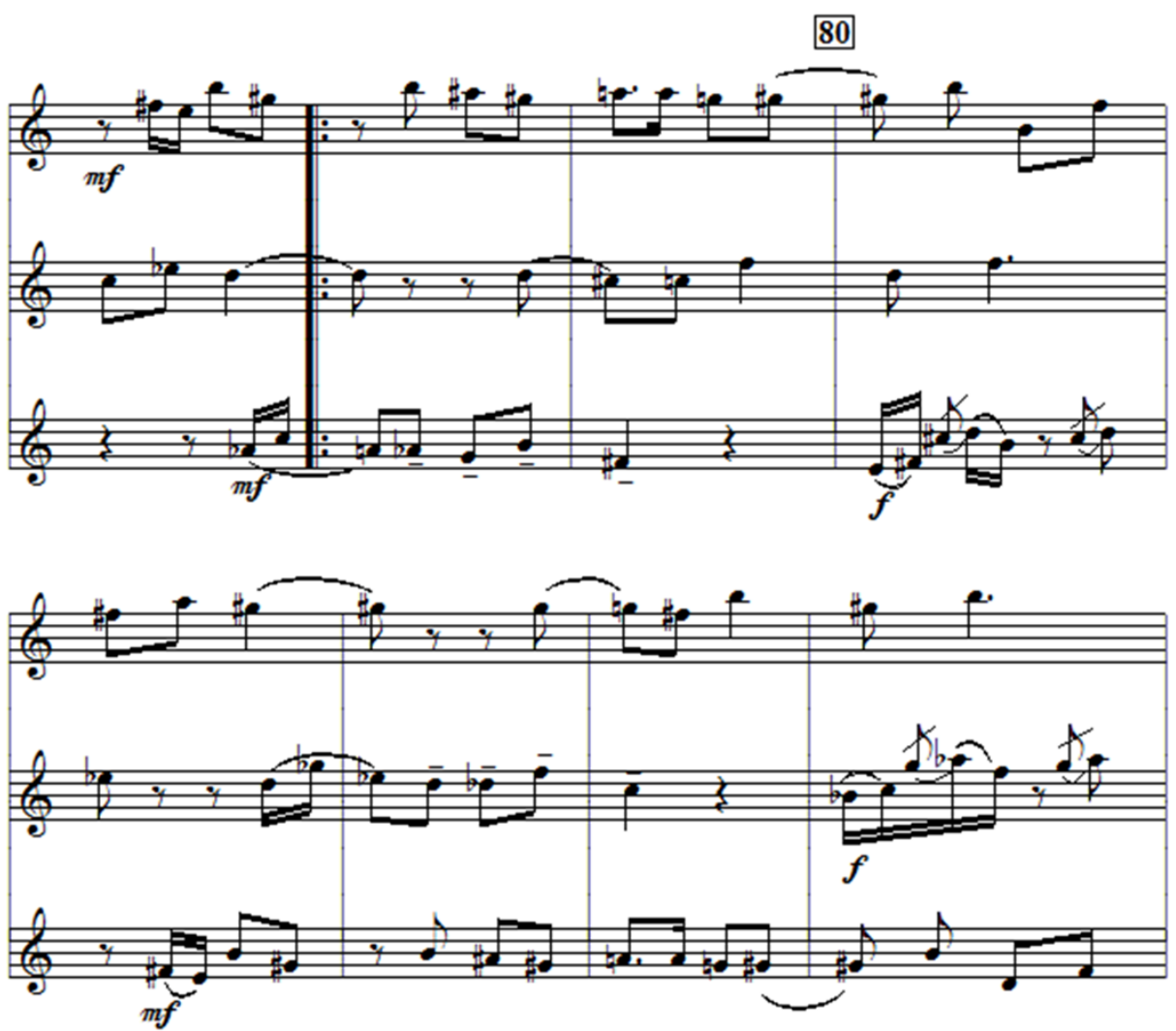

Exemplo 2b: Notas Irresponsáveis (segundo cânone) 3 antes de 80 a 4 depois de 80 . Imitação 
PRATES, V. D. Elementos melódicos e harmônicos recorrentes em Notas Irresponsáveis de Bruno Kiefer: uma abordagem Pós-Tonal

Kiefer insere dois pequenos solos na terceira flauta. Estes eventos ocorrem nas transições que antecedem os dois cânones e em um momento de contraste textural da região c (c. 29-52) (ver Ex. 3a e 3b).

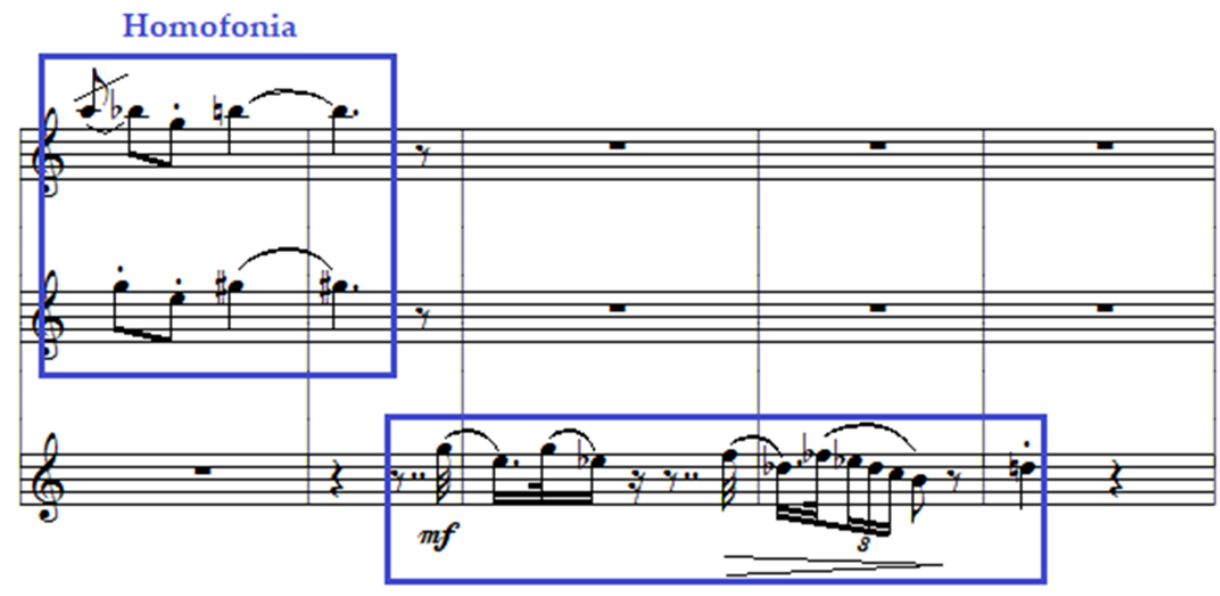

Solo na terceira voz

Exemplo 3 a: Notas Irresponsáveis c. 35-39. Pequeno solo na terceira voz

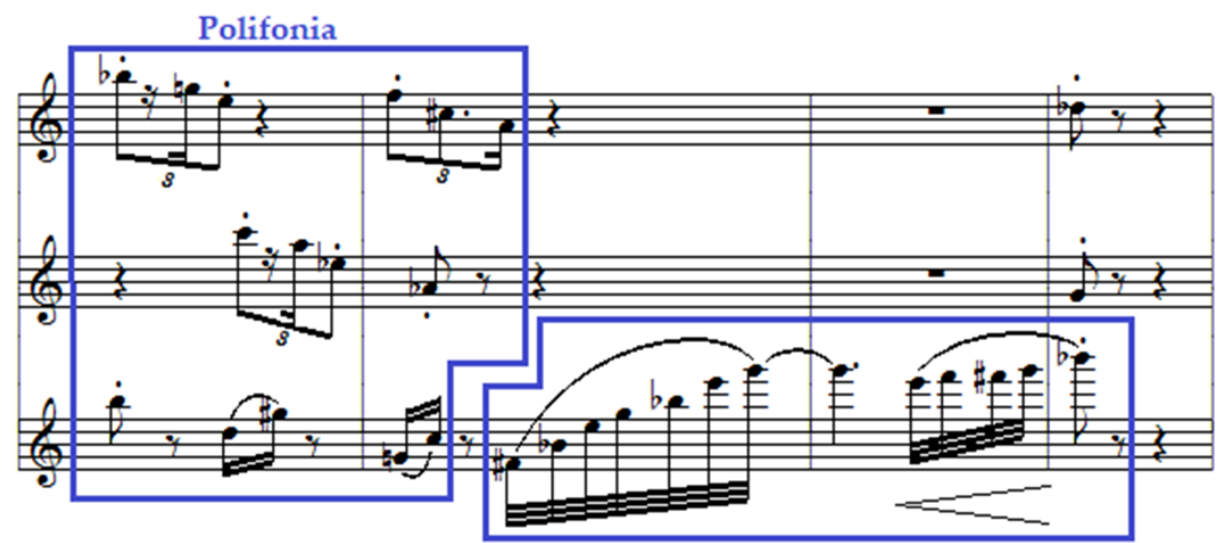

Solo na terceira voz

Exemplo 3b: Notas Irresponsáveis c. 45-48. Pequeno solo na terceira voz

Para a compreensão melódica e harmônica segundo a Teoria Pós-Tonal foi necessário um estudo de identificação de conjuntos. Nosso critério para a delimitação desses conjuntos se baseou na observação de como o compositor organiza seu material temático. Verificamos recorrência de ideias musicais curtas, abruptamente interrompidas por pausas, bem como ideias musicais curtas e isoladas com ritmos contrastantes a ideias anteriores e posteriores. Suas durações variam de um tempo a três compassos. Dessa forma, delimitamos 
MUSICA THEORICA Revista da Associação Brasileira de Teoria e Análise Musical 2019, v. 4, n. 1, p. 255-279-Journal of the Brazilian Society for Music Theory and Analysis@ TeMA 2019 - ISSN 2525-5541

conjuntos de notas que devem ser entendidos como o material melódico e harmônico trabalhado por Kiefer.

Além disso, o aspecto textural a três vozes teve de ser considerado. $\mathrm{Na}$ textura homofônica, os conjuntos foram interpretados de forma vertical e em blocos como em estudos de harmonia (Ex. 4a). Na textura polifônica adotamos dois critérios: vertical e horizontal. Os polifônicos verticais ocorrem quando há independência do movimento das vozes, mas fragmentos melódicos são passados de voz para voz com sensação de continuidade (vide Ex. 4b). Os polifônicos horizontais ocorrem apenas nos cânones e se assemelham ao estudo de contraponto, onde se leva em consideração a linha melódica (Ex. 4c).

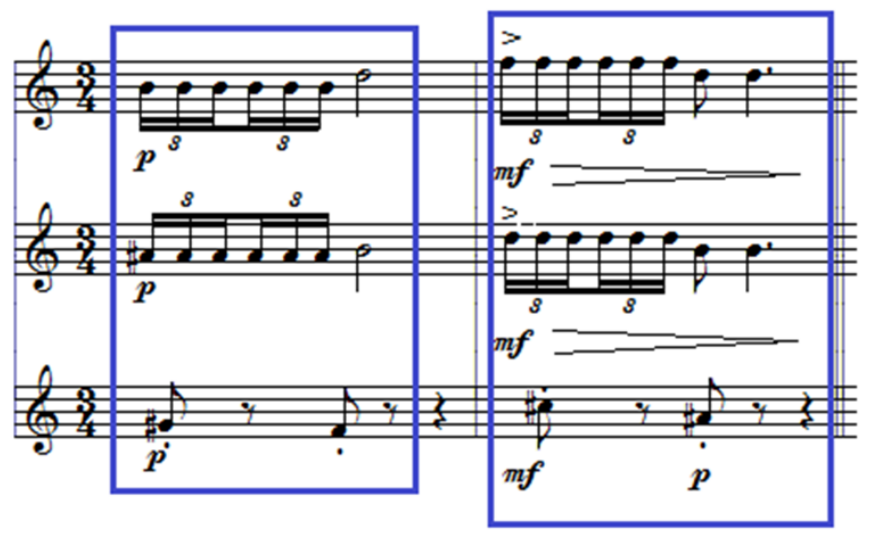

Exemplo 4a: Notas Irresponsáveis c. 15-16. Homofonia. Conjuntos verticais

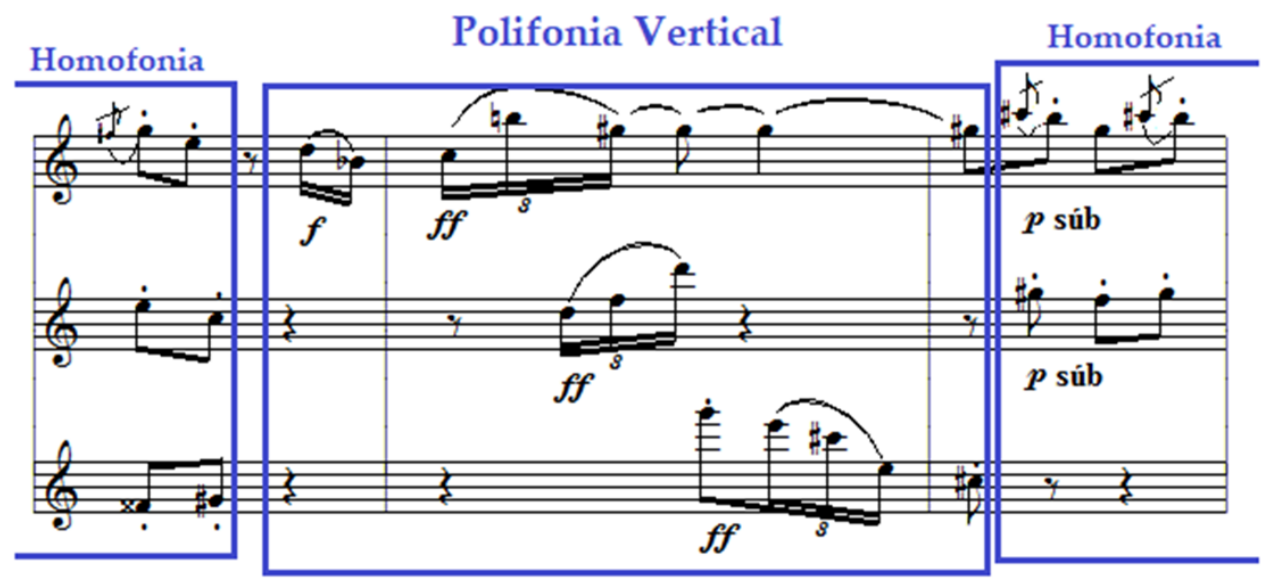

Exemplo 4b: Notas Irresponsáveis c. 22-24. Polifonia vertical. Conjunto vertical 
PRATES, V. D. Elementos melódicos e harmônicos recorrentes em Notas Irresponsáveis de Bruno Kiefer: uma abordagem Pós-Tonal

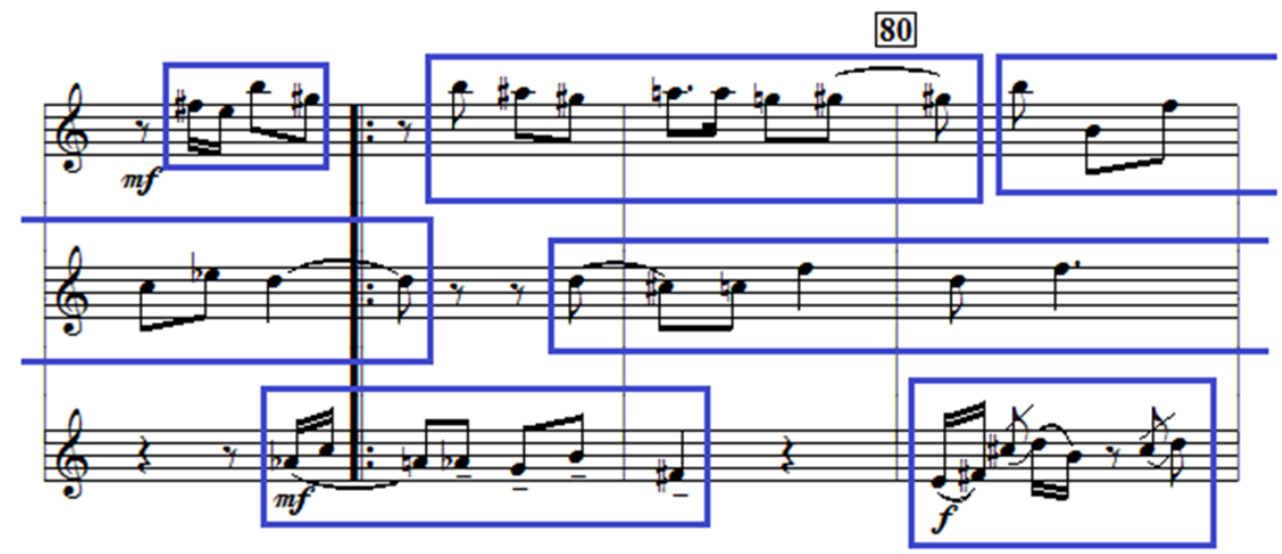

Exemplo 4c: Notas Irresponsáveis (segundo cânone) 3 antes de 80 a 80. Polifonia horizontal. Conjuntos horizontais

De acordo com nosso entendimento acerca dos elementos melódicos e harmônicos que compõem Notas Irresponsáveis, é possível notar a incidência de conjuntos octatônicos e cromáticos. Segundo Wilson (2001) a escala octatônica é um padrão simétrico formado pela intercalação de tons e semitons. Tal agrupamento gera na Teoria Pós-Tonal o conjunto de oitos sons [8-28], na classificação de Forte (1973), do qual podemos extrair subconjuntos de menor tamanho. Nessa classificação, o primeiro número indica a quantidade de sons presentes na coleção e o segundo a sua localização na listagem. Podemos considerar padrões octatônicos conjuntos de 3 a 8 sons. A Figura 1 apresenta os subconjuntos conforme nos mostra Gerling (2001):

[8-28]

\begin{tabular}{l}
\hline [7-31] \\
\hline$[6-27][6-30][6-Z 13][6-Z 23][6-Z 49][6-Z 50]$ \\
\hline$[5-10][5-16][5-19][5-28][5-31][5-32]$ \\
\hline$[4-3][4-9][4-10][4-12][4-13][4-17][4-18][4-25][4-26][4-27][4-28][4-Z 15][4-Z 29]$ \\
\hline$[3-2][3-3][3-5][3-7][3-8][3-10][3-11]$
\end{tabular}

Figura 1: Conjunto e subconjuntos octatônicos (Gerling 2001, p. 58)

Os conjuntos cromáticos são segmentos de sons em intervalos de semitons. São identificados na lista de Forte (1973) pelo número 1 ao final do nome conforme Figura 2:

$$
\text { [3-1] [4-1] [5-1] [6-1] [7-1] [8-1] }
$$

Figura 2: Conjuntos cromáticos 
MUSICA THEORICA Revista da Associação Brasileira de Teoria e Análise Musical 2019, v. 4, n. 1, p. 255-279-Journal of the Brazilian Society for Music Theory and Analysis @ TeMA 2019 - ISSN 2525-5541

Encontramos considerável recorrência de conjuntos octatônicos e cromáticos em Notas Irresponsáveis. Kiefer distribui esses conjuntos de forma equilibrada entre as regiões temáticas, dificultando a classificação de determinada região com características de determinado padrão. Existem regiões em que nenhuma dessas duas qualidades de conjuntos ocorre. Observa-se que a Seção A (c. 1-52) apresenta na região a (c. 1-11) apenas um conjunto cromático, 6 octatônicos na região $b$ (anacruse para c. 12-28) e um octatônico e 6 cromáticos na região c (c. 29-52). Essas alterações de padrões melódicos ocorrem paralelamente a alterações texturais.

A região a (c. 1-11), apesar de não classificada como octatônica ou cromática, apresenta conjuntos com características cromáticas, mas que não são assim classificados por alterações no padrão de semitons. Estes conjuntos chamaremos de pseudo-cromáticos, ou seja, agrupamentos com conteúdo cromático predominante, mas que, em determinado ponto de sua formação, apresentam algum intervalo que não se encaixe no padrão de sequência de semitons. Essa característica se manifesta já nos dois primeiros conjuntos da obra e em suas transposições. Os conjuntos [4-7] e [6-Z6] que possuem Formas Primas (0 14 5) e (0 1256 7), respectivamente, têm qualidades cromáticas embora sejam interrompidas por um salto de segunda aumentada em [4-7] e de terça menor (Classe de Intervalo 3) em [6-Z6] situados em suas regiões centrais, fato que, inclusive, os transforma em simétricos e similares entre si. O Exemplo 5 exibe esses conjuntos em suas Formas Normais da primeira aparição.

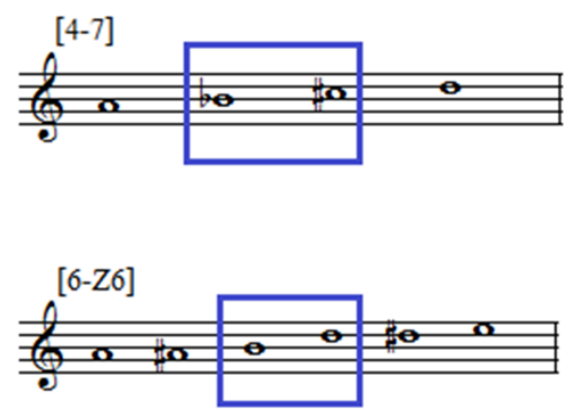

Exemplo 5: Conjuntos pseudo-cromáticos [4-7] e [6-Z6] em suas Formas Normais. Qualidades cromáticas interrompidas por saltos de segunda aumentada e terça menor (Classe de Intervalo 3), respectivamente 
PRATES, V. D. Elementos melódicos e harmônicos recorrentes em Notas Irresponsáveis de Bruno Kiefer: uma abordagem Pós-Tonal

A Classe de Intervalo 3 é elemento que merece destaque conforme será mostrado nesta análise de Notas Irresponsáveis. Aqui, o intervalo se insere no meio da sonoridade cromática. A ocorrência dos conjuntos [9-4] e [6-2], que possuem Formas Primas (0 1234578 9) e (0 1234 6), embora não totalmente cromáticos com seus padrões interrompidos por uma ocorrência de intervalo de segunda maior em cada um, reforça a sonoridade mais aproximada à cromática da região $a($ c. 1-11).

A região b (anacruse para c. 12-28), apesar de ter uma maior recorrência de padrões octatônicos, apresenta uma característica mista em seus padrões melódicos devido à inserção de alguns conjuntos pseudo-cromáticos como, por exemplo [9-10], [8-Z15] e [9-2] que possuem Formas Primas (0 1234679 10), (0 123468 9) e (0 1234567 9), respectivamente. A região c (c. 29-52), além de possuir maior indício cromático total pela utilização frequente do conjunto [3-1], Forma Prima (0 12 ), tem essa característica reforçada pela utilização dos conjuntos pseudo-cromáticos [8-13] e [4-5] com Formas Primas (0 1223467 9) e (0 12 6 6), respectivamente, além da ocorrência do conjunto (0 12345789 10) (mostrado aqui em sua Forma Prima) $)^{5}$, que possui quase que na sua totalidade intervalos de semitons.

Os cânones, compreendendo as regiões $d$ (anacruse para c. 53-62) e $d^{\prime}$ (anacruse para 11 depois de 60-5 depois de 100), são compostos de material melódico mais variado que a Seção $A$ (c. 1-52). Aqui ocorrem padrões cromáticos como [5-1], pseudo-cromáticos como [6-Z3], Forma Prima (0 102356 e octatônicos como [6-27], bem como conjuntos de características mais diatônicas e tonais. Ao analisarmos os conjuntos [5-23] (primeiramente utilizado na Forma

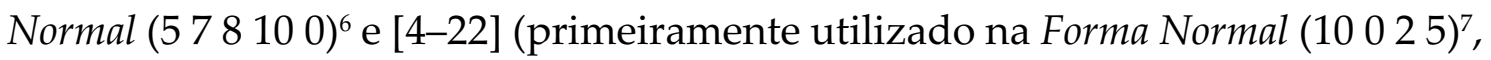
vemos que Kiefer explora sonoridades diferentes daquelas reforçadas anteriormente. O Exemplo 6 apresenta [5-23] e [4-22] em suas Formas Normais através de notação tradicional para uma melhor visualização.

\footnotetext{
${ }^{5}$ Este conjunto não possui nome na classificação de Forte (1973) por apresentar mais de 9 sons.

${ }^{6}$ Forma Prima (0 2357 ).

${ }^{7}$ Forma Prima (0 24 7).
} 

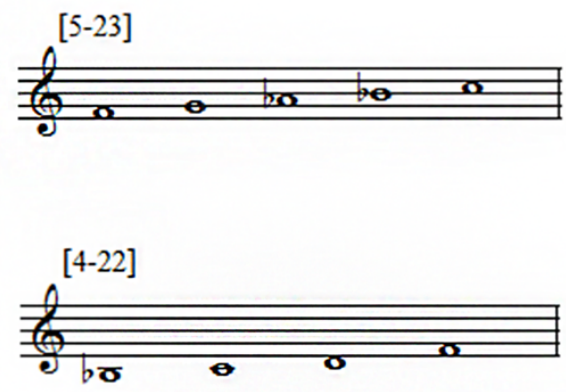

Exemplo 6: Conjuntos [5-23] e [4-22] em suas Formas Normais. Características diatônicas

Sob uma ótica tradicional tonal, o conjunto [5-23] pode ser entendido como um seguimento da escala de Fá menor. Portanto, aqui há uma interpretação diatônica. O conjunto [4-22] devido a um salto de terça menor entre seu terceiro e quarto graus, aumenta sua possibilidade de interpretação em um viés tonal. Este agrupamento pode ser inserido dentro das possibilidades de Fá menor melódico, Fá Maior, Si, Maior, entre outros, bem como ser entendido como segmento de uma escala pentatônica. No entanto, a abordagem Pós-Tonal não nos permite classificar esses conjuntos dessa forma, embora, como sonoridade, eles possam transmitir uma impressão de variação de padrões melódicos. Tendo em vista que todos os conjuntos dos cânones são submetidos a transposições e repetições, é possível afirmar que as sonoridades "diatônicas" exploradas por Kiefer enriquecem o material melódico da obra.

A região $f$ (6 depois de 100 - c. 116), apesar de não apresentar conjuntos inteiramente cromáticos, é composta por apenas quatro formações, todas pseudo-cromáticas. Os critérios de delimitação dos conjuntos aqui, como explicado anteriormente, se deram de forma vertical, respeitando os blocos sonoros a três vozes em suas respirações e cadências. Contudo, ao observarmos o movimento melódico das vozes individualmente, percebemos que essas se movem com alto índice de cromatismo. Dessa forma, afirmamos que a região $f$ é cromática.

Além da análise acerca de conjuntos e suas diferentes formações e utilizações por Kiefer, devemos dar atenção também a suas preferências intervalares, tanto de forma harmônica como melódica. Para isso, voltaremos às regiões canônicas de Notas Irresponsáveis. Mann, Wilson e Urguhart (2001) definem cânone como uma forma polifônica de execução musical na qual um performer executa uma ou mais linhas melódicas derivadas de uma dada 
melodia, a qual será imitada a uma distância de tempo e intervalo. Em seu trio de flautas, Kiefer opta pela prática menos frequente e constrói seus cânones com variações intervalares (ou seja, transposições) entre as vozes que realizam a imitação. Os conjuntos que iniciam as regiões canônicas são [6-Z3], [5-23] e [422] e aparecem nas Formas Normais (0 1235 6), (5 7810 0) e (10 02 5). Apesar de serem apresentados em nossa delimitação de conjuntos como três entidades diferentes e separadas, aqui devem ser entendidos como sequenciais, assumindo um sentido melódico e temático único. Esses três conjuntos formam a primeira melodia do cânone a ser imitada. Essa imitação ocorre transposta, gerando as Formas Normais (6 78911 0), (11 1246 ) e (4 6811$)$. Ao analisarmos a transposição é possível notar que a distância que separa os primeiros conjuntos dos demais é de 6 semitons (Classe de Intervalo 6), o que na Teoria Pós-Tonal corresponde à fórmula $\mathrm{T}_{6}{ }^{8} \mathrm{O}$ Exemplo 7 ilustra os conjuntos e suas transposições através de notação tradicional.

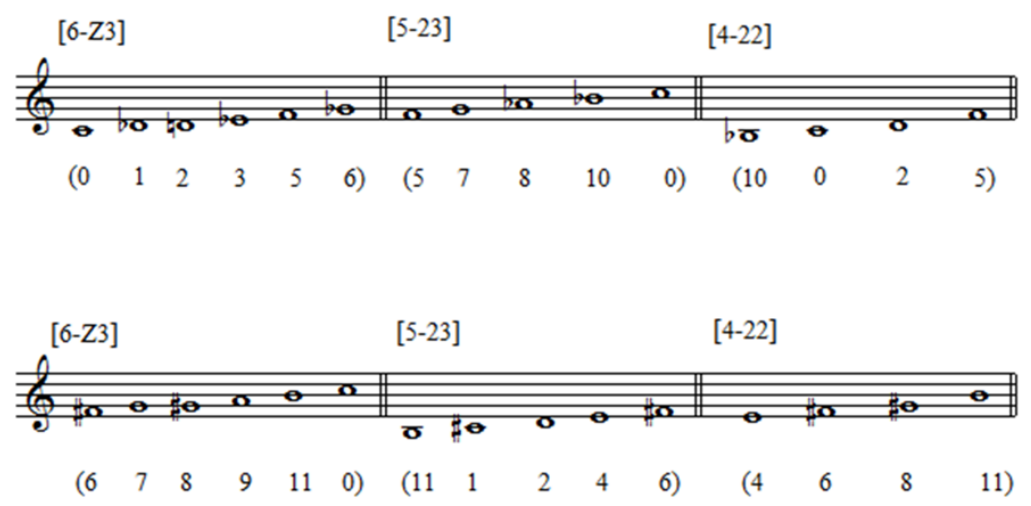

Exemplo 7: Conjuntos[6-Z3], [5-23] e [4-22] transpostos à Classe de Intervalo 6

Essa transposição domina na totalidade as regiões canônicas de tal modo que todos os conjuntos são alterados em 6 semitons. Contudo, sob a ótica desta constante, Kiefer teria cometido um equívoco transpondo uma nota da primeira flauta a uma distância de 3 semitons ao invés de 6 (ver nota Si grave destacada no Ex. 8c). A melodia correspondente a esta transposição apresenta a nota Láb em sua primeira exposição no primeiro Cânone (ver nota Láb destacada no Ex. 8a).

\footnotetext{
${ }^{8}$ Fórmula Tn. A letra $T$ significa Transposition (transposição) e a letra $n$ significa o número de semitons em que se deu a transposição. Deve-se levar em consideração o ciclo de 12 semitons para o cálculo correto.
} 
MUSICA THEORICA Revista da Associação Brasileira de Teoria e Análise Musical 2019, v. 4, n. 1, p. 255-279-Journal of the Brazilian Society for Music Theory and Analysis@ TeMA 2019 - ISSN 2525-5541

Na segunda região canônica, a mesma melodia apresentada na segunda flauta ainda sem transposição, reaparece inalterada, nos levando a crer que a forma original está correta pois Kiefer a repete Ipsis litteris (Ex. 8b). Uma vez que todos os conjuntos são transpostos a uma distância de 6 semitons nas regiões canônicas, a alteração correta nesta melodia reapresentada na primeira flauta deveria ser para nota Ré (6 semitons de Lá)) ao invés de Si (3 semitons de Láb), conforme Exemplo 8d.

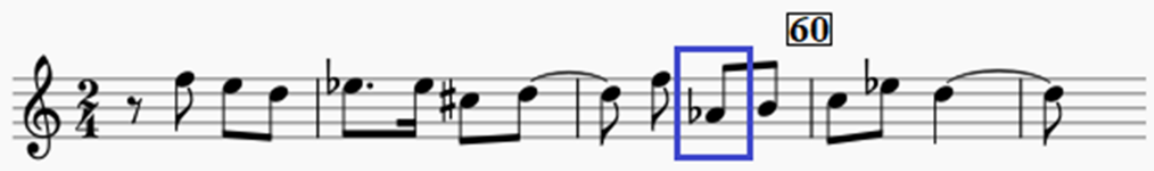

Exemplo 8a: Notas Irresponsáveis (segunda flauta) c. 57 a 1 depois de 60. Primeira exposição da melodia no primeiro Cânone

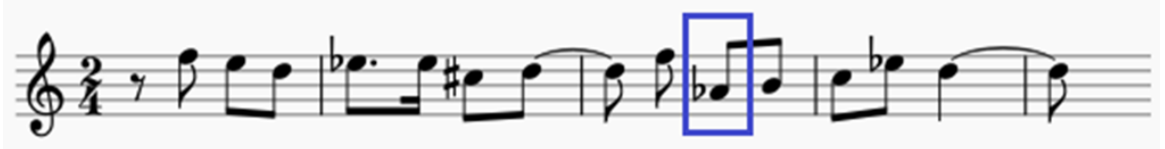

Exemplo 8b: Notas Irresponsáveis (segunda flauta) 6 antes de 80 a 2 antes de 80 . Reapresentação ipsis litteris da melodia no segundo Cânone

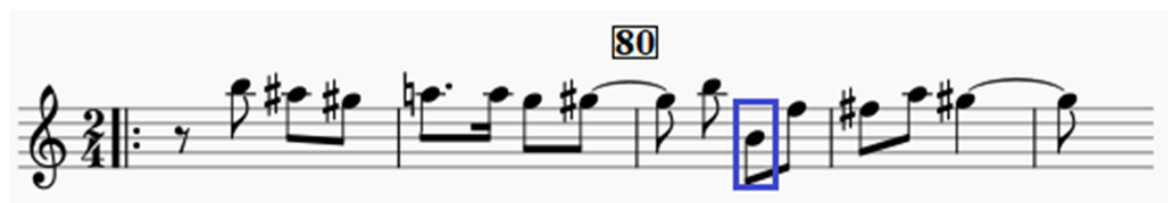

Exemplo 8c: Notas Irresponsáveis (primeira flauta) 2 antes de 80 a 2 depois de 80. Transposição com nota equivocada

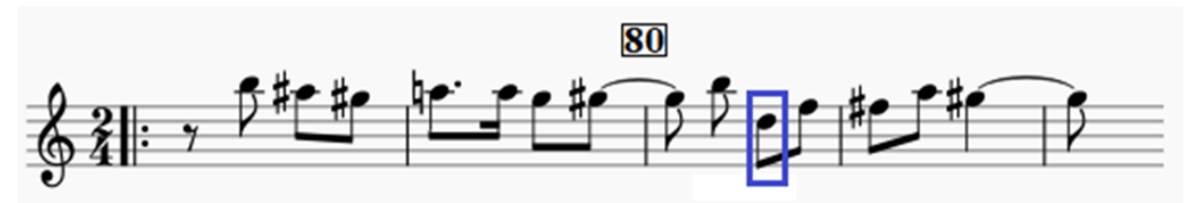

Exemplo 8d: Notas Irresponsáveis (primeira flauta) 2 antes de 80 a 2 depois de 80. Transposição correta. 
PRATES, V. D. Elementos melódicos e harmônicos recorrentes em Notas Irresponsáveis de Bruno Kiefer: uma abordagem Pós-Tonal

Chama a atenção que o compositor constrói a imitação baseada na Classe de Intervalo 6, que na teoria tradicional é conhecido como trítono, intervalo dissonante e instável. Além do cânone, outras duas utilizações desse intervalo merecem destaque, ambas relacionadas a alterações de textura e/ou seção. A primeira ocorre entre os dois cânones e possui textura homofônica em forma de coral, antecedendo uma breve região polifônica. $\mathrm{O}$ fato ocorre no modo como o compositor distribui os sons do conjunto [4-28] (Forma Prima (0 36 9 9)) à duas vozes, destacando de forma harmônica dois trítonos (Ex. 9a). Também devemos considerar que o conjunto [4-28], em harmonia tradicional, é uma tétrade diminuta, ou o acorde de sétima diminuta. A segunda utilização que destacamos ocorre na Coda (c. 130-134), em textura polifônica e com caráter melódico (ver Ex. $9 b)$. Chama a atenção aqui a impressão de grande instabilidade que o intervalo agrega ao final da peça.

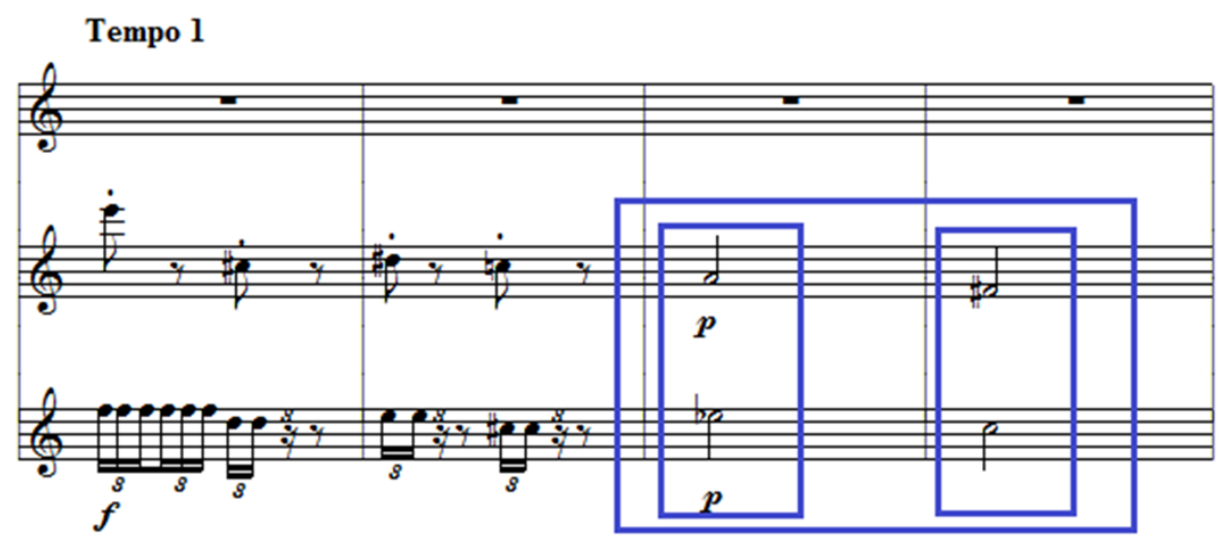

Exemplo 9a: Notas Irresponsáveis. 2 depois de 60 a 5 depois de 60. Utilização do trítono (Classe de Intervalo 6) harmônico

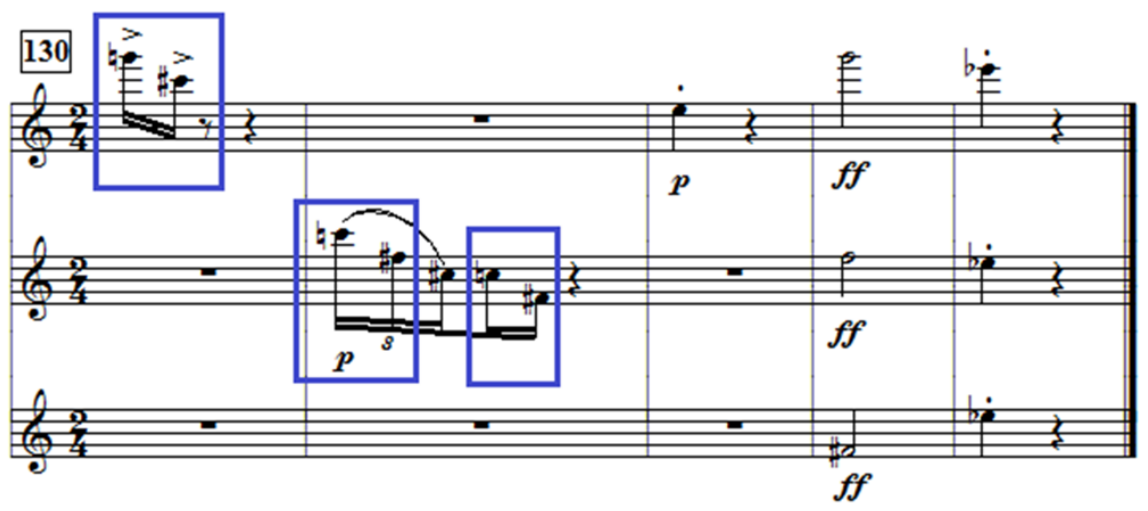

Exemplo 9b: Notas Irresponsáveis c. 130-134. Utilização do trítono (Classe de Intervalo 6) melódico 
MUSICA THEORICA Revista da Associação Brasileira de Teoria e Análise Musical 2019, v. 4, n. 1, p. 255-279-Journal of the Brazilian Society for Music Theory and Analysis @ TeMA 2019 - ISSN 2525-5541

Na música tradicional a relação do trítono (aqui vista como Classe de Intervalo 6) com formações diminutas, tanto tríades como tétrades, é muito comum. Nesses casos, normalmente encontramos agrupamentos de terças menores (aqui vista como Classe de Intervalo 3). Dessa forma, entendemos que é possível estreitar as relações entre essas duas Classes de Intervalos como associadas uma a outra. Lembramos que a tríade diminuta é uma superposição de duas terças menores, portanto existe uma proximidade de identidade intervalar.

Logo no início de Notas Irresponsáveis Kiefer utiliza a Classe de Intervalo 3 como elemento cadencial de forma melódica na região grave da flauta transversal. Outra utilização do intervalo que daremos destaque se manifesta de maneira similar à adotada pelo compositor conforme exemplificado no Exemplo 9a. Nessa situação é utilizado o conjunto [5-16] em Forma Normal (10 1112 5), sendo destacadas três possibilidades de configurações sonoras em Classe de Intervalo 3:

- Kiefer separa a primeira e segunda vozes à distância de terça menor, movendo as vozes de forma paralela;

- a terceira voz não forma terça menor com outras vozes, embora seu movimento melódico apresente o intervalo;

- as três vozes se movimentam explorando a Classe de Intervalo 3 (Ex. $10)$.

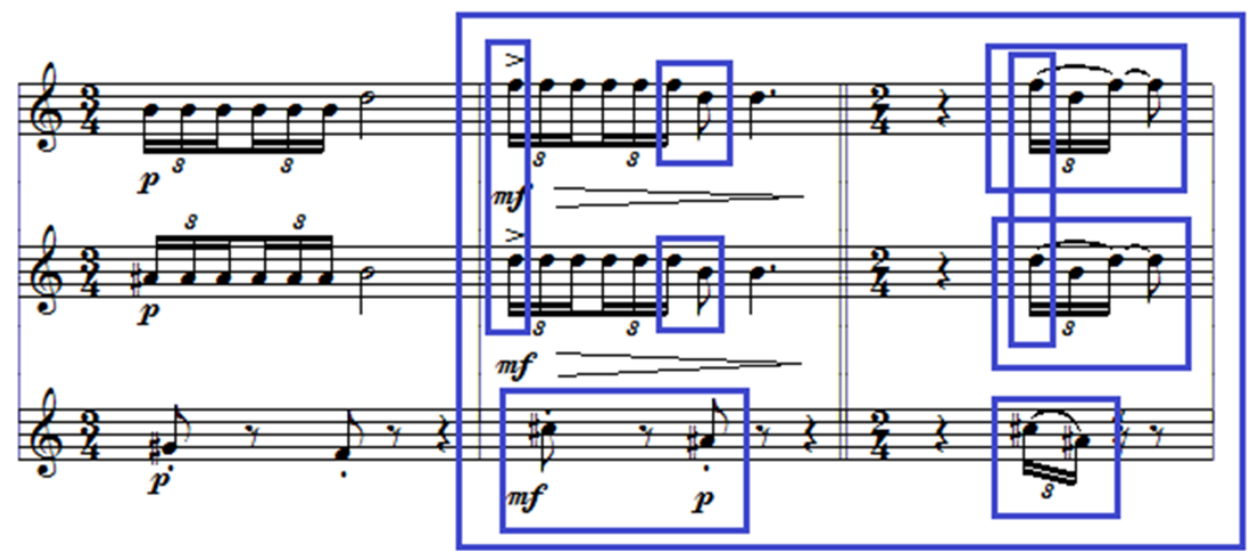

Exemplo 10: Notas Irresponsáveis c. 15-17. Utilização da terça menor (classe de intervalo 3) 
PRATES, V. D. Elementos melódicos e harmônicos recorrentes em Notas Irresponsáveis de Bruno Kiefer: uma abordagem Pós-Tonal

\section{Discussão: paralelo entre Notas Irresponsáveis (1986/87) e a literatura}

Em comparativos com a literatura analítica sobre a obra de Kiefer, é possível verificar afinidades de nossos resultados com trabalhos de Gerling (2001) e Mayer (2005). Conforme Gerling (2001) o componente octatônico através de [8-28] e seus subconjuntos é elemento de presença inequívoca nas peças para piano Terra Selvagem, Lamentos da Terra e Alternâncias. Segundo observação conclusiva da autora, "dos subconjuntos ordenados, [4-28], ou seja, o acorde diminuto propriamente dito, é o que tem sua presença definidora mais frequente, bem como [5-25], [5-19] e [4-27]" (Gerling 2001, p.69). Dentre os agrupamentos citados, apenas [5-25] não ocorre em Notas Irresponsáveis. Todos os outros recorrentes são octatônicos. A autora ainda destaca outros conjuntos de diferentes coleções, todos com ocorrência no trio de flautas: [4-10], [4-3] e [3-10]. Sobre esses grupos Gerling (2001) afirma que

ainda que estes subconjuntos de quatro e três sons pertençam a várias outras coleções, a interpretação octatônica é mais condizente com seu contorno característico e com a frequência de ocorrência (Gerling 2001, p. 69).

Mayer (2005) também traz em sua conclusão resultados que vão ao encontro de dados que obtivemos em Notas Irresponsáveis. Segundo o autor, "encontram-se os subconjuntos da coleção octatônica na maior parte do grupo de peças investigadas" (Mayer 2005, p. 81). O autor ainda reforça a "presença variada de subconjuntos de [8-28]" (Mayer 2005, p. 81). Apesar de [8-28] não ocorrer na obra que analisamos, a sonoridade característica desses grupos se sobressai em determinadas regiões temáticas e pontos específicos do trio de flautas. Entre os agrupamentos que Mayer (2005) destaca e que também ocorrem em Notas Irresponsáveis estão os octatônicos [3-3], [4-3] e [4-17] e o cromático [4$1]$.

Apesar de os conjuntos com características diatônicas encontrados na obra que investigamos não possuírem incidência significativa a ponto de serem considerados elementos preferenciais de Kiefer, devemos observar que suas ocorrências se assemelham a resultados de pesquisas anteriores. Mayer (2005) analisa que tríades de Quadro $\mathrm{n}^{\circ} 3$

compõem-se de configurações intervalares que vão ao encontro da coleção octatônica. No entanto, observa-se no início da peça um fragmento de ciclo 
MUSICA THEORICA Revista da Associação Brasileira de Teoria e Análise Musical 2019, v. 4, n. 1, p. 255-279-Journal of the Brazilian Society for Music Theory and Analysis@ TeMA 2019 - ISSN 2525-5541

de quintas dando a esses acordes um viés tonal, o que é logo eliminado (Mayer 2005, p. 80).

O autor ainda destaca a "presença tanto de tríades como de outros elementos diatônicos em meio a disposições claramente atonais. Assim, disponibiliza uma vasta gama de possibilidades ao compositor" (Mayer 2005, p. $81)$.

Embora Mayer (2005) não tenha citado conjuntos, suas afirmações mostram que há tendências sonoras tonais e diatônicas em dados momentos de determinadas peças de seu repertório, apesar de a característica de sonoridade não assumir um papel decisivo tonal/diatônico. Como vimos, foram identificados conjuntos em Notas Irresponsáveis que podem ser interpretados como segmentos de escala de uma determinada tonalidade. Assim como ocorre em Mayer (2005), essas sonoridades tonais surgem em momentos isolados na peça para flautas, sem que se tornem predominantes em alguma região ou sessão, mas enriquecendo o material melódico empregado por Kiefer.

Mayer (2005) comenta que, entre o repertório analisado por ele, “a $3^{\text {a }}$ Menor, neste conjunto de peças, também se apresentou como um gesto de autocitação" (Mayer 2005, p. 88). Com essa afirmação, o autor nos mostra a recorrência deste intervalo, fato que vai ao encontro de dados que obtivemos a partir da análise de Notas Irresponsáveis. A autocitação comentada pelo autor aproxima a linguagem da peça que analisamos a características já estudadas e identificadas em outras pesquisas sobre a obra de Kiefer, conforme veremos adiante.

As proximidades mais significativas entre a obra para flauta transversal abordada nesse artigo e os resultados de Gerling (2001) e Mayer (2005) ocorrem através dos subconjuntos de [8-28]. Igualmente, outros conjuntos de diferentes naturezas também se mostraram recorrentes entre nossos resultados e os desses autores. Dentre tais conjuntos destacamos o octatônico [4-28] que também possui forte relação com a terça menor por ser uma tétrade diminuta.

Além disso, a superposição de terças menores gera os conjuntos [3-10] e [4-28] (diminutos) que trazem consigo outro intervalo preferencial de Kiefer: o trítono. Verificamos que o compositor explora esse material, a exemplo da terça menor, tanto de forma melódica como harmônica. A relação que se estabelece entre esses intervalos pode ser entendida através de suas instabilidades, sendo a terça menor uma consonância imperfeita e o trítono uma dissonância. 
PRATES, V. D. Elementos melódicos e harmônicos recorrentes em Notas Irresponsáveis de Bruno Kiefer: uma abordagem Pós-Tonal

Acreditamos que a insistência de Kiefer nessas sonoridades é um dos fatores que contribuem para sua proposta estética de conflito e tensão presentes em Notas Irresponsáveis.

Apesar de o intervalo terça menor estar por vezes inserido entre os conjuntos pseudo-cromáticos como elemento de quebra do padrão de sucessão de semitons, não raro sua percepção fica diluída em meio aos desenhos melódicos construídos por Kiefer. Tais conjuntos em alguns momentos estão presentes em determinadas regiões temáticas como sonoridades únicas ou predominantes. Associando-se a grande recorrência de conjuntos totalmente cromáticos que verificamos em Notas Irresponsáveis, é possível afirmar que o compositor explora o cromatismo independente da qualidade do conjunto como um de seus principais materiais temáticos. Acreditamos que essa característica é outro ponto que reforça sua proposta estética de conflito e tensão. Da mesma forma, a rotatividade de padrões cromáticos, octatônicos e, embora raros, diatônicos, além de enriquecer o material melódico e harmônico da composição, gera também, através de seus contrastes, elemento na interrupção do discurso, característica estilística de Kiefer.

Para Cardassi (1998) a autocitação é uma estratégia composicional de Kiefer. A autora classifica essa recorrência de ideias musicais como um enfoque analítico não explorado até então acerca do estilo do compositor. Acrescenta ainda que

só a reflexão analítica sobre peças de diversos gêneros e instrumentações possibilita mostrar que, em Kiefer, a estratégia composicional envolve a reutilização de ideias musicais idênticas que transitam de peça para peça (Cardassi 1998, p. 140).

Em outra pesquisa a autora comenta que

Através do processo de autocitação, Kiefer investe esse conjunto de peças ${ }^{9}$ de um alto nível de redundância composicional, o que confere um caráter unitário ao conjunto de peças e denota o pensamento consistente do compositor (Cardassi 2004, p. 26).

Neste artigo, procuramos traçar comparativos que aproximem a obra que escolhemos das características destacadas na literatura analítica sobre $o$

\footnotetext{
${ }^{9}$ Cardassi (2004) investiga peças de diferentes formações instrumentais compostas entre 1970 e 1983.
} 
MUSICA THEORICA Revista da Associação Brasileira de Teoria e Análise Musical 2019, v. 4, n. 1, p. 255-279-Journal of the Brazilian Society for Music Theory and Analysis @ TeMA 2019 - ISSN 2525-5541

compositor. Entendemos que as compatibilidades de conjuntos mostradas anteriormente são indícios da aproximação que buscamos. Com relação à autocitação, a observação de Mayer (2005) sobre o intervalo de terça menor possuir característica de material reapresentado em diferentes obras do repertório de sua pesquisa nos traz outros indícios de que Notas Irresponsáveis possui familiaridade com outras composições de Kiefer por meio dessa estratégia de escrita.

\section{Conclusão}

A compreensão do material melódico e harmônico sob a ótica da Teoria Pós-Tonal necessita um estudo de relação dos sons entre si e, por isso, está atrelada à nossa interpretação de execução de Notas Irresponsáveis. Os critérios adotados e explanados no corpo deste artigo vão ao encontro do nosso entendimento de performance da composição, podendo ser divergentes a outros executantes.

Entretanto, mesmo com entendimento de caráter subjetivo sobre a interpretação musical, foi possível aproximar nossos resultados a conclusões obtidas por outros autores que investigaram o repertório de Kiefer. É inquestionável que em uma percepção diferente quanto à execução da obra poderia se fazer necessário outros métodos de investigação e acarretar em resultados distintos. Mesmo assim, a concordância que se averiguou entre o fruto de nossa análise e as observações de Mayer (2005) e Gerling (2001) são consideráveis pelo volume de informações compatíveis entre os trabalhos. Tal concordância ocorre ao cruzarmos resultados que obtivemos através de nossa investigação com os dados obtidos nas pesquisas de apoio, observando a recorrência de conjuntos, subconjuntos e tipos de formações iguais ou similares, em especial octatônicas.

Uma vez identificados conjuntos e subconjuntos similares entre si ou de mesma natureza fica claro ao intérprete a origem dos elementos, possibilitando a compreensão do material proposto pelo compositor. Assim, o fundamento teórico pode agregar coesão às escolhas interpretativas, permitindo que o executante interprete os elementos similares e contrastantes com sentido musical consciente. Acreditamos que os dados aqui explanados sobre a variedade e rotatividade dos conjuntos melódicos e harmônicos possam contribuir para que intérpretes possuam uma maior gama de informação e que os ajude a relacionar 
PRATES, V. D. Elementos melódicos e harmônicos recorrentes em Notas Irresponsáveis de Bruno Kiefer: uma abordagem Pós-Tonal

e executar esses materiais de forma mais fundamentada, tanto na obra focada aqui, quanto em outras composições de Bruno Kiefer.

\section{Referências}

1. Berry, Wallace. 1987. Structural functions in music. New York: Dover Publications, Inc.

2. Cardassi, Luciane. 1998. A música de Bruno Kiefer: "terra", "vento", "horizonte" e a poesia de Carlos Nejar. Dissertação de Mestrado em Música. Porto Alegre: Instituto de Música, UFRGS.

3. Cardassi, Luciane. 2004. Autocitação no processo composicional de Bruno Kiefer. Goiânia: Música Hodie, v. 4, n. 1, p. 11-27.

4. Forte, Allen. 1973. The Structure of Atonal Music. London, New Haven and London: Yale University Press.

5. Frobenius, Wolf; Cooke, Peter; Bithell, Caroline; Zemtsovsky, Izaly. 2001. Polyphony. Grove Music Online.

6. Gerling, Cristina Capparelli. 2001. Terra Selvagem, Lamentos da terra e Alternâncias: o componente octatônico nas últimas três peças para piano de Bruno Kiefer. Belo Horizonte: PerMusi Revista de Performance Musical, n. 4, p. 52-71.

7. Hyer, Brian. 2001. Homophony. Grove Music Online.

8. Kiefer, Bruno. 1986/87. Notas Irresponsáveis. Porto Alegre: manuscrito, partitura.

9. Mann, Alfred; Wilson, J. Kenneth; Urguhart, Peter. 2001. Canon. Grove Music Online.

10. Mayer, Germano G. 2005. Seis Pequenos Quadros (1981) de Bruno Kiefer: relações intervalares e outros parâmetros a partir da teoria dos conjuntos e gestos musicais. Dissertação de Mestrado em Música. Porto Alegre: Instituto de Artes, UFRGS.

11. Prates, Vinicius Dias; Winter, Leonardo Loureiro; Carvalho, Any Raquel. 2014. Recorrências rítmico-melódicas na produção composicional para flauta de Bruno Kiefer. Vitória: ABRAPEM, v. 1, n. 1, p. 388-393.

12. Prates, Vinicius Dias. 2015. Elementos melódicos e gestuais recorrentes em duas peças para flauta transversal de Bruno Kiefer: Notas Soltas e Notas Irresponsáveis. Dissertação de Mestrado em Música. Porto Alegre: Instituto de Artes, UFRGS.

13. Prates, Vinicius Dias. 2017. Elementos gestuais recorrentes em Notas Soltas para flauta transversal solo de Bruno Kiefer. Curitiba: Revista Vórtex, v. 5, n.1, p. 119. 
MUSICA THEORICA Revista da Associação Brasileira de Teoria e Análise Musical 2019, v. 4, n. 1, p. 255-279-Journal of the Brazilian Society for Music Theory and Analysis @ TeMA 2019 - ISSN 2525-5541

14. Prates, Vinicius Dias; WINTER, Leonardo Loureiro. 2018. Estudo sobre o aspecto gestual em Notas Irresponsáveis para trio de flautas transversais de Bruno Kiefer. Caderno de Resumos do V Simpósio Internacional de Música IberoAmericana. Manaus: UEA, p. 67-68.

15. Straus, Joseph N. 2005. Introduction to Post-Tonal Theory. $3^{\circ}$ ed. New Jersey: Prentice-Hall Upper Saddle River.

16. Wilson, Charles. 2001. Octatonic. Grove Music Online. 


\section{Sobre os autores}

Ilza Nogueira é graduada em Música (Bacharelado em Instrumento, 1972) e Letras (Licenciatura em Línguas Anglo-Germânicas, 1971) pela Universidade Federal da Bahia. Tem especialização em "Novo Teatro Musical"; realizada na Escola Superior de Música de Colônia/Alemanha (1977), sob a orientação de Maurício Kagel. Tem Mestrado em Composição realizado na Universidade Estadual de New York em Buffalo (1984) e Doutorado (Ph.D.) em Composição também realizado nessa última instituição (1985), sob a orientação de Lejaren Arthur Hiller. No período de 1989-1990, realizou pós-doutoramento em Teoria da música na Universidade de Yale, sob orientação da Dra. Janet Schmalfeldt. É professora aposentada do Departamento de Música da Universidade Federal da Paraíba (UFPB), onde lecionou disciplinas teóricas no Bacharelado em Instrumento, Composição e Teoria da Música no Programa de Pós-Graduação em Música, tendo sido Editor Chefe da publicação científica desse programa, o periódico Claves; Sua experiência na área de Artes/Música tem ênfases em Composição e Teoria Analítica da Música. Como pesquisadora, vem atuando principalmente nos seguintes temas: música brasileira contemporânea, teorias analíticas contemporâneas, narratividade e narratografia musical. É membro efetivo da Academia Brasileira de Música (cadeira N.․ 27) e membro fundador da Associação Brasileira de Teoria e Análise Musical (TeMA), tendo sido eleita Presidente para os biênios 2014-2016 e 2016-2018.

Carlos Almada, pesquisador, com principal interesse de estudo nas subáreas de Teoria e Análise Musical e Estudos Sistemáticos em Música Popular. Arranjador e compositor. Autor dos livros Arranjo (Editora da Unicamp, 2001), A estrutura do choro (Da Fonseca, 2006), Harmonia funcional (Editora da Unicamp, 2009), Contraponto em Música Popular (Editora da UFRJ, 2013) e Nas Fronteiras da Tonalidade (Prisma, 2016), bem como coautor de uma série de doze livros de partituras e estudos sobre música popular brasileira, publicados entre 1998 e 2010 pela editora americana MelBay. Em 2007 e 2010 obteve, respectivamente, os graus de Mestre e Doutor em Música pela Universidade Federal do Estado do Rio de 
MUSICA THEORICA Revista da Associação Brasileira de Teoria e Análise Musical 2019, v. 4, n. 1, p. 280-283 - Journal of the Brazilian Society for Music Theory and Analysis@ TeMA 2019 - ISSN 2525-5541

Janeiro (UNIRIO), com estudos analíticos feitos sobre a estrutura da Primeira Sinfonia de Câmara op. 9, de Arnold Schoenberg. Atualmente é professor de cursos de graduação e pós-graduação na Escola de Música da UFRJ.

Rodolfo Coelho de Souza, Professor Titular do Departamento de Música da Universidade de São Paulo, vinculado à Faculdade de Filosofia Ciência de Letras de Ribeirão Preto. Atua como orientador de doutorado na Pós-Graduação em Música da Escola de Comunicações e Artes da USP. De 2000 a 2005 foi Professor do Departamento de Artes da UFPR. Graduou-se em Engenharia pela Escola Politécnica da Universidade de São Paulo (1976), fez Mestrado em Musicologia na ECA-USP (1994) e Doutorado em Composição Musical na University of Texas at Austin (2000). Em 2009 realizou pesquisas de pós-doutorado University of Texas at Austin com E. Antokoletz e R. Pinkston. Em 2006 tornou-se Professor Livre Docente. Em 2018 tornou-se Professor Titular. Atua nas áreas de Composição Musical, Tecnologia da Música e Musicologia Analítica. Foi coordenador do Lacomus - Laboratório de Computação Musical da UFPR (20012004) e atualmente é coordenador do LATEAM - Laboratório de Teoria e Análise Musical do DM-FFCLRP-USP. Foi editor do pediódico Musica Theorica da TeMA - Associação Brasileira de Teoria e Análise Musica, da qual atualmente é presidente para o biênio 2019-20. Entre suas composições musicais destacam-se: O Livro dos Sons (2010) para orquestra e sons eletrônicos, Concerto para Computador e Orquestra (2000) e Tristes Trópicos (1991). É bolsista de Produtividade em Pesquisa PQ2 do CNPq.

Cassia Carrascoza Bomfim, doutora em Artes: Musicologia, Mestre em Artes: Processos de Criação Musical, Bacharel em Música com Habilitação em Instrumento Flauta, todos pela Escola de Comunicações e Artes- USP. Professora do Departamento de Música da FFCLRP-USP; realiza pesquisa na área de Ciências da Performance e áreas correlatas. Atua como solista na música contemporânea e frente a orquestras, como camerista junto ao Quinteto Pierrot, Percorso Ensemble e no Duo Graffitti. Foi a flautista da Camerata Aberta da EMESP do Estado de São Paulo e professora da mesma instituição. Atuou como primeira flautista da Orquestra Sinfônica do Teatro Municipal de São Paulo e na Orquestra Jazz Sinfônica do Estado de São Paulo. Tem experiência na área de Artes, com ênfase em Artes, atuando principalmente nos seguintes temas: flauta, flauta transversal e músico de orquestra. 
Heitor Martins Oliveira possui bacharelado em Música/Regência, licenciatura em Educação Artística pela Universidade de Brasília (2002 e 2006), mestrado em Música/Composição-Texas State University (2004), e doutorado em Música/Composição pelo Programa de Pós-graduação em Música da Universidade Federal do Rio Grande do Sul (2018), sob orientação do Prof. Dr. Celso Loureiro Chaves. Atualmente é docente da Universidade Federal do Tocantins, vinculado à área de Artes e Filosofia do câmpus de Palmas. Tem experiência na área de Artes, com ênfase em Música e Educação Musical, atuando principalmente nos seguintes temas: composição musical, teoria e análise musical. Mantém atividade constante como compositor de música para a sala de concerto, artes cênicas e audiovisual. Foi selecionado pelo programa Rumos Itaú Cultural 2017-2018, com o projeto Coletivo N.S.L·O: colaboração compositorintérpretes na criação musical contemporânea.

Kevin Gohon obteve seu Ph.D. na Université de Rennes 2 em 2018. Sua tese "Criticism of the musical discourse and emergence of a 'mixed' thought in Pierre Boulez's and Luigi Nono's electroacoustic works" identificou as implicações estéticas e técnicas de uma lógica musical não-unívoca em relação à integração de tecnologias eletrônicas e a renovação da espacialidade da música. Suas pesquisas mais recentes se concentram na análise de diferentes formas de lógica heterogênea na música contemporânea e na literatura, nas implicações estéticas de um pensamento ornamental na música moderna e na análise computacional da espacialização eletroacústica.

Gabriel Navia é doutor em Teoria e Análise Musical pela University of Arizona e Mestre em Performance Musical (violão) pela mesma universidade. Desde 2014, atua como professor de violão e disciplinas teóricas na Universidade Federal da Integração Latino-Americana (UNILA). De 2017 a 2019, foi coeditor do TeMA Informativo e atualmente faz parte da equipe editorial da revista Musica Theorica.

Bruno Yukio M. Ishisaki, compositor, cancionista e produtor fonográfico. Bacharel em Música Popular pela UNICAMP (2005), Especialista em Composição Musical pela FMCG (2009), Mestre em Música pela Unicamp (2014) e doutorando nesta mesma universidade. É membro do coletivo Tempo-Câmara e co-editor da revista Abate.

Denise Hortência Lopes Garcia, compositora paulista, professora doutora do Instituto de Artes da Unicamp. Bacharel em Música pela USP (1985), Mestre em 
MUSICA THEORICA Revista da Associação Brasileira de Teoria e Análise Musical 2019, v. 4, n. 1, p. 280-283 - Journal of the Brazilian Society for Music Theory and Analysis @ TeMA 2019 - ISSN 2525-5541

Artes pela Unicamp (1993) e Doutora em Comunicação e Semiótica pela PUC-SP (1998). Realizou estudos de composição na Musikakademie Detmold e na Musikhochshule de Munique (1979-1984). Fez estágio de doutorado junto ao INA-GRM em Paris. Realizou pós-doutorado junto à Escola de Música da UFRJ (2007).

Vinicius Dias Prates é Bacharel em música (habilitação em Flauta Transversal) pela Universidade Federal do Rio Grande do Sul (UFRGS) e Mestre em Práticas Interpretativas pela mesma instituição. Atuou como flautista convidado das principais orquestras do RS, entre elas OSPA, Orquestra Sinfônica da UCS, Orquestra do SESC, SESI, Unisinos, ULBRA, Orquestra do Theatro São Pedro, Orquestra de Sopros de Novo Hamburgo e Banda Municipal de Porto Alegre. Foi integrante efetivo da Orquestra de Sopros de Caxias do Sul, Orquestra Filarmônica da PUCRS como primeiro flautista e dos grupos de câmara Café Acústico e Sexta Brasileira, ambos voltados para o repertório de MPB. É professor de flauta transversal na Orquestra Jovem do RS e atua no Quinteto de Sopros Austro. Cursa Doutorado em Práticas Interpretativas no programa de PósGraduação em Música da UFRGS. 



\title{
Sumário
}

i

\author{
Liduíno Pitombeira entrevista Patrick McCreless \\ Carlos Almada entrevista Edgardo Rodríguez
}

\section{Artigos}

A Visita de Beethoven ao carnaval brasileiro em 2017: Ensaio sobre fantasia analítica e hermenêutica narrativa em música

11

Beethoven's Visit to Brazil During the 2017 Carnival: Essay on Analytical Fantasy and Narrative Hermeneutics in Music

Ilza Nogueira

Variation and Developing Variation under a Transformational Perspective

Variação e Variação Progressiva sob uma Perspectiva Transformacional Carlos Almada

Categorias de Análise Musical e Modelagem Física como Análise do Timbre Categories of Musical Analysis and Physical Modeling as Analysis of Timbre Rodolfo Coelho de Souza

O Pensamento Musical sobre o Tempo em Durações (1977) de Rodolfo Coelho de Souza Musical thought about time in Durações (1977) by Rodolfo Coelho de Souza Cássia Carrascoza Bomfim

Espaço, materiais e forma no teatro musical pós-1960: composição e dramaturgia em obras de Mendes, Kagel e Aperghis

Space, materials, and form in the post-1960 music theater: composition and dramaturgy in works by Mendes, Kagel e Aperghis

Heitor Martins Oliveira

Rethinking the Ornament with/in Luigi Nono's Late Electroacoustic Works Repensar o ornamento com/em obras eletroacústicas tardias de Luigi Nono Kevin Gohon

The Medial Caesura Declined in Schubert's Sonata-Form Expositions

188

A Cesura Medial Recusada nas Exposições de Obras em Forma Sonata de Schubert

Gabriel H. Bianco Navia

O Desvio no Fluxo Composicional

Deviation in the Compositional Flow

Bruno Yukio Meireles Ishisaki e Denise Hortência Lopes Garcia

Elementos melódicos e harmônicos recorrentes em Notas Irresponsáveis de Bruno Kiefer: uma abordagem Pós-Tonal

Recurring melodic and harmonic elements in Bruno Kiefer's Notas Irresponsáveis: a Post-Tonal approach

Vinicius Dias Prates

\section{Sobre os autores}

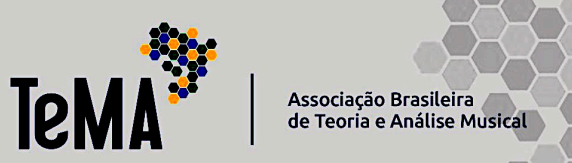

